\title{
Descriptive Models for Epithermal Gold-Silver Deposits
}

Chapter $\mathrm{Q}$ of

Mineral Deposit Models for Resource Assessment
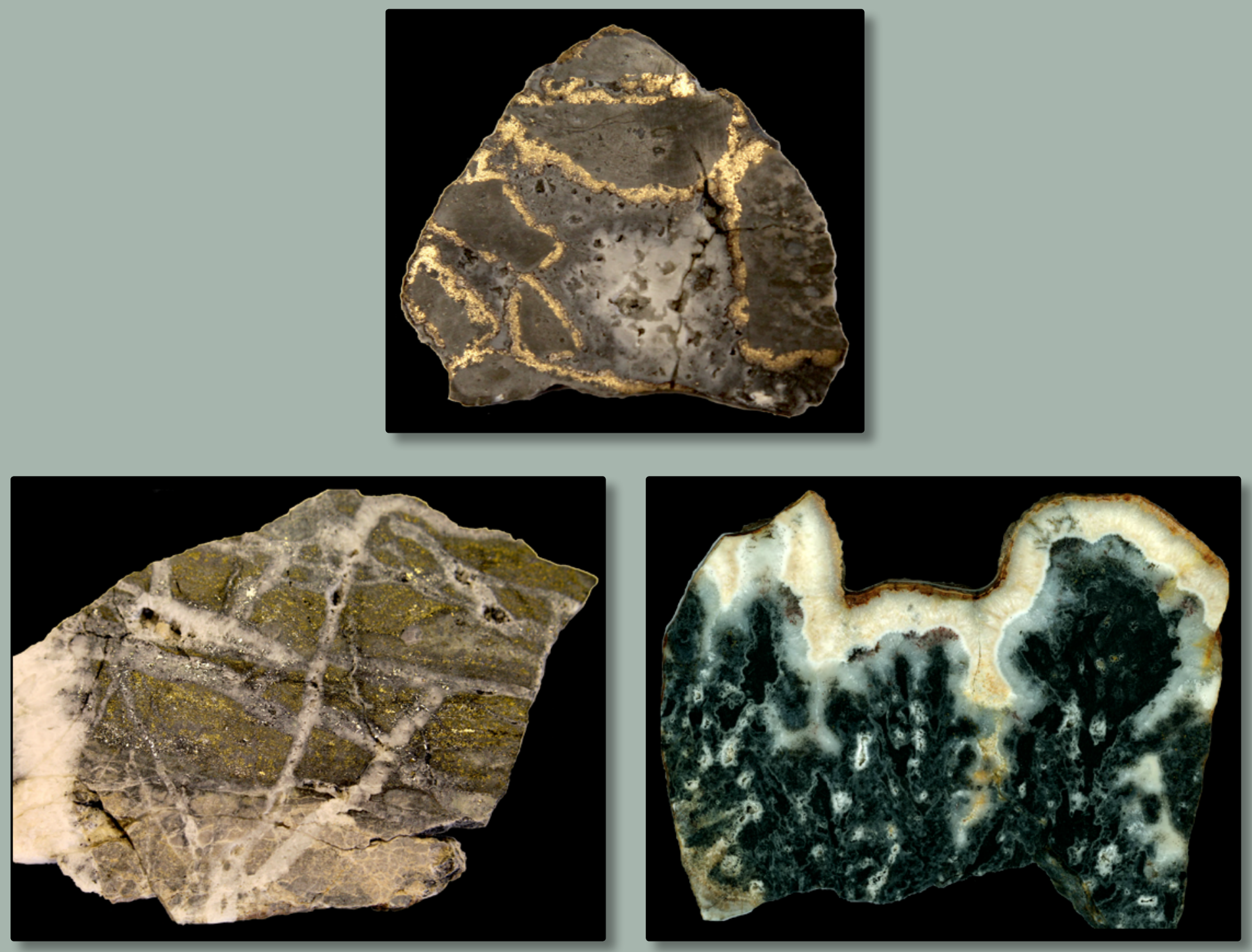

Scientific Investigations Report 2010-5070-0

U.S. Department of the Interior

U.S. Geological Survey 
Cover. Top center, sample of a breccia from the high-sulfidation Clermont mine, Goldfield district, Nevada, that consists of gold encrusting residual quartz-pyrite altered breccia fragments. The sample is about $4 \mathrm{~cm}$ across. Lower left, sample of bonanza ore consisting of golden electrum and silvery acanthite $\left(\mathrm{Ag}_{2} \mathrm{~S}\right)$ in white quartz and altered wallrock from the intermediate-sulfidation Con Virginia-California mine, Comstock Lode district, Nevada. The slab is about $25 \mathrm{~cm}$ across. Lower right, sample of the low-sulfidation Bell vein from Buckskin-National mine, National district, Nevada, which consists of white to beige layers of fine-grained quartz deposited on a hummocky surface of very fine grained gray quartz and black dendrites composed largely of naumannite $\left(\mathrm{Ag}_{2} \mathrm{Se}\right)$. The slab is about $12 \mathrm{~cm}$ across. Photographs by Peter Vikre. 


\section{Descriptive Models for Epithermal Gold-Silver Deposits}

By David A. John, Peter G. Vikre, Edward A. du Bray, Richard J. Blakely, David L. Fey, Barnaby W. Rockwell, Jeffrey L. Mauk, Eric D. Anderson, and Frederick T. Graybeal

Chapter $\mathrm{Q}$ of

Mineral Deposit Models for Resource Assessment

Scientific Investigations Report 2010-5070-0 


\section{U.S. Department of the Interior RYAN K. ZINKE, Secretary}

\section{U.S. Geological Survey James F. Reilly II, Director}

\section{U.S. Geological Survey, Reston, Virginia: 2018}

For more information on the USGS - the Federal source for science about the Earth, its natural and living resources, natural hazards, and the environment-visit https://www.usgs.gov or call 1-888-ASK-USGS (1-888-275-8747).

For an overview of USGS information products, including maps, imagery, and publications, visit https://store.usgs.gov.

Any use of trade, firm, or product names is for descriptive purposes only and does not imply endorsement by the U.S. Government.

Although this information product, for the most part, is in the public domain, it also may contain copyrighted materials as noted in the text. Permission to reproduce copyrighted items must be secured from the copyright owner.

Suggested citation:

John, D.A., Vikre, P.G., du Bray, E.A., Blakely, R.J., Fey, D.L., Rockwell, B.W., Mauk, J.L., Anderson, E.D., and Graybeal, F.T., 2018, Descriptive models for epithermal gold-silver deposits: U.S. Geological Survey Scientific Investigations Report 2010-5070-0, 247 p., https://doi.org/10.3133/sir201050700.

ISSN 2328-0328 (online) 


\section{Contents}

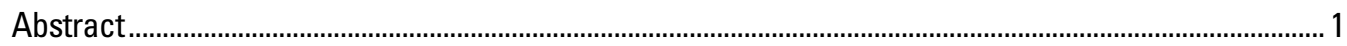

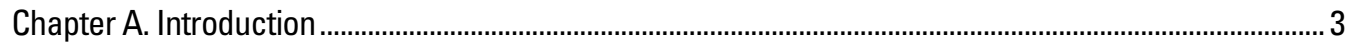

By David A. John

Chapter B. Definition and Classification of Epithermal Gold-Silver Deposits ...............................................

By David A. John and Peter G. Vikre

Chapter C. Deposit Type and Associated Commodities ................................................................................. 13

By David A. John

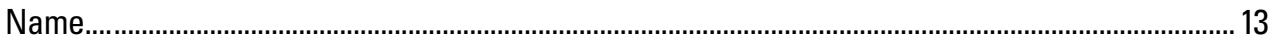

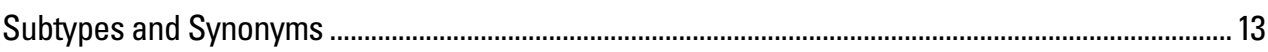

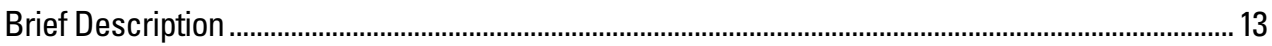

Associated and Transitional Deposit Types.................................................................................. 14

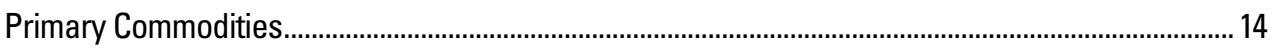

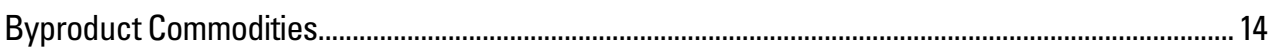

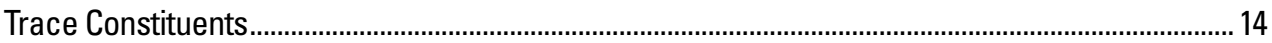

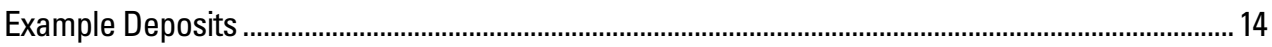

Chapter D. History of Epithermal Gold-Silver Deposits............................................................................ 15

By Jeffrey L. Mauk

Chapter E. Regional Environment ................................................................................................................ 17

By David A. John and Jeffrey L. Mauk

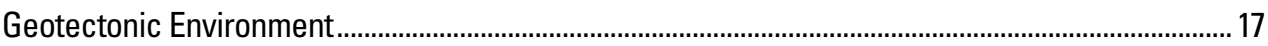

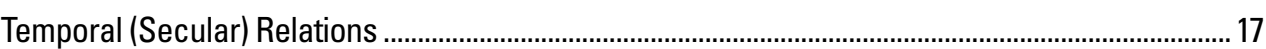

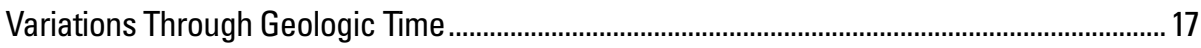

Duration of Hydrothermal Systems that Form Epithermal Gold-Silver Deposits ....................... 18

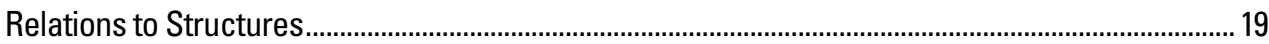

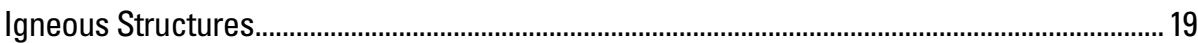

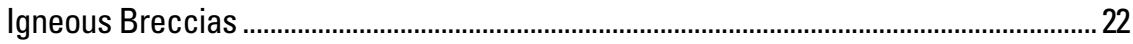

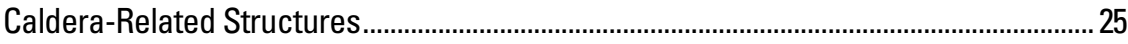

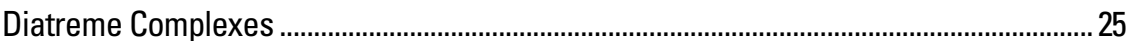

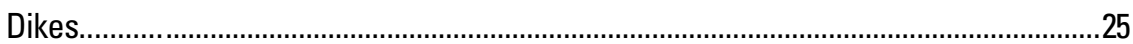

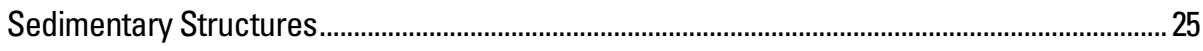

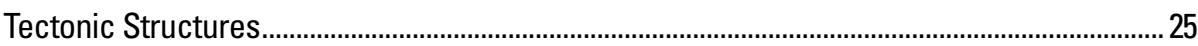

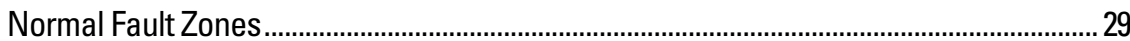

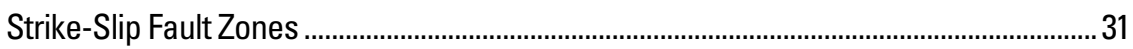

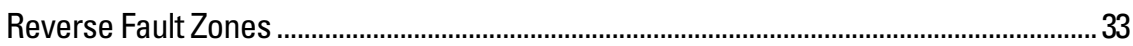

Postmineralization Faults....................................................................................................

Topography-Related Structures ..............................................................................................

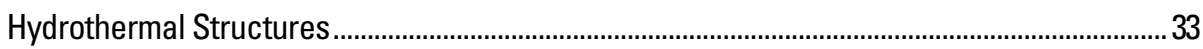

Veins.

Quartz Textures Observed in Hand Samples and by Microscopic Examination...34

Quartz Textures Observed Only Microscopically .......................................................... 36

Hydrothermal Breccias........................................................................................................ 36

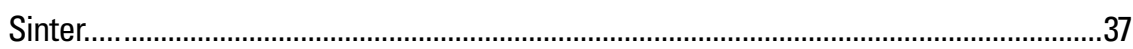

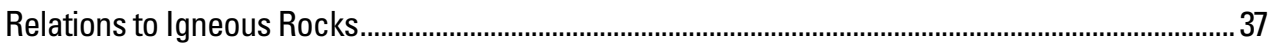

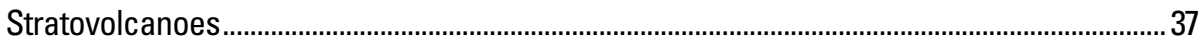




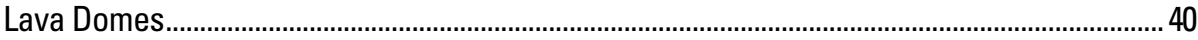

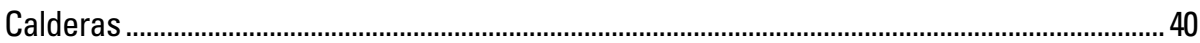

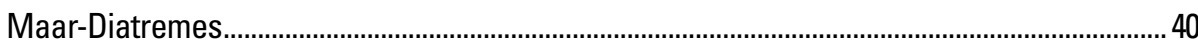

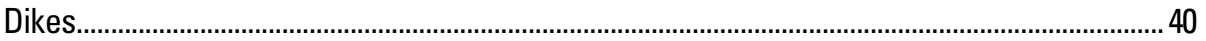

Relations to Sedimentary Rocks............................................................................................................ 41

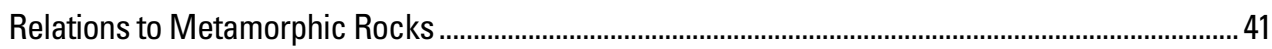

Chapter F. Physical Description of Deposits ...................................................................................... 43

By Peter G. Vikre

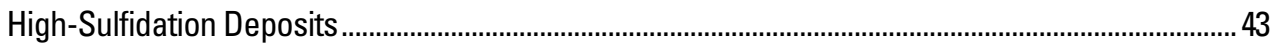

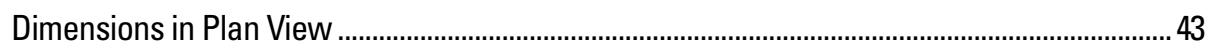

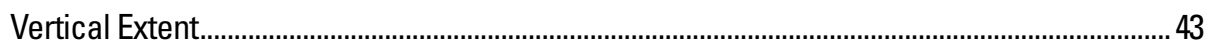

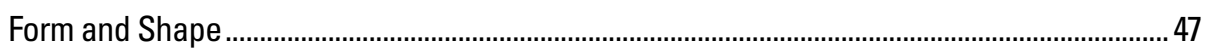

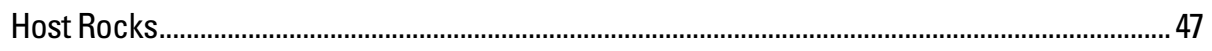

Structural Settings and Controls .................................................................................................. 47

Low- and Intermediate-Sulfidation Deposits ............................................................................. 47

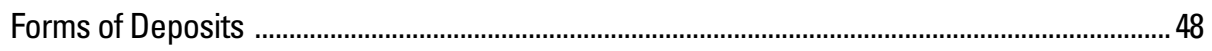

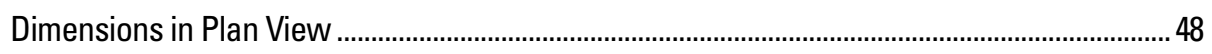

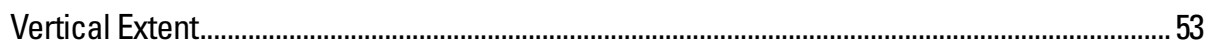

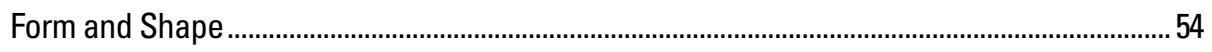

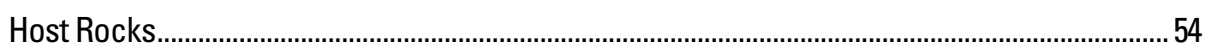

Structural Settings and Controls .................................................................................... 54

Chapter G. Geophysical Characteristics............................................................................................. 55

By Richard J. Blakely, David A. John, and Eric D. Anderson

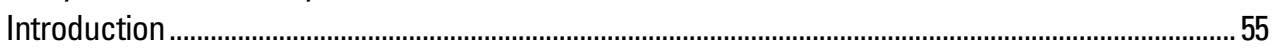

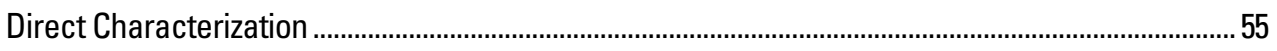

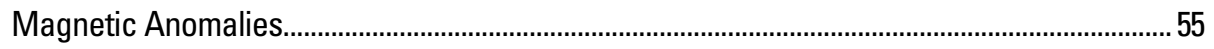

Electrical and Electromagnetic Methods.......................................................................... 58

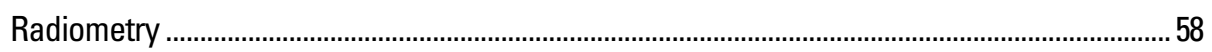

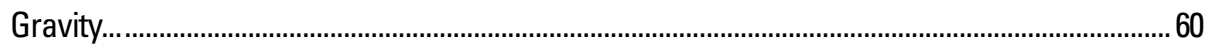

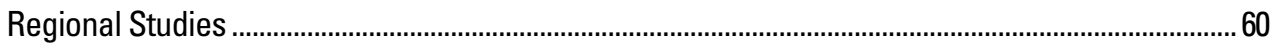

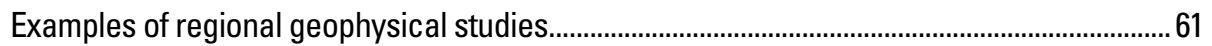

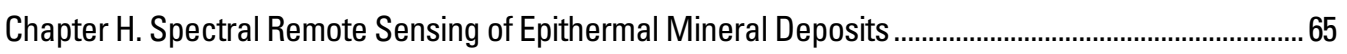

By Barnaby W. Rockwell

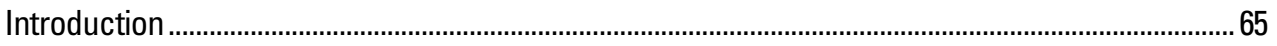

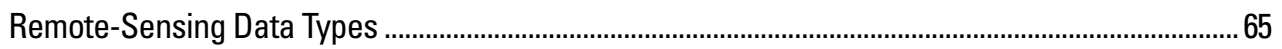

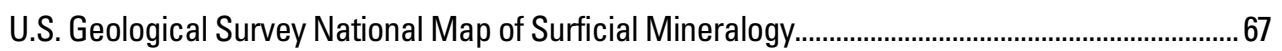

Remote-Sensing Expression of Epithermal Gold-Silver Deposits................................................... 68

Geoenvironmental Mapping of Epithermal Gold-Silver Deposits by using Landsat 8 Data.............. 76

Chapter I. Hypogene and Supergene Ore Characteristics ........................................................................ 81

By Peter G. Vikre

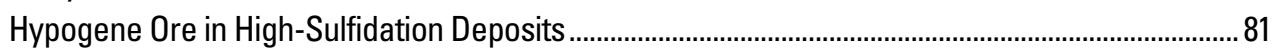

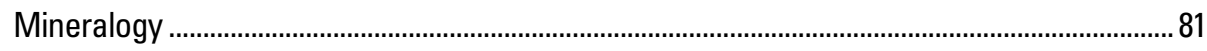

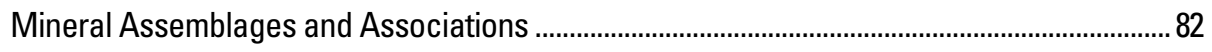

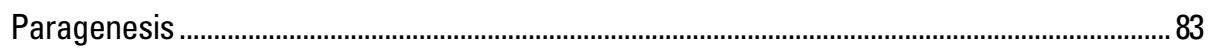

Zoning Patterns ................................................................................................................... 83

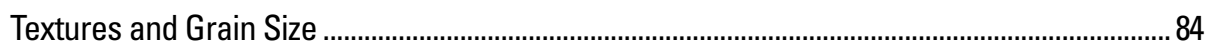


Supergene Ore in High-Sulfidation Deposits .............................................................................. 84

Hypogene Ore in Low- and Intermediate-Sulfidation Deposits......................................................... 85

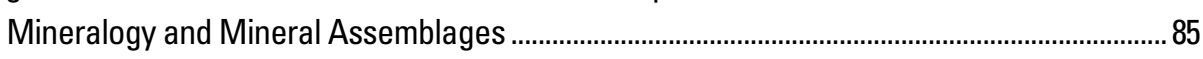

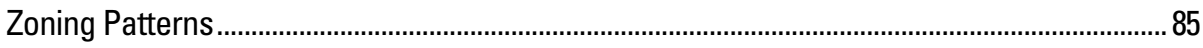

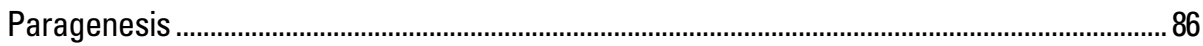

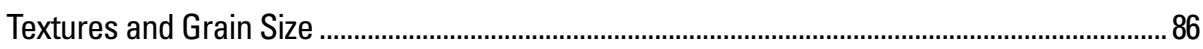

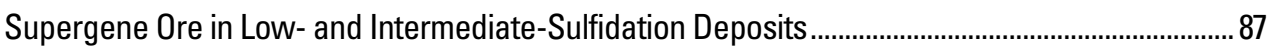

Chapter J. Hypogene and Supergene Gangue Characteristics.............................................................. 91

By Peter G. Vikre

Hypogene Gangue in High-Sulfidation Deposits ........................................................................... 91

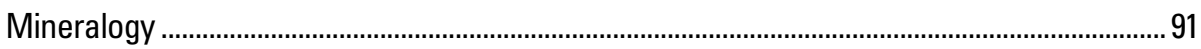

Mineral Assemblages, Paragenesis, and Zoning Patterns ..................................................... 91

Textures and Grain Size .......................................................................................................

Supergene Gangue in High-Sulfidation Deposits ……............................................................... 91

Hypogene Gangue in Low- and Intermediate-Sulfidation Deposits ............................................... 92

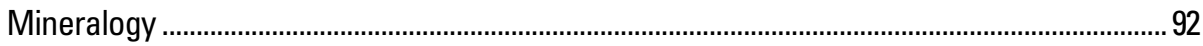

Mineral Assemblages, Paragenesis, and Zoning Patterns ....................................................... 92

Textures and Grain Size ...................................................................................................... 93

Supergene Gangue in Low- and Intermediate-Sulfidation Deposits............................................... 94

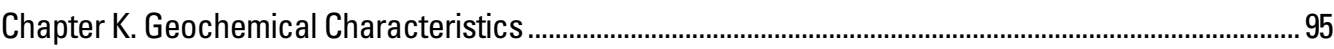

By Peter G. Vikre and David A. John

Trace Elements and Element Associations.....................................................................................95

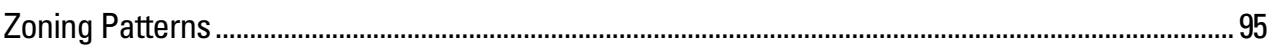

Geochemical Zoning in Ore Zones in Low- and Intermediate-Sulfiation Deposits................. 102

Pathfinder Elements in Wall Rocks of Low- and Intermediate-Sulfidation Deposits ............. 103

Geochemical Zoning of Hydrothermal Alteration in Low- and Intermediate-Sulfidation

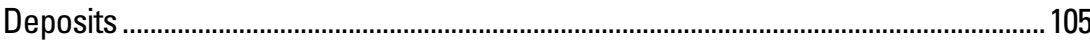

Geochemical Zoning in Ore Zones in High-Sulfidation Deposits.............................................. 105

Pathfinder Elements in Wall Rocks of High-Sulfidation Deposits............................................. 105

Fluid Inclusion Petrography, Thermometry, and Geochemistry .....................................................110

High-Sulfidation Deposits.................................................................................................... 110

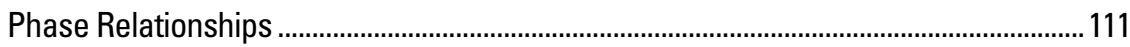

Homogenization Temperatures, Fluid Salinities, and Salt Dissolution Temperatures.. 111

Zoning and Depth of Deposit Formation ........................................................................111

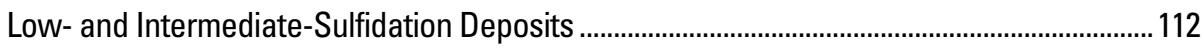

Phase Relationships ...............................................................................................112

Homogenization Temperatures, Fluid Salinities, and Fluid Pressures.............................. 112

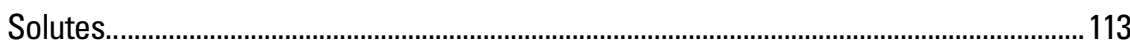

Volatile Species, Abundances, and Isotope Compositions............................................... 113

Zoning and Depth of Deposit Formation........................................................................ 115

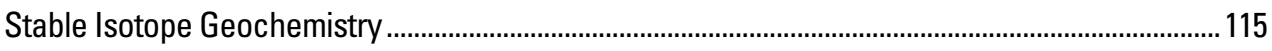

High-Sulfidation Deposits ......................................................................................... 115

Sources of Sulfur and Water ......................................................................................... 116

Isotope Equilibrium Temperatures ............................................................................... 118

Low- and Intermediate-Sulfidation Deposits .................................................................118

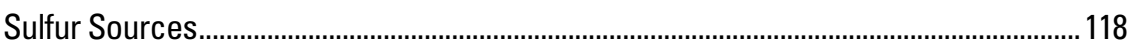


Isotope Equilibrium Temperatures........................................................................................ 118

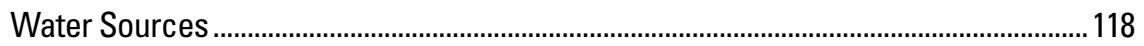

Radiogenic Isotope Geochemistry ....................................................................................... 120

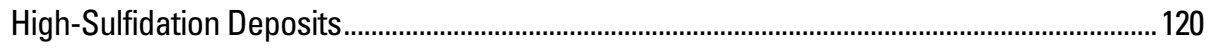

Low- and Intermediate-Sulfidation Deposits ....................................................................... 122

Chapter L. Hydrothermal Alteration ................................................................................................... 125

By Peter G. Vikre and David A. John

General Aspects of Hydrothermal Alteration in Epithermal Deposits ............................................ 125

End-Member Hydrothermal Systems, Types of Hydrothermal Fluids, and Hydrothermal

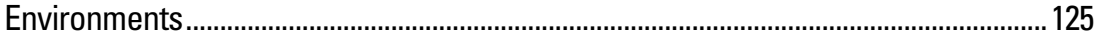

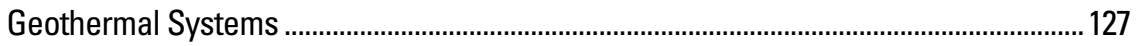

Magmatic-Hydrothermal Systems.............................................................................. 128

Hydrothermal Minerals, Hydrothermal Alteration Assemblages, Alteration Zoning, and

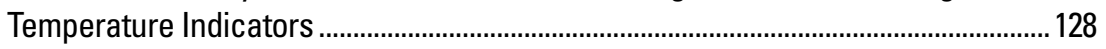

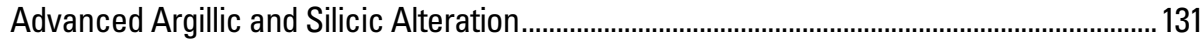

Hydrothermal Alteration in High-Sulfidation Deposits................................................................... 131

Structural, Stratigraphic, Chemical, and Physical Controls ..................................................... 132

Mineralogy, Lateral Zoning, and Paragenesis ................................................................... 133

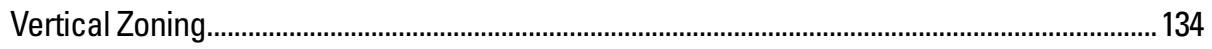

Hydrothermal Alteration in Low- and Intermediate-Sulfidation Deposits ...................................... 134

Structural, Stratigraphic, Chemical, and Physical Controls .................................................... 136

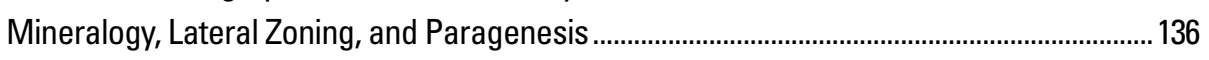

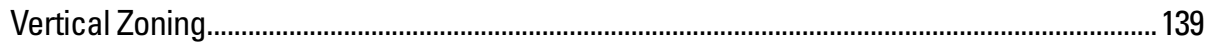

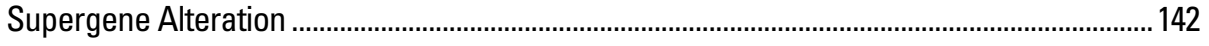

Chapter M. Petrology of Associated Igneous Rocks ........................................................................... 143

By Edward A. du Bray

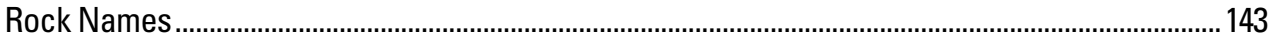

Forms of Igneous Rocks and Rock Associations ......................................................................... 145

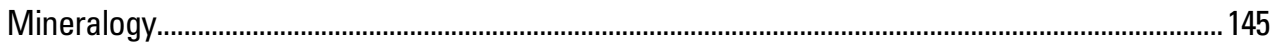

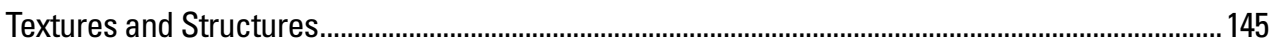

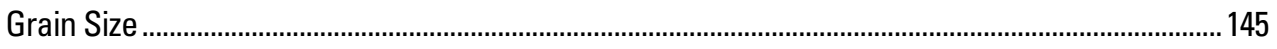

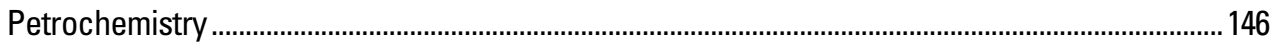

Trace-Element Geochemistry................................................................................................. 146

Isotope Geochemistry ............................................................................................................ 148

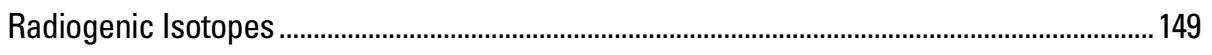

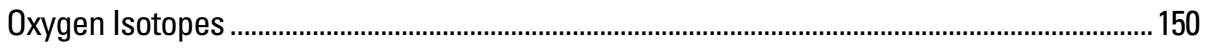

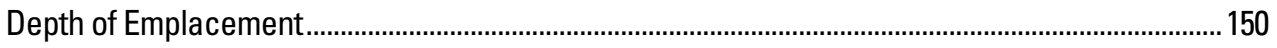

Chapter N. Petrology of Associated Sedimentary Rocks ...................................................................... 153

By Edward A. du Bray

Chapter O. Petrology of Associated Metamorphic Rocks ......................................................................... 155

By Edward A. du Bray

Chapter P. Theory of Deposit Formation.................................................................................................. 157

By Peter G. Vikre and David A. John

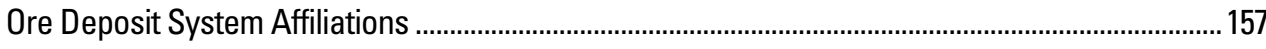

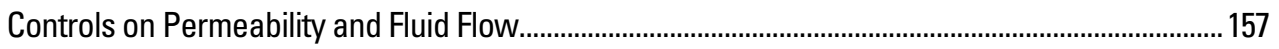

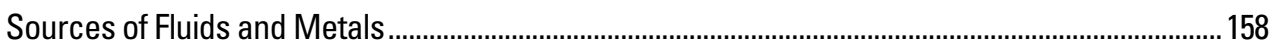


Chemical and Physical Transport and Transfer Processes............................................................... 159

Heat Transport and Transfer Processes....................................................................................... 159

Pressure Gradients during Ore Formation ................................................................................. 160

Wall-Rock Reactions and Ore-Mineral Depositional Processes...................................................... 161

Chapter Q. Weathering and Supergene Processes …………................................................................ 163

By David A. John

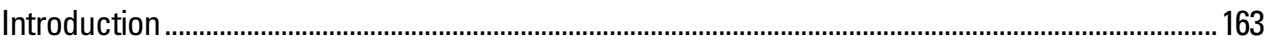

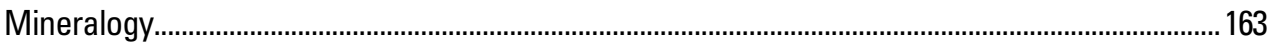

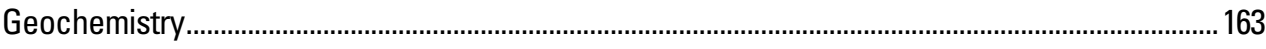

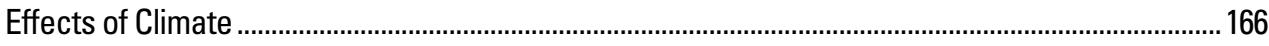

Chapter R. Geoenvironmental Features.................................................................................................. 167

By David L. Fey

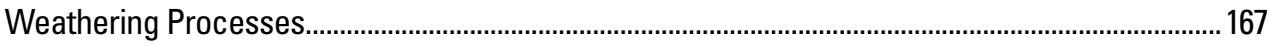

Soil and Sediment Signatures Before Mining .................................................................................. 167

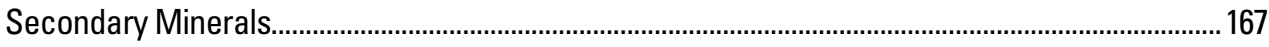

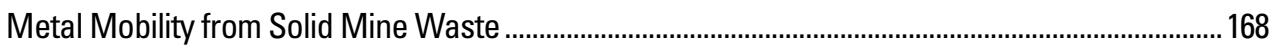

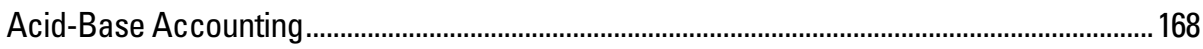

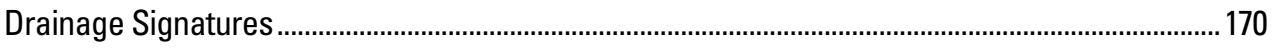

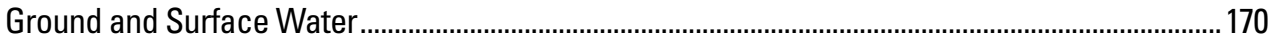

Past and Present Mining Methods and Ore Treatment.................................................................. 172

Volume and Footprint of Mine Waste and Tailings ......................................................................... 172

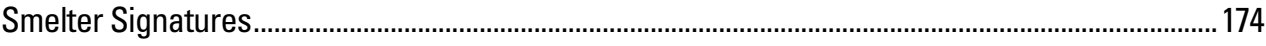

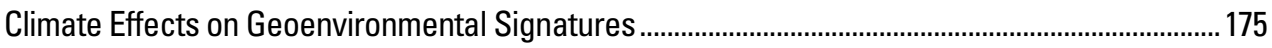

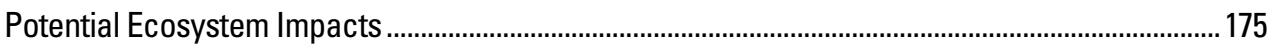

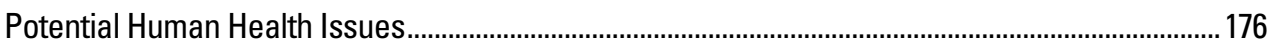

Chapter S. Exploration and Assessment Techniques …….................................................................. 179

By David A. John, Peter G. Vikre, and Frederick T. Graybeal

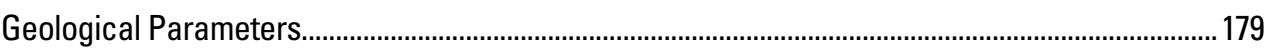

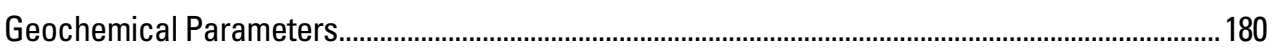

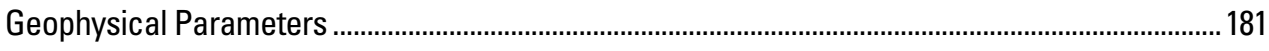

Attributes Required for Inclusion in Permissive Tracts at Various Scales ....................................... 182

Knowledge that Enables Favorability Zonation of Permissive Tracts.............................................. 182

Factors Affecting Undiscovered Deposit Estimates (Deposit Size and Density).............................. 182

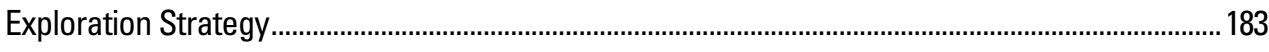

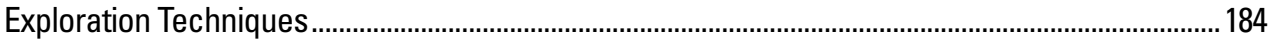

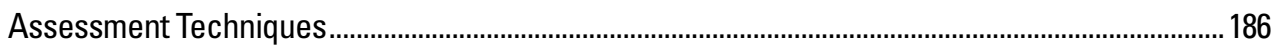

Chapter T. Research Directions .......................................................................................................... 187

By Peter G. Vikre

High-Sulfidation Deposits .......................................................................................................... 187

Low- and Intermediate-Sulfidation Deposits .......................................................................... 187

All Epithermal Gold-Silver Deposits Subtypes .................................................................................... 187

Acknowledgments............................................................................................................................ 188

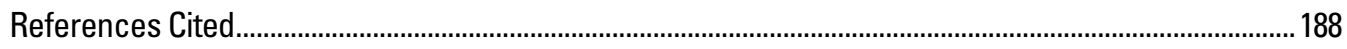

Appendix 1. Characteristics of Epithermal Gold-Silver Deposits ............................................................22

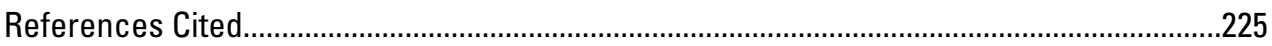


Appendix 2. Grade and Tonnage Data and Data Sources for Epithermal Gold Deposits ...........................243

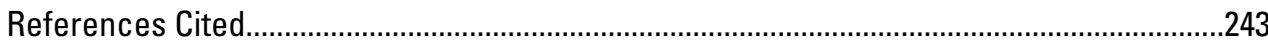

Appendix 3. Compilation of Isotopic Data for Epithermal Gold-Silver Deposits........................................247

\section{Figures}

A1. Map showing locations of epithermal gold-silver deposits summarized in appendix 1 ............. 4

A2. Graphs showing gold and silver grades and tonnages for most epithermal gold-silver deposits summarized in appendix 1 .

B1. Schematic cross sections showing end-member magmatic-hydrothermal and geothermal systems and positions of low-sulfidation (neutral) and high-sulfidation (acid) epithermal environments within these systems

B2. Sulfur fugacity $\left(f S_{2}\right)$-temperature diagram showing the variety of sulfide assemblages in epithermal deposits that reflect sulfidation state.

C1. Schematic cross section showing epithermal gold-silver deposits and other related or proximal deposit types

E1. Histogram showing ages of known epithermal gold-silver deposits

E2. Schematic cross sections showing volcanic landforms that commonly host epithermal gold-silver and related deposits and principal metals

E3. Cross section of the Kelian, Indonesia, intermediate-sulfidation deposit showing maar-diatreme dome complex and breccia bodies

E4. Cross section of diatreme-dome complex at Cerro de Pasco, Peru.

E5. Schematic cross section of ore zones at the Mule Canyon low-sulfidation deposit, Nevada.. 28

E6. Fault mesh model of Hill (1977) for earthquake swarms comprising interlinked shear, extensional, and extensional-shear fractures developed in a triaxial stress field...

E7. Cross section of the Golden Cross deposit, New Zealand, showing distribution of veins and ore types. Figure modified from Begbie and others (2007).

E8. Maps showing structural settings of geothermal and low-sulfidation epithermal systems ...30

E9. Cross section of the Hycroft (Crofoot-Lewis, Sulphur) low-sulfidation deposit, Nevada..........31

E10. Cross section and photograph of McLaughlin low-sulfidation deposit, California .....................32

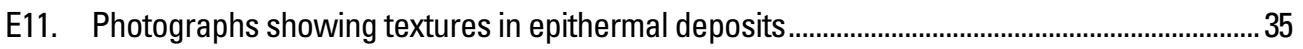

E12. Photographs of hydrothermal breccias........................................................................... 38

E13. Photographs of sinter and siliceous hydrothermal deposits in the Bodie Hills, California and

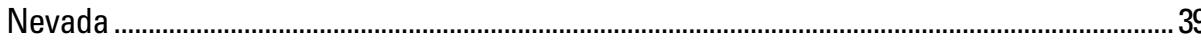

F1. Plan map and cross sections of high-grade, structurally controlled high-sulfidation gold-silver deposits

F2. Plan map and sections of low-grade, structurally and stratigraphically controlled high-sulfidation gold deposits

F3. Geologic maps and cross sections of low-sulfidation and intermediate-sulfidation epithermal gold-silver districts

F4. West-east section $8148 \mathrm{~N}$ through the low-sulfidation epithermal gold-silver deposit at Bullfrog, U.S.A.

F5. Geophysical sections through paleosurface deposits and subjacent low-sulfidation gold-silver veins

G1. Schematic diagram showing geophysical properties of hypothetical, generalized epithermal gold systems

G2. Maps showing analysis of aeromagnetic anomalies from the Waihi-Waitekauri region of New Zealand. 
G3. Map showing gradient-array resistivity survey of a part of the Pajingo low-sulfidation epithermal gold deposit, Australia, and cross sections determined from 50-meter dipole-dipole transects

G4. Maps showing potassium distribution determined from airborne radiation measurements of the Waihi-Waitekauri epithermal system.

G5. Maps showing aeromagnetic anomalies from the Yanacocha gold district, Peru and airborne time-domain electromagnetic anomalies, continued upward

G6. Geologic and aeromagnetic maps of the Goldfield mining district, Nevada

H1. Advanced Spaceborne Thermal Emission and Reflection Radiometer (ASTER)-derived mineral maps of the Hasbrouck Mountain and Divide low-sulfidation deposits located about 9 kilometers south-southwest of Tonopah, Nevada

H2. Preliminary Advanced Spaceborne Thermal Emission and Reflection Radiometer (ASTER)-derived shortwave-infrared (SWIR) mineral map of the Yanacocha highsulfidation deposit located 20 kilometers north of Cajamarca, Peru.

H3. Map of the high-sulfidation deposits in the Goldfield, Nevada

H4. Map of iron-bearing minerals produced from analysis of Airborne Visible/Infrared Imaging Spectrometer (AVIRIS) visible (VIS) and near-infrared (NIR) data................................................ 72

H5. Geologic map of the Goldfield district, Nevada .......................................................................... 73

H6. Mineral maps of the Florida Canyon low-sulfidation deposit, Nevada ..................................... 74

H7. Spectral plot of ferric iron minerals showing the visible (VIS), near-infrared (NIR), and shortwave-infrared (SWIR) regions .......................................................................................

H8. Map of mineral groups produced from analysis of Landsat $8 \mathrm{OLI}$ data .................................... 79

H9. Uncorrected Landsat $8 \mathrm{OLI}$ spectra from scene covering Goldfield, Nevada, collected on August 1, 2013.

H10. Laboratory reflectance spectra of field samples collected near Goldfield, Nevada, from undisturbed, highly altered rock

11. Photographs showing multigenerational breccias consisting of clasts variably altered to quartz \pm alunite \pm kaolinite \pm pyrite, leached, and variably encrusted by quartz, gold (>99 atom percent)+quartz, enargite (and other Cu-As-Sb-S minerals), bismuthinite+quartz, and no-iron sphalerite.

12. Photographs of low-sulfidation quartz-adularia veins............................................................... 87

13. Photographs of intermediate-sulfidation quartz-adularia veins................................................ 88

K1. Graphs showing lateral geochemical gradients in rocks surrounding quartz and quartz (qtz)-barite veins in the El Peñón district, Chile

K2. South-north cross section along section 229570E through the Penasco diatreme showing metal zoning in the Peñasquito intermediate-sulfidation deposit, Zacatecas, Mexico........... 103

K3. Schematic cross section showing mineralogical and geochemical zoning associated with the Gosowong intermediate-sulfidation deposit, Indonesia, including the alteration halo, upflow zone along downward extension of the Gosowong Fault, and at the surface............ 104

K4. Cross sections showing mass changes of precious metals, base metals, and epithermal pathfinder elements in altered rocks surrounding low-sulfidation veins at El Peñón, Chile. 106

K5. Cross sections showing distribution of trace elements relative to geologic features in the Moore ore body, Pueblo Viejo high-sulfidation deposit, Dominican Republic

K6. Plots of trace element concentrations versus lateral distance from vuggy silica (residual quartz) alteration for the Copper Hill ore zone in the center and the Science vein on the periphery of the Summitville high-sulfidation deposit, Colorado

K7. Schematic diagram showing distribution of trace elements and their relation to ore and alteration zoning in and above the Pueblo Viejo high-sulfidation deposits 
K8. Homogenization temperature versus depth profiles for low- and intermediate-sulfidation deposits with geologically established paleosurfaces at National, Nevada, U.S.A., and McLaughlin, California, U.S.A., and paleosurfaces fitted to aqueous vapor-liquid equilibria versus depth for deposits in Mexico

K9. $\delta^{18} 0-\delta^{34} S$ (in \%o) compositional fields of alunite environments: magmatic-hydrothermal, steam-heated, magmatic steam, and supergene

K10. $\delta D-\delta^{18} 0$ values (in \%) of hydrothermal minerals and igneous biotite, and water in equilibrium with each mineral in the Summitville, U.S.A. high-sulfidation deposit, relative to primary magmatic water, felsic magmatic water, present day meteoric water, the meteoric water line, and the kaolinite line

K11. Representative hydrogen and oxygen isotope values of minerals, waters, and rocks in low- and intermediate-sulfidation deposits.

L1. Schematic cross sections showing end-member geothermal and magmatichydrothermal systems associated with modest-relief, intermediate-composition volcanic edifices and the positions of low- and intermediate-sulfidation and highsulfidation epithermal environments within these systems.

L2. Schematic cross sections of low- and intermediate-sulfidation and high-sulfidation epithermal gold-silver deposits showing hydrothermal features, hydrothermal alteration assemblages and minerals, and ore minerals and ore zones

L3. Diagrams showing thermal stability and distribution of hydrothermal minerals in epithermal systems

L4. Photographs of residual quartz and alunitic advanced argillic alteration.

L5. Sections and plan maps of high-sulfidation gold-copper-silver deposits with representative zoning patterns of alteration types and mineral assemblages

L6. Plan distribution of zoned alteration mineral assemblages in the low-sulfidation deposit at Hog Ranch, Nevada and Sections through the East, White Mountain, Geib, and Bell Springs deposits showing distribution of assemblages in $(A)$ and other unexposed assemblages and sub-assemblages.

L7. Plan map and cross sections showing hydrothermal alteration at the Midas lowsulfidation deposit, Nevada.

L8. Schematic sections through mafic and felsic wall-rock alteration selvages at Midas, Nevada. 140

L9. West-east section through Buckskin Mountain, National district, U.S.A.. 141

M1. Total alkali-silica variation diagram showing compositions of igneous rocks associated with low- and intermediate-sulfidation and high-sulfidation epithermal mineral deposits ... 144

M2. Histogram showing the frequency distribution of samples of igneous rocks associated with low- and intermediate-sulfidation and high-sulfidation epithermal mineral deposits as a function of $\mathrm{SiO}_{2}$

M3. Variation diagram showing molar major-oxide compositions of igneous rocks associated with low- and intermediate-sulfidation and high-sulfidation epithermal mineral deposits as a function of relative alumina and alkali saturation

M4. $\mathrm{Na}_{2} \mathrm{O}+\mathrm{K}_{2} \mathrm{O}-\mathrm{CaO}$ versus $\mathrm{SiO}_{2}$ variation diagram showing the composition of igneous rocks associated with low- and intermediate-sulfidation and high-sulfidation epithermal mineral deposits.

$\mathrm{M} 5$. $\mathrm{FeO} /(\mathrm{Fe} \mathrm{O}+\mathrm{MgO})$ variation diagram showing the composition of igneous rocks associated with low- and intermediate-sulfidation and high-sulfidation epithermal mineral deposits relative to boundaries between ferroan and magnesian rocks as well as between tholeiitic and calc-alkaline rocks

M6. ${ }^{207} \mathrm{~Pb} /{ }^{204} \mathrm{~Pb}-{ }^{206} \mathrm{~Pb} / 204 \mathrm{~Pb}$ diagram showing compositions of igneous rocks associated with low- and intermediate-sulfidation and high-sulfidation epithermal deposits. 
M7. Neodymium-strontium isotope compositions of igneous rocks associated with low- and intermediate-sulfidation and high-sulfidation epithermal deposits

M8. Histogram showing the frequency distribution of samples of igneous rocks associated with low- and intermediate-sulfidation and high-sulfidation epithermal mineral deposits as a function of $\varepsilon_{\mathrm{Nd}}$ values

M9. Histogram showing the frequency distribution of samples of igneous rocks associated with low- and intermediate-sulfidation and high-sulfidation epithermal mineral deposits as a function of initial ${ }^{87} \mathrm{Sr} /{ }^{86} \mathrm{Sr}$ values.

M10. Histogram showing the frequency distribution of samples of igneous rocks associated with low- and intermediate-sulfidation and high-sulfidation epithermal mineral deposits as a function of $\delta^{18} 0$

P1. Diagrams showing boiling relations for water ................................................................... 160

01. Schematic diagram showing behavior of silver and gold in the supergene environment..... 164

R1. Plot of net acid production (NAP) versus the sum of dissolved metals $(\mathrm{Zn}+\mathrm{Cd}+\mathrm{Cu}+\mathrm{As}+\mathrm{Pb})$ from a static water 1:20 leach for samples from the upper Animas River watershed, southwest Colorado

R2. Modified Ficklin plot of drainage waters from high-sulfidation and low- and intermediatesulfidation epithermal deposits

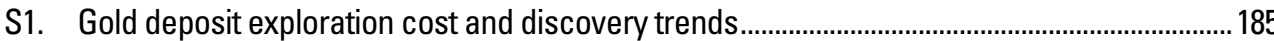

\section{Tables}

B1. Evolution of classification schemes applied to epithermal gold-silver deposits................................ 8

B2. Characteristics of epithermal gold-silver deposit subtypes and variants...................................... 10

E1. Summary of relationships between tectonic setting, magmatism, and epithermal gold-silver

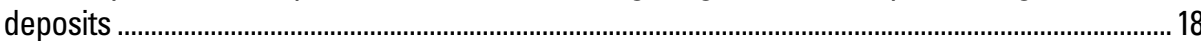

E2. Duration of hydrothermal systems forming epithermal gold-silver deposits ................................. 20

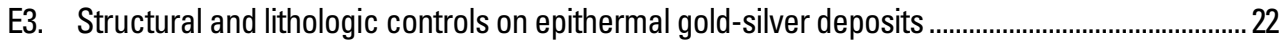

K1. Geochemical Characteristics of Ores from Epithermal Gold-Silver Deposits................................96

L1. Common hydrothermal alteration assemblages in epithermal deposits......................................127

L2. Types and Characteristics of Silicic Alteration....................................................................... 132

01. Mechanisms of gold mobilization and precipitation during weathering ...................................... 165

02. Common silver-bearing minerals in supergene zones of epithermal gold-silver deposits (modified from Sillitoe, 2009)......................................................................................................... 165

R1. Summary statistics for 37 water samples directly associated with high-sulfidation epithermal deposits

R2. Summary statistics for 13 water samples collected from low- and intermediate-sulfidation epithermal deposits

R3. Total disturbed area footprints, pit areas, in hectares, and ratio of pit area to total disturbed area for selected high-sulfidation epithermal deposits

R4. Total disturbed area footprints, pit areas, in hectares, and ratio of pit area to total disturbed area for selected surface-mined low- and intermediate-sulfidation epithermal deposits. ........ 174

R5. Total disturbed area footprints in hectares for selected underground-mined low- and intermediate-sulfidation epithermal deposits. 



\title{
Descriptive Models for Epithermal Gold-Silver Deposits
}

\author{
By David A. John, Peter G. Vikre, Edward A. du Bray, Richard J. Blakely, David L. Fey, Barnaby W. Rockwell, \\ Jeffrey L. Mauk, Eric D. Anderson, and Frederick T. Graybeal
}

\section{Abstract}

This report constitutes a new descriptive model for epithermal gold-silver deposits. It summarizes characteristics of known deposits, including their geological, geophysical, geochemical, and geoenvironmental aspects. Models concerning the genesis of epithermal gold-silver deposits are discussed. How descriptive and genetic aspects of the model can be applied to mineral exploration and resource assessment of undiscovered deposits is described. Finally, areas where additional research is needed to better understand the genesis of these deposits are identified. An extensive summary table outlining the characteristics of about 100 epithermal gold-silver deposits is included as an appendix; this summary table includes most of the world's largest epithermal gold-silver deposits, and many smaller, well-studied deposits.

Epithermal gold-silver deposits are shallowly formed vein, stockwork, disseminated, and replacement deposits that are mined primarily for their gold and silver contents; some deposits also contain substantial resources of lead, zinc, copper, and (or) mercury. Although many epithermal deposits are known for their high gold grades (bonanza ores with more than 1 troy ounce [31.10348 grams of gold per short ton] [34.3 parts per million]) amenable to mining by underground methods, many bulk tonnage deposits with as little as 1 part per million (ppm) gold or less are presently being exploited by open-pit mining.

Many deposit subtypes have been defined and alternative classification schemes developed for epithermal gold-silver deposits; these subtypes and classification schemes reflect variations in metal contents, gangue and ore minerals, or inferred composition of ore-forming hydrothermal fluids. In this descriptive model, epithermal gold-silver deposits are separated into low-, intermediate-, and high-sulfidation subtypes to reflect the most frequently used classification scheme. A variant of low-sulfidation deposits associated with alkaline igneous rocks is not discussed in this model.

Epithermal deposits form in the upper crust at the paleosurface to depths about $1,500 \mathrm{~m}$ below the water table and at temperatures that range from about 100 to $300^{\circ} \mathrm{C}$. Most deposits are genetically related to hydrothermal systems associated with subaerial volcanism and intrusion of subduction-related calc-alkaline magmas ranging in composition from basalt to rhyolite in island- and continental-arc settings; less commonly, these deposits are related to hydrothermal systems associated with continental rifting or hot spot magmatism. Lava dome and associated diatreme complexes are the volcanic features most commonly temporally and spatially associated with ore formation and host many epithermal deposits; less common volcanic hosts include stratovolcanoes, ignimbrite calderas, and dike complexes. Most epithermal deposits are related to hydrothermal systems that form in response to release of magmatic fluids (degassing) from crystallizing intrusions at depth.

Epithermal gold-silver deposits form in a variety of tectonic settings that range from extensional to transtensional, transpressional, and compressional. Within this broad range of regional tectonic settings, epithermal deposits most commonly occur as veins or breccias developed in local extensional or dilational fault and fracture zones. Disseminated and replacement ore also commonly forms in permeable lithologies where horizons intersect faults or fractures that allowed fluid ingress. Most known epithermal gold-silver deposits are Cenozoic, which reflects preferential preservation of these shallowly formed deposits in tectonically unstable regions; however, Paleoproterozoic deposits as old as $1.9 \mathrm{Ga}$ are preserved within some cratons, and veins showing classic epithermal textures and aged at $3.46 \mathrm{Ga}$ occur in the Pilbara Craton of Western Australia.

The character of hydrothermal alteration associated with epithermal deposits varies considerably between deposit subtypes, and within deposits, as a consequence of varying spatial relations with the paleowater table. High-sulfidation deposits are characterized by a core zone of residual (vuggy) quartz flanked by quartz-alunite and advanced argillic alteration containing kaolinite/dickite and (or) pyrophyllite produced by very low $\mathrm{pH}$ fluids below the paleowater table. In contrast, potassic alteration with quartz, adularia and (or) carbonate minerals and (or) illite, indicative of formation from near-neutral $\mathrm{pH}$ fluids, forms the core of low- and intermediate-sulfidation deposits. More distal argillic and propylitic alteration may fringe all deposit subtypes. Above the paleowater table, steam-heated advanced argillic and argillic alteration assemblages composed of alunite, kaolinite, smectite, and cristobalite or opaline silica may form in association with all deposit subtypes. Silica sinter deposits are present near and locally host some low-sulfidation deposits but are absent in high-sulfidation deposits.

Distinct ore and gangue mineral assemblages characterize each of the deposit subtypes. Ore minerals in low-sulfidation 
deposits include electrum, silver sulfides, selenides, and sulfosalts, and (or) gold and silver tellurides, and in intermediate-sulfidation deposits, base metal sulfides, including silver-bearing tetrahedritetennantite, chalcopyrite, galena, and sphalerite, also may be present. Gangue minerals in these deposits include quartz, adularia, illite/sericite, and carbonate minerals. Gold and (or) electrum, gold tellurides, acanthite, enargite, luzonite, and other copper sulfide and sulfosalt minerals, hosted by quartz gangue, characterize high-sulfidation deposits. Pyrite and (or) marcasite are common in all deposit subtypes.

Epithermal gold-silver deposits commonly contain elevated abundances of As, Sb, Hg, Se, Te, Tl, and (or) W; some deposits also are enriched in $\mathrm{Pb}, \mathrm{Zn}, \mathrm{Cu}$, and Mo. However, concentrations of these elements (ppm to weight percent) vary widely within individual deposits, between different deposits within each subtype of deposit, and between each deposit subtype; commonly gold abundance is the best indicator of gold mineralization.

Stable and radiogenic isotope and fluid inclusion studies of epithermal deposits indicate that meteoric waters, containing variable magmatic volatile contents, are principally responsible for gold-silver mineralization. High-sulfidation deposits typically have isotopic compositions consistent with larger magmatic fluid contributions than in low- and intermediate-sulfidation deposits. The ultimate origin of gold, silver, and other metals in epithermal gold-silver deposits remains uncertain but probably reflects multiple sources in the upper mantle and crust.

Hydrothermal alteration and ore formation variably alter the physical properties of epithermal deposit host rocks, which results in features detectable by using geophysical techniques. These changes include partial or complete destruction of rock magnetism, bulk density modification, altered electrical resistivity, and potassium enrichment or depletion. A combination of magnetic lows and high $\mathrm{K} / \mathrm{Th}$, as indicated by airborne radiometric data, can be effective in outlining the spatial distribution of potassic alteration potentially associated with lowand intermediate-sulfidation epithermal deposits.

Spectral data collected by airborne and satellite remotesensing systems may delineate the distribution of hydrothermal alteration minerals, notably clay minerals and alunite formed by magmatic-hydrothermal fluids associated with high-sulfidation systems and those formed by steam-heated fluids above epithermal deposits. Similarly, iron-oxide/hydroxide minerals and silica enrichment can be delineated by using remote-sensing data. Portable infrared spectrometers are commonly used to rapidly distinguish clay minerals and alunite as an aid in mapping hydrothermal alteration and logging drill core.

Potential geoenvironmental impacts on ecosystems surrounding epithermal deposits vary widely as a function of deposit subtype, host rocks, climate, topography, and mining and processing methods applied to epithermal gold-silver deposits. Acid mine drainage and accompanying metal loads can affect surface and groundwater resources. In addition, metal-enriched sediment can contaminate surface drainages, especially in humid or wet settings where topographic relief is significant. Water quality is most likely to be adversely impacted by elevated abundances of $\mathrm{Zn}, \mathrm{Cu}, \mathrm{Pb}, \mathrm{Hg}$, Sb, and As. High-sulfidation deposits are more likely than low- and intermediate-sulfidation deposits to generate metal-enriched acid mine drainage that impacts water quality, because of their large sulfide mineral and metal contents and low acid buffering capacity.

Techniques that have proven important in exploration for epithermal gold-silver deposits depend on deposit type, terrain, climate, vegetation, and extent of postmineralization cover rocks. In exploration for low- and intermediate-sulfidation systems, broad areas for more detailed study may be delineated by using airborne geophysical techniques, with magnetic surveys outlining the extent of hydrothermal alteration and radiometric surveys delimiting areas of potassium metasomatism, which mostly form toward the center of a hydrothermal system. In arid climates with limited vegetation, airborne and satellite remote-sensing data can define areas of advanced argillic alteration (magmatichydrothermal and steam-heated types) and silicic alteration, which form near the tops and cores of epithermal systems. Regional stream sediment sampling and follow-up delineation of bedrock sources of gold anomalies in stream sediment samples have proven especially effective in tropical climates. Also, because silicic alteration and veins are typically resistant to weathering, prospecting for fragments of these rocks in drainages can be an effective exploration technique. More detailed studies using geologic and alteration mapping, geochemical analyses, and electrical and electromagnetic geophysical techniques are focused on determining lateral and vertical position within epithermal systems, which may be defined by recognition of shallow hydrothermal features, such as sinters, explosion breccias, and steam-heated alteration, hydrothermal mineral, alteration, and geochemical zoning, vein textures and fluid inclusion populations. Ultimately, drilling is used to determine subsurface geology and the presence or absence of economic epithermal deposits. 


\title{
Chapter A. Introduction
}

\author{
By David A. John
}

Epithermal gold-silver deposits form in the uppermost parts of the crust, at less than about 1,500 meters (m) below the water table, and contain gold and (or) silver minerals in structurally controlled veins and breccias and disseminated in larger host rock volumes. These deposits are distributed throughout the world, most commonly along convergent plate margins (fig. A1). Epithermal gold-silver deposits range in size from tens of thousands to greater than 1 billion metric tons of ore and have gold contents of 0.1 to greater than 30 grams per metric ton $(\mathrm{g} / \mathrm{t})$ and silver contents of less than 1 to several thousand grams per metric ton (fig. A2). Historically, epithermal gold-silver deposits have been an important source of gold and silver; about 6 percent of all gold and about 16 percent of all silver have been mined from these deposits (Singer, 1995). Frimmel (2008) estimates that epithermal gold-silver deposits contain about 8 percent of global gold resources (combined past production, reserves, and resources). The wide range of tonnage-grade characteristics makes these deposits an attractive target for small and large exploration and mining companies.

This descriptive model of epithermal gold-silver deposits is part of a systematic effort by the U.S. Geological Survey Mineral Resources Program to update existing, and develop new, descriptive mineral deposit models. Recently published summaries of epithermal gold-silver deposits have added considerably to our knowledge of these deposits (for example, Hedenquist and others, 2000; Cooke and Simmons, 2000; Sillitoe and Hedenquist, 2003; Simmons and others, 2005; Taylor, 2007). The U.S. Geological Survey deposit modeling effort is intended to supplement these summaries by developing more complete models in a common format for use in mineral-resource and mineral-environmental assessments.

The new epithermal gold-silver deposit model described herein summarizes the characteristics of known deposits, including geological, geophysical, geochemical, and geoenvironmental aspects of these deposits. Models for the genesis of epithermal gold-silver deposits are discussed. The application of descriptive and genetic aspects of the model to mineral exploration and assessment of undiscovered deposits is discussed. Finally, areas where additional research is needed to understand the genesis of these deposits are identified. An extensive summary table of the characteristics of more than 100 epithermal gold-silver deposits from throughout the world (fig. A1) is included as appendix 1; this summary table includes most of the world's largest epithermal gold-silver deposits as well as smaller, well-studied deposits. 


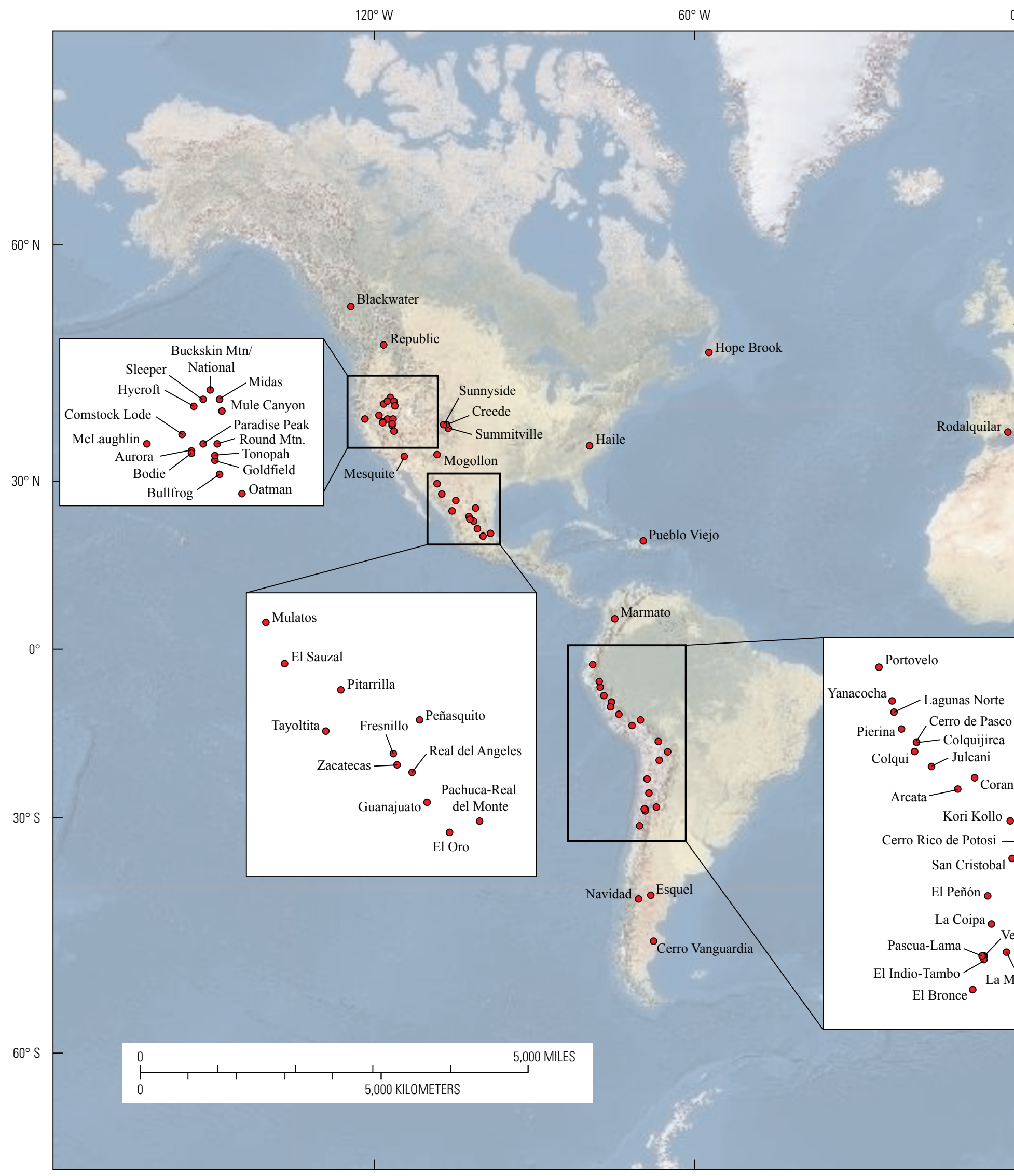

Base from ESRI world imagery map service ESRI_Imagery_World_2D,

1:133,000,000, 2013, available at

https://www.arcgis.com/home/item.html?id=10189d5ffbce4ef48f5bcc0661 cfaff9

Figure A1. Map showing locations of epithermal gold-silver deposits summarized in appendix 1. 


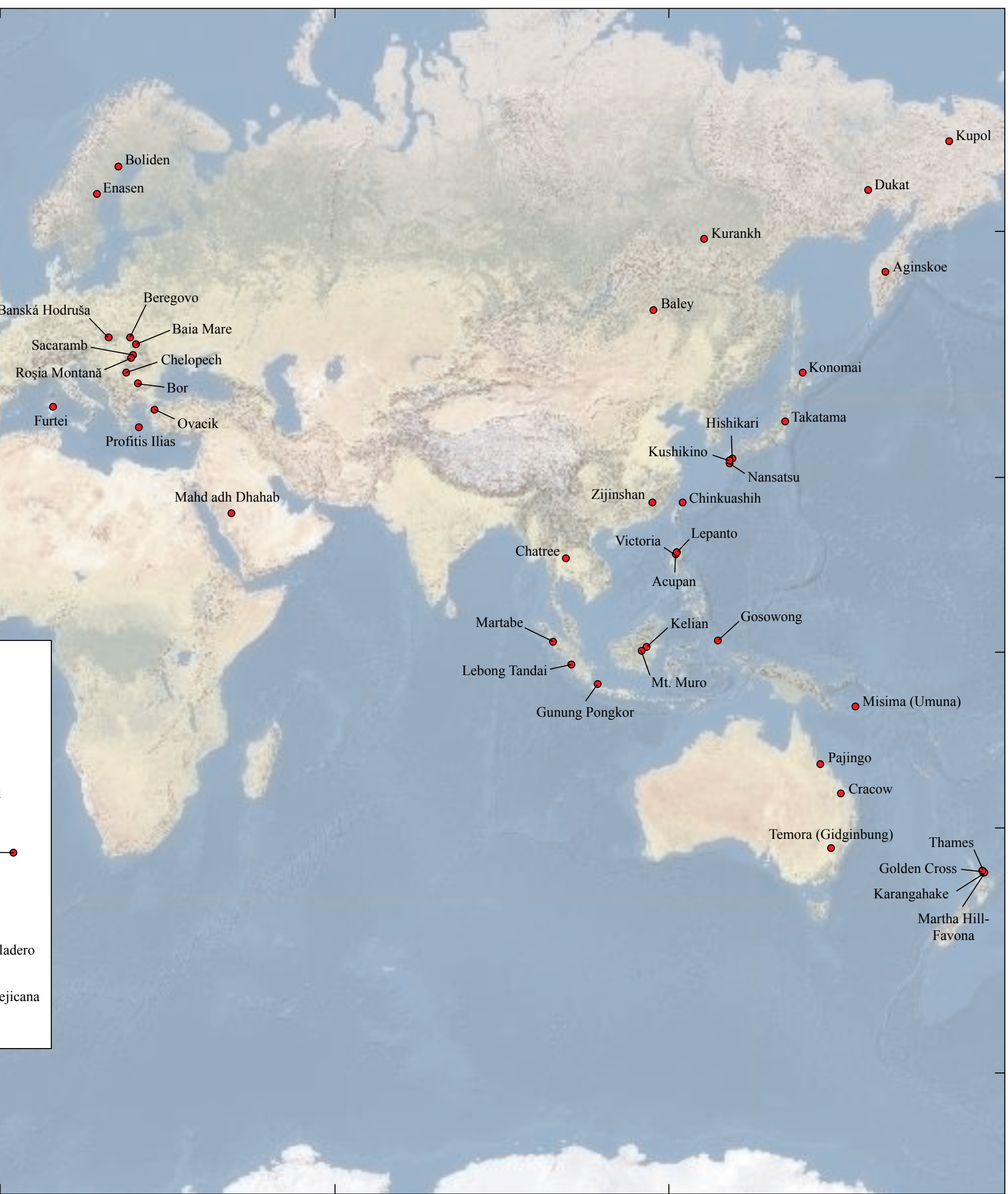



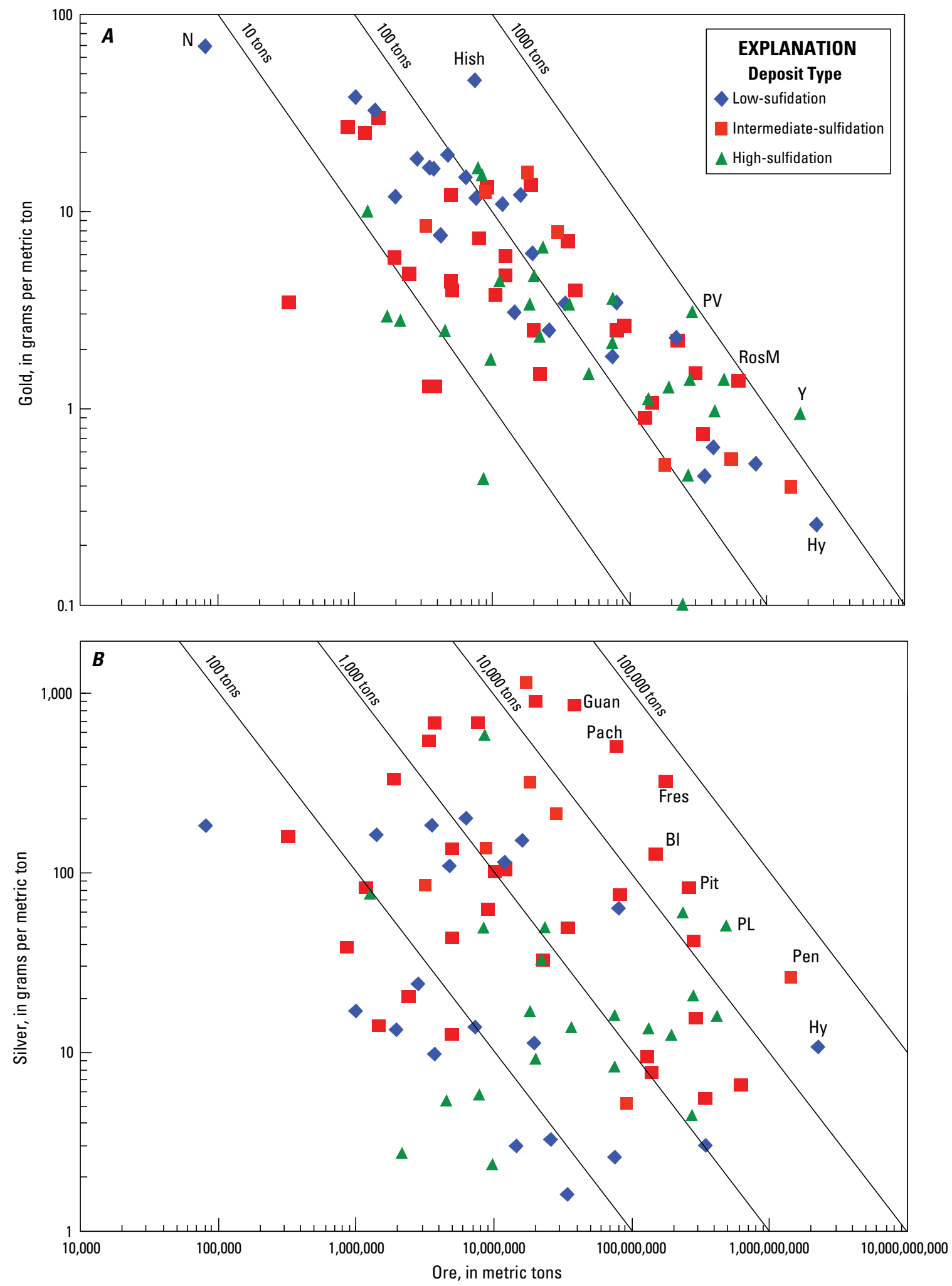

Figure A2. Graphs showing gold $(A)$ and silver $(B)$ grades and tonnages for most epithermal gold-silver deposits summarized in appendix 1. Data, data sources, and compilation methods are listed in appendix 2. Ore tonnages are a combination of production, proven and probable reserves, and measured and indicated resources, where available. Grades are averages of all ore types. Diagonal lines show total contained metal in metric tons. Abbreviations: BI, Blackwater, Canada; Fres, Fresnillo, Mexico; Guan, Guanajuato, Mexico; Hish, Hishikari, Japan; Hy, Hycroft, Nevada; N, National, Nevada; Pach, Pachuca-Rio Del Monte, Mexico; Pen, Peñasquito, Mexico; Pit, Pitarrilla, Mexico; PL, Pascua-Lama, Peru; PV, Pueble Viejo, Dominican Republic; RosM, Roşia Montană, Romania; Y, Yanacocha, Peru. 


\title{
Chapter B. Definition and Classification of Epithermal Gold-Silver Deposits
}

\author{
By David A. John and Peter G. Vikre
}

The term "epithermal" was originally applied by Lindgren $(1928,1933)$ to mineral deposits mined primarily for gold, silver, mercury, antimony, and base metals $(\mathrm{Cu}, \mathrm{Pb}$, and $\mathrm{Zn})$, and deposited "at slight depth below the surface," at temperatures "perhaps from 50 to $200{ }^{\circ} \mathrm{C}$," and at pressures that "scarcely exceed 100 atmospheres." He distinguished nine types of epithermal deposits according to their mineral and metal contents (table B1) and described examples of most types. Since Lindgren's seminal studies, it has been recognized that epithermal deposits form at temperatures as high as about $300{ }^{\circ} \mathrm{C}$ and at depths from about 50 to as much as $1,500 \mathrm{~m}$ below the water table, and that these deposits commonly represent the shallow parts of larger, mainly subaerial, hydrothermal systems (fig. B1; Henley and Ellis, 1983; Cooke and Simmons, 2000; Simmons and others, 2005).

Epithermal gold-silver deposit research was largely dormant from Lindgren's time until the late 1970s when deregulation of gold and silver renewed exploration interest and prompted extensive research, which resulted in proposal of more than a dozen classification schemes for epithermal gold-silver deposits (table B1). These classification schemes reflect the wide range of epithermal gold-silver deposit characteristics (appendix 1; Heald and others, 1987; White and Hedenquist, 1995; Hedenquist and others, 2000; Sillitoe and Hedenquist, 2003; Simmons and others, 2005).

As summarized by Simmons and others (2005), all modern classification systems consider ore or gangue mineralogy features, and many use chemical characteristics $(\mathrm{pH}$, oxidation state, or sulfidation state) of fluids associated with proximal hydrothermal alteration and (or) ore mineralization. The large number of proposed classification schemes reflects the wide range of characteristic features displayed by these deposits and the evolution in thinking about their origins.

The model presented here is restricted to deposits that fit the expanded definition of epithermal, and were, or are, mined because of their gold and (or) silver content. As a group, epithermal gold-silver deposits have common and distinctive characteristics (table B2). Broadly common characteristics include tectonic setting, host rocks, deposit forms, ages, and temperatures and depths of formation, whereas ore, gangue, and alteration mineral assemblages and zoning, ore-fluid chemistry, and sources of deposit components vary considerably among deposits. Especially noteworthy are differences in sulfide mineral assemblages that reflect differences in the sulfidation state of inferred ore-fluid chemistry (fig. B2, table B2; Hedenquist and others, 2000; Einaudi and others, 2003; Sillitoe and Hedenquist, 2003). The three deposit subtypes included in this model, high-, intermediate-, and low-sulfidation, are named to reflect differences in the sulfur fugacity of ore fluids that form major sulfide mineral assemblages (solid red lines, fig. B2). Silver sulfide minerals, silver selenide minerals, and electrum (gold alloy containing $>20$ weight percent silver) are largely restricted to low- and intermediate-sulfidation deposits formed at low and intermediate sulfur fugacities, respectively, whereas enargite and gold (gold alloy containing $<10$ weight percent silver) nearly universally occur in high-sulfidation deposits formed by ore fluids with high sulfur fugacity. Low- and intermediate-sulfidation subtypes are further distinguished by characteristic textures and metal contents (table B2).

Epithermal gold deposits associated with alkaline igneous rocks are a relatively uncommon variant of the low-sulfidation subtype and are described in detail by Kelley and others (in press). They are not considered further in this model.

New models described herein for the subtypes of epithermal deposits replace previous U.S. Geological Survey models for epithermal gold-silver deposits (Cox and Singer, 1986). Previous U.S. Geological Survey models consisted of Comstock epithermal veins, Creede epithermal veins, and Sado epithermal veins, which are combined into the low- and intermediate-sulfidation subtypes; hot spring gold-silver, which is divided between low- and high-sulfidation subtypes; and quartz-alunite gold, which is part of the high-sulfidation subtype (table B1). 


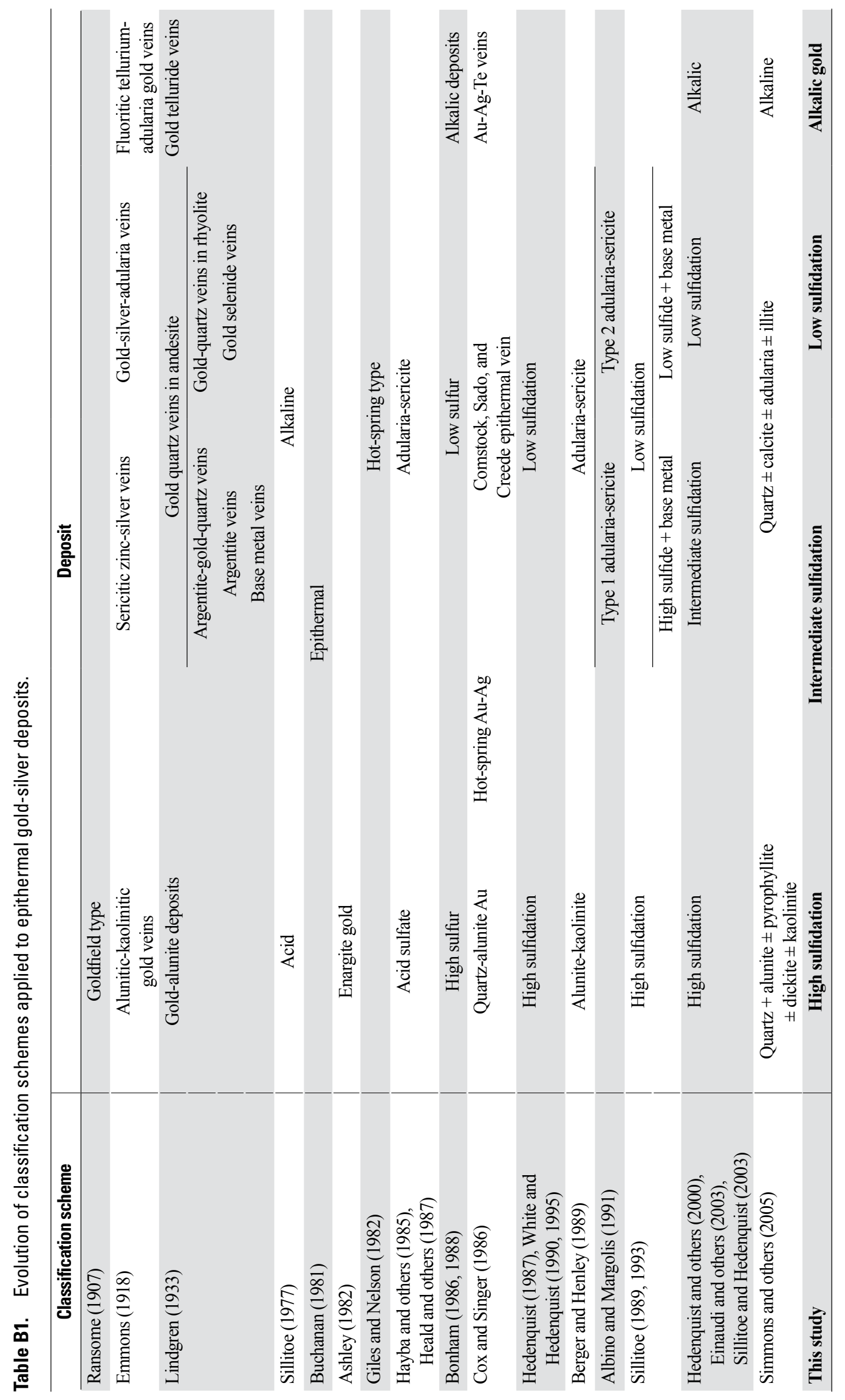




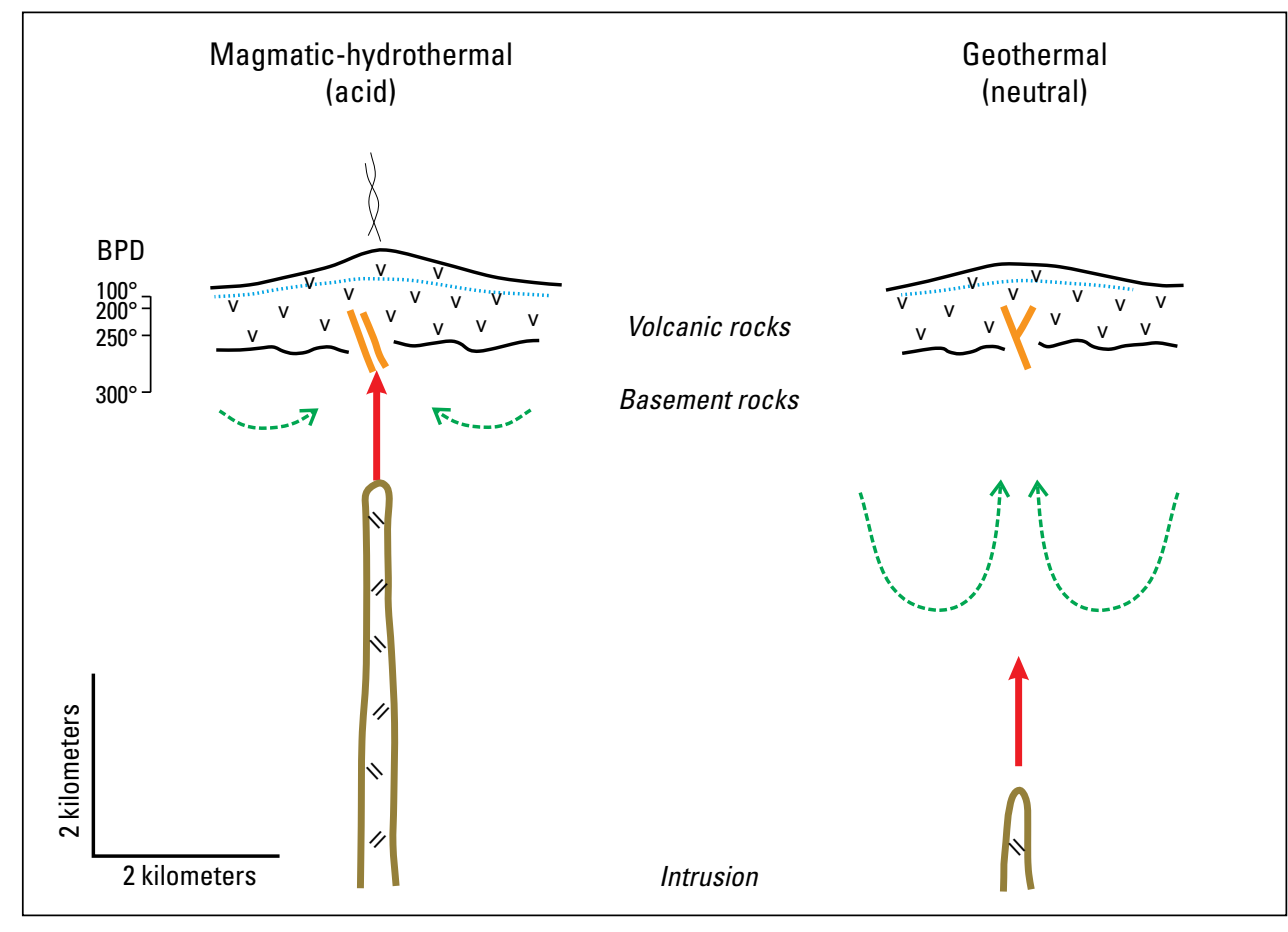

EXPLANATION

\begin{tabular}{llll} 
& Water table & Epithermal deposit \\
\hdashline & Magmatic fluid & Intrusion
\end{tabular}

Figure B1. Schematic cross sections showing end-member magmatic-hydrothermal and geothermal systems and positions of low-sulfidation (neutral) and high-sulfidation (acid) epithermal environments within these systems. The maximum pressure-temperature gradient under hydrostatic conditions is represented by boiling point for depth (BPD). Redrawn from Simmons and others (2005). 
Table B2. Characteristics of epithermal gold-silver deposit subtypes and variants.

[Ag, silver; Au, gold; As, arsenic; Bi, bismuth; equiv., equivalent; Fe, iron; Hg, mercury; m, meters; Mn, manganese; Te, tellurium; Sb, antimony; Se, selenium; Sn, tin; vol., volume; \%, percent]

\begin{tabular}{|c|c|c|c|}
\hline & High-sulfidation & Low-sulfidation & Intermediate-sulfidation \\
\hline $\begin{array}{l}\text { Spatially and temporally as- } \\
\text { sociated volcanic rocks }\end{array}$ & Calc-alkaline, andesite-dacite & $\begin{array}{l}\text { Calc-alkaline, andesite-rhyolite; } \\
\text { tholeiitic, bimodal basalt-rhyolite }\end{array}$ & Calc-alkaline, andesite-rhyolite \\
\hline $\begin{array}{l}\text { Volcanic landforms and } \\
\text { deposits }\end{array}$ & $\begin{array}{l}\text { Lava domes and flows, diatremes, tuff rings, } \\
\text { maars, and intrusive breccias associated with } \\
\text { diatremes; uplands and basins of pyroclastic } \\
\text { and volcaniclastic rocks }\end{array}$ & $\begin{array}{l}\text { Lava domes and flows; uplands } \\
\text { and basins of pyroclastic and } \\
\text { volcaniclastic rocks; dikes }\end{array}$ & $\begin{array}{l}\text { Lava domes and flows, diatremes, tuff } \\
\text { rings, maars, and intrusive breccias } \\
\text { associated with diatremes; uplands } \\
\text { and basins of pyroclastic and } \\
\text { volcaniclastic rocks }\end{array}$ \\
\hline Tectonic setting (table E1) & $\begin{array}{l}\text { Compressional-transpressional continental- } \\
\text { margin arc or back arc; compressional- } \\
\text { transpressional, neutral stress to mildly } \\
\text { extensional continental-margin arc }\end{array}$ & $\begin{array}{l}\text { Extensional continental-margin and } \\
\text { island arcs; extensional back arc; } \\
\text { post-arc continental extension }\end{array}$ & $\begin{array}{l}\text { Extensional continental-margin } \\
\text { arc; compressional island arc; } \\
\text { continental rift }\end{array}$ \\
\hline Proximal alteration minerals & $\begin{array}{l}\text { Alunite, kaolinite (dickite), pyrite, pyrophyllite, } \\
\text { residual, vuggy quartz, aluminum-phosphate- } \\
\text { sulfate (APS) minerals }\end{array}$ & Quartz-adularia \pm illite \pm pyrite & Quartz+adularia+illite+pyrite \\
\hline $\begin{array}{l}\text { Silica and carbonate gangue } \\
\text { and textural features }\end{array}$ & $\begin{array}{l}\text { Structurally and stratigraphically controlled } \\
\text { fine-grained silicification and residual, vuggy } \\
\text { quartz; no carbonate minerals }\end{array}$ & $\begin{array}{l}\text { Vein-filling crustiform and colloform } \\
\text { chalcedony and quartz; minor late } \\
\text { calcite and (or) calcite-replacement } \\
\text { texture }\end{array}$ & $\begin{array}{l}\text { Fault zone replacement and vein- } \\
\text { filling by fine- to coarse-grained } \\
\text { equigranular quartz, and crustiform } \\
\text { and comb quartz; calcite late or } \\
\text { distal to thermal centers }\end{array}$ \\
\hline Other gangue & Minor barite common, typically late & $\begin{array}{l}\text { Barite uncommon; fluorite present } \\
\text { locally }\end{array}$ & $\begin{array}{l}\text { Barite and manganiferous silicates } \\
\text { present locally }\end{array}$ \\
\hline $\begin{array}{l}\text { Gold-silver and other ore } \\
\text { minerals }\end{array}$ & $\begin{array}{l}\text { Gold, electrum, } \mathrm{Au}-\mathrm{Ag} \text { tellurides, acanthite, } \\
\text { Ag-bearing tennantite, tetrahedrite, enargite, } \\
\text { luzonite, chalcopyrite }\end{array}$ & $\begin{array}{l}\text { Electrum, Ag sulfides, selenides and } \\
\text { sulfosalts; low Ag/Au; generally no } \\
\text { other metals recovered }\end{array}$ & $\begin{array}{l}\text { Electrum, } \mathrm{Ag} \text { sulfides and sulfosalts; } \\
\text { high } \mathrm{Ag} / \mathrm{Au} \text {; chalcopyrite, galena, } \\
\text { sphalerite }\end{array}$ \\
\hline Sulfide abundance & 5 to 90 vol. $\%$ & $\begin{array}{l}\text { Typically }<1 \text { to } 2 \text { vol. } \% \text { except where } \\
\text { hosted by basalts (as much as } 20 \\
\text { vol. } \% \text { ) }\end{array}$ & 5 to $>20$ vol. $\%$ \\
\hline Sulfide minerals & $\begin{array}{l}\text { Pyrite, enargite, luzonite, covellite-digenite, } \\
\text { famatinite, chalcopyrite, tetrahedrite/ } \\
\text { tennantite, Fe-poor sphalerite }\end{array}$ & $\begin{array}{l}\text { Pyrite/marcasite, Au-Ag sulfides/ } \\
\text { sulfosalts, arsenopyrite, pyrrhotite, } \\
\text { Fe-poor to Fe-rich sphalerite, } \\
\text { cinnabar, stibnite }\end{array}$ & $\begin{array}{l}\text { Pyrite, Au-Ag sulfides/sulfosalts, } \\
\text { Fe-poor sphalerite, galena, } \\
\text { chalcopyrite, tetrahedrite/tennantite }\end{array}$ \\
\hline Other enriched metals & $\mathrm{As}, \mathrm{Sb}, \mathrm{Bi}, \mathrm{Sn}, \mathrm{Te}, \mathrm{Se}$ & $\mathrm{As}, \mathrm{Sb}, \mathrm{Se}, \mathrm{Hg}$ & $\mathrm{Mn}, \mathrm{Se}$ \\
\hline Te and Se minerals & $\begin{array}{l}\mathrm{Au}-\mathrm{Ag} \text { tellurides common; selenides present } \\
\text { locally }\end{array}$ & $\begin{array}{l}\text { Au-Ag selenides, Se sulfosalts com- } \\
\text { mon }\end{array}$ & $\begin{array}{l}\text { Tellurides common locally; selenides } \\
\text { uncommon }\end{array}$ \\
\hline $\begin{array}{l}\text { Deposit style, veins, and } \\
\text { mineralized structures }\end{array}$ & $\begin{array}{l}\text { Breccias; diatremes; residual vuggy quartz; } \\
\text { stratabound disseminated; massive sulfide; } \\
\text { veins and stockworks; veins generally late }\end{array}$ & $\begin{array}{l}\text { Multiple stage veins of fine concordant } \\
\text { and discordant layered mineral } \\
\text { assemblages and breccias, comb } \\
\text { and crustiform textures; sheeted } \\
\text { veins; vein stockworks and breccias; } \\
\text { fault intersections; disseminated }\end{array}$ & $\begin{array}{l}\text { Multistage veins and associated } \\
\text { breccias with coarse layers and } \\
\text { comb and crustiform textures; } \\
\text { disseminated; diatremes }\end{array}$ \\
\hline Paleosurface indicators & Steam-heated blankets over some deposits & $\begin{array}{l}\text { Sinter and explosion breccias; } \\
\text { chalcedony blankets; steam-heated } \\
\text { blankets over some deposits; thin } \\
\text { quartz veins and stockworks over } \\
\text { some deposits }\end{array}$ & $\begin{array}{l}\text { Rarely documented; thin quartz veins } \\
\text { and stockworks over some deposits }\end{array}$ \\
\hline $\begin{array}{l}\text { Depth to top of ore zones } \\
\text { (meters below water table) }\end{array}$ & Tens of meters to $700 \mathrm{~m}$ & Meters to several hundred meters & Several hundred meters \\
\hline Vertical extent of ore & 100 to $800 \mathrm{~m}$ & Mostly 100 to $400 \mathrm{~m}$ & Up to $\sim 1,000 \mathrm{~m}$ \\
\hline $\begin{array}{l}\text { Fluid inclusion homogeni- } \\
\text { zation temperature and } \\
\text { composition }\end{array}$ & $\begin{array}{l}\text { Mostly } 155 \text { to } 330^{\circ} \mathrm{C}\left(220 \text { to } 270^{\circ} \mathrm{C} \text { modes }\right) \text {; } \\
\sim 0-6 \text { weight } \% \mathrm{NaCl} \text { equiv.; halide saturated } \\
\text { fluids in some deposits }\end{array}$ & $\begin{array}{l}<100 \text { to } 390{ }^{\circ} \mathrm{C}\left(<130 \text { to } 290{ }^{\circ} \mathrm{C}\right. \\
\text { modes }) ; 0 \text { to } 6 \text { weight } \% \mathrm{NaCl} \\
\text { equiv. (mostly }<3 \%)\end{array}$ & $\begin{array}{l}135 \text { to } 385^{\circ} \mathrm{C}\left(220 \text { to } 310{ }^{\circ} \mathrm{C} \text { modes }\right) \text {; } \\
\text { as much as } 23 \text { weight } \% \mathrm{NaCl} \\
\text { equiv. (mostly } 1 \text { to } 12 \%)\end{array}$ \\
\hline Representative deposits & $\begin{array}{l}\text { Yanacocha, Pueblo Viejo, Pierina, Pascua- } \\
\text { Lama, Goldfield, Summitville }\end{array}$ & $\begin{array}{l}\text { Hishikari, Midas, Sleeper, } \\
\text { McLaughlin, National, Mule } \\
\text { Canyon }\end{array}$ & $\begin{array}{l}\text { Comstock Lode, Tonopah, Fresnillo, } \\
\text { El Peñón, Waihi, Peñasquito, Roşia } \\
\text { Montană }\end{array}$ \\
\hline
\end{tabular}




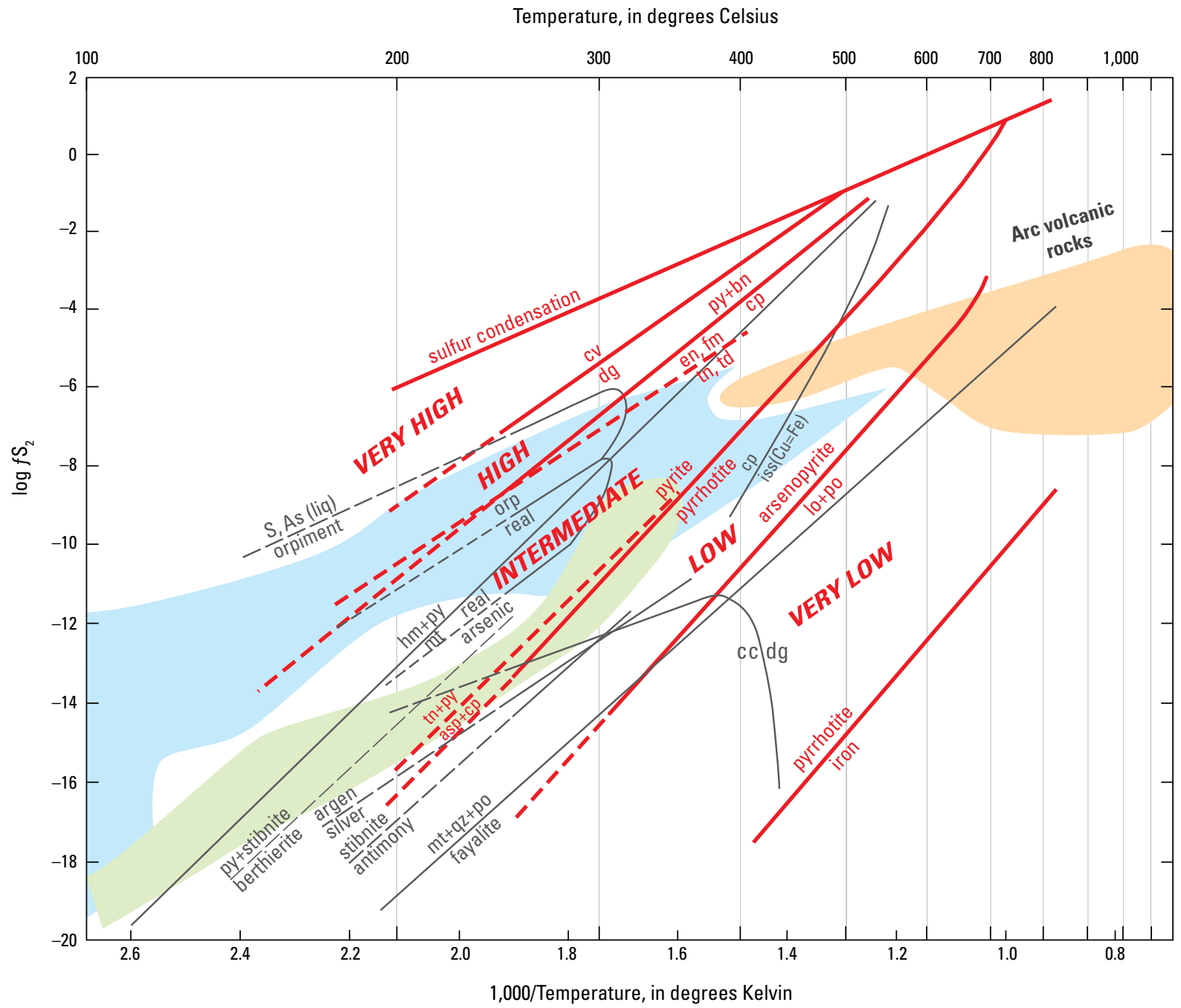

\section{EXPLANATION}

Magmatic-hydrothermal fluids

Geothermal fluids

Volcanic fumaroles

Figure B2. Sulfur fugacity $\left(f S_{2}\right)$-temperature diagram showing the variety of sulfide assemblages in epithermal deposits that reflect sulfidation state, from very low and low through intermediate to high and very high. Thick red lines represent boundaries between these sulfidation states. Compositional fields of arc volcanic rocks, high-temperature volcanic fumaroles, magmatic-hydrothermal fluids, and geothermal fluids also are shown, as discussed by Einaudi and others (2003). Low-sulfidation epithermal deposits are characterized by the low-sulfidation state assemblage, pyrite (py)-arsenopyrite (asp), with minor chalcopyrite (cp) and pyrrhotite (po) in some deposits. Intermediate-sulfidation epithermal deposits are characterized by intermediate-sulfidation state assemblages containing of pyrite, chalcopyrite, tetrahedrite (td)-tennantite (tn), and iron-poor sphalerite. High-sulfidation epithermal deposits typically contain sulfide-rich assemblages of high-sulfidation state, including pyrite-bornite (bn), pyrite-enargite (en), pyrite-luzonite, pyrite-famatinite (fm), and pyrite-covellite (cv) (Einaudi and others, 2003; Sillitoe and Hedenquist, 2003). Figure modified from Sillitoe and Hedenquist (2003). Element and mineral abbreviations: As, arsenic; argen, argentite; cc, chalcocite; $\mathrm{Cu}$, copper; dg, digenite; Fe, iron; hm, hematite; iss, intermediate solid solution; lo, loellingite; mt, magnetite; orp, orpiment; qz, quartz; real, realgar; $S$, sulfur. 



\title{
Chapter C. Deposit Type and Associated Commodities
}

\author{
By David A. John
}

Name

Epithermal gold-silver deposits

\section{Subtypes and Synonyms}

Low-sulfidation subtype: adularia-sericite; Comstock epithermal vein; Sado epithermal vein; Creede epithermal vein; hot spring; quartz \pm calcite \pm adularia \pm illite (near-neutral $\mathrm{pH}$ ).

Intermediate-sulfidation subtype: adularia-sericite; Comstock epithermal vein; Sado epithermal vein; Creede epithermal vein; quartz \pm calcite \pm adularia \pm illite (near-neutral $\mathrm{pH}$ ).

High-sulfidation subtype: acid-sulfate; hot spring; quartz ${ }^{+}$ alunite \pm pyrophyllite \pm dickite \pm kaolinite (acid $\mathrm{pH})$.

See table B1.

\section{Brief Description}

Epithermal gold-silver deposits are small to large (thousands to greater than 100 million metric tons [Mt]), low- to highgrade $(0.1$ to $>30 \mathrm{~g} / \mathrm{t}$ gold, $<1$ to $>1,000 \mathrm{~g} / \mathrm{t}$ silver; fig. A2), vein, disseminated, and breccia deposits most commonly hosted in broadly contemporaneous volcanic and volcaniclastic rocks. Epithermal gold-silver deposits form at shallow depths $(\leq 1,500 \mathrm{~m})$ and at temperatures $\leq 300^{\circ} \mathrm{C}$. These deposits are mined primarily for their gold and (or) silver contents, although copper, lead, zinc, and (or) mercury are important byproducts in some deposits (appendixes 1,2).

Although epithermal gold-silver deposits form in a wide range of tectonic environments, they are most common in subaerial volcanic arcs at convergent plate margins in continental and oceanic settings (appendix 1). They form primarily from subaerial hydrothermal systems driven by magmatic heat and, less commonly, by deeply circulating groundwater rising along basin-bounding faults. Analogous high-sulfidation deposits form in volcanic arcs in submarine environments, but few ancient submarine deposits have been recognized. Deposits range from Archean to Quaternary, although because of their formation at shallow depths and their poor preservation potential, most known deposits are Cenozoic.

The three deposit subtypes included in this model, low-, intermediate-, and high-sulfidation epithermal gold-silver deposits, are named to reflect differences in the sulfur fugacity of inferred ore-fluids that result in major ore mineral assemblages (White and Hedenquist, 1995; Hedenquist and others, 2000; Sillitoe and Hedenquist, 2003; Einaudi and others, 2003). Silver sulfide minerals, silver selenide minerals, silver-bearing sulfosalts, and electrum (gold alloy containing $>20$ weight percent silver) are mostly restricted to low- and intermediate-sulfidation deposits, whereas enargite and gold (gold alloy containing $<10$ weight percent silver) are present in nearly all high-sulfidation deposits. Characteristic forms and metal contents also vary between lowand intermediate-sulfidation deposits. Low-sulfidation deposits commonly consist of multiple stages of concordant and discordant banded or layered minerals and breccias, sheeted veins, and (or) vein stockworks and breccias adjacent to layered veins and faults that were mined exclusively for gold and silver. Intermediatesulfidation deposits consist of multistage veins and associated breccias that contain significant amounts of other metals in addition to gold and silver, and were (a) mined exclusively for gold and (or) silver, with no or minor production of copper, lead, and zinc, or (b) mined primarily because of their gold and silver contents but also produced appreciable copper, lead, and zinc.

Hydrothermal alteration mineral assemblages typically are zoned laterally and vertically around ore bodies and relative to the paleowater table. Alteration associated with low- and intermediate-sulfidation deposits includes near-neutral $\mathrm{pH}$ alkali-dominated assemblages formed below the water table and steam-heated acid assemblages formed at and above the water table. Below the paleowater table, hydrothermal alteration commonly is zoned around fluid conduits and ore zones from innermost silicification and potassic (adularia and [or] illite) alteration grading outward to argillic and propylitic assemblages. Argillic and advanced argillic alteration is present at and above the paleowater table. Silica sinter forms where hot, upwelling, neutral $\mathrm{pH}$ fluids reach the paleosurface and discharge. Hydrothermal alteration associated with high-sulfidation deposits results from intense acid leaching by low-pH fluids formed by condensation of $\mathrm{HCl}$ - and $\mathrm{SO}_{2}-$ rich fluid in groundwater; alteration is characteristically progressively zoned outward from inner residual (vuggy) quartz and quartz-alunite assemblages around fluid conduits to advanced argillic (kaolinite/dickite or pyrophyllite), argillic (illite-montmorillonite), and propylitic assemblages.

Geological and geochemical evidence demonstrate that subaerial epithermal gold-silver mineralization and associated cogenetic hydrothermal alteration form predominantly from meteoric waters with variable amounts of magmatic volatiles released during emplacement and crystallization of temporally and spatially associated mafic to silicic magmas. Highsulfidation deposits typically have hydrothermal alteration assemblages, geochemical characteristics, and isotopic compositions reflecting larger magmatic fluid components than intermediate- and low-sulfidation deposits. The ultimate origin of gold, silver, and other metals in epithermal gold-silver 
deposits remains uncertain but likely includes multiple sources in the upper mantle and crust.

\section{Associated and Transitional Deposit Types}

Because epithermal gold-silver deposits most commonly form in convergent margin magmatic arcs, a wide variety of mineral deposits may be associated with, and in some cases are transitional to, these deposits (fig. C1). Associated and transitional deposit types (with primary metals recovered in parentheses) include the following:

- Hot spring mercury $(\mathrm{Hg})$

- Porphyry copper $(\mathrm{Cu}, \mathrm{Mo}, \mathrm{Au})$

- Skarn (including $\mathrm{Cu}, \mathrm{Fe}, \mathrm{Au}, \mathrm{Zn}$ types)

- Polymetallic vein, including Cordilleran base metal lode (Au, Ag, Cu, Zn, Pb, Mn, As)

- Polymetallic replacement (manto), including Cordilleran base metal $(\mathrm{Ag}, \mathrm{Pb}, \mathrm{Zn}, \mathrm{Cu}, \mathrm{Au})$

- Intrusion-related breccia pipe ( $\mathrm{Au}, \mathrm{Ag}, \mathrm{Cu}, \mathrm{Pb}, \mathrm{Zn}$ )

- Sedimentary-rock hosted gold, including Carlin-type gold ( $\mathrm{Au}$ ) and distal-disseminated gold-silver ( $\mathrm{Au}, \mathrm{Ag})$

- Placer $(\mathrm{Au})$

- Stratiform sulfur (S)

\section{Primary Commodities}

Gold and (or) silver are the primary commodities in all epithermal gold-silver deposits. Figure A2 shows gold and silver grades and ore tonnages for most epithermal deposits summarized in appendix 1 .

\section{Byproduct Commodities}

Lead, zinc, and (or) mercury are the main byproducts recovered from some intermediate-sulfidation deposits, whereas copper is the main byproduct from high-sulfidation deposits (appendixes 1,2).

\section{Trace Constituents}

Arsenic, antimony, barium, bismuth, fluorine, molybdenum, selenium, thallium, and tungsten are commonly enriched in intermediate-sulfidation deposits and are recovered from some deposits. Bismuth, lead, mercury, molybdenum, selenium, tellurium, tin, and zinc are commonly enriched in highsulfidation deposits.

\section{Example Deposits}

Appendix 1 presents summary data for about 100 epithermal gold-silver deposits from throughout the world. Locations of these deposits are shown in figure A1.

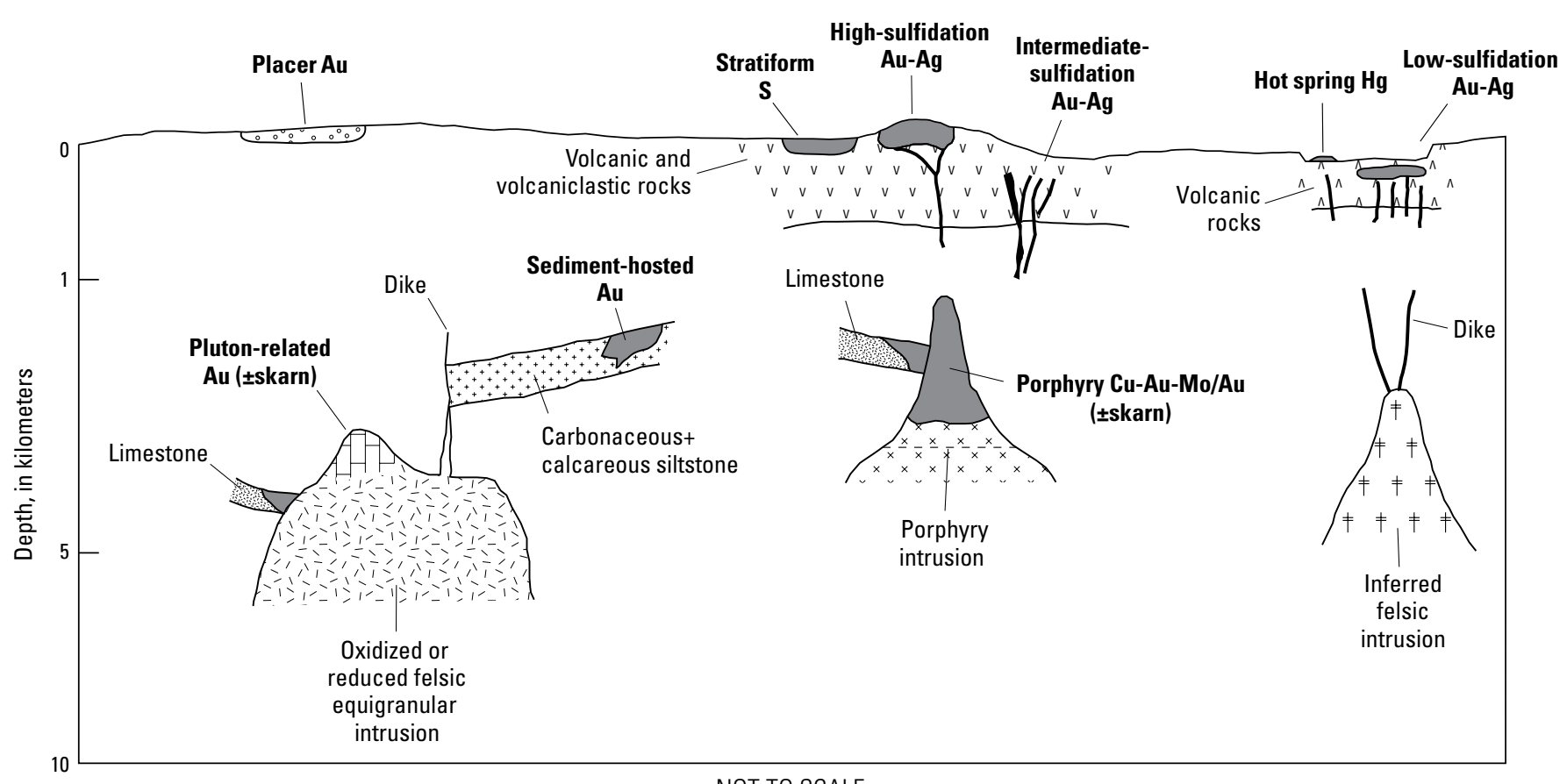

NOT TO SCALE

Figure C1. Schematic cross section showing epithermal gold-silver deposits and other related or proximal deposit types. Figure based on Sillitoe (2008). Abbreviations: Ag, silver; Au, gold; Cu, copper; Hg, mercury; Mo, molybdenum; S, sulfur. 


\title{
Chapter D. History of Epithermal Gold-Silver Deposits
}

\author{
By Jeffrey L. Mauk
}

Epithermal gold-silver deposits probably have been important sources of precious metals for as long as humankind has valued these metals. The Romans worked many epithermal deposits in Europe, such as Rodalquilar and Roşia Montană, and the Mahd adh Dhahab deposit in Saudi Arabia may have been King Solomon's gold mine (Baron and others, 2011). The Cerro Rico de Potosi deposit in Bolivia was worked by the Incas and by earlier cultures; smelting of those ores began around A.D. 1000 (Abbott and Wolfe, 2003; Cooke and others, 2008).

Early production from epithermal deposits was almost exclusively by underground mining. However, in 1971, United States President Nixon ended international convertibility of the U.S. dollar to gold, and the price of gold was subsequently raised from USD35 per troy ounce to USD38 per troy ounce, then to USD42.22 per troy ounce in 1973, and after that, the U.S. dollar was allowed to float. This led to an increase in the price of gold, first to more than USD150 per troy ounce, and then after a slight correction, to a peak of more than USD800 per troy ounce in January 1980. The price of gold then fell, and from 1981 until 2005, gold mostly traded between USD250 and USD450 per troy ounce. The peak in gold prices in the 1970s changed the economics of gold mining, and enabled open-pit mining of large tonnage, lowgrade resources. Simultaneous development of heap and tank leaching techniques that facilitated economic extraction of gold from these low-grade ores also encouraged development of these resources.

On a global basis, epithermal deposits are currently mined by underground and open-pit methods, and some deposits are exploited by both methods. The relatively high grades of some epithermal deposits can make them attractive exploration targets that are more likely to remain profitable during periods when precious metal prices are depressed.

Waldemar Lindgren introduced the term "epithermal" in the third edition of his book "Mineral Deposits" (Lindgren, 1928). However, as early as the first edition of this book in 1913, he described the geology, mineralogy, textures, alteration, and geochemistry of these deposits, and he linked their genesis to active hot springs (Lindgren, 1913). He recognized that these deposits and occurrences contain a range of metals, even though they are predominantly mined for precious metals. Donald E. White further recognized the links between epithermal deposits and hot springs, and his experience in active geothermal systems provided new insights into the origin of epithermal deposits (White, 1955, 1974, 1980).

Research during the 1970s and 1980s dramatically increased understanding of the depth, temperature, and chemical conditions under which epithermal deposits form. This improved understanding resulted from direct research on epithermal deposits, from models of hydrothermal systems and mineral precipitation, and from research on active geothermal systems. Gangue minerals in most epithermal deposits are not well-suited to fluid inclusion research, because the gangue is commonly very fine grained, and in many cases, it has replaced pre-existing phases, such as amorphous silica, opal, and chalcedony, and does not preserve primary fluid inclusions (for example, Bodnar and others, 1985; Sander and Black, 1988). Nonetheless, by focusing on coarsely crystalline minerals, many fluid inclusion studies have shown that epithermal deposits characteristically form at temperatures between 150 and $300{ }^{\circ} \mathrm{C}$ (Simmons and others, 2005; Bodnar and others, 2014, and references therein). Geological and mineralogical characteristics led to the recognition that epithermal deposits characteristically form from either nearneutral $\mathrm{pH}$ fluids or acidic fluids (Hayba and others, 1985; White and Hedenquist, 1990). Research on geothermal systems, and deep drilling of these systems for geothermal power development provided direct evidence of alteration mineral zonation in geothermal fields that is similar to the zonation in epithermal deposits, and linked differences in alteration mineralogy to differences in fluid chemistry and temperature (Berger and Bethke, 1985; Browne, 1978; Browne and Ellis, 1970; Henley and others, 1984). Similarly, stable isotope analyses of gangue minerals in veins have shown that meteoric water was the predominant component in the hydrothermal fluids that formed those gangue minerals, in agreement with stable isotope analyses of geothermal fluids that indicate strong involvement of meteoric water in active systems (for example, Blattner, 1985; O'Neil and Silberman, 1974; O'Neil and others, 1973). Precipitation of sulfide minerals and precious metals in geothermal systems indicates that geothermal fluids can transport the metals that are trapped in epithermal ore bodies (Browne and Ellis, 1970; McKibben and Elders, 1985; Brown, 1986; Simmons and Brown, 2006), and this observation led to reaction path modeling that provided further insights into likely mineral-fluid interactions in the hydrothermal systems responsible for epithermal deposit formation (Reed and Spycher, 1985).

Since 1990, numerous reviews of epithermal deposits have been completed (for example, White and Hedenquist, 1990; Sillitoe, 1993; Cooke and Simmons, 2000; Jensen and Barton, 2000; Hedenquist and others, 2000; Sillitoe and Hedenquist, 2003; Simmons and others, 2005; Taylor, 2007; Cook and others, 2009). Ongoing advances in analytical capability, particularly in situ analyses at the scale of tens of microns and smaller, have provided new insights into the origin of epithermal deposits that challenge old paradigms about the origin of these deposits. 



\title{
Chapter E. Regional Environment
}

\author{
By David A. John and Jeffrey L. Mauk
}

\section{Geotectonic Environment}

Epithermal gold-silver deposits form in a wide range of geotectonic settings (appendix 1). These deposits generally are associated with volcanic or shallow intrusive rocks, most commonly in convergent-margin arcs (continental and island arcs), although they also are associated with magmatism in back-arc, continental rift, postcollisional extensional, and transform margin settings, and less commonly, in areas of continental rifting with little or no temporally related magmatism (table E1; Sillitoe, 1993, 2008; Cooke and Simmons, 2000; Hedenquist and others, 2000; John, 2001; Sillitoe and Hedenquist, 2003; Simmons and others, 2005). Stress regimes of convergent margin arcs hosting epithermal gold-silver deposits range from extensional through neutral to compressional, although several major highsulfidation deposits formed in localized extensional zones during regional compression (appendix 1; Sillitoe and Hedenquist, 2003; Charchaflié and others, 2007; Sillitoe, 2008). In continental arcs, major high-sulfidation deposits also commonly occur in belts that are transverse to the arc (Sillitoe, 2008). Commonly observed relationships between tectonic setting, magmatism, and epithermal deposits are summarized in table E1, although as emphasized by Sillitoe and Hedenquist (2003), proof of a direct genetic connection between epithermal deposits and spatially and temporally associated volcanism and tectonism is rare.

\section{Temporal (Secular) Relations}

\author{
Variations Through Geologic Time
}

Epithermal gold-silver deposits, including all subtypes, probably formed throughout most of the Earth's history, dating back to the Archean (appendix 1; Harris and others, 2009; Huston and others, 2002; Kesler and Wilkinson, 2009; Garde and others, 2012). Because epithermal gold-silver deposits form in the shallow upper crust (less than about 1,500 $\mathrm{m}$ depth), most commonly in tectonically active convergent plate margins, and frequently in areas that are topographic highs and (or) subject to high uplift rates, most deposits are exhumed and removed by erosion over time. Therefore, most known deposits are Cenozoic, and many have argued that the present age distribution of epithermal gold-silver deposits reflects preferential preservation of the youngest deposits (for example, Huston and others, 2002; Kesler and Wilkinson, 2009). Kesler and Wilkinson (2009) provide age estimates for 464 epithermal gold-silver deposits that range from 3,450 to $0.3 \mathrm{Ma}$ (fig. E1); the median age is $14.8 \mathrm{Ma}$, and 90 percent of the deposits are younger than $175 \mathrm{Ma}$. Most of the oldest known deposits are strongly metamorphosed and are inferred to represent the high-sulfidation subtype based on their major element compositions, which indicate extreme acid leaching

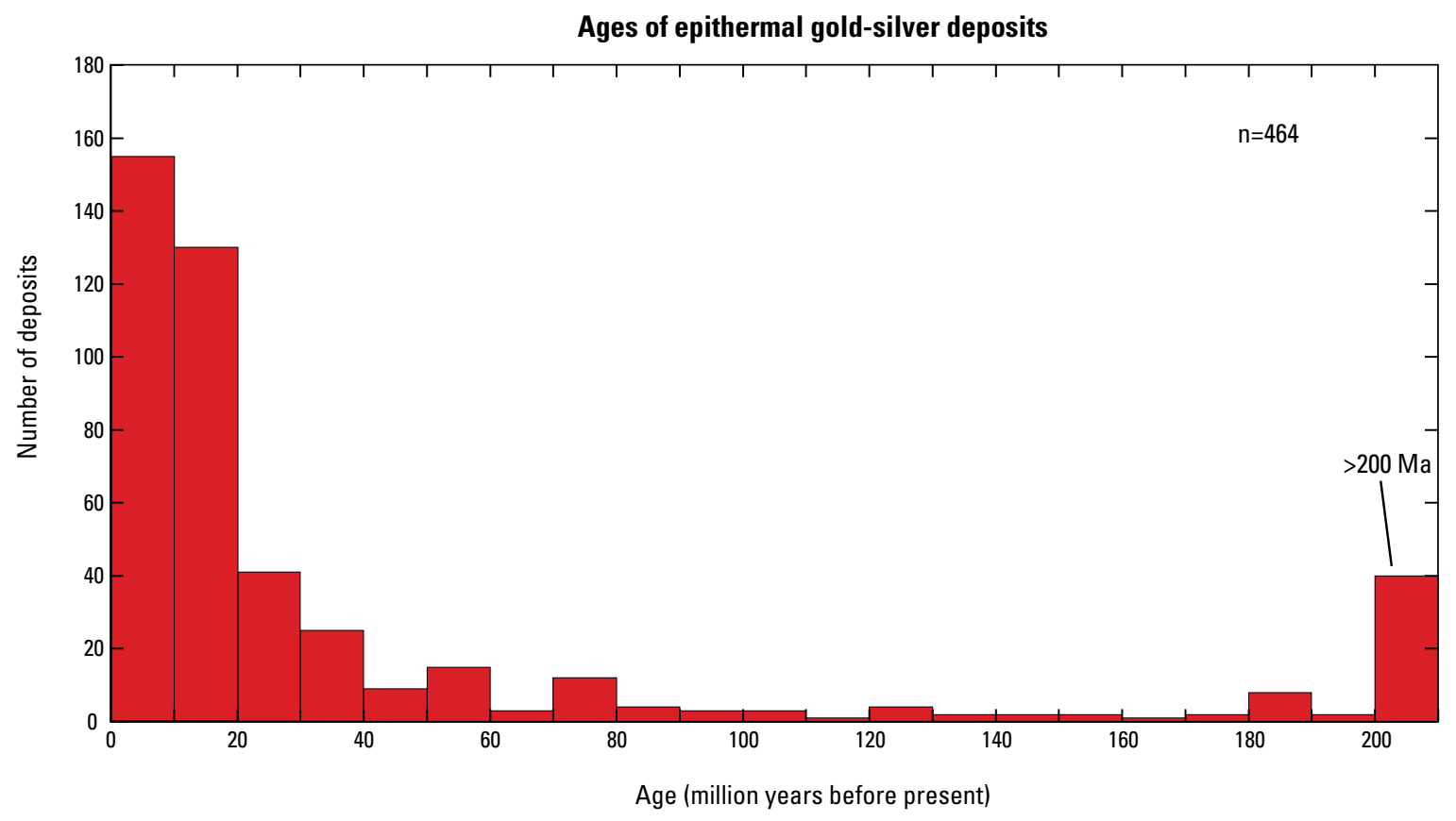

Figure E1. Histogram showing ages of known epithermal gold-silver deposits. Data from Kesler and Wilkinson (2009). 
Table E1. Summary of relationships between tectonic setting, magmatism, and epithermal gold-silver deposits.

[Au, gold; $\mathrm{Cu}$, copper; $\mathrm{Hg}$, mercury; $\mathrm{Sn}$, tin]

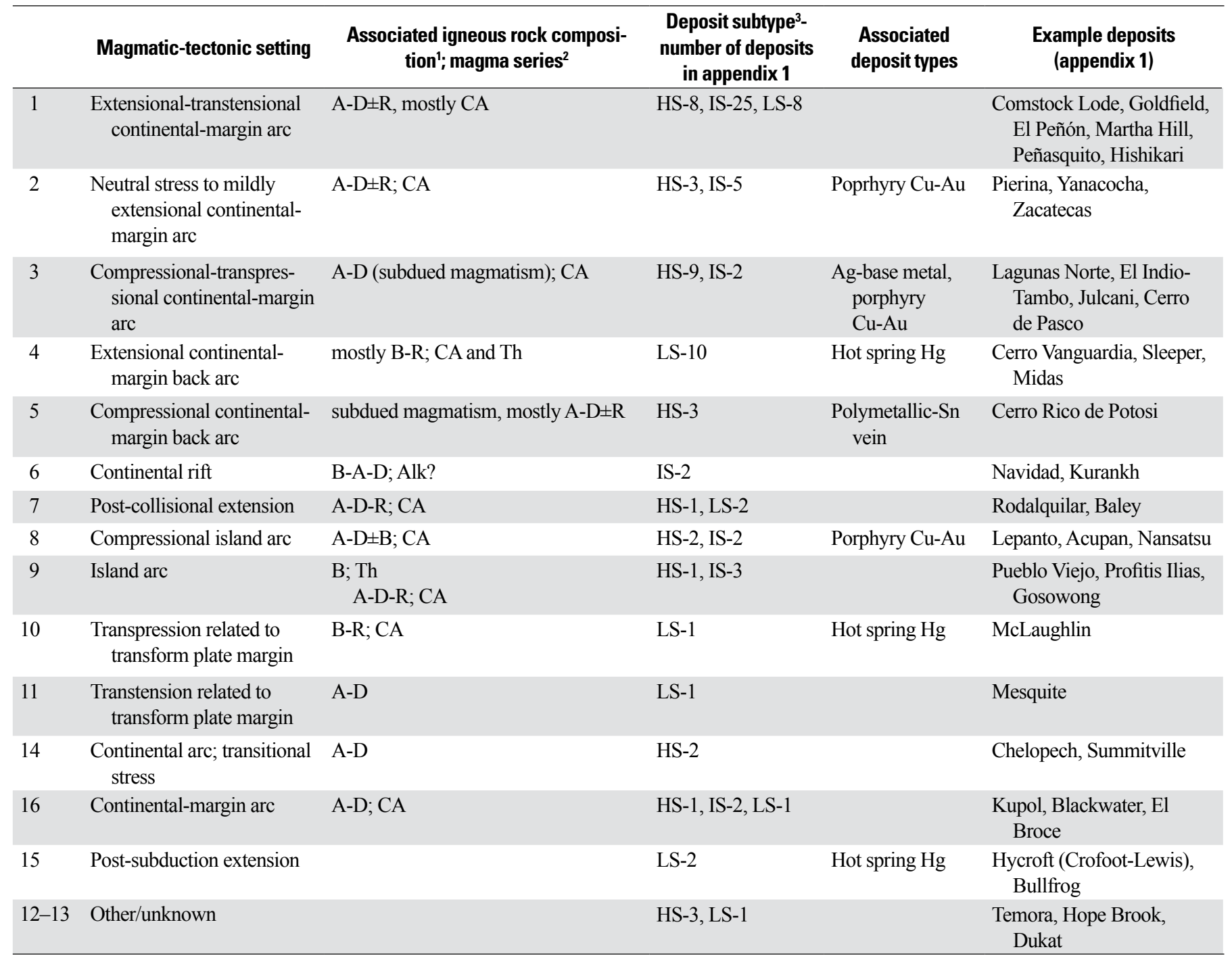

${ }^{1} \mathrm{~A}$, andesite; B, basalt; D, dacite; R, rhyolite

${ }^{2} \mathrm{Alk}$, alkaline; $\mathrm{CA}$, calc-alkaline; Th, tholeiitic

${ }^{3} \mathrm{HS}$, high-sulfidation; IS, intermediate-sulfidation; LS, low-sulfidation

(for example, early Proterozoic deposits in Sweden, Hallberg, 1994; Bergman Weihed and others, 1996).

\section{Duration of Hydrothermal Systems that Form Epithermal Gold-Silver Deposits}

The lifespan of hydrothermal activity that forms epithermal deposits has been estimated from (1) studies of metal fluxes and metal deposition rates in modern geothermal systems, and (2) geochronologic studies of deposits in which the ages of pre-ore host rocks, post-ore cap rocks, and (or) gangue minerals interpreted as coeval with ore mineral deposition have been determined (for example, Round Mountain, Nevada, Henry and others, 1997; Hishikari, Japan, Sanematsu and others, 2006). Theoretical studies based on active geothermal systems conclude that an epithermal gold deposit containing one million ounces (31 metric tons) of gold could form in a few thousand years, whereas geochronologic studies of actual deposits of this size suggest that individual hydrothermal events persist for tens of thousands to several hundred thousand years and that deposits form over periods of tens of thousands to several million years. 
Theoretical considerations of geothermal system dynamics suggest that rapid changes in the proximal groundwater regime, such as those associated with volcanic eruptions, major earthquakes, or sudden geomorphic changes (for example, sector collapse [landslide] events), could depressurize these systems sufficiently to cause extremely rapid precipitation of ore metals from hydrothermal fluids, which may result in formation of smallto moderate-size ore deposits in hundreds to thousands of years (Sillitoe, 1994; Simmons and others, 2005). Studies of precious metal fluxes and deposition rates in active geothermal systems conclude that formation of a million-ounce gold deposit could require as little as 1,500 years, and the largest known deposits could form in about 50,000 years (Brown, 1986; Hedenquist and others, 1993; Simmons and Brown, 2006, 2007; Rowland and Simmons, 2012). Although reasonable for truly disseminated deposits, these calculations, which assume 100 percent trapping and deposition throughout the lifetime of the hydrothermal system, are not valid for epithermal veins where ore minerals occur predominantly in specific bands within veins. Instead, textures in epithermal veins clearly demonstrate that ore mineral deposition is episodic and confined to very specific time intervals when fluid chemistry and geologic processes allowed deposition of bands rich in ore-forming elements (for example, Saunders, 1990; Saunders and others, 2008; Shimizu, 2014).

Estimates of the duration of hydrothermal activity that formed epithermal gold-silver deposits based on highprecision geochronologic studies range from less than the uncertainty of the dates, which commonly range from 40,000 to 200,000 years, to more than 5 million years for large and complex districts where multiple ore-forming hydrothermal systems were operative (for example, Yanacocha, Peru, Longo and others, 2010; table E2). Under most geological circumstances, conductive cooling of an intrusion requires about 100,000 years, whereas convective cooling spans 10,000 to 50,000 years. However, under ideal circumstances where large ultramafic sills are intruded at depth into rocks with permeabilities between 0.05 and 0.1 millidarcys $(\mathrm{mD})$, nearsurface hydrothermal systems can last for more than 800,000 years (Cathles and others, 1997). These results, combined with the age data shown in table E2, suggest that some epithermal deposits may form from a single intrusion, whereas others require multiple intrusive events to sustain long-lived hydrothermal systems.

Hishikari, Japan, is one of the most comprehensively dated low-sulfidation districts. The Hishikari district contains several ore zones each containing several sets of quartz veins, many of which have been dated by using high-precision ${ }^{40} \mathrm{Ar} r{ }^{39} \mathrm{Ar}$ and lower precision K-Ar geochronologic methods (Izawa and others, 1990; Sanematsu and others, 2005, 2006; Tohma and others, 2010). In these studies, adularia from several different bands of individual veins was dated, which allowed estimates of the total duration of hydrothermal activity that formed individual veins, and also the time between formation of various bands. For example, the Hosen-1 vein formed in four to six discrete stages during a period of about 260,000 years, with formation of individual bands separated by 30,000 to 110,000 years (Sanematsu and others, 2006). In contrast, the Fukusen vein formed within about 26,000 years (Izawa and others, 1990; Tohma and others, 2010). Hydrothermal activity that produced the overall epithermal mineralization in the Hishikari district spanned about 600,000 years between about 1.25 and $0.64 \mathrm{Ma}$ (Sanematsu and others, 2006). However, hot water continues to discharge at Hishikari, which indicates ongoing geothermal activity and suggests that the hydrothermal system(s) has been active for the past 1.25 m.y.

In contrast to Hishikari, detailed ${ }^{40} \mathrm{Ar} /{ }^{39} \mathrm{Ar}$ dating of igneous rocks and hypogene alunite alteration related to epithermal gold mineralization in the Yanacocha district, Peru, indicate that there were five stages of hydrothermal activity each lasting about 1.0 to 0.4 m.y., and in total, spanning about 5.4 m.y. (Longo and others, 2010). The epithermal highsulfidation gold deposits and an underlying porphyry coppergold deposit formed during these hydrothermal stages, which are part of protracted magmatism in the district that lasted about $11 \mathrm{~m} . \mathrm{y}$. Each of the major epithermal deposits was formed during two to three stages of hydrothermal activity.

\section{Relations to Structures}

The location and shape of ore bodies in most epithermal gold-silver deposits are intimately related to structural features that are associated with igneous, sedimentary, tectonic, topographic, and hydrothermal processes (table E3). These structures provide pathways and barriers for hydrothermal fluid flow and sites for gangue and ore mineral deposition (Sillitoe, 1993; Hedenquist and others, 2000). Many epithermal deposits contain several types of ore that result from the interaction of multiple sets of structural features. For example, low- and intermediate-sulfidation epithermal deposits commonly contain high-grade or bonanza ore shoots and lower grade, disseminated, stockwork, and (or) breccia ores that may represent juxtaposition of different parts of a single hydrothermal system or ores formed at different times (for example, Sleeper, Nevada, Nash and Trudel, 1996; Golden Cross, New Zealand, Begbie and others, 2007). Some highsulfidation deposits contain low-grade, disseminated ore formed by replacement of permeable strata and higher grade, structurally controlled breccia or vein ore (for example, Paradise Peak, Nevada, John and others, 1991; Sillitoe and Lorson, 1994).

\section{Igneous Structures}

Volcanic and hypabyssal intrusive rocks are the most common host rocks for epithermal gold-silver deposits (appendix 1). Igneous breccias, structures related to caldera collapse (ring fractures and craters), and resurgent domes, diatremes, and dikes are important host rocks of epithermal ore bodies (table E3; appendix 1). These structural features are related to volcanic landforms that commonly host epithermal deposits, including 


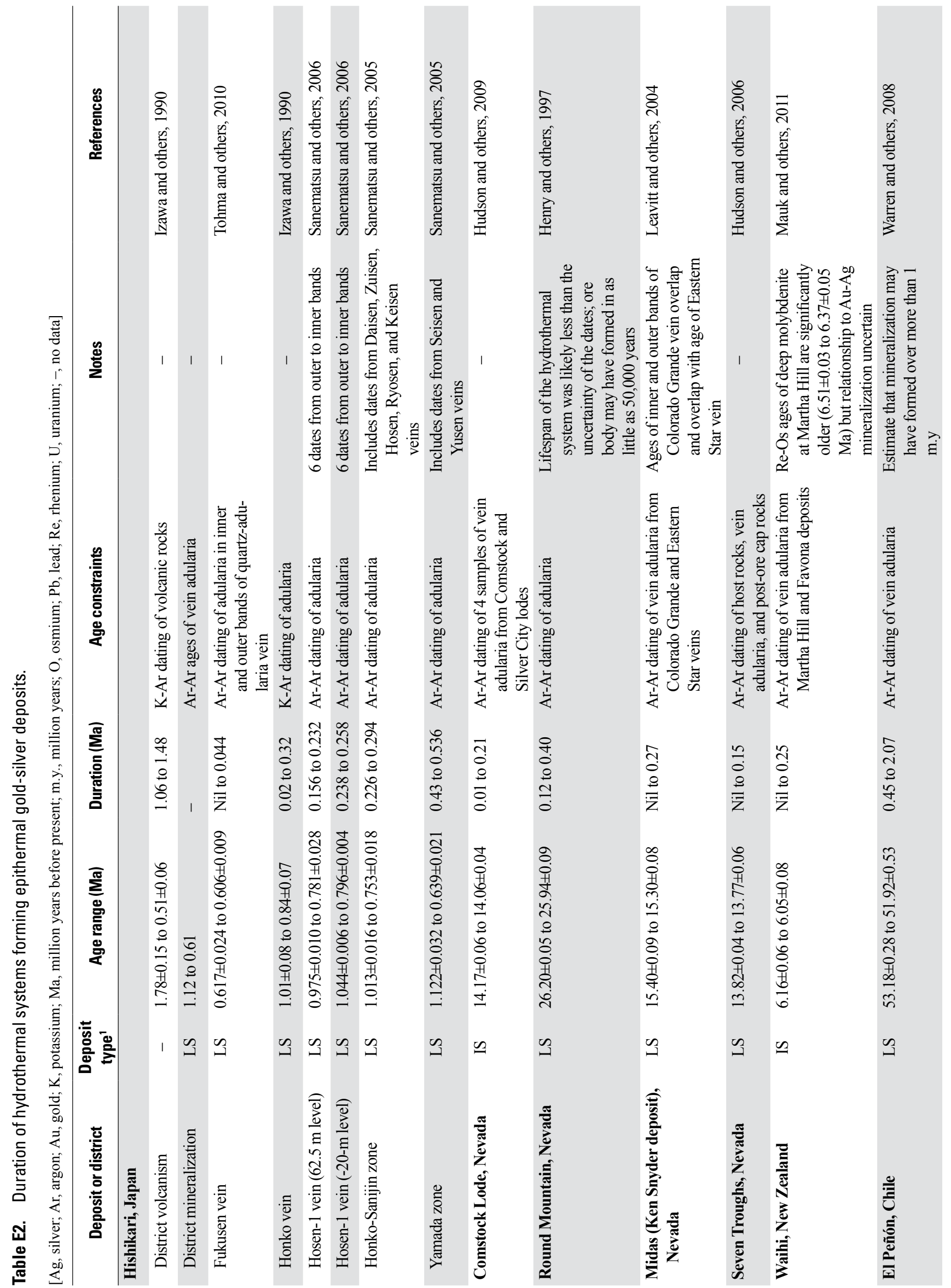




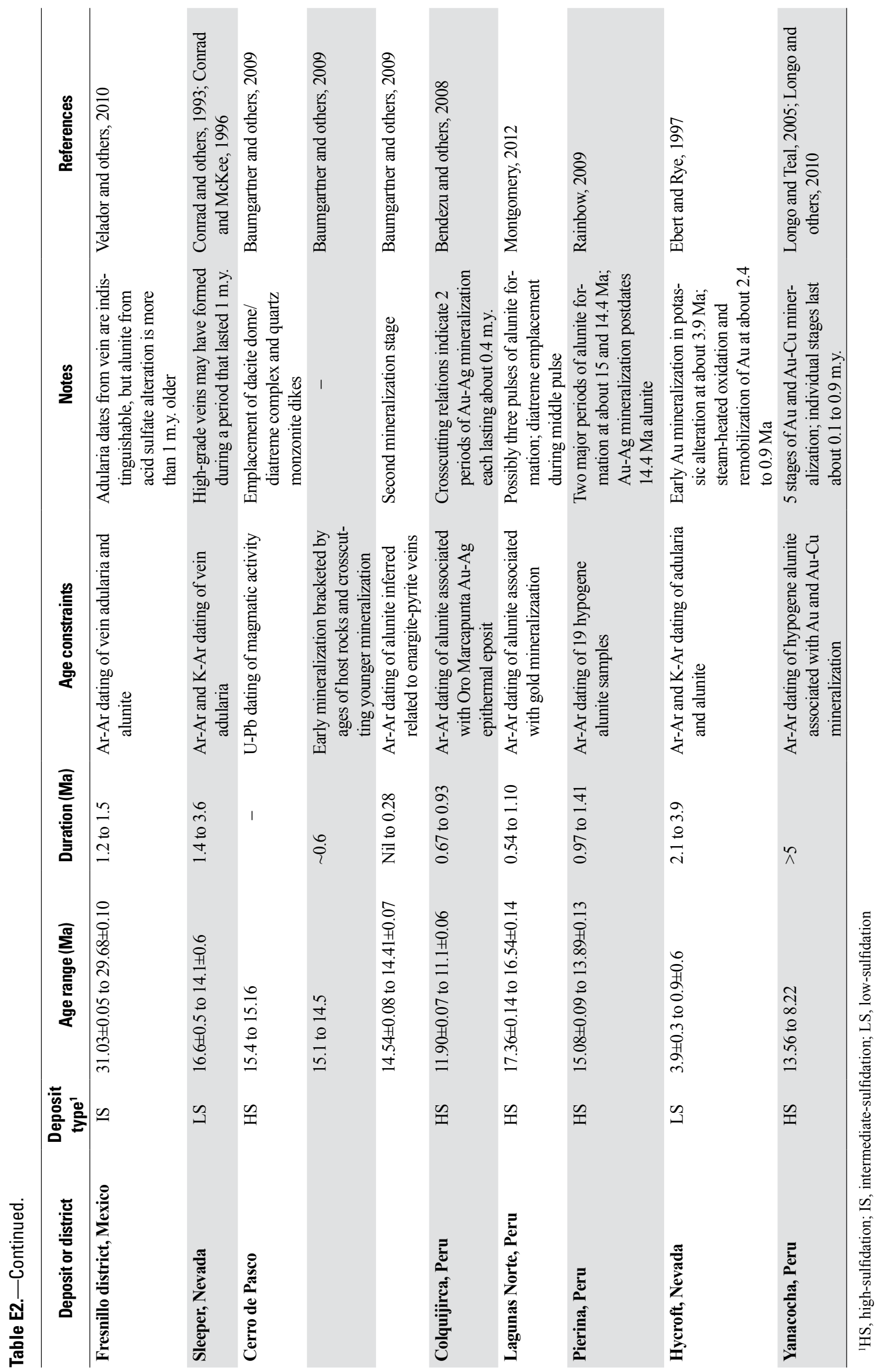


Table E3. Structural and lithologic controls on epithermal gold-silver deposits

\begin{tabular}{|c|c|c|c|}
\hline Type of control & Description & Example deposits & References \\
\hline \multicolumn{4}{|c|}{ Igneous } \\
\hline Domes & $\begin{array}{l}\text { Mineralization in and associated with } \\
\text { dome emplacement }\end{array}$ & $\begin{array}{l}\text { Summitville, Cerro Rico de } \\
\text { Potosi, Julcani }\end{array}$ & $\begin{array}{l}\text { Gray and Coolbaugh, 1994; Deen and } \\
\text { others, 1994; Cunningham and others, } \\
\text { 1996; Sillitoe and others, } 1998\end{array}$ \\
\hline Dikes & Mineralization along dike margins & Mule Canyon, El Oro & John and others, 2003; Caira, 2013 \\
\hline Ring fractures & Mineralization along caldera ring fracture & Round Mountain, Rodaquilar & $\begin{array}{l}\text { Arribas and others, 1995b; Sander and } \\
\quad \text { Einuadi, 1990; Henry and others, } 1997\end{array}$ \\
\hline Diatreme & $\begin{array}{l}\text { Mineralization in brecciated volcanic } \\
\text { conduits (diatreme) formed by } \\
\text { phreatomagmatic eruptions }\end{array}$ & $\begin{array}{l}\text { Kelian, Roşia Montană, Cerro } \\
\text { de Pasco }\end{array}$ & $\begin{array}{l}\text { Davies and others, 2008a, 2008b; Manske } \\
\text { and others, 2006; Wallier and others, } \\
\text { 2006; Baumgarnter and others, } 2008\end{array}$ \\
\hline \multicolumn{4}{|c|}{ Sedimentary } \\
\hline $\begin{array}{l}\text { Permeable units/ } \\
\text { aquitards }\end{array}$ & $\begin{array}{l}\text { Disseminated mineralization in } \\
\text { permeabile sedimentary, tuffaceous, and } \\
\text { volcaniclastic units }\end{array}$ & Hycroft, Paradise Peak & $\begin{array}{l}\text { Sillitoe and Lorson, 1994; Ebert and Rye, } \\
1997\end{array}$ \\
\hline \multicolumn{4}{|c|}{ Tectonic } \\
\hline $\begin{array}{l}\text { Faults, fractures, } \\
\text { and joints }\end{array}$ & $\begin{array}{l}\text { Mineralization controlled by pre- to } \\
\text { synmineral faults and other fractures }\end{array}$ & Golden Cross, Comstock Lode & Hudson, 2003; Begbie and others, 2007 \\
\hline $\begin{array}{l}\text { Fault breccias and } \\
\text { gouge }\end{array}$ & Ore hosted by fault breccias & Mule Canyon & John and others, 2003 \\
\hline \multicolumn{4}{|c|}{ Hydrothermal } \\
\hline Veins & Mineralization in veins & $\begin{array}{l}\text { Martha Hill, Golden Cross, } \\
\text { Sleeper }\end{array}$ & $\begin{array}{l}\text { Nash and Trudel, 1996; Begbie and others, } \\
\text { 2007; Christie and others, } 2007\end{array}$ \\
\hline Stockwork veins & $\begin{array}{l}\text { Mineralization in zones of small, randomly } \\
\text { oriented veins }\end{array}$ & $\begin{array}{l}\text { Martha Hill, Golden Cross, } \\
\text { Sleeper }\end{array}$ & $\begin{array}{l}\text { Nash and Trudel, 1996; Begbie and others, } \\
\text { 2007; Christie and others, } 2007\end{array}$ \\
\hline
\end{tabular}

stratovolcanoes, flow dome complexes, maar-diatreme systems, calderas, and dike systems (fig. E2; Sillitoe and Bonham, 1984; Sillitoe and Hedenquist, 2003), and are discussed in more detail in section, "Relations to Igneous Rocks."

\section{Igneous Breccias}

Breccias of diverse origins are ubiquitous features of epithermal deposits (Sillitoe, 1985). Breccias related to magmatic processes include magmatic-hydrothermal, hydromagmatic (phreatic and phreatomagmatic types), volcanic, and intrusion breccias (Sillitoe, 1985). Magmatic-hydrothermal breccias result from the explosive release of fluids from crystallizing magma and are more common in deep porphyry deposits than in epithermal deposits. Hydromagmatic breccias form by interaction of magma with externally sourced water, such as groundwater, or rarely, seawater. Magma and water are involved in phreatomagmatic breccia formation, resulting in diatremes with tuffaceous matrixes, whereas only a magmatic heat source and water are required for formation of phreatic breccias. Volcanic breccias result from fragmentation of igneous rocks, including pyroclastic rocks, such as block-and-ash flows, flow breccias, carapace (talus) breccias, and debris flows. Volcanic breccias are important host rocks in many epithermal deposits (Sillitoe, 1985; Nelson and Giles, 1985; Davies and others, 2008a; Holley, 2012). Intrusion breccias result from magma fragmentation during shallow emplacement of dikes and domes. Most igneous breccias are permeable, which allows 


\section{A. Stratovolcano}

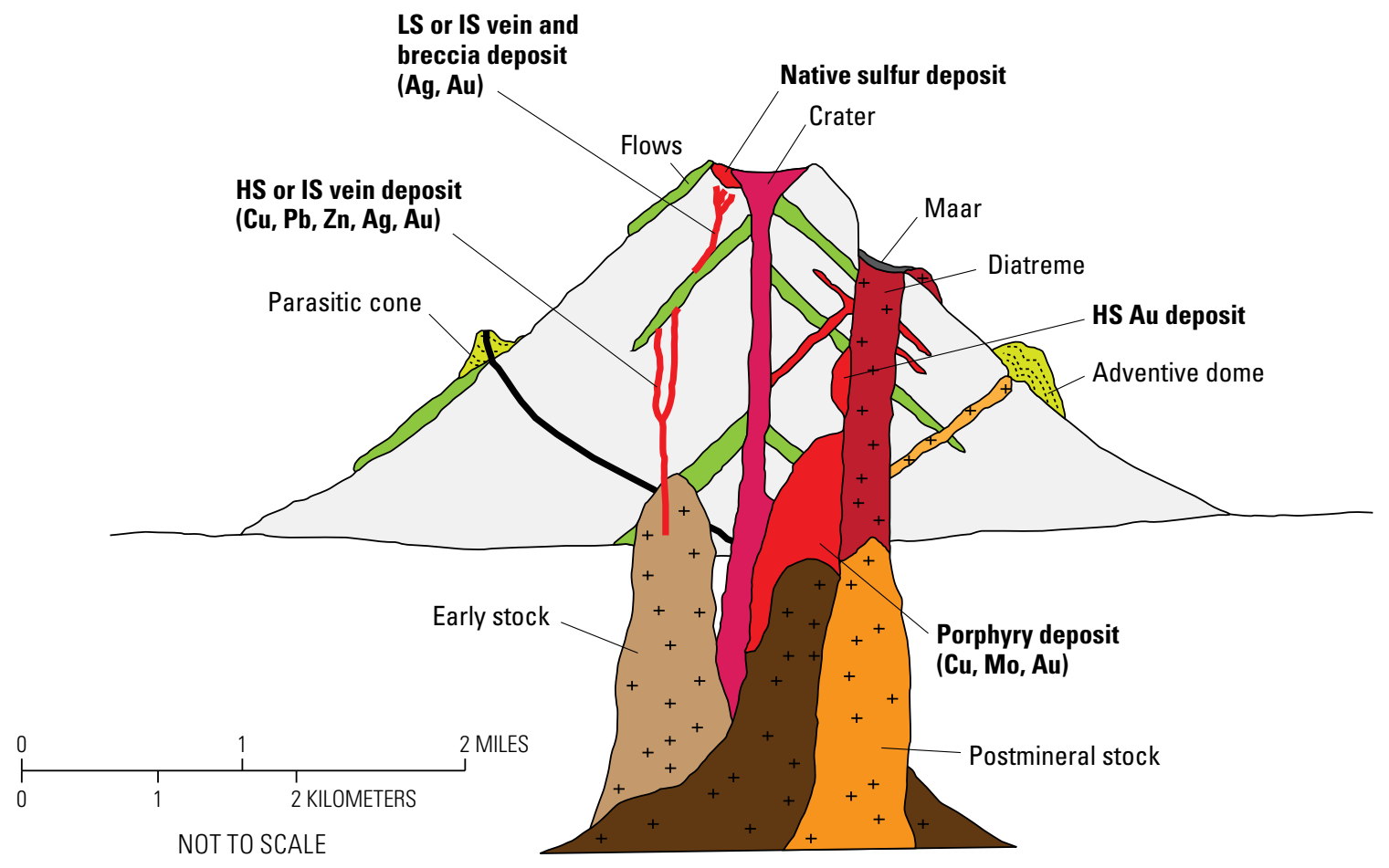

\section{B. Lava dome field}

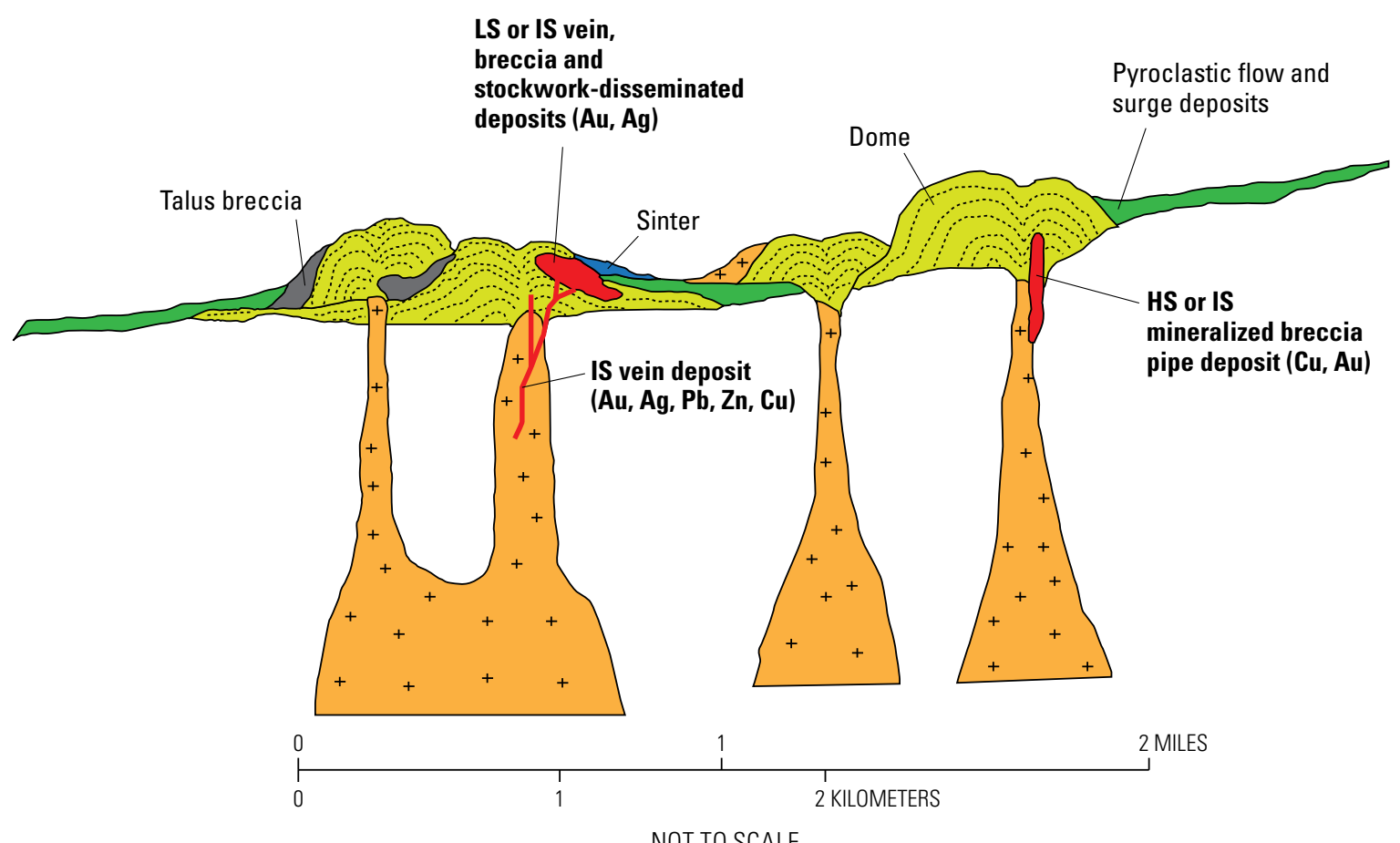

Figure E2. Schematic cross sections showing volcanic landforms that commonly host epithermal gold-silver and related deposits and principal metals. $A$, Stratovolcano; $B$, Lava dome field; $C$, Ignimbrite (ash-flow) caldera; $D$, Maar-diatreme complex. Figure modified from Sillitoe and Bonham (1984). 


\section{Ignimbrite ash-flow}

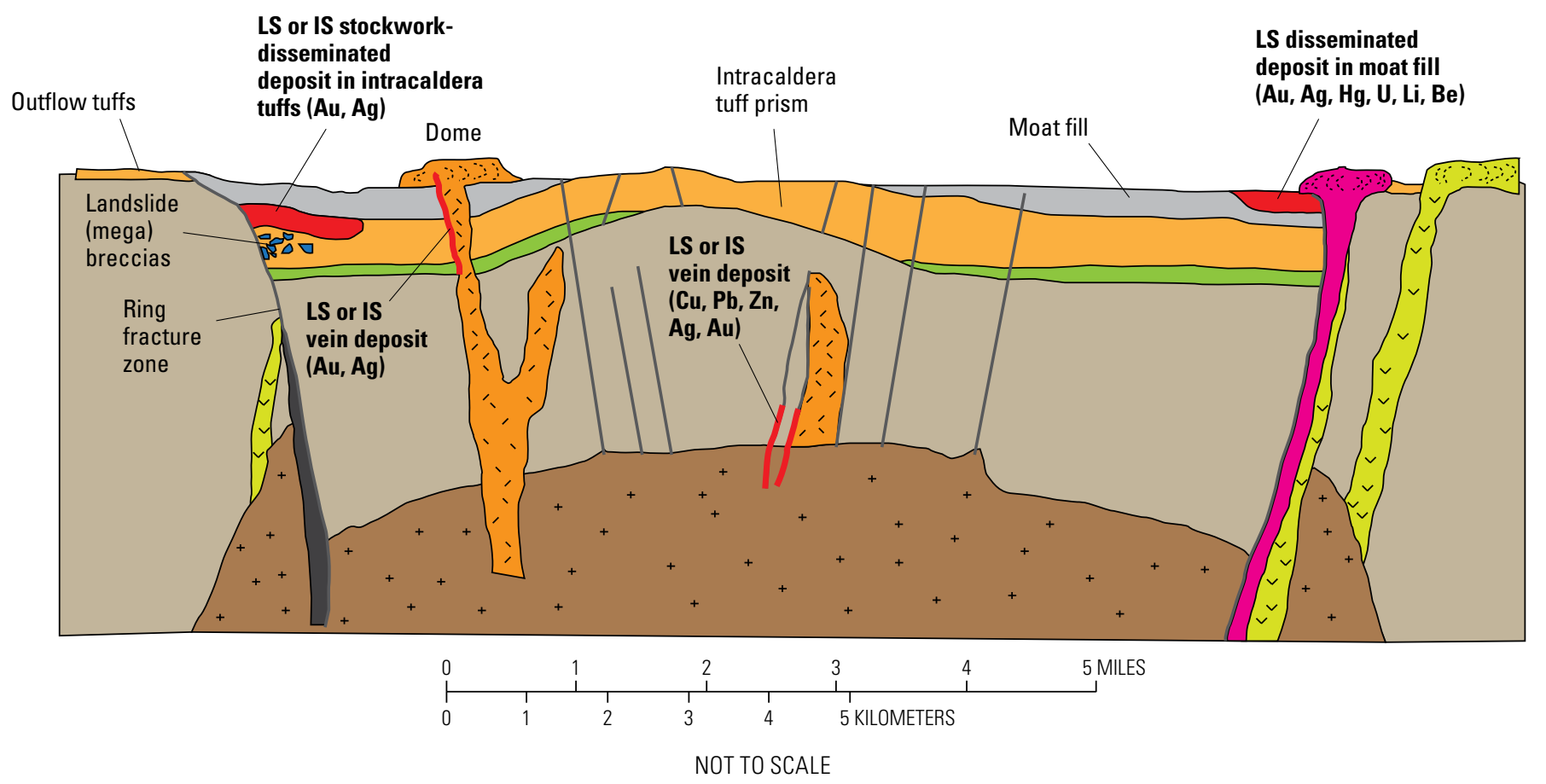

\section{Maar-diatreme complex}

LS stockwork-

disseminated

deposit in and below

lake beds (Au)

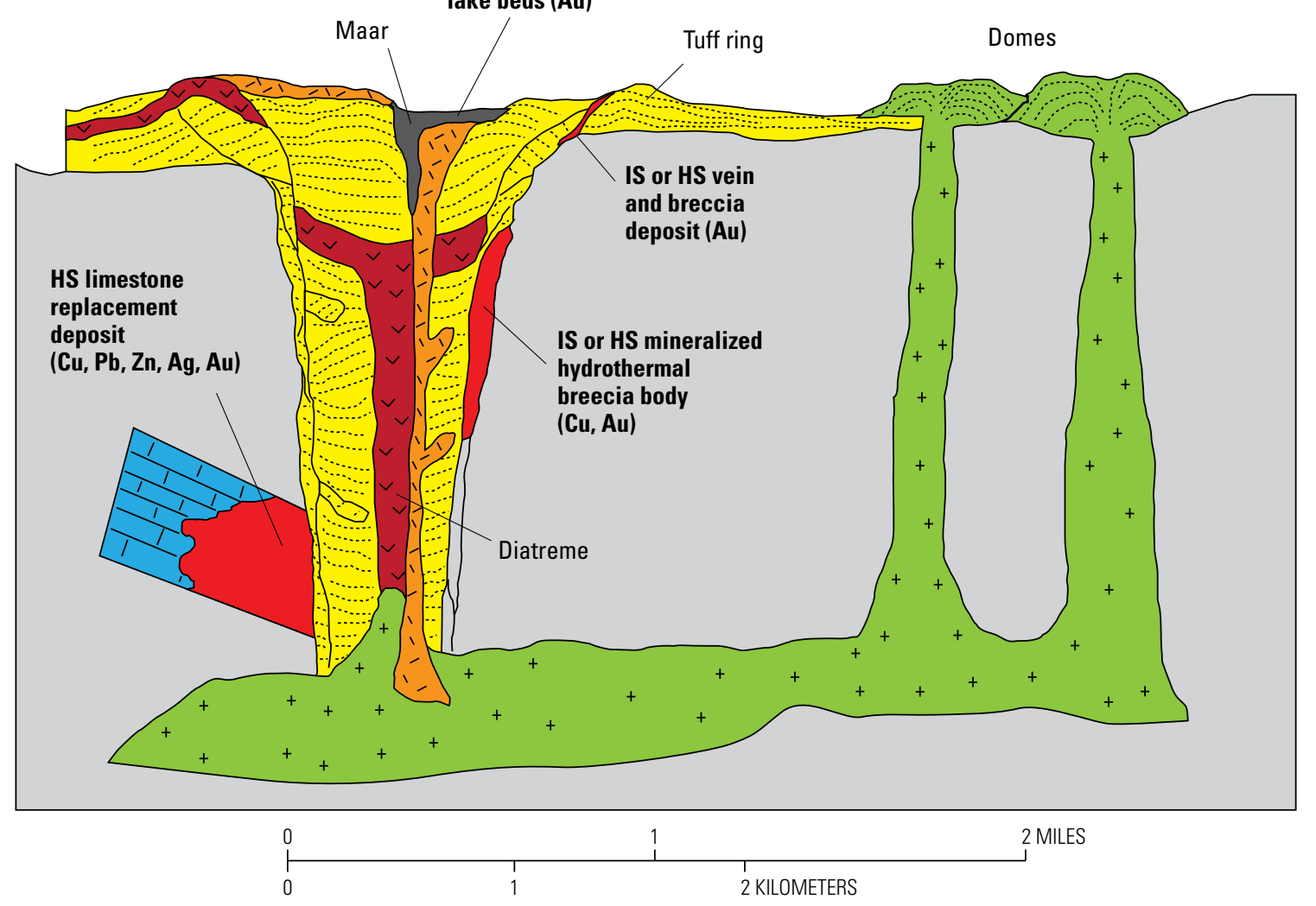

NOT TO SCALE

Figure E2.-Continued 
hydrothermal fluid flow and provides open space for deposition of ore minerals.

\section{Caldera-Related Structures}

Calderas form by volcanic edifice collapse into the underlying space vacated by magma removal during volcanic eruptions. Calderas can be divided into two types, larger ignimbrite (ash-flow or Valles-type) calderas formed by eruption of large-volume silicic ignimbrites and smaller calderas formed near the tops of stratovolcanoes (fig. E2; see "Relations to Igneous Rocks"). Epithermal gold-silver deposits form along ring fracture fault zones of ignimbrite calderas and in the collapsed interiors of both types of calderas (appendix 1). In large ignimbrite calderas, some epithermal deposits formed shortly after caldera collapse (for example, Round Mountain, Henry and others, 1997) and may be related to magma resurgence and dome emplacement (for example, Round Mountain, Nevada; San Cristobal, Bolivia; Columba and Cunningham, 1993; Rodalquilar, Spain, Arribas and others, 1995a). Other epithermal deposits formed several million years after caldera collapse along reactivated caldera ring fracture faults (Summitville, Colorado, Steven and Ratté, 1960; Beregovo, Ukraine, Vityk and others, 1994) or along reactivated faults formed during intracaldera resurgent doming magmatism (Creede, Colorado, Steven and Ratté, 1965). In smaller calderas related to stratovolcanoes, collapse craters may be partly filled with hyperacidic lakes into which continuously streaming magmatic gases can deposit highsulfidation-type epithermal gold mineralization (for example, Kawah Ijen, Java, Indonesia, Scher and others, 2013).

\section{Diatreme Complexes}

Dome-diatreme and maar-diatreme complexes commonly host intermediate- or high-sulfidation epithermal goldsilver deposits (appendix 1; fig. E2). Epithermal deposits are hosted by diatreme breccias inferred to have underlain maar structures (appendix 1; Roşia Montană, Romania, Manske and others, 2006; Kelian, Indonesia, Davies and others, 2008a; Valedero, Argentina, Charchaflié and others, 2007; Cerro de Pasco, Colquijirca, and Laguna Norte, Peru, Bendezú and others, 2003; Baumgartner and others, 2008; Cerpa and others, 2013; Peñasquito, Mexico, Belanger and others, 2011). Epithermal ore in these deposits may be disseminated in sedimentary rocks filling the maar crater (Pueblo Viejo, Sillitoe and Bonham 1984; Russell and Kesler 1991), form disseminated, vein, and breccia bodies in diatreme breccias (Cerro de Pasco, Peru; Peñasquito, Mexico), or form disseminated, breccia, or replacement bodies in host rocks of the diatreme (fig. E3; Kelian, Indonesia; Cerro de Pasco and Laguna Norte, Peru; Peñasquito, Mexico). At Cerro de Pasco, diatreme breccias and the steep diatreme walls repeatedly served as conduits for streaming magmatic-hydrothermal fluids (fig. E4; Baumgartner and others, 2008).

\section{Dikes}

Synmineralization dikes emplaced along normal faults in extensional terrains are common in several epithermal districts (Mule Canyon, Nevada, John and others, 2003; El Oro, Mexico, Caira, 2013; Kurankh, Russia, Rodionov and others, 2014). At Mule Canyon, gold mineralization is localized around a swarm of mafic dikes emplaced along normal faults (John and others, 2003). Dike margins and adjacent wall rocks were brecciated during faulting and dike emplacement, whereas the dense, impermeable dike cores served as barriers for ascending hydrothermal fluids. Ore at Mule Canyon consisted of narrow zones of mineralized breccias, disseminated mineralization, and quartz-adularia veins in dike margins and in adjacent wall rocks (fig. E5).

\section{Sedimentary Structures}

Sedimentary structures important for the genesis of epithermal gold-silver deposits include contacts between units with contrasting permeability, unconformities, and associated karst deposits (see "Relations to Sedimentary Rocks").

\section{Tectonic Structures}

Faults and associated fractures are abundant in most epithermal gold-silver deposits and may serve as the principal control on the location, distribution, and shape of ore bodies. Faults provide the primary pathways for ascent of deep, hightemperature hydrothermal fluids into the shallow, epithermal environment (Cox and others, 2001; Micklethwaite, 2009; Faulds and others, 2011; Rowland and Simmons, 2012) and also allow descent of cold ground (meteoric) water (Ebert and Rye, 1997). Mineralized veins commonly occupy complex fault meshes, especially in dilational jogs between en echelon fault segments and along sigmoidal bends connecting faults, and larger veins may form during numerous cycles of opening by earthquake faulting and sealing by precipitation of quartz, calcite, and other gangue and ore minerals (fig. E6; Sibson, 1987, 1996; Cox and others, 2001; Micklethwaite, 2009). Small extensional and shear fractures in the footwall and hanging wall of larger faults can form zones of narrow sheeted or stockwork veins (fig. E7; Begbie and others, 2007).

Permeability and fluid flow patterns in epithermal systems are complex and vary with the regional tectonic regime, lithology, and pre-existing structures; these may evolve in response to local stress perturbations, such as dike emplacement, oblique slip on normal faults, or pulses of high fluid pressure (Sibson, 1987, 1996; Cox and others, 2001; Micklethwaite, 2009; Micklethwaite and others, 2010; Ingebritsen and Appold, 2012; Rowland and Simmons, 2012). Permeability and fluid flow also increase and decrease through time: faults rupture and increase permeability and fluid flow (seismic pumping; Sibson and others, 1975), and open space is filled as hydrothermal minerals precipitate, which reduces 


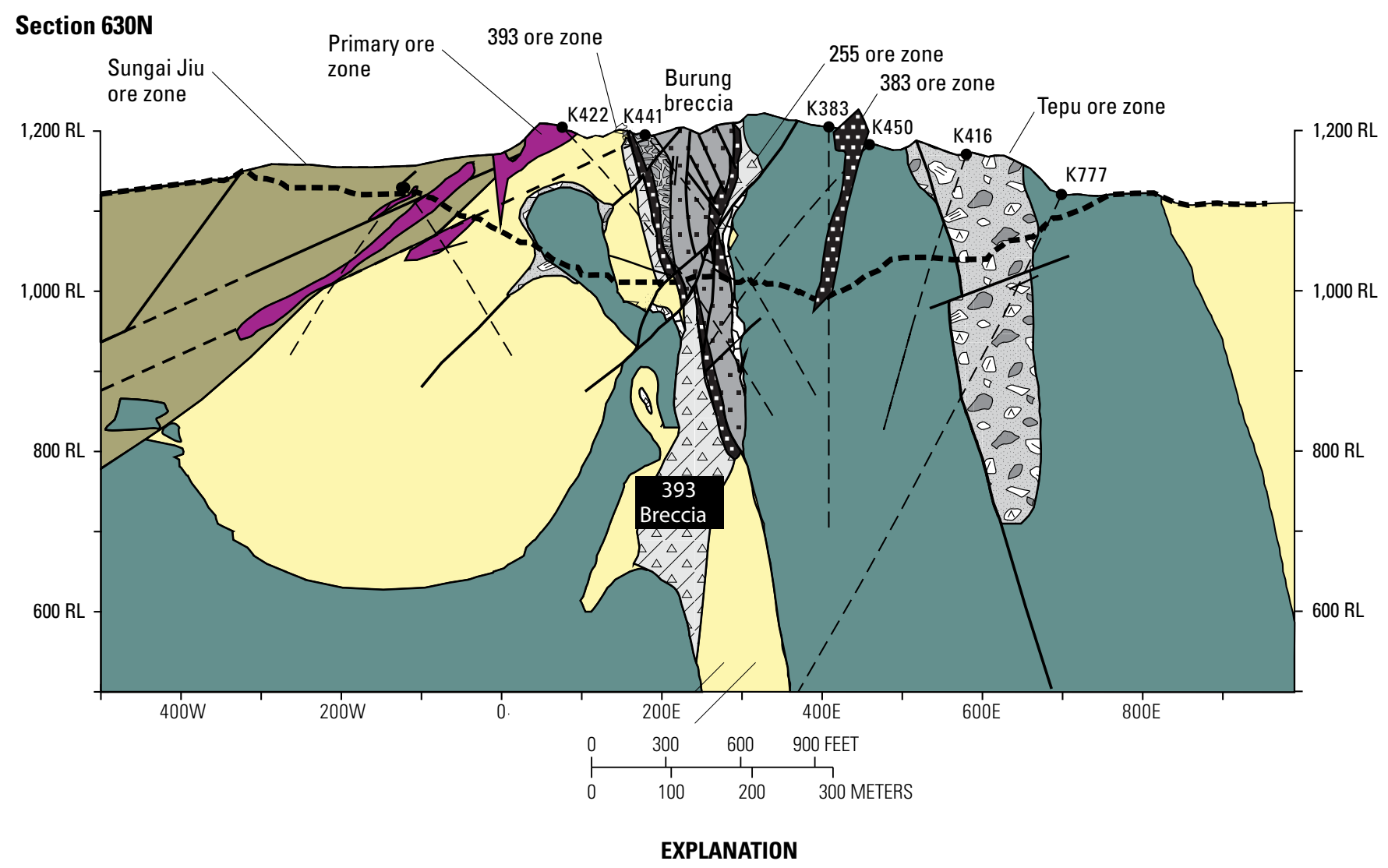

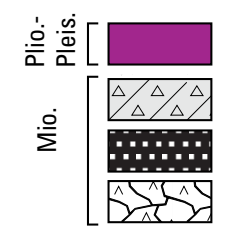

Coherent basalt dikes and lava flows

C3, C4, and C5 facies breccias

C2 facies-Pyrite-cemented breccia

C1 facies-Illite-pyrite-cemented breccia

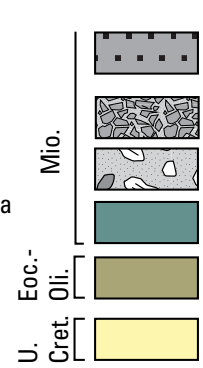

A4 facies-Polymict carbonaceous breccias with rhyolite clasts

A1 facies-Monomict carbonaceous breccia

A facies-Polymict carbonaceous breccias

Andesite

Carbonaceous quartz sandstone, siltstone, and coal

Undifferentiated felsic volcaniclastic rocks
- - Open-pit mine outline

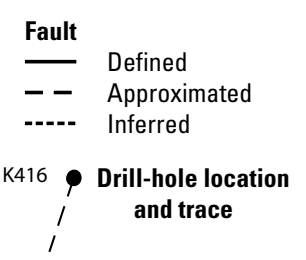

Figure E3. Cross section of the Kelian, Indonesia, intermediate-sulfidation deposit showing maar-diatreme dome complex and breccia bodies. High-grade ores (255 and 393 ore zones primarily in C3, C4, and C5 facies breccias) are localized in composite hydrothermal breccia bodies including the 393 Breccia. Figure modified from Davies and others (2008b). Abbreviations: Eoc., Eocene; Mio., Miocene; Oli., Oligocene; Pleis., Pleistocene; Plio., Pliocene; U. Cret., Upper Cretaceous. 


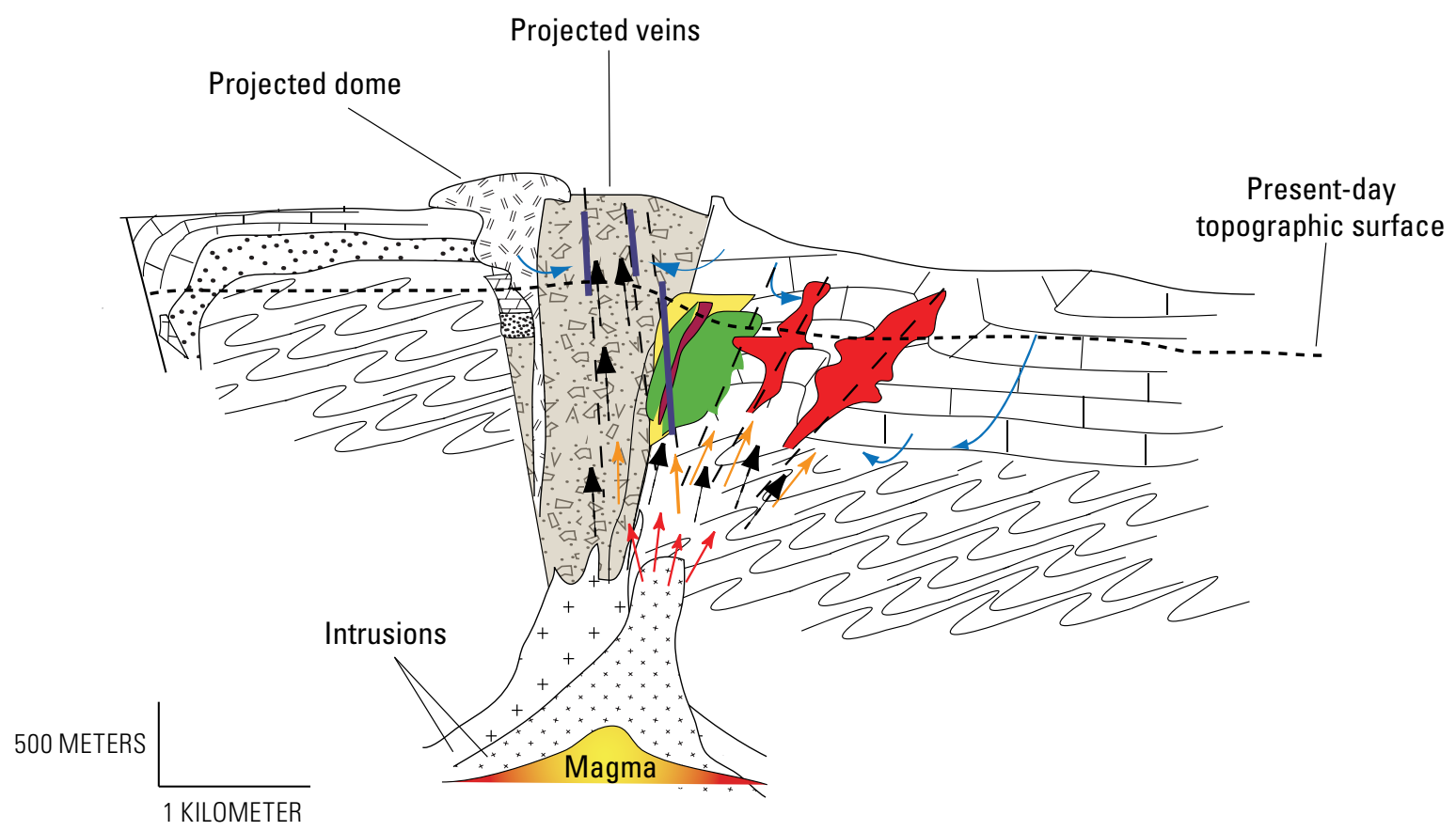

\section{EXPLANATION}

\section{Geological units}

" $1111 \Rightarrow$

11 $11 / 2$

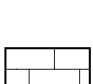

$\because \because{ }^{\prime} \quad$ Permian-Triasssic Mitu Group, sandstone

Devonian Excelsior Group, phyllite

Diatreme breccia sandstone

\section{Mineralization type}

Fluids

Quartz monzonite porphyry dikes

Dacite to rhyodacite porphyries (showing domal structures)

Cretaceous Goyllarizquizga Group,

Upper Triassic-Lower Jurassic Pucará Group, limestone and dolostone

$\left\{\begin{array}{l}3 \\ \frac{3}{2} \\ \frac{2}{0} \\ 1 \\ \frac{1}{3} \\ \frac{0}{0} \\ 0 \\ \frac{0}{0}\end{array}\right.$

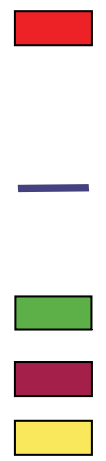

$\mathrm{Zn}-\mathrm{Pb}-(\mathrm{Bi}-\mathrm{Ag}-\mathrm{Cu})$ replacement bodies (Fe-poor sphalerite). Advanced argillic alteration in the core zone

$\mathrm{Cu}-\mathrm{Ag}-\mathrm{Au}-(\mathrm{Zn}-\mathrm{Pb})$ veins (enargite-pyrite veins). Advanced argillic alteration in the core zone

$\mathrm{Zn}$-Pb ore (Fe-rich sphalerite)

Pipe-like pyrrhotite bodies

Pyrite-quartz body

Figure E4. Cross section of diatreme-dome complex at Cerro de Pasco, Peru, showing high-sulfidation vein and polymetallic replacement deposits and fluid pathways. Figure modified from Baumgartner and others (2008). Abbreviations: Ag, silver; $\mathrm{Au}$, gold; $\mathrm{Bi}$, bismuth; $\mathrm{Cu}$, copper; $\mathrm{Fe}$, iron; $\mathrm{Pb}$, lead; $\mathrm{Zn}$, zinc. 
Figure E5. Schematic cross section of ore zones at the Mule Canyon low-sulfidation deposit, Nevada, showing distribution of hydrothermal alteration assemblages and ore types. Figure modified from John and others (2003).

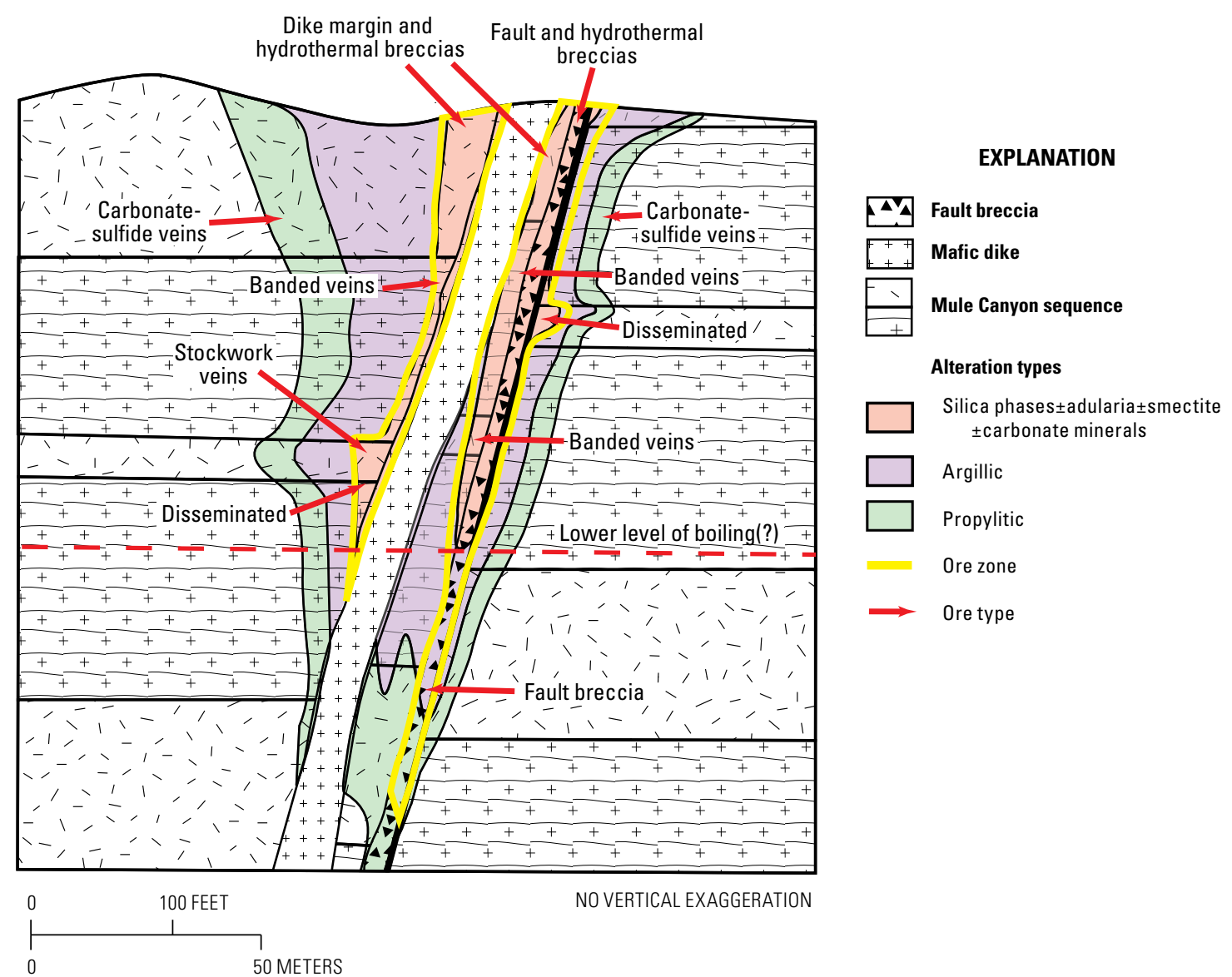

Figure E6. Fault mesh model of Hill (1977) for earthquake swarms comprising interlinked shear, extensional, and extensional-shear fractures developed in a triaxial stress field. Diagram represents an extensional normal-fault stress regime when viewed upright, a compressional thrust-fault regime when rotated 90 degrees, and a strike-slip regime in plan view. Red areas represent dilational zones. Arrows show direction of relative movement. Figure redrawn from Sibson (1996).

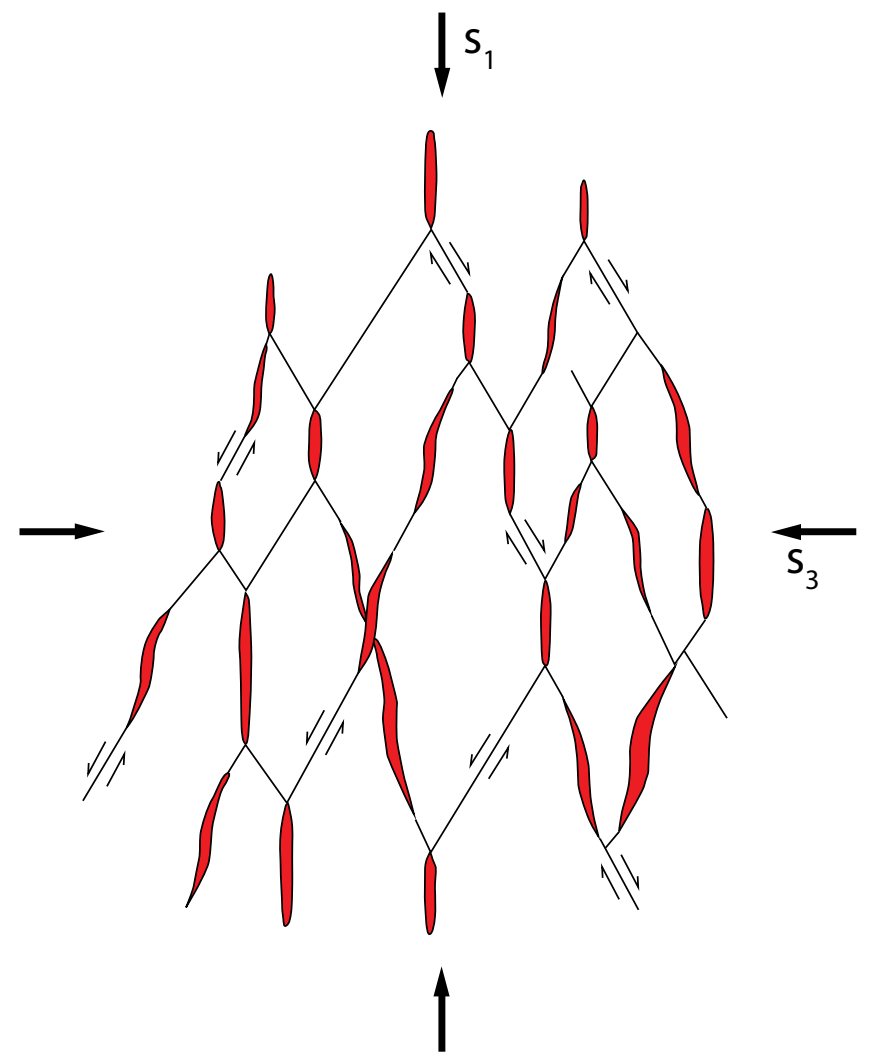




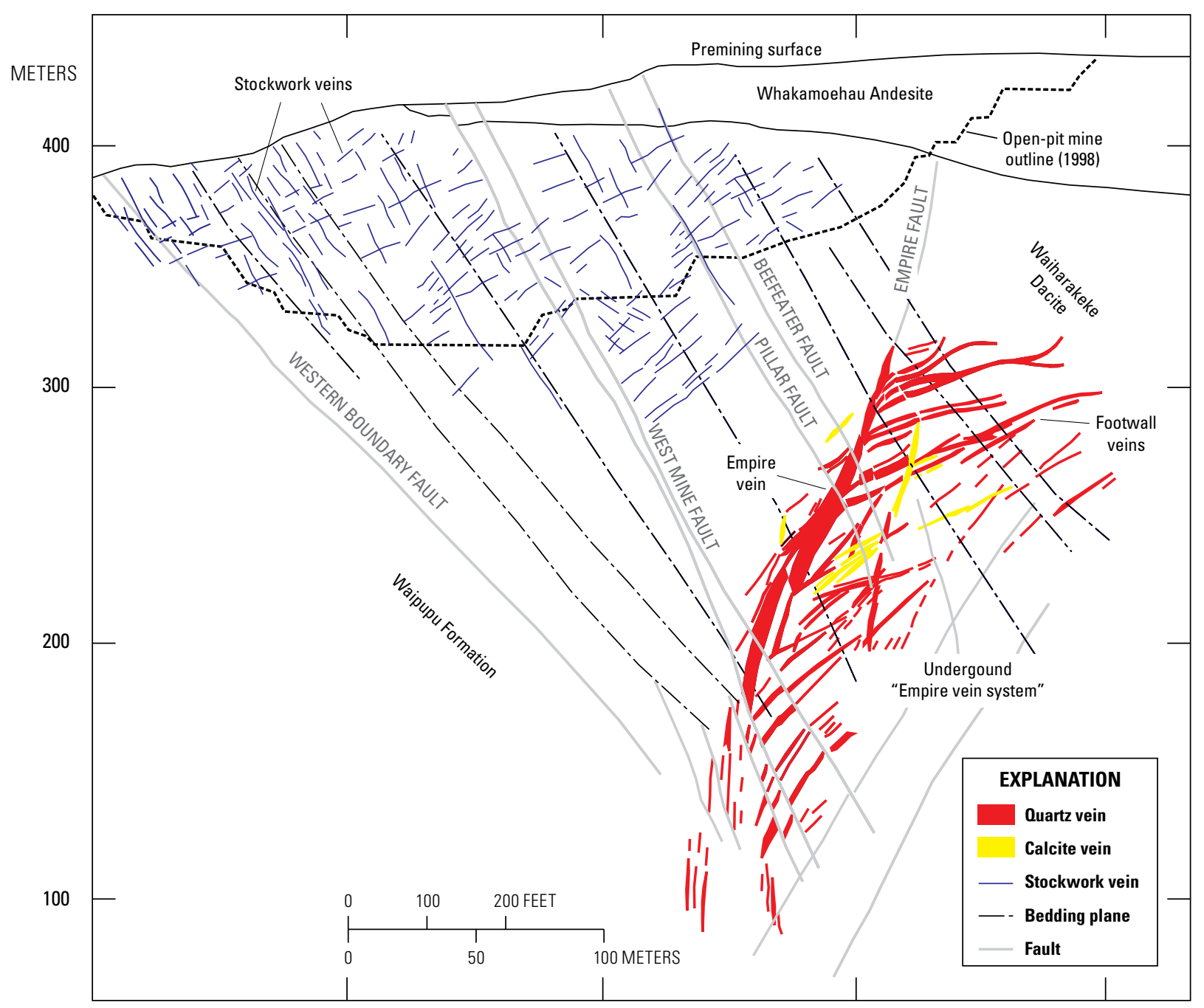

DATUM IS SEA LEVEL

Figure E7. Cross section of the Golden Cross deposit, New Zealand, showing distribution of veins and ore types. Figure modified from Begbie and others (2007).

permeability and fluid flow (self sealing; Facca and Tonani, 1967; White and others, 1975). Zones of enhanced vertical fluid flow are localized at the tips (ends) of faults, in stepover zones, and where fault dips change (fig. E8; Cox and others, 2001; Micklethwaite, 2009; Faulds and others, 2011; Rowland and Simmons, 2012). Detailed structural and textural studies of epithermal deposits show that epithermal gold-silver mineralization is typically associated with repeated, transient fluid flow pulses through fault meshes rather than steady-state processes (see "Duration of Hydrothermal Systems that Form Epithermal Gold-Silver Deposits"; Sanematsu and others, 2006; Micklethwaite, 2009).

Normal, oblique-slip, strike-slip, and reverse faults are common in epithermal gold-silver systems and strongly influence ore distribution (appendix 1). Postmineralization faults can dismember and displace epithermal deposits and inhibit or enhance erosion of these shallow deposits. Some examples of structural control on epithermal deposit formation by faults and postmineralization faulting follow.

\section{Normal Fault Zones}

Many low- and intermediate-sulfidation vein deposits formed along or at intersections between normal fault zones (appendix 1). At Golden Cross, New Zealand, the 2- to 10-m-thick Empire vein was produced by vertical hydrothermal fluid flow focused along the Empire Fault, a steeply dipping normal fault zone (fig. E7; Begbie and others, 2007). Stockwork vein mineralization also formed in narrow, subvertical extension fractures in the hanging wall of the 
$\boldsymbol{A}$

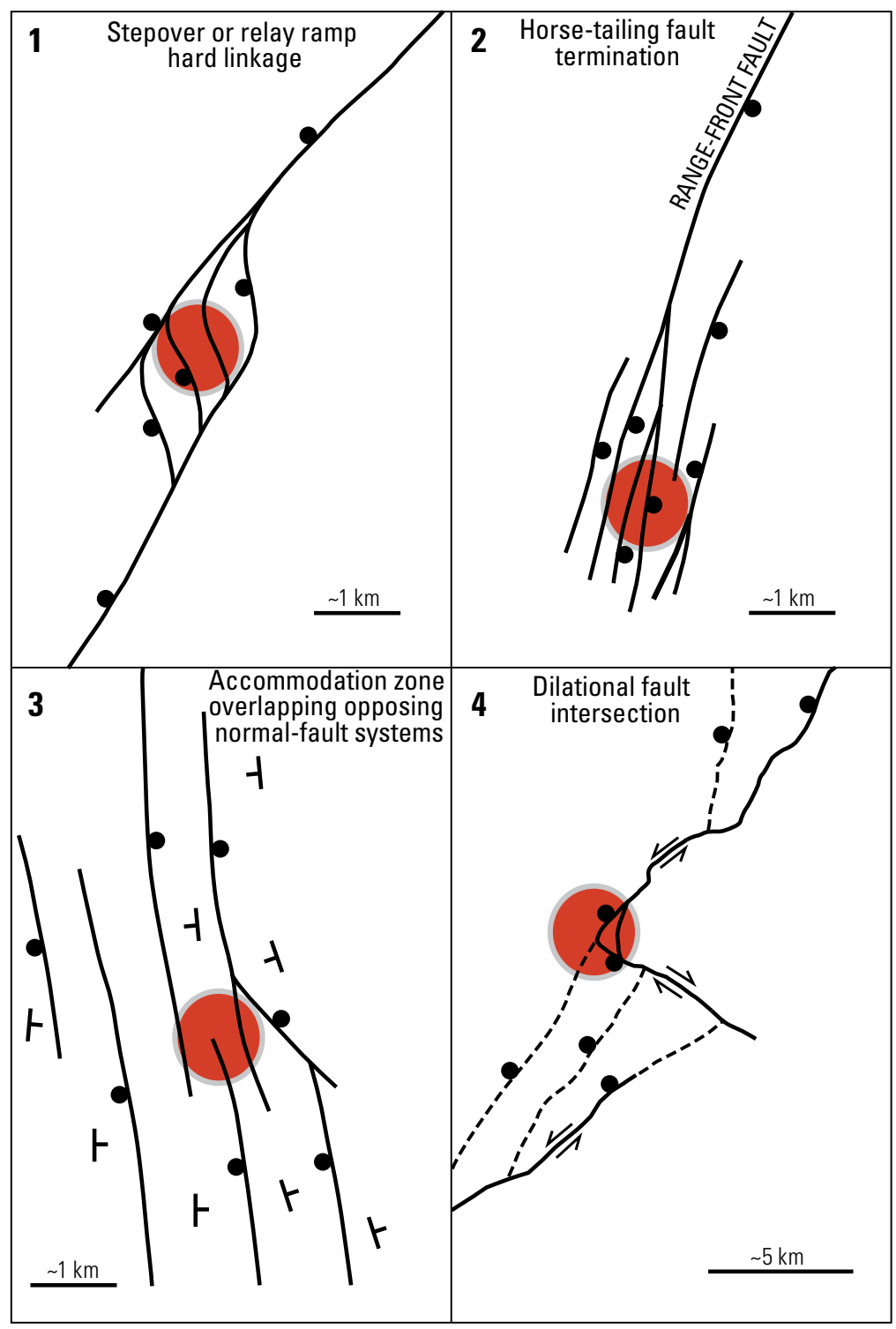

B

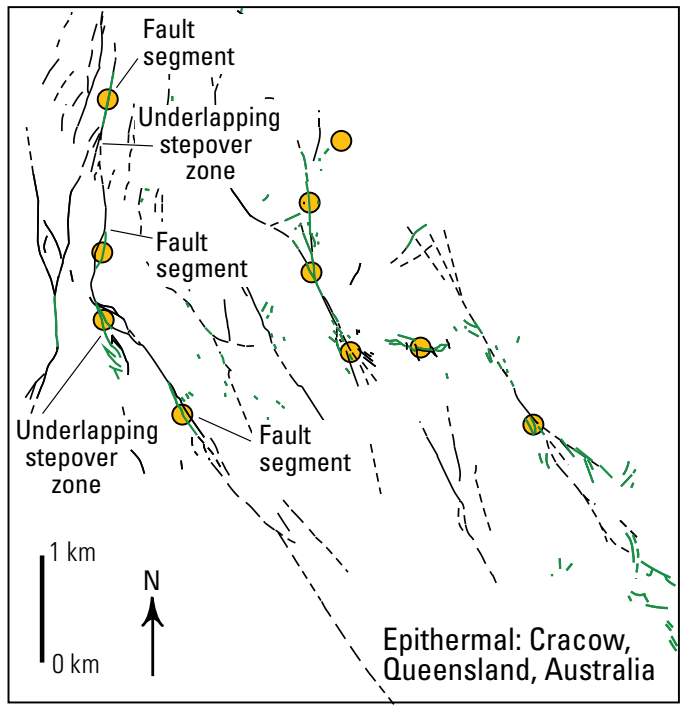

\section{EXPLANATION}

- Fault (displacement up to 250 meters, normal dip-slip)

- Epithermal vein or cementsupported breccia

Locations of historical open pits and active underground deposits

Geothermal upwelling

Figure E8. Maps showing structural settings of geothermal and low-sulfidation epithermal systems. $A$, Examples of favorable structural settings for active geothermal systems in the Great Basin, western United States (from Faulds and others, 2011). Areas of upwelling geothermal fluids are shaded in red; solid black circles located on downthrown fault block. 1, Stepover or relay ramp between two overlapping normal fault segments with multiple minor faults providing hard linkage between two major faults. 2 , Horsetail or fault splay at termination of major normal fault. 3, Accomodation zone between overlapping oppositely dipping normal fault systems that generate multiple fault intersections in the subsurface. Strike and dip symbols indicate tilt directions of fault blocks. 4, Dilational fault intersection between oblique-slip normal faults. $B$, Location of faults, epithermal veins, and breccias, and mines exploiting Paleozoic low-sulfidation epithermal deposits in the Cracow mining district, Queensland, Australia (from Micklethwaite, 2009). 
Empire Fault. At Cracow, Australia, gold-silver mineralization is contained in an epithermal fault-vein network developed around a central fault core with as much as $300 \mathrm{~m}$ of normal displacement (fig. E8B; Micklethwaite, 2009). The fault core comprises multiple increments of breccia bodies, surrounded by a damage zone that hosts extensional and shear veins.

Normal dip-slip movement dominates the fault-vein network, but varying slip directions and vein orientations reflect strikeslip and oblique-reverse slip movements attributed to transient stress rotation related to dike intrusion. The Hycroft (CrofootLewis), Nevada, deposit is at the margin of a late Cenozoic extensional basin where heated groundwater ascended along a basin-bounding normal fault, formed sinter terraces, and deposited low-grade low-sulfidation gold-silver mineralization near the top of the water table (fig. E9; Ebert and Rye, 1997).

\section{Strike-Slip Fault Zones}

Epithermal gold-silver deposits in strike-slip fault zones have formed in extensional (transtensional) and compressional (transpressional) stress fields. At McLaughlin, California, sheeted quartz veins containing bonanza grade gold mineralization formed in a dilational zone in the footwall of a thrust fault in a fold and thrust belt related to transpression along the San Andreas Fault system (Tosdal and others, 1996; Enderlin, 2002). The sheeted quartz vein complex formed a shallow-plunging, pipe-like body about $50 \mathrm{~m}$ in diameter. The vein complex formed in an unusual pressure shadow on the edge of a large block (lithon) of metabasalt in mélange along the Stony Creek Fault, a northwest-striking dextral fault related to the San Andreas Fault system (fig. E10).

NORTHWEST

Black Rock Range

Black Rock Desert

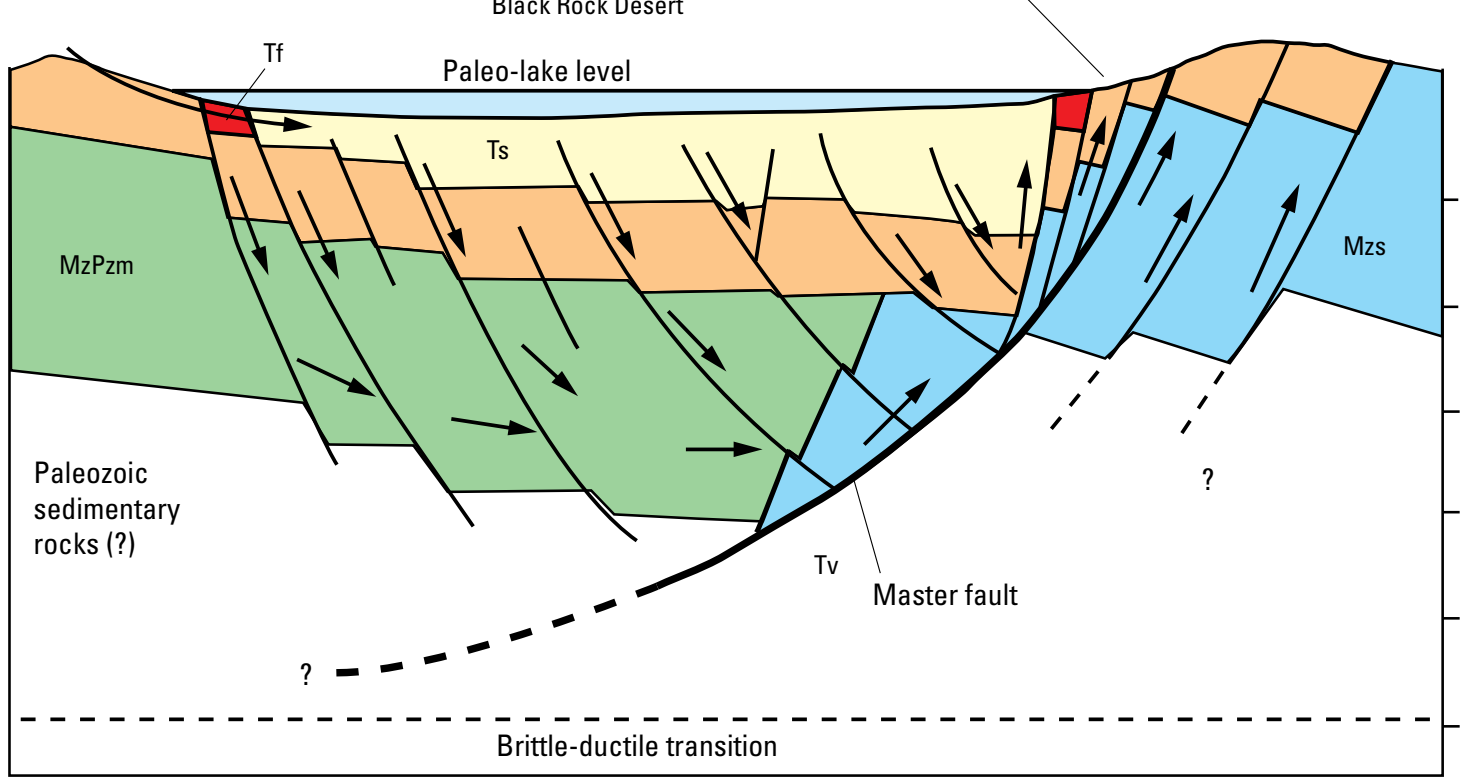

Hycroft

Au-Ag mine

SOUTHEAST

Kamma Mountains

NO VERTICAL EXAGGERATION

EXPLANATION

\begin{tabular}{|c|c|c|c|}
\hline Ts & Late Cenozoic basin sediments & MzPzm & Mesozoic-Late Paleozoic metavolcanic \\
\hline Tf & Talus-fanglomerate deposits & & \\
\hline Tv & Tertiary Kamma Mountains Group & & Hydrothermal fluid flow path \\
\hline Mzs & $\begin{array}{l}\text { Jurassic-Triassic metasedimentary } \\
\text { rocks (Auld Lang Syne Group) }\end{array}$ & & Contact \\
\hline
\end{tabular}

Figure E9. Cross section of the Hycroft (Crofoot-Lewis, Sulphur) low-sulfidation deposit, Nevada, showing structural setting and inferred flow paths for hydrothermal fluids. Modified from Ebert and Rye (1997).

Abbreviations: Ag, silver; Au, gold. 
Figure E10. Cross section and photograph of McLaughlin lowsulfidation deposit, California. $A$, Cross section through the sheeted vein complex at the McLaughlin low-sulfidation deposit, California (modified from Sherlock, 1996). $B$, Photograph of sheeted veins in McLaughlin mine. Hammer is about $45 \mathrm{~cm}$ long. Photograph by James Rytuba.

$\boldsymbol{A}$

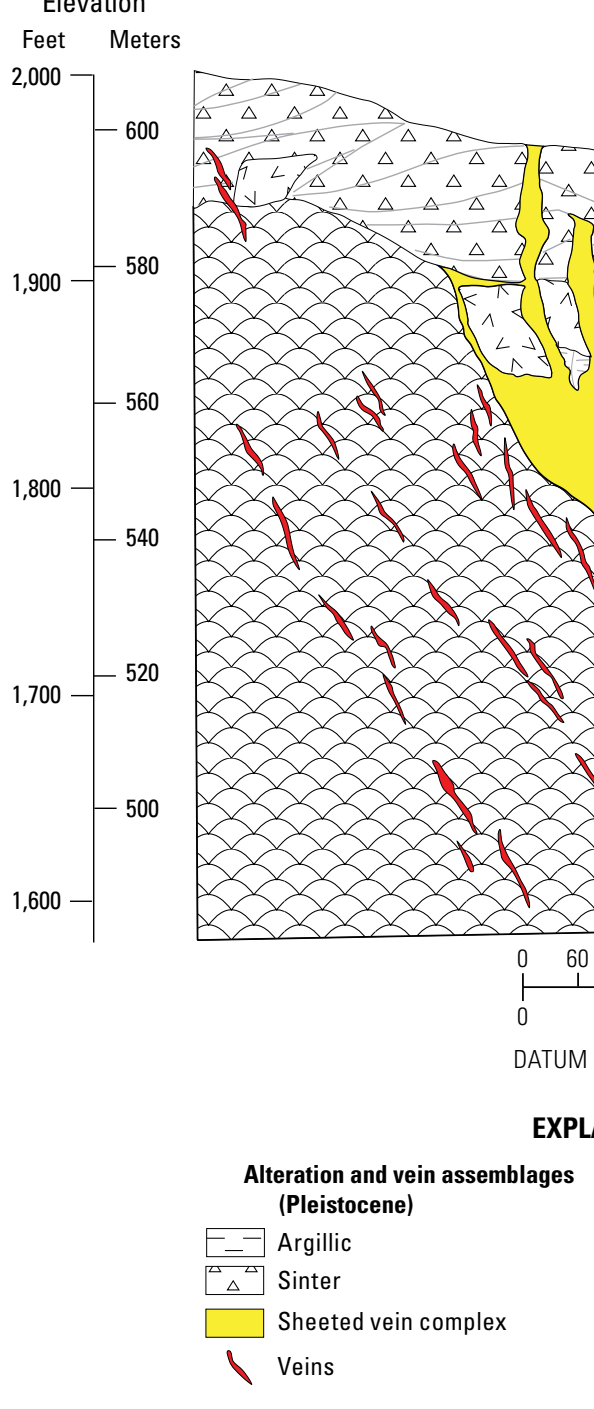

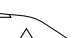
$\Delta \Delta$ $\Delta \Delta \Delta \Delta R$

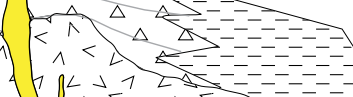

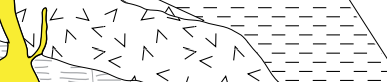

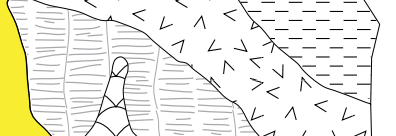

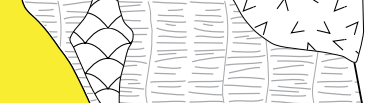
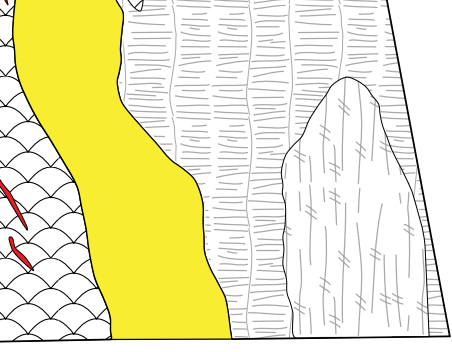

FEET

60 METERS

TUM IS SEA LEVEL

XPLANATION

Clear Lake Volcanic Suite (Pliocene)

$\Sigma^{4} \backsim$ Basaltic andesite flows

Coast Range ophiolite (Middle Jurassic)

Polymictic melange

Pillowed basalt

Serpentinite melange

B

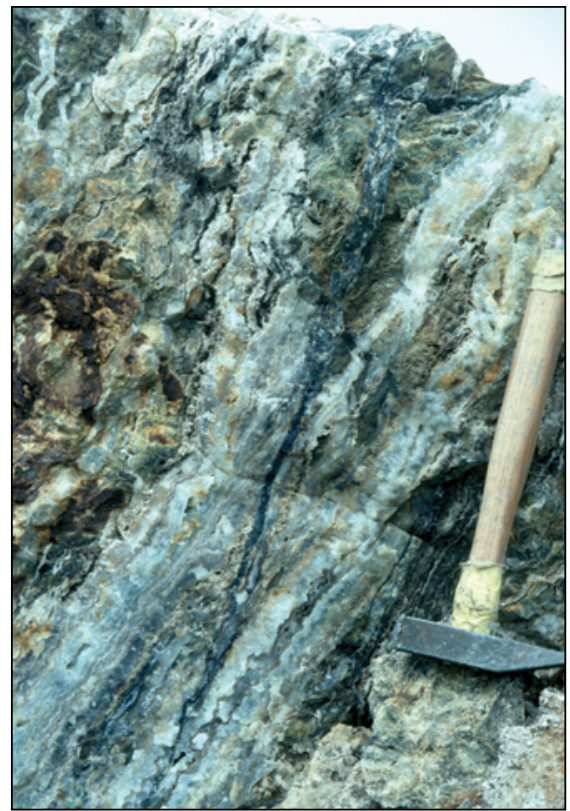


At the Mesquite deposit, California, Willis and Tosdal (1992) showed that gold-bearing quartz-adularia veins formed along northwest-striking dextral strike-slip faults and north-striking normal faults in a transtensional stress regime. These faults formed in a combination of strike-slip duplexes and fault jogs between several northwest-striking, dextral strike-slip faults related to the late Oligocene proto-San Andreas Fault system.

\section{Reverse Fault Zones}

Reverse faults have localized magma emplacement, hydrothermal alteration, and epithermal mineralization in several high-sulfidation deposits formed in compressional environments. At Cerro de Pasco, Colquijirca, and Lagunas Norte, Peru, highangle reverse faults localized emplacement of diatreme-dome complexes, subsequent streaming of magmatic-hydrothermal fluids, and formation of silver-base metal mineralization at Cerro de Pasco and Colquijirca and gold mineralization at Laguna Norte. Epithermal precious metal mineralization is hosted by the diatreme-dome complexes and by adjacent sedimentary wall rocks (fig. E4; Baumgartner and others, 2008; Bendezú and Fontboté, 2009; Montgomery, 2012; Cerpa and others, 2013).

\section{Postmineralization Faults}

Because epithermal deposits form in tectonically active regions at depths less than about 1,500 $\mathrm{m}$, they are highly susceptible to erosion, and most known deposits have late Cenozoic ages (see "Temporal (Secular) Relations"). Postmineralization faults cut and dismember many epithermal deposits, and some deposits have been preserved from erosion by down-faulting and subsequent concealment by overlying younger deposits. For example, the Sleeper, Nevada, low-sulfidation vein deposit was down-faulted by normal faults and covered by basin-filling sediments, which preserved most of the deposit (Nash and others, 1995). Faulting also can tilt, dismember, and displace parts of epithermal deposits. For example, the Paradise Peak high-sulfidation deposit was truncated by detachment faults and its root zone has not been discovered (Sillitoe and Lorson, 1994). Similarly, the Golden Cross deposit was tilted about $50^{\circ}$ by extensional faulting, so that stockwork veins formed in the hanging wall of the Empire Fault and vein are now in its footwall (fig. E7; Begbie and others, 2007).

\section{Topography-Related Structures}

In addition to the topographic effects of fluid flow on steep-sided stratovolcanoes (see "Stratovolcanoes"), steep topography formed during regional compression and crustal thickening can profoundly affect shallow hydrology in regions that lack significant volcanic edifices, as has been suggested for deposits in parts of the Andes Mountains in Argentina, Chile, and Peru (Bissig and others, 2002; Deyell and others, 2004; Charchaflié and others, 2007; Montgomery, 2012). Gravitational instability inherent in steep topography can result in local zones of extension, normal faulting, reactivation of reverse faults, and formation of large landslides resulting from rapid pediment incision. Changes in the hydrodynamic environment caused by catastrophic erosion and normal faulting include rapid water table lowering, increased lateral groundwater flow, and fluid boiling and mixing, all of which may be important factors in epithermal gold-silver deposit formation. In Argentina, Chile, and Peru, several large high-sulfidation deposits, including El IndioTambo, Pierina, Pascua-Lama, Veladero, and Lagunas Norte, are inferred to have formed during events related to evolution of the Miocene landscape associated with regional compression and subdued volcanism (Bissig and others, 2002, 2003; Chouinard and others, 2005; Charchaflié and others, 2007; Rainbow, 2009; Montgomery, 2012).

At the Pascua-Lama deposit, Chile and Argentina, the Brecha Central diatreme was emplaced at the 500-m-high headwall of an advancing valley developed because of rapid pediment incision (Chouinard and others, 2005). The diatreme is the main host rock for gold-silver mineralization. At Pierina, Peru, abrupt displacement of the water table resulted from pediment incision, which directed lateral flow of fresh groundwater into the epithermal environment, mixing with goldbearing bisulfide solutions, and precipitation of gold (Rainbow, 2009). The Veladero deposit in Argentina formed in a localized extensional zone where the tectonic environment changed from compressional to extensional as a result of gravitational instability associated with high elevation above sea level $(>4,000 \mathrm{~m})$ (Charchaflié and others, 2007). At Lagunas Norte, Peru, pediment incision may have triggered development of the Dafne diatreme breccia during decompression of an inferred shallow magma chamber (Montgomery, 2012). Diatreme emplacement caused intense brecciation of the surrounding rocks, which may have affected the prevailing hydrothermal-hydrological regime, and was rapidly followed by a major pulse of hydrothermal alteration and gold mineralization.

\section{Hydrothermal Structures}

Hydrothermal structures are common in epithermal deposits and include veins and zones of sheeted and stockwork veins, hydrothermal breccias, and sinter terraces (table E3).

\section{Veins}

Veins mark faults and other open fractures through which hydrothermal fluids flowed and precipitated hydrothermal phases, most commonly quartz and (or) carbonate minerals, but locally including adularia, clay minerals, and (or) zeolites. Veins, including zones of stockwork or sheeted veins (vein swarms), constitute the dominant ore type in most low- and intermediatesulfidation deposits and also are present in many structurally controlled high-sulfidation deposits (appendix 1). Examples of low- and intermediate-sulfidation deposits in which veins form the main orebodies include Midas, Sleeper, and Comstock Lode, Nevada (Goldstrand and Schmidt, 2000; Nash and others, 1991; Vikre, 1989a); Martha Hill, New Zealand (Brathwaite and Faure, 2002); Hishikari, Japan (Izawa and others, 1990); and many 
others (appendix 1). Stockwork veins also are common features in low- and intermediate-sulfidation deposits. In many places, these allow open-pit mining of ore bodies with relatively low gold-silver grades; examples include Golden Cross, New Zealand (Begbie and others, 2007), and Round Mountain, Nevada (Sander and Einaudi, 1990). In contrast, sheeted veins are less commonly associated with epithermal deposits; some examples include McLaughlin, California (Sherlock and others, 1995), and parts of Cerro Rico de Potossi, Bolivia (Turneaure, 1960a, 1960b).

Veins form in a range of physical and chemical conditions resulting in a wide variety of textures that are well described in the literature (for example, Adams, 1920; Dong and others, 1995). The following is a brief classification of these textures; some definitions have been refined based on new observations. Unless otherwise indicated, the textures can be observed in hand samples and by microscopic examination. Figure E11 shows examples of vein textures.

\section{Quartz Textures Observed in Hand Samples and by Microscopic Examination}

Epithermal veins are typically banded (layered); the bands are primary growth textures, and bands can be classified as colloform, crustiform, and ginguro.

Colloform banded veins contain undulating, botryoidal, or laminar bands of chalcedonic or crystalline quartz and other hydrothermal minerals; this texture is common and widespread in epithermal deposits (figs. E11B, 11F; Adams, 1920; Lindgren, 1933; Dong and others, 1995). Multiple bands in a single vein are generally parallel, although slight deviations from parallelism reflect spherical nodes or laminar bulges. Bands are mirrorplane symmetric across vein center lines because of progressive, open-space filling inward from the walls. Individual bands are as much as 5 millimeters $(\mathrm{mm})$ wide, and thicker bands commonly contain sub-bands that are approximately 100 to 200 micrometers $(\mu \mathrm{m})$ wide (Adams, 1920). Colloform bands probably represent deposition of amorphous silica or chalcedony that formed rapidly in boiling or flashing shallow hydrothermal systems; these silica materials later crystallized to form quartz (Fournier, 1985; Saunders, 1994; Henley and Hughes, 2000; Moncada and others, 2012; Shimizu, 2014).

Crustiform bands are commonly white, contain fine- to coarse-grained quartz and other hydrothermal minerals, and are as much as a centimeter in thickness. Comb quartz is a typical texture in crustiform bands. Individual bands reflect differences in color, mineralogy, and textures, and like colloform bands, crustiform bands are mirror-plane symmetric (fig. E11C; Adams, 1920; Dong and others, 1995). In crustiform bands, quartz grain size may show systematic gradation from coarse to fine, or vice versa. Cockade quartz is a subtype of crustiform quartz that forms in vein breccias where crustiform banding surrounds clasts of host rocks or fragments of earlier formed vein (fig. E11D).

Ginguro is a Japanese word that means "silver black," and it is used for extraordinarily high-grade bands in epithermal veins (Shimizu, 2014). Typically, these bands are dark gray to black, as much as $2 \mathrm{~cm}$ thick, and contain abundant sulfide minerals; they are particularly enriched in silver minerals and electrum (fig. E11E; Izawa and others, 1990; Faure and others, 2002). Samples with well-developed ginguro bands commonly contain gold concentrations that range from tenths of a percent to several percent, which are several orders of magnitude greater than the typical concentrations in most epithermal veins. Bonanza ore bodies, which contain more than $1 \mathrm{Moz}$ gold at greater than 1 troy ounce per ton (oz/t) gold (Sillitoe, 1993), commonly contain welldefined ginguro bands, and ginguro bands are present in many high-grade ore shoots in other low- and intermediate-sulfidation epithermal deposits. Ginguro bands are significant because, where present, they may host the majority of the gold in individual veins. Consequently, the geometallurgical characteristics of gold-bearing minerals in these bands have important implications for gold recovery. Ginguro bands probably form from flashing or extreme boiling, which can concentrate ore-forming elements from hydrothermal solutions (Brown, 1986).

Massive quartz consists of milky white, fine-grained quartz that is more or less uniform and contains no other textural features; colloquially, it is termed "bull" or "buck" quartz. It consists of anhedral to subhedral crystals as much as $400 \mu \mathrm{m}$ across. Massive quartz is typically granular and consists of interlocking crystals with a homogeneous appearance (Adams, 1920; Dong and others, 1995). Most massive quartz is probably primary, but in some places massive quartz may replace amorphous silica precursors.

Saccharoidal quartz is relatively uncommon in epithermal veins. It is typically white and fine grained, may be crumbly, and commonly occurs with comb or massive quartz. Published information on saccharoidal quartz is limited; unpublished observations suggest that it is a primary texture.

Breccias are common in epithermal deposits (see "Igneous Breccias" and "Hydrothermal Breccias"; Lindgren, 1933; Simmons and others, 2005). Breccias form by many processes, including tectonic, hydrothermal, magmatic hydrothermal, collapse, and volcanic and other igneous processes (for example, Sillitoe, 1985; Jébrak, 1997). Breccias contain angular to rounded clasts of host rock and vein material, and some breccia pipes include clasts from units at depth beneath ore bodies; clasts may be meters wide, though most are centimeters wide. Breccia matrix can consist of smaller clasts, rock flour, and hydrothermal minerals, or a mixture of these. Vein breccias, which are entirely enclosed within veins, and commonly contain clasts of vein material, can be very high grade (fig. E11F). Hydrothermal eruption breccias, which form in the shallow parts of hydrothermal systems can be important hosts for relatively shallow deposits (Hedenquist and Henley, 1985b; Browne and Lawless, 2001).

Comb quartz consists of prismatic, euhedral, and parallelarranged quartz crystals arrayed perpendicular to host rock margins or on previous vein surfaces. Quartz crystals generally taper, having narrow bases and wider prismatic terminations, and are not identical (Adams, 1920). Quartz is generally coarse grained $(>1 \mathrm{~mm})$ and forms clear, milky, or amethystine crystals.

Drusy quartz refers to prismatic crystals that coat surfaces or line vugs rather than forming bands within a vein (fig. E11G). The crystals are clear to white and commonly as much as $5 \mathrm{~mm}$ 
Figure E11. Photographs showing textures in epithermal deposits. $A$, Favona vein, New Zealand, with well-developed banded veins and multiple generations of crosscutting veins. Field of view is about 4 meters $(\mathrm{m})$ wide. Photograph by James Mortimer. B, Colloform banded vein from the Golden Cross deposit, New Zealand. $C$, Crustiform banded vein (Koryu No. 3 vein from the $30 \mathrm{~m}$ mine level, Japan) that developed symmetrically, involving successive subparallel layers of crusts of minerals, including euhedral quartz and ginguro bands. Photograph by Toru Shimizu. D, Cockade structure (Koryu No. 2 vein from the $0 \mathrm{~m}$ mine level, Japan) with concentric bands of quartz, johannsenite, and calcite growing around angular fragments of black mudstone host rock and early quartz. Photograph by Toru Shimizu. E, Dark ginguro band in vein from the Waihi deposit, New Zealand (sample AU58203). Ginguro band is crosscut by later barren white quartz shown in left part of photograph. Photograph by Shannon Martin. F, Colloform banded vein shown in right part of photograph and vein breccia in center and left part of photograph (sample AU58160 from the Martha mine, New Zealand).

Some vein clasts are overgrown by colloform banded quartz, indicating multiple generations of silica precipitation and brecciation. Cherty quartz clast shown in center of photograph. Photograph by Shannon Martin. $G$, Quartz after platy calcite with drusy quartz lining the vugs shown at bottom center and right part of photograph. Magnet is about $12 \mathrm{~cm}$ long. Photograph by Mark Simpson.

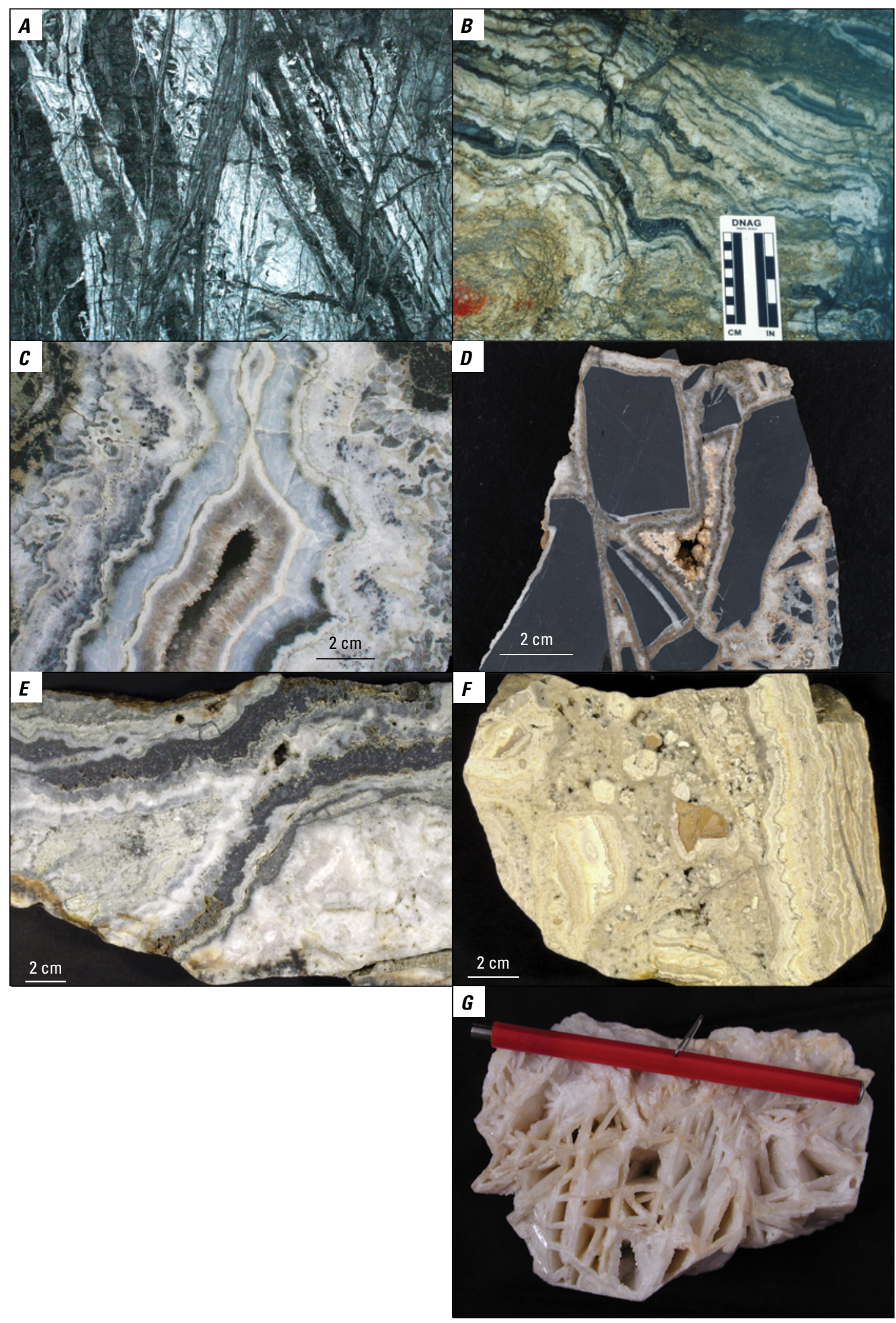


long, though larger, centimeters-long crystals occur in some deposits. Comb and drusy quartz form as primary textures from slow deposition of quartz in open space under near-equilibrium conditions; open space allows progressive growth and enlargement of quartz prisms (Dong and others, 1995; Rimstidt, 1997).

Platy or bladed calcite forms as a primary mineral from boiling hydrothermal fluids (Browne, 1978; Simmons and Christenson, 1994). Calcite blades range from microns to centimeters in length, and they commonly form in open spaces that are later surrounded by quartz. Calcite displays rhombohedral cleavage, which is perfect in three directions, none of which are at right angles. The cleavage helps control plate growth and is apparent microscopically.

Bladed or platy quartz is common in epithermal quartz veins (fig. E11G; Lindgren, 1933); it forms as a pseudomorphic replacement of platy calcite by quartz, and quartz also forms overgrowths on blades. The size of the blades reflects the size of the original calcite plates. Drusy quartz commonly lines the vugs between blades.

Cherty or chalcedonic quartz is characterized by homogenous cryptocrystalline to microcrystalline quartz that has a cherty or chalcedonic luster. Chalcedonic quartz forms masses having a variety of colors, including milky yellow, bluish, and reddish brown. Although common in some epithermal veins, this type of quartz has not been studied in detail; consequently, its origin remains unclear, though it probably represents replacement of diverse precursor silica phases that formed under variable conditions.

\section{Quartz Textures Observed Only Microscopically}

Microcrystalline quartz is common in epithermal veins. In some cases, other textural terms can be applied to this type of quartz, but in many cases, this general term is the preferred. Some microcrystalline quartz may be primary; however, much of it replaces precursor silica phases, such as amorphous silica and opal-A, which can recrystallize in 10,000 to 50,000 years to form opal-C or opal-CT, or both, and recrystallize again to form quartz after 20,000 to 50,000 years (Herdianita and others, 2000; Rodgers and others, 2004). Because most epithermal deposits are older than 50,000 years, the silica in these deposits is now quartz, and information about precursor phases can only be derived from textural studies and investigations of active geothermal systems.

Feathery quartz was first defined by Adams (1920); it forms fibrous to patchy microcrystalline quartz on the outer edges of prismatic quartz grains or in quartz grain interiors. It also may form zones that crosscut growth zones in individual quartz grains. Dong and others (1995) suggested that feathery textures result from growth of many tiny quartz crystals on the surface of larger quartz crystals, and that these smaller crystals later recrystallize to form quartz grains that are contiguous with larger quartz crystals; the resulting quartz grains contain optically discontinuous zones that reflect growth domains of the smaller crystals.

Flamboyant quartz is characterized by radial extinction of individual quartz grains that are typically rounded. Flamboyant quartz presumably results from recrystallization of silica gel that formed fibrous chalcedony aggregates (Dong and others, 1995; Moncada and others, 2012).

Ghost bladed quartz is massive quartz that does not have platy texture, but retains linear fluid inclusion trails that reflect the location and orientation of replaced calcite blades, or isolated bladed quartz grains that occur in a matrix of massive quartz. These textures form by replacement of isolated platy calcite grains that were originally intergrown with jigsaw quartz.

Microscopic examination of some massive quartz confirms the presence of jigsaw or mosaic quartz as a common microscopic quartz texture. Jigsaw or mosaic quartz consists of relatively equigranular, angular to rounded quartz grains, which range from 20 to more than $100 \mu \mathrm{m}$ across and have interpenetrating grain boundaries. This texture can be recognized only microscopically under crossed polars (Dong and others, 1995; Moncada and others, 2012). Jigsaw quartz has been interpreted as a recrystallization product of chalcedony or amorphous silica (Dong and others, 1995; Camprubi and Albinson, 2007).

Moss quartz and ghost sphere textures are typically observed microscopically. They occur as spherical shapes in quartz that are typically less than $50 \mu \mathrm{m}$ across. The spherical shapes are defined by arrays of fluid or mineral inclusions or compositional changes; the spheres may represent an earlier phase of amorphous silica gel that subsequently recrystallized to quartz (Dong and others, 1995; Moncada and others, 2012).

Zonal or ghost zonal textures are microscopically observed textures that preserve growth zones within quartz crystals. In most quartz, these zones are defined by fluid inclusion trails, but in other minerals, zonal textures commonly reflect compositional changes. Zonal textures are considered a primary growth texture (Adams, 1920; Bodnar and others, 1985; Moncada and others, 2012).

\section{Hydrothermal Breccias}

Hydrothermal breccias are common in most epithermal goldsilver deposits and commonly contain high-grade ore (appendix 1; Sillitoe, 1985). These breccias result from buildup and explosive release of fluid pressure beneath a local low-permeability barrier. Low-permeability barriers may reflect open-space filling and self sealing resulting from silica deposition associated with cooling (Facca and Tonani, 1967), clay-rich altered rock, fault zones, or the presence of shales, unfractured densely welded tuffs and dikes, or other low-permeability materials. In geothermal systems, pressure increases may reflect ascending hot fluids, addition of magmatic heat from igneous intrusions, or transmission of higher fluid pressure to the permeability barrier by a gas cap (mostly $\mathrm{H}_{2} \mathrm{O}$ and $\mathrm{CO}_{2}$ ) that separates when deep hydrothermal fluids boil (Hedenquist and Henley, 1985b; Nelson and Giles, 1985). Hydrothermal brecciation (hydraulic fracturing) occurs when fluid pressure exceeds the sum of the lithostatic load and the tensile strength of the rock and may be triggered by an external event, such as an earthquake or magma intrusion. Brecciation rapidly decreases fluid pressure, which may lead to fluid boiling (liquid flashing to vapor), exsolution and loss of dissolved volatile phases (such as $\mathrm{CO}_{2}$ and $\mathrm{H}_{2} \mathrm{~S}$ ) from the liquid phase, and deposition of gangue and ore minerals attributable to changes in the $\mathrm{pH}$, cooling, 
and reduced solubility of precious metals as bisulfide complexes (see "Theory of Deposit Formation").

Hydrothermal breccia masses range from small enclaves within veins and veinlets to large pipes, tabular masses, and irregular anastomosing bodies. Most hydrothermal breccias form at shallow depths, but they can be pipelike bodies that extend vertically for hundreds of meters (for example, Chinkuashih, Taiwan, Tan, 1991; Round Mountain, Nevada, Tingley and Berger, 1985). Some breccias grade into stockwork fractured masses. Other breccia bodies flare upward and may have breached the paleosurface forming hydrothermal eruption breccias (Nelson and Giles, 1985; Hedenquist and Henley, 1985b). Hydrothermal breccia textures range from clast-supported, jigsaw, or crackle breccias with rock flour matrixes, to matrix-supported breccias with hydrothermal minerals forming an open-space matrix (fig. E12; Jébrak, 1997). Many hydrothermal breccias have heterogeneous clast populations that suggest vertical transport of fragments and provide evidence for multiple stages of silicification, brecciation, and mineralization (fig. E12; Browne and Lawless, 2001). Hydrothermal quartz replaces fragments, forms breccia matrix, and is a characteristic feature of most hydrothermal breccias associated with epithermal deposits. Precious metals generally are concentrated in the matrix of mineralized hydrothermal breccias.

\section{Sinter}

Siliceous sinter terrace and pool deposits mark the discharge of hydrothermal fluids at the surface (fig. E13). Sinters form by cooling of near-neutral $\mathrm{pH}$, alkali chloride fluids that had subsurface temperatures greater than $175^{\circ} \mathrm{C}$ (Fournier and Rowe, 1966; Fournier, 1985). Siliceous sinter deposits may overlie low- and intermediate-sulfidation vein and breccia mineralization and may be a key indicator during epithermal gold-silver deposit exploration. However, these deposits commonly do not directly overlie hydrothermal reservoirs because of lateral fluid flow controlled by fluid conduit geometry, variable rock permeability, and topography. Although sinters typically do not contain ore unless overprinted by vein or breccia mineralization (fig. E10), concentrations of gold, silver, and other pathfinder elements may be highly enriched in individual sinter bands, and enriched element suites may correlate with similar enriched element suites in deeper ore-grade veins (for example, Buckskin Mountain, Nevada, Vikre, 2007).

\section{Relations to Igneous Rocks}

Volcanic rocks and hypabyssal intrusions associated with epithermal deposits range in composition from basalt to rhyolite, but generally fall into suites of andesite-dacite \pm rhyolite compositions or bimodal basalt-rhyolite compositions (see "Petrology of Associated Igneous Rocks"; Noble and others, 1988; John, 2001; Sillitoe and Hedenquist, 2003; Sillitoe, 2008; du Bray, 2017). Rocks of the andesite-dacite \pm rhyolite suite mostly have calc-alkaline compositions, whereas some bimodal basalt-rhyolite suites have tholeiitic compositions, notably rocks associated with low-sulfidation deposits of the northern Nevada rift that are related to crustal extension and hot spot or mantle plume magmatism in a back-arc setting (John, 2001). Several large epithermal gold deposits, including Cripple Creek, Colorado, Ladolam and Porgera, Papua-New Guinea, and Emperor, Fiji, are associated with alkaline magmatism and are not considered in this model (see "Definition and Classification of Epithermal Deposits"; Kelley and others, in press).

Distinct volcanic landforms that commonly host epithermal gold-silver deposits, include stratovolcanoes, lava domes and dome complexes, maar-diatreme systems, calderas, and dikes (appendix 1; fig. E2; Sillitoe and Bonham, 1984; Sillitoe and Hedenquist, 2003).

\section{Stratovolcanoes}

Stratovolcanoes or composite volcanoes are the most obvious volcanic landforms of most convergent margin arcs. They are large (as much as several tens of kilometers in diameter), steepsided edifices composed of thick sequences of interbedded lava flows, pyroclastic rocks (block-and-ash flows and tuffs), and debris-flow deposits (lahars) that generally dip away from a central vent. Proximal juvenile deposits generally grade laterally into reworked volcaniclastic rocks, including debris-flow deposits, that may extend more than $100 \mathrm{~km}$ from their source. Parasitic domes and cones are common on the flanks of many of these volcanoes. Stratovolcanoes in continental margin magmatic arcs generally have intermediate (andesite) to mafic (basalt) compositions.

The high topographic relief (often 1-3 km), steep sides, and interbedded sequences of highly permeable debris-flow deposits, block-and-ash flows, and relatively impermeable lava flows are notable features of stratovolcanoes that may be important in the genesis of associated epithermal goldsilver deposits. Steep topography and quaquaversally dipping sequences of permeable and impermeable rocks profoundly affect the local hydrology; accordingly, most groundwater flow is directed laterally down volcano flanks, and hydrothermal fluids that ascend through the cores of these systems are ultimately directed outward by lateral flow in permeable rock horizons. Consequently, epithermal deposits are more likely to form on the flanks of stratovolcanoes (Henley and Ellis, 1983; White and others, 1995; Hedenquist and others, 2000).

Steep-sided stratovolcanoes also are prone to sector collapse during which the upper flanks of the volcano catastrophically fail and form large-volume (cubic kilometers) debris-avalanche flows. Instantaneous removal of several cubic kilometers of a volcano flank can result in an abrupt decrease in confining pressure on underlying magmatic-hydrothermal systems and influx of groundwater or seawater into the magmatic environment (Sillitoe, 1994). Sudden pressure decrease may initiate boiling, hydrothermal brecciation, and deposition of gold and telescoping (superposition) of shallow epithermal mineralization on deeper, higher temperature porphyry-style mineralization, as has been inferred for the giant alkaline-intrusion-related epithermal gold 
Figure E12. Photographs of hydrothermal breccias. $A$, Heterolithic pebble dike, west summit of Preble Mountain, Goldfield district, Nevada. Photograph is about 7 centimeters $(\mathrm{cm})$ wide. Photograph by Peter Vikre.

$B$, Heterolithic breccia cut by quartz-alunite vein, Merger mine dump, Goldfield district, Nevada. Clasts include Jurassic granite, Paleozoic siliciclastic rocks, and Miocene quartz latite in a matrix of quartz and clay minerals. Photograph is about $13 \mathrm{~cm}$ wide. Photograph by Peter Vikre. $C$, Monolithic breccia composed of angular clasts of silicified ironsulfide-rich quartz feldspar porphyry in matrix of rock flour and white silica (white matrix breccia of John and others, 1991), Paradise Peak mine, Nevada. Breccia contains low but anomalous gold and silver contents. Coin is 19 millimeters $(\mathrm{mm})$ in diameter. Photograph by David John. $D$, Heterolithic breccia containing variably rounded clasts, including mineralized breccia clasts (upper right), in vuggy darkcolored silica matrix (black matrix breccia of John and others, 1991), Paradise Peak mine, Nevada. Breccia contains high gold and silver contents and formed richest part of Paradise Peak deposit. Photograph by David John. $E_{\text {, }}$ Breccia composed of variably rounded, silicified volcanic rocks in matrix of fine-grained hematite (after pyrite) and quartz and cut by banded chalcedonic veins, James Hardie quarry, White River alteration zone, Washington. Breccia is unmineralized. Red magnet is about $12 \mathrm{~cm}$ long. Photograph by David John. F, Sample AU57433: Hydrothermal breccia from the Waihi deposit, New Zealand. Large clast shown at bottom of photograph is a polymict breccia demonstrating that the entire sample reflects multiple stages of brecciation. Scale bar shown at top of photograph has large ticks in centimeters and small ticks in millimeters. Photograph by Jeff Mauk. G, Sample AU 57406: Hydrothermal breccia from the Waihi deposit, New Zealand. Most breccia clasts in this sample are cherty quartz, which is a hydrothermal precipitate in the veins. Note that some cherty quartz fragments are actually breccias themselves, with smaller cherty quartz fragments that are cemented together with cherty quartz. Scale bar shown at top of photograph has large ticks in centimeters and small ticks in millimeters. Photograph by Jeff Mauk.

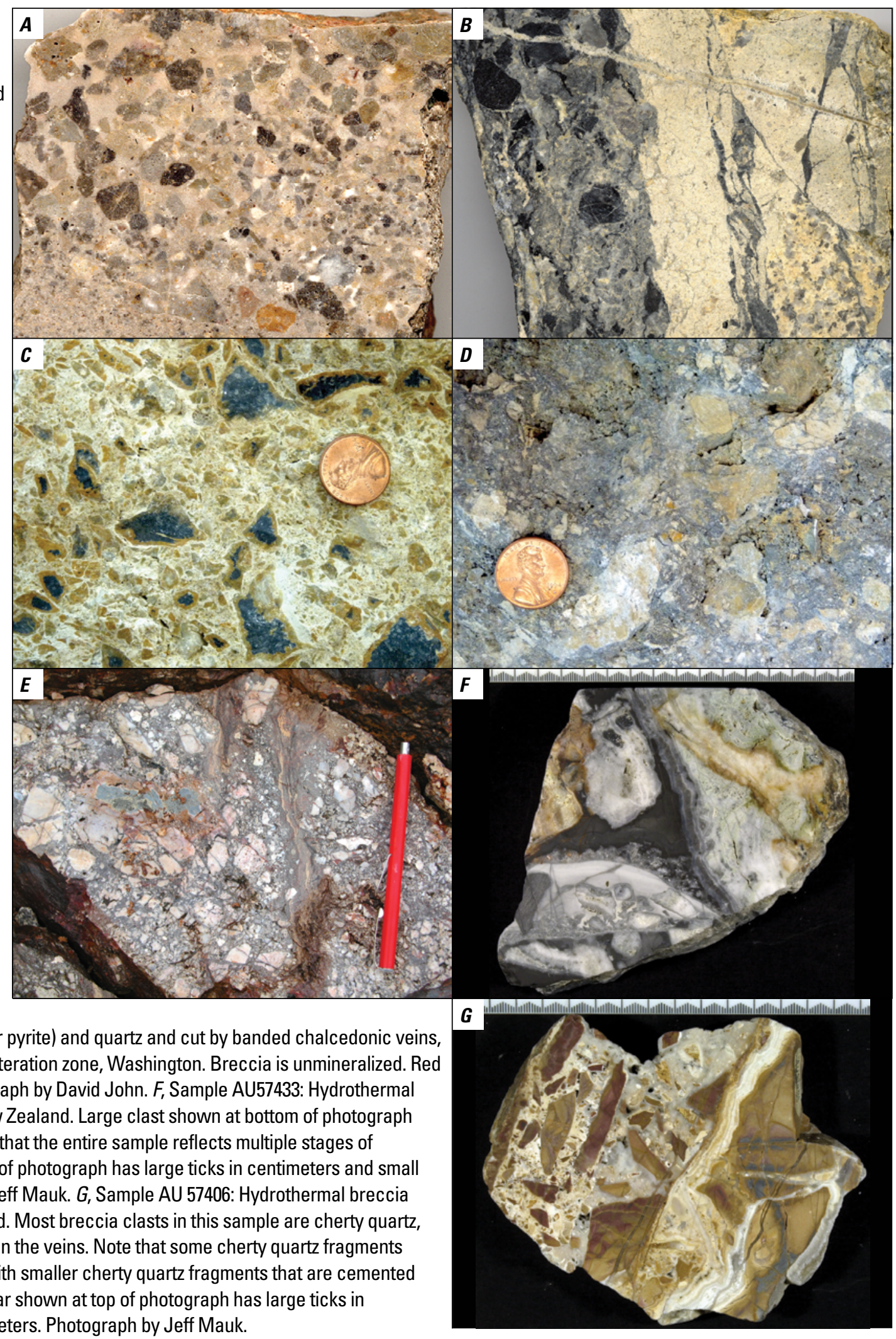




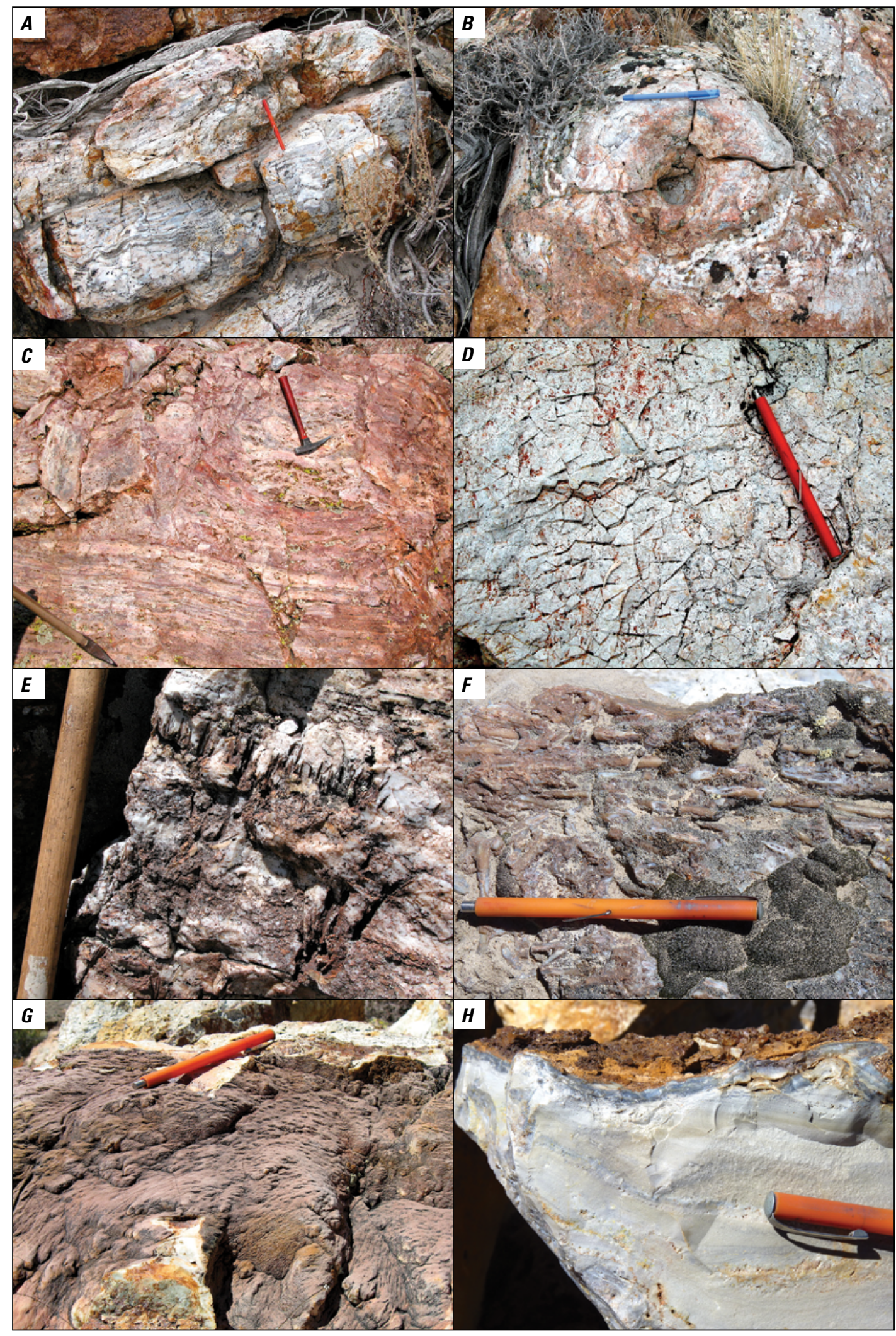

Figure E13. Photographs of sinter and siliceous hydrothermal deposits in the Bodie Hills, California and Nevada. All photographs by David John. $A$, Sinter beds in Atastra Creek. Red magnet about 12 centimeters $(\mathrm{cm})$ long. $B$, Hydrothermal fluid vent on sinter terrace in Atastra Creek. Pen about $12 \mathrm{~cm}$ long. $C$, Brecciated sinter near the Paramount mercury mine. Variably rotated sinter blocks are recemented with red chalcedonic quartz. Hammer handle approximately $45 \mathrm{~cm}$ long. $D$, Desiccation cracks on top of a sinter bed. Red magnet about $12 \mathrm{~cm}$ long. $E$, Reed molds in sinter. The most apparent molds are about $3-5 \mathrm{~cm}$ long and elongated perpendicular to sinter bedding in upper part of photograph. $F$, Casts of reeds in sinter. G, Flow textures in siliceous, hematitic mud that coats silicified volcaniclastic rocks about 1 kilometer southeast of the Paramount mine. $H$, Very fine-grained quartz beds filling voids in silicified and brecciated volcanic rocks and overlain by a gray layer of enargite+iron oxide replacing pyrite+chalcedonic quartz at Sarita mine, Masonic District. 
deposit at Ladolam, Papua New Guinea (Moyle and others, 1990; Sillitoe, 1994). Montgomery (2012) suggested that sector collapse of a stratovolcano near Lagunas Norte, Peru, triggered volatile saturation and fluid exsolution in an underlying magma chamber; the resulting fluids were probably responsible for the initial stage of hydrothermal activity that formed the high-sulfidation deposit at Laguna Norte.

Stratovolcanoes host several epithermal deposits and are inferred to have overlain many porphyry copper deposits (Sillitoe, 2010). However, epithermal deposits typically form on the flanks of stratovolcanoes late in their evolutionary history (Banská Hodruša, Slovakia, Koděra and others, 2005) or hundreds of thousands to millions of years after cone construction (Comstock Lode, Nevada, Hudson and others, 2009).

\section{Lava Domes}

Exogenous and endogenous flow (lava) domes, dome fields, and associated pyroclastic rocks and carapace (talus) breccia deposits, mostly of intermediate to silicic compositions (silicic andesite, dacite, and rhyolite), commonly host epithermal gold-silver deposits of all subtypes (appendix 1; fig. E2B). Lava domes and related deposits form in several distinct volcanic settings, including (1) the summits or flanks of stratovolcanoes during their late stages of construction; (2) during caldera-related resurgent magmatism in the caldera core and along caldera ring fracture faults; and (3) as clusters (fields) of domes and associated flows and breccias (Sillitoe and Bonham, 1984). Dome-hosted epithermal deposits form in a variety of tectonic environments, including domes that are parts of larger dome fields in continental margin magmatic arcs (Bodie, California; Comstock Lode, Goldfield, and Paradise Peak, Nevada; Yanacocha, Peru), domes emplaced along caldera ring-fracture faults (San Cristobal, Bolivia; Summitville, Colorado), domes associated with diatreme complexes in compressional (Lagunas Norte, Cerro de Pasco and Colquijirca, Peru; Lepanto and Victoria, Philippines) and extensional (Roşia Montană, Romania) settings, domes related to magma resurgence in caldera cores (Rodalquilar), and isolated domes in extensional terrains (Sleeper, Nevada) (see appendix 1 for references to above examples).

\section{Calderas}

Calderas form when the upper parts of large volcanoes collapse after magma eruption and partial reservoir evacuation. Calderas can be divided into two major types: relatively small $(<10 \mathrm{~km})$, approximately circular collapse features centered on the summits of stratovolcanoes and larger (10 to $>30-\mathrm{km}$-wide) circular to elliptical depressions formed by eruptions of large-volume silicic- to intermediatecomposition ignimbrites (fig. E2C; Sillitoe and Bonham 1984).

Epithermal gold-silver deposits form along caldera ring fracture fault zones and in collapsed caldera cores (appendix 1).
Most caldera-related deposits formed within a few hundred thousand years after caldera collapse and are related to resurgent magmatism (San Cristobal, Bolivia, Phillipson and Romberger, 2004; Round Mountain, Nevada, Henry and others, 1997; Rodalquilar, Spain, Arribas and others, 1995a), although some deposits formed several million years after caldera collapse along reactivated caldera ring fracture faults (Summitville, Colorado, Bethke and others, 2005; Beregovo, Ukraine, Vityk and others, 1994) or along reactivated faults formed during resurgent doming of the central parts of calderas (Creede, Colorado, Bethke and others, 1976), and are probably related to renewed magmatism. Minor high-sulfidation epithermal mineralization also has formed in hyperacidic lakes that fill small calderas on the summits of stratovolcanoes because of magmatic degassing into the lake (Kawah Ijen, Java, Indonesia, Scher and others, 2013).

\section{Maar-Diatremes}

Maar-diatreme complexes may host all subtypes of epithermal gold-silver deposits (appendix 1; fig. E2D). Maars are broad, low-relief volcanic craters surrounded by tuff rings and are formed by phreatomagmatic explosions that result from groundwater-magma interaction. Diatreme bodies are steep-sided breccia deposits commonly composed of mixtures of juvenile tuffaceous material and comminuted country rocks that intrude and crosscut older rocks and underlie eroded or partly eroded maar volcanoes. Epithermal deposits may be hosted by maars (Pueblo Viejo, Dominican Republic, Sillitoe and Bonham, 1984; Russell and Kesler, 1991) and more commonly by diatremes (Roşia Montană, Romania, Manske and others, 2006; Kelian, Indonesia, Davies and others, 2008a; Valedero, Argentina, Charchaflié and others, 2007; Lagunas Norte, Cerro de Pasco, and Colquijirca, Peru, Bendezú and others, 2003; Baumgartner and others, 2008; Cerpa and others, 2013; Peñasquito, Mexico, Belanger and others, 2011; appendix 1). Epithermal ore in these deposits may be disseminated in sedimentary rocks that fill the maar crater (Pueblo Viejo), form disseminated, vein, and breccia bodies in diatreme breccias (Cerro de Pasco, Peru; Peñasquito, Mexico), or form disseminated, fracture-filling, or replacement bodies in diatreme wall rocks (Lagunas Norte, Colquijirca, and Cerro de Pasco, Peru; Peñasquito, Mexico) (appendix 1, fig. E4).

\section{Dikes}

Synmineralization dikes emplaced along normal faults in extensional terrains are common in several districts (El Oro, Mexico, Caira, 2013; Kurankh, Russia, Rodionov and others, 2014; Mule Canyon, Nevada, John and others, 2003). At Mule Canyon, low-sulfidation deposits are associated with a mafic dike swarm emplaced along normal faults of the northern Nevada rift. Here, breccia-hosted and disseminated ore and small quartz-adularia veins formed in dike wall rocks and in brecciated dike margins (fig. E5). 


\section{Relations to Sedimentary Rocks}

Sedimentary rocks host epithermal gold-silver deposits in some districts; their variable physical and chemical properties, including permeability and chemical reactivity, are primary factors in the genesis of some of these deposits.

Permeability contrasts and boundaries, including contacts between highly permeable sedimentary and volcaniclastic rocks and low-permeability shales and mudstones (aquitards), strongly influence lateral and vertical fluid flow and ore body morphology (Sillitoe, 1993; Hedenquist and others, 2000). These contrasts can result in hydrothermal fluid flow through, and formation of replacement or disseminated deposits in permeable units at permeability boundaries. For example, in the Kelian deposit, Indonesia, impermeable carbonaceous matrixrich diatreme breccias focused hydrothermal fluid flow into adjacent wall rocks where hydrothermal brecciation and epithermal mineralization were localized (Davies and others, 2008a). At the Kurankh, Russia, low-sulfidation deposit, much of the ore is hosted by highly permeable karst breccias that formed at an unconformity between Cambrian carbonate rocks and overlying Jurassic sandstones (Rodionov and others, 2014).
Chemically reactive wall rocks associated with several epithermal deposits host replacement ores. These include carbonate wall rocks that host diatreme breccias at Cerro de Pasco and Colquijirca, Peru, (fig. E4; Einaudi, 1977; Baumgartner and others, 2008; Bendezú and Fontboté, 2009), calcareous sandstone and siltstone wall rocks associated with diatremes at Peñasquito, Mexico (Belanger and others, 2011), and carbonate cement in quartz sandstone at Chinkuashih, Taiwan (Wang, 2010).

\section{Relations to Metamorphic Rocks}

Metamorphic rocks can host epithermal gold-silver deposits, but their presence is not important in the formation of these deposits. Several older (pre-Cenozoic) epithermal gold-silver deposits are themselves metamorphosed, notably early Proterozoic high-sulfidation deposits in Sweden (Enåsen, Hallberg, 1994; Boliden, Bergman Weihed and others, 1996) and Paleozoic high-sulfidation deposits in Australia (Temora, Thompson and others, 1986) and in the southeastern United States (Haile, South Carolina, Feiss and others, 1993; Foley and Ayuso, 2012; Mobley and others, 2014). 



\title{
Chapter F. Physical Description of Deposits
}

\author{
By Peter G. Vikre
}

\section{High-Sulfidation Deposits}

Characteristics of high-sulfidation deposits, derived mostly from published descriptions supplemented by unpublished analyses and observations, are summarized below for medium-size (16-31 t gold; 0.5-1 Moz gold), large (31$311 \mathrm{t} ; 1-10 \mathrm{Moz})$, and very large deposits (>311 t; >10 Moz gold). Because of genetic significance, some characteristics of small deposits ( $<16 \mathrm{t} ;<0.5 \mathrm{Moz}$ gold) are also described.

\section{Dimensions in Plan View}

The configuration and size of mined deposits and resources are largely a function of gold grade and value over time, because gold grade and price (ore value) dominate the economics of mining. For example, initial production at Summitville and Goldfield, U.S.A., in the late nineteenth and early twentieth centuries was limited to relatively high-grade rock ( $\geq 17 \mathrm{~g} / \mathrm{t}$ gold; $\geq 0.5 \mathrm{opt}$ ), because the prevailing gold price was USD20.67/oz, and relatively high-cost underground mining was required. Production from these districts since the 1980s has been facilitated by elevated gold prices (hundreds to more than USD1,000/oz), large volumes of near-surface, oxidized rock containing several $\mathrm{g} / \mathrm{t}$ gold or less, and low-cost, open-pit mining and heap leach recovery techniques.

Gold in oxidized ore is readily dissolved in cyanide solution, enabling heap leach and carbon-in-pulp recoveries of 90 percent or greater, and bulk mining of relatively low-grade deposits ( $<1$ to $\sim 3 \mathrm{~g} / \mathrm{t}$ gold; $\leq 0.1 \mathrm{opt}$ ). Gold in most sulfide mineral assemblages is usually much more expensive to recover in terms of capital (development) and operating costs. Some large, low-grade deposits overlie, or internally include, significant volumes of mineralized rock containing $\geq 3 \mathrm{~g} / \mathrm{t}$ gold ( $\geq 0.1$ opt; for example, Pascua-Lama, Chile-Argentina; Tambo, Chile; Deyell and others, 2004, 2005a, 2005b; Jannas and others, 1999). In most deposits mined by open-pit methods, these internal, higher grade resources are enclosed by low-grade ore, thereby enabling low-cost mining of both ore types. However, some relatively high-grade resources may not be minable if they (1) are too deep or have insufficient grade to support underground mining, or (2) contain sulfide minerals that require costly oxidation and (or) milling to recover gold.

Only a few medium-size and large deposits included sufficient volumes of high-grade gold ore to warrant underground mining (for example, Summitville, Gray and Coolbaugh, 1994; Bethke and others, 2005; Goldfield, Ashley,
1974; Vikre, 1989b; Vikre and Henry, 2011; El Indio, Chile, Jannas and others, 1990, 1999). These deposits exhibit strong structural control; lateral dimensions of selectively mined ore zones were generally several to more than 10 meters in width, and hundreds to more than 1,000 meters along strike (fig. F1).

Most production worldwide in the past three to four decades has been derived from open-pit mining of largevolume, oxidized deposits that vary in size from millions to hundreds of millions of metric tons, and in grade mostly from less than 1 to $\sim 3 \mathrm{~g} / \mathrm{t}$ gold ( $\leq 0.1 \mathrm{opt}$; fig. A2). Resources also consist of large volumes of mineralized rock containing several grams per ton gold or less. Lateral dimensions of ore mined from individual open pits, as at Pueblo Viejo, Dominican Republic, and Pierina, Peru (fig. F2), are mostly hundreds of meters, although pits coalesce in districts with closely spaced deposits (Yanacocha, Peru). Resources have similar dimensions.

It is important to note that modern production from nearly all high-sulfidation deposits has been enabled by (1) the distribution of small amounts of gold in large volumes of near-surface rocks in which sulfide mineral decomposition by weathering allows high gold recoveries, and (2) prevailingly elevated gold prices. In the absence of these geologic and economic factors, much smaller production would have resulted from limited underground mining of high-grade structures.

\section{Vertical Extent}

Mined depths of high-grade gold deposits ( $\geq 17 \mathrm{~g} / \mathrm{t} ; 0.5 \mathrm{opt}$ gold), such as those at Summitville, Goldfield, and El Indio, and the vertical extent of ore, are $\sim 150-500 \mathrm{~m}$ below the erosion surface (fig. F1). Production at depth was limited by decreasing gold grades and by increased costs of mining and water control. Mining depth in the silver-rich Cerro Rico de Potosi, Bolivia, is $\sim 1,150 \mathrm{~m}$, commensurate with its lofty production estimated at 31-62 thousand metric tons silver ( 1-2 Goz; Bartos, 2000).

Mined depths of low-grade, large-tonnage deposits $(<1$ to $\sim 3 \mathrm{~g} / \mathrm{t} ; \leq 0.1$ opt gold) are mostly $\leq 300 \mathrm{~m}$ below the erosion surface, and the vertical extent of ore-grade rock is mostly less than or equal to $200 \mathrm{~m}$, as at Pierina (fig. F2; Rainbow and others, 2005; Fifarek and Rye, 2005). Higher costs associated with stripping ratios (waste/ore) that increase with depth, coupled with decreases in recoverable gold with incomplete oxidation of sulfide minerals at depth, rather than gold grade, usually preclude deeper mining of low-grade deposits. In general, larger tonnage deposits are mined to greater depths. 
A. Summitville, U.S.A.

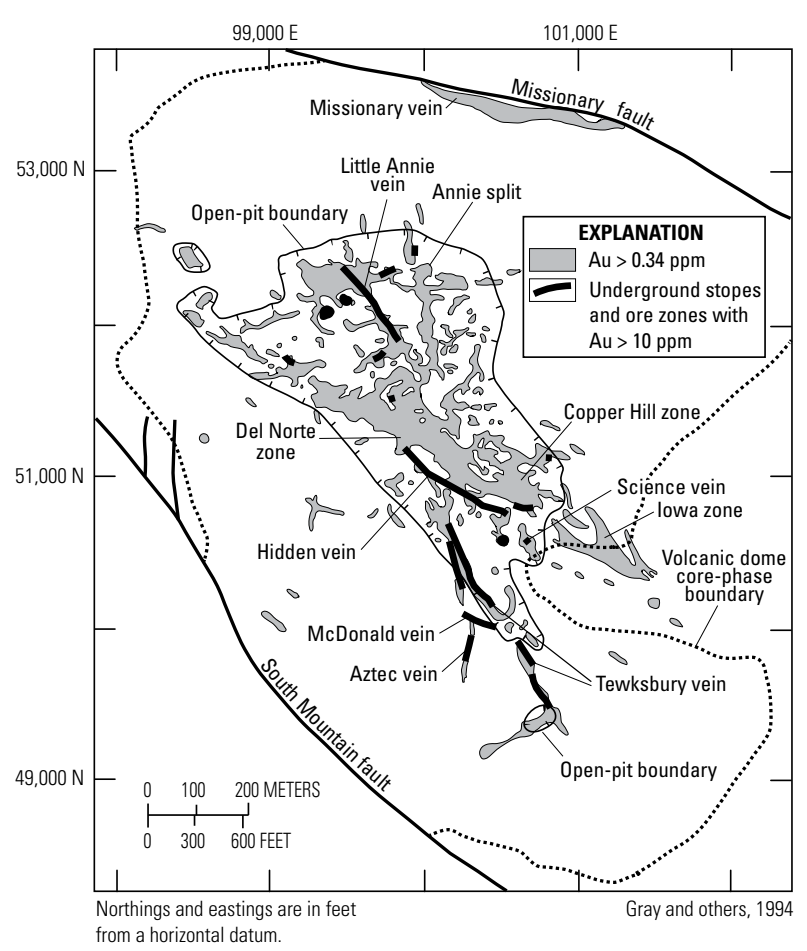

B. El Indio, Chile

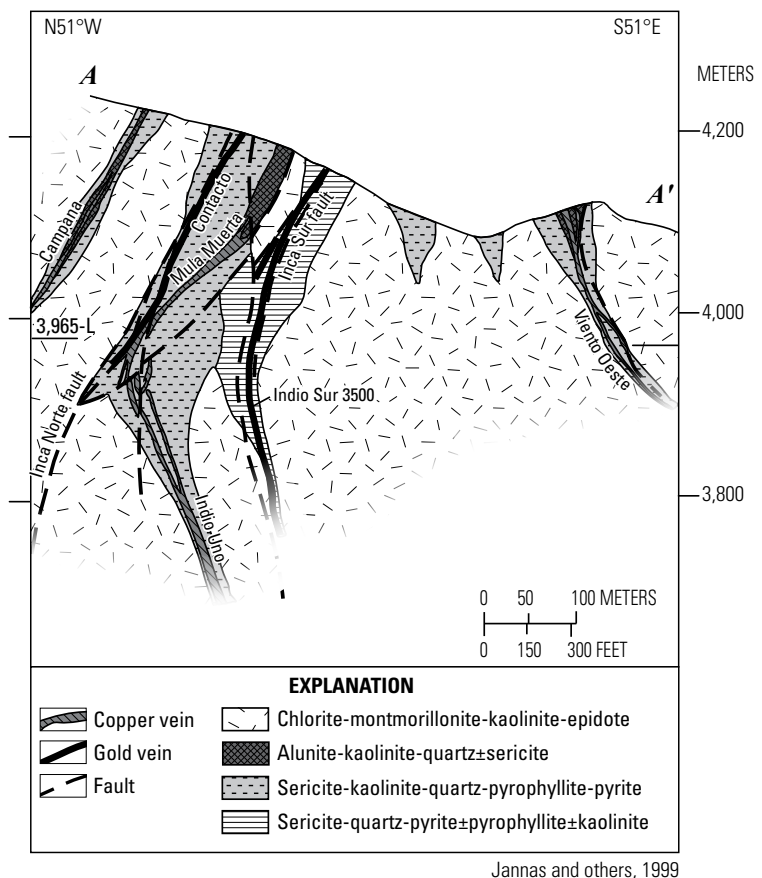

\section{Goldfield, U.S.A.}

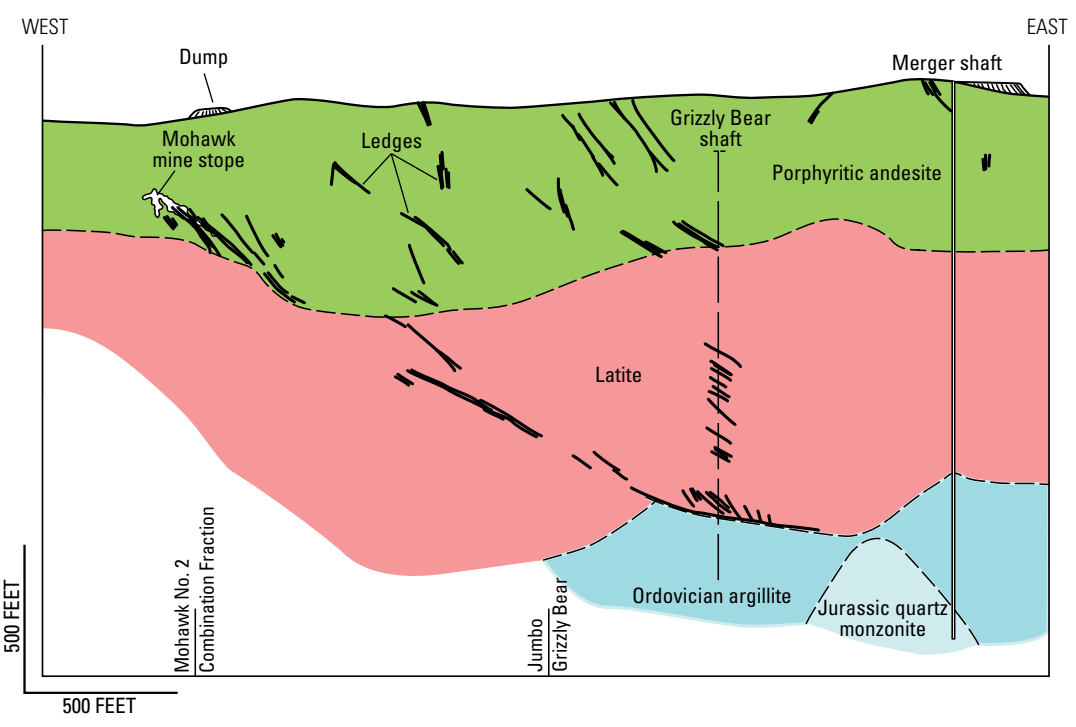

Figure F1. Plan map and cross sections of high-grade ( $\geq 17$ grams per metric ton [g/t] gold; $\geq 0.5$ troy ounce per ton [opt]), structurally controlled high-sulfidation gold-silver deposits. A, Summitville, U.S.A. Plan showing distribution of gold values greater than $1 \mathrm{~g} / \mathrm{t}(>0.03$ opt; shaded enclosures), projection of stopes with production grades greater than $10 \mathrm{~g} / \mathrm{t}(>0.3 \mathrm{opt}$; solid black lines), outline of open-pit mine, and north-northwest to northwest structural control of most elevated gold values. From Gray and others (1994). $B$, El Indio, Chile. Generalized northwest-southeast section showing copper veins (double subparallel lines enclosing northwest-southeast diagonal line pattern), gold veins (solid black lines), faults (dashed lines), and distribution of alteration mineral assemblages. Alunite-kaolinitequartz \pm sericite assemblage is pre-ore; sericite-kaolinite-quartz-pyrophyllite-pyrite assemblage is temporally associated with copper veins; sericite-quartz-pyrite \pm pyrophyllite \pm kaolinite is temporally associated with gold veins. Vertical scale is in meters above sea level. From Jannas and others (1999). C, Goldfield, U.S.A. west-east section through the Grizzley Bear (projected) and Merger shafts in the main district showing Miocene (porphyritic andesite; latite) and pre-Tertiary (Jurassic quartz monzonite; Ordovician argillite) stratigraphy, and distribution of mined "ledges" (tabular silicified fault zones). Section synthesized from 1935 maps by Goldfield Consolidated Mines Company and Eastern Exploration Company (https://gisweb.unr.edu/MiningDistricts/). 
$\boldsymbol{A}$

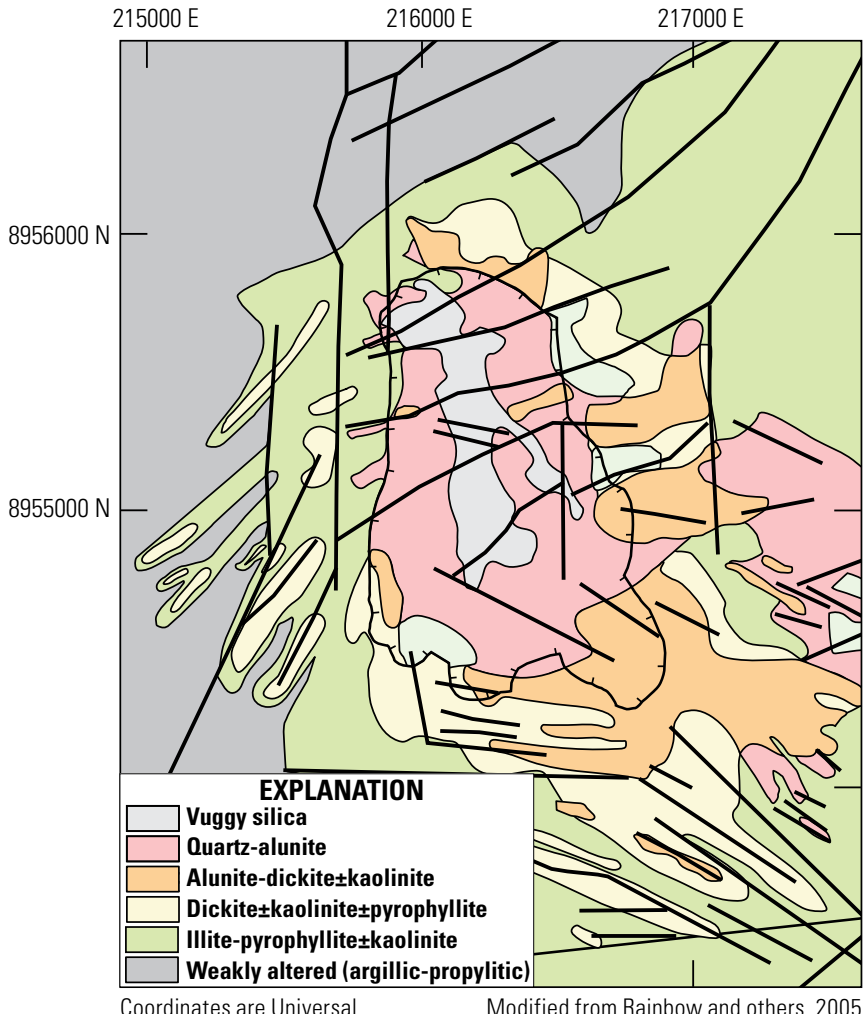

Coordinates are Universal Transverse Mercator
Figure F2. Plan map and sections of low-grade $(<1$ to $\sim 3 \mathrm{~g} / \mathrm{t}$ gold; $\leq 0.1$ opt), structurally and stratigraphically controlled high-sulfidation gold deposits. A, Plan map of the Pierina gold deposit, Peru, showing alteration mineral zoning (colored enclosures), faults (thick black lines), and proposed (2005) open-pit mine outline (black line enclosure). Although displayed as solid lines, alteration mineral assemblage boundaries are gradational and irregular. Coordinates are Universal Transverse Mercator (UTM). From Rainbow and others (2005). B, Southwest-northeast section through Pierina deposit showing stratigraphy (labeled), alteration mineral zones (patterned), faults (thick solid lines), drill holes (thin vertical lines), lower limit of sulfide oxidation (by weathering; dash-dot line), and gold-mineralized rocks $(>0.5 \mathrm{~g} / \mathrm{t}$, short-dash line enclosure). Vertical scale is elevation in meters above sea level. From Fifarek and Rye (2005). C, Martabe, Indonesia. northwest-southeast sections of the Baskara gold deposit showing volcanic stratigraphy and phreatomagmatic breccia (upper), alteration types (middle), and rocks containing $>0.5 \mathrm{ppm}$ gold ( $0.5 \mathrm{~g} / \mathrm{t} ; 0.015 \mathrm{opt})$, based on drill holes. Vertical scale is meters relative to an unspecified datum. From Harlan and others (2005). D, Jinxi-Yelmand, China. Section showing generalized hydrothermal model of stage 1 of the gold deposit. Note that vertical and horizontal scales (meters) differ. From Long and others (2005).

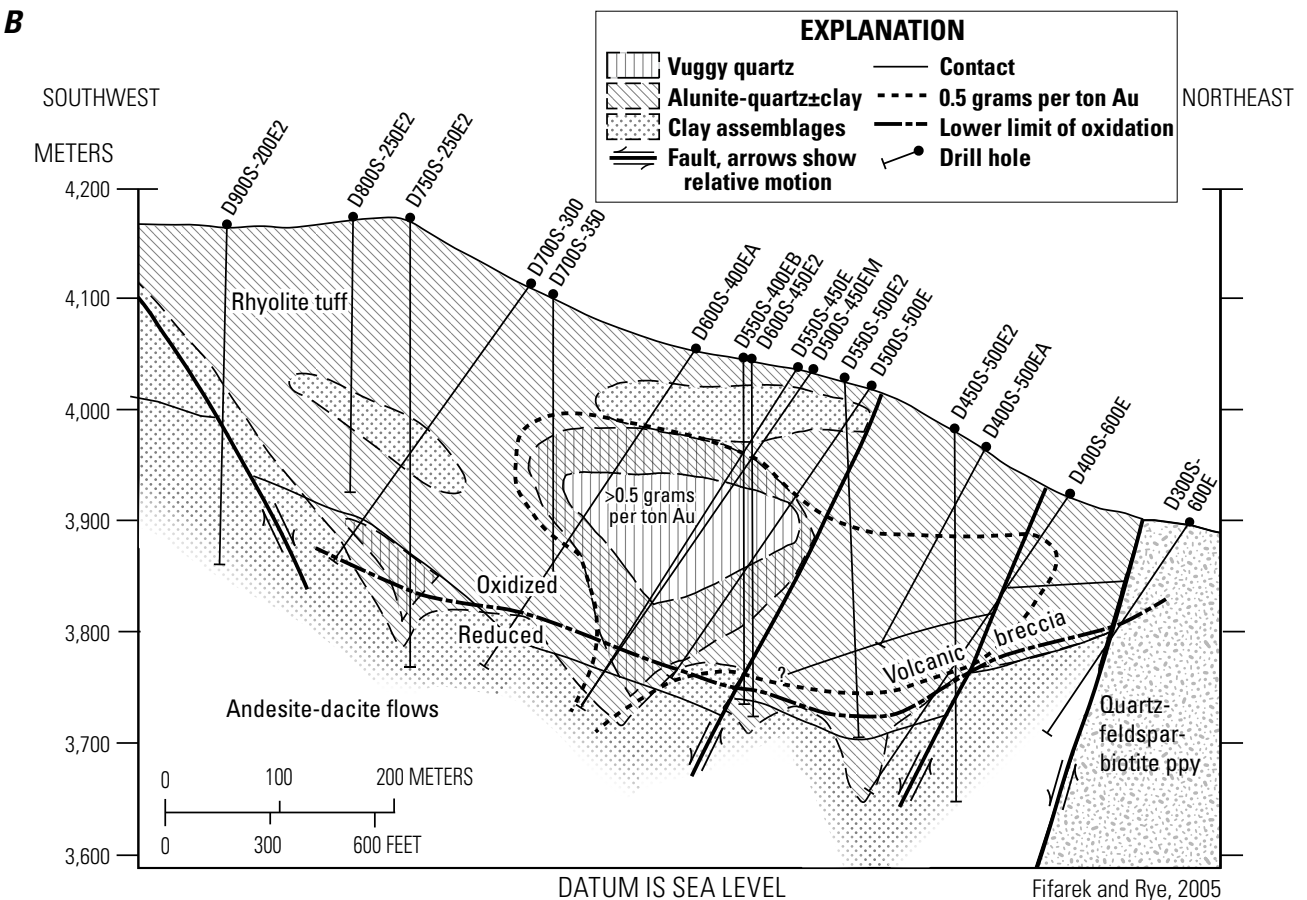



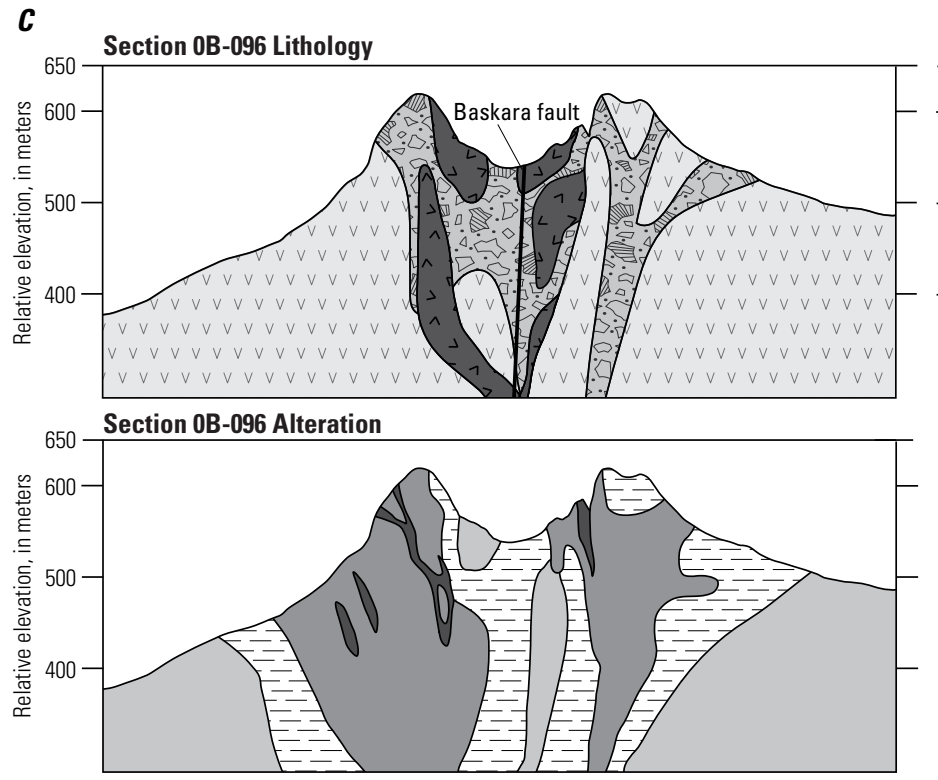

Section OB-096 modeled Au shape

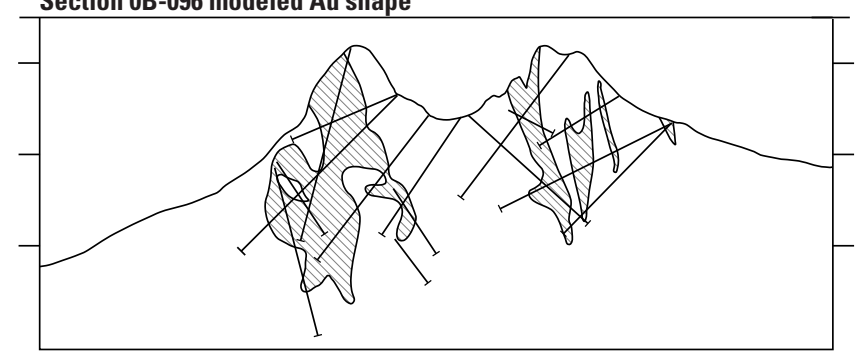

\begin{tabular}{|c|c|c|}
\hline \multicolumn{3}{|c|}{ EXPLANATION } \\
\hline B. Breccia phreatomagmatic & [ & Advanced argillic \\
\hline$\triangle$ Hornblende andesite & $E$ & Argillic \\
\hline$\vee \vee$ Dacite porphyry & $\square$ & Prophylitic \\
\hline Fault & MV & $>0.5 \mathrm{ppm} \mathrm{Au}$ (gold) \\
\hline Silica & $\sim$ & Drill hole \\
\hline
\end{tabular}

Harlan and others, 2005

D

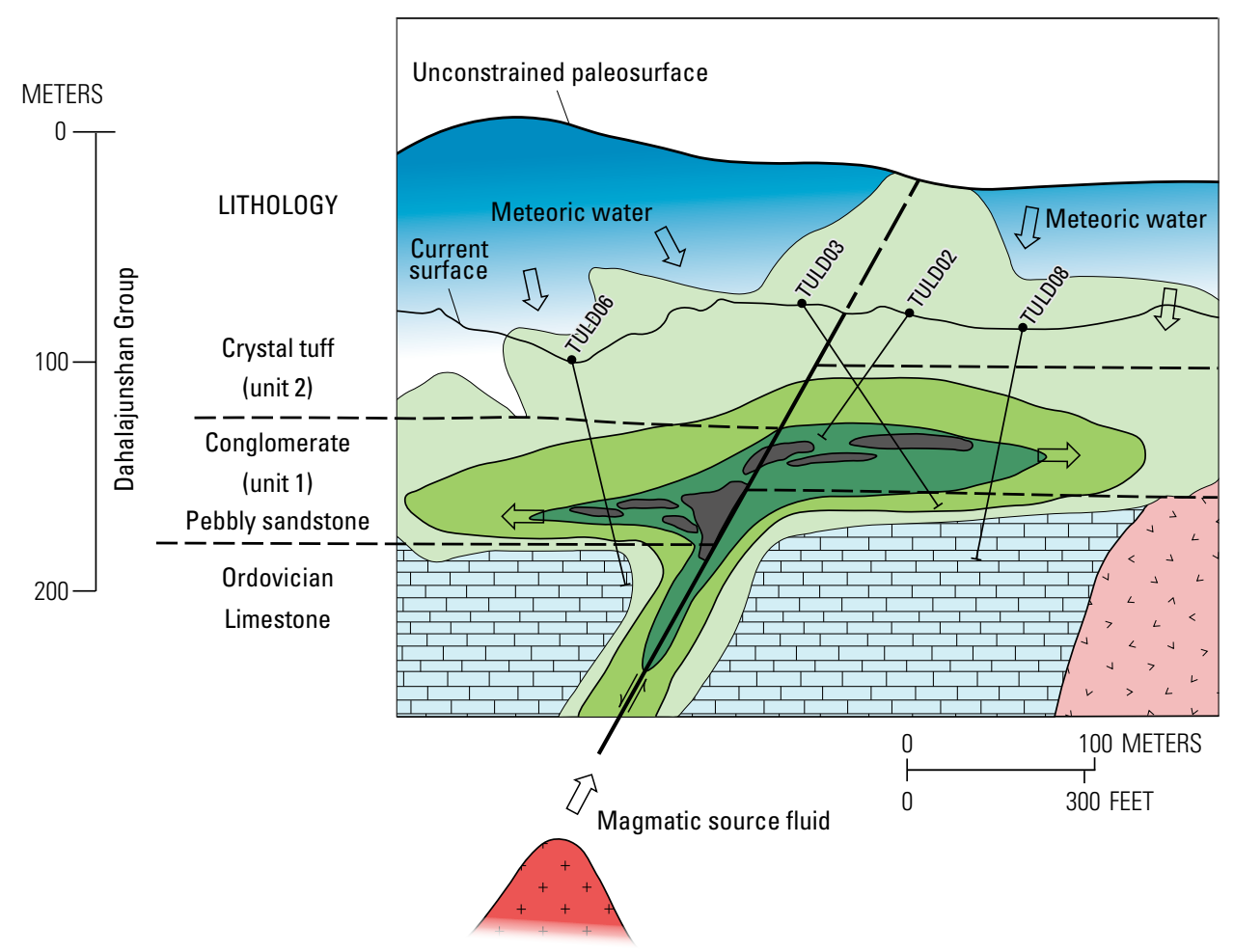

\begin{tabular}{|c|c|c|}
\hline \multicolumn{3}{|c|}{ EXPLANATION } \\
\hline & Intensively silicified zone (zone 1) & 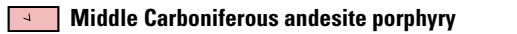 \\
\hline & Advanced argillic alteration (zone 2) & Ordovician limestone \\
\hline & Argillic alteration (zone 3) & $\leftrightharpoons$ Fault-dashed where projected above erosion \\
\hline & Vuggy quartz & Drill hole \\
\hline 5 & Intrusion & $\Rightarrow$ Inferred fluid flow direction \\
\hline
\end{tabular}

Long and others, 2005

Figure F2.-Continued 


\section{Form and Shape}

The correlation between deposit aspect, dimensions, gold grade, and gold price is described previously (see "Dimensions in Plan View"). High-grade deposits, largely mined by underground methods, are mostly high-angle to moderately dipping tabular to lensoidal zones that reflect the attitudes of the faults in which the deposits formed (for example, Summitville; Goldfield; El Indio; fig. F1). Deposit margins, which vary from relatively planar (El Indio) to irregular (defined by cutoff grades; Summitville and Goldfield), commonly reflect complex structural patterns produced by fault intersections and by multiple mineralizing events.

Deposits mined by open-pit methods have geometrically irregular forms and shapes that include internal waste and are constrained by many factors including gold grade and value, stripping ratios, structural and stratigraphic controls, and gold recovery (degree of oxidation of sulfide minerals). Careful grade control is required to ensure profitability. Reserves in most low-grade, open-pit mines include only oxidized rock in which elevated gold recoveries can be achieved by heap leach or to a lesser extent by vat leach cyanidation.

\section{Host Rocks}

Most deposits occur entirely to mostly in Tertiary volcanic rocks, including lava domes, flows, breccias, tuffs, and other volcaniclastic and epiclastic strata (appendix 1). Several deposits are associated with nested and juxtaposed calderas (for example, Summitville; Rodalquilar, Spain; Gray and Coolbaugh, 1994; Bethke and others, 2005; Arribas and others, 1995a), and phreatic/ phreatomagmatic breccias (diatremes; for example, Lagunas Norte, Peru; Martabe, Indonesia; Cerpa and others, 2013; Harlan and others, 2005; fig. F2). Eruptive host rocks vary in composition from andesite to rhyolite, and, where dated, range in age from 92 to $\sim 1 \mathrm{Ma}$. Eruptive rocks the same age as or slightly older than deposits, either contain the deposits, or are exposed near most deposits. In some districts, minable gold occurs in Tertiary and subjacent Mesozoic and Paleozoic rocks (for example, Goldfield, Ashley, 1974; Lagunas Norte, Cerpa and others, 2013; La Coipa, Oviedo and others, 1991a, 1991b) or occurs largely to entirely in pre-Tertiary rocks (for example, Pueblo Viejo, Dominican Republic; Pascua-Lama, Chile-Argentina; Kirk and others, 2014; Arribas and others, 2011; Sillitoe and others, 2006; Vennemann and others, 1993; Kesler and others, 2003; Muntean and others, 1990; Russell and Kesler, 1991; Kesler and others, 2005; Sillitoe and others, 2006; Deyell and others, 2004, 2005a).

Several medium-size deposits that have clear to suspected genetic affiliation with high-sulfidation deposits occur in metamorphosed Paleozoic and Proterozoic rocks (for example, Hope Brook, Canada, Dubé and others, 1998; Enåsen and Boliden, Sweden, Hallberg, 1994; Bergman Weihed and others, 1996; Peak Hill and Temora, Australia, Thompson and others, 1986; Masterman, and others, 2002; Squire and others, 2007). These deposits are interpreted as broadly contemporaneous with host rocks on the basis of relatively imprecise geochronology.
However, most high-sulfidation deposits are Miocene and Oligocene, regardless of host rock ages.

\section{Structural Settings and Controls}

Most medium-size and large high-sulfidation deposits in the Americas occur in Miocene volcanic fields that consist of successions of lava domes, ash-flow tuffs, and volcaniclastic strata that were erupted over several millions of years and have been dismembered by faults and eruption breccias (diatremes). The distribution of ore in most deposits is related to primary fluid permeability of volcanic stratigraphy and secondary permeability imposed by structure and hydrothermal alteration (primary mineral dissolution). For example, ore controls at Paradise Peak, Nevada (John and others, 1989, 1991; Sillitoe and Lorson, 1994); Pueblo Viejo, Dominican Republic (Kesler and others, 1981); Veladero, Argentina (Charchaflié and others, 2007; Holley, 2012, Holley and others, 2017); and Jinxi-Yelmand, China (Long and others, 2005), are dominantly the primary permeabilities of volcaniclastic and sedimentary strata. At Lagunas Norte, Tambo, Chile, and Pascua-Lama, ore controls include structural permeability provided by phreatic, phreatomagmatic, and tectonic breccias. At Yanacocha, ore distribution is partly controlled by breccias associated with flow domes (Longo and Teal, 2005; Longo and others, 2010). At El Sauzal and Mulatos, Mexico (Weiss and others, 2010; Staude, 2001), ore is largely controlled by closely spaced, high- to moderate-angle faults. Evidence of ore control by hydrothermally altered rocks includes the common occurrence of sulfide minerals, sometimes including ore minerals, in porous and vuggy igneous host rocks in which feldspar and mafic phenocrysts have been removed by dissolution in low-pH fluid. However, in many deposits, the ore distribution is controlled variably by stratigraphy, structure, and hydrothermally altered rocks (for example, Pierina, Yanacocha, Tambo, Mulatos, La Coipa, and Hog Heaven, U.S.A., Lange and others, 1994).

Localization and configuration of high-elevation gold deposits in the Andes of Chile and Argentina (for example, Pascua-Lama; Tambo) have been attributed to interactive climatic (aridity) and tectonic (uplift and erosion) controls that limited meteoric water reservoirs in near-surface rocks, and caused water table fluctuation and intermittent fluid boiling (see "Regional Environment"; Bissig and others, 2002; Deyell and others, 2004, 2005a, 2005b).

\section{Low- and Intermediate-Sulfidation Deposits}

Characteristics of low- and intermediate-sulfidation deposits described in this section are derived mostly from published descriptions of large deposits $(>31 \mathrm{t} ;>1 \mathrm{Moz}$ gold and $>3,100 \mathrm{t}$ silver; $>100$ Moz silver) supplemented by unpublished analyses and observations, in part from small deposits ( $<\sim 16 \mathrm{t} ;<0.5$ Moz gold and $<\sim 31 \mathrm{t} ;<1$ Moz silver). 


\section{Forms of Deposits}

Two forms or variants of low- and intermediate-sulfidation deposits can be distinguished by texture, mineralogy, and metal proportions:

Low-sulfidation deposits consist of multiple stages of concordant and discordant layered mineral assemblages and breccias (fig. F3; for example, Hishikari, Japan, Izawa and others, 1990, Shikazono and Nagayama, 1993; Midas, Leavitt and Arehart, 2005; Republic, Fifarek and others, 1996; Sleeper, Nash and others, 1991), sheeted veins (fig. E10; for example, McLaughlin, Sherlock and others, 1995), and vein stockworks and breccias adjacent to layered veins and faults (fig. F4; for example, Bullfrog, Eng and others, 1996; Dolores, Mexico, Overbay and others, 2001) that were mined exclusively for gold and silver. Among the largest deposits are Hishikari, with 1985-2010 production and reserves of $\sim 7.4 \mathrm{Mt}$ at 46-47 g/t gold (343,000 kilograms [kg]; 11 Moz; Porter GeoConsultancy database, accessed June 30, 2014); El Peñón, Chile, with 1999-2014 production and 2014 end-of-year resources of $29.4 \mathrm{Mt}$ at $7.6 \mathrm{~g} / \mathrm{t}$ gold $(223,440 \mathrm{~kg} ; \sim 7.2 \mathrm{Moz})$, $214 \mathrm{~g} / \mathrm{t}$ silver $(6,291,000 \mathrm{~kg} ; \sim 202.3 \mathrm{Moz}$; appendix 2); and Midas, U.S.A., with 1998-2013 production estimated at $\sim 5 \mathrm{Mt}$ at $15 \mathrm{~g} / \mathrm{t}$ gold $(\sim 74,650 \mathrm{~kg} ; 2.4 \mathrm{Moz})$ and $204 \mathrm{~g} / \mathrm{t}$ silver ( 1,020,194 kg; 32.8 Moz; Klondex Mines Ltd., 2015). Above layered veins in some deposits are stockwork veins and paleosurface deposits (sinter, sinter breccia, vent breccia, eruption breccia, epiclastic deposits) some of which contained sufficient gold and silver value for bulk mining (fig. F5; for example, McLaughlin, Sherlock and others, 1995; Ivanhoe, Bartlett and others, 1991; and Republic, Fifarek and others, 1996). Minor amounts of mercury were recovered from associated paleosurface deposits overlying gold-silver veins in some districts (for example, National; Vikre, 1985, 2007; McLaughlin; Ivanhoe).

Most low-sulfidation deposits mined underground and in open pits vary in size from thousands to tens of thousands of metric tons and grades range from several to more than 10 grams per metric ton gold ( $\geq 0.3 \mathrm{opt}$ ) and (or) tens to hundreds of grams per metric ton silver (several to several tens of ounces per ton; compare, Albinson and others, 2001; fig. A1). The relatively high grades of these veins, and their selective minability, have historically enabled production from small deposits.

Intermediate-sulfidation deposits consist of multistage veins and associated breccias that contain significant amounts of other metals in addition to gold and silver, and were (a) mined exclusively for gold and (or) silver with no or minor production of copper, lead, or zinc, and (b) mined primarily because of gold and silver values but produced appreciable copper, lead, and zinc. Among the largest deposits are in the Comstock Lode district, U.S.A., with 1859-1957 production of $17.6 \mathrm{Mt}$ at $14.6 \mathrm{~g} / \mathrm{t}$ gold $(\sim 256,800 \mathrm{~kg} ; \sim 8.3 \mathrm{Moz})$ and $340 \mathrm{~g} / \mathrm{t}$ silver ( 5,972,205 kg; 192 Moz; Bonham and Papke, 1969); San Dimas district (Tayoltita mine), Mexico, with 1880-1990 estimated production of more than $19 \mathrm{Mt}$ at $8 \mathrm{~g} / \mathrm{t}$ gold $(\sim 152,000 \mathrm{~kg} ; 4.89 \mathrm{Moz})$ and $500 \mathrm{~g} / \mathrm{t}$ silver $(\sim 9,500,000 \mathrm{~kg}$;
305 Moz; Albinson and others, 2001; Enriquez and Rivera, 2001a, 2001b; fig. F3); Tonopah district, U.S.A., with $1900-1957$ production of $8.0 \mathrm{Mt}$ at $7.3 \mathrm{~g} / \mathrm{t}$ gold $(57,900 \mathrm{~kg}$; $\sim 1.86 \mathrm{Moz})$ and $679 \mathrm{~g} / \mathrm{t}$ silver $(5,417,000 \mathrm{~kg} ; \sim 174 \mathrm{Moz}$; Bonham and Garside, 1979); Creede district, U.S.A., with estimated 1891-1985 production of $3.5 \mathrm{Mt}$ at $1.3 \mathrm{~g} / \mathrm{t}$ gold ( 4,672 kg; 0.15 Moz), 1,600 g/t silver $(2,619,388 \mathrm{~kg}$; $\sim 84 \mathrm{Moz}$ ), and 150,000 t of lead and zinc (Robinson and Norman, 1984; Long and others, 1998); Guanajuato district, Mexico, with colonial to 1990 s estimated production of more than $40 \mathrm{Mt}$ at $4 \mathrm{~g} / \mathrm{t}$ gold $(160,000 \mathrm{~kg} ; 5.14 \mathrm{Moz})$ and $850 \mathrm{~g} / \mathrm{t}$ silver (34,000,000 kg; $1.1 \mathrm{Goz}$; Albinson and others, 2001); and the Pachuca-Real del Monte district, Mexico, with colonial to late 1900s estimated production of $80 \mathrm{Mt}$ at $2.5 \mathrm{~g} / \mathrm{t}$ gold $(\sim 200,000 \mathrm{~kg} ; 6.4 \mathrm{Moz})$ and $500 \mathrm{~g} / \mathrm{t}$ silver $(40,000,000 \mathrm{~kg}$; $1.3 \mathrm{Goz}$; Albinson and others, 2001). Other large intermediatesulfidation deposits include Peñasquito, Mexico, which is currently being mined and has proven and probable mill ore reserves (as of December 31, 2014) of $547 \mathrm{Mt}$ at $0.55 \mathrm{~g} / \mathrm{t}$ gold $(301,704 \mathrm{~kg} ; \sim 9.7 \mathrm{Moz}), \sim 30 \mathrm{~g} / \mathrm{t}$ silver $(\sim 16,485,000 \mathrm{~kg}$; $\sim 530 \mathrm{Moz}), \sim 1.7 \mathrm{Mt}$ of lead at 0.31 weight percent, and $\sim 4.1 \mathrm{Mt}$ of zinc at 0.75 weight percent (Goldcorp, 2015).

Numerous districts containing intermediate-sulfidation deposits with known or suspected epithermal characteristics (that is, formation depths of $\sim 1.5 \mathrm{~km}$ or less, at temperatures less than $300{ }^{\circ} \mathrm{C}$; see "Definition and Classification of Epithermal Gold-Silver Deposits") in the U.S.A., Peru, Bolivia, Chile, Japan, Russia, and other countries, have been mined because of the combined value of gold, silver, copper, lead, zinc, and other metals (for example, tin, tungsten; compare, Vanderwilt, 1947; Koschmann and Bergendahl, 1968; Albinson and others, 2001; Petersen and others, 2004; Graybeal and Vikre, 2010). For many of these districts, multimetal recovery buffered variations in individual metal values and sustained district longevity resulting in millions to tens of millions of ounces of gold and silver production (for example, Creede, U.S.A., Steven and Ratté, 1965; Robinson and Norman, 1984). In Mexico and South America, high silver grades in epithermal veins commonly led to mining subjacent, lower grade carbonate-replacement silver-leadzinc deposits (Moller and others, 2001; Trejo, 2001; Albinson and Rubio, 2001). However, fluctuations in metal values and grades during decades of mining, combined with incomplete or composited production records and uneven distribution of gold, silver, and other metals in zoned multivein districts, make it difficult to determine if intermediate-sulfidation districts include deposits mined solely because of gold and silver value. Therefore, only intermediate-sulfidation deposits known to have been mined for gold (and other metals in some deposits) and (or) silver (and other metals in some deposits) are summarized in this section.

\section{Dimensions in Plan View}

Like high-sulfidation deposits, the dimensions of mined low- and intermediate-sulfidation deposits and resources are 

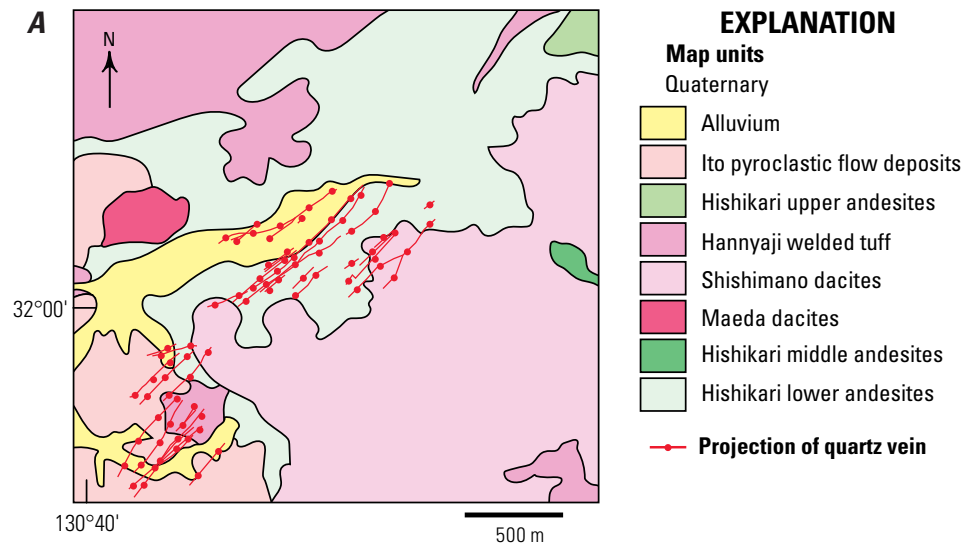

B
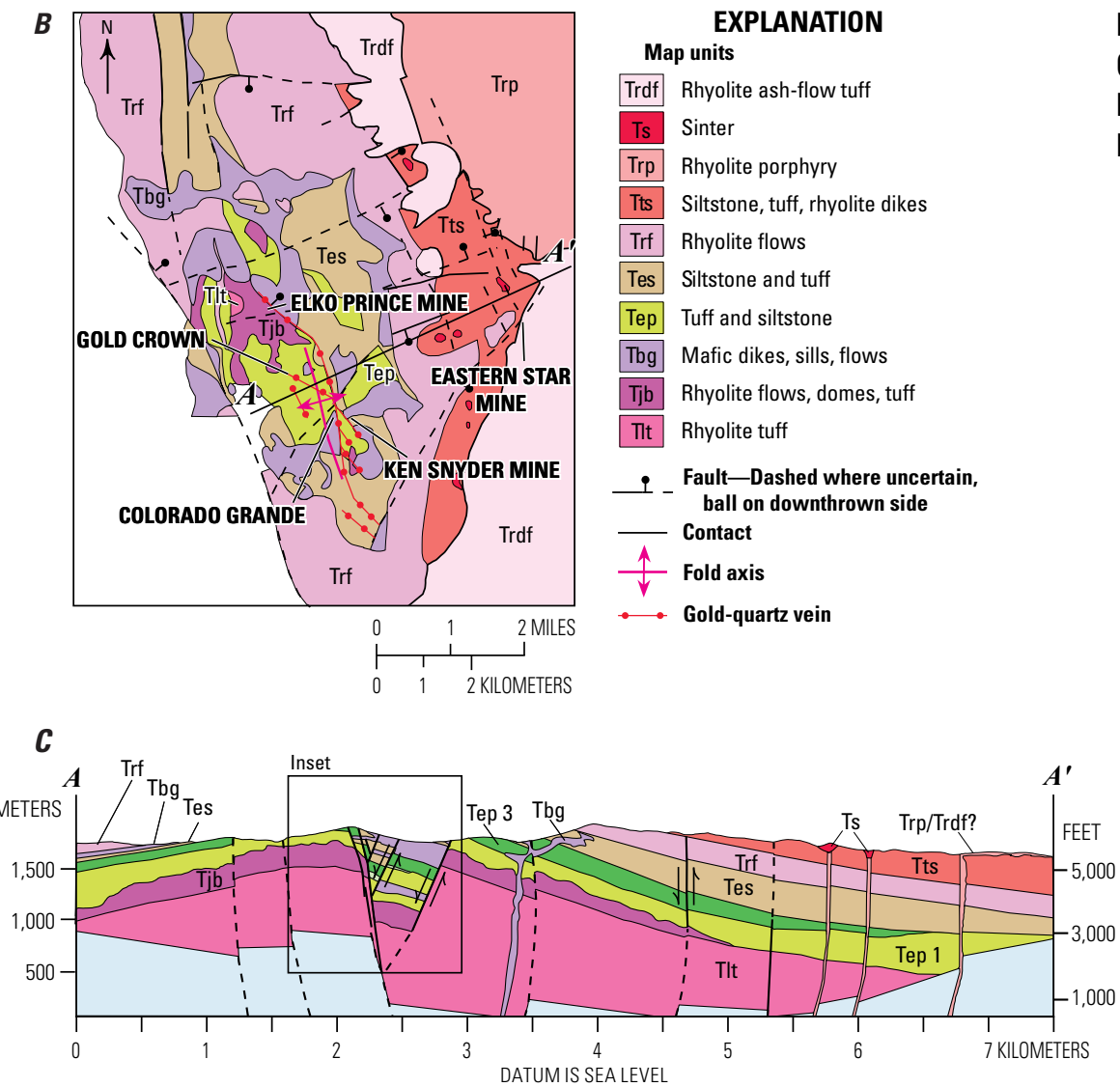

Map units

\begin{tabular}{|l|l}
\cline { 1 - 1 } Trdf & Rhyolite ash-flow tuff \\
\hline \hline Tts & Siltstone, tuff, rhyolite dikes \\
\hline Trf & Rhyolite flows \\
\cline { 1 - 1 } Tes & Siltstone and tuff \\
\cline { 1 - 1 } Tep 3 & Tuff and siltstone \\
\cline { 1 - 1 } Tep 2 & Tuff and siltstone \\
\hline
\end{tabular}

EXPLANATION
EXPLANATION

Trdf Rhyolite ash-flow tuff

Ts Sinter

Trp Rhyolite porphyry

Tts Siltstone, tuff, rhyolite dikes

Trf Rhyolite flows

Tes Siltstone and tuff

Tep Tuff and siltstone

Tbg Mafic dikes, sills, flows

Tjb Rhyolite flows, domes, tuff

Tlt Rhyolite tuff

I. Fault-Dashed where uncertain, ball on downthrown side

- Contact

$\frac{\uparrow}{\downarrow}$ Fold axis

․ Gold-quartz vein

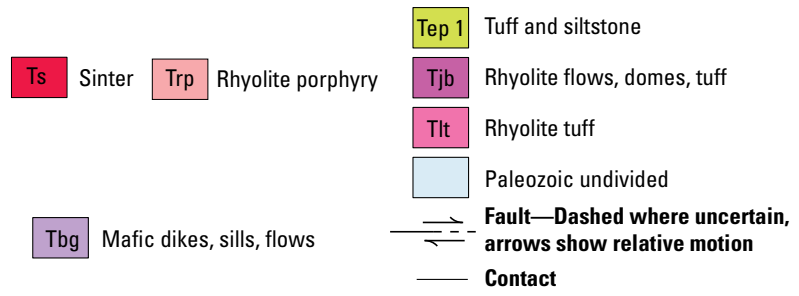

Figure F3. Geologic maps and cross sections of low-sulfidation $(A, B, C)$ and intermediate-sulfidation $(D, E)$ epithermal gold-silver districts. $A$, Hishikari, Japan (Sanematsu and others, 2006). $B$ and $C$, Midas, U.S.A. (Leavitt and Arehart, 2005). D, Comstock Lode, U.S.A. (Vikre, 1989a). E, San Luis stope, Tayoltita mine, San Dimas district, Mexico (Smith and others, 1982).

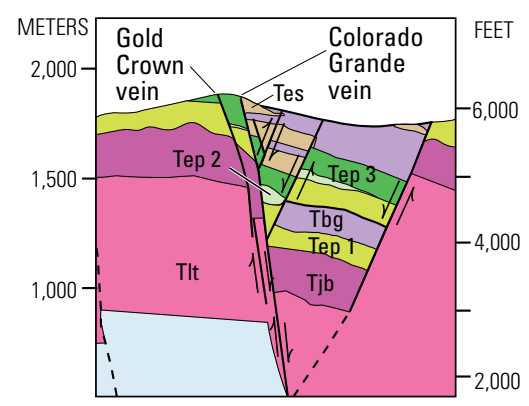


D

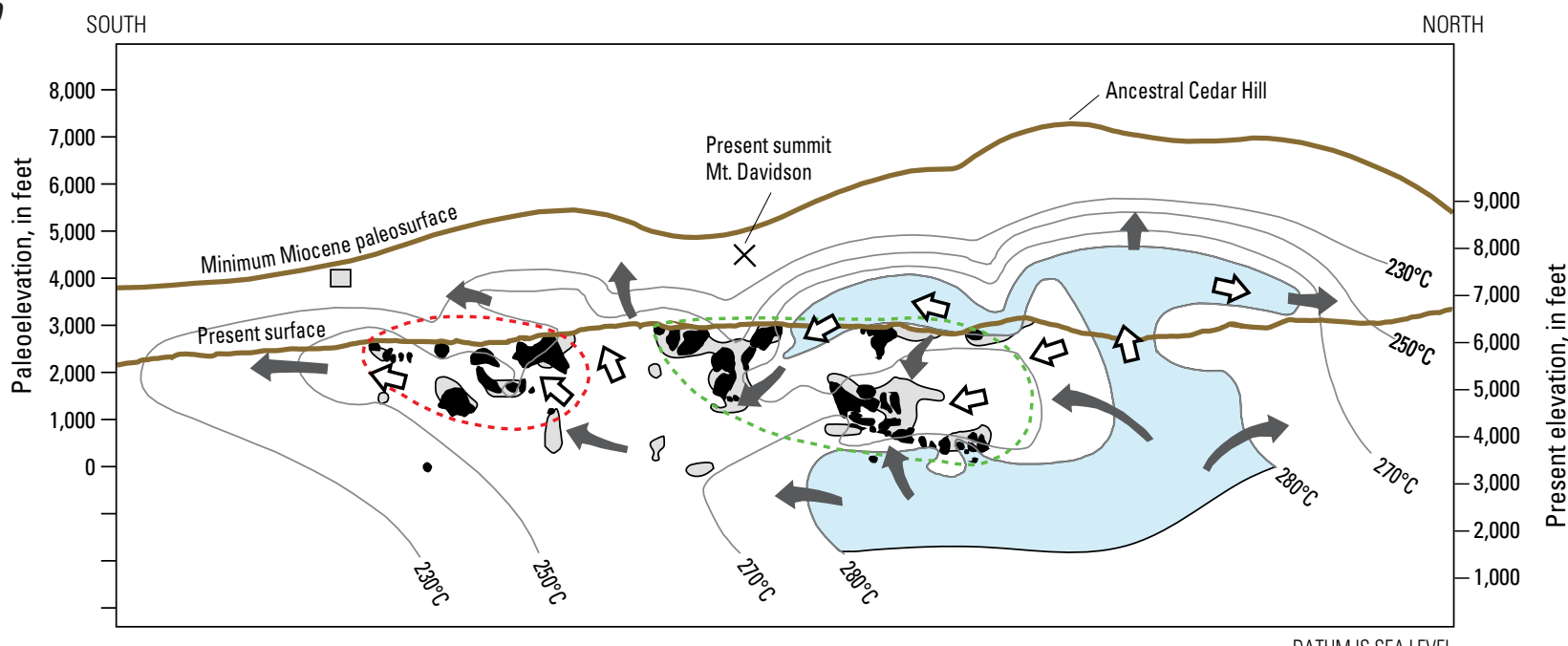

DATUM IS SEA LEVEL

Higher temperature mixed meteoric and magmatic waters

Bonanza orebodies $(\geq 0.4$ ounces per ton gold; $\geq 10$ ounces per ton silver)

Low-grade stopes

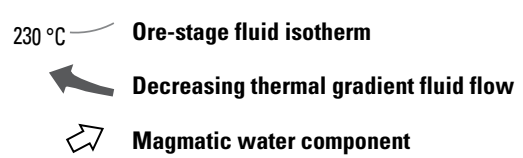

$230^{\circ} \mathrm{C}$ Ore-stage fluid isotherm

$\downarrow$ Magmatic water component
$\boldsymbol{E}$

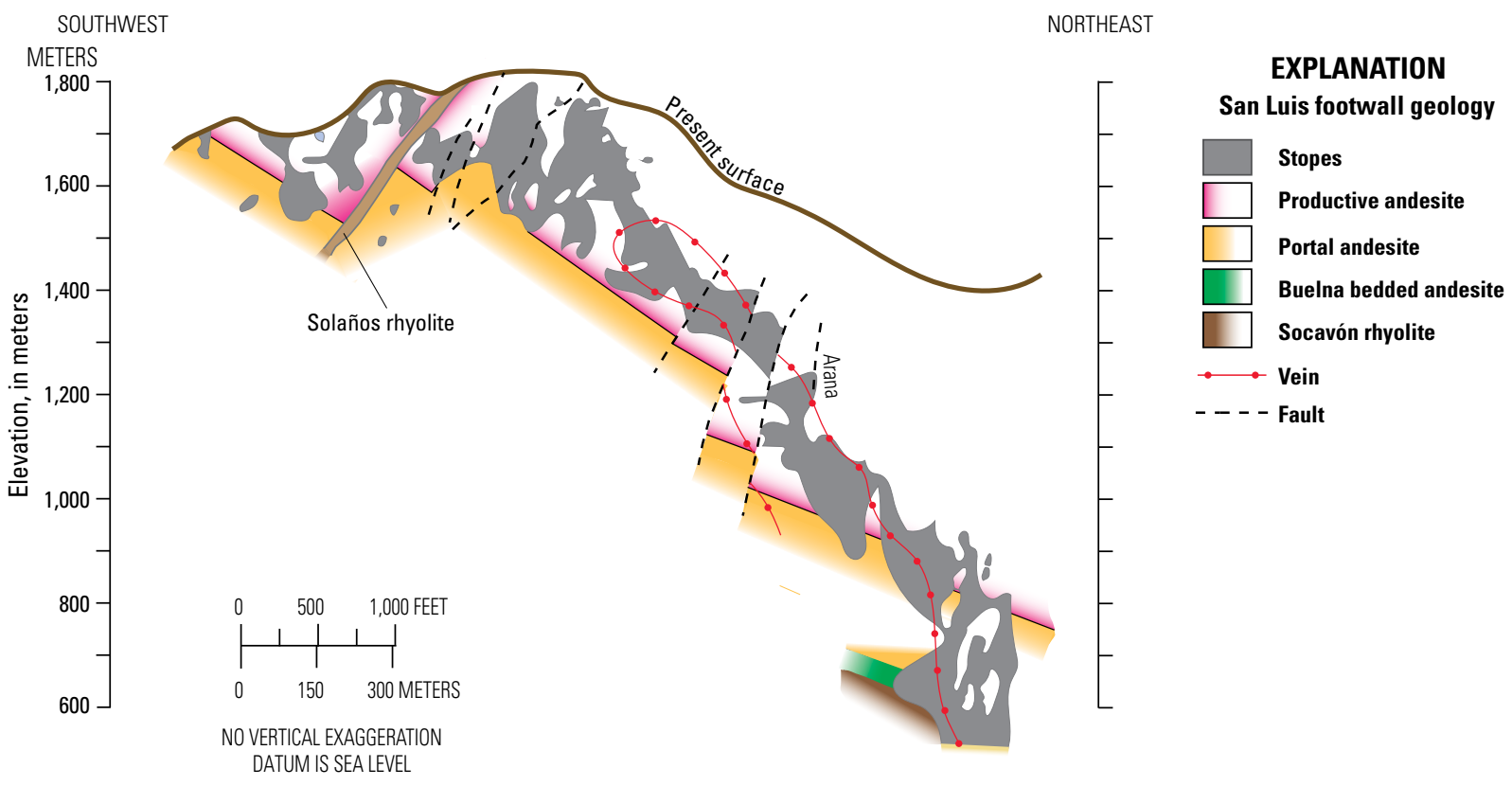

Figure F3.-Continued 


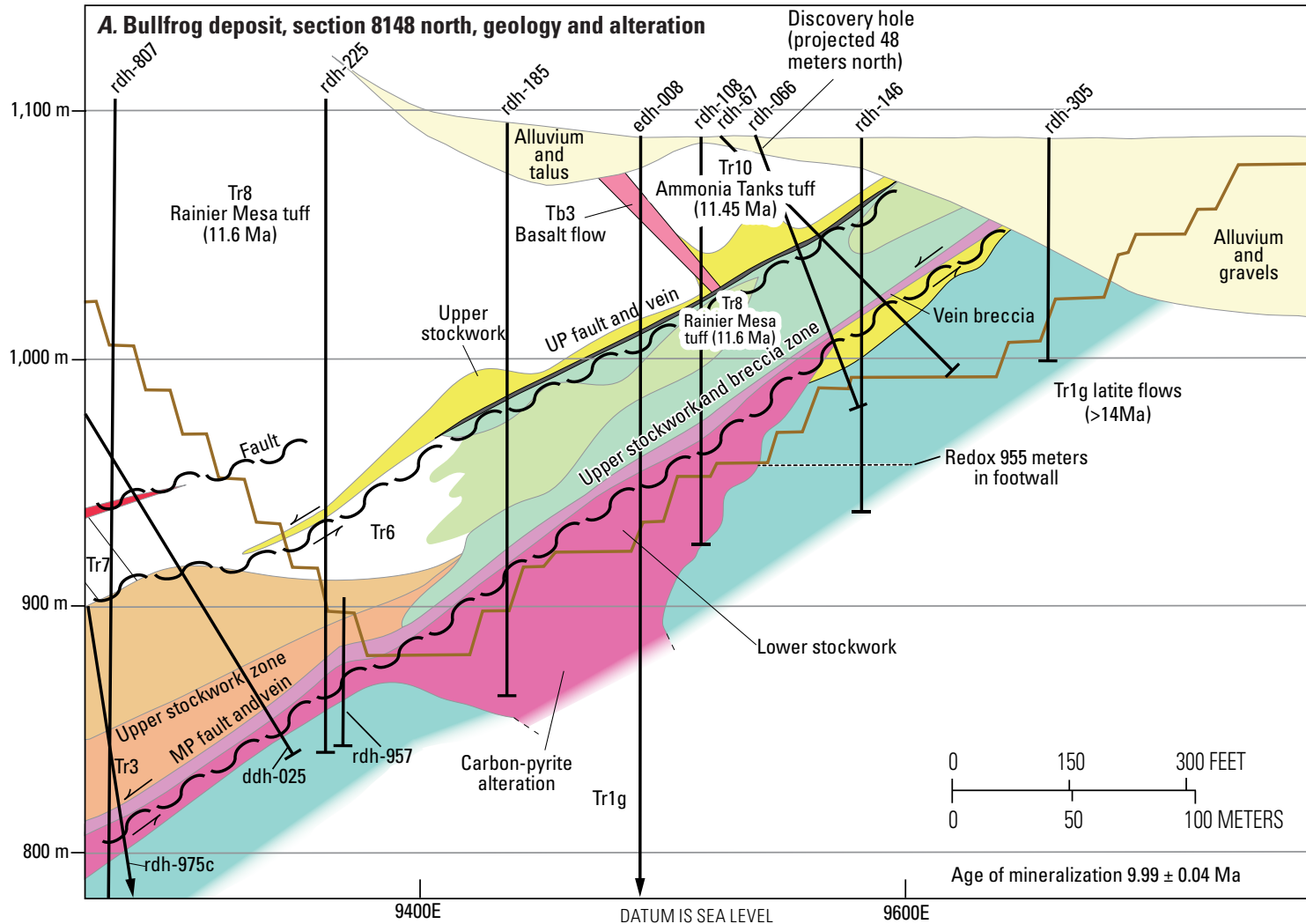

\section{EXPLANATION \\ Quartz-adularia flooded zone

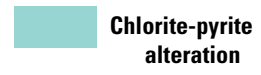 alteration \\ Basalt dike

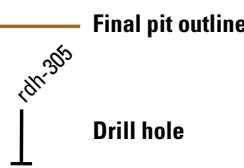

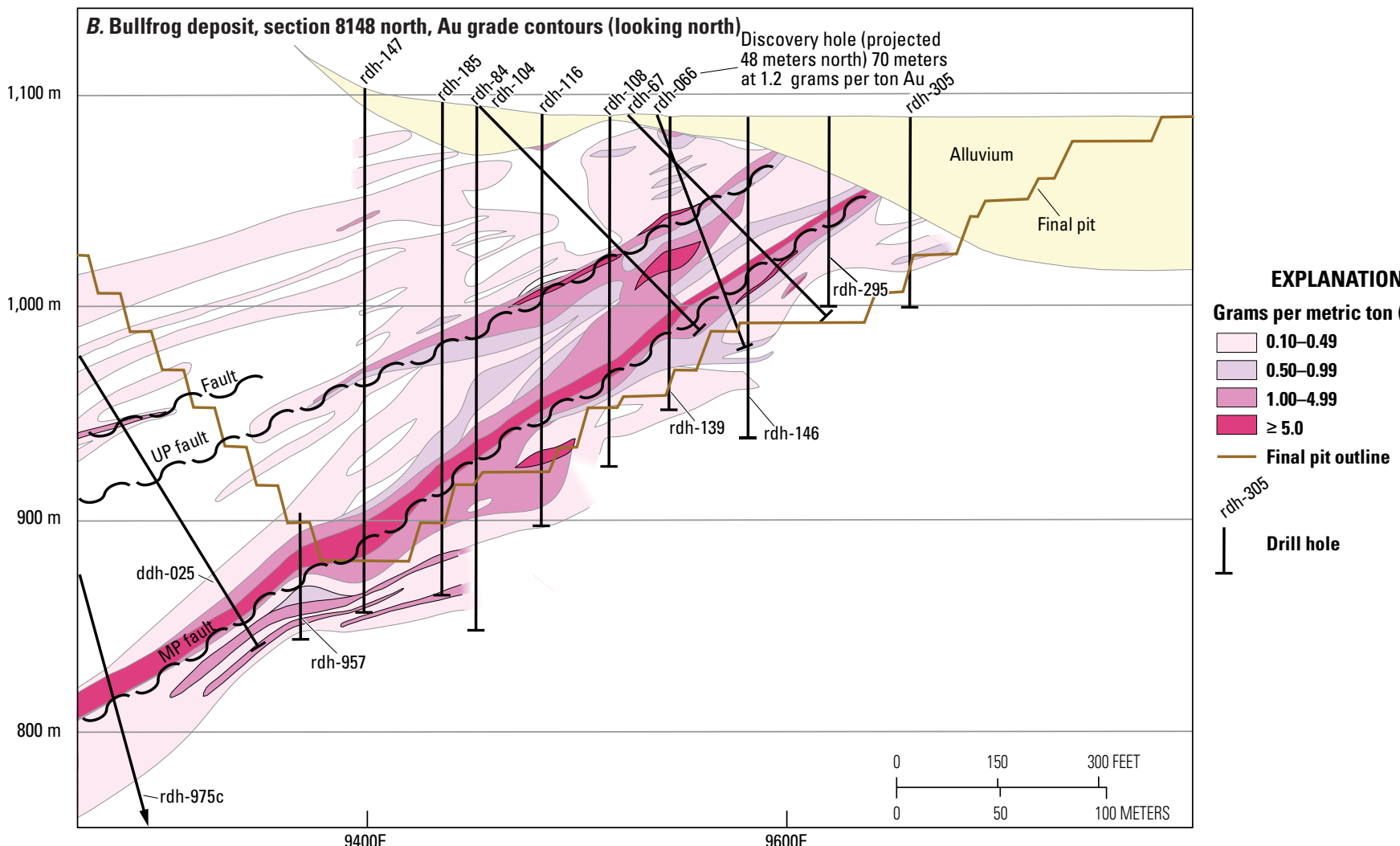

Figure F4. West-east section $8148 \mathrm{~N}$ through the low-sulfidation epithermal gold-silver deposit at Bullfrog, U.S.A. (Eng and others, 1996). $A$, Stratigraphy, quartz-adularia alteration, stockwork and breccia zone, UP and MP faults and veins, carbon-pyrite alteration and chlorite-pyrite alteration zones, and final open-pit mine profile. $B$, Gold grades in grams per metric ton. 


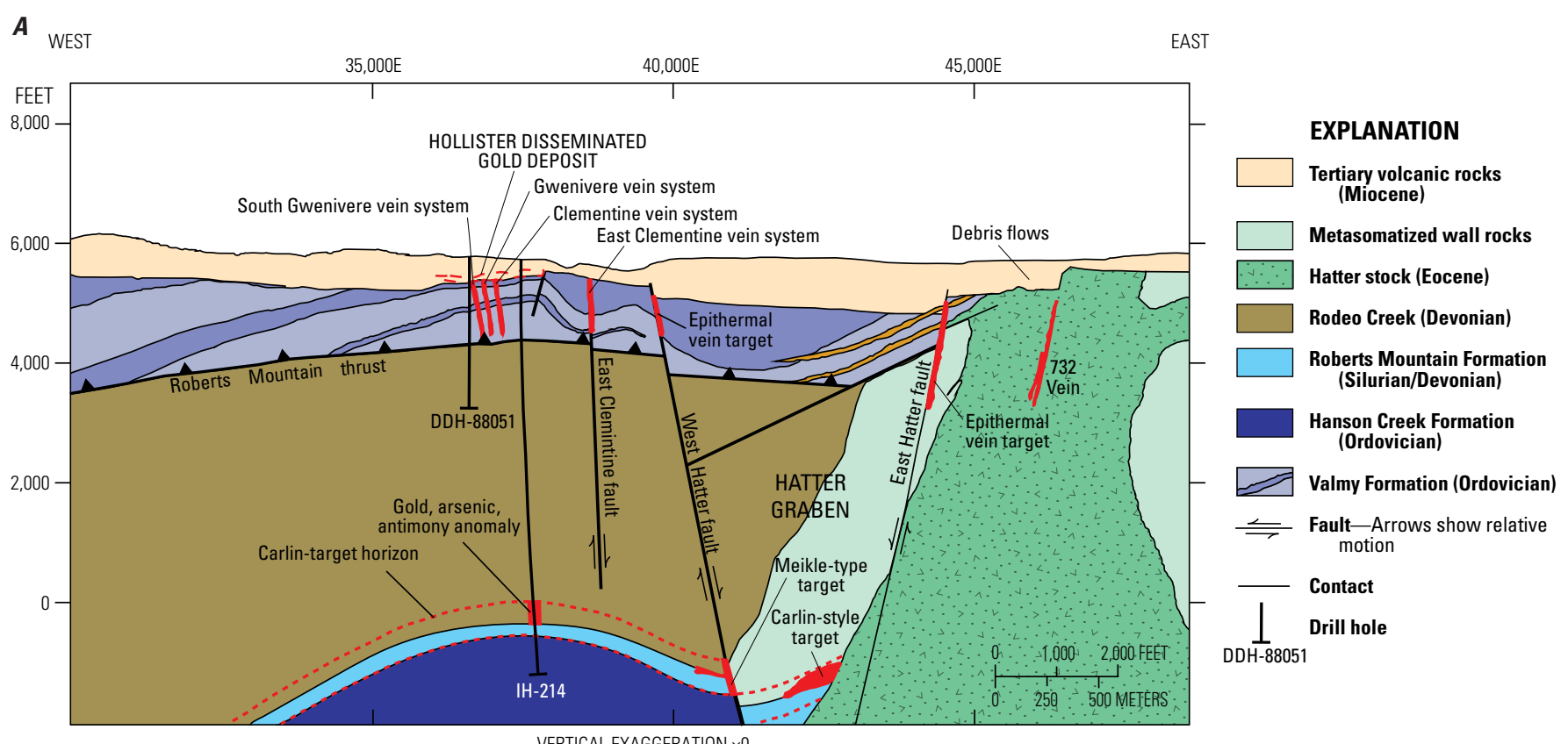

VERTICAL EXAGGERATION $\times 0$

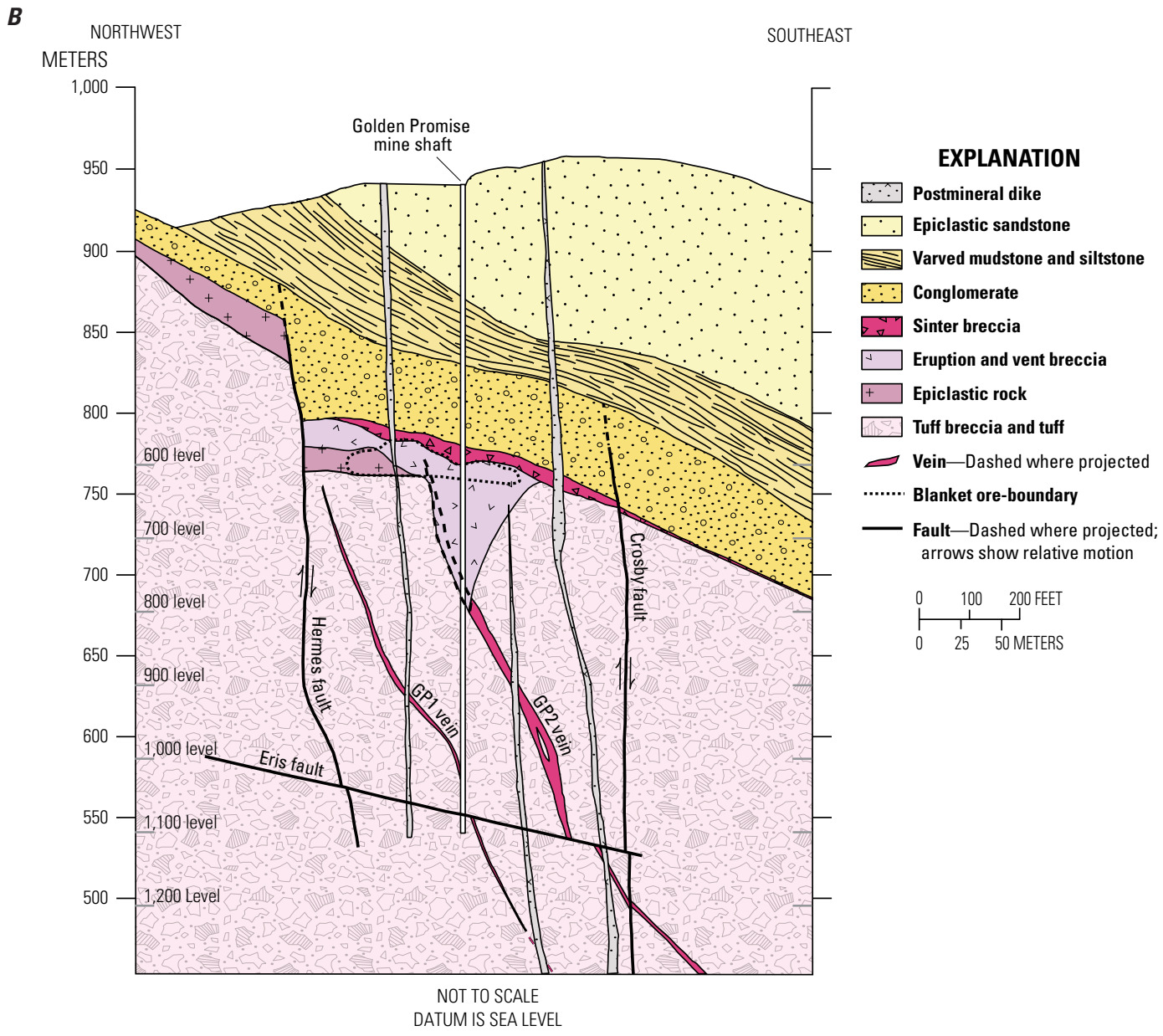

Figure F5. Sections through paleosurface deposits and subjacent low-sulfidation gold-silver veins. $A$, West-east section of the vein system at Ivanhoe, U.S.A. (modified from Bartlett and others, 1991). Light-green selvages of the Hatter stock (unlabeled in Bartlett and others, 1991) are assumed to be metasomatized wall rocks. Elevations (scale on left) are in feet. $B$, Northwest-southeast section of the Golden Promise vein system at Republic, U.S.A. (modified from Fifarek and others, 1996). Elevations (scale on left) are in meters; mines levels (scale on right) correspond to an unspecified scale and datum. 
closely tied to gold and silver grades and metal values over time, because ore values influence mining economics. Lowand intermediate-sulfidation deposits formed predominantly in high-angle fault zones and have been mined only if prevailing ore values offset the relatively high costs of underground mining, recovery by milling, and development and property costs (for example, leases, royalties, and taxes). Historically, gold grades of at least several tenths of ounces per ton gold combined with silver grades of several to tens of ounces per ton (tens to hundreds or more grams per ton) have been required for underground production. The same limitations of grade and ore value versus production, development, and property costs that limited underground mining in the nineteenth and twentieth centuries to relatively high-grade low- and intermediatesulfidation deposits (for example, Comstock Lode; Tonopah, U.S.A.), also constrain modern underground mining (for example, Midas and Ivanhoe, U.S.A.).

Low- and intermediate-sulfidation deposits selectively mined underground, vary in width from less than 1 meter to tens of meters in large districts (for example, Hishikari, Izawa and others, 1990; Midas, Leavitt and Arehart, 2005; Comstock Lode, Vikre, 1989a; Tonopah, Bonham and Garside, 1979; Guanajuato, Mango and others, 2014; and Tayoltita, Smith and others, 1982), and were intermittently mined along strike for hundreds of meters to several kilometers. En echelon veins in some districts span more than $7 \mathrm{~km}$ strike length (for example, Guanajuato, Aurora, Vikre and others, 2015; and Republic, Fifarek and others, 1996). Most mined low-sulfidation veins are narrower $(<1 \mathrm{~m}$ to $3 \mathrm{~m}$ wide) than mined intermediate-sulfidation veins ( $<1 \mathrm{~m}$ to $>10 \mathrm{~m}$ wide). High gold and silver grades (tens to hundreds of grams per metric ton) in centimeter-wide veins (for example, Bodie, U.S.A., Vikre and others, 2015), and in small segments of otherwise low-grade veins, have enabled small-scale mining (tens to hundreds of metric tons per day production) of thousands of vein deposits worldwide.

Significant production since the 1970s has been facilitated by elevated gold values (hundreds to more than a thousand dollars per ounce) and silver values (tens of dollars per ounce), by wide, near-surface oxidized vein, breccia, and stockwork deposits averaging several grams per metric ton or less gold and several tens of grams per metric ton silver (for example, Comstock Lode, MacIntosh, 1980; Round Mountain, Sander and Einaudi, 1990; and Florida Canyon, Fifarek and others, 2011), and by low-cost, open-pit mining and heap leach recovery techniques. Some near-surface vein deposits that consist of closely spaced vein, breccia, and vein stockworks with gold grades high enough to support underground mining were mined at lower cost by open-pit methods because of low waste/ore stripping ratios (fig. F4; for example, Sleeper, Nash and others, 1995; Bullfrog, Eng and others, 1996; and Bodie, Vikre and others, 2015). Vein deposits mined by open-pit methods vary in size mostly from tens of thousands to tens of millions of metric tons. Smaller production in recent decades has been derived from single veins, groups of closely spaced single veins (generally $<10 \mathrm{~m}$ apart), and breccias, that were mined by openpit methods to depths limited by waste/ore ratios and gold grade (for example, Aurora and Comstock Lode, U.S.A.). Individual vein widths mined by open-pit methods vary mostly from less than 1 meter to several meters, whereas open-pit mines are hundreds of meters to kilometers in dimension, with the longest pit dimension corresponding to average vein strike.

Gold in oxidized ore is readily dissolved in cyanide solution, and heap leach and vat-leach recoveries may exceed 90 percent. Silver recovery from oxidized ore seldom exceeds 50 percent even after lengthy leach cycles (years). The unit value of gold has historically been many times that of silver, and gold grades and recoveries have enabled bulk mining of most relatively low-grade gold and (or) silver vein deposits ( $\sim 1 \mathrm{~g} / \mathrm{t}$ gold; $\leq 0.03 \mathrm{opt}$ ). Gold and silver in sulfide mineral assemblages are commonly more expensive to recover in terms of capital and operating costs, precluding mining of many low-grade sulfide deposits. Thus, open-pit mining of low-grade vein deposits is often facilitated by sulfide mineral decomposition (weathering) that enables sufficient gold and (or) silver recovery.

\section{Vertical Extent}

Mined depths of the largest low-sulfidation deposits are as much as $\sim 500 \mathrm{~m}$ below erosion surfaces, or as much as $230 \mathrm{~m}$ below the water table based on stratigraphy of hydrothermal mineral assemblages and fluid inclusion microthermometry (for example, Republic and Hishikari, Fifarek and others, 1996; Izawa and others, 1990; see "Geochemical Characteristics"). The vertical extent of ore-grade veins is as much as $\sim 350 \mathrm{~m}$ (Bullfrog, El Peñón; Eng and others, 1996; Warren and others, 2004, 2008).

Mined depths of the largest intermediate-sulfidation deposits are $\sim 1,200 \mathrm{~m}$ below the erosion surface, or as much as $2,100 \mathrm{~m}$ below the water table based on fluid inclusion microthermometry and spatial and temporal distribution of hydrothermal mineral assemblages (for example, Comstock Lode and Tayoltita; Vikre, 1989a; Smith and others, 1982; Conrad and others, 1992; see "Geochemical Characteristics"). The vertical extent of ore is as much as $1,200 \mathrm{~m}$ in the Comstock Lode and San Dimas districts, and the San Luis ore shoot in the Tayoltita mine was stoped continuously from the erosion surface to a depth of $\sim 1,200 \mathrm{~m}$ (fig. F3). Production at depth for both vein types was limited by decreasing gold and silver grades and vein widths, and by increased costs of mining, including water control.

Mined depths of low-grade, large-tonnage deposits $(<1$ to $\sim 3 \mathrm{~g} / \mathrm{t} ; \leq 0.1 \mathrm{opt}$ gold) are mostly less than or equal to $100 \mathrm{~m}$ below the erosion surface. High costs associated with stripping ratios that increase with depth, and in some cases, decreases in recoverable gold and silver with incomplete oxidation of sulfide minerals at depth, preclude deeper mining of low-grade deposits. The exceptionally large Round Mountain deposit (1977-2013 production $>1.3 \mathrm{Gt}, 13.4 \mathrm{Moz}$ gold, $13.7 \mathrm{Moz}$ silver at $<1 \mathrm{~g} / \mathrm{t}$ gold and $<1 \mathrm{~g} / \mathrm{t}$ silver; Nevada Bureau of Mines and Geology, 2014) currently (2015) is being mined $\sim 575 \mathrm{~m}$ below the erosion surface (S. Howell, personal commun., July 10, 2015). 


\section{Form and Shape}

High-grade vein low- and intermediate-sulfidation deposits mined by underground methods have steeply to moderately dipping tabular geometries, with strike and dip dimensions much greater than widths, reflecting the aspect of faults in which the deposits formed. Deposit contacts with wall rocks are commonly planar even though many deposits consist of parallel to subparallel veins with intervening wall-rock septa. The consistency of deposit form and planar margins allows most deposits to be mined with little grade dilution by external wall rocks, although higher grades are necessary to offset dilution resulting from operating mining equipment in narrow vein $(<2 \mathrm{~m})$ stopes. Wall-rock incompetency imposed by wall-rock alteration and postdeposit faulting also dilutes grade.

\section{Host Rocks}

Most significant low- and intermediate-sulfidation deposits occur in Tertiary and Quaternary volcanic fields consisting of domes, flow-domes, flows, breccias, tuffs, and other volcaniclastic and epiclastic strata that range in composition from basalt to rhyolite (appendix 1; see "Relations to Igneous Rocks"). Synmineralization phreatic or hydrothermal breccias are associated with some low-sulfidation deposits and contain ore in some districts (for example,
Republic; Fifarek and others, 1996). Some intermediatesulfidation deposits are associated with nested and juxtaposed calderas (for example, San Juan Mountains, U.S.A., Slack, 1980; Hutchinson, 1988). At depth, pre-Tertiary rocks host mineralization in many mined deposits. Similar to highsulfidation deposits in volcanic rocks, low- and intermediatesulfidation vein deposits are the same age as or slightly younger than their volcanic host rocks, or nearby subvolcanic intrusions, including deposits in Mesozoic volcanic rocks (for example, Cerro Bayo, Chile, Poblete and others, 2014).

\section{Structural Settings and Controls}

Low- and intermediate-sulfidation deposits predominantly occur in Tertiary and Quaternary volcanic rocks that have been dismembered and brecciated by faults and catastrophic fluid expansion (phreatic eruptions). Low-sulfidation deposits largely formed in open, planar fractures, and in permeable paleosurface strata (sinter breccia, vent breccia, epiclastic deposits, and eruption breccias). Intermediate-sulfidation vein deposits formed in fault zones variably consisting of breccia fragments, gouge, and open space. Some low-grade intermediate-sulfidation deposits, notably Peñasquito, occur in diatreme breccias (Bryson and others, 2009; Belanger and others, 2011; see "Relations to Structures" and "Relations to Igneous Rocks"). 


\title{
Chapter G. Geophysical Characteristics
}

\author{
By Richard J. Blakely, David A. John, and Eric D. Anderson
}

\section{Introduction}

Hydrothermal fluids that form epithermal gold-silver deposits and their alteration haloes profoundly affect the physical properties of host rock. Depending on alteration intensity, mineralogy, and porosity of original rock types, rock magnetization decreases, whereas bulk density, electrical resistivity, and potassium concentration can increase or decrease. Airborne or ground-based geophysical surveys with proper design can detect each of these physical property changes, and consequently, geophysical methods are important for mapping and characterizing known epithermal deposits. Historically, geophysical methods have not been very important to the actual discovery of epithermal gold-silver deposits (Sillitoe, 1995, 2000), although this may change with improved field and processing techniques and with increasing importance of discovering concealed resources.

Geophysical methods used to locate and define the extent of epithermal gold-silver deposits and associated alteration haloes (fig. G1) can yield ambiguous results. Zones of hydrothermally altered rock can be volumetrically small and occur at variable depths below the topographic surface where increasing depth can decrease anomaly resolution. Zones of altered rock may be concealed beneath younger volcanic and sedimentary deposits, each associated with their own intrinsic geophysical anomalies that obscure the signals of buried altered rocks. To overcome these problems, high-resolution geophysical surveys, such as airborne surveys with low flight altitude and small flight-line spacing that are designed specifically for epithermal targets, may yield the most informative results.

The application of geophysical methods to exploration for epithermal gold-silver deposits falls into two broad categories that are scale dependent: (1) Focused studies use geophysical methods to directly characterize the location, volume, and degree of change in rock properties caused by associated hydrothermal alteration. Regions of decreased magnetic intensity, for example, may signal hydrothermal destruction of primary magnetite in affected rocks, and low-resistivity anomalies in airborne electromagnetic surveys may point to zones of sulfide mineralization, in contrast to high-resistivity anomalies indicating zones of silicification and veins. (2) Regional studies characterize the broad geologic, magmatic, and structural setting of epithermal deposits. Regional high-resolution aeromagnetic data, for example, can help map concealed crustal faults and fractures that focused hydrothermal fluid flow, and this mapping may lead to discovery of other base metal exploration targets. Gravity and magnetic surveys can also indicate basement structure, concealed calderas, and underlying intrusive rocks.
This chapter reviews the application of geophysical methods to locate, delineate, and characterize epithermal gold-silver deposits. We treat the spectrum of epithermal gold-silver deposits together in this discussion, because parts of the alteration halos that envelop these deposits have similar geophysical properties. There are, however, important exceptions. For example, highsulfide mineral contents are commonly associated with highsulfidation deposits, which contrast with generally lower sulfide mineral contents within low-sulfidation deposits. In addition, certain sulfide minerals that may typify a low- or high-sulfidation deposit can strongly affect electrical properties of host rock (fig. G1). The following discussion notes situations in which geophysical survey methods may differ between low- and highsulfidation deposit types.

\section{Direct Characterization}

Epithermal gold-silver deposits are the products of protracted flow of hydrothermal fluids through reactive host rocks, most commonly in volcanic terranes. Interactions between fluid and rock can contribute to gold-silver mineralization and destroy and (or) replace other minerals, resulting in local host rocks with altered physical properties (for example, magnetic susceptibility, bulk density, electrical resistivity, and radioactivity). Geophysical studies of epithermal deposits have focused historically on four geophysical disciplines: magnetic, geoelectric, radiometric, and gravity methods.

\section{Magnetic Anomalies}

The bulk magnetization of a rock is the vector sum of the induced and natural remanent magnetization components (for example, Blakely, 1995). Induced magnetization is directed parallel to the ambient magnetic field of the Earth and has a magnitude proportional to the magnetic susceptibility of a rock. Natural remanent magnetization has a vector direction and magnitude that reflect the formation and subsequent history of a rock. Unaltered volcanic rocks typically have high magnetic susceptibility (ranging from $0.2-35 \times 10^{-3}$ SIU (Le Système International d'Unités) for rhyolite to $160 \times 10^{-3} \mathrm{SIU}$ for andesite; Telford and others, 1990) and high natural remanent magnetization relative to other rock types. Bulk magnetization of volcanic rocks is highly variable from point to point; consequently, magnetic anomalies measured close to the ground above unaltered volcanic rocks have characteristically high amplitudes and short wavelengths. 


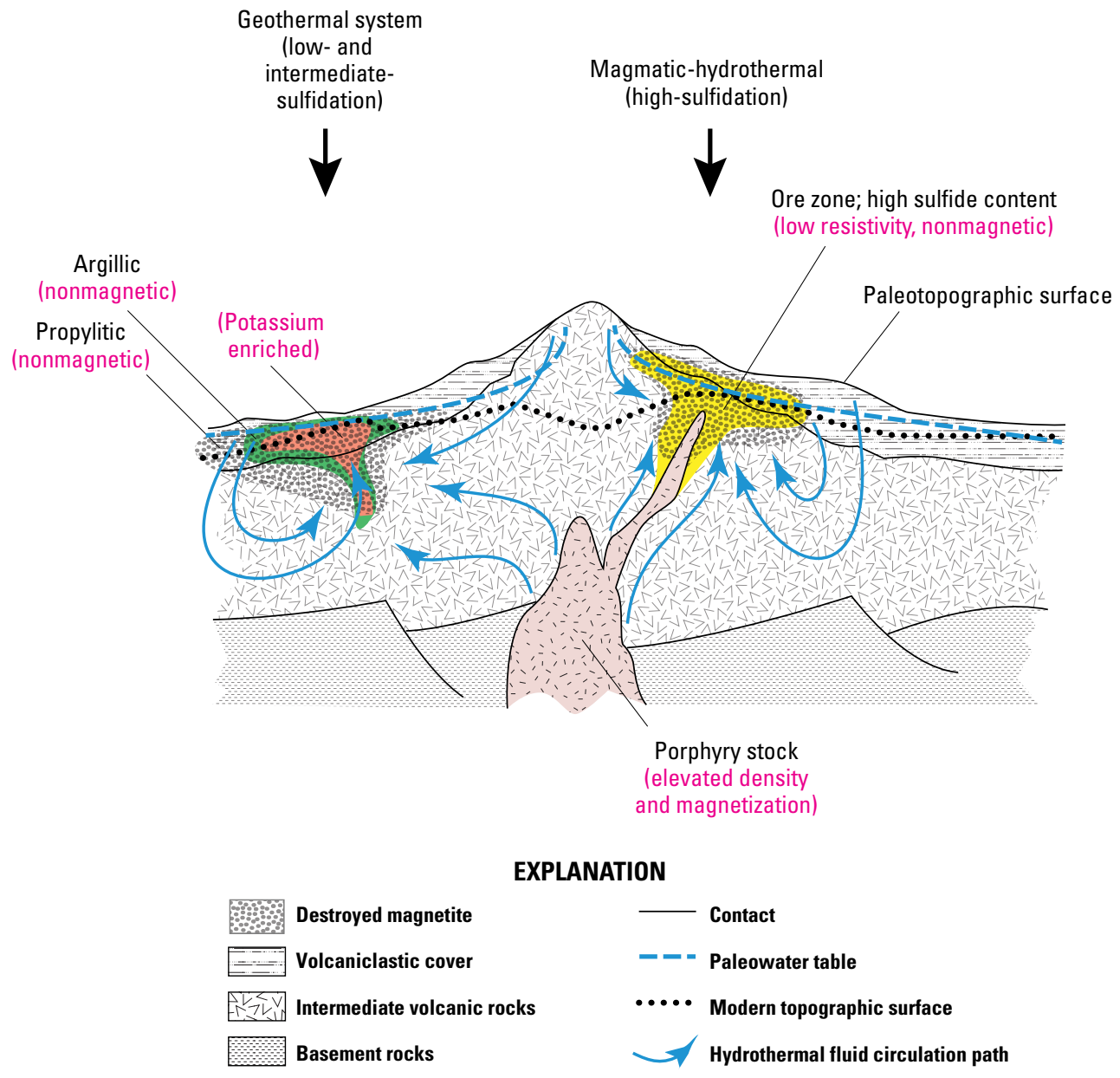

Figure G1. Schematic diagram showing geophysical properties of hypothetical, generalized epithermal gold systems. Lithology indicated by black-and-white patterns; geophysical anomaly source by colored regions and red labels.

Induced and natural remanent magnetizations in most igneous rocks originate almost entirely in magnetite. Hydrothermal fluids can destroy magnetite in host rocks, thereby reducing both types of magnetization (for example, Irvine and Smith, 1990; Allis, 1990; Morrell and others, 2011). Therefore, shallow zones of intensely and pervasively altered volcanic rock commonly appear on aeromagnetic maps as areas of subdued magnetic anomalies relative to high-amplitude, short-wavelength anomalies of surrounding unaltered volcanic rock (Morrell and others, 2011; Hoschke and Sexton, 2005; Feebrey and others, 1998). Detecting and mapping these variations in magnetic anomaly patterns require low-altitude (for example, $50 \mathrm{~m}$ above terrain) aeromagnetic surveys flown along closely spaced flight lines (for example, 100 $\mathrm{m})$. Where conditions permit, follow-on ground-based magnetic surveys can precisely determine lateral boundaries between altered and unaltered host rock (Irvine and Smith, 1990; Allis, 1990).

A variety of quantitative digital methods are available to assist in interpretation of aeromagnetic data (see Blakely, 1995, for theoretical development and review of methods). Reduction to the pole, for example, corrects magnetic anomalies for asymmetries imparted by nonvertical magnetization and nonvertical ambient field, thereby shifting the lateral position of anomalies so that they are located more nearly above their causative sources. Reduction to the pole is particularly important for magnetic anomalies measured at low latitudes. Using vertical derivatives of magnetic anomalies is a well-known technique to emphasize anomalies originating from shallow sources and is particularly useful in mapping shallow crustal faults that may focus hydrothermal alteration (for example, Blakely and others, 2007). Various forms of boundary analysis that require minimal geologic assumptions are available to automatically map magnetic contacts (Phillips and others, 2007; Grauch, 1988; Salem and others, 2010). The analytic signal, calculated by combining horizontal and vertical gradients of a magnetic anomaly, produces an anomaly form that depends on the position of the causative body independent of magnetization direction and ambient field; this method has been used successfully in various studies of hydrothermal alteration (for example, Morrell and others, 2011; Teal and Benavides, 2010).

Figure G2 from Morrell and others (2011) provides an example of the use of aeromagnetic anomalies to map and characterize hydrothermal alteration that envelops epithermal intermediate-sulfidation gold-silver deposits and prospects in the southern province of the Hauraki Goldfield in New Zealand. Associated epithermal deposits lie within Miocene to Pliocene 
andesite to rhyolite volcanic rocks that overlie Late Jurassic greywacke basement. Epithermal mineralization is characterized by haloes of pervasive clay alteration, potassium metasomatism, destruction of magnetic minerals, and formation of sulfide minerals. Short-wavelength, high-amplitude magnetic anomalies coincide with unaltered volcanic rocks, as expected, but this pattern also contains multiple areas of uniformly low magnetic intensity. Areas of subdued magnetic anomalies coincide with areas of known hydrothermal alteration and reflect hydrothermal destruction of magnetite. Morrell and others (2011) transformed high-resolution aeromagnetic data to the analytic signal to accurately map magnetic quiet zones. Low-pass filtering of the analytic signal revealed still wider zones of relatively low magnetic intensity, which Morrell and others (2011) interpreted as extended zones of hydrothermally altered rock concealed below younger, unaltered cover.
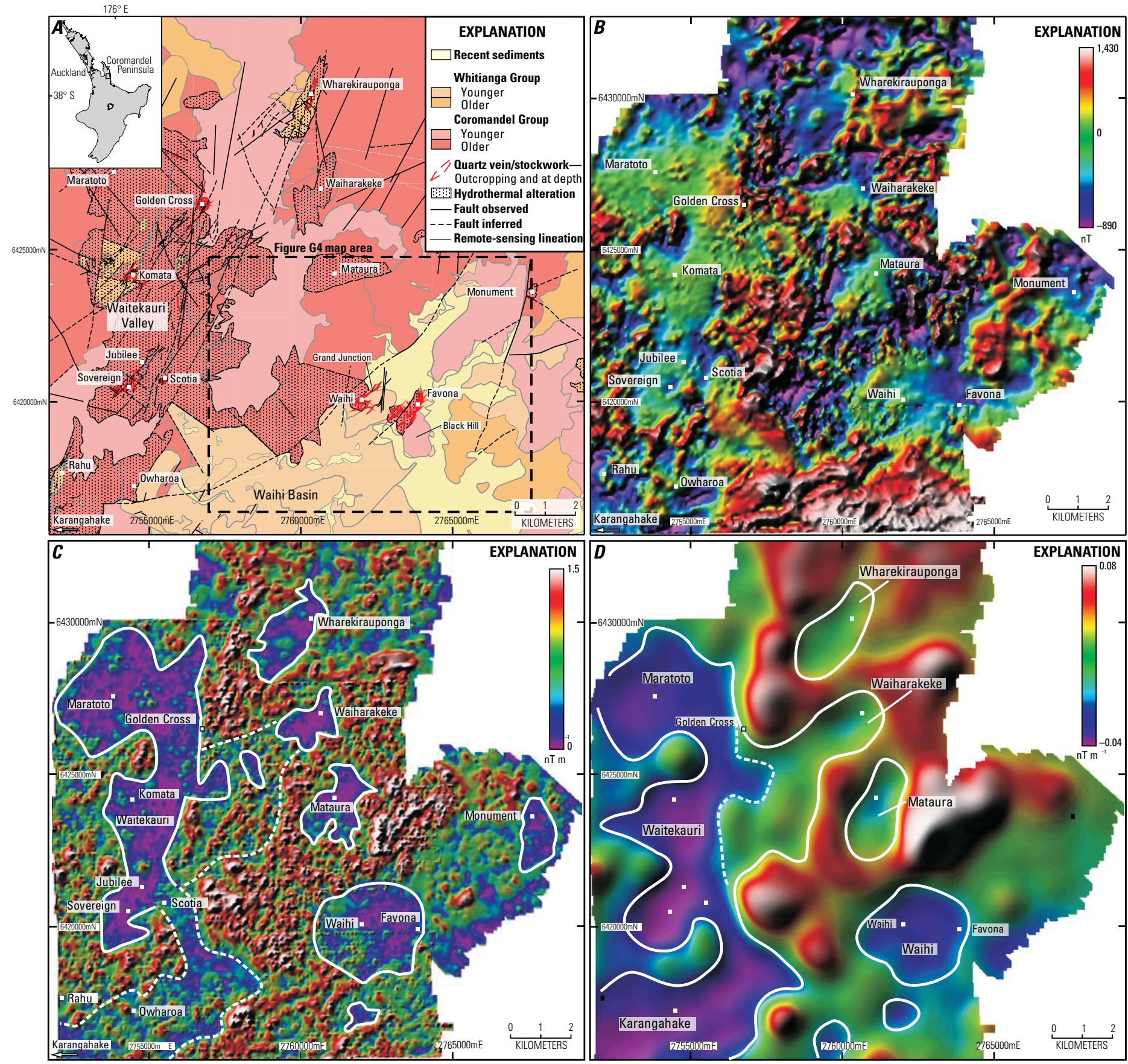

Figure G2. Maps showing analysis of aeromagnetic anomalies from the Waihi-Waitekauri region of New Zealand (Morrell and others, 2011). A, Simplified geologic map, showing areas of hydrothermal alteration and known quartz vein systems. $B$, Total-field magnetic anomalies. Deposits shown by white squares. $C$, Analytic signal calculated from total-field magnetic anomalies. White lines bound areas of very low (solid lines) and subdued (dashed lines) magnetic gradients. $D$, Application of a low-pass filter to the analytic signal. White lines as described previously but here applied to the low-pass-filtered analytic signal. Modified from Morrell and others (2011). 


\section{Electrical and Electromagnetic Methods}

Electrical resistivity (the reciprocal of conductivity) of geologic materials varies over 20 orders of magnitude, a broader range than any other geophysical property. Quartz, for example, is highly resistive ( $>10^{5} \mathrm{ohm}$-meters [ohm-m]), whereas native copper is extremely conductive $\left(\sim 10^{-8} \mathrm{ohm}-\mathrm{m}\right)$. Within the upper crust, the resistivity of geologic units is largely controlled by fluid content and salinity, porosity, degree of interconnected fracturing, temperature, and conductive mineral content (Keller, 1987). Saline fluids within pore spaces and fracture openings can reduce bulk resistivities by several orders of magnitude, as can the presence of clay minerals, graphite, and sulfide minerals.

Gold itself is highly conductive, but gold concentrations in epithermal deposits are insufficient to be directly detectable at the surface of the Earth. In contrast, hydrothermal alteration associated with gold mineralization commonly involves replacement of feldspar and mafic silicate minerals by phyllosilicate and zeolite minerals, which can decrease electrical resistivity by several orders of magnitude (for example, Irvine and Smith, 1990). Moreover, the introduction of disseminated sulfide minerals into high-sulfidation epithermal deposits may dominate parts of the altered zone, causing electrical resistivity to decrease significantly. Therefore, electrical methods focused on shallow parts of the crust are particularly useful in delineating zones of hydrothermal alteration associated with reduced electrical resistivity.

Whereas resistivity decreases in the presence of interconnected sulfide grains, some parts of hydrothermal alteration zones may have high resistivity because of increased concentrations of silica, including zones of quartz veins, chalcedony, sinter terraces, and lithocaps (Irvine and Smith, 1990; Hedenquist and others, 2000). Silica phases are highly resistive; accordingly, zones of anomalously high resistivity may indicate quartz veins and silica-rich parts of epithermal deposits.

Geoelectrical methods fall into two categories: electrical methods, always applied on the ground, and electromagnetic (EM) methods, conducted on the ground and from airborne platforms. Electrical methods measure the ability of electrical charge to flow through or be stored in Earth materials (for example, induced polarization). Electromagnetic methods, on the other hand, involve electrical and magnetic fields. In EM methods, a time-varying magnetic field, either from natural sources (for example, lightning) or from a controlled transmitter, induces electrical currents in the crust, while receivers measure the resulting secondary electrical and magnetic fields. Airborne EM methods operate in either the frequency domain or time domain (TDEM). In frequency domain techniques, transmitters generate an alternating electromagnetic field, which is compared with the resulting secondary electromagnetic field for differences in phase and amplitude. In time-domain methods, short pulses are transmitted, and the time decay of the resulting secondary field is measured.

A variety of geoelectrical techniques have been used to locate epithermal gold deposits. These techniques include Schlumberger resistivity (Allis, 1990); very low-frequency (VLF) resistivity (Wynn and Luce, 1984); time-domain EM, both ground and airborne (Teal and Benavides, 2010); induced polarization (Locke and others, 1999; Fritz and others, 2011; Teal and Benavides, 2010; Bonham, 1988); self-potential (Goldie, 2002); and controlled-source audiomagnetotellurics (Irvine and Smith, 1990). Targets are either low-resistivity zones associated with sulfide-rich alteration or highly resistive zones dominated by quartz veins or silicification.

Hoschke and Sexton (2005) applied two geoelectrical techniques to evaluate the Pajingo epithermal deposit in northeastern Australia (fig. G3). Pajingo is a low-sulfidation epithermal deposit with gold mineralization occurring in thin quartz veins and associated silicified wall rocks. Quartz-rich rocks like these typically coincide with anomalously high electrical resistivity. Veins at Pajingo are hosted by Paleozoic intermediate composition intrusions, lavas, and volcaniclastic rocks overlain by Tertiary sedimentary deposits. Gradient-array resistivity surveys began in the $1980 \mathrm{~s}$, culminating with 3,500-4,500 km of gradient-array resistivity data measured along lines spaced $40 \mathrm{~m}$ apart (Hoschke and Sexton, 2005). Electrical resistivities over mineralized quartz veins (fig. G3A) were found to be an order of magnitude higher than average background resistivities (Hoschke and Sexton, 2005). Dipole-dipole resistivity profiles provide a three-dimensional view of mineralization and depict the relation between electrical resistivity and quartz veining (fig. G3 $B$; Hoschke and Sexton, 2005).

Natural-source magnetotelluric surveys offer the potential to reveal large-scale structures, but field testing in the Hauraki Goldfield of New Zealand showed that this method can miss key faults that control the location of epithermal deposits (Walter and others, 2012). By contrast, data processing improvements have made controlled-source audiomagnetotellurics (CSAMT) a useful tool for identifying resistive zones that correspond with quartz veins and silicified alteration zones, and in many areas, CSAMT is now the electrical method of choice for epithermal deposit exploration (Walter and others, 2012).

\section{Radiometry}

Potassium, uranium, and thorium are radioactive elements that occur naturally in all rocks and soils. Modern airborne spectrometers can distinguish these and other radioactive elements, thus providing a means to map nearsurface lithologies that contain greater or lesser amounts of these elements.

The alteration that envelops intermediate-sulfidation epithermal deposits, like those at Waihi-Waitekauri, New Zealand, and Hokusatsu, Japan, can be imaged by using gamma-ray spectroscopy (Morrell and others, 2011; Feebrey and others, 1998). Gamma-ray spectroscopy can be used to delineate radioelement variations among host rocks as well as potassium enrichment that forms during hydrothermal alteration. Radiometric signals are strongly attenuated by cover, including soil and vegetation, and so potassium concentrations alone commonly reflect several parameters, including rock type, amount of cover, and intensity of hydrothermal alteration. However, potassium 
$\boldsymbol{A}$

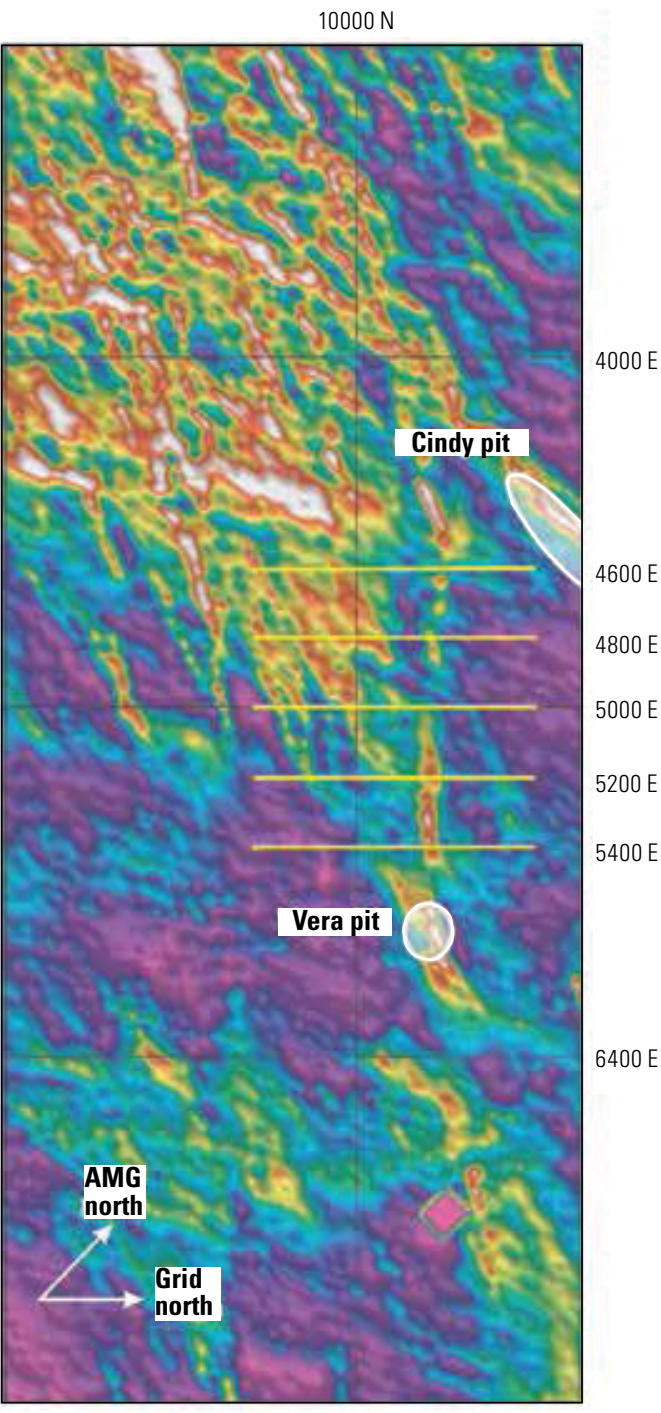

B

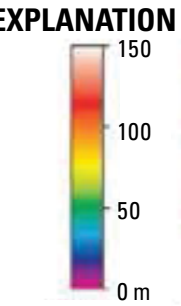

ohm-metres

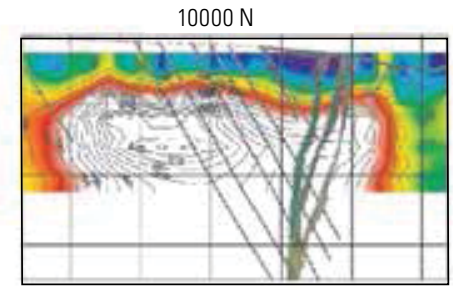

$4600 \mathrm{E}$
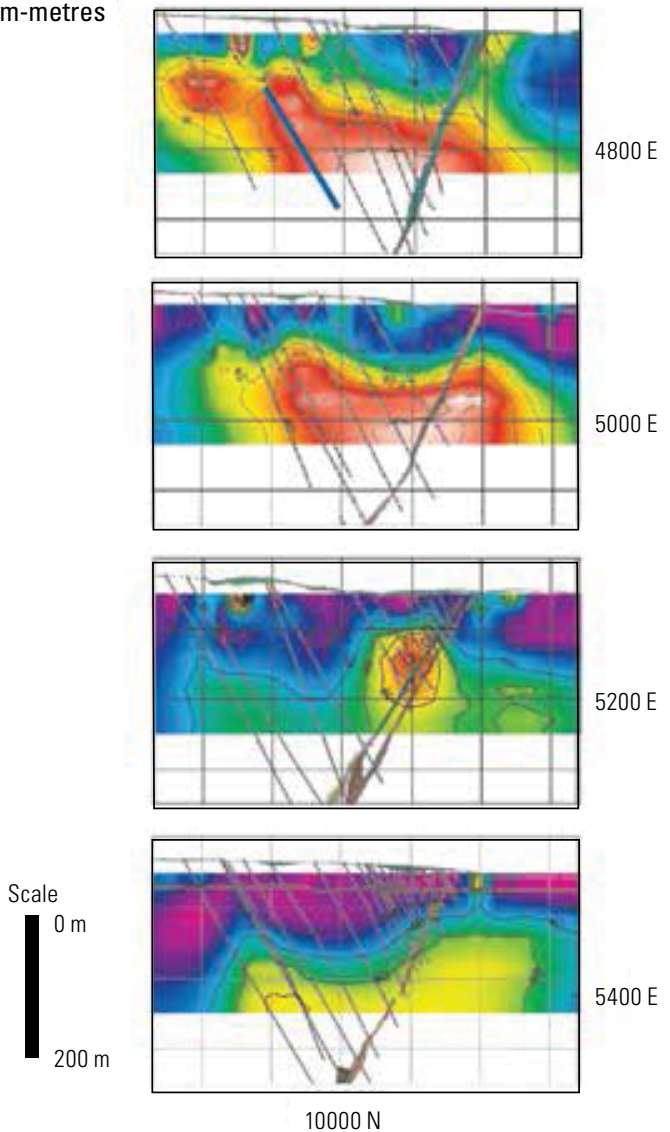

Figure G3. A, Map showing gradient-array resistivity survey of a part of the Pajingo lowsulfidation epithermal gold deposit, Australia. Gold deposits indicated by labeled ovals. Yellow lines show location of dipole-dipole profiles. $B$, Cross sections determined from 50-meter dipoledipole transects. Brown lines are quartz veins. Blue line is approximate location of mineralized vein intersected by drilling. Modified from Hoschke and Sexton (2005). and thorium generally covary with changing silica content in unaltered igneous rocks, and because thorium is commonly unaffected by hydrothermal alteration, the $\mathrm{K} / \mathrm{Th}$ ratio image may be preferred over potassium concentrations to identify potassic alteration (Dickson and Scott, 1997). The combination of airborne radiometric surveys (to map potassium enrichment) and airborne magnetic surveys (to map areas of magnetite destruction) provides a cost-effective way to rapidly locate and characterize near-surface hydrothermal systems that may contain low- or intermediatesulfidation gold-silver epithermal deposits.

The Waihi-Waitekauri region of New Zealand (fig. G4) provides an excellent example (Morrell and others, 2011) of the utility of radio element surveys. Gold-silver deposits at Waihi-Waitekauri consist predominantly of quartz veins hosted in andesite that has been affected by clay mineral formation, potassium metasomatism, magnetite destruction, and disseminated sulfide minerals. Regions of low potassium, mostly in the central and western parts of the map area (fig. G4A), correspond to areas of unaltered andesite. A broad region of high potassium in the southern part of the map area is associated with a southward thickening package of potassium-rich silicic ignimbrites. Superimposed on this broad pattern are distinct, very high potassium anomalies, including anomalies coincident with the Waihi and Wharekiraupongo deposits. Both of these potassium anomalies fall within separate regions of subdued magnetic anomalies that reflect zones of magnetite destruction (Morrell and others, 2011). The $\mathrm{K} / \mathrm{Th}$ ratio image (fig. G4B) shows attenuated signals from silicic ignimbrites in the south, but also has a pronounced high ratio associated with epithermal low- or intermediate-sulfidation veins (for example, Waihi). The broader elevated $\mathrm{K} / \mathrm{Th}$ anomalies, some of which coincide with magnetic lows (fig. G2), may reflect minor regional potassium enrichment. In sum, these radiometric data delineated local potassium enrichment in the core of hydrothermal alteration zones. 


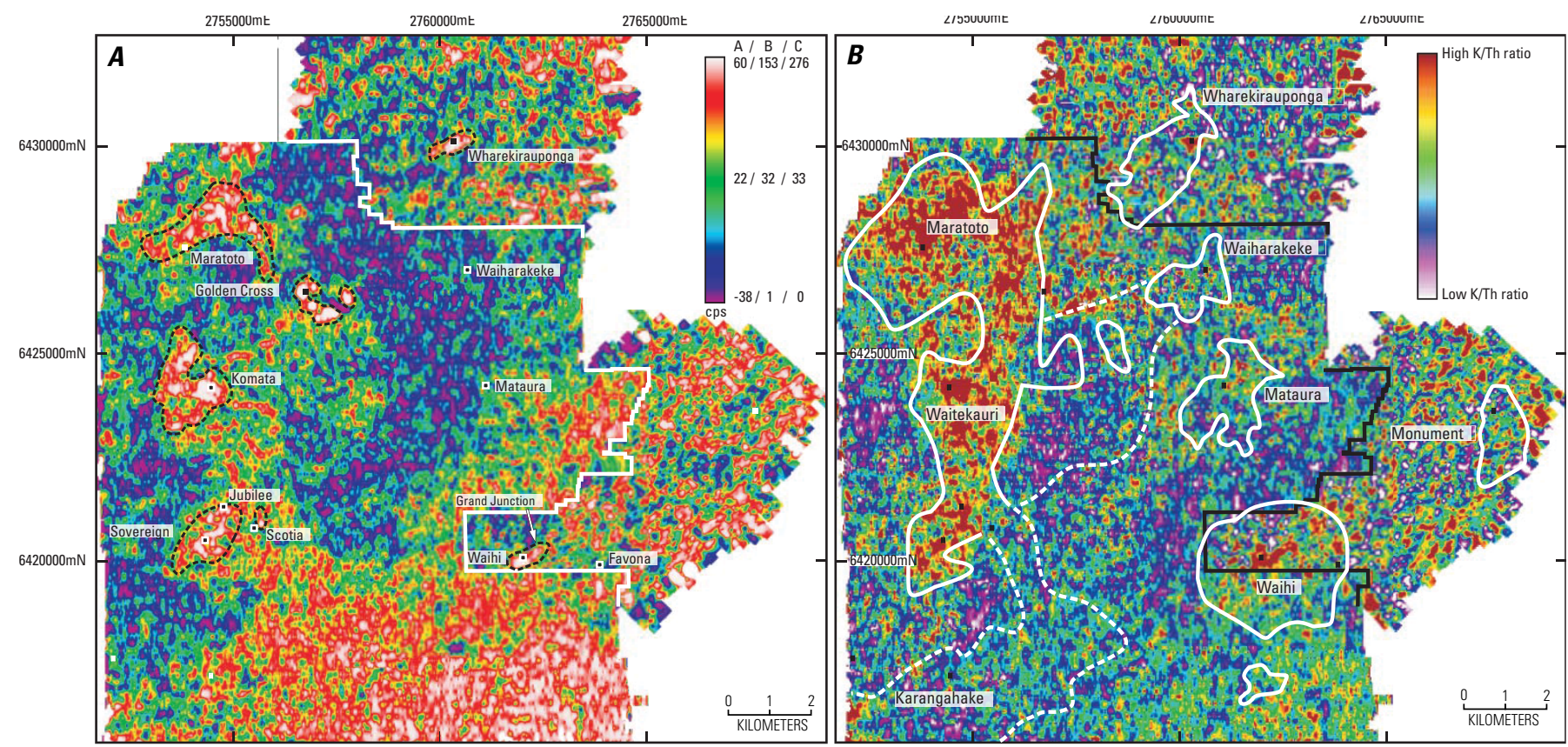

Figure G4. Maps showing potassium distribution determined from airborne radiation measurements of the Waihi-Waitekauri epithermal system. Same area as figure G2. A, Potassium count. White lines are survey boundaries (A, B, C). Warm colors indicate high potassium counts, cool colors are low potassium counts. Black dashed lines outline areas of anomalous potassium. $C p s$, counts per second. $B$, Potassium/thorium (K/Th) ratio. White lines bound areas of very low (solid lines) and subdued (dashed lines) magnetic gradients (fig. G2). Modified from Morrell and others (2011).

\section{Gravity}

In the study of epithermal gold-silver deposits, the primary application of gravity anomalies is in mapping and characterizing regional structures associated with deposits; for example, concealed basins and calderas and underlying intrusive rocks. These regional-scale applications are discussed in the next section of this chapter.

High-resolution gravity measurements provide clues useful for directly characterizing hydrothermal alteration. For example, silicification may reduce porosity, thereby increasing density. If unaltered host rocks are low in density and high in porosity, then subtle density increases resulting from mineral precipitation may be detectable in ground-based gravity measurements (Allis, 1990). In the Waihi-Waitekauri region, New Zealand, Morrell and others (2011) noted positive gravity anomalies that correlated with magnetic quiet zones. They presented a number of interpretations for this association, including the possibility of dense sulfide mineralization. Positive Bouguer gravity anomalies of the Hokusatsu region of Kyushu, Japan, also are spatially associated with epithermal gold mineralization (Feebrey and others, 1998). Most gravity highs at Hokusatsu are interpreted as basement structures in rocks that predate epithermal deposit formation, but at the Yamagano deposit of Hokusatsu, a 16-milligal (mGal) anomaly lies directly above a silicic vein system (Feebrey and others, 1998). Negative gravity anomalies also may indicate the presence of epithermal mineralization caused by increased porosity resulting from fracturing, dissolution, and leaching.

\section{Regional Studies}

Geologic structures that juxtapose rocks with differing magnetization or density produce small magnetic or gravity anomalies, respectively, that facilitate delineation of contacts even when concealed beneath vegetation, water, or sedimentary deposits. Moreover, gravity and magnetic anomaly shapes provide additional insights concerning contacts, including dip, depth extent, depth of burial, and magnitude of magnetization or density contrast. Consequently, regional geophysical studies can help define the geologic framework associated with epithermal mineral deposits.

Faults that promoted the flow of mineralizing hydrothermal fluids may produce linear magnetic anomalies that define fault trends beyond known epithermal deposits, thereby providing additional exploration targets (for example, Irvine and Smith, 1990). Magnetic anomaly magnitudes partly depend on magnetization contrast across fault contacts; faults in volcanic rocks commonly produce obvious high-amplitude magnetic anomalies in airborne magnetic surveys (for example, Blakely and others, 2011), but faults in sedimentary deposits also can be detected by using properly designed 
airborne magnetic surveys depending on the character of the sedimentary rock (for example, Sherrod and others, 2008; Grauch, 2001). Linear gravity anomalies also may coincide with faults and other structures associated with mineralization. For example, known epithermal gold-silver deposits in northern Nevada tend to be proximal to gravity gradients that are assumed to be caused by deep crustal discontinuities (Ponce and Glen, 2002).

\section{Examples of regional geophysical studies}

The northern Great Basin contains many important Miocene and early Pliocene epithermal gold-silver deposits hosted by volcanic assemblages associated with two magmatic events: a bimodal (basalt-rhyolite) assemblage formed during incipient continental rifting, and an andesitic assemblage that formed during arc-related magmatism (John, 2001). Aeromagnetic maps of northern Nevada display a series of at least three, and possibly as many as six, regional-scale, arcuate, north-northwest-striking magnetic anomalies (Ponce and Glen, 2002). The easternmost and most prominent of these anomalies corresponds to middle-Miocene mafic dikes of the northern Nevada rift (Zoback and Thompson, 1978; Zoback and others, 1994; John and others, 2000). Isostatic residual gravity gradients are colinear with several of these magnetic lineaments, which suggests that all the subparallel anomalies reflect major crustal discontinuities formed during middle-Miocene rift-related magmatism or earlier. Ponce and Glen (2002) identified a statistical correlation between known Miocene and younger epithermal gold-silver deposits and deep, geophysically expressed crustal structures that may have served as conduits for hydrothermal fluids in northern Nevada (Ponce and Glen, 2002).

The strong structural controls that underlie the Yanacocha gold mining district in northern Peru, one of the largest in the world, make it particularly suited for regional geophysical investigations. Yanacocha gold deposits are aligned eastnortheastward and lie within the northwest-striking central Andean orogenic belt, where Cretaceous basement sediments have been subjected to multiple periods of northeast-directed compression in Paleocene and middle-Eocene time (Teal and Benavides, 2010). Yanacocha gold deposits are hosted by a Miocene andesitedacite volcanic complex that lies within and subparallel to the northwest-trending orogenic belt (Longo and others, 2010). The east-northeast strike of the Yanacocha gold deposits is interpreted as indicating a trans-arc crustal break, known as the ChicamaYanacocha structural corridor (Turner, 1997).
Regional geophysical investigations, including electromagnetic, magnetic, gravity, and radiometric surveys, have contributed to integrated studies of Yanacocha since the earliest stages of exploration (Teal and Benavides, 2010). The entire district is encompassed by a broad region of subdued, relatively low-amplitude magnetic anomalies (fig. G5A) that corresponds with the mapped extent of alteration and is probably caused by magnetite destruction (Teal and Benavides, 2010). The subduedanomaly region is crossed by a pronounced, northeast-striking alignment of positive magnetic anomalies (fig. G5A) apparently caused by porphyry intrusions beneath the volcanic section and along the trans-arc crustal break. Radiometric potassium response also exhibits a broad relative low over the entire district, reflecting destruction of potassium feldspar within the envelope of advanced argillic alteration (Teal and Benavides, 2010). Geophysical methods have also contributed to deposit-scale exploration of the Yanacocha district, notably induced polarization and ground- and airborne time-domain electromagnetic (TDEM) surveys. Massive vuggy quartz bodies host the gold mineralization and generally serve as resistivity targets, displaying pronounced resistivity highs in airborne electromagnetic surveys (fig. G5B; Teal and Benavides, 2010).

An application of gravity and magnetic data to delineate the structural framework of the Goldfield mining district is shown in figure G6. The Goldfield deposit is hosted in calc-alkaline volcanic rocks of the Basin and Range Province of southwestern Nevada. With 4.2 Moz gold recovered, Goldfield ranks as the largest known high-sulfidation gold-silver deposit in North America. Transverse deformation between overlapping strike-slip faults probably localized Goldfield mineralization, with faults and fractures providing channels for hydrothermal fluid flow (Ashley, 1990a; Berger and others, 2005). Alteration at Goldfield is concentrated in a broad zone of northwest-striking strike-slip faults and north- to northeast-striking normal faults. High-resolution aeromagnetic anomalies are aligned along many of these faults (fig. G6) and suggest continuation of fault segments beyond their mapped extent. A prominent, narrow, west-northwest-striking zone of faults and fractures corresponds to a discontinuous magnetic anomaly low (fig. G6D) and extends east-southeast from the main ore body for a distance of at least 8 to $10 \mathrm{~km}$. Broad positive gravity and magnetic anomalies coincide with the district and together may indicate the presences of a pluton in the shallow subsurface; magmatic-hydrothermal fluids released during emplacement and crystallization of this pluton are likely responsible for hydrothermal alteration and ore mineralization in the district (Blakely and others, 2007). 
A

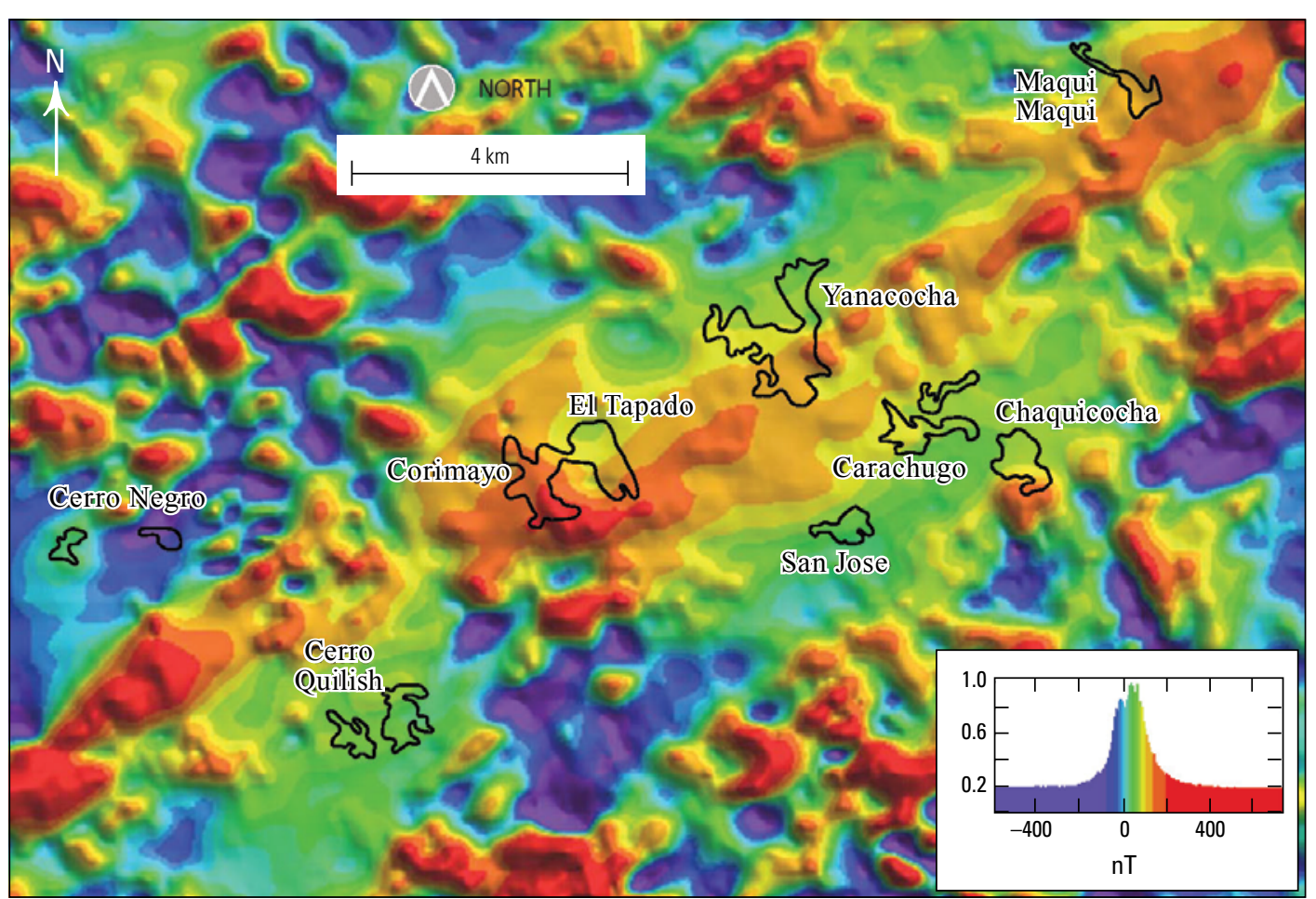

B

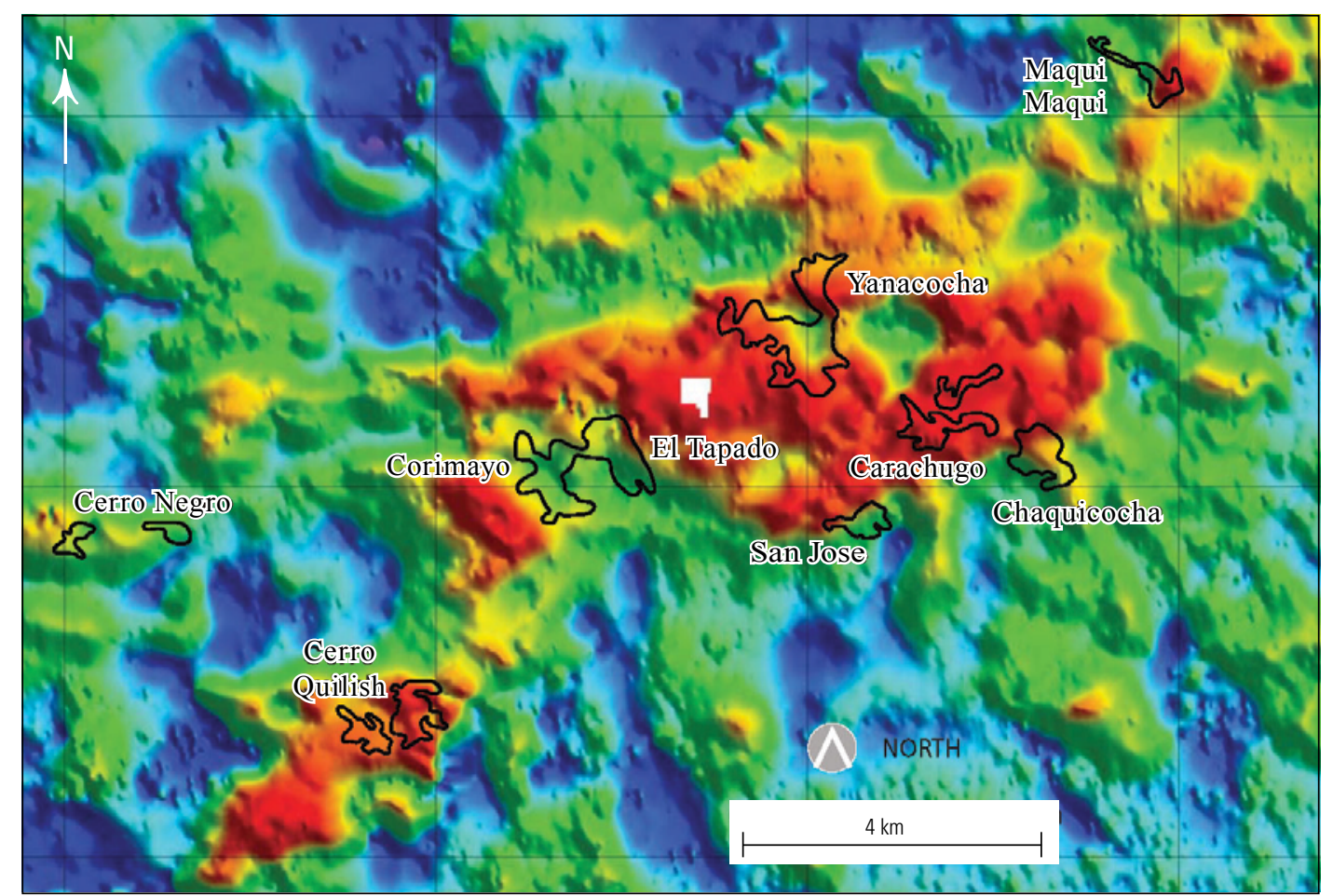

EXPLANATION

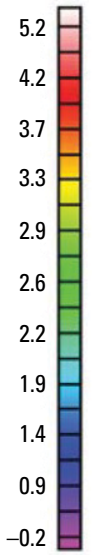

log ohm-m

Figure G5. Maps of the Yanacocha gold district, Peru. A, Aeromagnetic anomalies, reduced to the pole. Black lines indicate gold-deposit footprints. Inset figure is an equal-area histogram of magnetic anomaly intensity in nanoteslas. $B$, Airborne time-domain electromagnetic anomalies, continued upward. Modified from Teal and Benavides (2010). 


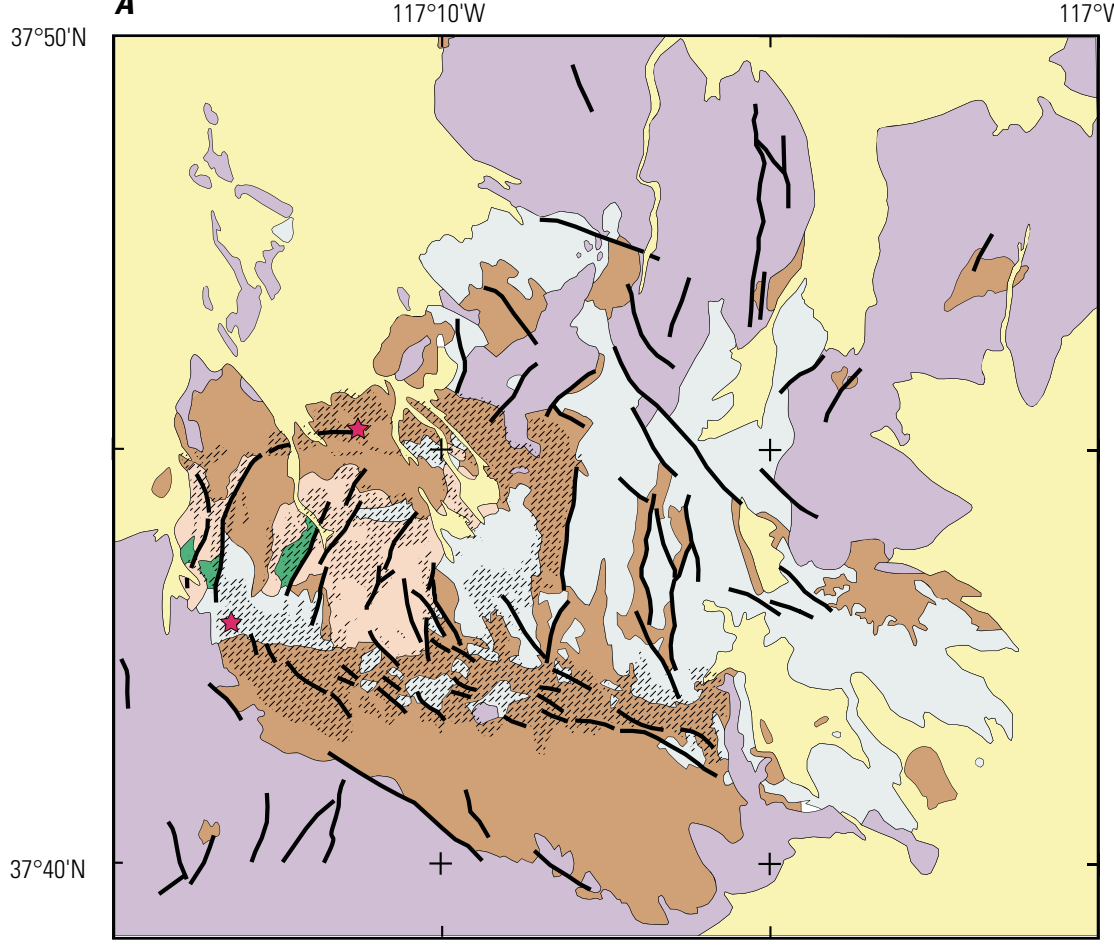

\section{EXPLANATION}

Quaternary alluvium

Basalt, tuff, rhyolite (upper and middle Miocene)

Porphyritic rhyodacite, rhyolite domes and flows (lower Miocene)

\section{Intermediate lavas (lower Miocene)}

Silicic flows and tuffs (Oligocene)

Jurassic quartz monzonite and Palmetto Formation (Ordovician)

Altered zones

Main ore-bearing zones

B

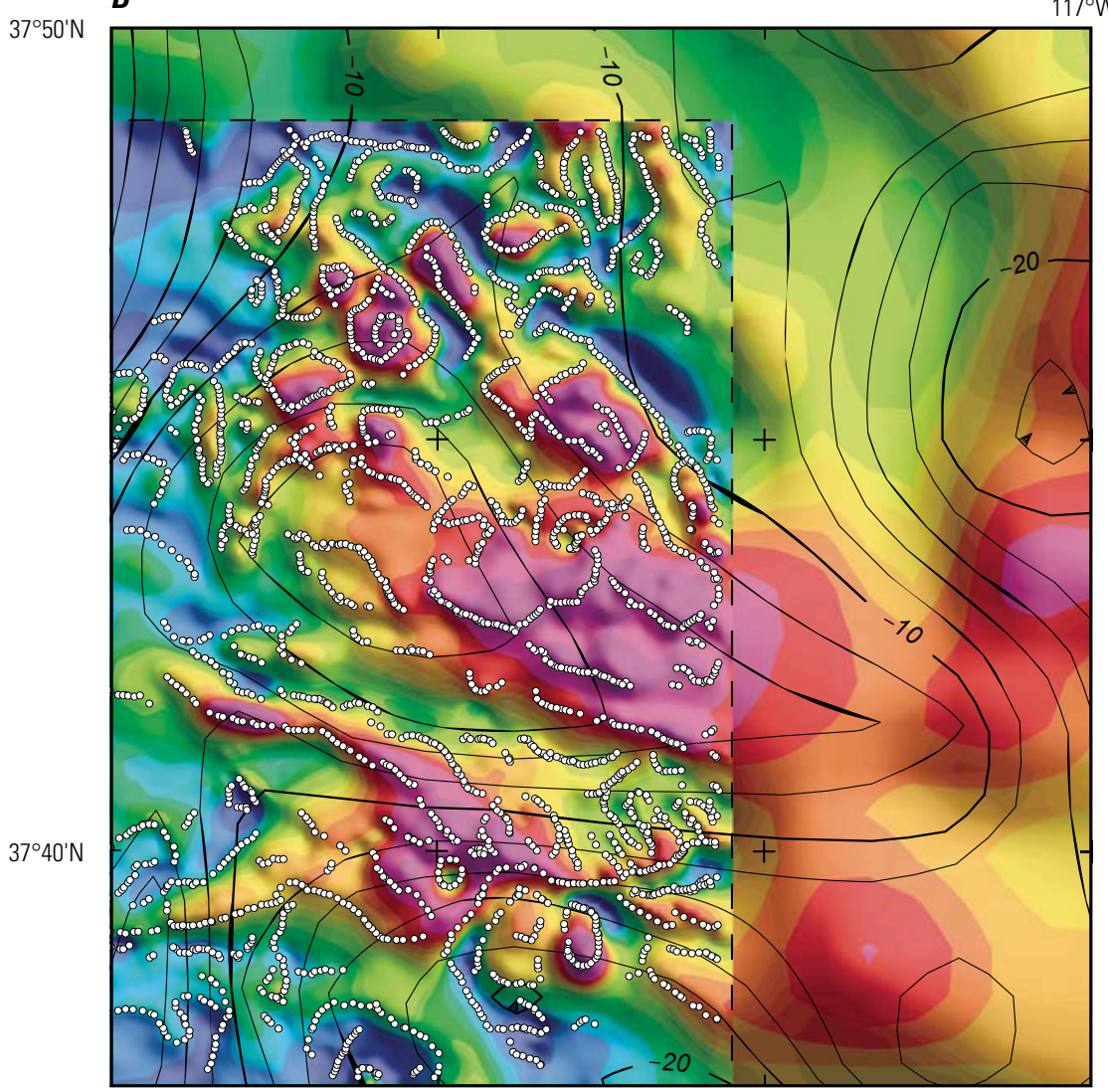

\section{EXPLANATION}

Magnetic intensity, $\mathrm{nT}$

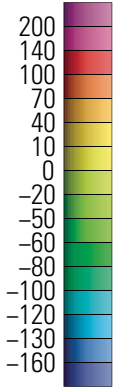

Magnetization boundaries

- -10 - Gravity contour

Figure G6. Geologic and aeromagnetic maps of the Goldfield mining district, Nevada. A, Geologic map of the Goldfield mining district, from Blakely and others (2007) as modified from Ashley (1990a). Stipple pattern indicates zones of alteration. $B$, Aeromagnetic anomalies, shown as color-shaded relief, and gravity anomalies, show as line contours. Gravity contour interval, 2 milligal (mGal). Two aeromagnetic surveys are shown, separated by dashed black line. White dots are computer-generated interpretations of magnetic contacts. Modified from Blakely and others (2007). 



\title{
Chapter H. Spectral Remote Sensing of Epithermal Mineral Deposits
}

\author{
By Barnaby W. Rockwell
}

\section{Introduction}

Exposed epithermal gold-silver deposits are ideal for detection and surface characterization by using spectral remotesensing data, because host rocks are commonly enriched in hydrothermal minerals that have diagnostic absorption features in the visible (VIS), near-infrared (NIR), shortwave-infrared (SWIR), and thermal infrared (TIR) regions of the electromagnetic spectrum. The surficial mineralogic expression of epithermal deposits is directly related to the spatial and spectral resolution of the data being analyzed, in addition to deposit type, surface disturbances caused by mining activity, exposure related to terrain and vegetation, and the extent of deposit exhumation and weathering. Multispectral data collected by the Landsat satellites can be used to identify zones of hydrothermally altered rocks at regional scales. Data acquired by the Advanced Spaceborne Thermal Emission and Reflection Radiometer (ASTER) sensor include additional spectral bands, which permit mineralogical differentiation of various alteration types, carbonate minerals, and high concentrations of quartz. Spectroscopic or "hyperspectral" data acquired by airborne imaging spectrometers typically have more than one hundred spectral bands that allow accurate identification of specific minerals and mineral mixtures, and generation of detailed mineral maps that can be used to delineate patterns of mineral zonation surrounding permeable structures and other target features. Field-portable and laboratory spectrometers, including core-scanning devices, provide the most detailed spectral information available and are commonly used tools for alteration mineral identification, although spatial patterns of mineral zonation are difficult and time consuming to delineate. New portable imaging devices designed to acquire hyperspectral data of outcrops and open-pit mine walls are becoming more widely used tools for mineral zonation mapping. This chapter reviews types of remote-sensing data, their capabilities and limitations, and presents some examples of spectral characterization of epithermal goldsilver deposits by using remote-sensing data.

\section{Remote-Sensing Data Types}

At district and regional scales, broadband Landsat Thematic Mapper (TM) data can be used to identify hydrothermally altered rocks containing anomalous concentrations of phyllosilicate and (or) sulfate minerals (Rockwell, 2013; Rockwell and Bonham, 2013). These altered rocks can be subdivided spatially on the basis of presence and abundance of ferric and (or) ferrous iron minerals that can occur with phyllosilicate and sulfate minerals common in the halos of altered rock surrounding faults, fractures, and other conduits of hydrothermal fluids. Landsat data analysis has been used for decades as a mineral exploration tool (Ashley and others, 1979; Segal and Rowan, 1989), and has been applied successfully to exploration programs for epithermal gold deposits in Patagonia, Argentina (Crosta and others, 2009), and many other locations, mostly in arid and semiarid climates with minimal vegetative cover.

ASTER VIS, NIR, and SWIR data allow identification of illite and muscovite (aluminum versus iron-magnesiumrich); kandite clays (kaolinite, dickite, halloysite); smectite (montmorillonite); alunite, pyrophyllite, dolomite, propylitic alteration minerals (such as calcite, epidote, and chlorite); opaline and chalcedonic silica having SWIR absorptions near $2.20 \mu \mathrm{m}$ related to -OH and (or) Si-OH bending; and undifferentiated ferric and ferrous iron minerals (Rowan and others, 2003; Rockwell and others, 2006; Rockwell, 2009; Rockwell, 2010; Rockwell, 2012; Crosta and others, 2009; Pour and Hashim, 2012; Mars, 2013). Direct spectral matching of ASTER SWIR data to reference reflectance spectra of mineral mixtures (for example, kaolinite and illite, alunite and kaolinite, calcite and illite or smectite) can produce detailed maps that depict alteration mineral zonation associated with epithermal deposits (Rockwell, 2009). ASTER data have a ground spatial resolution of $15 \mathrm{~m}$ per pixel in the VIS-NIR (bands 1-3), $30 \mathrm{~m}$ per pixel in the SWIR (bands 4-9), and $90 \mathrm{~m}$ per pixel in the thermal infrared band (TIR). Quartz concentrations in sinters (most commonly found in well-preserved low-sulfidation systems) and hydrothermal quartz (common in high-sulfidation systems and in phyllic alteration assemblages) can be identified by using ASTER TIR data (Rockwell and Hofstra, 2008; Rockwell, 2010). Rockwell and Bonham (2013) present results derived from TIR data that portray quartz distribution in the Hasbrouck Mountain, Tonopah, and Divide, Nevada, low- and intermediate-sulfidation deposits and in the Goldfield and Gemfield, Nevada, high-sulfidation deposits. Relict sinter at Hasbrouck Mountain is well preserved and is associated with a prominent quartz response in the TIR, which distinguishes it from other lithologically similar outcrops in the area; older, chalcedonic sinter interbedded in variably altered tuffaceous sedimentary rocks and related colluvium shed to the southwest was clearly identified by using TIR data, and younger, opaline sinter atop Hasbrouck Mountain was identified as hydrous silica by using SWIR data (fig. H1).

Airborne hyperspectral sensors, such as Airborne Visible/Infrared Imaging Spectrometer (AVIRIS), collect image data that provide continuous, high-resolution coverage over the VIS, NIR, and SWIR spectral regions, and have varying spatial resolution (ground pixel size) depending on 
A. True-color satellite image

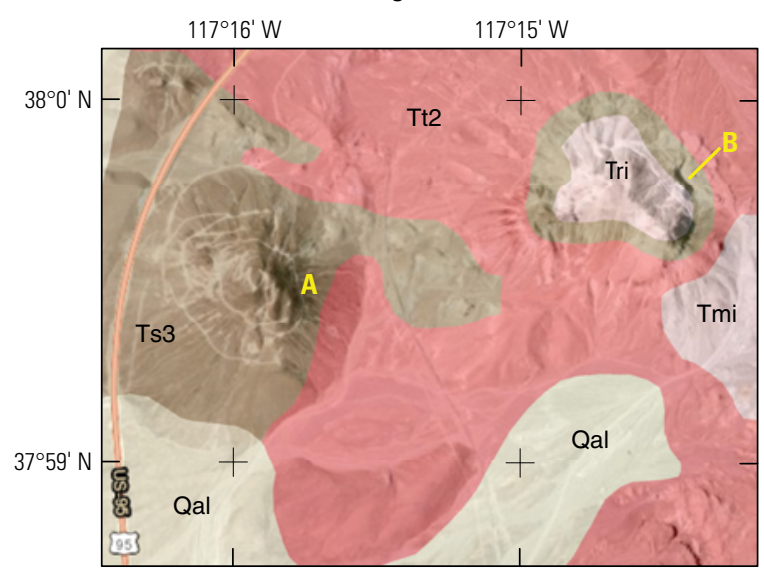

EXPLANATION

Lithologic units

Qal Quaternary alluvium

Ts3 Middle Miocene tuffaceous sedimentary rocks (conglomerates, siltstones, sandstones, and interbedded tuffs of Siebert Formation)

Tt2 Miocene intermediate silicic ash flow tuff

Tri Miocene rhyolitic intrusive rocks

Tmi Miocene mafic phaneritic intrusive rocks

\section{ASTER SWIR map}

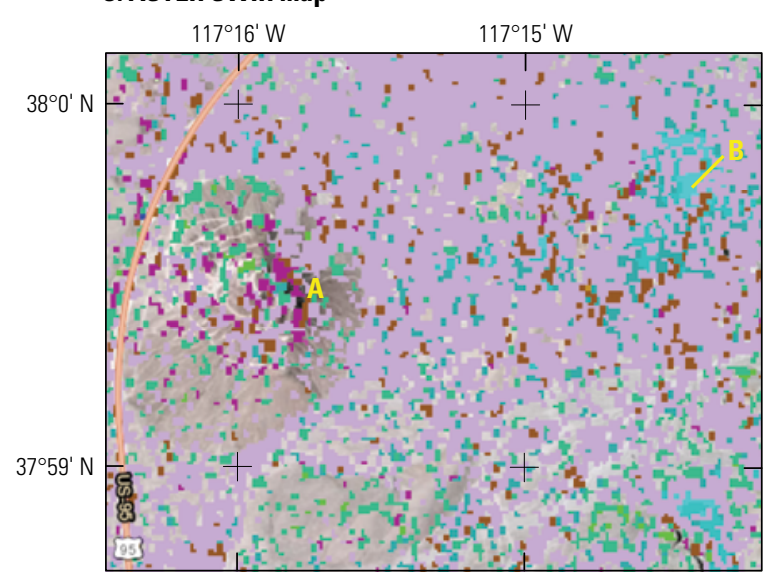

B. ASTER TIR map

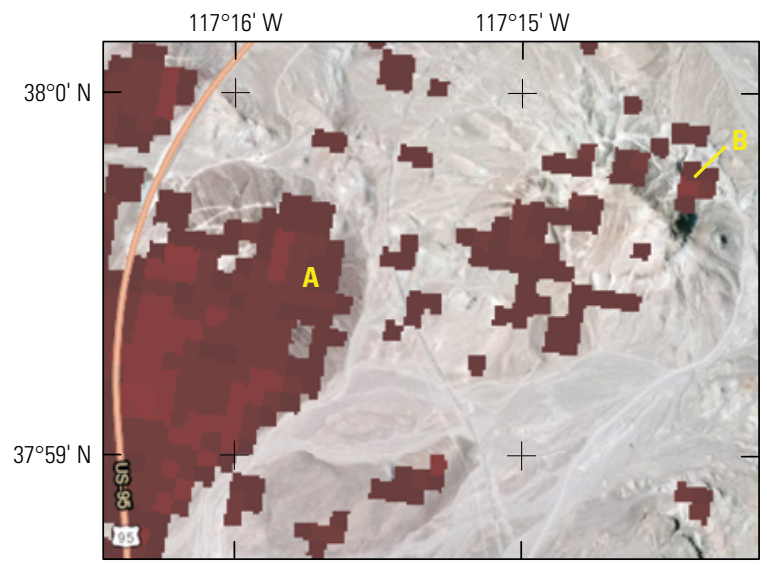

EXPLANATION

Relative quartz abundance
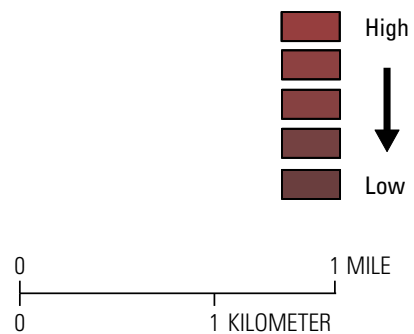

\section{EXPLANATION}

Maximum fit $x$ depth ( $\approx$ abundance)

Al sericite ( \pm kaolinite)

Minimum fit $x$ depth ( $\approx$ abundance)

Calcite

Calcite (or chloride/epidote)+sericite (or smectite)

Chlorite (Mg-OH SWIR+ferrous/ferric iron absorptions)

Epidote, or calcite+dolomite mixture

$\mathrm{Fe} / \mathrm{Mg}$ sericite or muscovite+chlorite mixture

Jarosite \pm gypsum, or ferric iron+opal/chalcedony

Kaolinite \pm smectite (typically supergene)

Opal and (or) chalcedony

Smectite (montmorillonite) or low-abundance sercite

Figure H1. Advanced Spaceborne Thermal Emission and Reflection Radiometer (ASTER)-derived mineral maps of the Hasbrouck Mountain and Divide low-sulfidation deposits located about 9 kilometers $(\mathrm{km})$ south-southwest of Tonopah, Nevada. $A$, High-resolution, true-color satellite image showing drilling roads on Hasbrouck Mountain $(A)$ and mine workings at Divide deposit (B) overlain by translucent lithologic map (Crafford, 2007). $B$, Map of quartz abundance derived from thermal infrared (TIR) data analysis (Rockwell and Hofstra, 2008). Lighter shades of red indicate higher quartz abundance in variably altered bedrock of Hasbrouck Mountain (see lithologic map in $A$ ) in contrast with related alluvium shed from the mountain. Alluvium with detected quartz extends southwestward from the mountain nearly $6.5 \mathrm{~km}$ into the Big Wash/Alkali Lake basin (Rockwell and Bonham, 2013). Pixels in which quartz was not detected are transparent. C, Mineral map from shortwave-infrared (SWIR) data analysis (Rockwell, 2009). Note identification of opaline silica(shown in purple on map, opal and (or) chalcedony) near top of mountain based on curve fitting over Si-OH feature between 2.20 and 2.27 micrometers, and quartz-sericite in mine waste rock of Divide deposit. Scattered occurrences of calcite (or chlorite) \pm sericite, most likely related to weak propylitic alteration, were detected on the lower slopes of Hasbrouck Mountain. Small exposures of undifferentiated ferric iron minerals were detected at Hasbrouck Mountain and Divide deposit by using ASTER visible (VIS)-near-infrared (NIR) data. Also, note occurrence of smectite (local, brown) and muscovite-chlorite (widespread, light purple). Argillic alteration with illite-kaolinite is absent except in the immediate vicinity of the mines at the Divide deposit $(B)$, in strong contrast with the large argillic halos typically observed in high-sulfidation deposits. Satellite image from ESRI Corp. (ESRI_Imagery_World_2D, http://services.arcgisonline.com/arcgis/services, 2013, available from within ArcGIS). 
the altitude at which the aircraft was flown. Spectroscopic analysis of these data can identify a wide variety of minerals and mineral mixtures and yield very detailed maps that show the distribution of mineral assemblages on the Earth's surface (for example, Rockwell and others, 2005, 2006; Swayze and others, 2014). Such maps provide a synoptic view of surface mineralogy that would be time consuming to generate by using hand samples and field spectrometers, and can be of significant utility in vectoring towards zones of high fluid flow (typically along faults, fractures, and permeable lithologies) and other prospective targets. The value of these maps for vectoring is enhanced when mineral mixtures are included in the analysis, and identified minerals and (or) mixtures are subdivided into classes on the basis of relative abundances. Abundances of particular minerals and mineral mixtures can be inferred from the degree of spectral curve fit to reference spectra and the depth of diagnostic absorption features, although mineral grain size also affects spectral shape and feature depth (Clark, 1999). Portrayal of detected mineral gradational abundances can also help differentiate bedrock and derived alluvium, as bedrock will typically exhibit higher, less diluted mineral abundances. Hyperspectral data are also useful in identification of specific iron-bearing minerals that can occur with phyllosilicate, sulfate, and carbonate minerals in many types of mineral deposits.

Portable and laboratory spectrometers are widely used for mineral identification and for calibrating data acquired by airborne and satellite remote-sensing systems to reflectance units, enabling direct comparison of unknown spectra to libraries of mineral reflectance spectra. Altered rock spectra acquired by field spectrometers are compared with AVIRIS spectra (Rockwell and others, 2006) and ASTER spectra (Ducart and others, 2006) from high-sulfidation deposits. More recently, hyperspectral imaging devices have been developed for scanning drill core and outcrops, enabling more efficient generation of alteration mineral zonation maps. Alteration mineral spectra of the Trinity intermediate-sulfidation silver deposit in Nevada acquired by hyperspectral imaging systems at prospect (airborne overflight), outcrop (mine wall), rock chip, and drill-core scales are compared by Kruse and others (2012). Hyperspectral core scanning was used to improve three-dimensional geological and alteration modeling of the Alturas high-sulfidation epithermal gold deposit in the El Indio district of Chile by providing an efficient way to map alteration mineral zonation and develop vectors toward mineralization (Martini, 2015).

Comparisons of mineral maps derived from spectroscopic (spectral curve-fitting) analysis of AVIRIS data (having $\sim 3$-m and $\sim 17$-m spatial resolution) and ASTER data were presented over primarily steam-heated replacement alunite systems at Marysvale, Utah (Rockwell and others, 2005; Rockwell, 2009), the magmatic-hydrothermal alunite system at Goldfield, Nevada (Rockwell, 2012), and polymetallic replacement, replacement vein, and fissure vein deposits in the Tintic mining district, Utah (Rockwell and others, 2005), and are available online for interactive viewing and comparison (Rockwell and Bonham, 2013). Maps derived from analysis of higher resolution data more closely resemble mineral assemblages identified in outcrops, whereas maps from lower resolution data inherently show greater influence of spectral mixing of materials.

Some minerals characteristic of epithermal deposit subtypes, such as adularia, enargite, and diaspore (Ransome, 1907), do not have sharp, diagnostic absorption features in the VIS, NIR, and SWIR spectral regions (Clark and others, 2007), and are thus not typically detectable in remote-sensing data. Zunyite, a high-temperature mineral found in some magmatic-hydrothermal high-sulfidation deposits, such as Summitville, Colorado (in drill core), and Rodalquilar, Spain (Arribas and others, 1995a), and in higher temperature porphyry systems (Oyu Tolgoi, Mongolia, Khashgerel and others, 2009), has a variety of diagnostic spectral features that permit its accurate identification in hand sample and drill core by using portable and laboratory spectrometers. However, these minerals commonly occur along veins and fractures at abundances below the detection limit of typical spectral analysis of airborne and satellite-borne remote-sensing data.

\section{U.S. Geological Survey National Map of Surficial Mineralogy}

The U.S. Geological Survey National Map of Surficial Mineralogy (Rockwell and Bonham, 2013) is an online map resource that presents mineral maps derived from Landsat 7 Enhanced Thematic Mapper Plus (ETM+) (Rockwell, 2013) and ASTER (Rockwell, 2012) satellite data covering the western conterminous United States and locations of significant epithermal mineral deposits (modified from Long and others, 1998). More detailed mineral maps derived from spectroscopic analysis of ASTER and hyperspectral data, including HyMap and AVIRIS, over some important mining districts and mineralized areas are also included. The more detailed maps cover several significant epithermal gold-silver deposits in the western United States, including Goldfield, Gemfield, Tonopah, Divide, Hasbrouck Mountain, Florida Canyon, Borealis, and Aurora, Nevada; Summitville and Lake City, Colorado; Bodie, Patterson, and Masonic, California; and Gold Mountain (Kimberly) and Mount Baldy/Ohio districts, Utah (for detailed maps, see "Regional Studies").

The web resource can be used to compare mineral deposit expression at a variety of spatial and spectral resolutions as well as mineral mapping capabilities of different sensors. Minerals and other materials identified in a pixel can be interactively queried by using the Identify Tool. Mineral maps from the United States cited in this chapter are available for viewing in the web resource and can be compared with lithology and geologic structure maps derived from state geologic maps, high-resolution imagery, topographic maps, and hydrologic data. 


\section{Remote-Sensing Expression of Epithermal Gold- Silver Deposits}

Although the hydrothermal mineral assemblages characteristic of all epithermal deposit subtypes overlap (appendix 1; see "Hydrothermal Alteration"; Hedenquist and others, 2000), mineral maps derived from analysis of remotesensing data can provide important clues to deposit type.

High-sulfidation deposits typically have large halos of barren, argillically and advanced-argillically altered rock commonly containing alunite and kaolinite, and quartz-dickite locally along fractures; these halos grade outward from the center to illite, smectite, and chlorite, and finally, to propylitic alteration assemblages, which include chlorite, epidote, and (or) calcite (figs. H2, H3; see "Hydrothermal Alteration"). Alteration centers are typically characterized by alunite \pm pyrophyllite high in purity and abundance. Kaolinite abundances increase with distance from these centers before grading into clay-bearing mixtures (commonly illite or mixed illite-smectite). Pyrophyllite locally occurs in veins, fractures, and replacements, most commonly in alteration core zones, where it may occur with alunite (fig. H3; Rockwell and others, 2005, 2006). In some instances, pyrophyllite occurs at the periphery of altered zones along fractures in less intensely altered rock (fig. H3), and at depth, where it replaces muscovite (Khashgerel and others, 2009). Ferric iron minerals, such as hematite, goethite, and jarosite, are typically present in weathered parts of the argillic halo. However, in epithermal deposits, jarosite and goethite have supergene origins and are produced by oxidation of pyrite and other sulfide minerals in veins and wall rock, with jarosite indicating more sulfide-rich rock. Hematite may occur as a hypogene mineral in coexistence with alunite, especially magmatic steam alunite, such as at Alunite Ridge in the Marysvale volcanic field, Utah; hematite inclusions have been claimed to give the vein alunite its pinkish color (Cunningham and others, 1984; Rockwell and others, 2005; Rockwell and Bonham, 2013). Hypogene hematite has also been observed above chalky, whitish steamheated alunite near Marysvale (Cunningham and others, 1984). Hematite was identified locally with magmatic-hydrothermal alunite, such as on Preble Mountain and the Goldfield Hills near Goldfield, Nevada (figs. H3, H4). In the Goldfield Hills, hematite occurs as staining (probably derived from weathering) on resistant "ledges" of hydrothermal quartz, some of which are gold bearing, along faults and fractures. Hematite occurrences in this area identified by using AVIRIS data may represent areas of increased quartz forming local topographic highs where ledges intersect, and which indicate zones of greater hydrothermal fluid flow and greater penetration of descending waters producing supergene oxidation.

Intimate mixtures of alunite and pyrite, jarosite (after pyrite), and (or) pyrophyllite, detectable by using hyperspectral data (for example, Preble Mountain in the Goldfield district, Nevada, fig. H3, Rockwell, 2002; the Red Mountain area of the Silverton caldera, Colorado, Bove and others, 2007; the Rodalquilar high-sulfidation deposit in Spain, Arribas and others, 1995a), usually indicate a magmatic-hydrothermal origin of alunite alteration if detected minerals are coeval. Alunite and pyrophyllite locally coexist in advanced argillic envelopes surrounding quartz ledges in the Goldfield Hills. However, intergrown coarse-grained crystals of jarosite and alunite in veins on Preble Mountain (Keith and others, 1979) may indicate a hypogene origin of jarosite in an area where vein alunite resembling that of magmatic steam origin is present. In contrast, coeval alunite-smectite associations suggest a lower temperature, steam-heated alunite origin (see "Hydrothermal Alteration"). Alunite can be present at all vertical levels in high-sulfidation deposits as vein fillings and (or) wall-rock replacements, and can have either hypogene or supergene origins.

A geologic map of the Goldfield district, Nevada, showing the most productive gold-copper mining areas is shown in figure H5. Most high-grade ore was open-space filling in fractures and brecciated zones within vuggy, acidleached residual quartz alteration in areas having abundant alunite and kandite minerals. However, some rich ores were mined on McMahon Ridge in the northern part of the district from fracture zones with quartz-dickite selvages cutting rocks with less intense argillic alteration (quartz-kaoliniteillite). Alunite is absent from surface exposures in this area, suggesting that quartz-dickite assemblages should be included as an exploration target in high-sulfidation deposits. Resistant, quartz-dickite selvages were also mined for polymetallic vein deposits of silver, copper, and lead at the Showers mine, $500 \mathrm{~m}$ from alunite-pyrophyllite alteration in the Treasure Hill area of the Main Tintic Mining district, Utah (Rockwell and others, 2005; Rockwell and Bonham, 2013).

Figure H2. Preliminary Advanced Spaceborne Thermal Emission and Reflection Radiometer (ASTER)-derived shortwave-infrared (SWIR) mineral map of the Yanacocha high-sulfidation deposit located 20 kilometers $(\mathrm{km})$ north of Cajamarca, Peru. Results have not been field verified. ASTER data acquired on September 15, 2003. A, ASTER 431/RGB color composite showing mine development. Green vegetation is shown in shades of green. Reddish color indicates concentrations of ferric iron minerals in open pits. $B$, Mineral map from spectral curve-fitting analysis of ASTER SWIR data (Rockwell, 2009). Note extensive quartz-alunite-kaolinite alteration and local exposures of jarosite in pyritic waste rock indicating potential non-point sources of acid rock drainage. Inset map (Teal and Benavides, 2010) shows gold deposits in the Yanacocha area in red and alteration halo in orange within undifferentiated Tertiary volcanic rocks (light yellow). Undifferentiated Tertiary intrusive rocks to the northeast are shown in pink; solid black lines are geologic contacts; solid and dashed purple lines are known and inferred faults, respectively. Mineral exposures related to advanced argillic alteration are primarily limited to areas disturbed by mining activity because of vegetation and alluvial cover. 

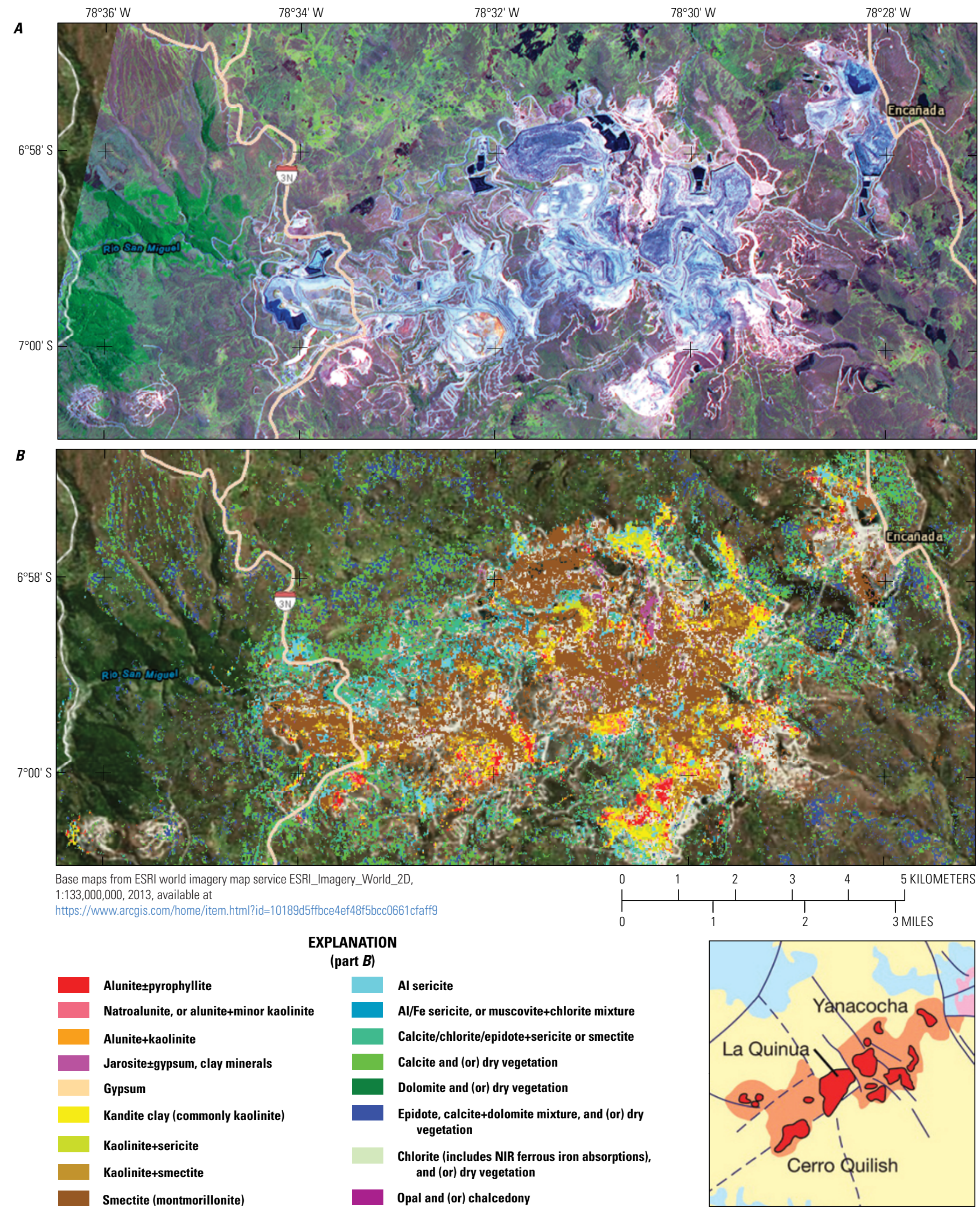


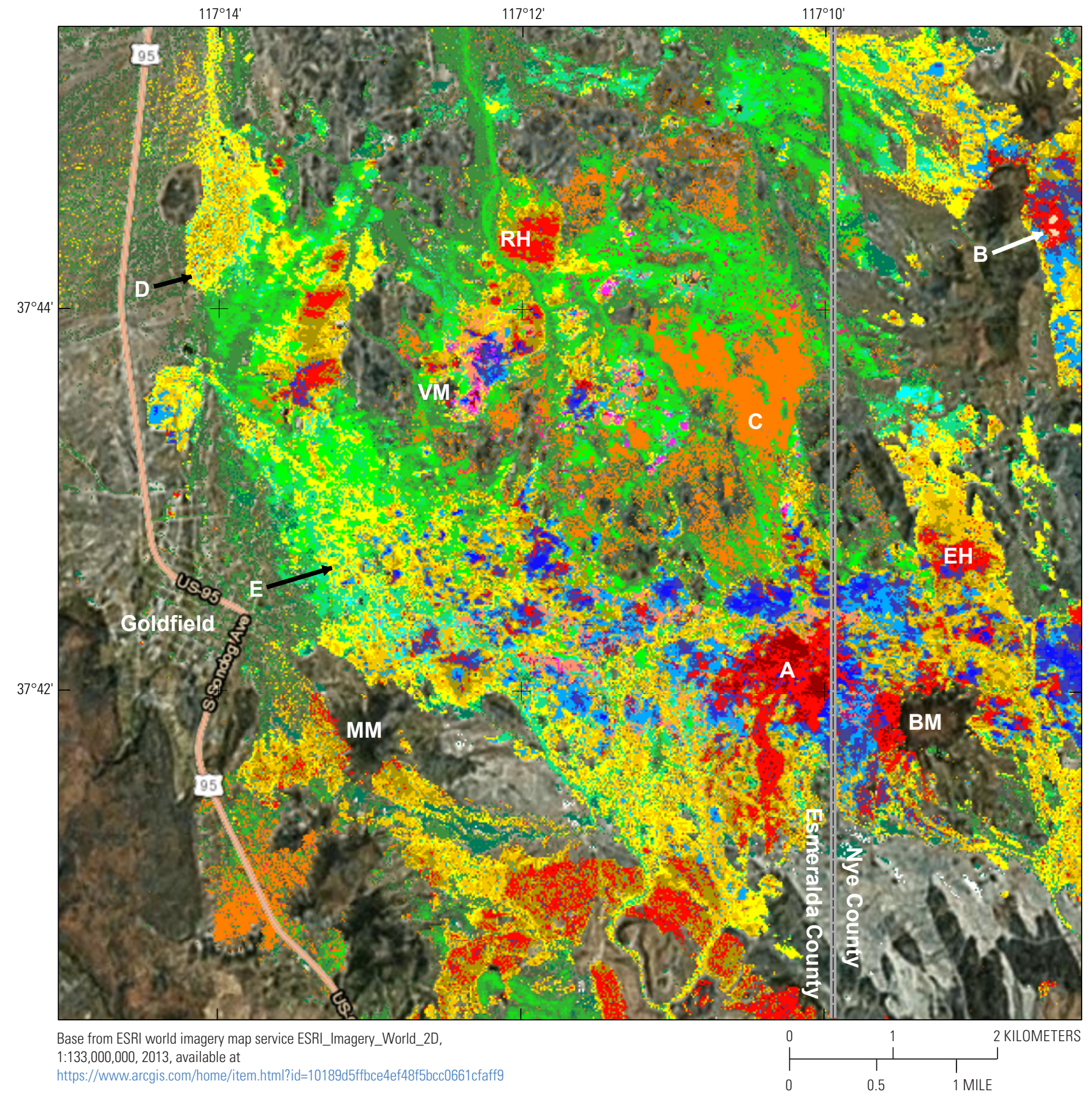




\begin{tabular}{|c|c|}
\hline \multicolumn{2}{|c|}{ EXPLANATION } \\
\hline Alunite \pm minor kaolinite \pm minor jarosite & Kaolinite $\mathbf{7 5} \%$ +alunite $\mathbf{2 5} \%$ areal mix \\
\hline Alunite+pyrophyllite \pm jarosite & Kaolinite and (or) halloysite \\
\hline Jarosite & Dickite \\
\hline Alunite, intermediate $\mathrm{Na} / \mathrm{K}$ composition, or & Kaolinite \pm smectite \\
\hline $\begin{array}{l}\text { alunite/natroalunite areal mix (high to } \\
\text { low fit } x \text { depth) }\end{array}$ & Smectite (montmorillonite) \\
\hline Natroalunite & Chalcedony (mainly in tuffaceous units), or opal \\
\hline Natroalunite+kaolinite & Weak argillic (sericite) and propylitic alteration \\
\hline Natroalunite \pm dickite, other clays & Sericite \pm kaolinite (high to low fit $x$ depth) \\
\hline Pyrophyllite & High-Al sericite \\
\hline Kaolinite+pyrophyllite & Low-Al sericite or muscovite+chlorite mixture \\
\hline Pyrophyllite+sericite & Calcite \\
\hline Alunite/natroalunite+pyrophyllite \pm sericite & Calcite+sericite \\
\hline Alunite+kaolinite \pm sericite & Epidote \\
\hline
\end{tabular}

Figure H3. Map of the high-sulfidation deposits in the Goldfield, Nevada, area showing surface distribution of minerals produced from analysis of 1998 high-altitude Airborne Visible/Infrared Imaging Spectrometer (AVIRIS) remote-sensing data having a ground spatial resolution of $\sim 17$ meters (m) per pixel (Rockwell, 2012; Rockwell and Bonham, 2013). Spectral analysis of AVIRIS data was performed by using methodologies described by Rockwell $(2002)$ and Rockwell and others $(2005,2006)$. Map shows phyllosilicates, sulfate, carbonate, sorosilicate, and hydrous silica minerals produced from analysis of AVIRIS near-infrared (NIR) and shortwave-infrared (SWIR) data. Two mineral assemblages have been subdivided relative to spectral fit $x$ depth of the results, which is the degree of least-squares curve correspondence of image spectrum to reference spectrum over one or more diagnostic absorption features multiplied by the depth of the feature(s). Fit $x$ depth is roughly equivalent to abundance of identified mineral assemblage given constant grain size, with high fit $x$ depth values correlating with higher abundance (and detection confidence) of the assemblage. Abbreviations: $A$, Preble Mountain volcanic center; $B$, jarosite in mainly undisturbed quartz-alunite alteration also detected by analysis of Advanced Spaceborne Thermal Emission and Reflection Radiometer (ASTER) data (Rockwell, 2012); BM, Blackcap Mountain; C, muscovite-chlorite in weakly propylitized quartz latite tuffs and lapilli tuffs; D, tailings deposits from Consolidated 100-stamp mill; E, main mining area; EH, Espina Hill; MM, Myers Mountain; RH, Ruby Hills; VM, Vindicator Mountain. The Goldfield Hills extend eastward from E to Preble Mountain $(A)$ and beyond. Satellite image from ESRI Corp. (ESRI_Imagery_World_2D, http://services.arcgisonline.com/arcgis/services, 2013, available from within ArcGIS). 


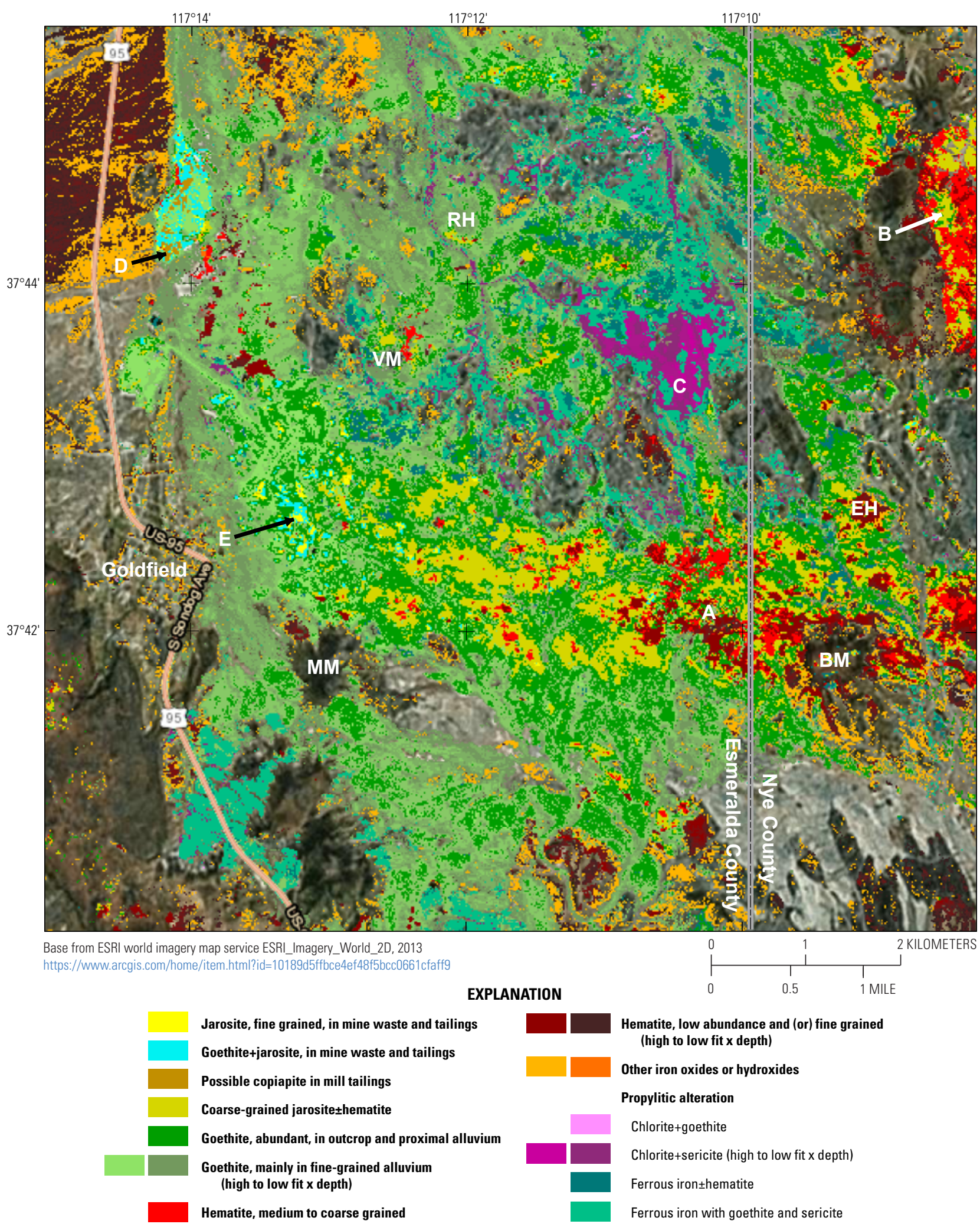

Figure H4. Map of iron-bearing minerals produced from analysis of Airborne Visible/Infrared Imaging Spectrometer (AVIRIS) visible (VIS) and near-infrared (NIR) data. Fine-grained jarosite coatings (yellow) and jarosite+goethite (cyan) were only detected in pyritic mine waste rock and mill tailings. Abbreviations: A, Preble Mountain; B, jarosite in mainly undisturbed, quartz-alunite alteration also detected using AVIRIS shortwave-infrared (SWIR) data (fig. G3); BM, Blackcap Mountain; C, weakly propylitized quartz latite tuffs and lapilli tuffs. Note detection of ferrous iron in the muscovitechlorite mixture (fig. G3); D, tailings deposits from mill containing the iron-sulfate minerals jarosite and possible copiapite; $\mathrm{E}$, main mining area; $\mathrm{EH}$, Espina Hill; MM, Myers Mountain; RH, Ruby Hills; VM, Vindicator Mountain. Satellite image from ESRI Corp. (ESRI_Imagery_World_2D, http://services. arcgisonline.com/arcgis/services, 2013, available from within ArcGIS) 

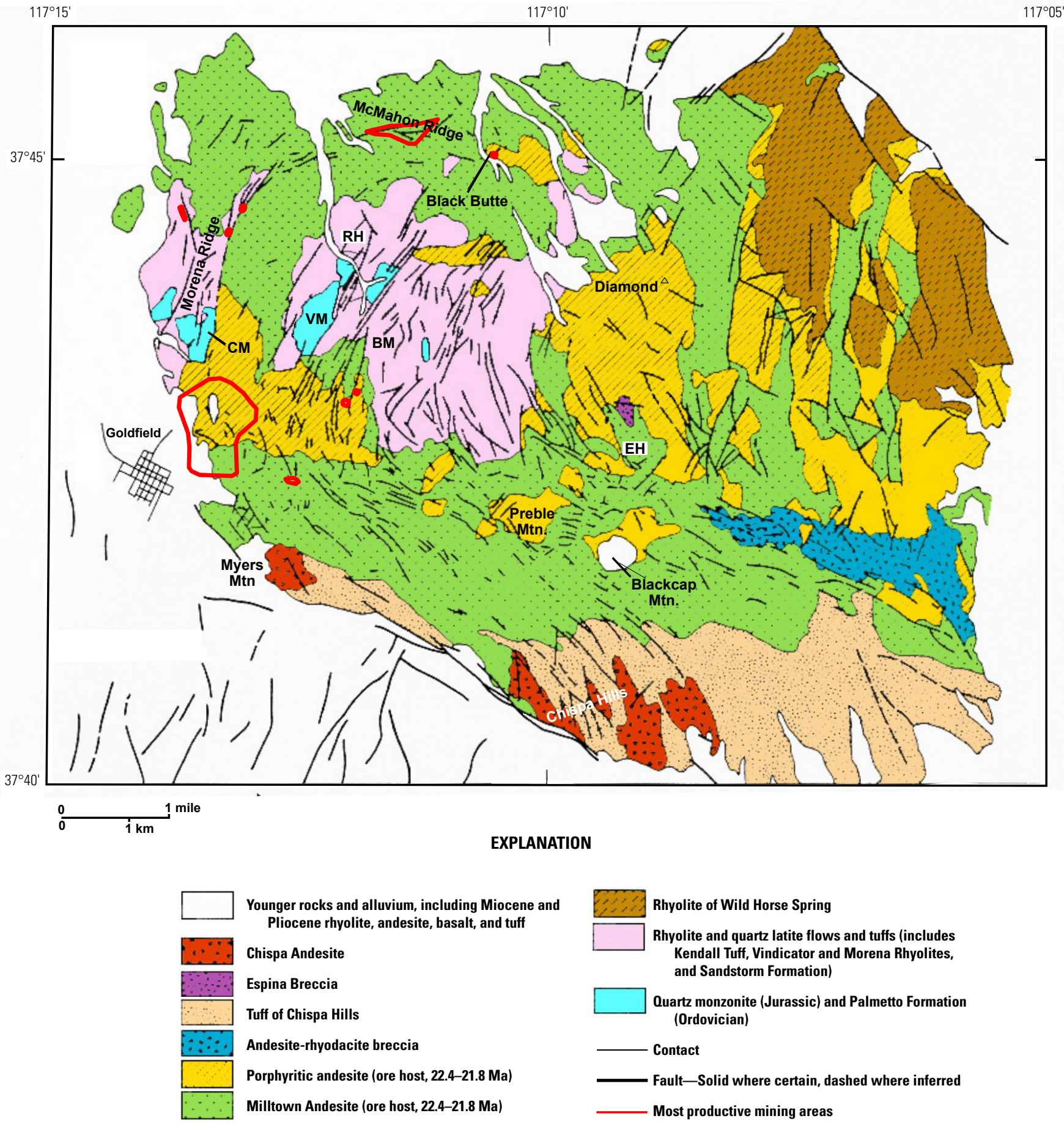

Figure H5. Geologic map of the Goldfield district, Nevada, adapted from Ashley and Keith (1976). Tertiary volcanic rocks range in age from early Miocene to early Pliocene. Abbreviations: BM, Banner Mountain; CM, Columbia Mountain; EH, Espina Hill; RH, Ruby Hills; VM, Vindicator Mountain. 
Deposit exhumation depth can have profound effects on present-day surface mineralogical expression. Rockwell and others (2005) and Cunningham and others (2005) showed that deep erosion along the Marysvale River exposed the underlying pyritic, phyllically altered feeder zone of the Miocene steam-heated alunite system at Big Rock Candy Mountain in the Marysvale volcanic field, Utah. Alunite is exposed only in subhorizontal cliffs at the top of Big Rock Candy Mountain near the paleowater table level. Where the present ground surface is near that of the paleowater table, such as at the nearby coeval White Horse alunite deposit, the feeder zone, with distinctive supergene natrojarosite (after pyrite), kaolinite, illite, smectite, and gypsum, is mostly unexposed (Rockwell and others, 2006).

In low- and intermediate-sulfidation deposits not substantially affected by overprinting associated with fluctuations in the paleowater table, hypogene alunite and kaolinite are present only in steam-heated alteration formed near the paleowater table at the upper levels of deposits (Hedenquist and others, 2000; see "Hydrothermal Alteration"). As such, hypogene, kaolinite-rich argillic alteration halos typically have smaller areal footprints in low- and intermediate-sulfidation deposits than in high-sulfidation deposits, especially when the upper parts of the hydrothermal system have been removed by deep erosion. For example, the deposit at Bodie, California, has a spatially limited, illite-, smectite-, and quartz-dominated expression as determined from analysis of ASTER data (Rockwell, 2010). Steam-heated alunite-kaolinite+jarosite (after pyrite) alteration in the upper part of the Buckskin Mountain deposit in Nevada is well preserved, and is clearly identifiable by automated analysis of ASTER data (Rockwell and Bonham, 2013; Rye and others, 1992; Vikre, 2007).

Typically, the largest volume of altered rock in low- and intermediate-sulfidation systems consists of smectite and (or) mixed-layer illite-smectite that grades progressively outward to chlorite and then propylitic alteration that may have formed earlier in deeper, higher temperature conditions, especially if epidote is present (fig. H1; for example, the Comstock Lode, Nevada, Hudson, 2003; Taranik and Aslett, 2009). This early alteration may be replaced by sericite (illite) \pm adularia close to fractures and adjacent permeable lithologies, with veins and fractures dominated by crustiform quartz and (or) chalcedony \pm adularia \pm carbonate minerals (for example, calcite and rhodochrosite) \pm albite \pm barite \pm fluorite (Hedenquist and others, 2000; Simpson and Mauk, 2007). Illite (and carbonate minerals) may be replaced by adularia with the release of $\mathrm{CO}_{2}$ during boiling of hydrothermal fluids and increase in
pH (Simmons and Browne, 2000). Mineral maps of Nevada derived from analysis of remote-sensing data indicate that low- and intermediate-sulfidation deposits are often characterized by TIR- and SWIR-detectable quartz (mainly from relict sinter deposits), illite and (or) smectite, and ferric iron minerals where the ore zone has been exposed by erosion and (or) mining activity. However, supergene oxidation of pyrite during weathering can overprint hypogene alteration resulting in extensive zones of clay (kaolinite and smectite replacing illite and adularia)+ferric-iron minerals, which mimic oxidized pyrite-bearing argillic halos characteristic of high-sulfidation deposits. Weathered phyllic alteration, including that associated with porphyry copper and (or) molybdenum deposits and steamheated alunite deposits, can have a similar mineral assemblage (quartz+jarosite + kaolinite + illite/muscovite \pm smectite \pm goethite \pm gypsum) (Cunningham and others, 2005; Rockwell and others, 2005; Rockwell, 2012).

The expression of low- and intermediate-sulfidation deposits varies greatly as a function of the types of remotesensing data and analysis techniques used. Using automated ASTER analysis methodologies (Rockwell, 2012), "argillic + ferric iron" assemblages were identified in the central mining areas of a variety of low-sulfidation deposits, including the Rawhide and Florida Canyon deposits in Nevada (Rockwell and Bonham, 2013).

Overprinting of quartz-adularia alteration by steamheated alteration and weathering can complicate the use of traditional and remote-sensing techniques for interpretation and characterization of low- and intermediate-sulfidation systems. At the Florida Canyon deposit, ore is hosted by Late Cretaceous orogenic gold-quartz veins overprinted by Neogene stockwork veins of quartz-adularia-sulfide \pm gold crosscut by veins of pyrite-marcasite \pm quartz that are locally enriched in $\mathrm{Au}, \mathrm{Ag}, \mathrm{As}, \mathrm{Hg}$, and Se (Fifarek and others, 2011). Analysis of HyMap hyperspectral data indicated that these mineralized systems are expressed as mixtures of kaolinite \pm sericite (illite) \pm smectite that grade outward to illite + chlorite \pm smectite \pm trace kaolinite (fig. H6; Rockwell and Bonham, 2013). This older, dark-gray, unoxidized, pyritic hypogene alteration has been overprinted by unmineralized, white, steam-heated quartz-alunite-kaolinite-illite-dickite alteration focused along and at intersections of faults and shear zones (Samal and Fifarek, 2005). Pyrite oxidation during nearsurface steam-heated alteration and subsequent weathering has produced porcelaneous veins of potassium-sodium alunite and hematite \pm goethite staining and fracture fillings that replace earlier alteration and mineralization assemblages.

Figure H6. Mineral maps of the Florida Canyon low-sulfidation deposit, Nevada, derived from spectral curve-fitting analysis of HyMap airborne imaging spectrometer data acquired in 2003. The HyMap data have a ground spatial resolution of $\sim 3$ meters per pixel. Analysis was performed by using an expert system designed for analysis of 128-band HyMap data adapted from the system developed by Clark and others (2003). An explanation of the subdivision of identified mineral assemblages based on spectral fit $x$ depth is given in figure RS3 and in the text (this report). $A$, High resolution, true-color satellite image showing mine workings. $B$, Map of iron-bearing minerals and water. $C$, Map of clay, sulfate, mica, and carbonate minerals. These maps were a part of the study reported by Fifarek and others (2011). Satellite image from ESRI Corp. (ESRI_Imagery_ World_2D, http://services.arcgisonline.com/arcgis/services, 2013, available from within ArcGIS). 


\section{A. True-color satellite image}

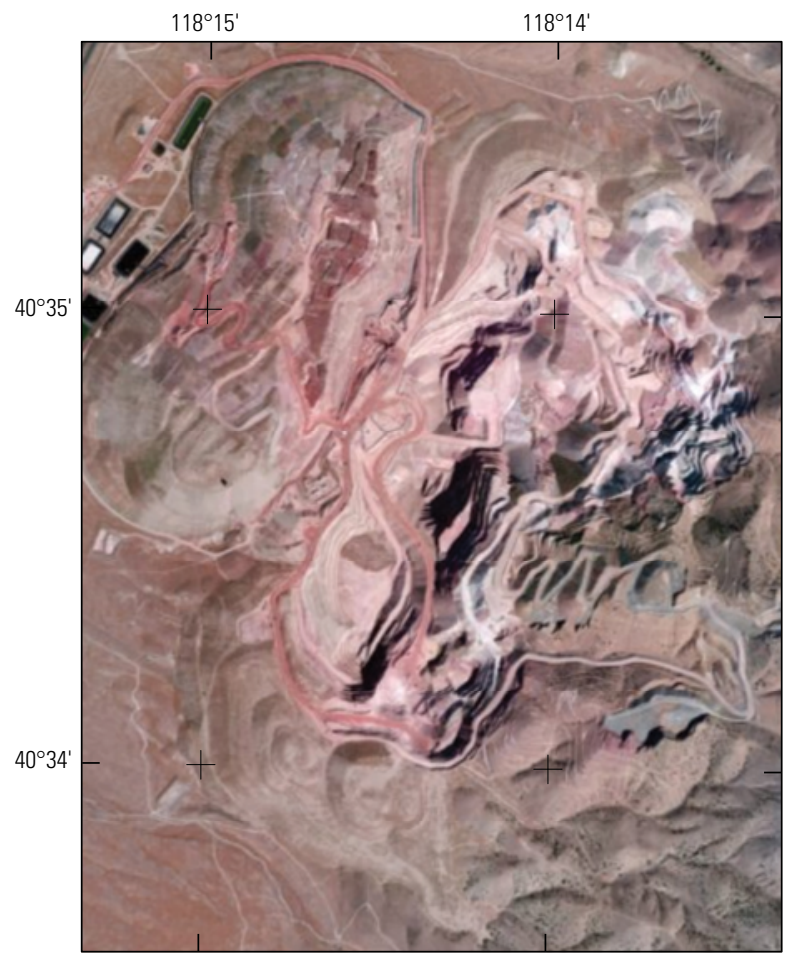

Base from ESRI world imagery map service ESRI_Imagery_World_2D, 2013

https://www.arcgis.com/home/item.html?id=10189d5ffbce4ef48f5bcc0661 cfaffg

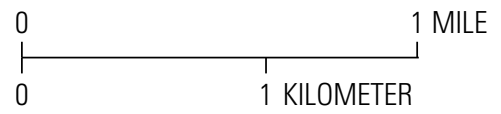

\section{HyMap SWIR map}

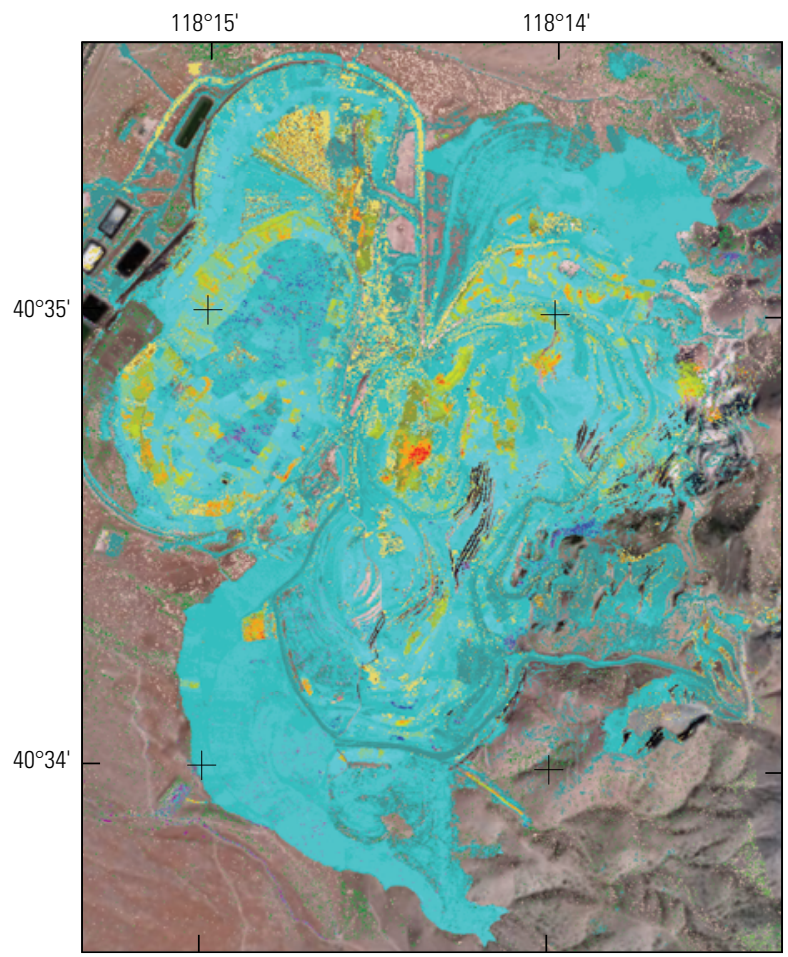

\section{B. HyMap VIS-NIR map}

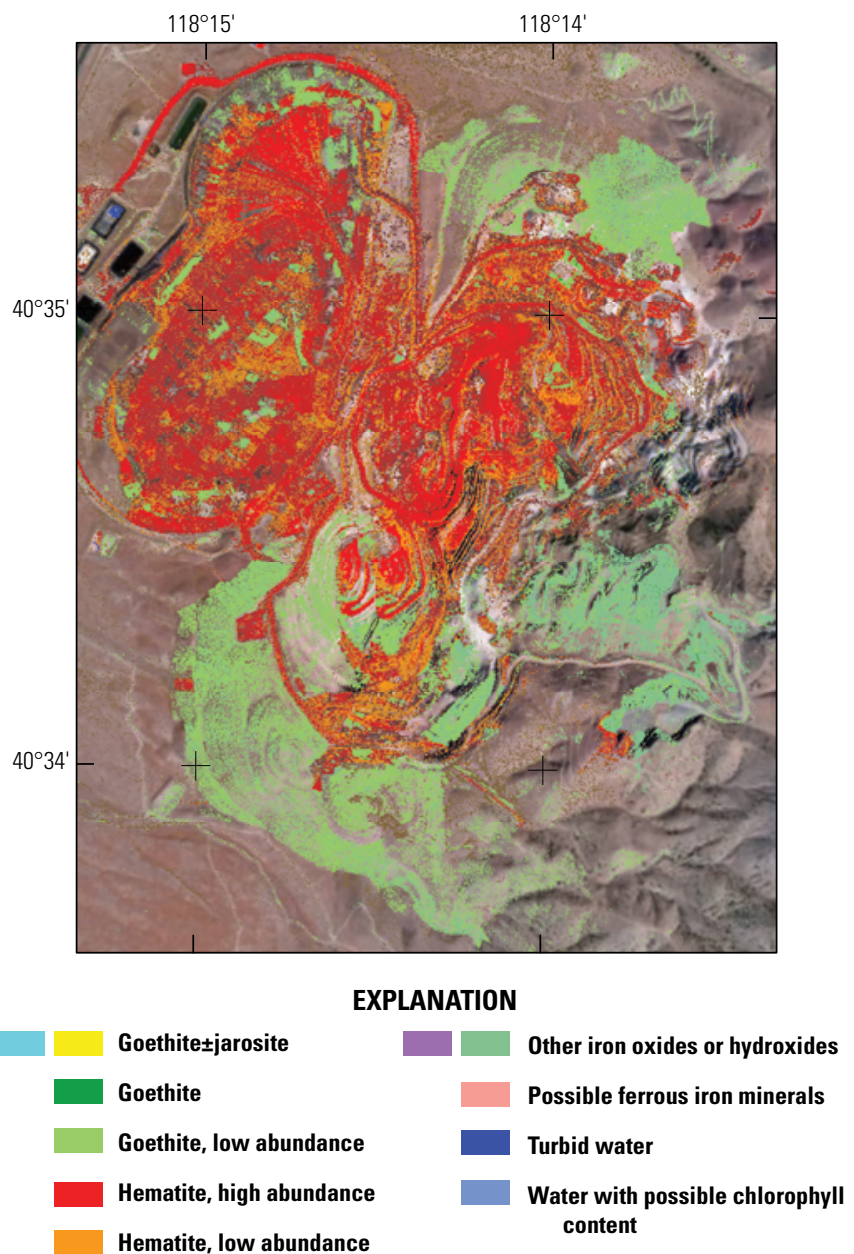

\section{EXPLANATION}

Alunite

Alunite+minor kaolinite

Possible natroalunite

Kaolinite+minor alunite

Kaolinite \pm trace alunite (high to low abundance)

Kaolinite \pm sericite (high to low abundance)

Kaolinite \pm smectite

Halloysite, or kaolinite+trace sericite or smectite

Sericite \pm chlorite \pm trace kaolinite

Smectite (montmorillonite)

Calcite \pm kaolinite

Calcite \pm sericite \pm smectite

Calcite \pm dolomite

Possible buddingtonite 
The kaolinite-bearing alteration assemblage detected in most of the mine area has been interpreted as largely hypogene in origin, but some of the kaolinite may be derived from younger supergene weathering of pyritic rocks and (or) younger steamheated alteration minerals deposited as dust associated with mining activity.

\section{Geoenvironmental Mapping of Epithermal Gold- Silver Deposits by using Landsat 8 Data}

During weathering, pyrite and other sulfide minerals oxidize in altered rock, mine waste, and mill tailings and produce sulfuric acid that can leach metals into ground and surface water (see "Geoenvironmental Features"). Jarosite and other iron sulfate minerals are surficial indicators of this oxidation process and can be accurately identified by using hyperspectral remote-sensing data (Rockwell and others, 2005; Dalton and others, 2007). Because jarosite is among the most insoluble of these oxidation products, it is the most commonly observed of these sulfate minerals. The abundance and distribution of jarosite in altered but undisturbed rocks in a mineralized area can be used as a criterion for establishing pre-mining geoenvironmental baselines.

Because high-sulfidation deposits typically have more extensive areas of advanced argillic and argillic alteration than low- and intermediate-sulfidation deposits, and they commonly contain more abundant sulfide minerals available for oxidation (especially in high-sulfidation systems, such as Goldfield, Nevada; Summitville and Lake City, Colorado; and Yanacocha, Peru, fig. H2), they thus have greater potential for associated acid rock drainage. However, quartz-alunite-kaolinite assemblages associated with steam-heated alteration in the upper parts of lowand intermediate-sulfidation systems are devoid of pyrite; this alteration may overlie pyrite-bearing quartz-illite-pyrite-altered feeder zones formed below the paleowater table (Rockwell and others, 2006; Cunningham and others, 2005; see "Hydrothermal Alteration"). Mixtures of coarse-grained jarosite \pm hematite are extensively exposed in mostly undisturbed rocks of the Goldfield Hills between the main mining area and Preble Mountain (fig. $\mathrm{H} 4$, labels E and A, respectively). This assemblage consists of mixtures of ledge-forming hematite-stained quartz and jarosite from oxidized pyrite in quartz-alunite \pm pyrophyllite assemblages in altered wall-rock envelopes surrounding the ledges. Mine waste rock piles and tailings contain fine-grained jarosite \pm goethite derived from pyrite oxidation (fig. H4, yellow and cyan areas, respectively).

A new method for automated analysis of Landsat 8 Operational Land Imager (OLI) data is being developed by the U.S. Geological Survey to support large-area mineral resource and geoenvironmental assessments. The spectral characteristics of the Landsat 8 OLI bands have been described by the U.S. Geological Survey (2014). The methodology exploits the strong absorption at the "coastal aerosol" band $1(0.43-0.45 \mu \mathrm{m})$ relative to band $2(0.45-0.51 \mu \mathrm{m})$ for jarosite and other iron sulfate minerals compared with iron oxide and hydroxide minerals such as hematite and goethite (fig. H7). Figure H8 shows a material map produced from Landsat 8 OLI data acquired on August 1, 2013, by using the new method in which surfaces with identified iron sulfate minerals, and thus increased potential Net Acid Production (see "Geoenvironmental Features"), are shown in shades of red. Surfaces of this type include waste rock piles and tailings deposits (classes 12, 14, 17, and 18) as well as mainly undisturbed, quartzalunite-jarosite rocks (class 9, fig. H9). In addition to absorption at band 1 and hydroxyl-related (Fe-OH and $\mathrm{Al}-\mathrm{OH})$ vibrational absorption at band 7 (2.11 to $2.29 \mu \mathrm{m})$, undisturbed, altered rock in which iron sulfate was identified has high reflectance at band $6(1.57-1.65 \mu \mathrm{m})$ and a deep, wide crystal field electronic transition feature related to ferric iron near $1.00 \mu \mathrm{m}$ (Landsat band $5,0.85-0.88 \mu \mathrm{m}$, fig. H10). These NIR spectral features result in high values for a Landsat $(3+6) /(4+5)$ compound band ratio for pixels coincident with these altered rocks. Class 9 was also identified in undisturbed magmatic-hydrothermal quartz-alunitepyrite alteration on the south face of Red Mountain $4.7 \mathrm{~km}$ south of the intermediate-sulfidation deposit in Lake City, Colorado (Rye and others, 1992). Quartz-illite-pyrite (phyllic) alteration and pyrite-bearing, argillically altered rocks are typically identified as classes $12,14,17$, and (or) 18, and can thus be distinguished from advanced argillic alteration assemblages containing iron sulfate minerals (class 9).

The new Landsat 8 OLI analysis algorithm has the potential to provide a cost-effective tool for large-area mapping of abundant iron sulfate minerals in mine waste, tailings, and argillically altered rock. The algorithm also holds promise for identification and differentiation of phyllic alteration and undisturbed pyrite-bearing magmatichydrothermal advanced argillic alteration. If the Landsat 8 OLI data analysis detects iron sulfate minerals in altered rocks in which alunite has been detected by using other data, then a magmatic-hydrothermal origin for alunite is more likely. 


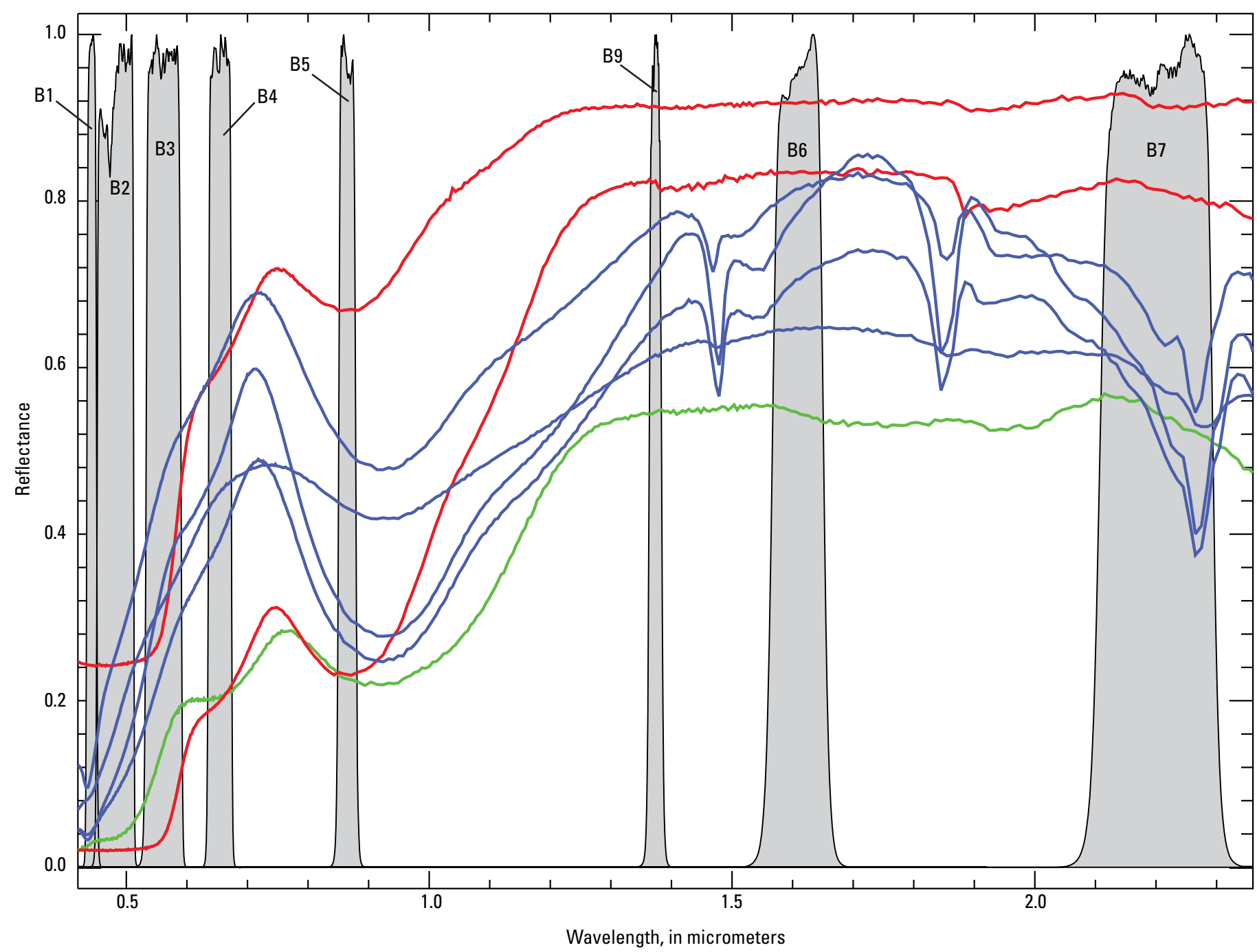

Figure H7. Spectral plot of ferric iron minerals showing the visible (VIS), near-infrared (NIR), and shortwave-infrared (SWIR) regions. Jarosites are shown in yellow, goethite in green, and hematites in red (Clark and others, 2007). Bandpasses of the Landsat $80 \mathrm{LI}$ bands are shown in blue. Note deep absorption in Landsat band 1 (B1) relative to band 2 (B2) for jarosites that is not present for goethite and hematite. Also note deep and wide absorption feature near band 5 ( $B 5, \sim 0.9$ micrometers) caused by crystal field electronic transitions. This feature is typically deeper for jarosite than for goethite and hematite. Jarosite will always show some vibrational absorption at band 7 (B7), whether it be from the $\mathrm{Fe}-\mathrm{OH}$ feature (shown), or an $\mathrm{Al}-\mathrm{OH}$ feature caused by phyllosilicate (for example, clays and micas) and (or) sulfate (for example, alunite) minerals that occur in the same rock, especially on weathered pyritic rock where supergene clay minerals are common (Rockwell and others, 2005). Ground surfaces with goethite and hematite will not necessarily have this feature. 


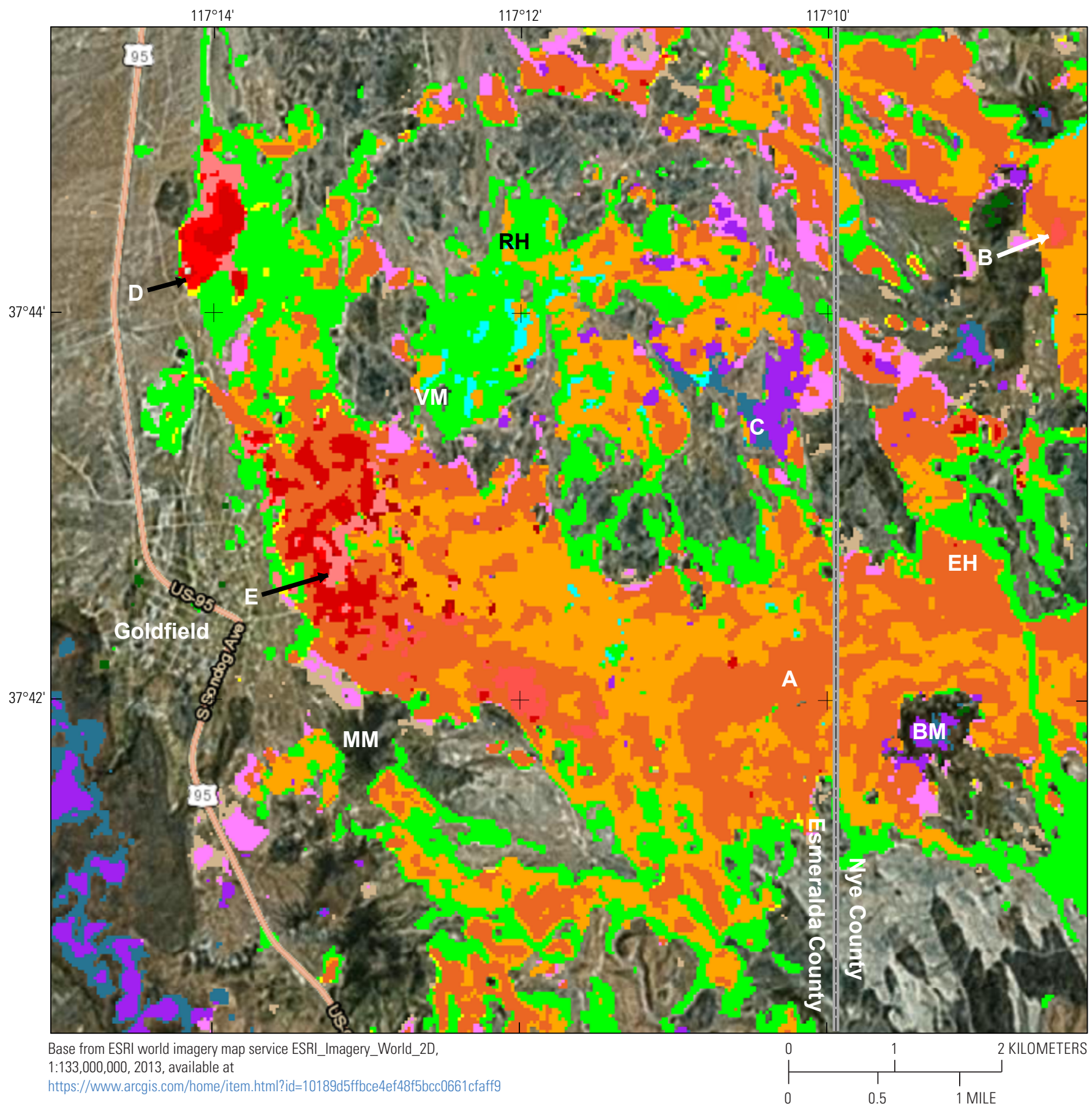

\section{EXPLANATION}

Minor ferric iron (high redness, often includes hematite)

Major ferric iron

Ferric \pm ferrous iron

Ferrous or coarse-grained ferric iron (may include oxidized basalt) Clay, sulfate, mica, and (or) marble

Clay, sulfate, mica, and (or) marble+minor ferric iron

Clay, sulfate, mica, and (or) marble+moderate to major ferric iron

Clay, sulfate, mica, and (or) marble+major ferric iron

Clay, sulfate, mica, and (or) marble+major ferric iron with possible iron sulfate and hydroxide
Clay, sulfate, mica, and (or) marble+ferrous or coarse-grained ferric iron

Dense, green vegetation

Clay, sulfate, mica, and (or) marble+major ferric iron with possible oxidizing sulfides and major iron sulfate

Clay, sulfate, mica, and (or) marble with possible oxidizing sulfides and minor iron sulfate

Clay, sulfate, mica, and (or) marble+major ferric iron with possible major iron sulfate and hydroxide (proximal zones)

Clay, sulfate, mica, and (or) marble+major ferric iron with possible moderate to major iron sulfate and hydroxide (commonly distal zones of weathered, highly pyritic rocks and mine waste

Clay, sulfate, mica, and (or) marble+ferrous or coarse-grained ferric iron with possible minor iron sulfate 
Figure H8. Map of mineral groups produced from analysis of Landsat $8 \mathrm{OLI}$ data that have a ground spatial resolution of 30 meters per pixel. Class numbers mentioned in the report text are shown within colored rectangles in the map explanation. Note correspondence of detected iron sulfate minerals (shown in shades of red) with jarosite \pm goethite identified by using Airborne Visible/Infrared Imaging Spectrometer (AVIRIS) data (fig. H4). Iron sulfate minerals were detected in the mill tailings $(D)$, in waste rock piles in the main mining area of the Goldfield district $(E)$, and in isolated pyritic waste rock piles throughout the district. A, Preble Mountain; B, jarosite in mainly undisturbed, quartz-alunite alteration also detected by AVIRIS data (figs. $\mathrm{H3}, \mathrm{H} 4$ ). BM, Blackcap Mountain; $\mathrm{C}=$ Ferrous iron identified in weakly propylitized quartz latite tuffs and lapilli tuffs. Ferrous iron was also detected here by using AVIRIS visible (VIS) and near-infrared (NIR) data (fig. $\mathrm{H} 4$ ) in the muscovite-chlorite mixture (fig. $\mathrm{H} 3$ ); EH, Espina Hill; MM, Myers Mountain; RH, Ruby Hills; VM, Vindicator Mountain.

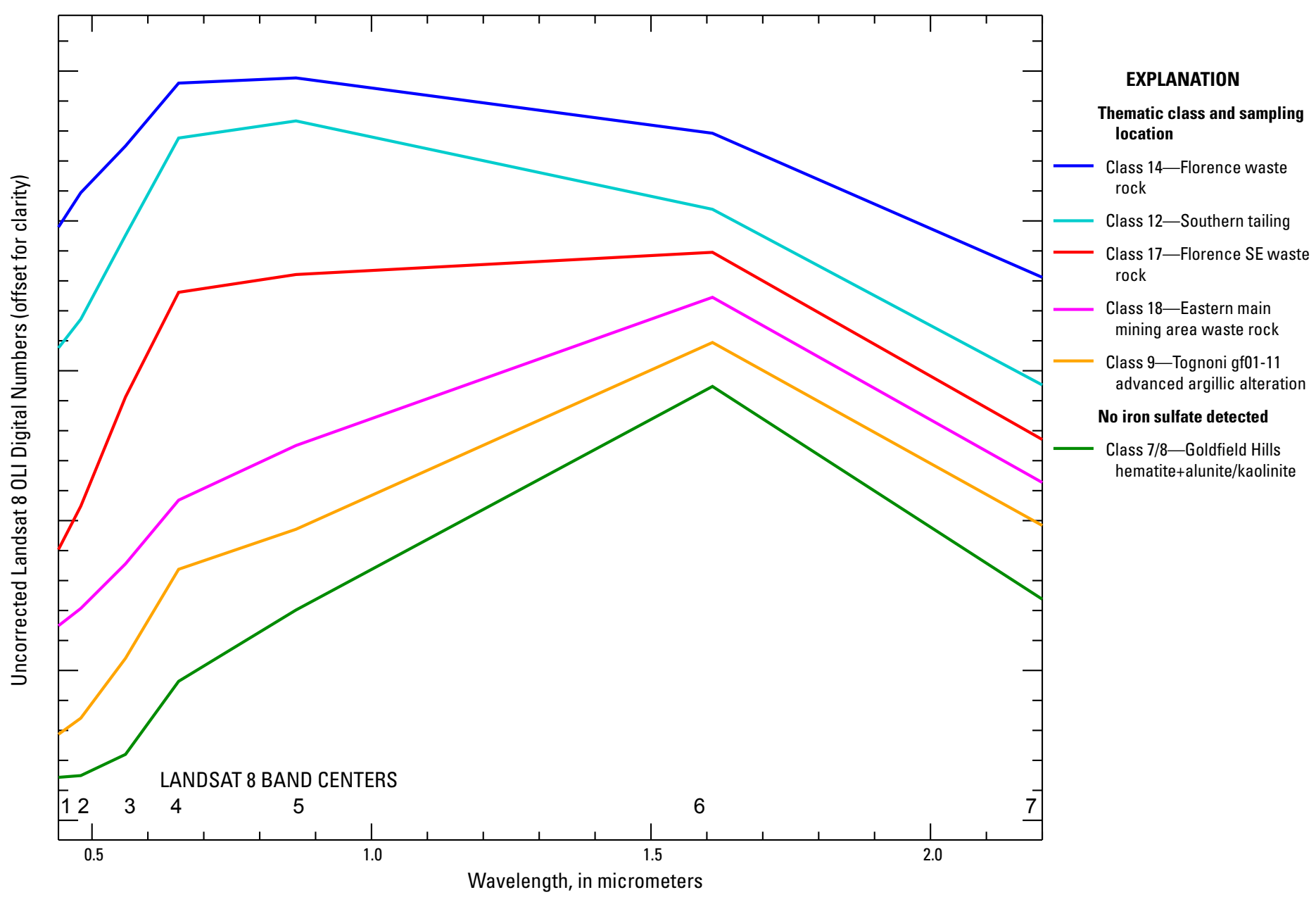

Figure H9. Uncorrected Landsat $8 \mathrm{OLI}$ spectra from scene covering Goldfield, Nevada, collected on August 1, 2013. Class numbers correspond to those shown in figure $\mathrm{H} 8$ and represent the thematic output class of the automated analysis algorithm. The estimated relative net acid production, based on interpretation of near-surface pyrite abundance derived from iron sulfate mineral occurrence and comparison with Airborne Visible/Infrared Imaging Spectrometer (AVIRIS)-derived mineral maps, increases from bottom to top. Spectra from waste rock were collected from the vicinity of the Florence mine in the main mining area (location $\mathrm{E}$ in figs. $\mathrm{H4}$, $\mathrm{H8}$ ), and the spectrum of jarosite-bearing, altered rock (class 9 , shown in orange) was sampled from location B in figure $H 3$. The spectrum shown in dark cyan (class 14 ) was sampled from the southern end of the tailings deposit where copiapite and minor jarosite and goethite were identified by using AVIRIS data (location D in fig. H4). Copiapite is characterized by a slight decrease in reflectance between 0.87 micrometers (Landsat 8 band 5) and 1.65 micrometers (Landsat 8 band 6), whereas jarosite typically shows a strong increase (Clark and others, 2007). The spectrum shown in green (class 7/8) was sampled from quartz-alunite alteration in the Goldfield Hills east of Preble Mountain in which no iron sulfate minerals were detected by using Landsat 8 data, and hematite was identified by using AVIRIS data. Note the flat spectral response between bands 1 and 2 . 


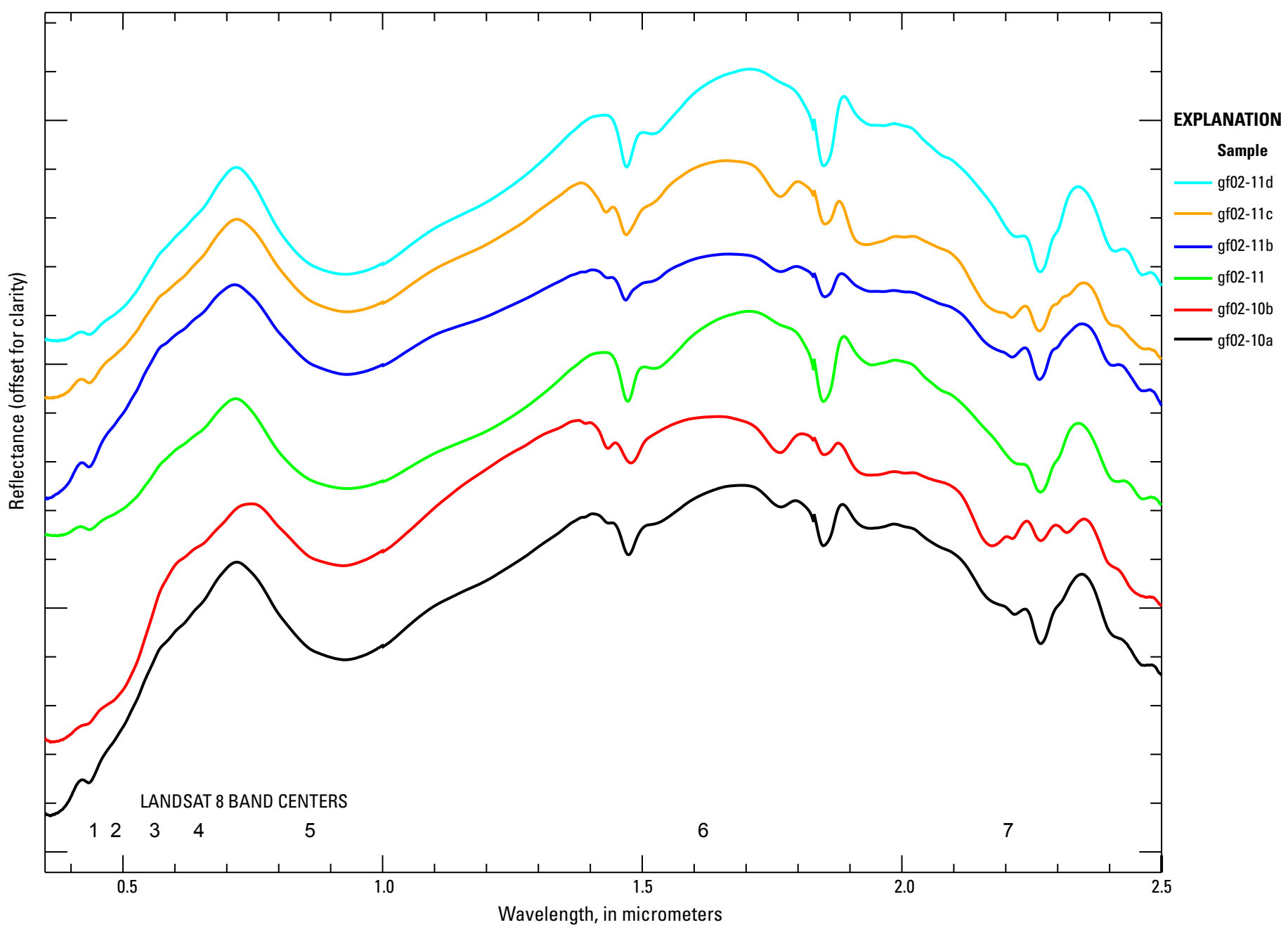

Figure H10. Laboratory reflectance spectra of field samples collected near Goldfield, Nevada, from undisturbed, highly altered rock (location B in fig. H3). All samples contain a mixture of jarosite with minor natrojarosite as determined by bulk X-ray diffraction. Sample gf02-10b (shown in red) contains a mixture of alunite and natroalunite and trace kaolinite. Samples gf02-11b, gf02-11c, and gf02-10a contain trace alunite and kaolinite. Sample locations (WGS84 datum): gf02-10 (117.14436 $\left.\mathrm{W}, 37.74255^{\circ} \mathrm{N}\right)$, gf02-11 (117.14280 $\left.\mathrm{W}, 37.74138^{\circ} \mathrm{N}\right)$. 


\title{
Chapter I. Hypogene and Supergene Ore Characteristics
}

\author{
Peter G. Vikre
}

\section{Hypogene Ore in High-Sulfidation Deposits}

\section{Mineralogy}

Hypogene minerals that define ore in nearly all high-sulfidation deposits are gold ( $>80$ atom percent gold, $<20$ atom percent silver) and electrum (20-80 atom percent gold, 80-20 atom percent silver). Reported compositions of gold and electrum in several deposits are more than 93 and more than 70 weight percent (often $>90$ weight percent) gold, respectively; several weight percent copper occurs in electrum in the copper and gold vein stages at El Indio (Goldfield, Vikre, 1989b; Vikre and Henry, 2011; El Indio, Chile, Jannas and others, 1990, 1999; Rodalquilar, Spain, Arribas and others, 1995a; Lepanto, Philippines, Hedenquist and others, 1998). Minor amounts of gold in telluride minerals (mostly calaverite) have been recovered in many deposits (for example, Goldfield; Pueblo Viejo, Arribas and others, 2011; Mulatos, Staude, 2001; Perama, Greece, Voudouris and others, 2011; Rodalquilar; El Indio; Chinkuashih, Taiwan, Wang and others, 1999; Shen and Yang, 2004; Wang, 2010; Khan Krum, Bulgaria, Marinova and others, 2014).

Copper, primarily in enargite and luzonite, has been recovered from many deposits and districts (for example, Goldfield, Vikre, 1989b; El Indio, Jannas and others, 1990; 1999; Chelopech, Bulgaria, Kouzmanov and others, 2004; Chambefort and Moritz, 2006; Chambefort and others, 2007; Lepanto, Hedenquist and others, 1998; Disini and others, 1998; Nansatsu, Hedenquist and others, 1994; Bor, Yugoslavia, Jankovic 1990; Herrington and others, 1998; Chinkuashih, Wang, 2010). In some deposits, ore was partially defined by copper grades combined with gold grades (Lepanto, Bor, Chelopech). Other copper minerals that commonly occur in gold \pm silver \pm copper ore include famatinite, tennantite, chalcopyrite, goldfieldite, tetrahedrite, chalcocite, covellite, digenite, and bornite. Small amounts of recovered copper have been derived from these minerals, and they also are common in small amounts in high-sulfidation deposits from which copper was not recovered.

Silver minerals defined most ore at Hog Heaven, U.S.A. (Lange and others, 1994), defined some ores in the zoned La Coipa, Chile, Oviedo and others, 1991b; Julcani, Peru, Deen and others, 1994; and other districts (Muntean and Einaudi, 2000), and added significant value to ores and resources at Paradise Peak (John and others, 1991; Sillitoe and Lorson, 1994), PascuaLama (Deyell and others, 2004, 2005a), and numerous other deposits. However, silver recovery in the majority of highsulfidation deposits has been contingent on mining and processing gold \pm copper ores (for example, Goldfield, Pueblo Viejo, Lepanto). In these ores, silver primarily occurs in acanthite, tennantite, tetrahedrite, enargite, telluride minerals, halide minerals, argentojarosite, and as elemental silver.

Many uncommon to rare $\mathrm{Cu}-\mathrm{As}-\mathrm{Sb}-\mathrm{Pb}-\mathrm{Fe}-\mathrm{Zn}-\mathrm{Bi}-\mathrm{Ag}-\mathrm{Sn}-\mathrm{V}-$ $\mathrm{S}-\mathrm{Se}-\mathrm{Te}$ minerals are reported in deposits for which hydrothermal minerals and assemblages have been described in detail (for example, Goldfield, Vikre, 1989b; Perama, Voudouris and others, 2011; Rodalquilar, Arribas and others, 1995a). These minerals have been mined and processed because of proximity to gold, copper, and silver ore minerals, but in most deposits there is no recorded production of metals in these minerals (for example, $\mathrm{Bi}$, $\mathrm{Sn}, \mathrm{Pb}, \mathrm{Zn}, \mathrm{Te}$ ) other than copper and silver.

Many zoned polymetallic districts that were mined primarily for silver, lead, zinc, and copper include volumes of rocks or vein selvages altered to vuggy quartz, quartz-alunite, and quartz-dickite/ kaolinite-pyrophyllite assemblages, which are common to all highsulfidation deposits (for example, Julcani, Deen and others, 1994; Castrovirreyna, Peru, Wise, 2005; Cerro de Pasco, Einaudi, 1977; Baumgartner and others, 2008, 2009; Colquijirca, Bendezú and others, 2003, 2008; Vidal and Ligarda, 2004; Chocolimpie, Chile, Gröpper and others, 1991). These alteration mineral assemblages are both paragenetically early (Deen and others, 1994; Bendezú and others, 2003) and late relative to lead and zinc deposits (Einaudi, 1977), although ages of deposits and alteration mineral assemblages are not well constrained in some districts. Deposits in polymetallic districts contain, in addition to minerals listed above, other silver (for example, polybasite, pyrargyrite, boulangerite), arsenic (realgar, orpiment; Castrovirreyna, Peru, Wise, 2005), tin (stannite, cassiterite), tungsten (wolframite), and carbonate (calcite, rhodochrosite) minerals. Some alteration mineral assemblages and deposits formed near the surface, at relatively low temperatures, and by processes in part similar to those that formed high-sulfidation deposits. These zoned, silver-lead-zinccopper-dominant, low-gold districts have been classified mostly as magmatic-hydrothermal, carbonate replacement, and vein deposits (for example, Graybeal and Vikre, 2010) or Cordilleran base metal deposits (for example, Baumgartner and others, 2008).

Some porphyry copper systems include large volumes of mostly near-surface igneous rocks that have been altered to vuggy quartz and quartz-alunite-kaolinite-pyrophyllite assemblages, and contain elevated copper and silver concentrations (for example, Resolution, Red Mountain, and Sunnyside, Arizona, Graybeal and Vikre, 2010; Vikre and others, 2014a). Silver and copper grades are generally low in porphyry copper deposits $(\leq \sim 8 \mathrm{~g} / \mathrm{t}$; $\leq 0.23$ opt, and 0.175 weight percent, respectively, at Sunnyside), but large amounts of these metals $(\sim 5,200 \mathrm{t} ; \sim 167 \mathrm{Moz}$ silver, and $\sim 1.3 \mathrm{Mt}$ copper at Sunnyside) are contained in large volumes of mineralized rock (hundreds of millions to billions of metric tons $\mathrm{Mt}$ to Gt). Although copper-silver resources at Sunnyside and 
Red Mountain formed $\sim 0.5$ to $1.5 \mathrm{~km}$ beneath paleosurfaces, they are clearly part of larger porphyry copper systems because they overlie large volumes of igneous rocks that contain disseminated and vein chalcopyrite and molybdenite. Similar to the zoned polymetallic districts in Peru and Chile, vuggy quartz and quartzalunite-aluminosilicate alteration in southern Arizona porphyry copper districts is paragenetically late and postdates subjacent chalcopyrite+molybdenite resources by $\sim 1 \mathrm{~m}$.y. or less (Vikre and others, 2014a). Similar to paragenetic relations in high-sulfidation deposits, copper- and silver-bearing minerals in high elevation alteration zones in porphyry copper systems were deposited after or simultaneously with or after quartz, alunite, and aluminosilicate minerals. At Yanacocha, three magmatic-hydrothermal events consist of simultaneous quartz-alunite-aluminosilicate alteration and gold mineralization that span $\sim 11-8 \mathrm{Ma}$; one event also includes porphyry copper-style veins and minerals (Longo and others, 2010). Quartz-alunite-pyrophyllite alteration ( $\sim 9.3 \mathrm{Ma})$ associated with emplacement of Kupfertal porphyry transitions at 90-150 m depth to sericitic and potassic alteration containing biotite, pyrite, chalcopyrite, and bornite.

\section{Mineral Assemblages and Associations}

Gold and electrum largely occur as discrete submillimeter crystals and crystalline aggregates in quartz, as micron-size (or smaller) inclusions in enargite, tennantite, and pyrite, and intergrown with enargite and other copper-arsenic-sulfur minerals, pyrite, and bismuthinite. Gold and electrum are spatially and temporally associated with alunite, barite, pyrite, enargite, telluride minerals, and quartz, in several distinct mineralization stages and veins at Summitville, Goldfield, Pascua-Lama, El Indio, Tambo, Yanacocha, Mulatos, and other districts. In these districts, large to small amounts of gold occur within iterative encrustations of quartz, alunite, and kaolinite on breccia fragments (fig. I1), in barite, and in latestage veins and breccia pipes consisting of barite, gold, pyrite and other sulfide minerals, and iron oxides (for example, Russin and Fifarek, 2009). At Pierina, gold is dispersed in vuggy quartz, fractures and veins, and as submicron inclusions in acanthite and iron oxide minerals (interpreted as hypogene; Fifarek and Rye, 2005).

Copper minerals commonly occur in aggregates with gold, electrum, pyrite and other sulfide and telluride minerals, in discrete crystals and crystalline aggregates in quartz, in fractures in dense quartz and chalcedony, and, less commonly, in voids in vuggy quartz and breccia matrices.

Silver sulfide (for example, acanthite) and telluride minerals, and sulfide minerals containing lesser silver (for example, enargite, tennantite), occur in aggregates with other sulfide minerals and gold and electrum, as inclusions in sulfide minerals, in discrete crystals and crystalline aggregates in quartz, and in fractures in dense quartz and chalcedony. At Cerro Rico de Potosi and Hog Heaven, major to significant amounts of silver occur in vuggy quartz. Like gold and electrum, copper and silver mineralization takes place during several stages. At Pierina, silver occurs in less
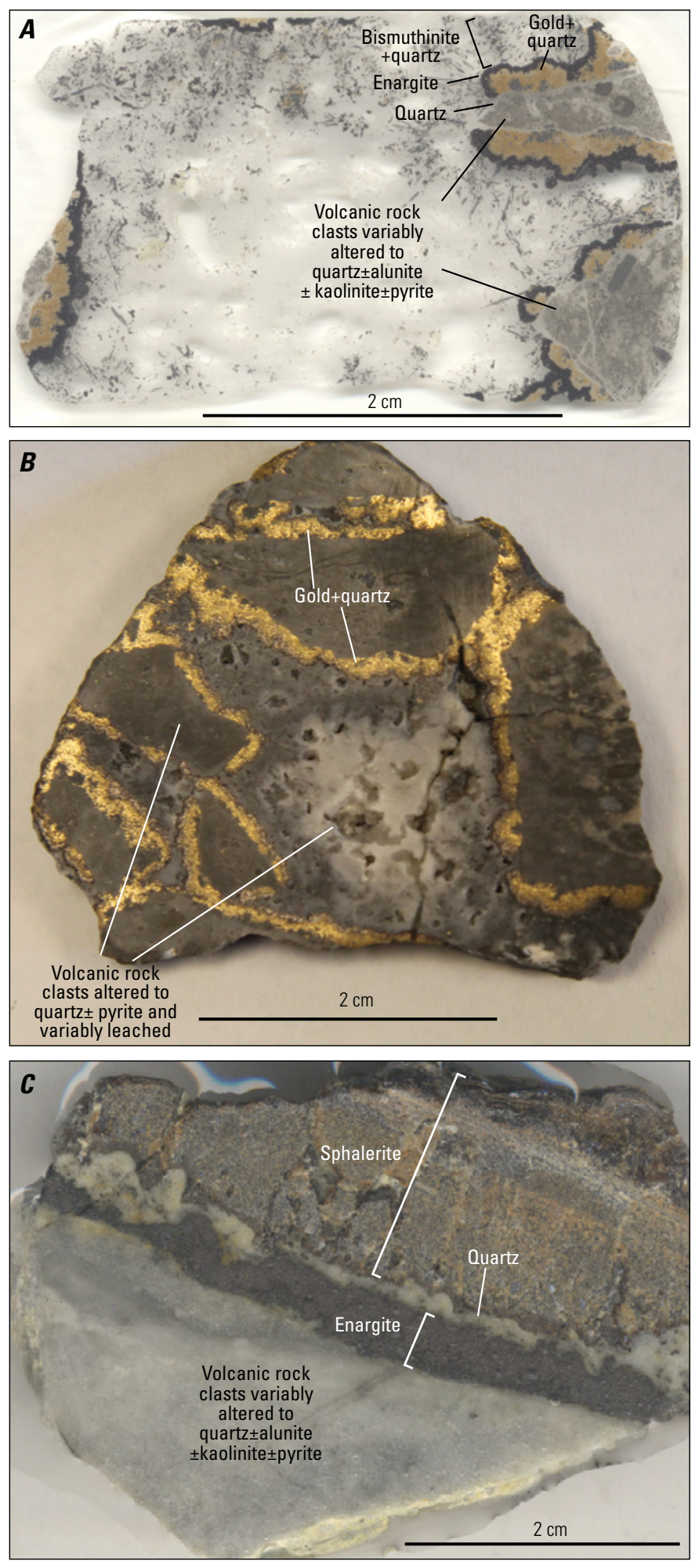

Figure 11. Photographs showing multigenerational breccias consisting of clasts variably altered to quartz \pm alunite \pm kaolinite \pm pyrite, leached, and variably encrusted by quartz, gold ( $>99$ atom percent)+quartz, enargite (and other Cu-As-Sb-S minerals), bismuthinite+quartz, and no-iron sphalerite from the Goldfield district, Nevada. $A$, Mohawk mine; $B$, Clermont mine; $C$, GoldfieldHazel mine. Photographs by Peter Vikre. $\mathrm{cm}$, centimeters. 
than $1 \mathrm{~mm}$ aggregates in quartz and barite as well as in acanthite and enargite.

\section{Paragenesis}

Numerous consecutive fluid-mineral events, one or more of which deposited ore minerals and all of which deposited gangue minerals, are recognized in most well-described deposits and resources, and nearly all deposits contain evidence of several events. These fluid-mineral events, which link the artificially separate report sections (based on economic distinctions) on "Hypogene and Supergene Ore Characteristics," "Hypogene and Supergene Gangue Characteristics," and "Hydrothermal Alteration," are broadly described in the report section "Hydrothermal Alteration." Fairly complete system parageneses have been described for a few well-exposed high-sulfidation deposits (for example, Summitville, Bethke and others, 2005), although most systems have subsets of similar magmatic and hydrothermal events. Some specific paragenetic relations of gold, copper, and silver ore minerals are described below.

Within hydrothermal mineral assemblages that contain ore minerals (gold, electrum, and in some deposits, copper and silver minerals), paragenetic relations range from relatively simple to intricate. Simple parageneses are inclusions of gold/electrum in enargite and pyrite and intergrowths of ore minerals in apparent equilibrium that appear to represent a single fluid-mineral event (for example, the alunite-pyrite-enargite-gold/electrum-calaverite assemblage at Pascua-Lama, Deyell and others, 2004, 2005a), and separate vein sets (for example, El Indio, Jannas and others, 1990, 1999). At El Indio, layered to massive enargite, pyrite, gold, electrum, and other minerals compose early copper veins; enargite/ tennantitie, gold, and other minerals compose a transition stage; and layered quartz, gold, calaverite, and other minerals compose paragenetically late gold veins (fig. F1).

Intricate parageneses involve complex intergrowths of gold and electrum and numerous $\mathrm{Cu}-\mathrm{As}-\mathrm{Sb}-\mathrm{Pb}-\mathrm{Fe}-\mathrm{Zn}-\mathrm{Bi}-\mathrm{Ag}-$ Sn-V-S-Se-Te minerals (for example, Goldfield, Vikre, 1989b; Perama, Voudouris and others, 2011; Rodalquilar, Arribas and others, 1995a), and breccia fragments encrusted with hydrothermal minerals. At Goldfield, fragment encrustations include fine-grained quartz with variable amounts of gold, pyrite, bismuthinite, numerous $\mathrm{Cu}-\mathrm{As}-\mathrm{Sb}-\mathrm{Pb}-\mathrm{Zn}-\mathrm{Te}-\mathrm{Se}-\mathrm{S}$ minerals, layers of enargite, layers of pyrite, layers of alunite, and layers of galena and sphalerite (fig. I1). Many encrusted layers are iterative, some layers broadly correspond in relative position among adjacent mines, and galena and sphalerite, where present, are outermost layers. However, hydrothermal mineral stratigraphy is not consistent on a district-wide scale. At Perama, deposition of earthy enargite, iron-free sphalerite, covellite, bismuthinite, gold, and numerous $\mathrm{Cu}-\mathrm{As}-\mathrm{Sb}-\mathrm{Zn}$ $\mathrm{Fe}-\mathrm{Sn}-\mathrm{Pb}$-Ag-Bi-Ni-Te-Se-S minerals (watanabeite, kesterite, lillianite, kawasulite-tetradymite, and goldfieldite) was followed by assemblages of ferrian-zincian tennantite, tellurobismuthite, tetradymite, melonite, tellurium, gold-silver tellurides, altaite, and electrum with quartz, barite, kaolinite, sericite (fine-grained illite or muscovite), and minor aluminum-phosphate-sulfate minerals (Voudouris and others, 2011).

Deposits for which detailed parageneses have been determined also include one or more stages of gold-copper-silver mineralization that consist of common and diverse gold, copper, silver, silicate, aluminosilicate, and sulfate minerals. For example, at Tambo, early silicification (residual quartz) is followed by associations of (1) electrum, barite, alunite, and minor sulfide and telluride minerals in veins and breccias; (2) electrum and quartz deposited on association (1); and (3) gold, alunite, barite, and other minerals in fractures, vugs, and veins, and encrustations on breccia fragments (Deyell and others, 2005b; Jannas and others, 1999). At Lagunas Norte, quartz, pyrite, gold, and other minerals in fractures, faults, and breccia matrices predate diatreme emplacement and two subsequent hydrothermal mineral stages consisting of variable amounts of gold, pyrite, alunite, enargite, and other silicate, aluminosilicate, and sulfate minerals in breccias and fractures (Cerpa and others, 2013). Two or more generations of alunite are observed in many deposits, and numerous alunite generations have been described at Perina (Fifarek and Rye, 2005; Rainbow and others, 2005). Paragenetic relations involving ore and other hydrothermal minerals are described at Summitville (Bethke and others, 2005); Mulatos, (Staude, 2001); Cerro Rico de Potosi (Sillitoe and others, 1998), Pascua-Lama (Deyell and others, 2004, 2005a); Yanacocha, (Teal and Benavides, 2010); Rodalquilar (Arribas and others, 1995a); and Perama (Voudouris and others, 2011).

Sphalerite and galena occur in various paragenetic stages, but commonly compose, with barite and other sulfide minerals, a late or the latest hydrothermal mineral assemblage (Goldfield, Vikre, 1989b; Summitville, Bethke and others, 2005; Pueblo Viejo, Kesler and others, 1981; Yanacocha, Teal and Benavides, 2010; Chelopech, Bulgaria, Kouzmanov and others, 2004; Chambefort and Moritz, 2006; Chambefort and others, 2007; and Lepanto, Hedenquist and others, 1998). In some deposits, combinations of gold, base metal minerals, including sphalerite and galena, barite, pyrite, and kaolinite occur in veins and tabular to pipelike breccias that crosscut earlier assemblages. Sphalerite compositions at Goldfield (Vikre, 1989b), Pueblo Viejo (Muntean and others, 1990); El Indio (Jannas and others, 1999); and Perama (Voudouris and others, 2011) are nearly stoichiometric $\mathrm{ZnS}$, with less than 1 weight percent or no detectable iron, manganese, and cadmium (based on electron microprobe analyses). Sphalerite, gold, and electrum compositions partly distinguish high-sulfidation from low- and intermediate-sulfidation deposits (see "Classification of Epithermal Gold-Silver Deposits").

\section{Zoning Patterns}

District-scale zoning of ore minerals and assemblages is most pronounced in polymetallic silver-dominant districts that include vuggy quartz and quartz-alunite altered rocks (for example, Julcani, Castrovirreyna, Colquijirca, Cerro de Pasco, Peru). Zoning of ore minerals is variably evident in high-sulfidation deposits and is largely reflected by gold concentrations. 
Lateral zoning of ore and other minerals in high-sulfidation deposits and districts varies with degree of stratigraphic control (for example, permeable rocks) and structural control (for example, faults and breccias) of ore mineral assemblages. In deposits where stratigraphic control is important, gold grades are mostly low ( $<1$ to $\sim 3 \mathrm{~g} / \mathrm{t}$ gold; $\leq 0.1 \mathrm{opt}$ ) and deposits are mined by open-pit methods. In literature about these deposits, lateral (and vertical) zoning of ore mineral assemblages is usually described as having open-pit boundaries or by cutoff gold grade enclosures (figs. F1, F2), and ore mineral zoning is seldom addressed. Broad proxies for ore mineral zoning, in the form of minor element distributions (for example, $\mathrm{Au}, \mathrm{Pb}, \mathrm{Ag}, \mathrm{Sb}, \mathrm{Te}$, $\mathrm{As}, \mathrm{Hg}, \mathrm{Cu}, \mathrm{Se}$, and $\mathrm{Zn}$ ), have been published for several, largely stratigraphically controlled deposits (Paradise Peak, John and others, 1991; Pueblo Viejo, Kesler and others, 2003). In deposits in which structural control dominates ore mineral assemblages, lateral zoning on a stope scale is also evident from the distribution of gold, silver, and other elements, mostly in cryptic phases, in ore zones, and adjacent altered rocks (for example, Summitville; Gray and Coolbaugh, 1994). Lateral zoning of ore and associated mineral assemblages at mining scale has been described at El Indio where early "high-sulfidation" pyrite-enargite \pm alunite veins and late quartz \pm tennantite, chalcopyrite, gold, galena, sphalerite, and carbonate mineral veins ("intermediate sulfidation") occur separately or together as composite assemblages in single veins (Jannas and others, 1990, 1999).

Vertical zoning of ore mineral assemblages, based largely on underground mining and a few deep drill holes, is generally known for a limited number of structurally controlled deposits (Summitville, Goldfield, El Indio, Cerro Rico de Potosi, and Lepanto; see appendix 1). Vertical zoning of ore mineral assemblages in low-grade and stratigraphically controlled deposits is seldom described. In general, unweathered near-surface ore mineral assemblages in gold \pm copper deposits consist of pyrite, enargite, and small amounts of gold, electrum (discrete crystals and inclusions in sulfide minerals), and silver-bearing minerals that usually make up less than 10 volume percent of ore. With increasing depth, the variety of metallic minerals (enargite, pyrite, and numerous $\mathrm{Cu}-\mathrm{As}-\mathrm{Sb}-\mathrm{Pb}-\mathrm{Fe}-\mathrm{Zn}-\mathrm{Bi}-\mathrm{Ag}$-Sn-V-S-Se-Te minerals) increases fairly rapidly, their abundance attains as much as several tens of percent, copper concentrations markedly increase, and gold concentrations decrease. In the Mankayan, Philippines (Lepanto-Far Southeast deposits), Hedenquist and others, 1998; Disini and others, 1998; Corbett and Leach, 1998;

Zijinshan, China, So and others, 1998; and Bor, Serbia, Jankovic, 1990; gold and copper districts, disseminated, stockwork, and structurally controlled vein and massive ( $>90$ percent sulfide minerals) enargite +pyrite ( $\mathrm{Au}$ ) deposits are $\sim 400 \mathrm{~m}$ from subjacent and (or) coeval porphyry copper+gold deposits.

The vertical extent of gold \pm silver \pm copper-mineralized rocks, based on a few reported drill-hole intercepts, seldom exceeds $500 \mathrm{~m}$, although a deep drill hole as much as $900 \mathrm{~m}$ below the erosional surface at Summitville penetrated narrow zones of massive aggregates of $\mathrm{Cu}-\mathrm{As}-\mathrm{Sb}$-Bi-Sn-S minerals, with low gold and silver concentrations. At Summitville, the deep drill hole and erosional relief vertically expose about 2,000 m of host rock (a dome of quartz latite of South Mountain) and hydrothermal mineral assemblages. However, the maximum vertical extent of mined ore, based on stopes at Goldfield and El Indio, is about $500 \mathrm{~m}$.

\section{Textures and Grain Size}

Ore minerals are usually contained within subequigranular, fine-grained to microcrystalline aggregates of quartz, silicate, sulfide, sulfate, and telluride minerals. In some deposits gold/electrum, enargite, and other $\mathrm{Cu}$-As$\mathrm{Au}-\mathrm{Ag}-\mathrm{Te}-\mathrm{S}$ ore minerals occur as monomineralic layers on breccia fragments and in layered veins. Most gold, copper, and silver ore minerals, and other hydrothermal minerals are fine grained $(<1 \mathrm{~mm})$ to microcrystalline. Some ore and associated gangue minerals, usually those deposited in fractures or voids, are millimeters to centimeters in dimension (for example, quartz, barite, and enargite and other sulfide minerals). Rarely, euhedrons of chalcopyrite, covellite, and enargite occur in voids (leached phenocryst and rock fragment sites; for example, Summitville), occasionally with sulfur and cinnabar (for example, Paradise Peak; Vikre, 2000). These relatively coarse-grained minerals have been commonly used for fluid inclusion microthermometry and for bulk analysis of stable and radiogenic isotopes.

\section{Supergene Ore in High-Sulfidation Deposits}

Supergene ore, or gold-copper-silver-mineralized rocks that have been enriched to ore grades by weathering, apparently does not constitute a significant economic component of most high-sulfidation deposits and resources, although grade enrichment is seldom addressed. In a number of medium-size and large deposits (for example, Mulatos; Veladero; El Indio; Yanacocha; La Coipa; Rodalquilar; Nansatsu; Pierina; see appendix 1) supergene gold, copper, and silver minerals (chalcocite, digenite, covellite, silver halide minerals, and argentojarosite) have been identified or are suspected. Silver halides and argentojarosite largely occur in fractures and voids, commonly with iron oxide, hydroxide, and other sulfate minerals (for example, Veladero, Argentina, Holley, 2012; Holley and others, 2017). Weathering of pyrite, which is widely distributed in porous and fractured altered rocks in nearly all deposits, produced low-pH fluids that caused enrichment of copper and silver, and conceivably gold in these deposits. However, it is difficult to distinguish supergene enrichment of gold grades in low-grade deposits $(<1$ to $\sim 3 \mathrm{~g} / \mathrm{t}$ gold; $\leq 0.1 \mathrm{opt})$ from variations in the distribution of hypogene gold.

Regardless of gold enrichment, mining of nearly all low-grade gold deposits has been enabled by near-surface oxidation of pyrite and other sulfide minerals. Weathering has converted gold, electrum, and gold telluride inclusions and intergrowths with sulfide minerals into discrete gold particles in aggregates of porous iron oxide minerals, facilitating 
recovery by low-cost, high-extraction cyanidation, and making low-grade deposits minable. At Pierina, gold+sulfide mineral assemblages were oxidized by late-stage hypogene fluids as indicated by spatial relations and stable isotope compositions (Fifarek and Rye, 2005).

\section{Hypogene Ore in Low- and Intermediate- Sulfidation Deposits}

\section{Mineralogy and Mineral Assemblages}

Hypogene minerals that define ore in all low- and intermediate-sulfidation deposits are electrum (20-80 atom percent gold, 80-20 atom percent silver), numerous silverantimony-arsenic-copper-sulfide minerals, and silver selenide minerals, including acanthite, pyrargyrite, miargyrite, stephanite, tetrahedrite, polybasite, pearcite, jalpaite, naumannite, and aguilarite (Smith and others, 1982; Vikre, 1985, 1989a, 2007; Izawa and others, 1990; Camprubi and others, 2001a). Gold-silver telluride minerals are relatively abundant in some low-sulfidation deposits (for example, Aginskoe, Russia; Sunshin, Korea; Andreeva and others, 2013; Kim and others, 2012) and in some intermediatesulfidation districts (for example, Lake City district, Colorado, U.S.A., Burbank, 1947; Slack, 1980). Minor amounts of gold ( $>80$ atom percent gold, $<20$ atom percent silver), and small amounts of gold-silver-sulfide-telluride minerals (for example, uytenbogaardtite, sylvanite, petzite, and hessite) occur in many deposits (for example, Bullfrog and Bodie, U.S.A., Eng and others, 1996; Vikre and others, 2015). Electrum compositions vary mostly from approximately $\mathrm{Au}_{0.8} \mathrm{Ag}_{0.2}$ to $\mathrm{Au}_{0.4} \mathrm{Ag}_{0.6}$, and electrum may contain several tenths weight percent copper and sulfur (for example, Vikre, 1985; Izawa and others, 1990; Vikre and Henry, 2011; Vikre and others, 2015).

Silver-antimony sulfosalt minerals are common in large low- and intermediate-sulfidation deposits, whereas silver-antimony-arsenic minerals are somewhat less common, although arsenopyrite, proustite, and other silverantimony-arsenic minerals occur in many deposits (for example, Temascaltepec district, Mexico, Camprubi and others, 2001a), and small amounts of realgar, orpiment, and arsenic are reported at McLaughlin, U.S.A. (Sherlock, 2005). Silver selenides are the dominant silver minerals in some low-sulfidation deposits (for example, Silver CityDelamar, National, Jarbidge, Midas, U.S.A.; Hishikari, Japan; Broken Hills, New Zealand; Vikre, 1985, 2007; Leavitt and others, 2004; Izawa and others, 1990; Cocker and others, 2013), whereas they are uncommon or undocumented in intermediate-sulfidation deposits.

In some low-sulfidation deposits, paragenetically late stibnite, cinnabar, metacinnabar, and tiemannite occur in vein centers, crosscutting fractures, and peripheral veins, and in paleosurface deposits (sinter, sinter breccia, vent breccia, eruption breccia, epiclastic deposits; National; Hishikari, Japan; Ivanhoe, U.S.A.; McLaughlin; Tui, New Zealand;
Vikre, 1985, 2007; Izawa and others, 1990; Bartlett and others, 1991; Sherlock, 2005; Christie and others, 2007). Minor amounts of mercury were recovered from associated paleosurface deposits overlying gold-silver veins in several relatively uneroded districts (for example, National, McLaughlin, and Ivanhoe, U.S.A).

In addition to pyrite and marcasite and other gangue minerals, chalcopyrite and other copper minerals, galena, and sphalerite commonly occur with ore minerals, and in some intermediate-sulfidation deposits, minor to significant amounts of copper, lead, and zinc were recovered (for example, Comstock Lode, Bonham and Papke, 1969; Tonopah, Bonham and Garside, 1979; districts in Mexico, Albinson and others, 2001; districts in the San Juan Mountains, Colorado, U.S.A., including Creede, Eureka [Sunnyside mine], Animas, SneffelsRed Mountain [Camp Bird mine], and Telluride, Emmons and Larsen, 1923). Gold and silver values defined ore in the Comstock Lode and Tonopah districts, but byproduct base metal recovery probably sustained mining in many intermediate-sulfidation districts.

Sphalerite in low- and intermediate-sulfidation deposits, where analyzed, mostly contains less than 1-5 mole percent $\mathrm{FeS}$, although sphalerite in low-sulfidation deposits in the National and Temascaltepec districts contains as much as 17 mole percent FeS (for example, Vikre, 1985, 2007; Izawa and others, 1990; John, 2001; Camprubi and others, 2001b; Vikre and Henry, 2011; Andreeva and others, 2013; Mango and others, 2014). Sphalerite, electrum, and gold compositions, where constrained by coexisting pyrite and acanthite, broadly distinguish low- and intermediate-sulfidation deposits from high-sulfidation epithermal deposits (see "Definition and Classification of Epithermal Gold-Silver Deposits").

\section{Zoning Patterns}

Low- and intermediate-sulfidation deposits form during multiple stages of dilation, brecciation, and mineral deposition in fault zones, reflecting sustained mechanical stress and hydrothermal fluid flow. Paragenetic relations among vein stages are more easily correlated than in high-sulfidation deposits, because veins generally have consistent tabular aspects and relatively abrupt contacts with wall rock. On a local scale, many vein stages are cospatial, and at the scale of an entire vein, they overlap along strike or dip. Vein stages include internal, concordant mineral assemblages, crosscutting assemblages, and concordant and discordant breccias that are described in section "Hypogene and Supergene Gangue Characteristics." Predictable vein geometry and visual distinctions between vein stages have facilitated numerous detailed descriptions of time-space relations among mineral assemblages that comprise vein stages (Bastin and Laney, 1918; Slack, 1980; Vikre, 1985, 2007; Shimizu and others, 1998; Fifarek and others, 1996).

Lateral zoning of ore minerals at deposit scale is broadly reflected by abundances of associated gangue minerals and lateral distribution of vein stages (see "Hypogene and Supergene Gangue 
Characteristics"), by silver/gold (for example, Tayoltita; Smith and others, 1982), and by hydrodynamic reconstructions based on mineral and fluid compositions (including fluid inclusion microthermometry and stable isotope compositions summarized in the section "Geochemical Characteristics"). Base metal sulfide minerals are commonly most abundant in the geographic and interpreted thermal centers of large districts (for example, Guanajuato, Comstock Lode; Mango and others, 2014; Vikre, 1989a), and their abundance also broadly corresponds to zoning of gangue minerals (for example, Tayoltita, Comstock Lode; Smith and others, 1982).

Vertical zoning of ore minerals in low- and intermediatesulfidation deposits at deposit scale is broadly reflected by the distribution of gold and silver minerals and mine stopes, and, where determined, by hydrodynamic reconstructions. In many large multivein districts, ore minerals are most abundant in subhorizontal tabular to downward concave zones with lateral dimensions of many kilometers and vertical dimensions of hundreds of meters (for example, Guanajuato, Tonopah, Tayoltita, Comstock Lode, Moncada and others, 2012; Mango and others, 2014; Nolan, 1935; Smith and others, 1982; Vikre, 1989a; Christie and others, 2007). These "favorable" or "productive" zones are generally parallel or subparallel to erosion surfaces and (or) paleosurfaces, and their upper margins are tens to hundreds of meters below those surfaces. Irregular lower margins of zones are largely defined by minable vein grades and widths combined with costs of deep mining (including water control). These zones are as much as 1,000 $\mathrm{m}$ in vertical dimension (Tayoltita; Comstock Lode; Smith and others, 1982; Vikre, 1989a), and are thickest in large intermediate-sulfidation vein districts. Within mined intervals of some low-sulfidation deposits, concentrations of base metal sulfide (chalcopyrite, galena, sphalerite) and silver minerals increased with depth (for example, McLaughlin; Sherlock and others, 1995), and in others, coarser grained, base metal-rich veins occurred at elevations hundreds of meters deeper than stoped silver-gold-enriched veins (for example, Guanajuato, Mango and others, 2014).

\section{Paragenesis}

On a vein scale, paragenesis in layered veins is reflected by paired layers of ore and gangue minerals that have filled dilatencies from margins inward, and by veins and breccias that crosscut or parallel earlier veins and are composed of the same or different mineral assemblages as earlier veins (fig. I2; see "Hypogene and Supergene Gangue Characteristics"). For example, at Aginskoe, gold $\left(\mathrm{Au}_{0.86-}\right.$ $\left.{ }_{0.95} \mathrm{Ag}_{0.14-0.05}\right)$ is dominant in $\mathrm{Au}-\mathrm{Ag}$-Te mineral+chalcopyrite veins, whereas electrum $\left(\sim \mathrm{Au}_{0.6-0.5} \mathrm{Ag}_{0.4-0.5}\right)$ occurs in veins in which pyrite is the dominant sulfide mineral (Andreeva and others, 2013). At millimeter and micron scales, paragenesis is recognized by observing diverse features, such as quartz textures that commonly reflect self organization (for example, Ostwald ripening) of initial amorphous and microcrystalline silica phases, by crosscutting relationships, by numerous replacement textures, and by growth zoning in crystals, features common to most magmatic-hydrothermal metal deposits (Bastin and Laney, 1918; Ramdohr, 1980; Saunders and Schoenly, 1995; see "Hydrothermal Structures").

In intermediate-sulfidation deposits, paragenesis is similarly recognized as discordant mineral assemblages superimposed on earlier assemblages (for example, Lake City, Slack, 1980; Tayoltita, Smith and others, 1982; Comstock Lode, Vikre, 1989a), by various replacement textures, and by crystal zoning. Many intermediate-sulfidation deposits with gold, silver, and base metals consist of veins with numerous stages that are nested on a local scale and laterally zoned on vein and district scales (for example, Lake City district, Colorado, Slack, 1980).

Individual veins in some large intermediate-sulfidation districts formed during several mostly concordant stages, few to no discordant stages, and little medial (temporal or spatial) brecciation (for example, Tonopah; Tayoltita; Bastin and Laney, 1918; Smith and others, 1982). At Tonopah, variable vein textures compose a largely continuous sequence of concordant mineral layers deposited by open-space filling and replacement of gouge and wall-rock fragments in fault zones (fig. I3; Bastin and Laney, 1918). Apart from millimeter- to centimeter-wide pyrargyrite veins, there are few volumetrically and economically significant discordant mineral assemblages. Other intermediate-sulfidation deposits formed by circulation of hydrothermal fluids in faults that episodically ruptured. In the Comstock Lode fault zone, numerous generations of gangue minerals, some containing ore and other sulfide minerals, cement multigenerational breccias by replacing gouge and breccia fragments and by filling open spaces between fragments (fig. I3; Vikre, 1989a).

\section{Textures and Grain Size}

Gold and silver minerals in both low- and intermediatesulfidation deposits occur as discrete, submicron- to millimeter-size crystals and crystalline aggregates in quartz, and less commonly, adularia and carbonate minerals, as inclusions in sulfide and selenide minerals, and intergrown with millimeter- to centimeter-size aggregates of sulfide, selenide, quartz and other silicate minerals, including adularia, $\mathrm{K}-\mathrm{Ca}-\mathrm{Na}-\mathrm{Mg}$ phyllosilicate minerals (sericite [fine-grained illite or muscovite] and smectite minerals), carbonate minerals, and chlorite.

Electrum, other silver minerals, and other sulfide-selenide minerals in low-sulfidation deposits are usually evenly distributed within single millimeter-wide quartz \pm adularia layers, or compose separate layers, both of which visually contrast with adjacent white to beige silicate or carbonate layers. Locally, ore minerals compose dendritic to sagenitic aggregates, and clots of very fine-grained crystals that are semiregularly spaced in one to many parallel quartz \pm adularia layers. Individual veins consist of tens to hundreds of symmetrically opposed layers that initially encrusted the 
margins of open fractures and then successively encrusted preceding layers (fig. E11). Higher frequencies of dark vein layers and vein layers with clots correlate with elevated gold and silver grades; ore and associated metallic minerals compose as much as several volume percent of high-grade veins (fig. I2).

Electrum and other silver minerals in intermediatesulfidation deposits typically occur with gangue minerals in indistinct layers that parallel wall-rock contacts, in aggregates with little discernable crystal orientation or association, and in pronounced layers that parallel wall-rock contacts and encrust breccia fragments. Layers and aggregates consist of variable proportions of ore minerals, sulfide minerals, quartz, and other gangue minerals; ore and associated metallic minerals may compose tens of volume percent of veins (fig. I3). In general, intermediate-sulfidation vein minerals are coarser grained than in low-sulfidation veins, and layers, aggregates, and vugs commonly consist of millimeter- to centimeter-size crystals.

\section{Supergene Ore in Low- and Intermediate- Sulfidation Deposits}

Gold, produced by dissolution of silver in electrum during weathering, and silver and copper minerals (for example, silver, chlorargyrite, acanthite, pyrargyrite; copper, covellite, chalcocite, malachite) derived from weathering of sulfide minerals, were recovered in the near-surface segments of many low- and intermediate-sulfidation deposits (for example, El Peñón, Chile, Warren and others, 2004, 2008; Bullfrog, Eng and others, 1996; Comstock Lode; Tonopah, Bastin and Laney, 1918). Enrichment was an important factor in the mining economics of some silverrich intermediate-sulfidation deposits (for example, Creede, Emmons, 1917; Emmons and Larsen, 1923), and the common association of gold and manganese oxides (for example, Bullfrog, Midas, Uncompaghre, and Telluride districts, U.S.A., Ransome, 1901; Emmons, 1917) implies weathering-related enrichment of gold. However, recognition of significant enrichment of gold,

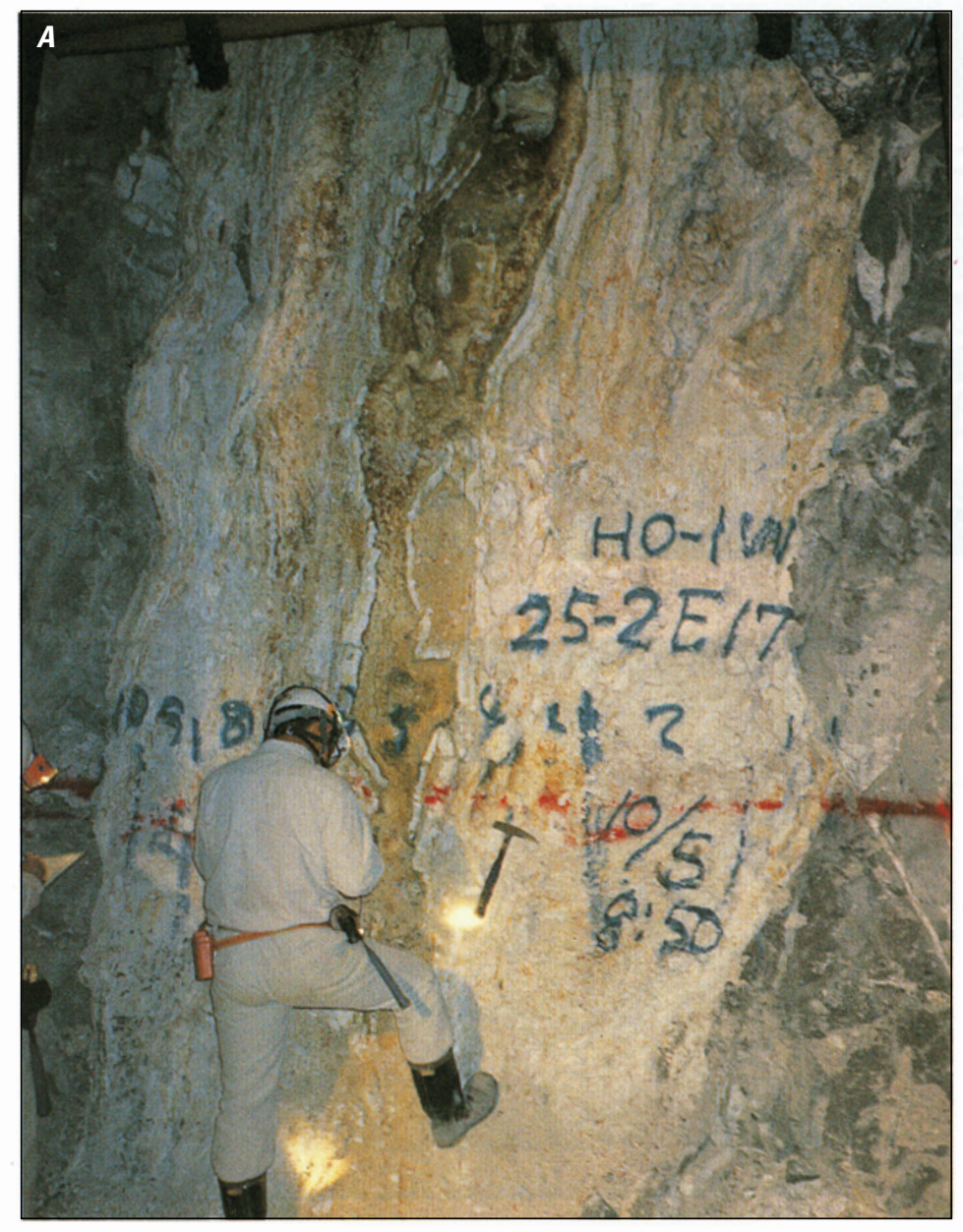

Figure 12. Photographs of low-sulfidation quartz-adularia veins. $A$, Yamada gold-silver vein, Hishikari, Japan (Shikazono and Nagayama, 1993). $B$, Colorado Grande gold-silver vein, Midas, U.S.A. C, Bell gold-silver vein, National, U.S.A. (Vikre, 2007). cm, centimeters.
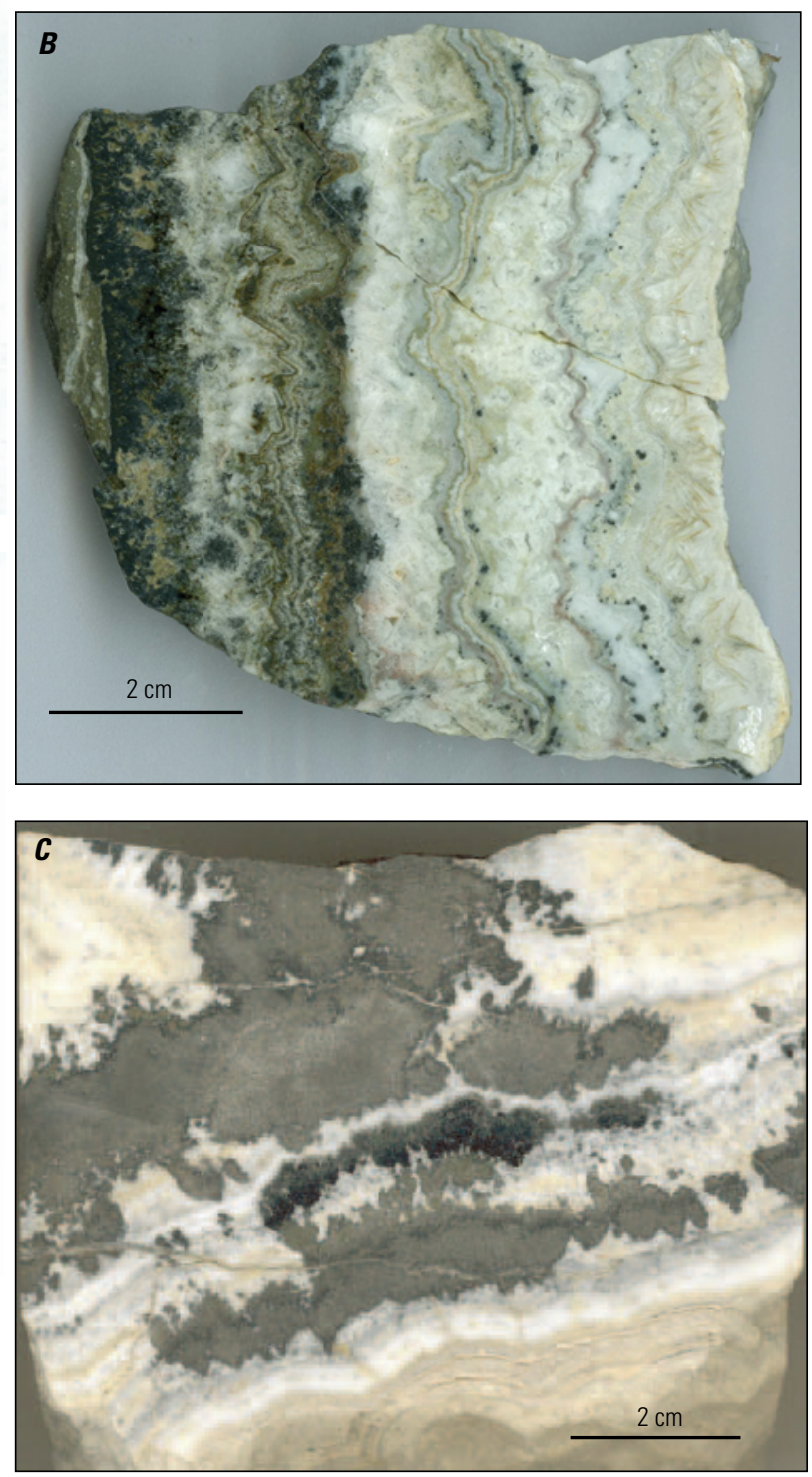

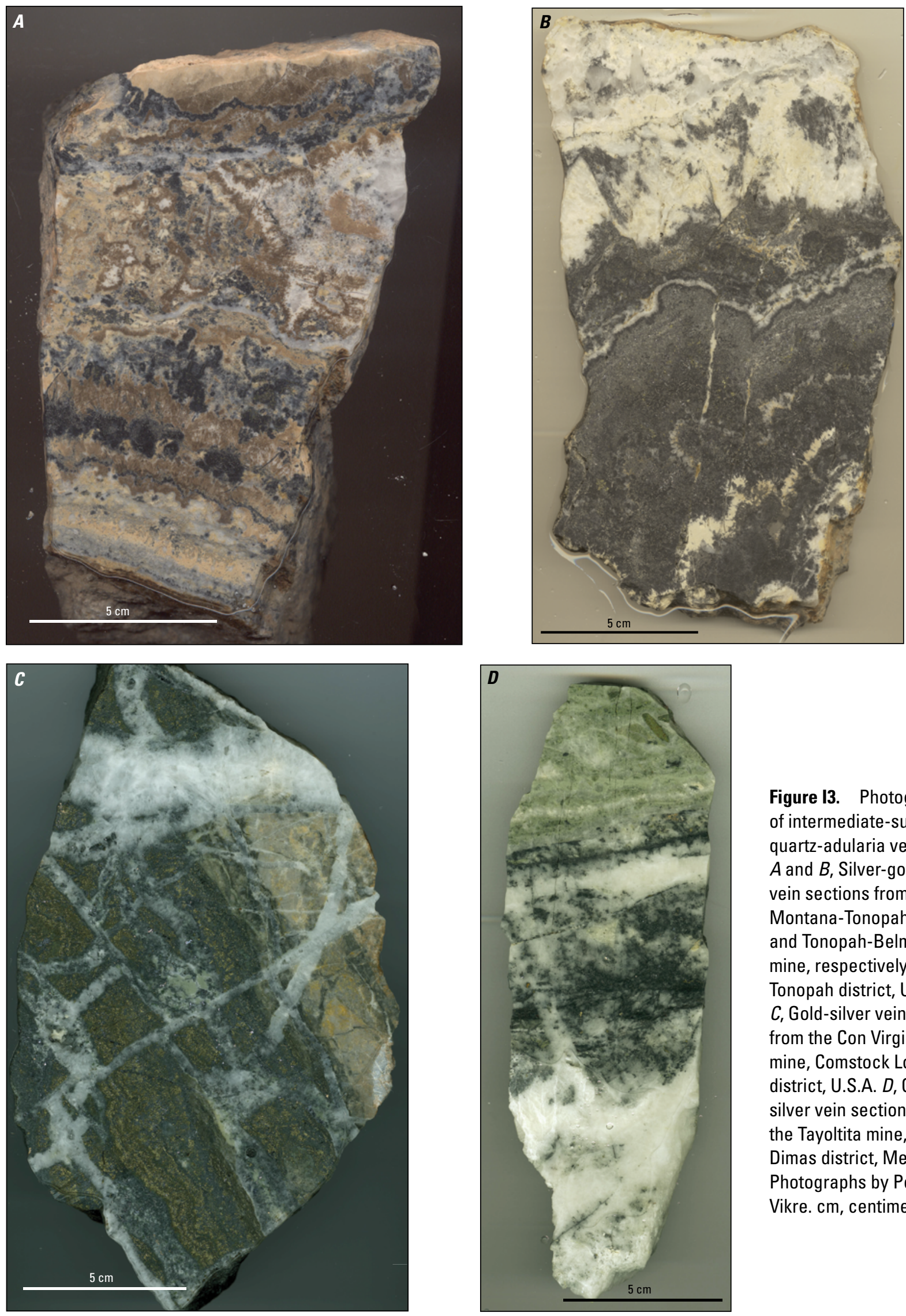

Figure I3. Photographs of intermediate-sulfidation quartz-adularia veins. $A$ and $B$, Silver-gold vein sections from the Montana-Tonopah mine, and Tonopah-Belmont mine, respectively, Tonopah district, U.S.A.; $C$, Gold-silver vein section from the Con Virginia mine, Comstock Lode district, U.S.A. D, Goldsilver vein section from the Tayoltita mine, San Dimas district, Mexico. Photographs by Peter Vikre. cm, centimeters. 
copper, and especially silver in veins is complicated by vertical zoning and uneven distribution of hypogene ore and sulfide minerals in veins, incomplete records of production and early mining practices, and uncertainty in determining mineral origin on the basis of textural and paragenetic relationships (Emmons, 1917; Bastin and Laney, 1918; Ramdohr, 1980; Cocker and others,
2013). Although initial mining of relatively near-surface vein segments probably benefitted financially from locally enriched gold, silver, and copper grades, the abundance of hypogene ore minerals determined minability of low-sulfidation and most intermediate-sulfidation deposits, especially those with large gold and silver production. 



\title{
Chapter J. Hypogene and Supergene Gangue Characteristics
}

\author{
By Peter G. Vikre
}

\section{Hypogene Gangue in High-Sulfidation Deposits}

\section{Mineralogy}

Hypogene gangue in high-sulfidation deposits consists of valueless minerals that coexist with ore minerals. If gangue minerals can be separated from ore at the scale of mining, then they are discarded as waste. If gangue minerals are inseparable from ore minerals during mining, then they are either separated by milling and discarded as tailings or they remain in heap leach piles after cyanidation to recover gold and silver. Hypogene gangue minerals are predominantly quartz, lesser other silica minerals, and lesser potassium-aluminum-silicatehydroxide, sulfide, and sulfate minerals.

Quartz and chalcedony are the most widespread and abundant gangue minerals. Aluminosilicate, aluminum hydroxide, and potassium aluminum silicate gangue minerals that occur in most deposits include kaolinite, dickite, pyrophyllite, and sericite (fine-grained illite or muscovite); zunyite, topaz, and diaspore are reported in a few deposits (appendix 1). Sulfide gangue minerals common to all deposits are pyrite and lesser marcasite, although gold has been recovered from pyrite in some deposits. A large number of subordinate $\mathrm{Cu}-\mathrm{As}-\mathrm{Sb}-\mathrm{Pb}-\mathrm{Fe}-\mathrm{Zn}$-Bi-Ag-Sn-V-S-Se-Te minerals, described in section "Hypogene and Supergene Ore Characteristics," are intergrown with gold in many deposits. These minerals are mostly not recovered or processed except in mines that produce copper and silver in addition to gold. Sulfate gangue minerals include alunite, barite, and rare gypsum. In some deposits, sulfur (occasionally with alunite, enargite, pyrite, cinnabar, and other sulfide minerals) occurs in voids, former sites of phenocrysts and rock fragments, and in breccia matrices, where it is a late stage gangue mineral.

In many gold-copper-silver deposits gangue minerals other than quartz and sulfide minerals are largely confined to altered wall rocks which, to varying degrees, are spatially separated from ore. However, in many low-grade deposits quartz, aluminum-potassium-silicate minerals, sulfide minerals, and sulfate minerals are bulk mined with ore minerals because they are inseparable from ore minerals at the scale of mining.

\section{Mineral Assemblages, Paragenesis, and Zoning Patterns}

Hypogene gangue minerals occur with ore minerals in temporal (paragenetic) and spatial (zoning) relations that are described in sections "Hypogene and supergene ore characteristics" and "Hydrothermal Alteration."

\section{Textures and Grain Size}

Hypogene quartz and lesser chalcedony, mostly occur in subequigranular and fine-grained $(<1 \mathrm{~mm})$ to microcrystalline aggregates that commonly include gold, copper, and silver ore minerals, pyrite, and other $\mathrm{Cu}-\mathrm{As}-\mathrm{Sb}-\mathrm{Pb}-\mathrm{Fe}-\mathrm{Zn}$-Bi-Ag$\mathrm{Sn}-\mathrm{V}-\mathrm{S}-\mathrm{Se}-\mathrm{Te}$ minerals (see "Hypogene and Supergene Ore Characteristics"). Coarse-grained (millimeter-centimeter) quartz, alunite, and sulfide minerals (enargite, pyrite, galena, sphalerite, chalcopyrite, covellite, and cinnabar) occasionally fill or encrust veins, breccia matrices, and voids that represent leached phenocrysts and rock fragments. In some deposits, these coarse-grained, usually easily separated minerals have been analyzed for stable and radiogenic isotope compositions $(\mathrm{H}, \mathrm{O}, \mathrm{S}, \mathrm{Pb}, \mathrm{Re}-\mathrm{Os}, \mathrm{Sr}, \mathrm{Ar})$ and used to characterize fluid inclusion phase relations, compositions, and microthermometric properties (see "Geochemical Characteristics").

\section{Supergene Gangue in High-Sulfidation Deposits}

Supergene gangue minerals in high-sulfidation deposits consist of minerals that formed during one or more weathering cycles by reactions between oxygenated groundwater and hypogene minerals, earlier formed supergene minerals, and primary minerals in wall rocks. Similar to hypogene gangue minerals, supergene gangue minerals are discarded as mine waste, mill tailings, or heap leach residue.

Supergene gangue minerals are predominantly hydroxides, and lesser sulfate, sulfide, aluminum silicate, silicate, oxide, and phosphate minerals. Iron hydroxides, mostly goethite, limonite, and hematite, occur in all deposits and formed by weathering of pyrite and other sulfide minerals. Scorodite, an iron-arsenic hydroxide derived from weathering of coexisting pyrite and $\mathrm{Cu}-\mathrm{As}-\mathrm{S}$ minerals (for example, enargite and famatinite), occurs in many deposits.

The supergene iron and silver sulfate minerals, jarosite and argentojarosite, and the $\mathrm{K}-\mathrm{Ca}-\mathrm{Na}$ sulfate minerals, alunite and gypsum, occur in variable, but generally low abundances (several percent or less) in many deposits. Barite is considered supergene in some deposits (for example, Mulatos, Staude, 2001; La Coipa, Oviedo and others, 1991b; Yanacocha, Longo and Teal, 2005; Longo and others, 2010), although barite, like alunite, is a fairly common mineral in hypogene mineral 
assemblages. Components of supergene sulfate minerals are derived from decomposition of feldspars and mafic minerals in wall rocks, and sulfide minerals.

Supergene copper and silver sulfide minerals, including chalcocite, covellite, digenite, and acanthite, and supergene silver and copper, are reported in many deposits. These minerals were derived from decomposition of hypogene and supergene $\mathrm{Cu}-\mathrm{Ag}$-S-bearing minerals. Because of low abundances, they are usually not recovered. However, in some deposits, these minerals have locally increased copper and silver concentrations in ore (for example, El Indio; Jannas and others, 1990, 1999), although the effects of this enrichment on mining economics do not appear to be significant. Gold, electrum, and silver are considered or suspected to be supergene in a number of deposits and supergene or residual enrichment may have slightly increased gold grades in these deposits (for example, Mulatos, Staude, 2001; Veladero, Charchaflié and others, 2007; Yanacocha, Longo and Teal, 2005; Longo and others, 2010; La Coipa, Oviedo and others, 1991b; Rodalquilar, Arribas and others, 1995a; Nansatsu, Hedenquist and others, 1994).

The aluminum silicate and silicate minerals, kaolinite and dickite, and chalcedony, are considered supergene in a few deposits (for example, Mulatos; Staude, 2001). Supergene phosphate minerals and tin, manganese, and tellurium oxide and hydroxide minerals have been observed in a small number of deposits (for example, Goldfield, Ransome and others, 1909; Tambo, Jannas and others, 1999; Deyell and others, 2005b; Yanacocha, Longo and Teal, 2005; Longo and others, 2010; Rodalquilar, Arribas and others, 1995a).

Supergene and hypogene gangue minerals are distinguished by mineral modes, crystal forms, and compositions (chemical and isotopic), by textural and paragenetic relationships including the presence or absence of sulfide minerals, by age, and by position relative to the erosion surface or paleowater table. Despite these distinguishing criteria, determining the hypogene or supergene origin of some common epigenetic minerals (for example, alunite, barite, and kaolinite) is commonly difficult. Radiometric and stable isotope compositions have been used to determine ages and genesis of minerals with equivocal origin (for example, alunite, kaolinite; Summitville, Bethke and others, 2005; Tambo, Deyell and others, 2005b; Russin and Fifarek, 2009; see "Geochemical Characteristics").

\section{Hypogene Gangue in Low- and Intermediate- Sulfidation Deposits}

\section{Mineralogy}

Hypogene gangue minerals and phases in low- and intermediate-sulfidation deposits are predominantly quartz, chalcedony, adularia and calcite, and in some veins, variable amounts of sericite (fine-grained illite or muscovite), Ca-Fe$\mathrm{Mn}-\mathrm{Mg}$ smectite minerals, vermiculite, chlorite, kaolinite, manganese minerals (rhodochrosite, rhodonite), albite, other carbonate minerals (dolomite, siderite), barite, fluorite, and zeolite minerals, which usually comprise no more than several volume percent of deposits. Pyrite, marcasite, and numerous other sulfide gangue minerals (for example, chalcopyrite, sphalerite, galena, and arsenopyrite) that are not recovered from most deposits compose less than one to tens of volume percent of deposits. These gangue minerals, and ore minerals, mostly occur in tabular veins and fault breccias that are enclosed by unmineralized wall rocks and can be selectively mined. Most low-sulfidation deposits consist of more than 90 volume percent quartz, chalcedony, and other silicate and carbonate minerals, whereas widely varying abundances of silicate, carbonate, and sulfide gangue minerals occur in intermediate-sulfidation deposits.

Hypogene gangue minerals in mined epiclastic and paleosurface strata (sinter, sinter breccia, vent breccia, and eruption breccia), and in stockwork veins above some low-sulfidation deposits in uneroded districts (for example, Republic, Fifarek and others, 1996; Ivanhoe, Bartlett and others, 1991; McLaughlin, Sherlock and others, 1995; Bodie, Vikre and others, 2015; and Hycroft [Sulphur], Ebert and Rye, 1997), include opaline silica, chalcedony, porcelainous quartz, pyrite, marcasite, adularia, and clay minerals, mainly kaolinite. In some low-sulfidation deposits, silicate minerals in veins, wall rocks, and epiclastic deposits overlying veins within several hundreds of meters of paleosurfaces and paleowater tables, have been altered to illite, kaolinite, and alunite (for example, National [Buckskin Mountain], Vikre, 2007; Hog Ranch, Bussey, 1996; Ivanhoe, McLaughlin, and Hycroft). These minerals formed in groundwater acidified by oxidation of $\mathrm{H}_{2} \mathrm{~S}$ exsolved during boiling of subjacent hydrothermal fluids (steam-heated [SH] alunite; see "Hydrothermal Alteration").

\section{Mineral Assemblages, Paragenesis, and Zoning Patterns}

Hypogene gangue and ore minerals compose assemblages that are artificially separated by the economic distinctions "ore" and "gangue." Some paragenetic (temporal) and zoning (spatial) relationships among gangue minerals are described below.

Parageneses of gangue minerals are no different than parageneses of ore minerals, because the two economically categorized groups of minerals are invariably intergrown in coeval assemblages. Low- and intermediate-sulfidation deposits commonly consist of an initial vein mineral assemblage and later concordant or discordant vein and breccia stages. Later veins and breccias may be internal, tangential, or subparallel to earlier veins, or may crosscut earlier veins at moderate to high angles (for example, Hishikari, Nagayama, 1993; Naito, 1993; Republic, Fifarek and others, 1996; Lake City and Sneffels-Red Mountain districts, Slack, 1980; Hutchinson, 1988). All stages may consist of similar to different mineral assemblages, and different mineral assemblages are commonly used to distinguish stages. Breccias include fragments of wall rocks that are variably replaced by fine-grained quartz, silica minerals, potassium-aluminum silicate minerals, sulfide minerals, and in some instances, ore minerals, 
and fragments of earlier vein mineral assemblages. Breccia matrices usually consist of fine-grained quartz, potassiumaluminum silicate minerals, pyrite and other sulfide minerals, and in some cases, ore minerals. In general, later vein and breccia stages maintain structural continuity with the initial vein mineral assemblage, demonstrating sustained mechanical stress and hydrothermal fluid flow.

All or some vein and breccia stages may contain ore minerals in sufficient quantities to make entire segments of veins minable. At Hishikari, elevated gold and silver grades occur in layers predominantly consisting of adularia (adularia/quartz $>0.5$; Faure and others, 2002). However, late vein and breccia matrices commonly consist of quartz and (or) calcite that dilute metal grades of the entire vein, because these barren stages usually cannot be separated at the scale of mining.

Calcite in vein deposits is usually, but not always, a paragenetically late gangue mineral that composes the central parts of veins, fills crosscutting fractures, and encrusts lenticular to ovoid vugs in vein layers and centers. In the low-sulfidation deposits in the Midas and Bullfrog districts, U.S.A. (Eng and others, 1996; Leavitt and others, 2004; Leavitt and Arehart, 2005), calcite layers are paragenetically early and late. In these and other low-sulfidation deposits (for example, Torres mine, Guanajuato district, Mexico, Buchanan, 1981; Moncada and others, 2012; Mango and others, 2014), calcite, in part, coexists with ore minerals. A bladed form of calcite is common in internal vugs in low-sulfidation veins where it commonly has been replaced by quartz, or is represented by perimorphous quartz euhedra that enclose tabular voids left by dissolution of bladed calcite (fig. E11G; consult Vikre and others, 2015). Calcite euhedra in some instances cover quartz and sulfide euhedra in vugs. In some large intermediate-sulfidation districts, calcite is the predominant gangue mineral in veins that are distal to quartz-sulfide mineraldominant veins; in these veins calcite apparently coexists with ore minerals (for example, Occidental vein, Comstock Lode, U.S.A., Vikre, 1989a; Cedral vein, Tayoltita mine, San Dimas district, Mexico, Smith and others, 1982).

In some multivein low- and intermediate-sulfidation districts, lateral zoning of gangue minerals is manifested by broadly consistent proportions of quartz, adularia, other silicate minerals, and calcite (for example, Simpson and Mauk, 2011). In low-sulfidation veins in the Bullfrog district, distal parts of mineralized veins contain a higher proportion of calcite relative to mined segments of veins (Eng and others, 1996). In intermediatesulfidation veins in the Tayoltita mine, gangue minerals in the easternmost Arana vein are dominantly quartz, adularia, and chlorite, whereas adjacent veins to the west are composed largely of quartz, manganese silicate minerals (rhodonite, johannsenite), and lesser albite. Distal veins to the north primarily consist of quartz and calcite (Smith and others, 1982). In the Comstock Lode district, intermediate-sulfidation veins in the Comstock Lode and Silver City faults consist predominantly of quartz, adularia, and sulfide minerals, whereas veins in the Occidental Fault $\sim 1.5 \mathrm{~km}$ to the east and veins in the southern part of the district include large proportions of calcite (Vikre, 1989a). Lateral (and vertical) zoning of gangue and ore mineral assemblages is pronounced in many intermediate-sulfidation districts in the San Juan Mountains, Colorado (for example, Slack, 1980).

Vertical zoning of gangue minerals has been qualitatively described for uneroded low-sulfidation deposits. In mined epiclastic and paleosurface strata, and in near-surface stockwork veins, chalcedony and opaline silica are abundant. Quartz in subjacent veins, and in internal and tangential, vein-parallel breccias near the paleosurface, is fine grained and becomes progressively coarser grained with depth, although quartz crystals in deep vein layers seldom exceeds $1 \mathrm{~mm}$ in dimension (for example, National, Vikre 1985, 2007; McLaughlin, Sherlock and others, 1995). Based on petrography, X-ray diffraction analyses, and infrared spectral analyses, fine-grained and incompletely ordered hydrous potassium-silicate minerals (illite structure) in near-surface vein segments also become progressively coarser grained and crystalline (muscovite structure) in deeper vein segments (Bodie, Vikre and others, 2015; National; Republic, Fifarek and others, 1996; Hauraki Goldfield deposits, New Zealand, Christie and others, 2007). Vertical zoning of gangue minerals in intermediate-sulfidation veins is reflected by increased abundances of illite and kaolinite in wall rocks adjacent to and overlying near-surface vein segments known or suspected to have been deposited by fluids that at least intermittently boiled (Comstock Lode, Tonopah, U.S.A., Vikre 1989a; numerous vein deposits in Mexico, Albinson and others, 2001).

\section{Textures and Grain Size}

Quartz textures and grain sizes largely define layered veins (fig. E11). Most vein layers are millimeters to one centimeter thick and consist entirely of quartz, chalcedony, or calcite. Some vein layers consist entirely of adularia (and pseudomorphs) or ore and sulfide minerals, and many are variably composed of quartz, adularia (and pseudomorphs), ore minerals, and sulfide minerals (fig. I2). Grain sizes of quartz and other minerals in layers generally increase with depth.

Quartz and lesser adularia (and pseudomorphs) that define many vein layers consist of millimeter to about one centimeter acicular crystals oriented orthogonally between layer margins, and very fine-grained equigranular, anhedral quartz aggregates between the acicular crystals. The layers are usually white to beige, depending on adularia content, and on degree of alteration of adularia to illite and kaolinite. Dendritic trains of liquid and solid inclusions that span the inter-acicular quartz aggregates indicate that layers originated as "forests" of silica dendrites that nucleated on the subjacent layer and were densified by rapid nucleation of amorphous silica and self-organization (Ostwald ripening) of quartz crystals between dendrites. In ore, quartzadularia layers alternate with layers of quartz containing clots and aggregates (in petrographic section) of ore and sulfide minerals that are modified dendrites (see "Hypogene and Supergene Ore Characteristics"). Infrequent millimeter- to centimeter-thick, graytone layers consist of microcrystalline quartz in semi-equigranular aggregates, and aggregates of relatively coarse-grained quartz crystals (as much as $\sim 1 \mathrm{~mm}$ ). Lenticular to pod-like vugs lined 
with quartz and uncommon ore and sulfide minerals occur between some layers, but are mostly located in vein centers where they compose the surfaces of the youngest opposing layers. Vein center vugs and pods, as much as tens of centimeters in length, are commonly lined with calcite and quartz pseudomorphs and perimorphs.

Quartz and sulfide minerals, the predominant gangue minerals in intermediate-sulfidation veins, occur in subequigranular aggregates with ore minerals that are either unoriented relative to wall-rock contacts and breccia fragments, or indistinctly layered parallel to wall-rock contacts. Locally, gangue and ore mineral assemblages compose relatively distinct centimeter-thick layers (fig. I3). Relative to low-sulfidation vein gangue (and ore) minerals, intermediate-sulfidation vein minerals are commonly coarser grained with millimeter to centimeter crystal dimensions, and millimeter to centimeter euhedra encrusting vugs.

Crystal morphology, size, and paragenetic position of gangue minerals, primarily quartz, calcite, and adularia, have been used to infer physical properties of hydrothermal fluids (boiling; $\mathrm{CO}_{2}$ degassing), based largely on fluid inclusion microthermometry and by comparison to geothermal fields in which temperatures and compositions of hydrothermal fluids are easily measured (for example, Moncada and others, 2012).

\section{Supergene Gangue in Low- and Intermediate- Sulfidation Deposits}

Supergene gangue minerals in low- and intermediatesulfidation deposits consist of valueless minerals that formed at and near erosion surfaces by weathering, and, along with hypogene gangue minerals, are discarded as mine waste, mill tailings, or heap leach residue.
Supergene gangue minerals generally make up small percentages of low- and intermediate-sulfidation deposits. They include iron hydroxides (goethite, limonite, and hematite) derived from oxidation of pyrite and other sulfide minerals by weathering, clay minerals, manganese oxide minerals, and silica minerals. Small amounts of sulfate minerals (for example, jarosite, gypsum, alunite, barite, and anglesite), and metal sulfide and carbonate minerals (for example, covellite, chalcocite, malachite, and cerrusite), have been assigned supergene origins on the basis of mineral textures and associations (for example, Emmons, 1917; Bastin and Laney, 1918), position relative to erosion surface, and isotope compositions. Supergene copper, lead, and other metallic minerals are usually present in small amounts in most deposits and were not recovered during initial mining.

Based on production records, descriptions of nearsurface, oxidized (by weathering) mineral assemblages (for example, Emmons, 1917; Bastin and Laney, 1918), and descriptions of initial mining and milling practices, supergene gangue minerals have not significantly affected the mining economics of most low- and intermediate-sulfidation deposits. However, in some deposits, clay and silica phases (supergene and hypogene) have increased milling costs by requiring additional comminution for separation of ore and clay minerals, and for liberation of encapsulated ore minerals. In low-grade deposits, heap leach recoveries have been impeded or prolonged by solution channeling caused by finely divided supergene and hypogene gangue minerals. In a few deposits, clay minerals have increased mining and handling costs by adhering ore and waste to shovels, trucks, and processing equipment. Mining costs have been marginally reduced by veins in which gangue and sulfide minerals have been disaggregated by dissolution of sulfide minerals during weathering, and by acidic solutions generated by sulfide mineral dissolution. 


\title{
Chapter K. Geochemical Characteristics
}

\author{
By Peter G. Vikre and David A. John
}

\section{Trace Elements and Element Associations}

\author{
By David A. John
}

Published, detailed geochemical studies of epithermal gold-silver deposits are relatively uncommon, and published geochemical characteristics of many deposits are inferred from ore mineralogy. For example, the presence of telluride or selenide minerals in ore samples usually indicates elevated tellurium or selenium contents, respectively. For deposits with published geochemical data, many elements in ore samples have concentration ranges spanning two to four orders of magnitude (parts per million to weight percent). This large range complicates definition of what concentrations constitute anomalous or enriched values. Table K1 summarizes geochemical characteristics of some epithermal gold-silver deposits that have published geochemical data. Elements listed as enriched in this table are subjectively defined either by the cited references or from inspection of published data and comparison to average crustal rock compositions (for example, Rudnick and Gao, 2003).

Epithermal gold-silver deposits are by definition enriched in gold and (or) silver to the point that they can be economically exploited solely for their gold and (or) silver contents. These deposits commonly are enriched in other metals and metalloids that include As, Sb, Hg, Se, Te, Tl, Mo, and (or) W, a group of elements sometimes referred to as the "epithermal suite" and used as pathfinder elements in geochemical exploration (table K1; White and Hedenquist, 1995; Saunders and others, 2014). The relative enrichment of these non-ore elements served as the basis for early classification schemes for epithermal gold-silver deposits (Lindgren, 1933). Most intermediate-sulfidation deposits also are variably enriched in base metals, including $\mathrm{Pb}, \mathrm{Zn}, \mathrm{Cu}$, and $\mathrm{Mo} ; \mathrm{Pb}$ and (or) $\mathrm{Zn}$ are important byproducts of some deposits (appendixes 1,2). In addition to the pathfinder elements, highsulfidation deposits commonly are enriched in $\mathrm{Cu}, \mathrm{Pb}, \mathrm{Zn}, \mathrm{Mo}$, $\mathrm{Bi}$, and (or) $\mathrm{Sn}$, and may be enriched in $\mathrm{Hg}$, $\mathrm{Te}$, and $\mathrm{Se}$. Copper is commonly recovered from these deposits. Barium, fluorine, and boron, which are not normally incorporated into ore or silicate alteration minerals, also are commonly enriched in epithermal gold-silver deposits.

There are large variations in absolute and relative concentrations of gold, silver, and other metals and metalloids in ores within individual deposits, between different deposits within each subtype of deposit, and between the three subtypes of epithermal gold-silver deposits. These variations preclude assignment of a suite of elements that is always anomalous in epithermal gold-silver deposits and generalization of the abundances of individual elements that constitute anomalous concentrations (Hedenquist and others, 2000). As noted by many workers, the best indicator element for gold in epithermal deposits is gold itself (Simmons and others, 2005).

The large variations in concentrations of gold, silver, and other metals and metalloids in epithermal gold-silver deposits reflect the diverse environments in which these deposits form and the complex processes of ore formation (see "Theory of Deposit Formation"; appendixes 1,2). Aspects of epithermal deposits that influence their geochemical diversity include basement and host (wall) rock types, ore fluid sources and compositions, ore fluid and host rock interactions, metal transport mechanisms (ligands that complex metals and liquid versus vapor transport), and ore deposition processes (including boiling, cooling, fluid mixing, or wall-rock reaction). Many deposits show vertical and (or) lateral geochemical zoning (see "Zoning Patterns"; table K1), which reflects temperature and pressure gradients and may indicate variable processes of ore deposition. Epithermal gold-silver deposits also commonly have multiple stages of ore deposition that may have resulted from several distinct ore fluids or from different deposition processes. For example, in the Bodie mining district, California, gold-silver ore was mined from at least three sets of quartz veins, each of which had characteristically different textures, ore mineralogy, and geochemistry, including significantly different $\mathrm{Au} / \mathrm{Ag}$ and $\mathrm{As}, \mathrm{Sb}, \mathrm{Se}, \mathrm{Te}$, and base metal contents (table K1; Vikre and others, 2015).

In summary, low- and intermediate-sulfidation deposits are enriched in gold and (or) silver, commonly have elevated concentrations of As, $\mathrm{Sb}, \mathrm{Hg}$, Se, Te, Tl, and (or) W, and many deposits, notably intermediate-sulfidation deposits, also are enriched in $\mathrm{Pb}, \mathrm{Zn}, \mathrm{Cu}$, and (or) Mo. High-sulfidation deposits are enriched in gold and (or) silver, generally are enriched in $\mathrm{Cu}, \mathrm{Pb}, \mathrm{Zn}, \mathrm{Mo}, \mathrm{Bi}$, and (or) Sn, and may be enriched in $\mathrm{Zn}, \mathrm{Sn}$, $\mathrm{Hg}$, Te, and Se. Barium, fluorine, and boron also are enriched in some deposits of all subtypes.

\section{Zoning Patterns}

\section{By David A. John}

There are relatively few published studies of the vertical and lateral distribution of gold, silver, and other metals and metalloids in epithermal deposits (table K1), and models for geochemical zoning of epithermal gold-silver deposits, especially low-sulfidation deposits, are based largely on analogy with active geothermal systems (for example, White, 1955, 1980; Buchanan, 1981; Berger and Eimon, 1983; Henley and Ellis, 1983; Silberman and Berger, 1985). 


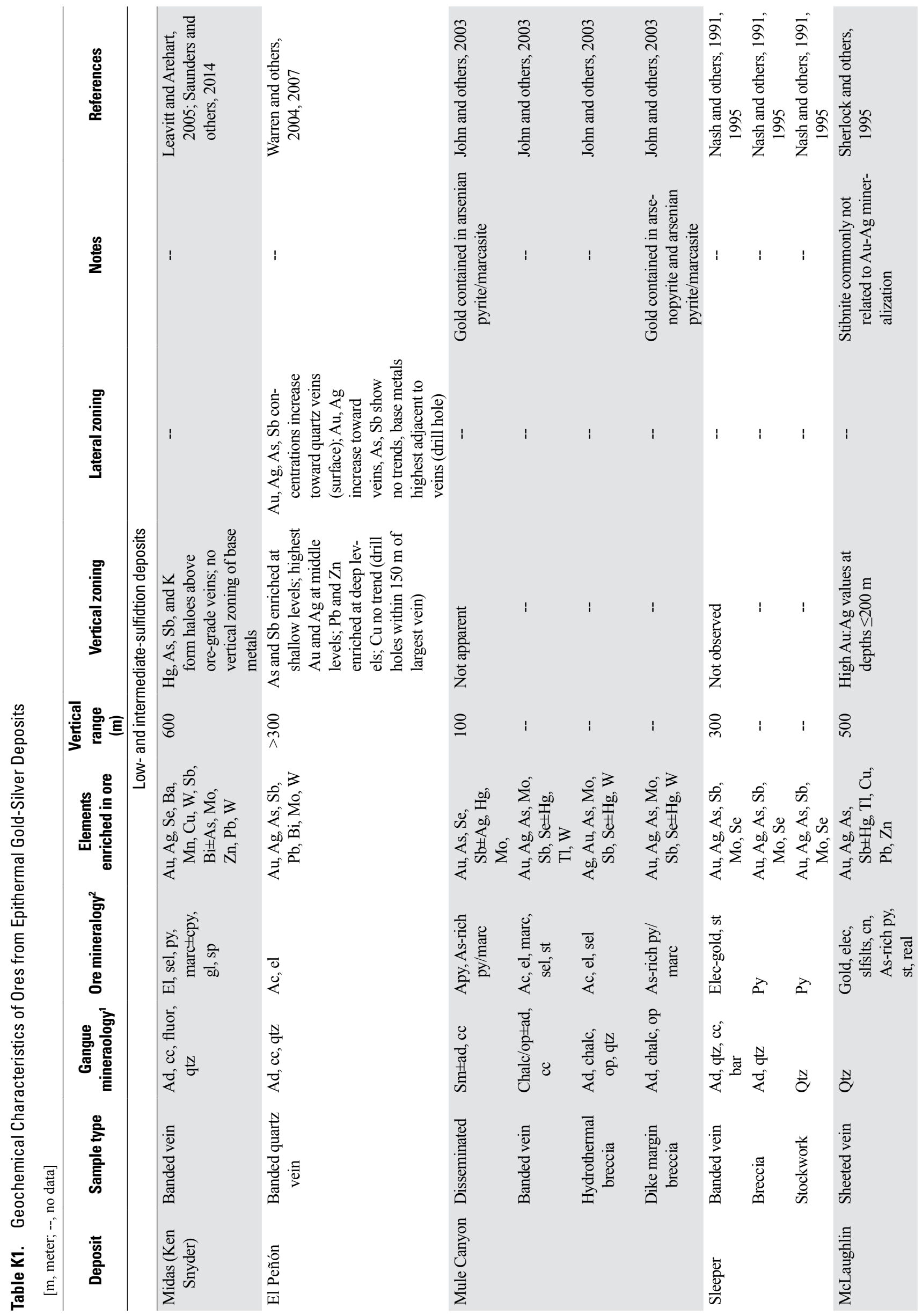




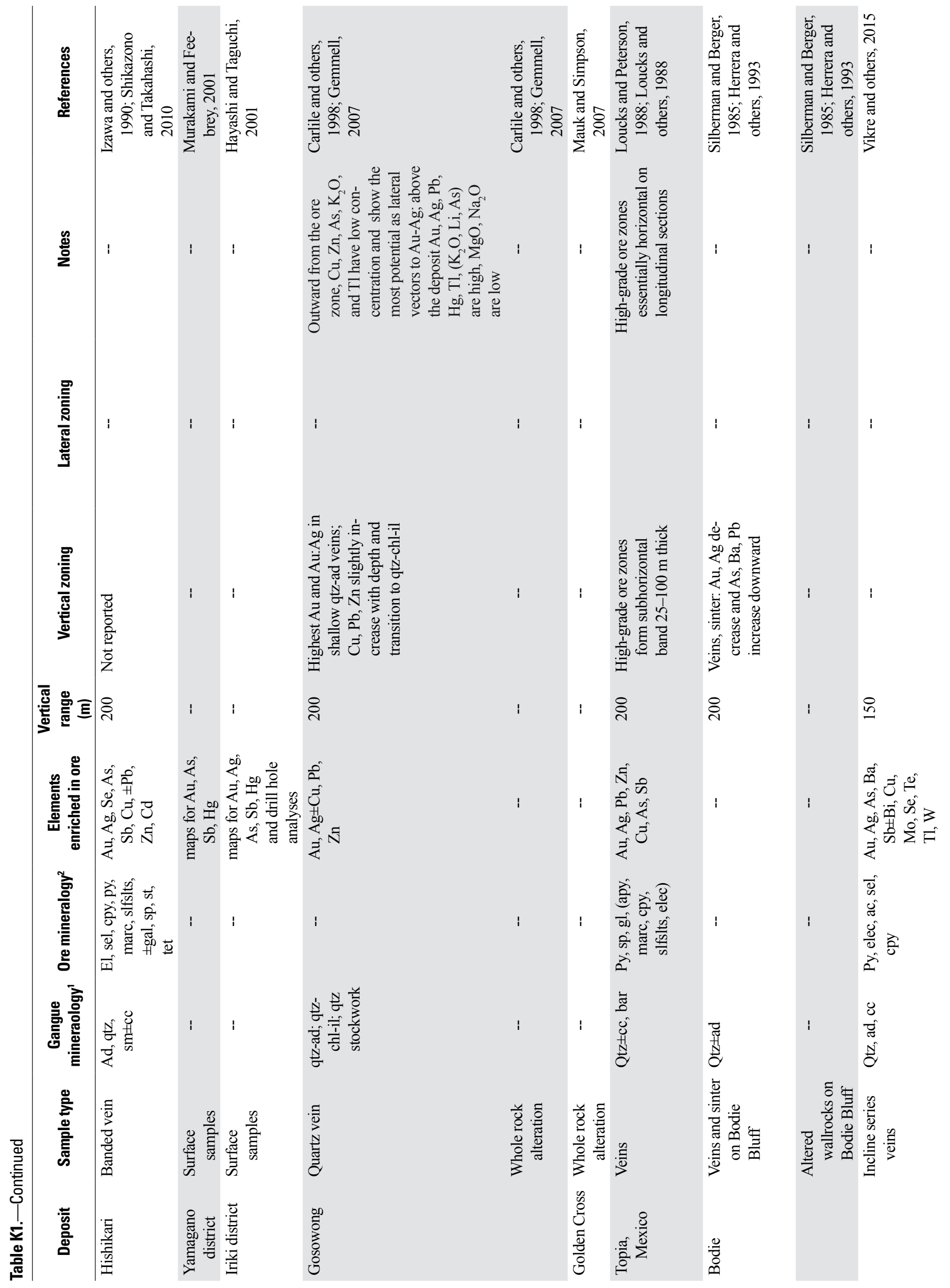




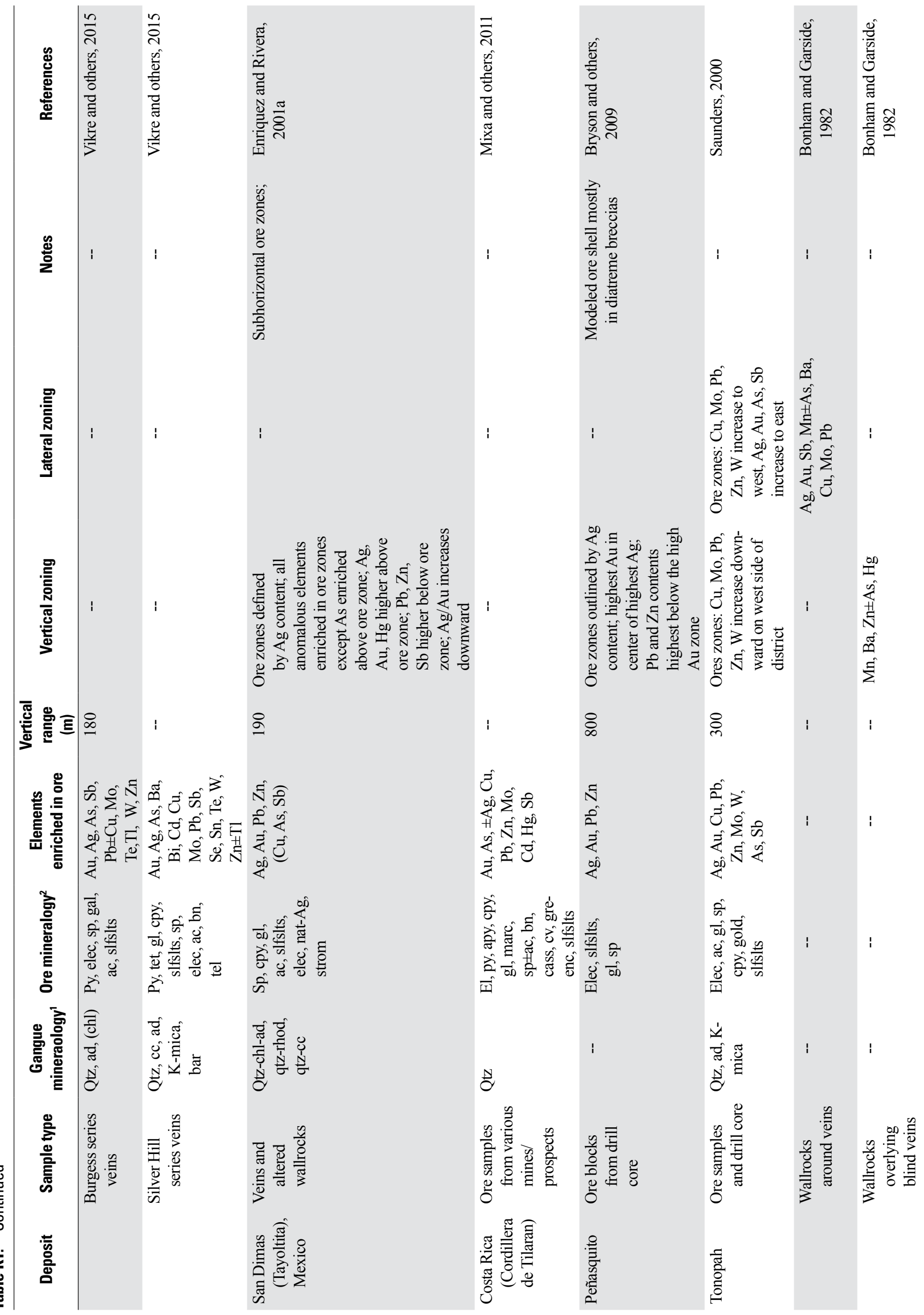




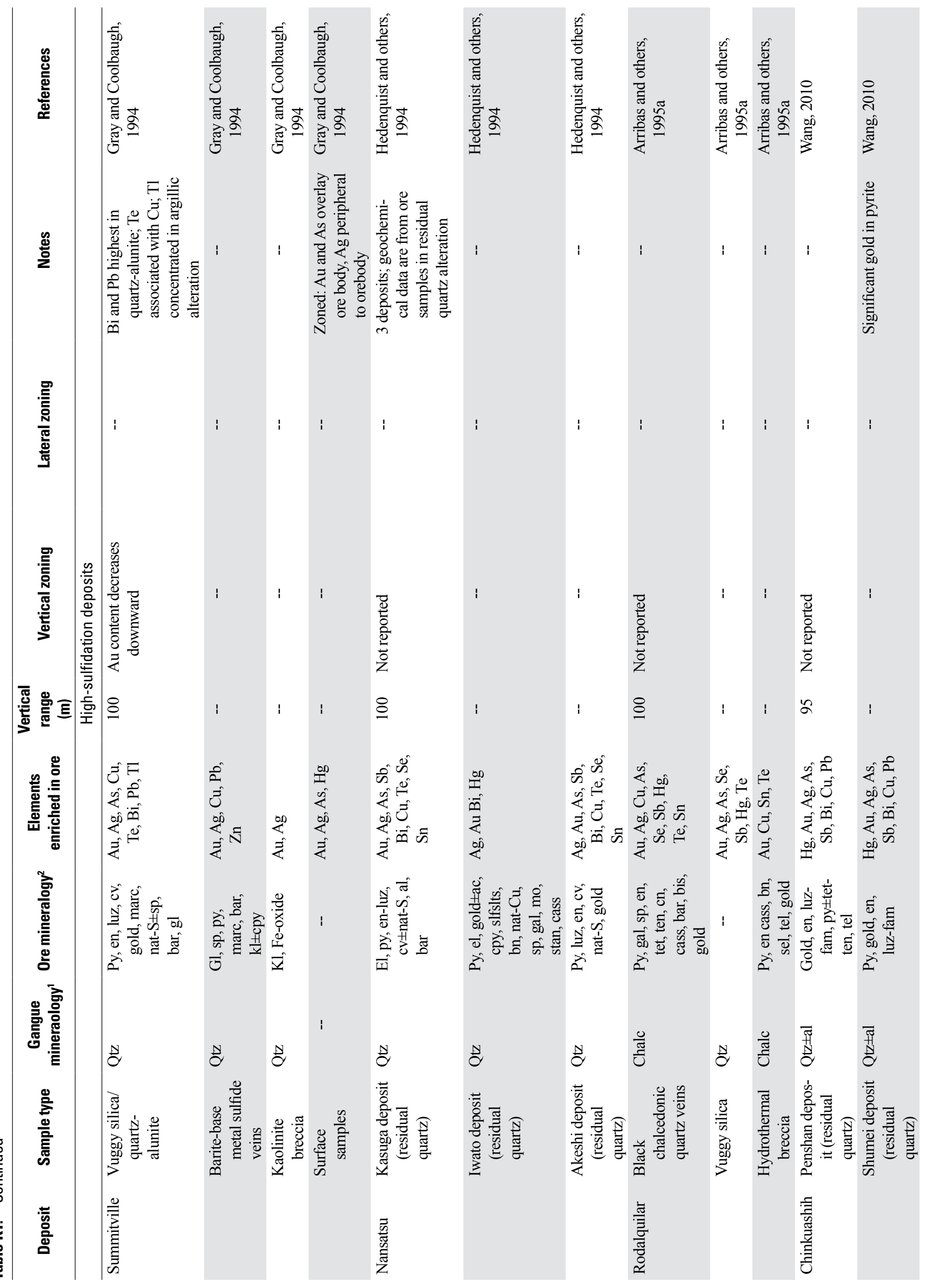




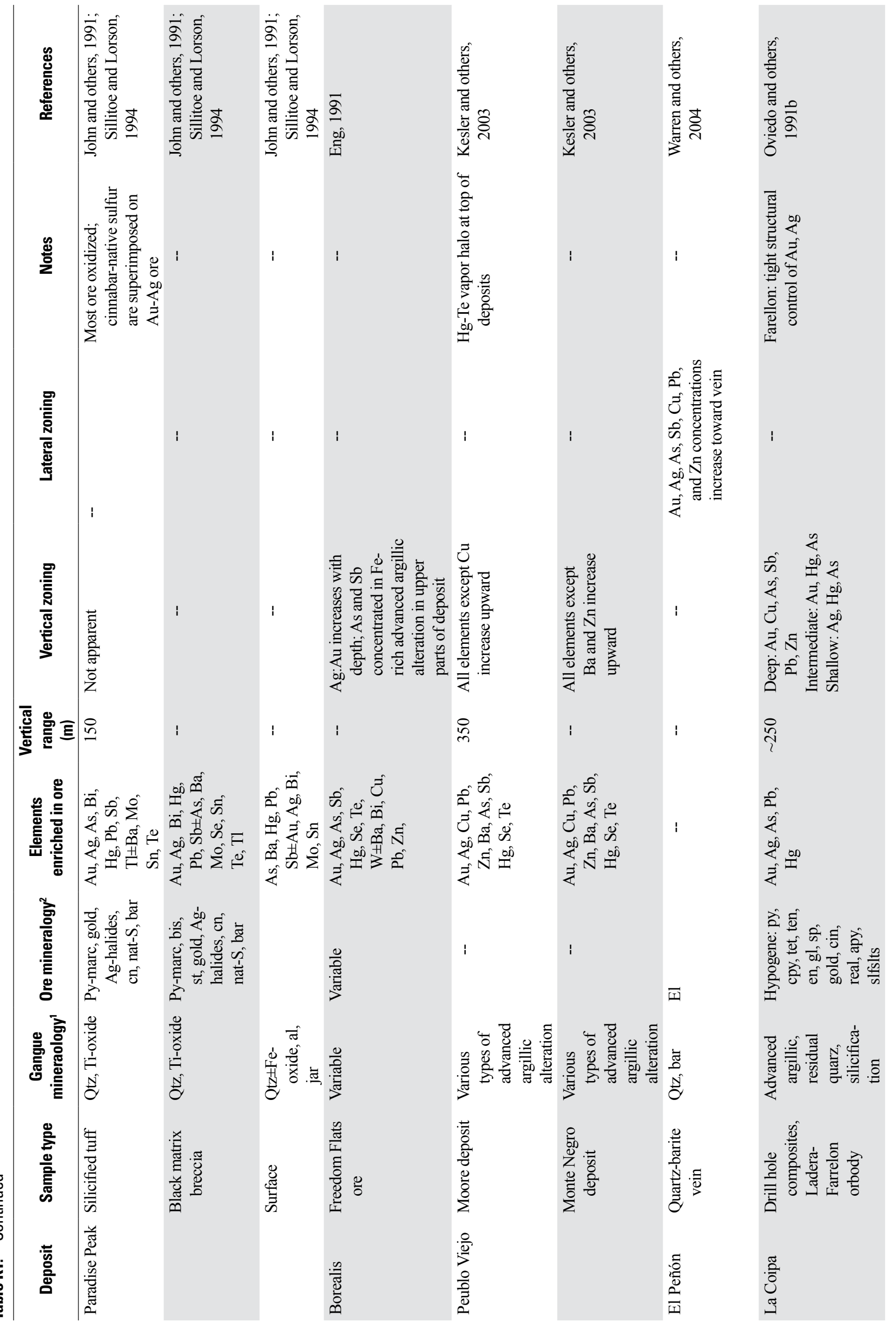




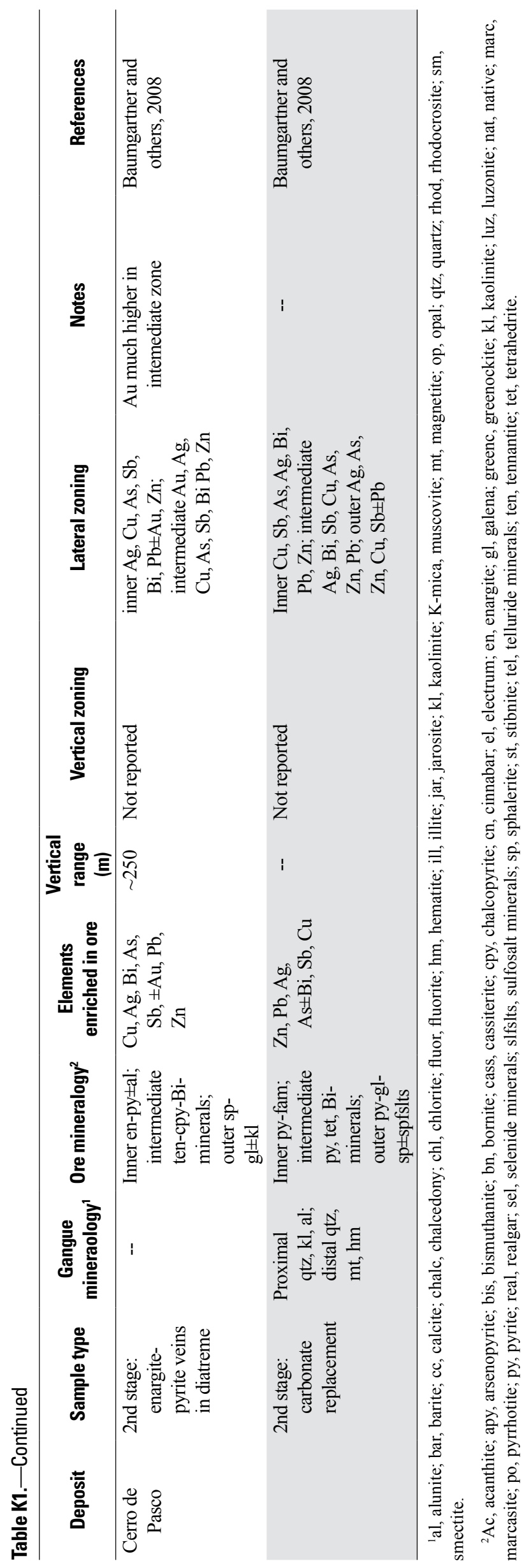


Three types of data germane to geochemical zoning of epithermal deposits have been reported: (1) ore-related metals and metalloids (pathfinder elements) within ore bodies; (2) dispersion of pathfinder elements in wall rocks of ores, above and lateral to ores; and (3) major and trace elements that form hydrothermal alteration minerals in wall rocks of ore bodies. Table K1 summarizes geochemical data for some epithermal deposits that show evidence for geochemical zoning.

\section{Geochemical Zoning in Ore Zones in Low- and Intermediate-Sulfiation Deposits}

In low- and intermediate-sulfidation deposits, the highest gold contents and $\mathrm{Au} / \mathrm{Ag}$ generally are present in the upper
(McLaughlin, San Dimas, Gosowong) to middle (El Peñón, Midas) parts of ore zones (fig. K1). Absolute silver concentrations and $\mathrm{Ag} / \mathrm{Au}$ tend to increase with increasing depth within goldsilver ore zones. At Bodie, $\mathrm{Au} / \mathrm{Ag}$ vary significantly between different generations of veins (Vikre and others, 2015), and it has been inferred that deeper veins have greater silver concentrations and $\mathrm{Ag} / \mathrm{Au}$ (Hollister and Silberman, 1995). Arsenic, antimony, and mercury generally are enriched at shallow depths and may form halos above ore-grade veins (Midas, El Peñón). Base metals (copper, lead, zinc) tend to increase with depth in ore zones (Gosowong, El Peñón, San Dimas) or remain relatively constant (Midas).

Few trace element data are available for intermediatesulfidation deposits (table K1). In the Penasco diatreme at the
Figure K1. Graphs showing lateral geochemical gradients in rocks surrounding quartz and quartz (qtz)-barite veins in the El Peñón district, Chile. Mean and median values for 0 - to 50 -, 50 - to $100-$, and 100 - to 150 -meter intervals around each vein type were determined for all the rocks in each interval after replacing values below the detection limits (bd) with one half the lower limit of detection. Colored columns show mean values, and white bands show median values. Mean and median values from the veins are shown for comparison. Figure modified from Warren and others (2004). ppb, parts per billion; ppm, parts per million.
Quartz veins
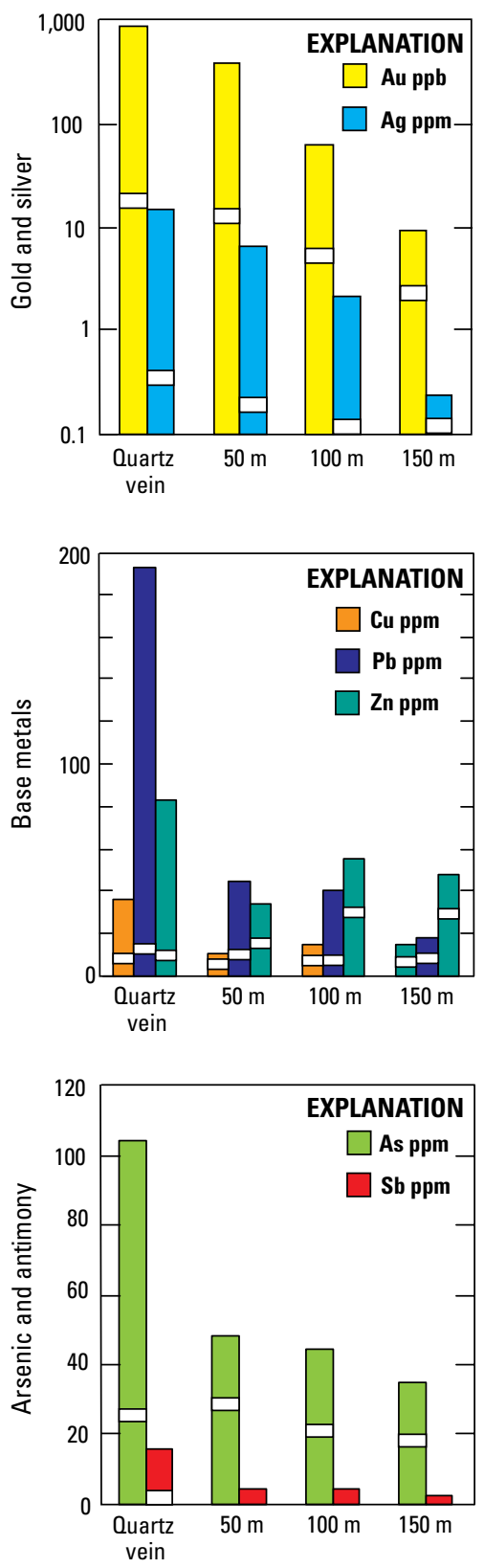

Quartz-barite veins
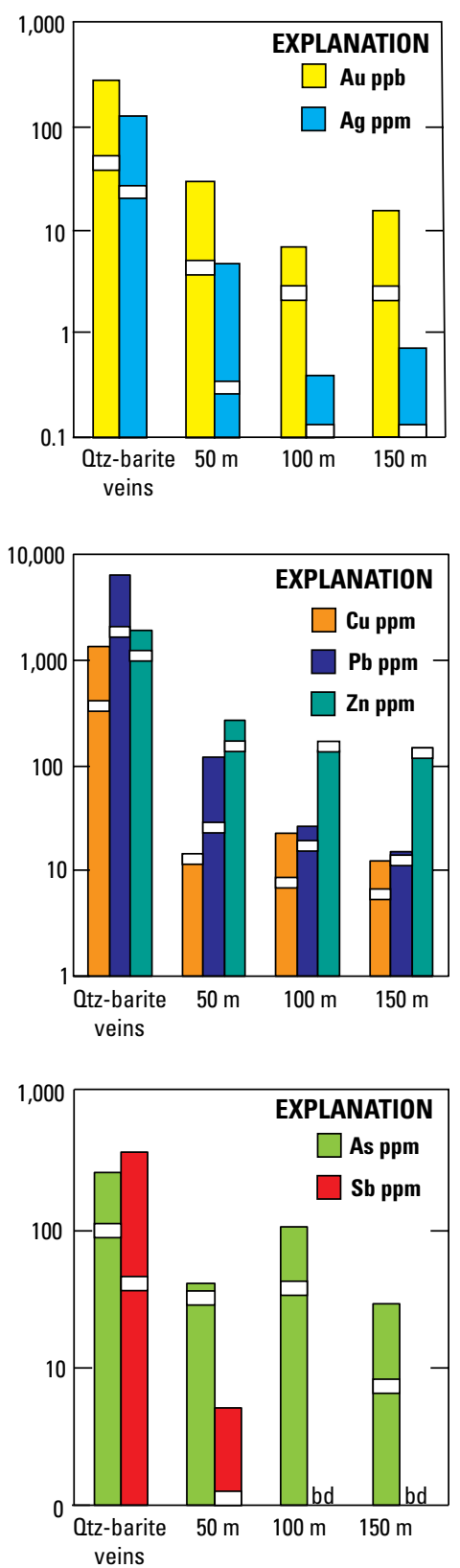
Peñasquito Ag-Au-Pb-Zn deposit in Mexico, high silver contents extend throughout the entire $800 \mathrm{~m}$ thickness of ore; gold content is highest in the central part of the silver zone, the greatest lead values lie just below the highest gold grades in the central part of the ore zone, and zinc is more widely dispersed but its highest grades also lie just below the central gold zone (Bryson and others, 2009; fig. K2). In the Tonopah district, Nevada, $\mathrm{Pb}, \mathrm{Zn}, \mathrm{Mo}, \mathrm{Cu}$, and $\mathrm{W}$ appear to increase with depth in ores in the western part of the district, whereas $\mathrm{Au}, \mathrm{Ag}, \mathrm{As}$, and $\mathrm{Sb}$ tend to increase with depth in ores the eastern part of the district (Saunders, 2000).

\section{Pathfinder Elements in Wall Rocks of Low- and Intermediate-Sulfidation Deposits}

Warren and others (2004) report pathfinder element zoning patterns for rocks and drill-hole samples adjacent to intermediate-sulfidation veins at El Peñón, Chile. In surface samples, they show that gold, silver, arsenic, and antimony concentrations increase toward exposed quartz veins. Geochemical analyses of altered rocks from drill holes surrounding the Quebrada Colorada vein, the highest grade

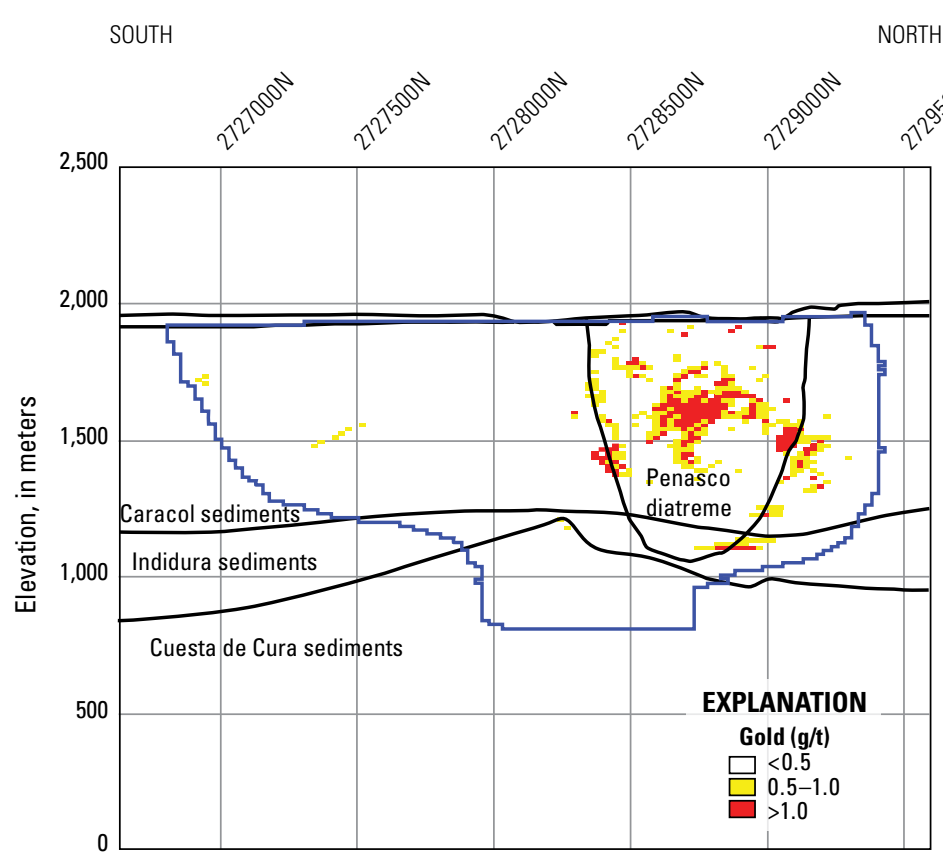

SOUTH
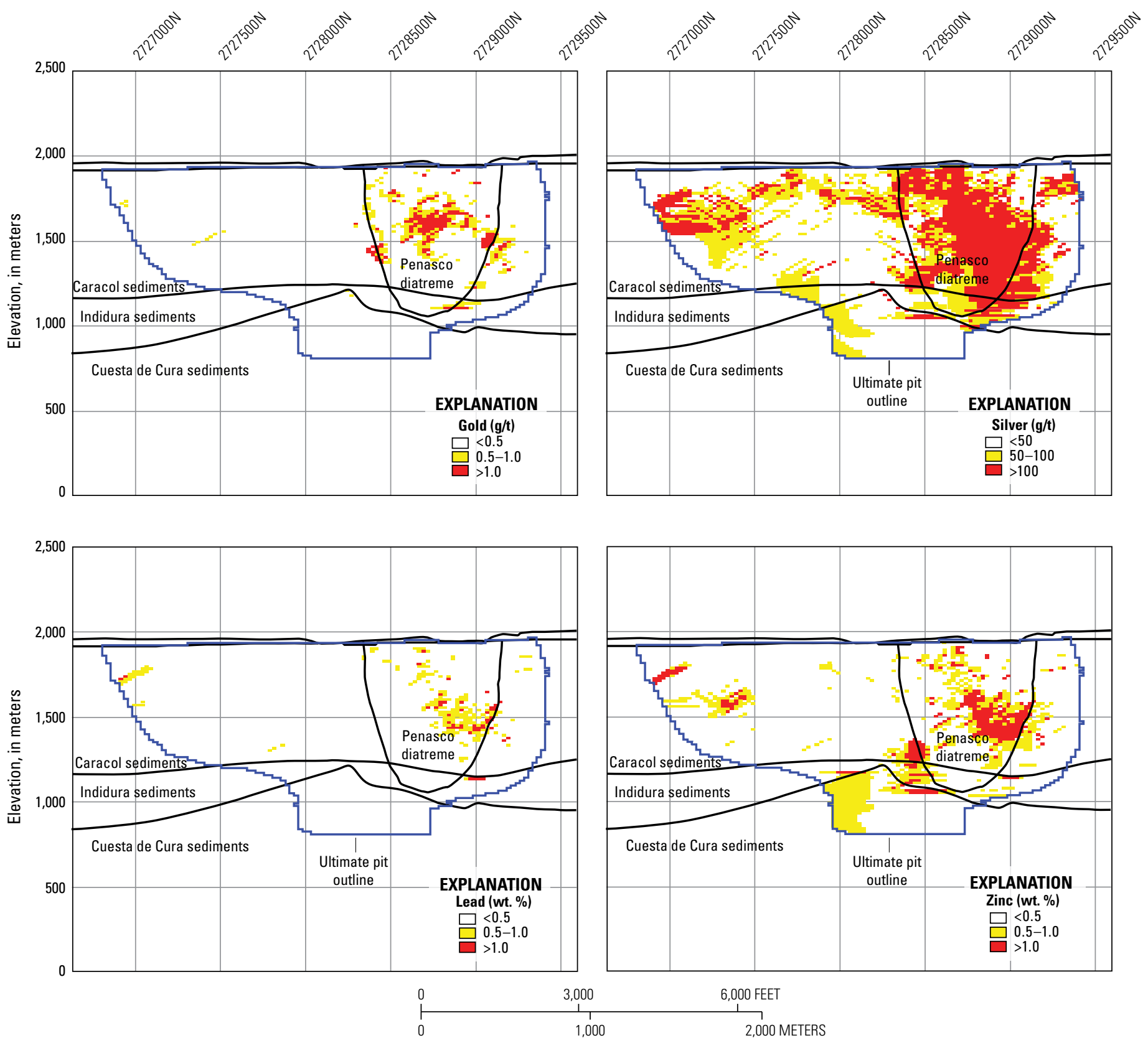

DATUM IS SEA LEVEL

Figure K2. South-north cross section along section 229570E through the Penasco diatreme showing metal zoning in the Peñasquito intermediate-sulfidation deposit, Zacatecas, Mexico. Geology and metal concentrations simplified from Bryson and others (2009). g/t, grams per metric ton; wt. \%, weight percent. 
vein of the deposit, show enrichment of gold and silver toward the vein, arsenic and antimony show no trends, and copper, lead, and zinc have their highest values near the vein (fig. K1). Arsenic and antimony anomalies occur in rocks above the Quebrada Colorada vein that are barren or contain only low levels of gold and silver.

At Tonopah, Nevada, Bonham and Garside (1982) reported geochemical data for surface samples of altered rocks that crop out around quartz veins and overlie blind ore bodies. Rock samples around exposed veins are strongly anomalous in silver, gold, and antimony, and weakly to moderately anomalous in arsenic, copper, barium, and lead. Samples overlying blind ore bodies are moderately to strongly anomalous in manganese, weakly anomalous in barium and zinc, and locally anomalous in arsenic and mercury.

Gemmell (2007) describes geochemical zoning around the Gosowong vein deposit, Indonesia, and downward extension of alteration along the Gosowong Fault, which provided structural control for hydrothermal fluid flow (fig. K3). At the surface, altered whole rock samples are enriched in $\mathrm{Hg}, \mathrm{Au}, \mathrm{Ag}, \mathrm{Pb}, \mathrm{Mo}$, $\mathrm{Tl}, \mathrm{As}, \mathrm{K}_{2} \mathrm{O}$, and Li. Proximal to the deposit, $\mathrm{Au}, \mathrm{Ag}, \mathrm{As}, \mathrm{Cu}$, and $\mathrm{Pb}$ are enriched. In the alteration halo, $\mathrm{K}_{2} \mathrm{O}, \mathrm{Mo}, \mathrm{Tl}, \mathrm{As}$, and $\mathrm{S}$ are enriched. $\mathrm{K}_{2} \mathrm{O}, \mathrm{Tl}, \mathrm{Ba}$, and $\mathrm{Li}$ concentrations are high along the downward extension of the Gosowong Fault zone. The concentrations of $\mathrm{Au}, \mathrm{Ag}, \mathrm{As}, \mathrm{Cu}, \mathrm{Pb}, \mathrm{Tl}, \mathrm{As}, \mathrm{K}_{2} \mathrm{O}$, and $\mathrm{Li}$ are high in the ore zone but decrease outward over the distance of tens to hundreds of meters. These elements have the most potential as lateral vectors to precious metal mineralization.

At Bodie, California, Silberman and Berger (1985) and Herrera and others (1993) described geochemical zoning in quartz veins and altered wall rocks from a greater than $200 \mathrm{~m}$ depth range on Bodie Bluff. They noted that zoning patterns are irregular and do not strictly agree with models based on active hot springs. Silberman and Berger (1985, p. 224) concluded that "the alteration mineral assemblages and physical features of rocks appear to be much better guides to vertical and lateral position in the district" and the "best indicator of economic $\mathrm{Au}$ mineralization at Bodie is Au in the quartz veins!"

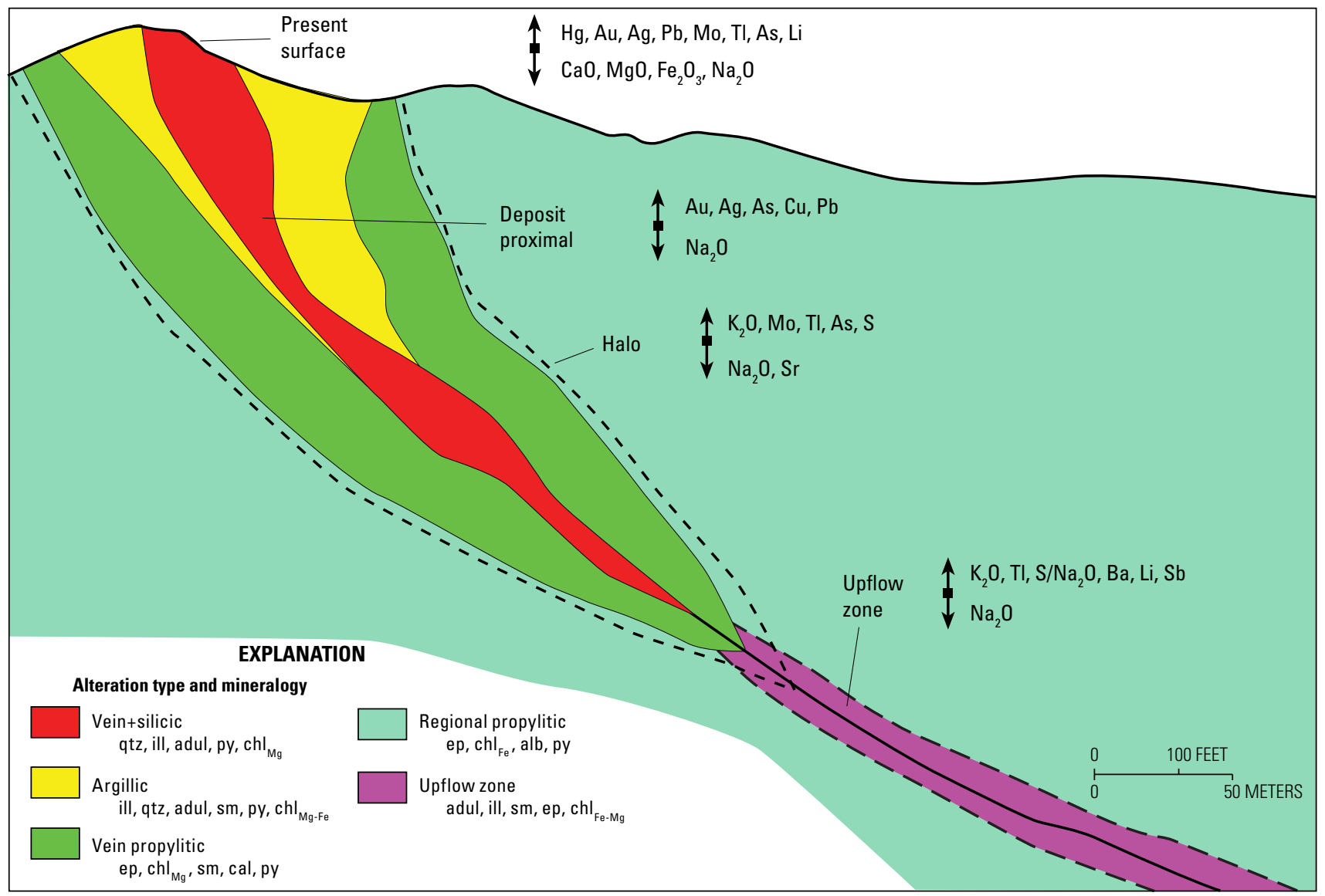

Figure K3. Schematic cross section showing mineralogical and geochemical zoning associated with the Gosowong intermediate-sulfidation deposit, Indonesia, including the alteration halo, upflow zone along downward extension of the Gosowong Fault, and at the surface. Small up and down arrows indicate an increase or decrease in element or oxide

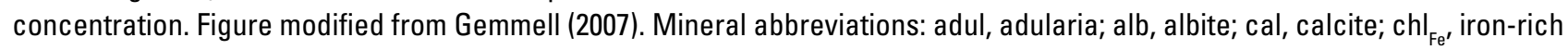
chlorite; $\mathrm{chl}_{\mathrm{Mg}^{\prime}}$ magnesium-rich chlorite; ep, epidote; ill, illite; py, pyrite; qtz, quartz; sm, smectite. Element abbreviations: Ag, silver; As, arsenic; Au, gold; Ba, barium; Ca, calcium; Cu, copper; Fe, iron; Hg, mercury; K, potassium; Li, lithium; Mg, magnesium; Mo, molybdenum; $\mathrm{Na}$, sodium; O, oxygen; $\mathrm{Pb}$, lead; $\mathrm{S}$, sulfur; Sb, antimony; $\mathrm{Sr}$, strontium; TI, thallium. 


\section{Geochemical Zoning of Hydrothermal Alteration in Low- and Intermediate-Sulfidation Deposits}

Several studies have examined major element geochemical haloes and mass changes associated with hydrothermal alteration around low- and intermediate-sulfidation vein deposits and their potential use as an exploration tool (Silberman and Berger, 1985; Berger and Silberman, 1985; Herrera and others, 1993; Warren and others, 2004, 2007; Leavitt and Arehart, 2005; Gemmell, 2007; Mauk and Simpson, 2007; Booden and others, 2011; Simpson and Mauk, 2011). These studies show that (1) commonly there is widespread potassium metasomatism associated with formation of adularia and (or) illite and removal of calcium and sodium in rocks that surround quartz veins, (2) areas of more intense potassium metasomatism correlate with high concentrations of precious and base metals and pathfinder elements, and (3) the area affected by potassium metasomatism is more extensive (hundreds to thousands of meters distant from major veins) than the area containing anomalous concentrations of precious and base metals and pathfinder elements (tens to hundreds of meters from veins). Warren and others (2007) presented data from several low- and intermediate-sulfidation deposits that show the intensity of potassium metasomatism can be modeled by molar $\mathrm{K} /(2 \mathrm{Ca}+\mathrm{Na}+\mathrm{K})$ of altered and unaltered rocks; samples with the largest values of this ratio also have the greatest concentrations of precious metals and pathfinder elements and are proximal to ore zones (fig. K4). Therefore, pathfinder elements (As, $\mathrm{Sb}, \mathrm{Hg}$, and so on) and whole-rock major element geochemical anomalies are complementary.

\section{Geochemical Zoning in Ore Zones in High- Sulfidation Deposits}

Published geochemical studies of high-sulfidation deposits showing distribution of trace elements are sparse (table K1). Styles of hydrothermal alteration and mineralization vary between structurally controlled deposits that have narrow alteration and ore zones around structures (for example, Summitville, La Coipa) and lithologically controlled deposits, which have broad zones of hydrothermally altered rock and disseminated mineralization dispersed by highly permeable or chemically reactive wall rocks (for example, Pueblo Viejo).

Kesler and others (2003) presented the most comprehensive data set for a high-sulfidation deposit and provided a model for geochemical zoning of the Moore and Monte Negro deposits in the Pueblo Viejo district, Dominican Republic. They showed that $\mathrm{Au}, \mathrm{Ag}, \mathrm{Pb}, \mathrm{As}, \mathrm{Sb}, \mathrm{Hg}$, Se, and Te all increase upward toward the paleosurface within the Moore and Monte Negro deposits; Ba and $\mathrm{Zn}$ also increase upward in the Moore deposit and $\mathrm{Cu}$ increases upward in the Monte Negro deposit (fig. K5). Concentrations of these elements show an approximate ten-fold increase over about $350 \mathrm{~m}$ depth in funnel-shaped ore bodies.

At Summitville, Colorado, Gray and Coolbaugh (1994) noted $\mathrm{Au} / \mathrm{Ag}$ values decrease from the center of the deposit outward and the overall gold content decreases downward. In the Freedom Flats deposit at Borealis, Nevada, $\mathrm{Au} / \mathrm{Ag}$ also decreases downward in the deposit and arsenic and antimony are concentrated in ironrich advanced argillic alteration in the upper parts of the deposit (Eng, 1991).

Oviedo and others (1991b) describe the geochemistry of the Coipa Norte, Farellon, and Coipa Norte ore bodies at La Coipa, Chile. They note that the La Coipa ore bodies are somewhat unusual, because Triassic black shales and sandstones underlying Tertiary pyroclastic rocks host much of the ore. In addition, much of the ore has undergone supergene oxidation resulting in variable leaching or enrichment of silver, copper, and zinc. Vertical zoning of hypogene ore minerals suggests enrichment in $\mathrm{Au}, \mathrm{Cu}, \mathrm{As}$, $\mathrm{Sb}, \mathrm{Pb}$, and $\mathrm{Zn}$ at deep levels, enrichment in $\mathrm{Au}, \mathrm{Hg}$, and $\mathrm{As}$ at intermediate depths, and enrichment in $\mathrm{Ag}, \mathrm{Hg}$, and As at shallow depths. Gold-rich, silver-poor ores are confined to sedimentary rocks underlying the pyroclastic rocks, and they suggest that the unusual $\mathrm{Au}-\mathrm{Ag}$ zoning may result from precipitation of gold by carbonaceous material in the black shales.

Baumgartner and others (2008) describe lateral zoning in second stage mineralization at the Cerro de Pasco deposit, Peru. Second stage mineralization consists of enargite-pyrite veins in a diatreme complex in the western part of the deposit and carbonate replacement bodies in the eastern part. The enargite-pyrite veins are zoned from a core enriched in $\mathrm{Cu}, \mathrm{As}, \mathrm{Sb}, \mathrm{Ag} \pm \mathrm{Bi}$ to an intermediate zone with much higher $\mathrm{Au}$ and $\mathrm{Sb}$ contents. Lead and zinc have relatively low concentrations in both zones. Carbonate replacement bodies are strongly zoned with an inner zone highly enriched in $\mathrm{Cu}, \mathrm{Sb}, \mathrm{Bi}, \mathrm{As}, \mathrm{Ag}, \mathrm{Zn}$, and $\mathrm{Pb}$; an intermediate zone with a similar suite of elements but much higher Ag contents; and an outer zone that has very high $\mathrm{Pb}$ and $\mathrm{Zn}$ contents, relatively low $\mathrm{Ag}, \mathrm{Cu}$, $\mathrm{Sb}$, and As concentrations, and no Bi. Gold contents are below detection levels throughout the carbonate replacement ore bodies.

\section{Pathfinder Elements in Wall Rocks of High- Sulfidation Deposits}

At Summitville, Colorado, anomalous $\mathrm{Ag}, \mathrm{Cu}, \mathrm{As}, \mathrm{Te}$, and ore grade Au are restricted to narrow zones of residual (vuggy) quartz alteration (Gray and Coolbaugh, 1994; fig. K6). Outward from residual quartz alteration, an inner $(0-3 \mathrm{~m})$ zone of quartzalunite alteration is enriched in lead and bismuth and an outer (3-10 m) zone of argillic alteration is enriched in thallium.

Warren and others (2004) discussed geochemical data for surface samples around uneconomic quartz-barite veins related to high-sulfidation hydrothermal systems in the El Peñón area, Chile. They showed that $\mathrm{Au}, \mathrm{Ag}, \mathrm{As}, \mathrm{Sb}, \mathrm{Cu}, \mathrm{Pb}$, and $\mathrm{Zn}$ concentrations increase toward quartz-barite veins (fig. K1).

At Pueblo Viejo, Dominican Republic, the upper parts of the deposits are notably enriched in mercury and tellurium, which Kesler and others (2003) interpreted as a vapor halo related to the deposits (fig. K7). They noted that argillic and advanced argillic alteration assemblages replace most rocks in a $40 \mathrm{~km}^{2}$ area centered on the Pueblo Viejo ore bodies. Mercury is anomalous throughout much of this area, although samples with the highest mercury concentrations are not adjacent to the known ore bodies; they suggested that the high mercury samples may overlie covered gold mineralization similar to the Pueblo Viejo deposits. 
Figure K4. Cross sections showing mass changes of precious metals, base metals, and epithermal pathfinder elements in altered rocks surrounding low-sulfidation veins at El Peñón, Chile. Hachures indicate areas of potassium gain. Figure modified from Warren and others (2007). ppb, parts per billion; ppm, parts per million.
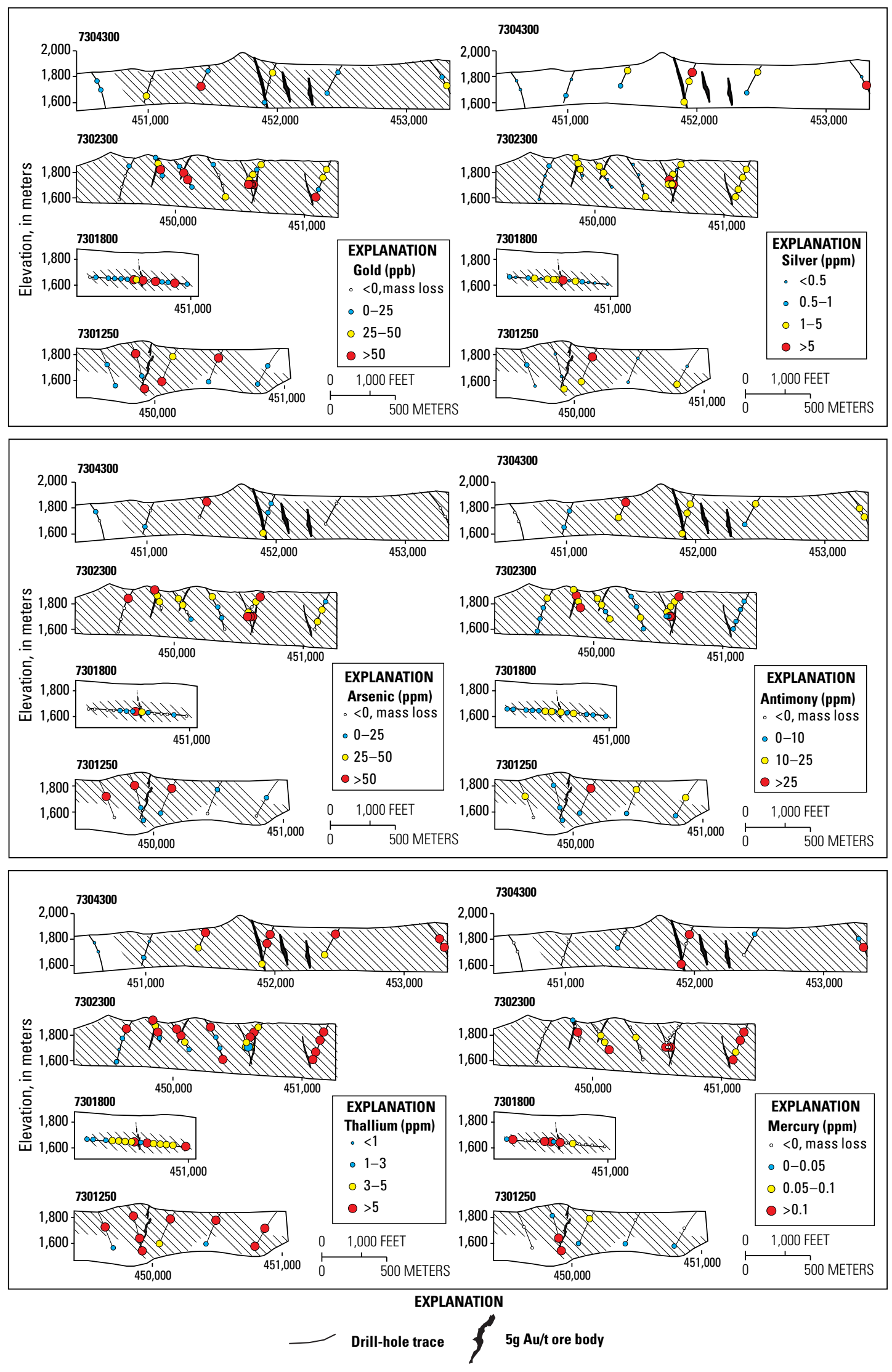

DATUM IS SEA LEVEL 
$\boldsymbol{A}$

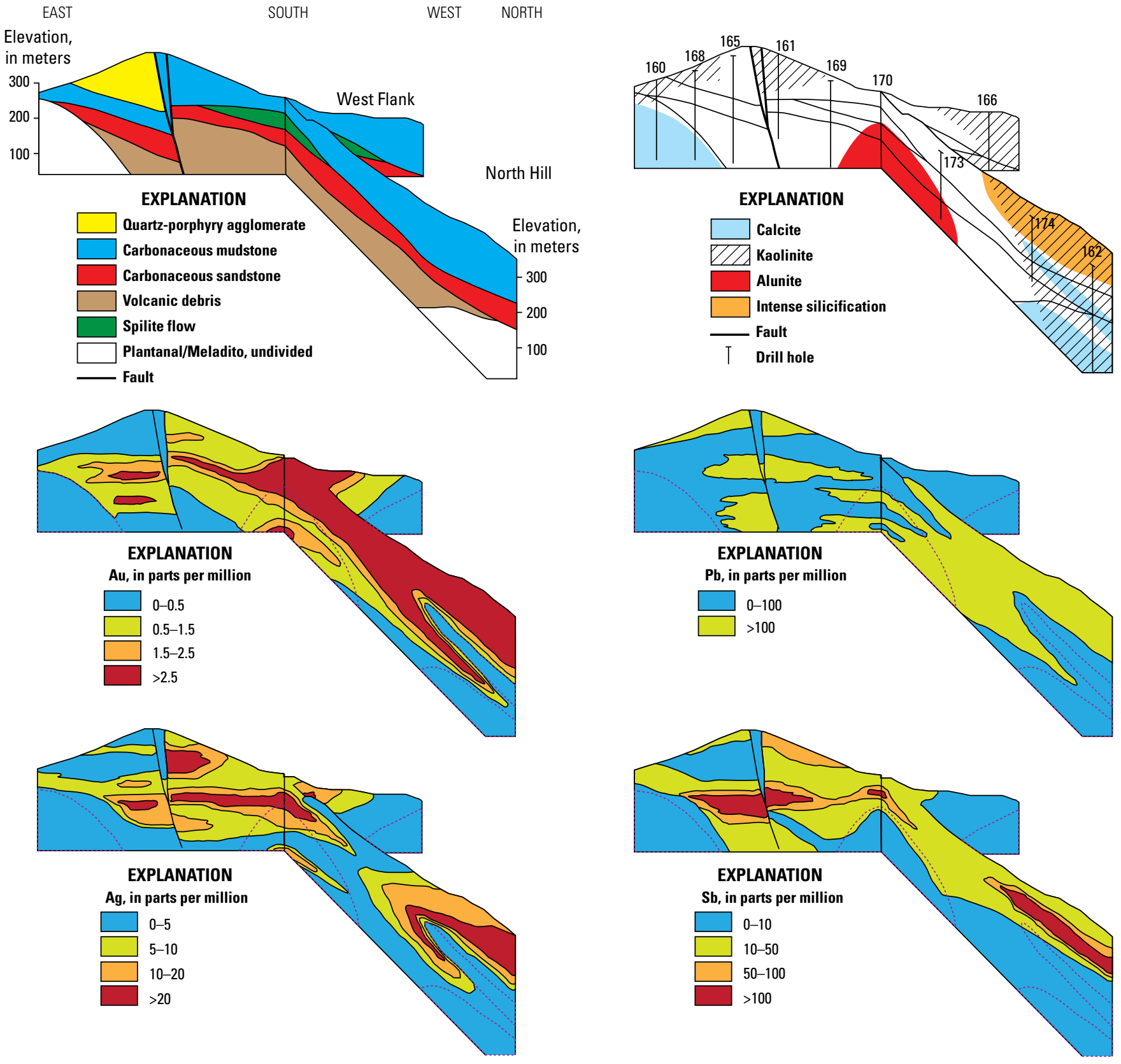

DATUM IS SEA LEVEL

Figure K5. Cross sections showing distribution of trace elements relative to geologic features in the Moore ore body, Pueblo Viejo high-sulfidation deposit, Dominican Republic. $A$, Top two diagrams show geologic and alteration features and locations of drill holes used to construct other diagrams. Other four diagrams show distribution of gold ( $\mathrm{Au}$ ), lead ( $\mathrm{Pb})$, silver ( $\mathrm{Ag}$ ), and antimony (Sb). Dotted lines show outlines of alteration zones. B, Cross sections showing distribution of tellurium (Te), arsenic $(\mathrm{As})$, mercury $(\mathrm{Hg})$, copper ( $\mathrm{Cu})$, selenium (Se), and zinc ( $\mathrm{Zn})$. Dotted lines show outlines of alteration zones. Figures modified from Kesler and others (2003). 


\section{B}
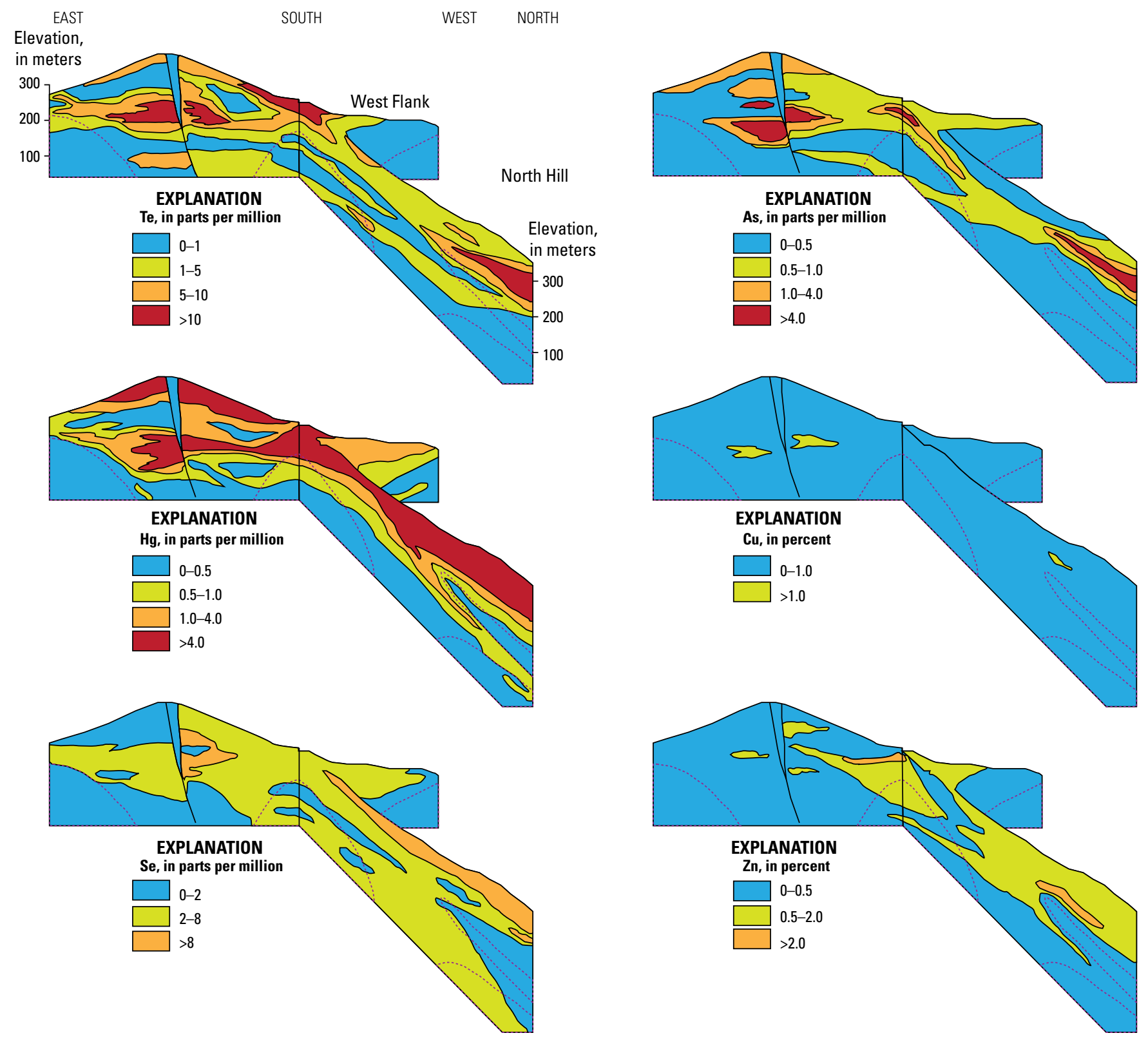

EXPLANATION

$\mathrm{Zn}$, in percent

$\square$ 0-0.5

$0.5-2.0$

$>2.0$

DATUM IS SEA LEVEL

Figure K5.-Continued 

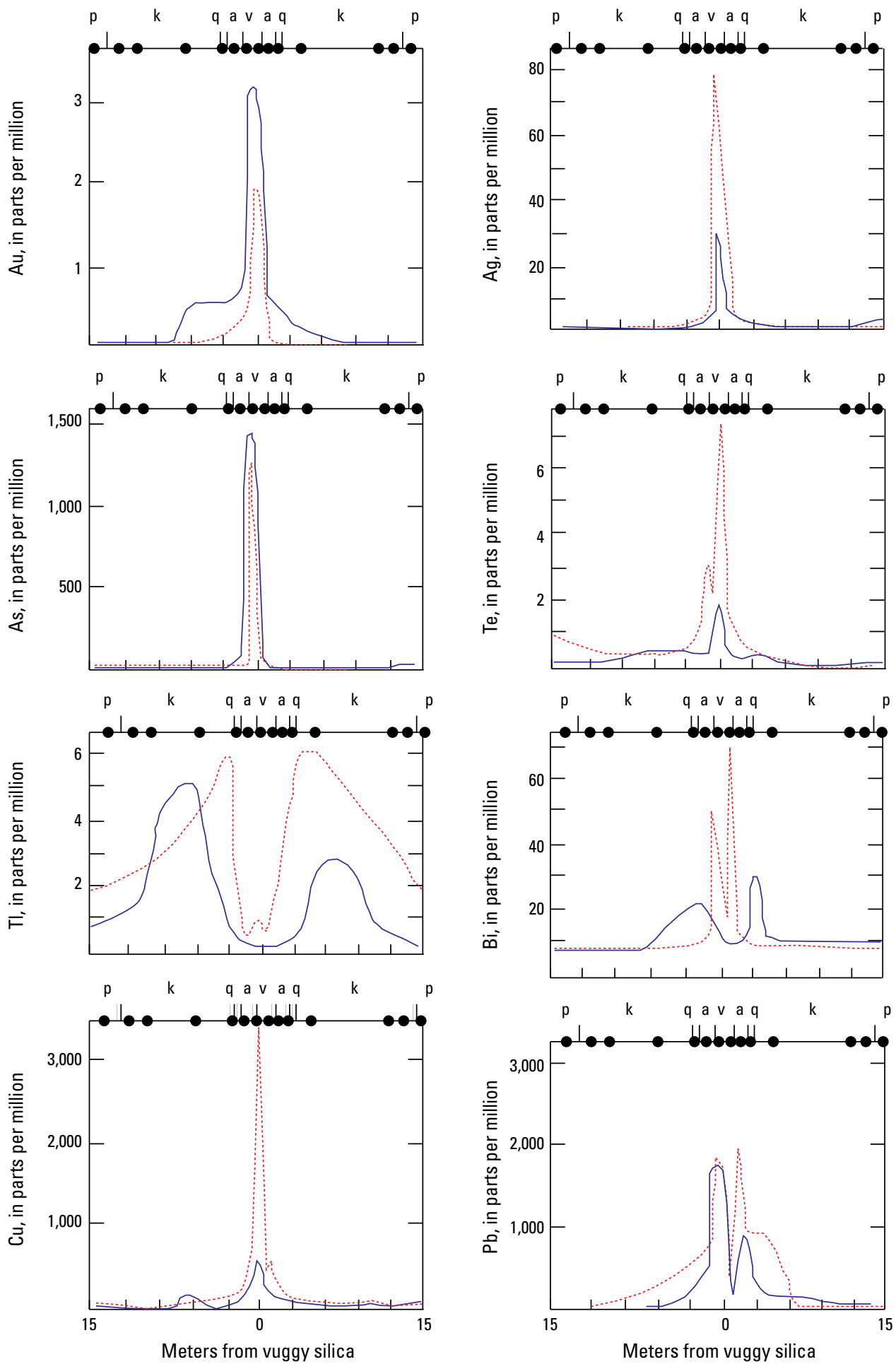

\section{EXPLANATION}

Science vein

Figure K6. Plots of trace element concentrations versus lateral distance from vuggy silica (residual quartz) alteration for the Copper Hill ore zone (solid purple lines) in the center and the Science vein (red dashed lines) on the periphery of the Summitville high-sulfidation deposit, Colorado (redrawn from Gray and Coolbaugh, 1994). Altered rock zones: a, quartz-alunite; $k$, argillic; $p$, propylitic; q, quartz-kaolinite; v, vuggy quartz. Element abbreviations: Ag, silver; As, arsenic; $\mathrm{Au}$, gold; $\mathrm{Bi}$, bismuth; $\mathrm{Cu}$, copper, $\mathrm{Pb}$, lead; $\mathrm{Te}$, tellurium; $\mathrm{Tl}$, thallium. 


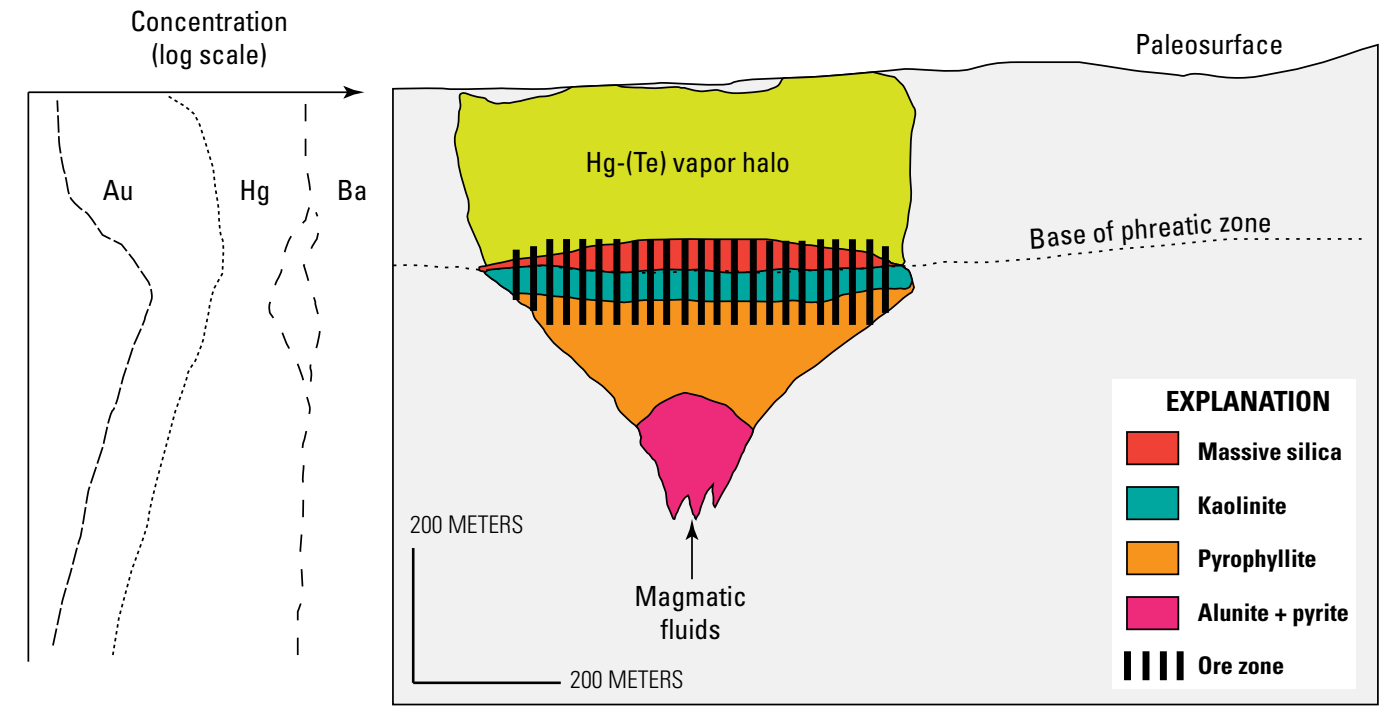

Figure K7. Schematic diagram showing distribution of trace elements and their relation to ore and alteration zoning in and above the Pueblo Viejo high-sulfidation deposits. The pattern for gold $(\mathrm{Au})$ is similar to most other trace elements, especially arsenic, antimony, and silver. The pattern for mercury $(\mathrm{Hg})$ probably is similar to tellurium. The pattern for barium $(\mathrm{Ba})$ is unique and shows either no enrichment or slight depletion. Figure redrawn from Kesler and others (2003).

\section{Fluid Inclusion Petrography, Thermometry, and Geochemistry}

\author{
By Peter G. Vikre
}

\section{High-Sulfidation Deposits}

Fluid inclusions in high-sulfidation deposits have been used to quantify physical and chemical characteristics of aqueous fluids known or assumed to have formed the deposits and altered their host rocks. These characteristics include phase relationships, temperatures, pressures, major solutes (salts and volatiles), and oxygen and deuterium isotope compositions of water. In conjunction with isotope compositions of water in fluid inclusions, fluid inclusion petrography and microthermometry can enable, given sufficient sample distribution, reconstruction of the hydrodynamics of deposit formation by defining (1) fluid temperature and pressure gradients, (2) temperatures and depths below paleowater tables (potentiometric surfaces) at which deposits formed, (3) sources of water in hydrothermal fluids, and (4) depths of vapor-brine separation of magmatic (critical) fluid, a process common to all high-sulfidation deposits and to other mineralized magmatic-hydrothermal systems. They also provide a basis for evaluating fluid cooling and degassing by boiling and mixing, processes that commonly cause mineral precipitation in the near-surface domain of hydrothermal systems.

Fluid inclusion characteristics are determined by petrography, microthermometry, in situ microbeam analyses, and analysis of fluids extracted from bulk samples of hydrothermal minerals. All fluid inclusion investigations are limited by paragenetic control.
Correlation of the multiple fluid generations invariably present in hydrothermal minerals, at the scale of a petrographic section, a deposit, or a district, is never straightforward. In addition, the relative ages of cores and growth zones of transparent hydrothermal minerals, from which the large majority of fluid inclusion data are obtained, and ages of opaque minerals, including gold, copper, and silver ore minerals, are typically difficult to determine. Furthermore, because of the fine grain size of most hydrothermal minerals, fluid inclusion data have been collected from quartz phenocrysts in altered wall rocks. Regardless of these uncertainties and practices, fluid inclusion petrography, microthermometry, and analyses provide specific to broad quantification of physical and chemical properties of hydrothermal fluids that cannot be obtained by other methods.

In high-sulfidation deposits, characteristics have been mostly determined for fluid inclusions in quartz, and less commonly for inclusions in barite, sphalerite, alunite, enargite, and pyrite (the latter two minerals absorb visible light wavelengths but transmit infrared radiation; Mancano and Campbell, 1995; Kouzmanov and others, 2004). Optically resolvable inclusions seldom exceed tens of microns in dimension. Microthermometric precision is limited by small inclusion size, and by light diffraction and scattering by grain boundaries, solid inclusions, and voids in samples consisting of fine-grained minerals.

Investigations involving fluid inclusions in some highsulfidation deposits have been used, based on their temperatures and compositions, to associate these relatively near-surface deposits with subjacent porphyry copper systems that are known or suspected to be coeval, or to infer concealed porphyry copper systems (for example, Lepanto, Philippines; La Fortuna, Chile; Zijinshan, China; Radka, Bulgaria; La Caridad, Mexico; Nevados 
de Famatina, Argentina; Mancano and Campbell, 1995; Perelló and others, 1996; Hedenquist and others, 1998; So and others, 1998; Kouzmanov and others, 2004; Valencia and others, 2008; Pudack and others, 2009). Fluid inclusion microthermometry also has been used to substantiate calculated sulfur isotope equilibrium temperatures (see Rye, 2005). Physical and chemical characteristics of fluid inclusions in high-sulfidation deposits, based on comprehensive published investigations and unpublished microthermometry, are summarized in the sections that follow.

\section{Phase Relationships}

Liquid-rich inclusions (usually $\leq 30$ volume percent vapor) occur in quartz and other hydrothermal minerals in all deposits; vapor-rich inclusions (usually $\geq 70$ volume percent) are found in many deposits, and salt-saturated fluid inclusions are reported in a smaller number of districts that have been deeply mined or drilled. Coexistence of liquid-rich and vapor-rich inclusions in some deposits and districts (for example, Furtei, Italy; PascuaLama, Chile-Argentina; Nansatsu, Japan; Motomboto, Indonesia; Nalesbitan, Philippines; Chinkuashih, Taiwan; Ruggieri and others, 1997; Deyell and others, 2004; Hedenquist and others, 1994; Perelló, 1994; Sillitoe and others, 1990; Wang and others, 1999) is cited as evidence of fluid boiling. Saturated inclusions, containing halite, sylvite, and other daughter minerals (for example, at Goldfield; Summitville, Bethke and others, 2005; Fifarek and others, 2006; Fifarek, 2009; Chinkuashih, Taiwan, Wang and others, 1999; Rodalquilar, Spain, Arribas and others, 1995a; and Nansatsu, Japan, Hedenquist and others, 1994), are considered evidence of decompressional separation of a supercritical magmatic fluid into vapor (gas) and high-density, high-salinity aqueous fluid (brine). Based on homogenization temperatures and phase diagrams (Sterner and others, 1988), dissolution temperatures of sylvite and halite in "brine" fluid inclusions at Goldfield correspond to fluids containing 33-37 weight percent $\mathrm{KCl}$ and $\sim 19-20$ weight percent $\mathrm{NaCl}$.

\section{Homogenization Temperatures, Fluid Salinities, and Salt Dissolution Temperatures}

Most fluid inclusion microthermometric data have been obtained from quartz samples collected at depths less than about $1,400 \mathrm{~m}$ below erosion surfaces. Paragenetic stages represented by microthermometric data include "early" and "vuggy" quartz in silica-rich core alteration zones, quartz in "ore-stage" hydrothermal mineral assemblages that include sulfide and gold-copper-silver minerals, quartz in "late" barite \pm quartz \pm gold veins and breccias, and quartz phenocrysts in altered wall rocks. The reported range of homogenization temperatures of liquid-rich and vapor-rich inclusions in quartz of all forms and stages is $\sim 150-530^{\circ} \mathrm{C}$ (appendix 1).

"Ore-stage" fluid temperatures, based on homogenization of inclusions in quartz, lesser sphalerite, enargite, and pyrite, vary from 150 to $300^{\circ} \mathrm{C}$, with most modes $220-270{ }^{\circ} \mathrm{C}$

(Summitville, Bethke and others, 2005; El Indio, Chile, Jannas and others, 1990, 1999; Pascua-Lama, Deyell and others, 2004; Lepanto, Mancano and Campbell, 1995; Hedenquist and others, 1998; and Perama, Greece, Voudouris and others, 2011). Homogenization temperatures in paragenetically late barite (Motomboto, Indonesia; Perama, Greece; Goldfield; Paradise Peak) vary from about 155 to $330^{\circ} \mathrm{C}$, with most modes also $220-270{ }^{\circ} \mathrm{C}$ (Dobak, 1988; John and others, 1991; Perelló, 1994; Voudouris and others, 2011; Vikre, 1989b). However, paragenetic relationships of quartz and barite to ore minerals and other hydrothermal minerals in many deposits are incompletely known or imprecisely reported.

Compared with homogenization temperatures, fewer determinations of salinities of unsaturated, liquid-rich inclusions, and of salt-saturated inclusions, are reported, attesting to small size and poor visual resolution of most inclusions, and limited availability of deep samples. Salinities of inclusions in "ore-stage" quartz, sphalerite, and enargite, vary mostly from about 0 to 5.5 weight percent $\mathrm{NaCl}$ equivalent. In paragenetically earlier, later, and unconstrained quartz, and in late barite, fluid salinities mostly vary from about 0.5 to 9 weight percent. Salinities of salt-saturated inclusions vary from about 30 to 55 weight percent $\mathrm{NaCl}$ equivalent. At Summitville, Goldfield, and Rodalquilar, salt dissolution and vapor to liquid homogenization temperatures vary from about 220 to $385^{\circ} \mathrm{C}$ and from about 330 to $400{ }^{\circ} \mathrm{C}$, respectively (Bethke and others, 2005; Fifarek, 2009; Fifarek and others, 2006; Russin and Fifarek, 2009; Arribas and others, 1995a).

\section{Zoning and Depth of Deposit Formation}

Several fluid inclusion investigations provide spatially controlled microthermometry of zoned hydrothermal mineral assemblages (see "Hydrothermal Alteration"). At Zijinshan, China, homogenization temperature modes and salinities of liquid-rich fluid inclusions in quartz in the silicic zone are $\sim 130$, 220,260 , and $350^{\circ} \mathrm{C}$, and less than 3 weight percent $\mathrm{NaCl}$ equivalent, respectively; in the alunite+quartz+pyrite zone are $\sim 190,230,260$, and $340^{\circ} \mathrm{C}$, and 1-25 weight percent $\mathrm{NaCl}$ equivalent, respectively; in the dickite+quartz+pyrite \pm zunyite \pm se ricite zone are $\sim 210^{\circ} \mathrm{C}$, and $3-9$ weight percent $\mathrm{NaCl}$ equivalent, respectively; and in the phyllic zone are $\sim 250$ and $340{ }^{\circ} \mathrm{C}$, and 3-20 weight percent $\mathrm{NaCl}$ equivalent, respectively (So and others, 1998).

At Rodalquilar, homogenization temperature modes and salinities of liquid-rich inclusions associated with gold mineralization, and in advanced argillic assemblages $(\leq 300 \mathrm{~m}$ below the erosion surface) vary from 170 to $30{ }^{\circ} \mathrm{C}$ (with modes at $\sim 220$ and $280^{\circ} \mathrm{C}$ ) and 2-30 weight percent $\mathrm{NaCl}$ equivalent. At depths greater than $450 \mathrm{~m}$ in the sericitic alteration zone, homogenization temperatures are $350-420^{\circ} \mathrm{C}$ for assumed primary liquid-rich inclusions, and some populations that homogenize at more than $400{ }^{\circ} \mathrm{C}$ consist of salt-saturated $(>40$ weight percent $\mathrm{NaCl}$ equivalent) and vapor-rich inclusions. Homogenization temperature modes and salinities of liquidrich fluid inclusions in quartz in the propylitic zone mostly vary from 200 to $300^{\circ} \mathrm{C}$ (some are $350-400^{\circ} \mathrm{C}$ ), and less than 15 weight percent $\mathrm{NaCl}$ equivalent, respectively (Arribas and others, 1995a). 
At Summitville, most homogenization temperatures of liquid-rich inclusions in the vuggy quartz alteration zones, quartzalunite alteration zone, and illite and smectite alteration zones, are $\sim 190-270{ }^{\circ} \mathrm{C}$, although populations with homogenization temperatures of $\sim 280-310^{\circ} \mathrm{C}$ and $330-390{ }^{\circ} \mathrm{C}$ occur in the vuggy quartz and illite and smectite zones. Inclusion salinities are predominantly less than 8 weight percent $\mathrm{NaCl}$ equivalent; a small proportion are 10-25 weight percent $\mathrm{NaCl}$ equivalent. These temperature ranges and salinities are virtually identical to those in ore-stage quartz, a quartz+enargite + gold assemblage in the Missionary vein, and a quartz+enargite+pyrite + kaolinite assemblage in a shallow $(<100 \mathrm{~m})$ drill hole. Homogenization temperatures vary mostly from 290 to more than $500{ }^{\circ} \mathrm{C}$ (Bethke and others, 2005) in liquid-rich, vapor-rich, and salt-saturated inclusions in quartz+enargite+gold assemblages in the Missionary vein, and in quartz veins from tens of meters to $\sim 1,060 \mathrm{~m}$ below the erosion surface, or $\sim 800-2,000$ m paleodepths.

In deposits in which fluids are interpreted to have boiled, comparison or "fitting" of liquid-rich and vapor-rich homogenization temperature modes and ranges to boiling point curves (Haas, 1971), indicate that low-salinity fluids boiled at depths of $\sim 0.1-0.5 \mathrm{~km}$ below paleowater tables. The vertical extent of mined gold-silver-copper ore is $\sim 0.3 \mathrm{~km}$ (see "Hypogene and Supergene Ore Characteristics"), and most, if not all, ore is cospatial with low-salinity, liquid-rich inclusions, and in some districts with liquid-rich and vapor-rich inclusions. Based on microthermometry and depths of salt-saturated inclusions below erosion surfaces and paleosurfaces at Goldfield, Summitville, Rodalquilar, and Chinkuashih, decompression vapor-brine separation of magmatic fluid occurred at $\sim 0.7$ to $\geq 1.1 \mathrm{~km}$. According to these depth estimates, ore in highsulfidation deposits formed at $\sim 0.1-0.7 \mathrm{~km}$ below paleowater tables. However, the variations in depths and salinities of saltsaturated and vapor-rich inclusions within districts (Goldfield and Summitville) indicate more than one magmatic degassing event and complicated hydrodynamics involving magmatic fluid components and meteoric water.

\section{Low- and Intermediate-Sulfidation Deposits}

Temperatures, pressures, compositions, and sources of fluids that formed low- and intermediate-sulfidation deposits, and altered wall rocks, have been quantified in numerous investigations by using fluid inclusion microthermometry, and by analysis of fluid gas, solute, and isotope (mostly water oxygen and hydrogen) compositions. The thematic purpose of these investigations is to model the hydrodynamics of oreforming systems by paragenetic correlation of fluid temperature and pressure gradients with depths below paleowater tables, with stratigraphically controlled fluid permeabilities, with alteration mineral assemblages, and with sources of water in hydrothermal fluids (for example, Vikre, 1985, 1987, 2007).

Fluid characteristics in low- and intermediate-sulfidation deposits have been determined mostly from inclusions in quartz and calcite, and less commonly in adularia, sphalerite, fluorite, and rhodochrosite, in samples collected at the elevations of erosion surfaces to depths $\sim 1,000$ m below erosion surfaces. Comprehensive investigations of multistage veins include representative microthermometric data from pre-ore ("early" or "barren"), ore, and post-ore ("late" or "barren") paragenetic stages. Fluid inclusion microthermometry is commonly coupled with stable isotope analyses of fluids extracted from inclusions and minerals that host inclusions to determine sources of water in inclusions.

Fluid inclusion investigations of low- and intermediatesulfidation deposits involve the same techniques, limitations, and governing properties of aqueous fluids as for highsulfidation deposits. The major limitations are (1) optically resolvable primary and pseudosecondary inclusions that seldom exceed a few tens of microns in maximum dimension, especially in low-sulfidation deposits, (2) fluid inclusion populations in multistage veins that are commonly difficult to isolate paragenetically, and (3) most reported analyses of fluid gas and isotope compositions represent "paragenetic mixtures" because analysis requires bulk fluid extraction (for example, Foley and others, 1989). Arrays of homogenization temperatures, salinities, and isotope values derived from individual or adjacent samples commonly span tens of degrees Celsius, several weight percent $\mathrm{NaCl}$ equivalent, and many parts per mil, respectively, reflecting paragenetically different fluids, or a "parent" fluid modified by fluid-mineral reactions, fluid mixing, and (or) fluid boiling (for example, Simpson and others, 2015). However, large datasets collected over a range of elevations and with established stratigraphic and structural context usually provide consistent temperature-depth relations, on the basis of resemblance to geothermal systems, the modern analogues, in many respects, of low- and intermediatesulfidation deposits.

\section{Phase Relationships}

Liquid-rich inclusions (usually $\leq 20$ volume percent vapor) occur in quartz and other hydrothermal minerals in all low- and intermediate-sulfidation deposits, and vapor-rich inclusions ( $\geq 80$ volume percent vapor) are found in many deposits, but salt-saturated inclusions have not been reported for ore-stage inclusions. Homogenization temperatures of coexisting liquidrich and vapor-rich inclusions, indicative of fluid boiling during entrapment, are commonly compared with calculated temperatures and pressures of coexisting liquid and vapor in aqueous solutions (water $+\mathrm{NaCl}+$ volatiles; commonly referred to as "boiling point curves"; for example, Haas, 1971; Hedenquist and Henley, 1985a) to estimate sample depths relative to paleowater tables during deposit formation.

\section{Homogenization Temperatures, Fluid Salinities, and Fluid Pressures}

The reported range of homogenization temperatures of liquid-rich and vapor-rich inclusions in quartz, adularia, and other minerals in all stages of low- and intermediate-sulfidation deposits is less than 100 to $390{ }^{\circ} \mathrm{C}$ (for example, National, Nevada, Vikre, 1985; McLaughlin, California, Sherlock and 
others, 1995; Mule Canyon, Nevada, John and others, 2003; Hog Ranch, Nevada, Bussey, 1996; Hart district, California, Ausburn, 1991; Hishikari, Izawa and others, 1990; Matsuhisa and Aoki, 1994; Guanajuato, Moncada and others, 2012; Mango and others, 2014; numerous precious metal deposits in Mexico, Albinson and others, 2001; Camprubi and others, 2001b; El Peñón, Chile, Warren and others, 2004; Buritica, Colombia, Lesage and others, 2013; Roşia Montană, Romania, Wallier and others, 2006; Toodoggone River, British Columbia, Diakow and others, 1991; Hauraki Goldfield, New Zealand, Simpson and Mauk, 2011; Simpson and others, 2015; Aginskoe, Russia, Andreeva and others, 2013; Sunshin, Korea, Kim and others, 2012). In multistage veins, homogenization temperatures vary by tens of degrees to more than $100^{\circ} \mathrm{C}$ among stages. Modal ore-stage fluid temperatures, where constrained, vary widely from about less than 130 to about $290{ }^{\circ} \mathrm{C}$ (for example, National; McLaughlin; Hog Ranch; Hishkari; Aginskoe; Guanajuato), and homogenization temperatures of earlier and later stage fluid inclusions in quartz and calcite also vary widely from about 90 to greater than $300{ }^{\circ} \mathrm{C}$ (for example, Hishikari, Guanajuato, Hog Ranch, El Peñón, Roşia Montană).

Fluid inclusion salinities in low- and intermediate-sulfidation veins are mostly less than 3 weight percent $\mathrm{NaCl}$ equivalent in near-surface vein segments or throughout vertical intervals of ore-stage vein assemblages, and as much as about 6 weight percent $\mathrm{NaCl}$ equivalent locally or in deeper vein segments, with salinity variations by depth and by paragenetic stage documented in some deposits (for example, Guanajuato, Mango and others, 2014; Roşia Montană, Romania, Wallier and others, 2006; Hauraki Goldfield, New Zeland, Simpson and Mauk, 2011; Simpson and others, 2015). In multistage veins, salinities vary by several weight percent or more among stages. Rare, higher fluid salinities ( $\sim-10$ weight percent $\mathrm{NaCl}$ equivalent) are attributed, in part, to boiling in low-permeability fractures, based on fluid enthalpysalinity trends (for example, McLaughlin; Sherlock and others, 1995), and to paragenetically different fluids. Boiling increases salinity of residual aqueous fluid, and dissolved gases which lower ice melting temperatures may cause erroneously high salinity estimates in fluids that contain more than a few weight percent dissolved gases (Hedenquist and Henley, 1985a). Based on a comprehensive compilation of metal ratios (from production), fluid inclusion microthermometry, volatile abundances, and isotope values of water elements of epithermal gold-silver-base metal deposits in Mexico, Albinson and others (2001) showed that fluids that formed gold-silver and silver-gold (low-sulfidation) deposits are (1) distinctly less saline (mostly $<6$ weight percent $\mathrm{NaCl}$ equivalent) than fluids that formed polymetallic silver-goldlead-zinc-copper (intermediate-sulfidation) deposits (as much as $\sim 23$ weight percent $\mathrm{NaCl}$ equivalent), and (2) formed nearer to the surface than polymetallic deposits.

The reported range of homogenization temperatures of liquid-rich and vapor-rich inclusions in quartz, sphalerite, fluorite, barite, and rhodochrosite in all forms and stages of intermediatesulfidation vein deposits is $\sim 135-385^{\circ} \mathrm{C}$ (for example, Tonopah, Fahley, 1981; Tayoltita, Smith and others, 1982; Conrad and others, 1992; Comstock Lode, Vikre, 1989a; Sunnyside mine,
Creede, and Lake City districts, San Juan Mountains, U.S.A., Casadevall and Ohmoto, 1977; Foley and others, 1989; Slack, 1980; Buritica, Colombia, Lesage and others 2013). Modal orestage fluid temperatures, where constrained, mostly vary from 220 to $310^{\circ} \mathrm{C}$. Fluid inclusion salinities in intermediate-sulfidation veins mostly vary from $\sim 1$ to 12 weight percent $\mathrm{NaCl}$ equivalent with distinctly different value ranges among districts and deposits (for example, Tonopah 1-3 weight percent; Comstock Lode 1-6 weight percent; Tayoltita 2-10 weight percent; Creede 6-11 weight percent; Sunnyside $\sim 0-4$ weight percent; Buritica 2-8 weight percent). Elevated salinities have been interpreted to reflect a magmatic water component in ore-forming fluids, an interpretation that is supported by stable isotope values of fluids.

Fluid pressures can be estimated by comparing fluid inclusion homogenization temperatures, salinities, and gas concentrations with boiling point curves of aqueous solutions (Haas, 1971; fig. K8), and for liquid-rich populations, converted to minimum paleodepths. For populations that include liquid-rich and vapor-rich inclusions, the relative elevation of paleowater tables during inclusion entrapment can be more accurately determined by comparison with appropriate boiling point curves, provided that solute (salts and volatiles) concentrations, which strongly affect temperature and pressure of vapor-liquid equilibrium, are known (Hedenquist and Henley, 1985a). Pressures (paleodepths) and temperatures have also been calculated from gas abundances in fluid inclusions (for example, McLaughlin; Sherlock and others, 1995).

\section{Solutes}

Concentrations of some lithophile $(\mathrm{Na}, \mathrm{K}, \mathrm{Ca}, \mathrm{Rb}$, $\mathrm{Sr}, \mathrm{Cs}$, and $\mathrm{Ba})$ and chalcophile $(\mathrm{Cu}, \mathrm{Pb}, \mathrm{Zn}, \mathrm{Mn}, \mathrm{Sb}$, and As) elements in water extracted from fluid inclusions by crushing and laser ablation have been determined by chemical techniques (atomic absorption analysis of leachate) and LA ICP-MS (laser ablation inductively coupled plasmamass spectrometry) (for example, Casadevall and Ohmoto, 1977; Wallier and others, 2006; Simpson and others, 2015); concentrations vary from less than ten to thousands of parts per million. At Roşia Montană, broad correlations among $\mathrm{K}, \mathrm{Na}, \mathrm{Cs}, \mathrm{Zn}$, and $\mathrm{Cu}$ concentrations, coupled with fluid inclusion petrography, microthermometry, and $\delta^{18} \mathrm{O}$ values, were interpreted to reflect predominance of magmatic water in ore-forming fluid, and possible fluid phase separation (vapor and brine) at depth.

\section{Volatile Species, Abundances, and Isotope Compositions}

Abundances of $\mathrm{H}_{2} \mathrm{O}, \mathrm{N}_{2}, \mathrm{Ar}, \mathrm{He}, \mathrm{CH}_{4}$, and other hydrocarbon phases, $\mathrm{CO}_{2}, \mathrm{H}_{2}, \mathrm{H}_{2} \mathrm{~S}$, and $\mathrm{SO}_{2}$, and isotope compositions of $\mathrm{He}$ and $\mathrm{Ar}$, in fluid inclusions in quartz, calcite, sulfide minerals, and fluorite, have been determined in some deposits by mechanical extraction of fluids from host mineral (crushing) and mass spectrometry (for example, Sunnyside, Casadevall and Ohmoto, 1977; numerous vein deposits in Mexico including La Guitarra, Albinson and others, 2001; Camprubi and others, 2006; Sunshin, Korea, 


\section{A. National, Nevada, U.S.A.}

WEST

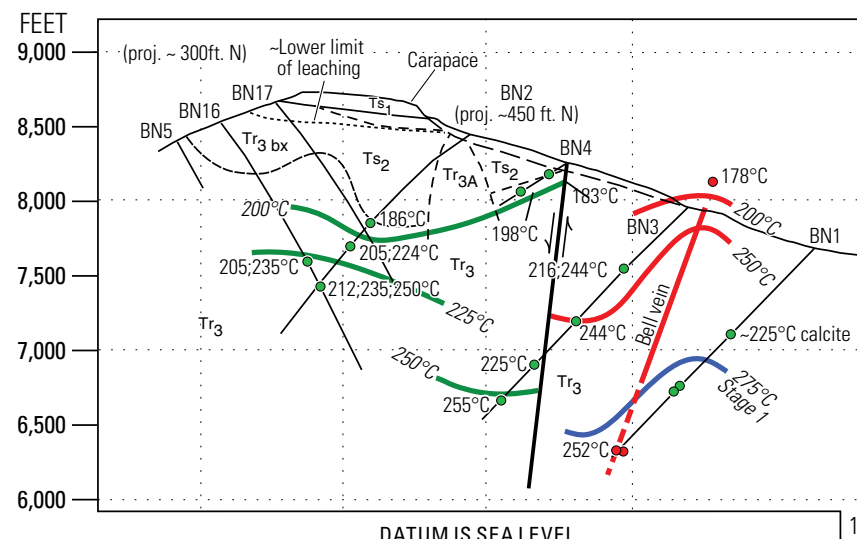

DATUM IS SEA LEVEL
EAST

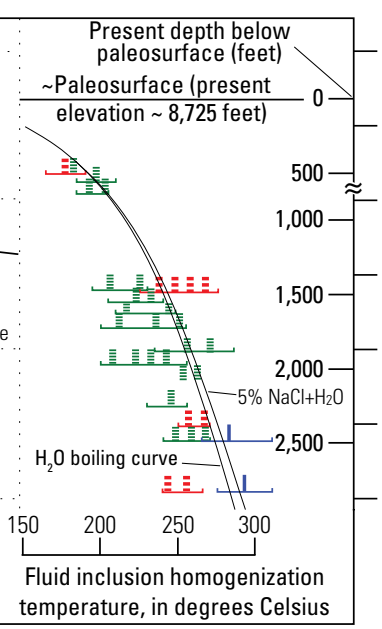

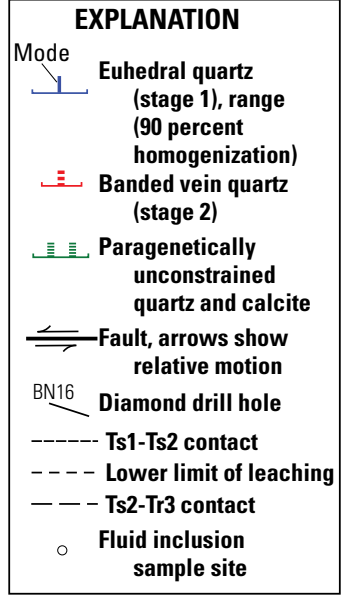

B. McLaughlin, California, U.S.A.

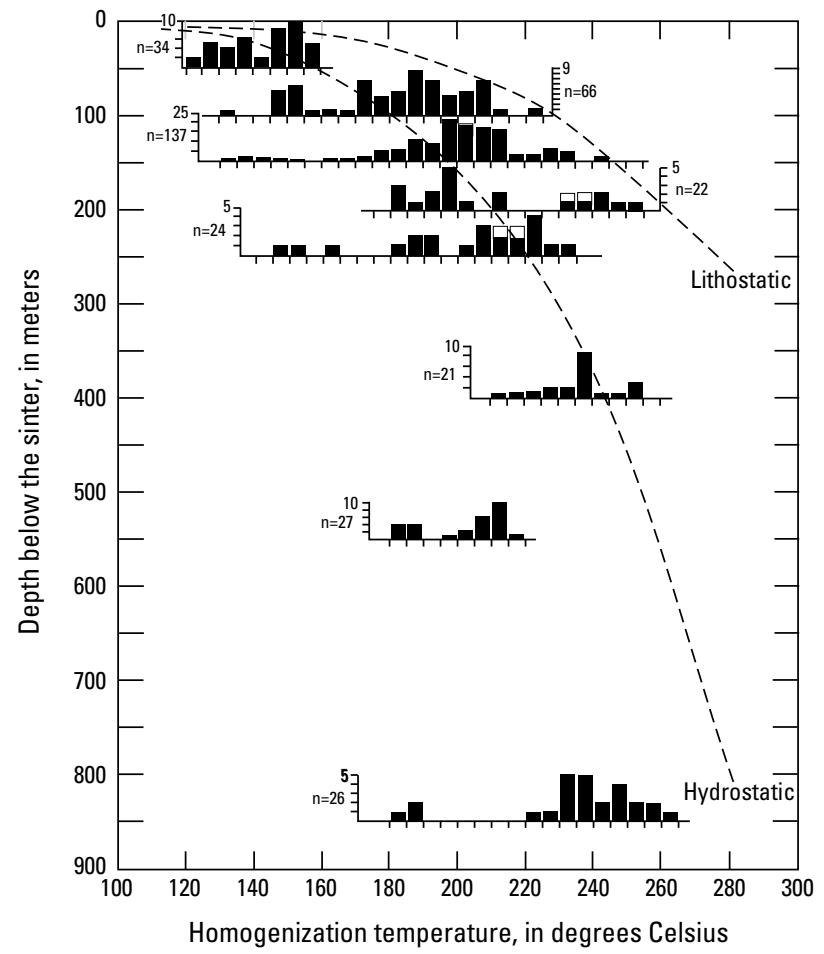

\section{Deposits in Mexico}

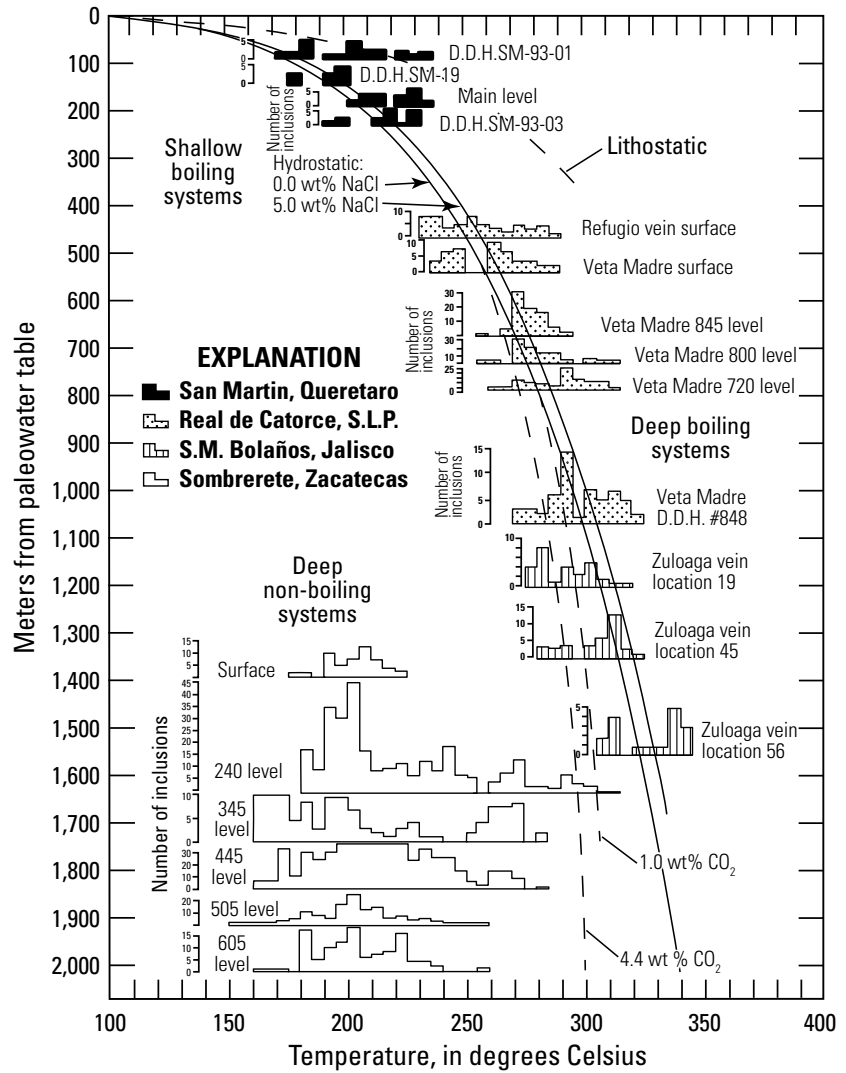

Figure K8. Homogenization temperature versus depth profiles for low- and intermediate-sulfidation deposits with geologically established paleosurfaces at ( $A$ ) National, Nevada, U.S.A. (Vikre 2007), and (B) McLaughlin, California, U.S.A. (Sherlock and others 1995), and paleosurfaces fitted to aqueous vapor-liquid equilibria versus depth ("boiling point curves" [bpc]; Haas, 1971) for (C) deposits in Mexico (Albinson and others, 2001). Horizontal scales of profile arrays are homogenization temperatures in degrees Celsius $\left({ }^{\circ} \mathrm{C}\right)$, and vertical scales include paleodepths in feet $(A)$ and meters $(B$ and $C$ ). In the National profile $(A)$, 2 vein stages, homogenization temperature arrays (colored horizontal lines on or near curves) and modes (vertical short-dashed columns on colored lines), and sample locations relative to stratigraphy are shown (abbreviations are Ts1, sinter-epiclastic deposits; Ts2, volcaniclastic deposits; Ts3, rhyolite of Buckskin Mountain). In the McLaughlin profile ( $B$ ) homogenization temperature arrays and frequencies are scaled horizontal lines and vertical bars of stacked solid black $(\mathrm{V} \rightarrow \mathrm{L})$ and open $(\mathrm{L} \rightarrow \mathrm{V})$ rectangles, respectively, and bpc are for 2.5 weight percent $\mathrm{NaCl}$ equivalent aqueous fluid. Profiles for Mexican deposits profiles $(C)$ include bpc for several solute $\left(\mathrm{NaCl}\right.$ and $\mathrm{CO}_{2}$ ) concentrations and deposits interpreted to have formed over a 2,000 $\mathrm{m}$ range of paleodepths. 
Kim and others, 2012). Combined volatile concentrations (other than water) seldom exceed several mole percent, but their proportions have been used to interpret sources (see Graney and Kesler, 1995).

Relative $\mathrm{N}_{2}, \mathrm{CH}_{4}, \mathrm{He}, \mathrm{Ar}, \mathrm{CO}_{2}, \mathrm{H}_{2} \mathrm{~S}$, and $\mathrm{SO}_{2}$ abundances in fluid inclusions, compared with relative abundances in magmatic (volcanic) gases, gases in air-saturated meteoric water, "crustal" gases (for example, $\mathrm{CH}_{4}$ and $\mathrm{H}_{2} \mathrm{~S}$ derived from organic-rich sedimentary rocks), and gases in part derived from mantle rocks (for example, $\mathrm{He}$ ), broadly indicate variable contributions in space and time within individual deposits from all sources. Variability can be partially attributed to volatile vapor-liquid fractionation and volatile loss during boiling, to differences in volatile solubility in aqueous fluids, and to disproportionate analysis of vapor-rich inclusions. Based on volatile analyses of fluid inclusions in veins at La Guitarra, precious metals are interpreted to have been deposited by relatively oxidized magmatic fluids, whereas base metals are thought to have been leached from deep crustal rocks by crustal and magmatic fluids (Camprubi and others, 2006).

\section{Zoning and Depth of Deposit Formation}

In deposits in which fluid microthermometric data (homogenization temperatures and salinities) have been collected over a range of depths below geologically established paleosurfaces (or paleowater tables), arrays of fluid inclusion homogenization temperatures are commonly plotted relative to boiling point curves for low salinity and low-volatile aqueous fluids, following the portrayal by Vikre (1985; fig. K8). Sinters, which represent hydrothermal (mostly silica) minerals deposited on a paleosurface, coincide with paleowater tables, and where coeval with vein deposits, approximate the elevation of $100^{\circ} \mathrm{C}$ isotherms. In such preserved systems, hydrodynamics of sinter and vein deposition can be relatively precisely reconstructed, and paleodepths of ore accurately determined (for example, Vikre, 1985, 2007). However, in some sinter-vein systems (for example, National, Ivanhoe), paragenetically late steam-heated alunite, replacement of vein and wall-rock potassium feldspar by illite and kaolinite, and leached sinter-volcaniclastic sequences overlying veins, attest to subsidence of paleowater tables below sinters. This subsidence, which can be caused by uplift and (or) extensive fluid vaporization during prolonged boiling, may lead to errors in estimation of ore paleodepths, if unrecognized.

In fluid inclusion microthermometric investigations of low-sulfidation deposits that are constrained by geologic paleosurfaces (sinter), homogenization temperatures of some liquid-rich inclusions and calculated volatile pressures plot above the liquid-vapor boundary or exceed lithostatic pressure (for example, McLaughlin; Sherlock and others, 1995). Because paleowater tables at higher elevations are not justified by geologic evidence, these apparently overpressured fluids reflect (1) vapor-rich inclusions in the bulk samples analyzed, or (2) fluid pressure that is occasionally exceeded by lithostatic pressure. Geologic evidence for overpressured fluids are the "hydrothermal eruption breccias" reported in many low-sulfidation districts, which form when confined fluid pressure exceeds the lithostatic pressure (weight) and tensile strength of overlying strata (in some cases including sinter). If confined fluid temperatures are above $\sim 100{ }^{\circ} \mathrm{C}$ and fluids are suddenly depressurized, then vapor rapidly separates from liquid ("flash" boiling) and a low-density, high-velocity vapor stream transports ruptured rock fragments to the paleosurface, commonly leaving small ejecta deposits adjacent to vents and fissures (see "Relations to Structures").

In eroded low- and intermediate-sulfidation gold-silver deposits and districts, paleodepths of most homogenization temperature arrays are either geologically unconstrained or approximated by stratigraphic reconstruction. In these deposits, demonstrable fluid boiling (coeval liquid-rich and vapor-rich inclusions) and interpreted fluid boiling (hydrothermal mineral morphology [for example, bladed calcite; Simmons and Christenson, 1994], assemblages that include opal, chalcedony, alunite, and kaolinite, and variable concentrations of volatiles in fluid inclusions) are used to position homogenization temperature modes on appropriate boiling point curves, providing quantified to qualitative paleodepth estimates (for example, Hauraki Goldfield, New Zealand, Christie and others, 2007; Simpson and Mauk, 2011; Simpson and others, 2015).

Based on system hydrodynamics, determined from fluid inclusion microthermometry and other geologic evidence (sinters; hydrothermal mineral assemblage zoning; fluid $\delta \mathrm{D}$ and $\delta^{18} \mathrm{O}$ values), and on gold and silver concentrations, the upper parts of low-sulfidation gold-silver ore zones formed at paleodepths of meters (McLaughlin; Sherlock and others, 1995) to more than 100 m (for example, National; Vikre, 1985, 2007). Based entirely on gold and silver concentrations, the vertical dimensions of most ore zones are tens to hundreds of meters (appendix 1).

Coeval sinters are conspicuously absent from intermediatesulfidation districts, implying that water tables during vein deposition were above erosion surfaces. Temperatures of fluid inclusion populations and alteration mineral assemblages that reflect boiling in upper segments of veins or during some stage of vein deposition (for example, Tonopah, Fahley, 1981; Comstock Lode, Vikre, 1989a; Tayoltita, Smith and others, 1982; Sunnyside, Casadevall and Ohmoto, 1977; Lake City district, U.S.A., Slack, 1980) provide evidence that gold-silver-mineralized vein segments formed at least hundreds of meters below water tables. Vertical dimensions of minable gold-silver grades in the largest intermediate-sulfidation districts exceed $1 \mathrm{~km}$ (Tayoltita, Comstock Lode; figs. F3, K8; appendix 1).

\section{Stable Isotope Geochemistry}

\author{
By Peter G. Vikre
}

\section{High-Sulfidation Deposits}

Sulfur, hydrogen, and oxygen isotope compositions have been determined for common hydrothermal minerals in many high-sulfidation deposits and districts, and less commonly, for primary minerals in host rocks. Purposes of these analytical investigations include (1) identification of sulfur sources in sulfate and sulfide minerals and water sources in fluid inclusions 
or equilibrated with hydrous minerals, (2) calculation of isotope equilibrium temperatures from $\delta^{34} \mathrm{~S}$ sulfate-sulfide fractionation, and (3) reconstruction of magmatic-hydrothermal systems before, during, and after deposition of gold-silver-copper ore.

Sulfur isotope values $\left(\delta^{34} \mathrm{~S}\right.$ in \%o) of sulfide and sulfate minerals can be determined from mineral separates that can represent paragenetic stages. In order to compare and track aqueous fluids during system evolution, hydrogen ( $\delta \mathrm{D}$ in \%o) and oxygen $\left(\delta^{18} \mathrm{O}\right.$ in \%o) isotope values of hydrous minerals, isolated by paragenetic stage, are converted to isotope values of water in equilibrium with hydrous minerals at their known or assumed depositional temperatures. Depositional temperature estimates for calculation of temperature-dependent mineral-water isotope fractionations are derived from fluid inclusion microthermometry or calculated from sulfur isotope compositions of coeval sulfate and sulfide minerals. Some $\delta \mathrm{D}$ water values are determined directly by extraction and analysis of fluids in fluid inclusions, mostly in quartz. Water $\delta^{18} \mathrm{O}$ values in quartz inclusions and all oxygen-rich minerals are calculated from experimentally determined fractionations and temperature estimates. However, water $\delta \mathrm{D}$ values determined by this bulk sample analytic method can mix paragenetically different fluids (for example, Foley and others, 1989). Water $\delta^{18} \mathrm{O}$ values calculated from bulk quartz samples may also reflect a blend of isotopically heterogeneous quartz that is caused by variable $\delta^{18} \mathrm{O}$ values of water from which quartz precipitated and by nonequilibrium fractionation during structural transition from noncrystalline silica phases to quartz (for example, Tanner and others, 2013). In many recent investigations, the stable isotope systematics $\left(\delta^{34} \mathrm{~S}, \delta \mathrm{D}, \delta^{18} \mathrm{O}\right)$ of alunite, pyrite, and kaolinite, coupled with the distribution and paragenetic relationships of these minerals to other hydrothermal minerals and assemblages, are used to reconstruct system hydrodynamics, including weathering, an approach developed by Robert Rye and associates (see Rye, 2005). Applications of stable isotope systematics to high-sulfidation deposits are broadly summarized in the sections that follow.

\section{Sources of Sulfur and Water}

Determination of sulfur sources is complicated by the large variation in isotope values that reflect the temperature, $\mathrm{pH}$, oxidation state, and $\mathrm{H}_{2} \mathrm{~S} / \mathrm{SO}_{4}{ }^{2-}$ of fluids from which sulfide and sulfate minerals were deposited. Sulfur sources based on $\delta^{34} \mathrm{~S}$ values are seldom unique, but they can be constrained if $\delta^{34} \mathrm{~S}, \delta \mathrm{D}$, and $\delta^{18} \mathrm{O}$ values of coexisting sulfide and sulfate minerals are known.

Sources of sulfur, in part, and water are revealed by multisite isotope analyses of alunite (sulfur in $\mathrm{SO}_{4}^{2-}$; oxygen in $\mathrm{SO}_{4}^{2-}$ and $\mathrm{OH}^{-}$; hydrogen in $\mathrm{OH}^{-}$), by analyses of coexisting sulfide minerals, and by calculation of isotope values of water in equilibrium with alunite and other hydrous minerals, by using experimentally determined fractionations (for example, Stoffregren and others, 1994) and temperature estimates.

Sulfur and water sources enable evaluation of fluid mixing and isotope exchange trajectories during the evolution of magmatichydrothermal systems that form high-sulfidation deposits.
Multisite isotope analyses have been used to define four distinct depositional environments (Rye and others, 1992; Rye, 2005; fig. K9): (1) Magmatic-hydrothermal (MH) alunite forms by condensation of magmatic $\mathrm{SO}_{2}$ in water, and disproportionation to $\mathrm{H}_{2} \mathrm{~S}$ and $\mathrm{SO}_{4}^{2-}$. $\mathrm{MH}$ alunite commonly coexists with pyrite and has highly positive $\delta^{34} \mathrm{~S}$ values that are much larger than $\delta^{34} \mathrm{~S}$ pyrite values, reflecting as much as tens of parts per thousand (\%o) fractionation between $\mathrm{H}_{2} \mathrm{~S}$ and $\mathrm{SO}_{4}{ }^{2-}$ at temperatures of most hydrothermal fluids $\left(<400^{\circ} \mathrm{C}\right)$. Measured $\delta^{18} \mathrm{O}_{\mathrm{SO} 4}$ values of $\mathrm{MH}$ alunite vary from about 2 to $15 \%$, and measured $\delta \mathrm{D}$ values are highly variable, reflecting mixtures of magmatic and meteoric water, and exchange with meteoric water. (2) Steam-heated (SH) alunite, which forms by oxidation of $\mathrm{H}_{2} \mathrm{~S}$ in meteoric water near paleosurfaces, has $\delta^{34} \mathrm{~S}$ values similar to $\delta^{34} \mathrm{~S}_{\text {sulfide minerals }}, \delta^{18} \mathrm{O}_{\text {SO4 }}$ values that vary from about 8 to $15 \%$, and $\delta \mathrm{D}$ values of meteoric water. However, $\delta^{34} \mathrm{~S}$ and $\delta^{18} \mathrm{O}_{\mathrm{SO} 4}$ values may also reflect variable exchange with $\mathrm{H}_{2} \mathrm{~S}$ and high ${ }^{18} \mathrm{O}$ water. (3) Magmatic steam (MS) alunite, which is thought to form by rapid condensation of magmatic vapor containing $\mathrm{SO}_{2}$, has $\delta^{34} \mathrm{~S}$ values similar to $\delta^{34} \mathrm{~S}_{\Sigma \mathrm{S}}$ values, usually $\sim 0 \%$, $\delta^{18} \mathrm{O}_{\mathrm{SO} 4}$ values of $10-15 \%$, and $\delta \mathrm{D}$ values similar to magmatic water values. Because of rapid transport and deposition, MS alunite is commonly in isotopic disequilibrium with other hydrothermal minerals. (4) Supergene (SG) alunite forms by weathering of sulfide minerals, has $\delta^{34} \mathrm{~S}$ values that are the same as the sulfide minerals, $\delta^{18} \mathrm{O}_{\mathrm{SO} 4}$ values that range from meteoric water to atmospheric oxygen values, and $\delta \mathrm{D}$ values of meteoric water. Magmatic-hydrothermal, steam-heated, and supergene alunites are reported for most high-sulfidation deposits. Magmatic steam alunite has been recognized in a few deposits (for example, Tambo and Pascua-Lama).

Sulfur isotope values in high-sulfidation deposits and districts have been determined for pyrite, enargite, bismuthinite, sphalerite, galena, covellite, sulfur, alunite, barite, and apatite (for example, Summitville, Bethke and others, 2005; Russin and Fifarek, 2009; Borealis, Eng, 1991; Paradise Peak, John and others, 1991; Goldfield, P. Vikre, unpublished data; Mulatos, Mexico, Staude, 2001; El Indio, Chile, Jannas and others, 1990, 1999; Tambo, Chile, Deyell and others, 2005b; Pierina, Peru, Fifarek and Rye, 2005; Lagunas Norte, Peru, Cerpa and others, 2013; Rodalquilar, Spain, Arribas and others, 1995a; Nansatsu, Japan, Hedenquist and others, 1994; Lepanto, Philippines, Hedenquist and others, 1998; Berger and others, 2014). Deuterium and $\delta^{18} \mathrm{O}_{\mathrm{SO} 4}$ values also have been determined for alunite and barite in several deposits and districts (Goldfield; Summitville; Pierina; Lagunas Norte; Vikre, 1989b; Bethke and others, 2005; Rainbow and others, 2005; Fifarek and Rye; 2005; Cerpa and others, 2013). Sulfur isotope values of sulfide minerals vary from -15.5 to $8 \%, \delta^{34} \mathrm{~S}_{\text {sulfate mineral }}$ values vary from $\sim-1$ to $34 \%$, $\delta \mathrm{D}$ values vary from -39 to $-97 \%$, and $\delta_{18} \mathrm{O}_{\mathrm{SO} 4}$ values vary from 1 to $16.5 \%$. These variations reflect numerous processes including $\mathrm{SO}_{2}$ disproportionation, $\mathrm{H}_{2} \mathrm{~S}$ oxidation, magmatic $\mathrm{SO}_{2}$ vapor condensation, fluid mixing, isotope exchange, sulfide mineral weathering, and possible variations in $\Sigma \mathrm{S}$ isotope values. 
Water sources have also been determined from $\delta \mathrm{D}$ and $\delta^{18} \mathrm{O}$ analyses of water extracted from fluid inclusions, and from water isotope compositions calculated from $\delta \mathrm{D}$ and $\delta^{18} \mathrm{O}$ values of igneous and hydrothermal silicate minerals at assumed equilibrium temperatures (for example, Summitville, Bethke and others, 2005; Goldfield, Vikre, 1989b; Pierina, Fifarek and Rye, 2005; Nansatsu, Hedenquist and others, 1994; Rodalquilar, Arribas and others, 1995a; Lepanto,
Hedenquist and others, 1998; El Indio, Jannas and others, 1999; Mulatos, Staude, 2001; Chinkuashih, Wang and others, 1999; Jinxi-Yelmand, China, Long and others, 2005). In some investigations, fluid inclusions and silicate minerals have been analyzed in conjunction with multisite isotope analyses of alunite (sulfur in $\mathrm{SO}_{4}^{2-}$; oxygen in $\mathrm{SO}_{4}{ }^{2-}$ and $\mathrm{OH}^{-}$; hydrogen in $\mathrm{OH}^{-}$). Values of $\delta \mathrm{D}_{\text {water }}$ and $\delta^{18} \mathrm{O}_{\text {water }}$ in fluid inclusions, and of water in equilibrium with quartz, biotite, kaolinite, dickite,

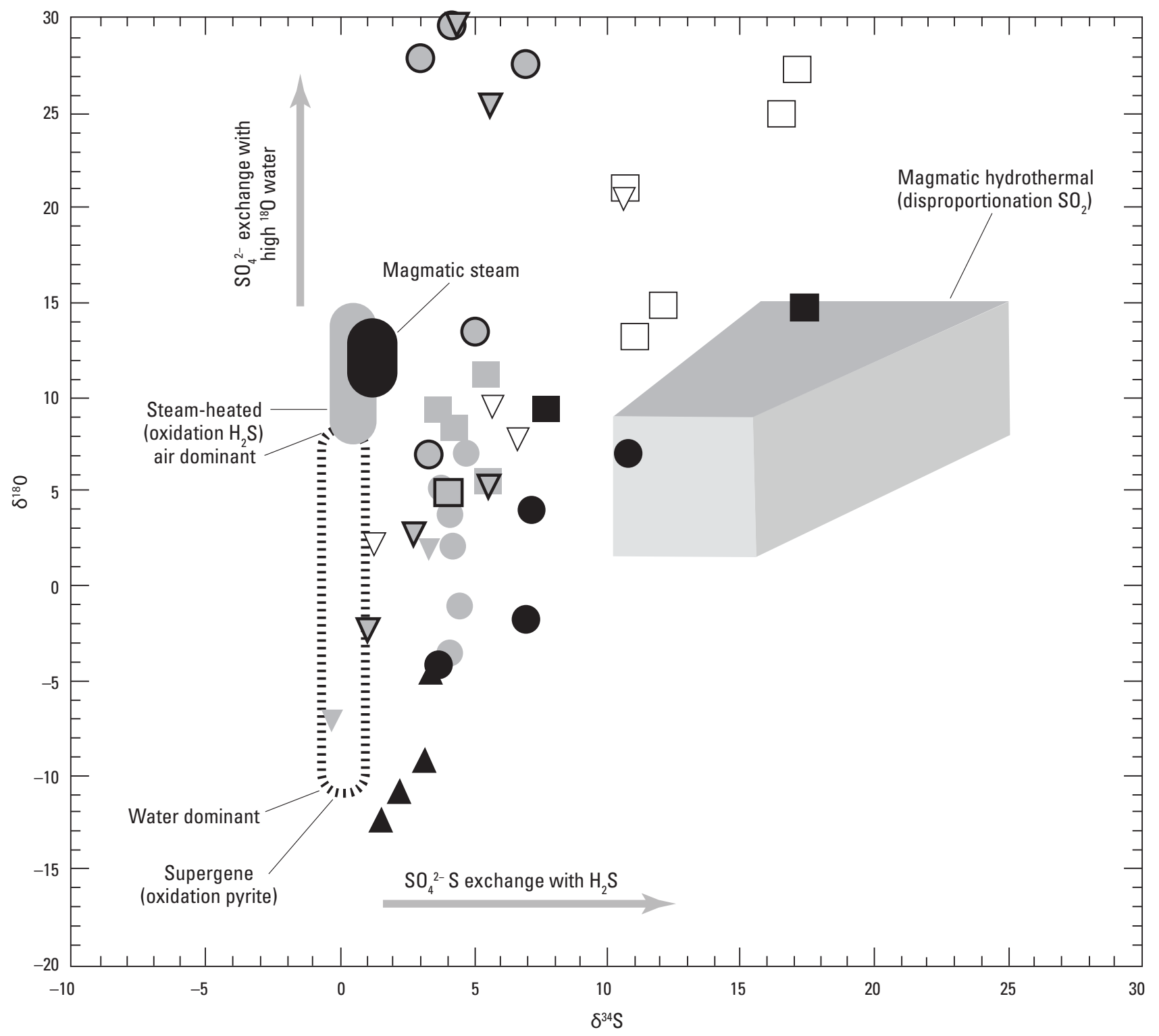

EXPLANATION

$\begin{array}{llcl}\text { Citlaltépetl } & \text { Mt. Rainier } & \text { Mt. Adams } & \text { Mt. Shasta } \\ \square \text { Alunite } & \text { Alunite } & \text { Alunite } & \square \text { Alunite } \\ \nabla \text { Al-Fe hydroxysulfate } & \bigcirc \text { Gypsum } & \text { Gypsum } & \bigcirc \text { Gypsum } \\ & \Delta \text { Jarosite } & \nabla \text { Al-Fe hydroxysulfate } & \nabla \text { Al-Fe hydroxysulfate }\end{array}$

Figure K9. $\delta^{18} 0-\delta^{34} S$ (in \%o) compositional fields of alunite environments: magmatic-hydrothermal, steam-heated, magmatic steam, and supergene. Modified from Rye (2005). Abbreviations: Al, aluminum; Fe, iron; H, hydrogen; 0, oxygen; S, sulfur. 
sericite (fine-grained illite or muscovite), and pyrophyllite, range from about -20 to $-115 \%$, and about -6 to $11 \%$, respectively. These values are within, or isotopically lighter than, the range of calculated isotope compositions of water in equilibrium with alunite, and broadly imply large components of meteoric water in hydrous silicate alteration minerals in some deposits.

Fluid inclusion, hydrous silicate, and alunite water values reflect variable fluid temperatures, and isotope compositions of magmatic water, meteoric water, mixtures of magmatic and meteoric water, and mixtures of magmatic and "exchanged" meteoric water, in which $\delta \mathrm{D}-\delta^{18} \mathrm{O}_{\text {water }}$ and $\delta \mathrm{D}-\delta^{18} \mathrm{O}_{\text {mineral }}$ have variably exchanged before mixing (fig. K10). Paragenetically early hydrothermal mineral assemblages in some deposits are dominated by magmatic water and other magmatic volatiles (for example, Summitville; Lepanto). In other deposits, meteoric water contents increase in later paragenetic stages (for example, Mulatos), and magmatic-meteoric water mixtures may be associated with all paragenetic stages (for example, Pierina). In many deposits, the entire paragenesis is associated with variably exchanged and mixed magmatic and meteoric waters (for example, Summitville; Goldfield). Most deposits contain isotopic evidence of at least small increments of magmatic water, although fluid inclusion waters in the $\sim 1$-Ma Chinkuashih gold deposit are very similar to present meteoric water in Taiwan.

\section{Isotope Equilibrium Temperatures}

Isotope equilibrium temperatures, calculated nearly entirely from $\delta^{34} \mathrm{~S}$ values of coexisting alunite and pyrite, range from about 180 to $390^{\circ} \mathrm{C}$ in pre-ore-stage and ore-stage mineral assemblages (gold \pm silver \pm copper minerals and other minerals), and about 150 to $280{ }^{\circ} \mathrm{C}$ in late-stage assemblages (barite, sulfur, iron oxides, gold; Jannas and others, 1990, 1999; Hedenquist and others, 1994; Arribas and others, 1995a; Staude, 2001; Bethke and others, 2005; Rainbow and others, 2005; Deyell and others, 2004, 2005a; Russin and Fifarek, 2009; Cerpa and others, 2013). Most equilibrium temperatures are $\sim 200-270{ }^{\circ} \mathrm{C}$, broadly similar to depositional temperatures of hypogene mineral assemblages estimated from fluid inclusion microthermometry. At Summitville, an alunite-pyrite sulfur isotope equilibrium temperature of $390{ }^{\circ} \mathrm{C}$ was estimated in the transition zone between hydrostatic and lithostatic pressure (Bethke and others, 2005).

\section{Low- and Intermediate-Sulfidation Deposits}

Sulfur, hydrogen, oxygen, and carbon isotope compositions have been determined for sulfide minerals, quartz, and mica-clay minerals in many low- and intermediatesulfidation gold-silver deposits and districts, commonly in conjunction with fluid inclusion microthermometry. Purposes of these investigations included (1) identification of sulfur sources in sulfate and sulfide minerals, and water sources in fluid inclusions or equilibrated with hydrous minerals,
(2) calculation of sulfur and oxygen isotope equilibrium temperatures, and (3) reconstruction of the hydrodynamics of gold-silver-mineralized systems, including processes that deposited gold, silver, and vein minerals.

\section{Sulfur Sources}

Sulfur isotope values $\left(\delta^{34} \mathrm{~S}\right.$ in \%o) of sulfide minerals in many low- and intermediate-sulfidation deposits are $0 \pm 3 \%$ o (for example, Hauraki Goldfield deposits, New Zealand, Christie and others, 2007). These values largely reflect derivation from a homogeneous source, presumably mantlederived magmas, and, consistent with the absence of sulfate minerals in most deposits, indicate negligible sulfide-sulfate fractionation in vein fluids, as opposed to widespread sulfidesulfate mineral fractionation in high-sulfidation deposits. The wider range of $\delta^{34} \mathrm{~S}_{\text {sulfide mineral }}$ (and calculated $\delta^{34} \mathrm{~S}_{\mathrm{H} 2 \mathrm{~S}}$ ) values in some deposits (for example, National, Vikre 1985, 2007; McLaughlin, Sherlock and others, 1995; Guanajuato, Mango and others, 2014; La Guitarra, Camprubi and others, 2001b; Sunnyside, Casadevall and Ohmoto, 1977; Mule Canyon, U.S.A., John and others, 2003) indicates sulfur derived from magmatic and crustal sources, including volcanic and sedimentary rocks, and possibly by concentration of $\delta^{34} \mathrm{~S}_{\mathrm{H} 2 \mathrm{~S}}$ in residual fluid following boiling. Large variation in $\delta^{34} \mathrm{~S}$ values of $\mathrm{Hg}$-Se-S minerals in near-surface strata, and gradients in values in subjacent vein sulfide minerals at National $(\sim-20$ to $3 \%$ ), are attributed to widespread isotope exchange in thermal pools and permeable volcaniclastic deposits, metal concentrations in fluid greater than $\mathrm{H}_{2} \mathrm{~S}$ concentrations, and derivation of some sulfur from subjacent Mesozoic black shale (Vikre, 2007).

\section{Isotope Equilibrium Temperatures}

Sulfur isotope equilibrium temperatures have been calculated for sphalerite-galena, pyrite-galena, and other mineral pairs in several intermediate-sulfidation deposits, although most calculations have large analytic errors (tens to $>100{ }^{\circ} \mathrm{C}$ ) or yield temperatures that differ considerably from fluid inclusion homogenization temperature modes (Sunnyside, Casadevall and Ohmoto, 1977; Buritica, Lesage and others, 2013; epithermal deposits in Argentina, Lanfranchini and others, 2013). At Buritica, average isotope equilibrium temperatures are $\sim 10-60{ }^{\circ} \mathrm{C}$ higher than fluid inclusion homogenization temperature modes for the same paragenetic stage (stage 1), which vary from 290 to $312{ }^{\circ} \mathrm{C}$. Oxygen isotope equilibrium temperatures calculated for quartz-adularia pairs in vein layers at Hishikari vary from 170 to $250^{\circ} \mathrm{C}$, similar to average homogenization temperatures of $180-220^{\circ} \mathrm{C}$ in those minerals (Faure and others, 2002).

\section{Water Sources}

Water sources and $\mathrm{CO}_{2}$ in low- and intermediatesulfidation gold-silver deposits have been determined from $\delta \mathrm{D}$ and $\delta^{13} \mathrm{C}$ analyses of water and $\mathrm{CO}_{2}$ extracted from fluid 
$\boldsymbol{A}$
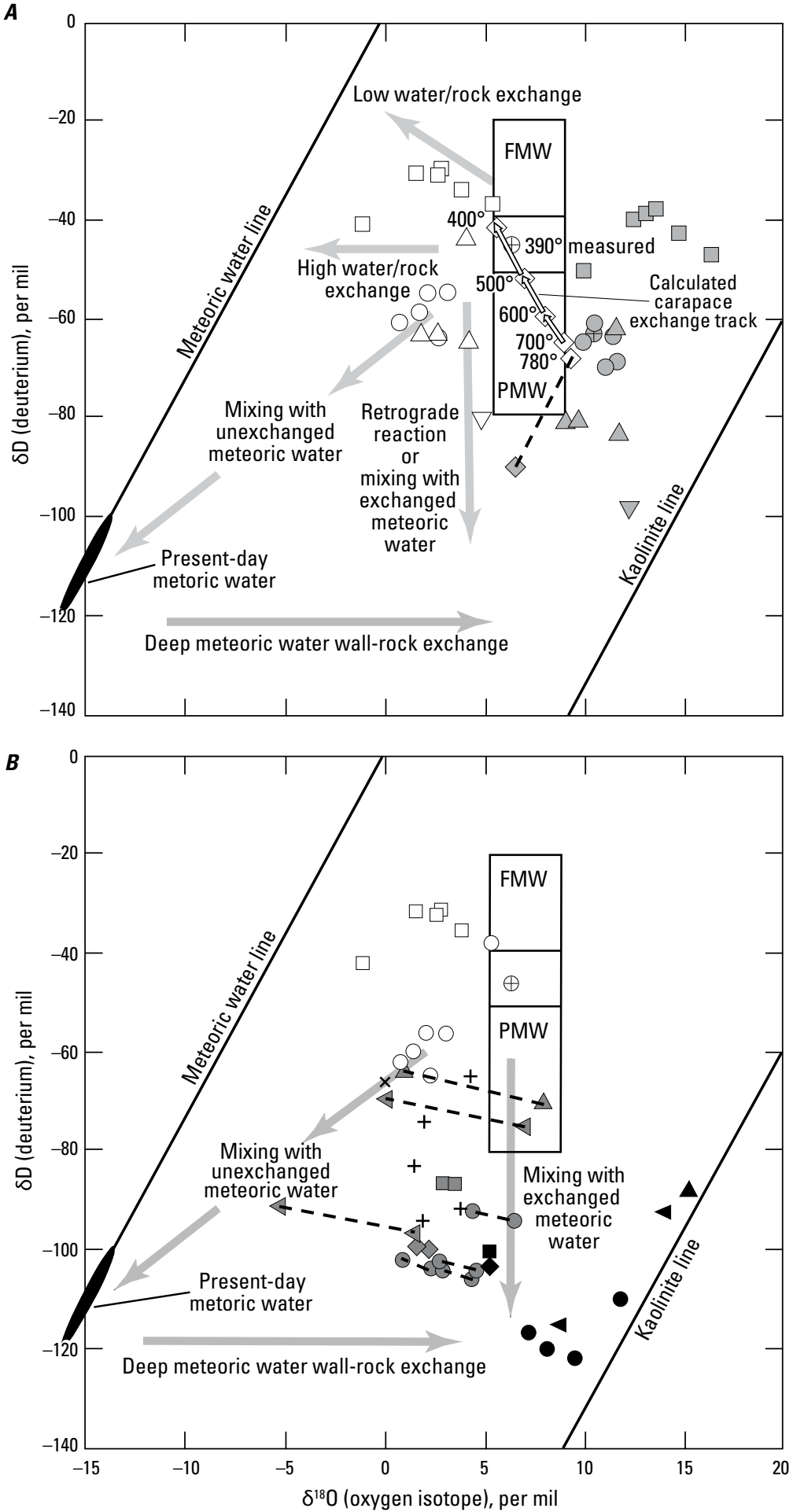

EXPLANATION

South Mountain Porphyry

$\square$ Distal alunite

$\diamond$ Water in equilibrium with South Mountain quartz latite

$\bigcirc$ Proximal alunite

$\oplus$ Deep alunite

$\triangle$ Distal kaolinite

$\nabla$ Proximal kaolinite

Fluid calculations from mineral data

$\square$ Distal alunite

$\checkmark$ Biotite in South Mountain quartz latite porphyry

Proximal alunite

(1) Deep alunite

$\triangle$ Distal kaolinite

$\nabla$ Proximal kaolinite

- - Calculated carapace water

\section{EXPLANATION}

Measured mineral and fluid isotope compositions

- Main mineralization kaolinite

- Deep stockwork kaolinite

- Deep stockwork pyrophyllite

+ Deep stockwork fluid inclusions

A Barite/base-metal stage kaolinite

4 Late bx/vein stage kaolinite

$\times$ Enargite fluid inclusion

Calculated mineral and fluid isotope compositions

- Main mineralization kaolinite

$\diamond$ Deep stockwork kaolinite

$\square$ Deep stockwork pyrophyllite

$\triangle$ Barite/base-metal stage kaolinite

$\checkmark$ Late bx/vein stage kaolinite

Alunite data from figure $\boldsymbol{A}$ (above)

$\bigcirc$ Proximal alunite

$\oplus$ Deep alunite

$\square$ Distal alunite

Figure K10. $\delta D-\delta^{18} 0$ values (in \%) of hydrothermal minerals and igneous biotite (filled symbols), and water in equilibrium with each mineral (open symbols) in the Summitville, U.S.A. high-sulfidation deposit, relative to primary magmatic water (PMW), felsic magmatic water (FMW), present day meteoric water (North America), the meteoric water line, and the kaolinite line. $A$, Mixing trajectories of magmatic water, meteoric water, and exchanged meteoric water at low and high water/rock are shown by labeled arrows. The linked dash line and double line paths represent magmatic water (calculated from igneous biotite, filled diamond) and calculated water values (at declining temperatures, open diamonds) in the carapace of the South Mountain quartz latite porphyry stock that hosts the gold+silver+copper deposits. $B$, Mixing trajectories (dashed lines) of waters in equilibrium with kaolinite from several paragenetic stages (a complete explanation of these diagrams is in Bethke and others, 2005, from which they were slightly modified). 
inclusions, and calculated from $\delta \mathrm{D}, \delta^{18} \mathrm{O}$, and $\delta^{13} \mathrm{C}$ values of hydrothermal and igneous silicate minerals at temperatures constrained by fluid inclusion microthermometry, mineral assemblages, and depth of analyzed sample (for example, Hishikari, Imai and others, 1998; Faure and others, 2002; Morishita and Nakano, 2008; Guanajuato, Mango and others, 2014; National, Vikre, 1987; Mule Canyon, John and others, 2003; Hart, U.S.A., Ausburn, 1991; McLaughlin, Sherlock and others, 1995; epithermal deposits in Mexico, Albinson and others, 2001; Roşia Montană, Romania, Wallier and others, 2006; Sunshin, Kim and others, 2012; epithermal deposits in Argentina, Lanfranchini and others, 2013; Buritica; Lesage and others, 2013; Sunnyside, Casadevall and Ohmoto, 1977; Creede, Bethke and Rye, 1979; Foley and others, 1989;

Toodoggone River, Canada, Diakow and others, 1991). Values of $\delta \mathrm{D}_{\text {water }}$ in fluid inclusions in quartz, adularia, sphalerite, pyrite, and rhodochrosite, $\delta \mathrm{D}$ and $\delta^{18} \mathrm{O}$ values of quartz, adularia, smectite, vermiculite, kaolinite, illite, and chlorite, and calculated $\delta \mathrm{D}$ and $\delta^{18} \mathrm{O}$ values of water in equilibrium with these minerals range from about -37 to $-132 \%$, and about -5.9 to $30 \%$, respectively, in low- and intermediate-sulfidation deposits. Values of $\delta^{13} \mathrm{C}$ in carbonate minerals (calcite, siderite, and rhodochrosite) and calculated $\delta^{13} \mathrm{C}_{\mathrm{CO} 2}$ fluid values range from -10.8 to $-2.7 \%$ (for example, Guanajuato, Mango and others, 2014; Creede, Bethke and Rye, 1979).

Fluid inclusion and silicate water values broadly reflect (1) variable exchange of $\mathrm{D}$ and ${ }^{18} \mathrm{O}$ in meteoric waters with $\mathrm{D}$ and ${ }^{18} \mathrm{O}$ in wall-rock minerals, or with $\mathrm{D}$ and ${ }^{18} \mathrm{O}$ in subjacent rocks, (2) variable mixtures of magmatic and meteoric water,

(3) predominant magmatic water in a few deposits, (4) modern meteoric water in Pleistocene-Holocene deposits, and (5) fractionation by boiling and evaporation (fig. K11). Much of the range in water isotope compositions results from global variations in $\delta \mathrm{D}$ and $\delta^{18} \mathrm{O}$ values of meteoric water that are controlled by latitude and elevation (for example, Taylor, 1974), and by variable but commonly large components of meteoric water in ore-forming fluids of nearly all deposits.

In a low-sulfidation vein in the Hishikari deposit, $\delta^{18} \mathrm{O}$ values of individual quartz, quartz+adularia, and quartz \pm adularia+electrum-sulfide mineral layers that vary by as much as $\sim 7.5 \%$ among layers within stages and between stages, were interpreted as permissive evidence that boiling and mixing of magmatic and meteoric waters are causes of silicate and ore mineral deposition (Matsuhisa and Aoki, 1994; Hayashi and others, 2001; Faure and others, 2002). Elevated quartz and quartz water $\delta^{18} \mathrm{O}$ values (5 to $30 \%$ ) in some deposits have been attributed in part to evaporation in nearpaleosurface strata (for example, National, Vikre, 2007), and to magmatic water in other deposits (for example, Buritica, Lesage and others, 2013; Roşia Montană, Wallier and others, 2006). Deuterium values $(<-120 \%)$ in some hydrous silicate vein minerals are lower than deuterium values of paleo-meteoric water, and may reflect mineral-water isotope fractionation greater than estimated from fractionation equations calibrated at high temperature.
The dominance of meteoric water in the formation of low- and intermediate-sulfidation gold-silver deposits is also demonstrated by $\delta^{18} \mathrm{O}$ "depletion" in altered wall rocks as well as in hydrothermal minerals (for example, Tonopah, Taylor, 1973, 1974, 1997). Depletion refers to exchange of oxygen in igneous minerals in wall rocks, with relatively high $\delta^{18} \mathrm{O}$ values (mostly $>8 \%$ ), with oxygen in meteoric waters, with lower $\delta^{18} \mathrm{O}$ values (mostly $<-5 \%$; Taylor, 1974), producing altered wall rocks and hydrothermal minerals with $\delta^{18} \mathrm{O}$ values lower than initial values of unaltered wall rocks. Contoured $\delta^{18} \mathrm{O}$ values of "whole rock" and paragenetically grouped vein samples that define circular to elliptical enclosures have been interpreted to represent projections of subjacent magmatic heat sources thought to have caused circulation of hightemperature meteoric water through host rocks and water-rock oxygen isotope exchange (fig. K11). However, $\delta^{18} \mathrm{O}$ depletion contours in some district-wide investigations (for example, Comstock Lode, Criss and Champion, 1991; Tonopah, Taylor, 1973, 1974) do not distinguish among partly cospatial magmatichydrothermal events that span as much as several million years (Vikre and others, 1988; Bonham and Garside, 1979).

\section{Radiogenic Isotope Geochemistry}

\section{By Peter G. Vikre}

\section{High-Sulfidation Deposits}

Lead, osmium, strontium, neodymium, and hafnium isotope values have been determined for host rocks and hydrothermal minerals in a small number of high-sulfidation deposits and districts. The purposes of these analytical investigations, which are summarized below along with unpublished analyses, were primarily to determine sources of igneous host rocks, degree of mixing of mantle and crustal isotope reservoirs during generation and emplacement of igneous host rocks, and sources of components of hydrothermal minerals in deposits. In some districts, lead, uranium, and thorium isotope compositions of zircons have been determined for calculation of crystallization ages of igneous rocks based on $\mathrm{U}-\mathrm{Th}-\mathrm{Pb}$ isotope decay series, although zircons contain little ${ }^{204} \mathrm{~Pb}$ and are not useful for sourcing investigations.

Chalcophile elements, those that commonly form minerals with sulfur, are thought to be in isotopic equilibrium in sulfide mineral deposits. Thus, common radiogenic isotope values of (chalcophile) lead and osmium are assumed for all sulfide minerals. Because of low abundances and uncertain modes, radiogenic isotope values of the lithophile elements strontium and neodymium have been infrequently analyzed in metallic sulfide minerals. They have been determined mostly in hydrothermal carbonate and silicate minerals that coexist with sulfide minerals, and in wall rocks. Uranium and thorium, parent elements of radiogenic lead, and rhenium, rubidium, and samarium, the respective parents of radiogenic osmium, strontium, and neodymium, are relatively depleted 


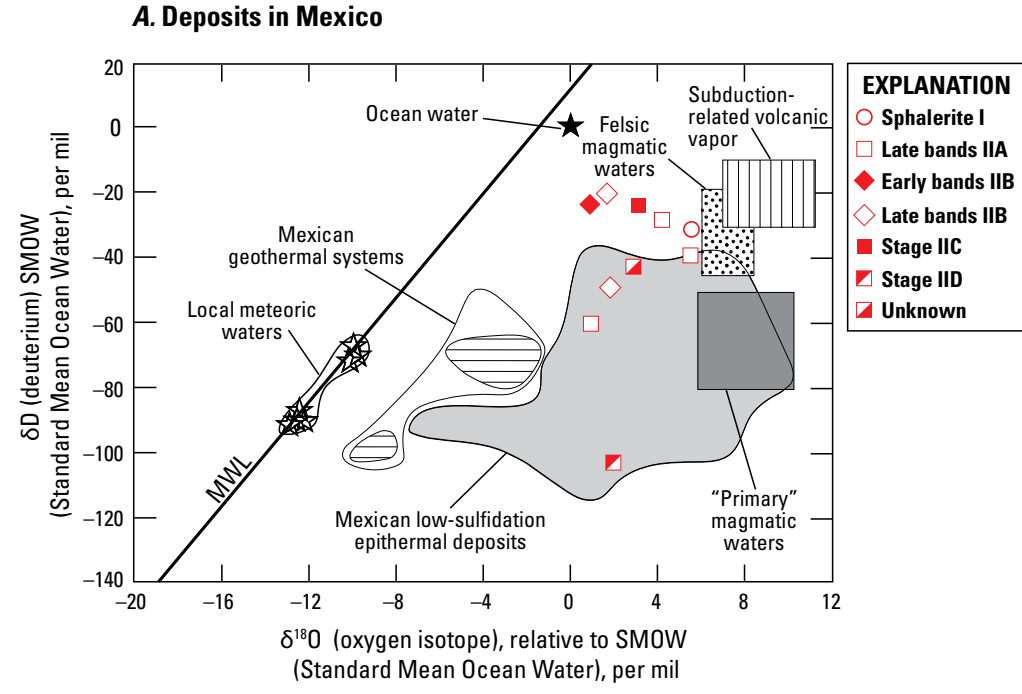

C. Tonopah, Nevada, U.S.A.

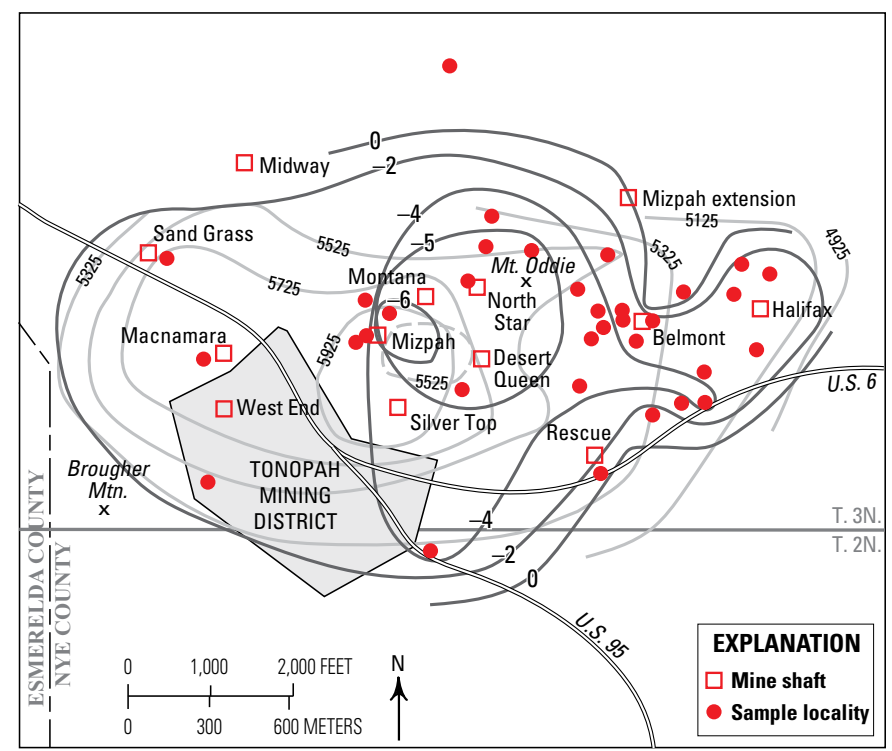

\section{B. Hishikari, Japan}

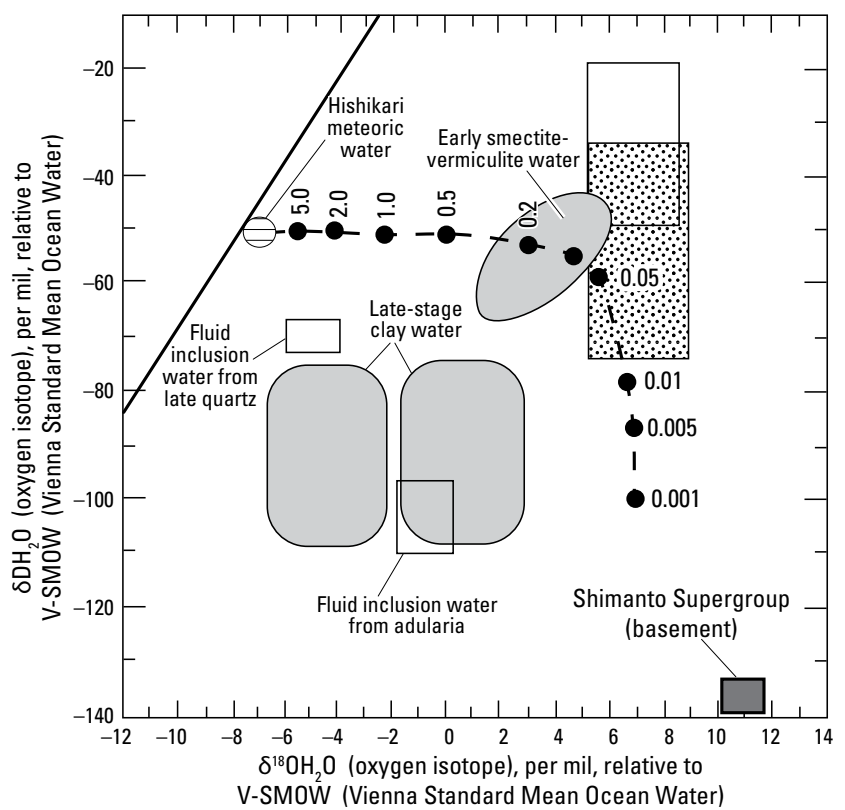

Figure K11. Representative hydrogen and oxygen isotope values of minerals, waters, and rocks in low- and intermediate-sulfidation deposits. $A$, Measured and calculated $\delta \mathrm{D}$ and $\delta^{18} 0$ values of waters in Mexican epithermal deposits (shaded enclosure) and geothermal systems (shaded and horizontal line enclosures; Albinson and others, 2001), and of quartz and sphalerite waters from La Guitarra, Mexico (Camprubi and others, 2001b). Isotope value ranges for local meteoric waters, andesitic waters, felsic magmatic waters, and "primary" magmatic waters are the star enclosure and patterned rectangles, respectively. Deposit waters were largely derived from magmas or represent mixtures of magmatic and meteoric waters. $B$, Measured and calculated $\delta D$ and $\delta^{18} 0$ values of fluid inclusion water in quartz and adularia, water in equilibrium with late-stage clay minerals, and water in equilibrium with early smectite-vermiculite in Hishikari vein deposits (shaded enclosures), compared with isotope compositions of meteoric water and subjacent pre-Tertiary sedimentary rocks which are linked by a gradient (line and filled black circles) of increasing water/rock (Faure and others, 2002). Unfilled and patterned rectangles are isotope values of felsic magmas and porphyry ore deposits and degassed melt, respectively. Water isotope values are interpreted to represent several sources. C, Contoured whole rock and vein quartz $\delta^{18} 0$ values (per mil) in the Tonopah district (dark thick lines; Taylor, 1974) and contoured upper elevations of productive vein stopes (light thick lines; after Nolan, 1935), interpreted to reflect ${ }^{18} 0$ depletion by exchange between wall rocks and hydrothermal fluid composed of Miocene meteoric water. 
in mantle rocks and enriched in crustal rocks. Initial values of ${ }^{206} \mathrm{~Pb} / 204 \mathrm{~Pb},{ }^{207} \mathrm{~Pb} / 204 \mathrm{~Pb},{ }^{208} \mathrm{~Pb} / 204 \mathrm{~Pb},{ }^{187} \mathrm{Os} /{ }^{188} \mathrm{Os}$, and ${ }^{87} \mathrm{Sr} /{ }^{86} \mathrm{Sr}$, and $\varepsilon_{\mathrm{Nd}}$ are commonly used in mixing models to determine proportions of lead, osmium, strontium, and neodymium in hydrothermal minerals and host rocks that were derived from mantle and crustal sources.

Lead isotope values in igneous host rocks (based on whole rock analyses) and in galena in deposits vary from relatively "primitive" (mantle-like) in the highly metamorphosed, $\sim 1.9 \mathrm{Ga}$ Enåsen gold deposit, Sweden $\left({ }^{206} \mathrm{~Pb} /{ }^{204} \mathrm{~Pb}\right.$ mostly $\sim 15.5-16.8$; Hallberg, 1994), to highly uranogenic in the Miocene volcanic host rocks and galena at Goldfield $\left({ }^{206} \mathrm{~Pb} /{ }^{204} \mathrm{~Pb}>19\right.$; Vikre and Henry, 2011). Initial strontium isotope values in host rocks and hydrothermal sulfate minerals at Goldfield are mostly $\sim 0.707$ to 0.714 , supporting derivation of strontium and lead, at least, from evolved (quartzofeldspathic) crustal rocks.

Lead isotope values of other deposits are within the range of Enåsen and Goldfield values, whereas strontium isotope values are lower and higher than those at Goldfield. Galena and felsic host rocks in the Oligocene Hog Heaven, U.S.A., silver deposit have relatively low ${ }^{206} \mathrm{~Pb} /{ }^{204} \mathrm{~Pb}(\sim 16.8)$ and initial ${ }^{87} \mathrm{Sr} /{ }^{86} \mathrm{Sr}(\sim 0.704)$ values, compatible with lower crustal sources (Lange and others, 1994). In the Brewer gold deposit, U.S.A., and at Rodalquilar, Spain, ${ }^{206} \mathrm{~Pb} /{ }^{204} \mathrm{~Pb}$ values in sulfide minerals and host rocks are mostly $\sim 18.5 \pm 0.3$ and $18.83 \pm 0.3$, respectively. They comprise, in part, a positively inclined array of values, relative to isochrons of average crustal lead evolution (Stacey and Kramers, 1975), when plotted against ${ }^{207} \mathrm{~Pb} /{ }^{204} \mathrm{~Pb}$ values and ${ }^{208} \mathrm{~Pb} /{ }^{204} \mathrm{~Pb}$ values (Arribas and others, 1995a; Ayuso and others, 2005; Foley and Ayuso, 2012). These trends and $\varepsilon_{\mathrm{Nd}}$ values at Brewer have been interpreted to indicate that lead and neodymium, at least in host rocks and hydrothermal minerals, represent a mixture of mantle $\left({ }^{206} \mathrm{~Pb} /{ }^{204} \mathrm{~Pb} \sim 18.2 ;{ }^{207} \mathrm{~Pb} /{ }^{204} \mathrm{~Pb} \sim 15.56\right)$ and crustal $\left({ }^{206} \mathrm{~Pb} /{ }^{204} \mathrm{~Pb}\right.$ $\sim 18.5 ;{ }^{206} \mathrm{~Pb} /{ }^{204} \mathrm{~Pb} \sim>15.74$ ) lead.

At Summitville, the similar lead isotope values in galena and $\sim 23$-Ma quartz latite host rock $\left({ }^{206} \mathrm{~Pb} /{ }^{204} \mathrm{~Pb} \sim 17.8\right.$ and 17.95, respectively) are among the most primitive values relative to other galena and rock leads in the San Juan Mountains, U.S.A., and permit derivation of galena lead from the host rock or from a cogenetic magmatic source that acquired lead from 1.8- to 1.7-Ga Precambrian metamorphic and igneous rocks (Lipman and others, 1978; Doe and others, 1979). Initial strontium values in quartz latite and other volcanic rocks are among the least radiogenic values ( 0.7048 to 0.7055$)$ in the San Juan volcanic field, and suggest derivation from sources in the lower crust or lithospheric mantle, consistent with lead isotope values (Lipman and others, 1978).

${ }^{187} \mathrm{Os} /{ }^{188} \mathrm{Os}(0.135$ to 01.062$)$ and initial ${ }^{87} \mathrm{Sr} /{ }^{86} \mathrm{Sr}(\sim 0.705$ to 0.718 ) values in hydrothermal sulfide minerals, clastic sedimentary rocks, and volcaniclastic deposits at Chinkuashih, Taiwan, and Rodalquilar, are consistent with variable derivation of deposit components from crustal sources, including local Miocene-Pleistocene sedimentary and volcanic host rocks at Chinkuashih, and mantle sources (Shen and Yang, 2004; Arribas and others 1995a). $\varepsilon_{\mathrm{Hf}}$ values in igneous zircons suggest that andesitic host rocks in the Chelopech gold-copper deposit reflect a homogeneous, mixed crust-mantle source (Chambefort and others, 2007).

In general, lead, strontium, osmium, neodymium, and hafnium isotope compositions of host rocks and hydrothermal minerals in high-sulfidation deposits and districts broadly to specifically imply sources that range from relatively primitive mantle and lower crust, to evolved upper crust, including local volcanic and sedimentary host rocks (see "Isotope Geochemistry").

\section{Low- and Intermediate-Sulfidation Deposits}

Lead and strontium isotope values have been determined for host rocks and hydrothermal minerals in some lowsulfidation deposits. Rhenium-osmuim and copper isotope values have also been determined for a few deposits in the northern Great Basin, U.S.A. (Saunders and others, 2014, 2016). Published lead isotope compositions of host rocks and hydrothermal minerals in intermediate-sulfidation deposits are mostly from districts in the San Juan Mountains, U.S.A. (Casadevall and Ohmoto, 1977; Lipman and others, 1978; Doe and others, 1979). The purposes of these investigations, (which for lead and strontium are summarized below) were to evaluate (1) sources of igneous host rocks, (2) degree of mixing of mantle and crustal isotope reservoirs during generation and emplacement of igneous host rocks, and (3) sources of components of hydrothermal minerals in deposits.

Broadly linear arrays are defined by lead isotope values in low-sulfidation quartz-adularia-gold-silver veins at Hishikari, Japan, that vary from $\sim 18.34$ to $18.46\left({ }^{206} \mathrm{~Pb} /{ }^{204} \mathrm{~Pb}\right), \sim 15.62$ to $15.65\left({ }^{207} \mathrm{~Pb} /{ }^{204} \mathrm{~Pb}\right)$, and $\sim 38.58$ to $38.81\left({ }^{208} \mathrm{~Pb} /{ }^{204} \mathrm{~Pb}\right)$; by values in volcanic host rocks that vary from $\sim 18.30$ to $18.36\left({ }^{206} \mathrm{~Pb} /{ }^{204} \mathrm{~Pb}\right)$, $\sim 15.56$ to $15.68\left({ }^{207} \mathrm{~Pb} /{ }^{204} \mathrm{~Pb}\right)$, and $\sim 38.44$ to $38.67\left({ }^{208} \mathrm{~Pb} /{ }^{204} \mathrm{~Pb}\right)$; and by values in subjacent Cretaceous clastic sedimentary and igneous "basement" rocks that vary from $\sim 18.46$ to 18.68 $\left({ }^{206} \mathrm{~Pb} /{ }^{204} \mathrm{~Pb}\right), \sim 15.58$ to $15.65\left({ }^{207} \mathrm{~Pb} /{ }^{204} \mathrm{~Pb}\right)$, and $\sim 38.68$ to 38.98 $\left({ }^{208} \mathrm{~Pb} /{ }^{204} \mathrm{~Pb}\right.$; Hosono and Nakano, 2004). Array slopes do not support direct derivation of lead in veins from less radiogenic volcanic host rocks and more radiogenic sedimentary host rocks. Hosono and Nakano (2004) proposed that ore fluid consisted of a mixture of "deep crustal fluid" and fluid exsolved from volcanic host rock magmas. The deep crustal fluid obtained lead from lower crust strata, and from upper crust rocks similar in isotopic composition to sedimentary host rocks.

Lead isotope values of ore and sulfide minerals (electrum, pyrite, pyrargyrite, sphalerite, galena, and stibnite) and chalcedony in low-sulfidation veins at McLaughlin, U.S.A., vary from $\sim 18.85$ to $18.97\left({ }^{206} \mathrm{~Pb} /{ }^{204} \mathrm{~Pb}\right), \sim 15.61$ to 15.65 $\left({ }^{207} \mathrm{~Pb} /{ }^{204} \mathrm{~Pb}\right)$, and $\sim 38.60$ to $38.79\left({ }^{208} \mathrm{~Pb} /{ }^{204} \mathrm{~Pb}\right.$; Sherlock and others, 1995). The mostly similar values suggest derivation from a homogeneous crustal source, or homogenization by fluids before mineral deposition. Values of some host and local rocks are similar to ore and sulfide mineral isotope values, suggesting possible derivation of ore and sulfide mineral leads from local rocks and Sierra Nevada batholithic detritus. More radiogenic values in basaltic andesite host rocks, as much as 
$19.61,15.84$, and 39.46, respectively, are thought to reflect magmatic incorporation of upper crustal rocks.

Correspondence of lead isotope values of gold, electrum, pyrite, selenide minerals, and sulfide minerals in low-sulfidation deposits and basalts in the northern Great Basin, U.S.A., were interpreted to reflect relatively primitive (upper mantle) magmatic sources of gold and associated Se-S minerals, whereas values of vein silicate minerals (adularia, "Si fraction") indicate derivation of lead from local volcanic and sedimentary rocks (Kamenov and others, 2007).

Initial ${ }^{87} \mathrm{Sr} /{ }^{86} \mathrm{Sr}$ values in the Pliocene and Pleistocene low-sulfidation quartz-adularia-calcite veins at Hishikari and Kushikino, Japan, vary from 0.7048 to 0.7081 (most are $\sim 0.7075$ ), whereas values in volcanic rocks are 0.7045 to 0.7052 , and values in subjacent Cretaceous "basement" clastic sedimentary rocks are 0.7105 to 0.7254 (Hosono and Nakano, 2004; Morishita and Nakano, 2008). Instead of derivation of strontium in veins entirely from volcanic and sedimentary host rocks, Hosono and Nakano (2004) propose that at least some vein strontium (and lead) was derived from a "deep crustal fluid" that obtained strontium, in part, from a source similar to enriched mantle (EM1). Higher initial strontium values, and lower $\delta^{13} \mathrm{C}_{\text {calcite }}$ and $\delta \mathrm{D}$ values in major ore veins at Hishikari relative to shallow barren veins, also support deep circulation of ore-forming fluids in basement sedimentary rocks (Imai and others, 1998; Morishita and Nakano, 2008).

Initial strontium values in vein quartz and adularia (presumably including strontium in fluid inclusions) in the $\sim 12$ Ma low-sulfidation veins in the Hart district, U.S.A., are $\sim 0.714$, whereas values in altered and unaltered volcanic wall rocks vary from $\sim 0.708$ to 0.715 , and are $\sim 0.787$ in subjacent Precambrian mafic and felsic schists, gneisses, and granitic rocks (Ausburn, 1991), with a linear relationship between early $\left({ }^{87} \mathrm{Rb} /{ }^{86} \mathrm{Sr}>10\right)$ and late ore stage $\left({ }^{87} \mathrm{Rb} /{ }^{86} \mathrm{Sr}<5\right)$. These data suggest that vein strontium was largely derived from wall rocks.

Initial ${ }^{87} \mathrm{Sr} /{ }^{86} \mathrm{Sr}$ values of calcite and other carbonate minerals, barite, and fluorite in Tertiary intermediatesulfidation deposits and Tertiary wall rocks in the San Juan Mountains (Telluride and Eureka districts; Reesman, 1968; Casadevall and Ohmoto, 1977), and low-sulfidation veins in the Oatman district (Tom Reed mine), U.S.A., which range from $\sim 0.708$ to 0.714 , are interpreted to indicate derivation of strontium from "deep-seated" source regions, or from Tertiary host rocks, although subjacent Precambrian rocks are a possible contributing source.

Comprehensive lead and strontium isotope analyses of galena in vein deposits and of host or associated volcanic and preTertiary rocks in the San Juan volcanic field, U.S.A., which mostly vary from $\sim 17.3$ to $19.1\left({ }^{206} \mathrm{~Pb} /{ }^{204} \mathrm{~Pb}\right), 15.42$ to $16.50\left({ }^{207} \mathrm{~Pb} /{ }^{204} \mathrm{~Pb}\right)$, 36.9 to $38.6\left({ }^{208} \mathrm{~Pb} /{ }^{204} \mathrm{~Pb}\right.$ ), and 0.7048 to 0.7075 , respectively, include analyses of intermediate-sulfidation vein minerals and host rocks (Casadevall and Ohmoto, 1977; Lipman and others, 1978; Doe and others, 1979). The variation in lead isotope values, especially pronounced in galena, and of initial strontium values, broadly reflects variable sourcing of lead and strontium from $\sim 1.8$ to 1.45 -Ga Precambrian metamorphic and granitic rocks with differing $\mathrm{Th} / \mathrm{U}$ ratios, or sedimentary rocks derived from them, or Tertiary intrusions (and derivative volcanic rocks) that obtained lead and strontium from Precambrian and derivative rocks. 



\title{
Chapter L. Hydrothermal Alteration
}

\author{
By Peter G. Vikre and David A. John
}

\section{General Aspects of Hydrothermal Alteration in Epithermal Deposits}

\author{
By David A. John
}

\section{End-Member Hydrothermal Systems, Types of Hydrothermal Fluids, and Hydrothermal Environments}

Hydrothermal alteration is a characteristic feature of epithermal gold-silver deposits. Low-sulfidation and high-sulfidation gold-silver deposits form from different types of hydrothermal systems, geothermal and magmatichydrothermal, respectively; consequently, each deposit subtype has distinctive types and zoning of hydrothermal alteration (figs. L1, L2; table L1; see "Definition and Classification of Epithermal Gold-Silver Deposits").

However, because several distinct hydrothermal environments related to water table position (which may vary through the lifetime of a hydrothermal system) can operate in each type of hydrothermal system, the mineralogy and types of hydrothermal alteration may be quite similar, and the final pattern of hydrothermal alteration associated with epithermal

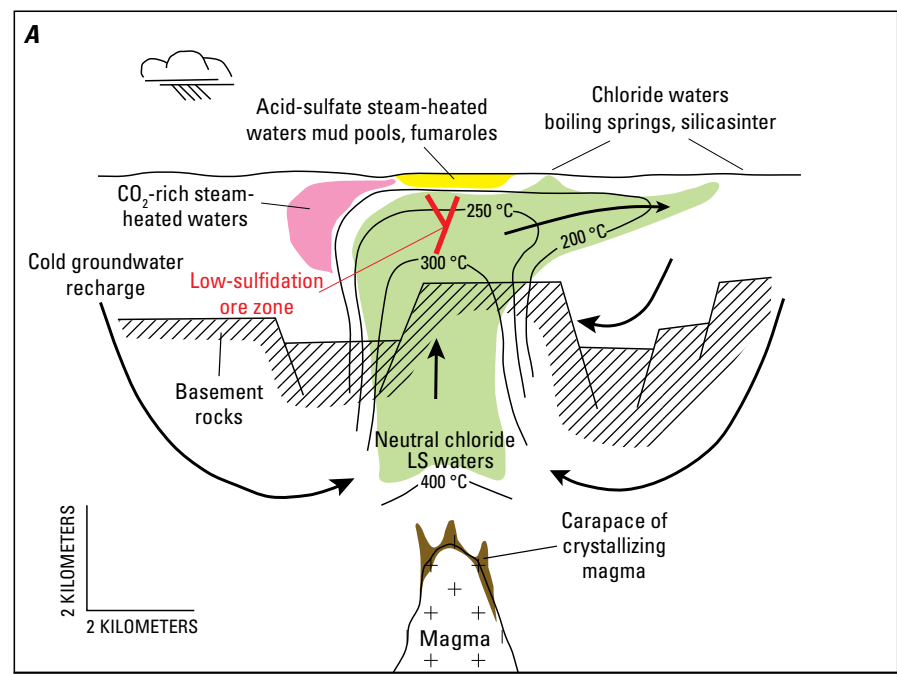

deposits commonly represents superposition of multiple types of hydrothermal fluids.

Two principal types of hydrothermal systems, geothermal and magmatic-hydrothermal, are distinguished among active hydrothermal systems; these are commonly considered analogues to ancient ore-forming low-sulfidation and high-sulfidation systems, respectively (figs. B1, L1; see, for example, Henley and Ellis, 1983; Cooke and Simmons, 2000; Simmons and others, 2005). Each end-member hydrothermal system has a distinct relationship with temporally and spatially associated magma and crystallizing and degassing magmatic intrusions: intrusions linked to geothermal systems are relatively deep $(\geq 4 \mathrm{~km})$ but are shallower in magmatic-hydrothermal systems, which results in variable magmatic fluid input to hydrothermal fluids responsible for genesis of the two deposit subtypes (Henley and Ellis, 1983; Giggenbach, 1997; Cooke and Simmons, 2000; Hedenquist and others, 2000; Simmons and others, 2005; Heinrich, 2005). Variable magmatic fluid input is manifest in characteristically distinct types of hydrothermal fluids, alteration minerals, and hydrothermal alteration assemblages for each type of hydrothermal system (table L1; figs. B1, L1, L2). However, at shallow depths above the water table, acid-sulfate waters form in both types of hydrothermal systems and produce similar steamheated argillic and advanced argillic alteration (Sillitoe, 2015).

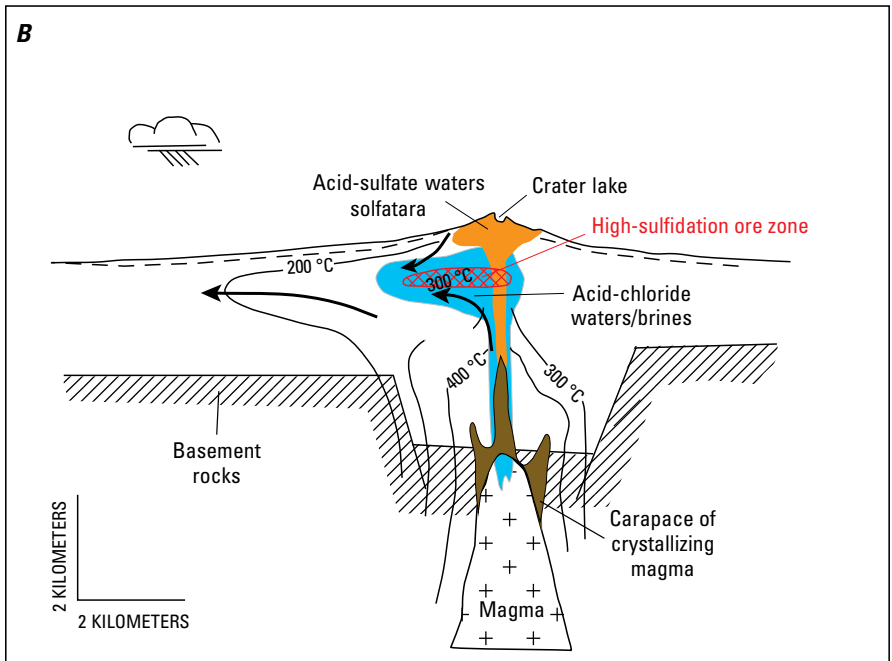

Figure L1. Schematic cross sections showing end-member geothermal and magmatic-hydrothermal systems associated with modestrelief, intermediate-composition volcanic edifices and the positions of low- and intermediate-sulfidation and high-sulfidation epithermal environments within these systems ( $A$ and $B$, respectively) (redrawn from Cooke and Simmons, 2000, which is modified from Henley and Ellis, 1983). See text for description of figures. 


\section{A. Low-sulfidation deposit}

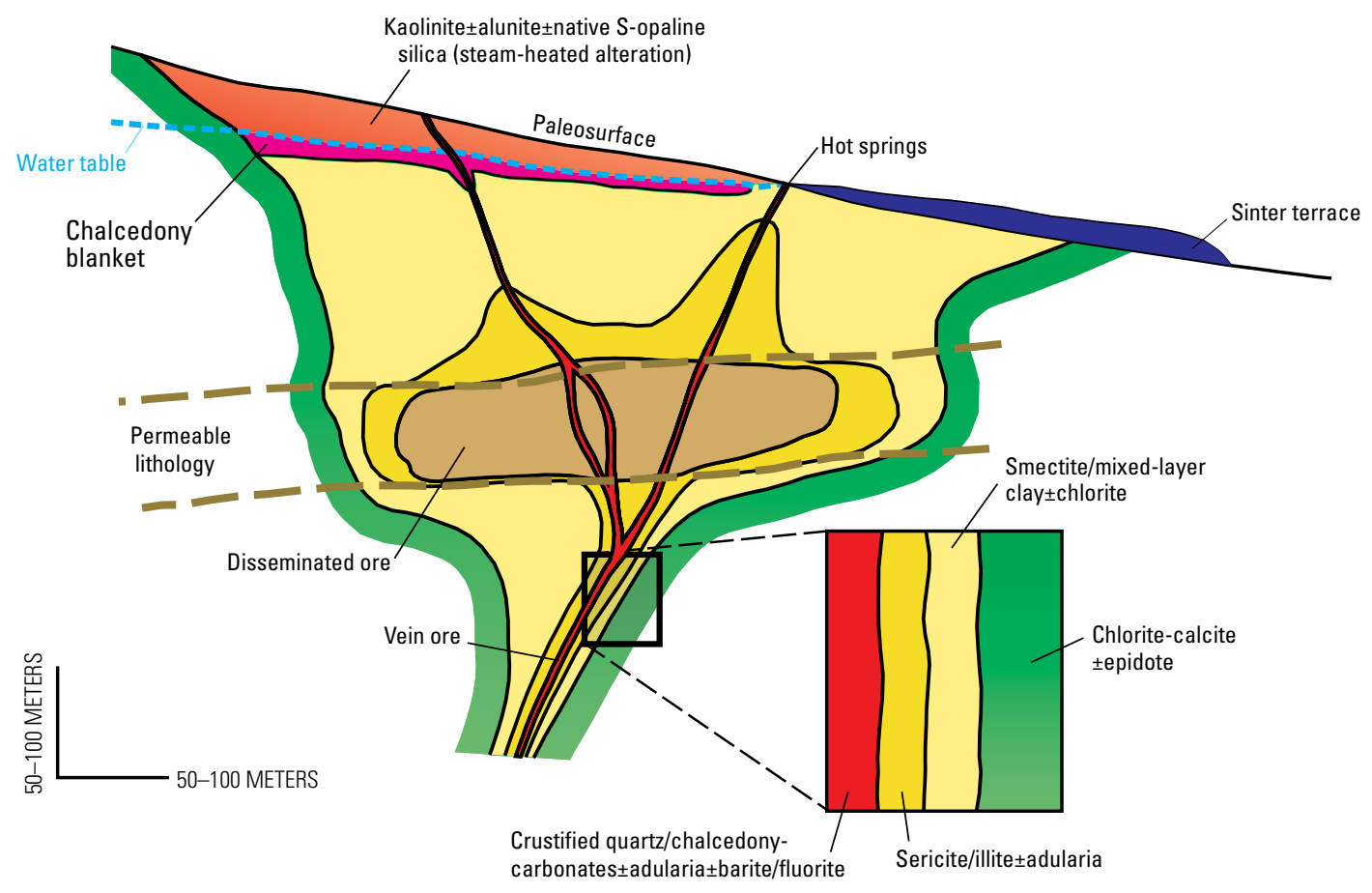

\section{B. High-sulfidation deposit}

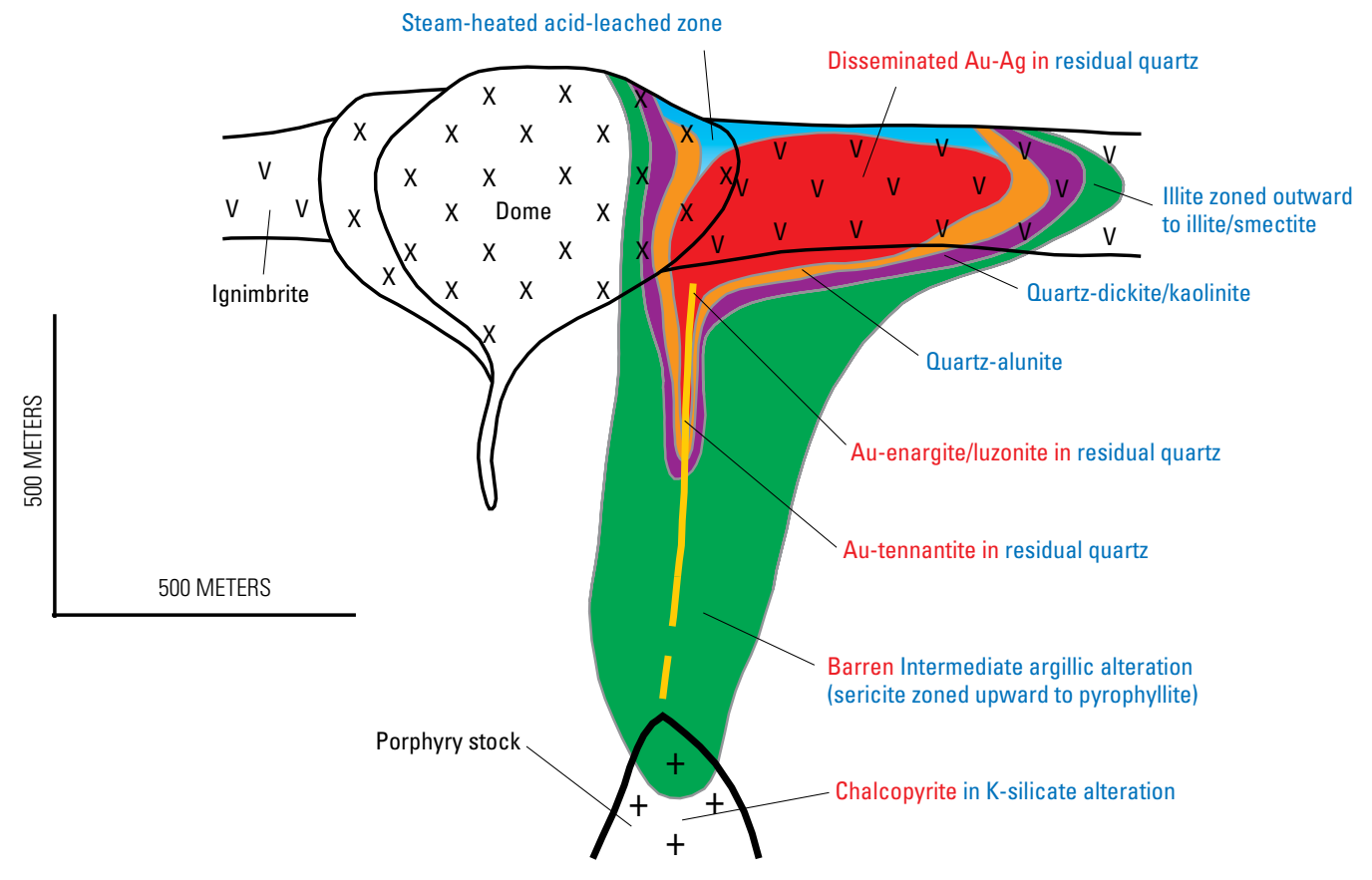

Figure L2. Schematic cross sections of $(A)$ low- and intermediate-sulfidation and $(B)$ high-sulfidation epithermal gold-silver deposits showing hydrothermal features, hydrothermal alteration assemblages and minerals (blue lettering), and ore minerals and ore zones (red lettering). Modified from Sillitoe (1999) and Hedenquist and others (2000). 
Table L1. Common hydrothermal alteration assemblages in epithermal deposits (modified from Hedenquist and others [2000] and Simmons and others [2005]).

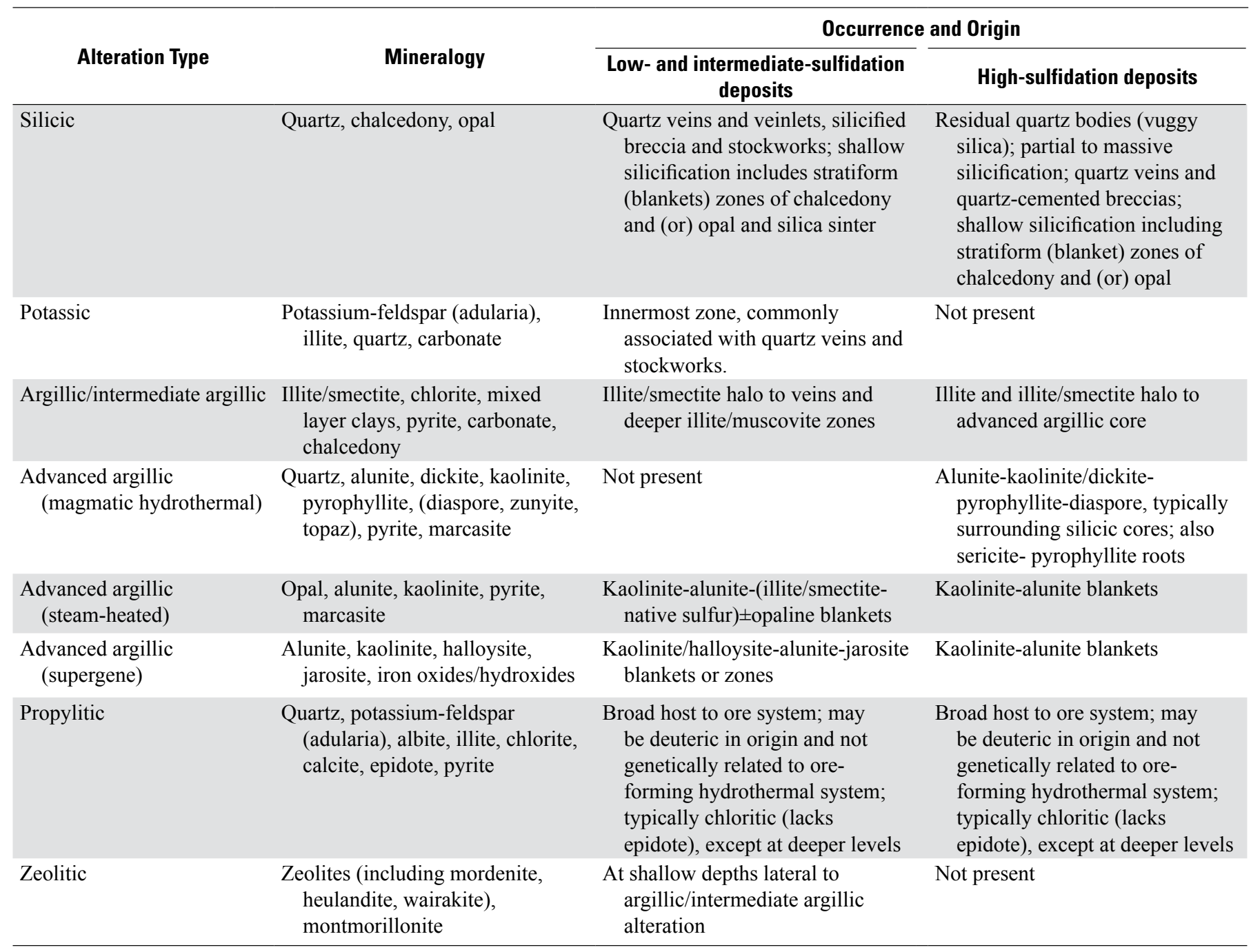

\section{Geothermal Systems}

Geothermal systems in volcanic arcs and rifts form where crystallizing magmatic intrusions emplaced at depths greater than about $4 \mathrm{~km}$ release heat that drives deep convective flow of meteoric water (fig. L1A). Resultant "neutral chloride fluids" are reduced, have near-neutral $\mathrm{pH}$, and contain from 0.1 to more than 1 weight percent $\mathrm{Cl}$, as much as 3 weight percent $\mathrm{CO}_{2}$, and tens to hundreds of parts per million $\mathrm{H}_{2} \mathrm{~S}$ (Simmons and others, 2005). Concentrations of the main dissolved components are consistent with fluid in equilibrium with a propylitic alteration assemblage that includes quartz, albite, adularia, illite, chlorite, pyrite, calcite, and epidote (table L1; Barton and others, 1977; Giggenbach, 1997). These fluids equilibrate with wall rock where fluid flow is slow, through a "rock-dominated" or rock-buffered environment (Giggenbach, 1997). Boiling occurs in a central column down to 1- to 2-km depth below the water table where hot neutral chloride fluid rises buoyantly along through-going faults and fractures (see
"Controls on Permeability and Fluid Flow") and is controlled by near-hydrostatic pressure-temperature conditions (Henley, 1985). In this epithermal environment, quartz, chalcedony, adularia, and calcite precipitate from the boiling and (or) cooling liquid in open space and subvertical channels (for example, Simmons and Browne, 2000; Rowland and Simmons, 2012). Depending on the permeability structure, the chloride water may rise to the surface, discharge, and deposit silica sinter where topography intersects the geothermal water table or disperse laterally through an outflow zone (fig. L1A).

In contrast to liquids, during boiling, gases (mainly $\mathrm{CO}_{2}$ and $\mathrm{H}_{2} \mathrm{~S}$ ) dissolved in the neutral chloride fluids separate from the liquid into vapor and rise to the surface independently of the residual liquid. $\mathrm{CO}_{2}$ and $\mathrm{H}_{2} \mathrm{~S}$ may be partially or completely absorbed by groundwater at shallow levels forming $\mathrm{CO}_{2}$-rich and acid-sulfate steam-heated waters (fig. $\mathrm{L} 1 A$ ). $\mathrm{CO}_{2}$-rich steam-heated waters contain high concentrations of dissolved $\mathrm{CO}_{2}(>1$ weight percent) and tend to accumulate at shallow levels (Simmons and 
Browne, 2000). These fluids drape the stagnant margins of the upflow zone to depths as much as $1,000 \mathrm{~m}$ below the water table. Their distribution is best known at Broadlands-Ohaaki, New Zealand, where weakly acidic steam-heated waters alter volcanic rocks to an argillic assemblage dominated by clay minerals (illite, illite-smectite, smectite, and kaolinite), calcite, and siderite at temperatures as much as about $150^{\circ} \mathrm{C}$ (Hedenquist, 1990; Simmons and Browne, 2000). Similar $\mathrm{CO}_{2}$-rich steam-heated fluids are possibly responsible for late calcite vein formation in low- and intermediate-sulfidation deposits, such as Golden Cross, New Zealand (fig. E7; Simmons and others, 2000).

Acid-sulfate steam-heated waters form in the vadose zone where $\mathrm{H}_{2} \mathrm{~S}$ released by boiling contacts the atmosphere and oxidizes to $\mathrm{H}_{2} \mathrm{SO}_{4}\left(\mathrm{H}_{2} \mathrm{~S}+2 \mathrm{O}_{2}=\mathrm{H}_{2} \mathrm{SO}_{4}\right.$; Schoen and others, 1974). The resulting acid-sulfate water has a $\mathrm{pH}$ of about 2 and can contain as much as $1,000 \mathrm{mg} / \mathrm{kg}$ sulfate (Simmons and others, 2005). These nearly $100{ }^{\circ} \mathrm{C}$ fluids alter rocks to an advanced argillic assemblage composed of opal (cristobalite), alunite, kaolinite, and variable amounts of pyrite and a deeper argillic assemblage composed of smectite and pyrite as they percolate downward and are neutralized near the water table (table L1; fig. L3C; Schoen and others, 1974).

The distribution of these three types (near-neutral $\mathrm{pH}$ chloride, steam-heated $\mathrm{CO}_{2}$-rich, and steam-heated acidsulfate) of hydrothermal fluids associated with geothermal systems depends on topographically controlled hydraulic gradients. In low-relief volcanic settings (for example, calderas, flow-dome complexes, rift basins), steam-heated waters accumulate above and on the periphery of the neutral chloride-water plume (fig. L1 $A$ ). In contrast, in high-relief settings (for example, andesitic composite volcanoes), the steam-heated water accumulations may extend from the summit to the lower flanks of the volcanic edifice. In such areas with high topographic relief and a steep hydraulic gradient, neutral chloride waters may flow laterally for long distances $(>5 \mathrm{~km})$, and emerge in outflow zones where they intersect the surface (Henley and Ellis, 1983). The vertical extent of acid-sulfate fluid accumulation and alteration depends on water table position, especially in low-relief settings where a shallow (near-surface) water table results in a very thin zone of steam-heated acid-sulfate alteration (for example, Broadlands, Simmons and Browne, 2000). In contrast, a deep water table can result in extensive vertical development of steam-heated acid-sulfate alteration (for example, Waiotapu, New Zealand, Hedenquist and Browne, 1989; Indo Muro, Indonesia, Simmons and Browne, 1990).

\section{Magmatic-Hydrothermal Systems}

In magmatic-hydrothermal systems, a central upflow zone, dominated by acid chloride fluid (magmatic vapor plume), overlies shallow degassing intrusions and residual brine (fig. L1 $B$ ). Within this central upflow column, fluids are dominated by magmatic components, including $\mathrm{HCl}$, $\mathrm{SO}_{2}$, and HF. Where these magmatic gases condense into groundwater, $\mathrm{SO}_{2}$ disproportionates forming $\mathrm{H}_{2} \mathrm{SO}_{4}$ and $\mathrm{H}_{2} \mathrm{~S}$ $\left(4 \mathrm{SO}_{2}+4 \mathrm{H}_{2} \mathrm{O}=3 \mathrm{H}_{2} \mathrm{SO}_{4}+\mathrm{H}_{2} \mathrm{~S}\right.$; Sakai and Matsubaya, 1977; Rye and others, 1992), which results in a very acidic $(\mathrm{pH} \leq 1)$ solution that contains subequal amounts of $\mathrm{HCl}$ and $\mathrm{H}_{2} \mathrm{SO}_{4}$ (Giggenbach, 1997; Hedenquist and Taran, 2013). This acidic solution is strongly out of equilibrium with host rocks and reacts with them through a series of hydrolysis reactions that progressively neutralize acidity and form a characteristic sequence of alteration assemblages zoned outward from fluid conduits (fig. L2B; Steven and Ratté, 1960). Alteration assemblages commonly are cored by residual (vuggy) quartz (fig. L4), and have inner and deeper zones that include alunite, pyrophyllite, dickite, quartz, anhydrite, diaspore, and topaz, and outer zones in which illite, chlorite, montmorillonite, and mixed layer clay minerals dominate. The inner zones are characteristic of "fluid-dominated" alteration conditions (Reyes, 1990; Giggenbach, 1992, 1997). Residual quartzaltered rocks are the principal host rocks for superimposed gold-silver mineralization.

Outflow zones for magmatic-hydrothermal systems result from the hydraulic gradient or the water table (see dashed line, which almost follows the trace of topography, in fig. L1B). Silica sinter deposits are absent, however, because of acidic conditions that inhibit silica polymerization and amorphous silica deposition (Fournier, 1985).

Surficial steam-heated acid-sulfate waters also form in the vadose zone overlying magmatic-hydrothermal systems because of the oxidation of $\mathrm{H}_{2} \mathrm{~S}$ exsolved from the vapor (fig. L1 $B$ ). Steamheated advanced argillic alteration assemblages, containing opal, alunite, and kaolinite, form where host rocks interact with these fluids (fig. L2B).

\section{Hydrothermal Minerals, Hydrothermal Alteration Assemblages, Alteration Zoning, and Temperature Indicators}

Distinct high-temperature fluid compositions developed in the two types of hydrothermal systems are associated with distinctly different hydrothermal minerals, hydrothermal alteration assemblages, and alteration zoning. These differences are key characteristics that define and distinguish low- and intermediate-sulfidation from high-sulfidation deposits (figs. L2, L3, table L1). Hydrothermal alteration assemblages are commonly regularly zoned about veinor breccia-filled fluid conduits, but may be less regularly zoned in near-surface environments, or where permeable rocks have been replaced. Inner zones of potassic alteration, including adularia and (or) illite and carbonate minerals, are characteristic of low- and intermediate-sulfidation deposits formed from geothermal systems and indicate near-neutral $\mathrm{pH}$ to alkaline fluids. Zeolite minerals, indicative of alkaline fluids, are components of some of these systems. In contrast, the central parts of magmatic-hydrothermal systems and high-sulfidation deposits, formed from very acidic fluids that commonly have $\mathrm{pH}$ of less than 2 (Stoffregen, 1987), are characterized by residual (vuggy) quartz alteration and 
A

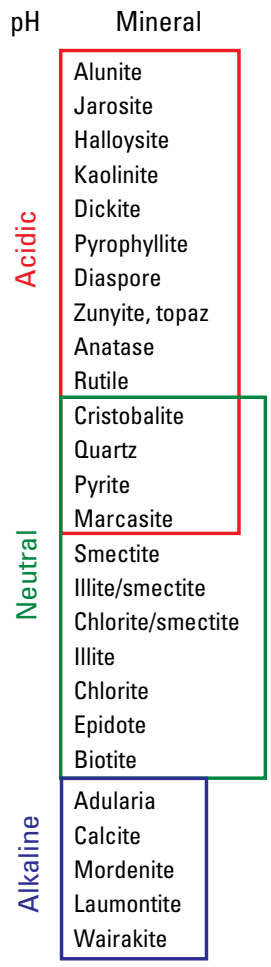

$\mathrm{pH}$

$\frac{0}{\frac{0}{0}}$
Temperature, in degrees Celsius

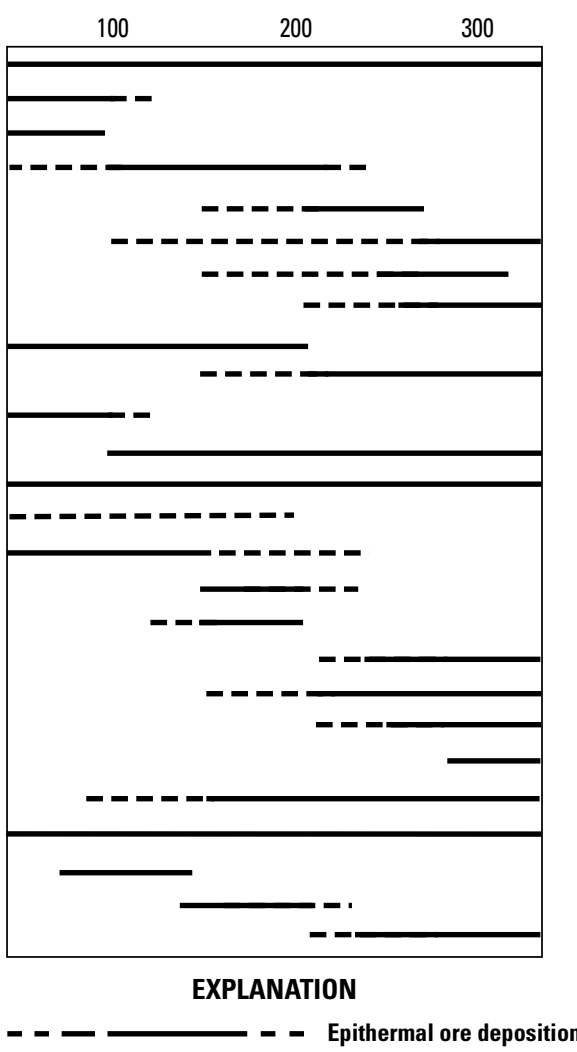

B

\author{
Vertical distribution \\ of minerals \\ in boiling upflow zone
}

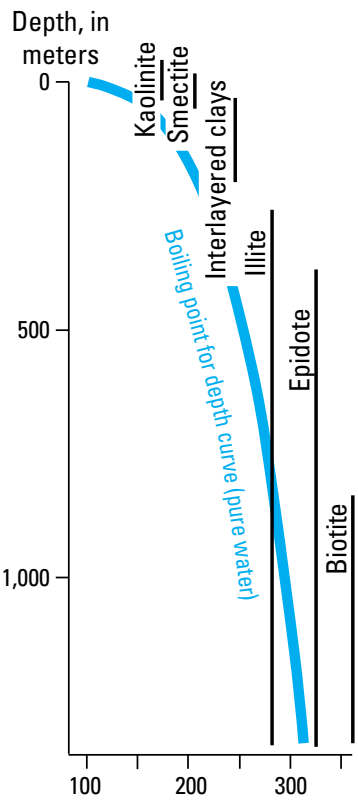

Temperature, in degrees Celsius

C

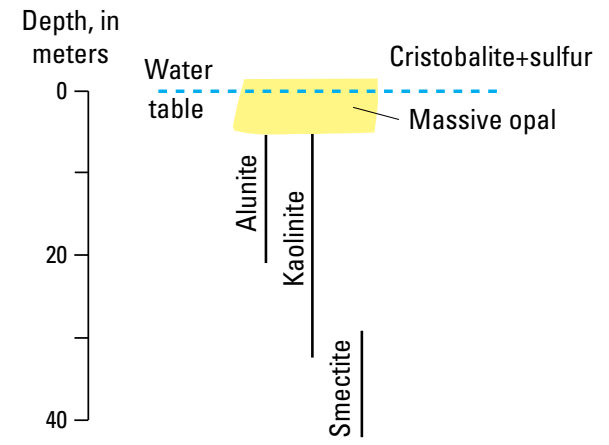

Figure L3. Diagrams showing thermal stability and distribution of hydrothermal minerals in epithermal systems. $A$, Thermal stability of various hydrothermal minerals that occur in the epithermal environment in acidic and neutral-pH conditions and the typical range for deposition of epithermal ore (modified from Hedenquist and others, 2000). $B$, Vertical distribution of some of the same minerals plotted according to depth, using the hydrostatic boiling curve of water as the reference temperature gradient (modified from Simmons and others, 2005). C, Vertical zoning in steam-heated advanced argillic alteration at the water table (Schoen and others, 1974; Simmons and others, 2005): cristobalite and sulfur form at and above the water table; tabular massive opal forms at and below the water table; alunite and kaolinite form at and below the water table and the zone of massive opal (light-yellow shading) with smectite below alunite and kaolinite. 


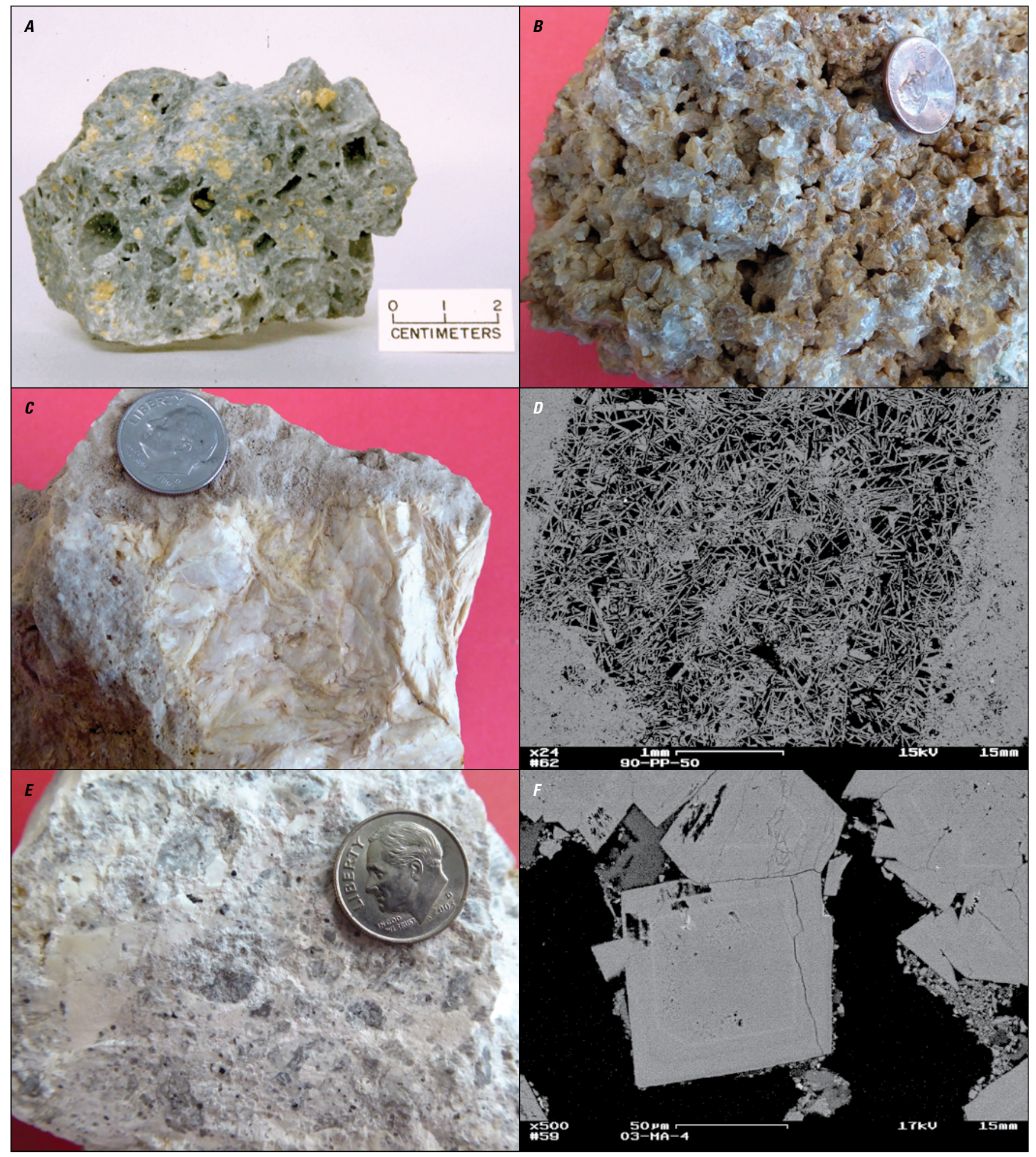

Figure L4. Photographs of residual quartz and alunitic advanced argillic alteration. $A$, Residual (vuggy) quartz alteration of quartz latite, Science mine dump, Summitville district, Colorado. Cavities (vugs) formed by leaching of coarse feldspar phenocrysts are partly filled by elemental sulfur. Photograph by Peter Vikre. B, Rock composed of residual quartz phenocrysts leached from coarse-grained granite, Santa Fe district, Gabbs Valley Range, Nevada. Coin is 19 millimeters $(\mathrm{mm})$ in diameter. Photograph by David John. C, Coarse bladed magmatic-hydrothermal alunite from East Preble Mountain, Goldfield district, Nevada. Coin is about $18 \mathrm{~mm}$ in diameter. Photograph by David John. D, Back-scattered scanning electron microscope (SEM) image of aggregates of prismatic magmatic-hydrothermal alunite replacing plagioclase phenocryst, Paradise Peak mine, Nevada. E, Very fine-grained steamheated alunite cementing silicified volcaniclastic rocks near top of Buckskin Mountain, Nevada. Photograph by David John. F, Back-scattered SEM image of steam-heated, pseudocubic alunite crystals filling voids in leached andesite breccia from near summit of Mount Adams volcano, Washington. 
magmatic-hydrothermal advanced argillic alteration that includes magmatic-hydrothermal alunite, dickite and (or) kaolinite, and (or) pyrophyllite.

Temperatures prevailing during hydrothermal alteration can be estimated from the distribution of hydrothermal minerals, as determined by geothermal drilling in active hydrothermal systems (fig. L3; Reyes, 1990; Reyes and others, 2003; Hedenquist and others, 2000; Simmons and others, 2005), and compositions of temperature-dependent minerals (for example, chlorite, Conrad and others, 1992). Variable thermal stability limits and the corresponding distribution of key alteration minerals (notably the transition in clay mineral assemblages, such as the change from smectite to mixed layer clays to illite and of kaolinite to pyrophyllite with increasing temperature) define paleoisotherms and help infer paleofluid flow directions in epithermal systems, which, in turn, may indicate the direction toward fluid flow conduits. For example, hydrothermal clay mineral distribution corresponds to temperature zonation in the Broadlands geothermal system, New Zealand (Simmons and Browne, 2000). Similar patterns of hydrothermal clay mineral distribution have been demonstrated around the surface projection of the high-grade veins at Hishikari, Japan (Izawa and others, 1990), and around epithermal deposits and prospects in the Hauraki Goldfield, New Zealand (Simpson and Mauk, 2011).

\section{Advanced Argillic and Silicic Alteration}

Distinct types of advanced argillic alteration associated with the two types of epithermal systems (geothermal and magmatic-hydrothermal) constitute a diagnostic difference between low- and intermediate-sulfidation and high-sulfidation systems (table L1; fig. L2; Hedenquist and others, 2000). Epithermal systems are accompanied by any of three types of advanced argillic alteration: magmatic-hydrothermal or hypogene, steam-heated, and supergene (figs. L2 $A, \mathrm{~L} 2 B$, L4; table L1; Rye and others, 1992; Sillitoe, 1993). In addition, silicic alteration varies widely with residual (vuggy) quartz alteration characteristic of the cores of high-sulfidation systems but absent in low-sulfidation systems (figs. E13, K4; table L2; Fournier, 1985; Hedenquist and others, 2000).

Magmatic-hydrothermal or hypogene advanced argillic alteration includes minerals, such as pyrophyllite, dickite, diaspore, zunyite, and topaz, that form at temperatures greater than $200{ }^{\circ} \mathrm{C}$ (table L1). Alunite formed in this environment is generally tabular, in some instances coarse grained, and commonly pale pink in color (figs. L4C, L4D). This alteration type typically cuts across stratigraphy and follows high-angle structures, although it can be stratabound in permeable host rocks (fig. L3B). Hypogene advanced argillic alteration can either form barren lithocaps or parts of mineralized high-sulfidation systems (Sillitoe, 2010; Hedenquist and Taran, 2013).

Steam-heated advanced argillic alteration forms at and above the water table at about $100^{\circ} \mathrm{C}$ and forms horizons that display pronounced vertical mineral zonation. In general, this alteration blanket does not exceed 10 to $20 \mathrm{~m}$ in thickness, although $\mathrm{CO}_{2}-$ rich steam-heated water can extend locally to $1,000 \mathrm{~m}$ depth
(Simmons and Browne, 2000). Tabular but discontinuous bodies of massive opal that mimic and identify the position of the paleowater table are underlain by a discontinuous zone composed of alunite, kaolinite, opal, and variable amounts of pyrite and marcasite that transitions at greater depth to a kaolinite zone that contains kaolinite plus opal, with variable amounts of pyrite which may be underlain by a smectite + pyrite assemblage (fig. L3C; Schoen and others, 1974; Simmons and Browne, 2000). These alteration minerals are typically very fine grained, and the alunite generally forms pseudocubic crystals (figs. L4E, L4F).

Supergene advanced argillic alteration forms during weathering and oxidation of sulfide-rich rocks and postdates hydrothermal activity (see "Weathering and Supergene Processes"). Supergene alteration forms at less than $40^{\circ} \mathrm{C}$ within the vadose zone and includes alunite, kaolinite, halloysite, jarosite, and iron oxide and hydroxide minerals. Supergene alunite commonly is cryptocrystalline and commonly forms porcellaneous intergrowths with silica phases. Supergene advanced argillic alteration typically has a blanket-like geometry that mimics topography, but it may line subvertical fractures that were pathways for descending surface water.

Silicic alteration in epithermal deposits includes addition of silica (silicification and deposition of hydrothermal silica phases) and residual concentration of silica resulting from acid leaching (residual or vuggy quartz) (Hedenquist and others, 2000). The distribution and origin of silicic alteration assemblages reflect the distinctly different processes responsible for low- and intermediate-sulfidation versus high-sulfidation deposit genesis (table L2).

\section{Hydrothermal Alteration in High-Sulfidation Deposits}

\section{By Peter G. Vikre}

Because of strong chemical and physical disequilibrium between host rocks and fluids that formed high-sulfidation deposits, hydrothermal alteration affected large volumes of rocks in nearly all deposits and districts. The structural and stratigraphic controls of fluid permeability that determined the configuration of deposits (see "Regional Environment" and "Physical Description of Deposits") also influenced the aspect and spatial relationships of the broadly coeval alteration zones that enclose deposits. Alteration mineral assemblages adjacent to major fluid conduits, usually moderate- to high-angle structures, display pronounced lateral and vertical variation, at least to mined and (or) drilled depths (figs. F1, F2, L2). Assemblages in layered rocks with lateral fluid permeability have stratiform aspects and, in general, are more vertically condensed (figs. F1, F2, L2). Assemblages in most deposits reflect structural and stratigraphic control of fluid flow.

Alteration mineral assemblage zoning in high-sulfidation deposits is so distinct and consistent that quartz and alunite, the diagnostic minerals of zones most closely associated with ore, are commonly linked to identify this deposit type. The predictability of alteration zoning is also routinely applied to exploration strategy (for example, Hedenquist and others, 2000). 
Table L2. Types and Characteristics of Silicic Alteration (modified from Hedenquist and others, 2000).

[Ag, silver; As, arsenic; Au, gold; Cu, copper; $\mathrm{Hg}$, mercury; km, kilometer; m, meter; Sb, antimony; Se, selenium; Si, silicon; Tl, thallium; >, greater than; $<$, less than; \%, percent]

\begin{tabular}{|c|c|c|c|c|c|}
\hline Type & Origin & Distribution & Significance & Associated metals & Deposit type \\
\hline Sinter & $\begin{array}{c}\text { Cooling of near- } \\
\text { neutral pH hot } \\
\text { spring fluids at } \\
\text { paleosurface }\end{array}$ & Paleosurface & $\begin{array}{l}\text { Indicator of } \\
\text { paleosurface, } \\
\text { topographic } \\
\text { (hydrologic) } \\
\text { depression, focus } \\
\text { of upflow }\end{array}$ & $\begin{array}{l}\text { Variable: } \mathrm{As}, \mathrm{Sb}, \mathrm{Hg} \\
\mathrm{Tl}(\mathrm{Au}, \mathrm{Ag} \text { if flared } \\
\text { vent) }\end{array}$ & $\begin{array}{l}\text { Low- and } \\
\text { intermediate- } \\
\text { sulfidation }\end{array}$ \\
\hline $\begin{array}{l}\text { Residual silica } \\
\text { (opaline) }\end{array}$ & $\begin{array}{l}\text { Moderate leaching } \\
\left(80-90 \% \mathrm{SiO}_{2}\right) \\
\text { from fluids with } \mathrm{pH} \\
\sim 2-3\end{array}$ & Vadose zone & $\begin{array}{l}\text { Steam-heated origin } \\
\text { above paleowater } \\
\text { table }\end{array}$ & $\mathrm{Hg}$ & $\begin{array}{l}\text { Low-, intermediate-, } \\
\text { and high-sulfidation }\end{array}$ \\
\hline Chalcedony horizon & $\begin{array}{l}\text { Silica remobilized } \\
\text { from steam- } \\
\text { heated zone; deep } \\
\text { chloride fluids } \\
\text { may contribute to } \\
\text { outflow }\end{array}$ & $\begin{array}{l}\text { At paleowater table; } \\
\text { horizon may extend } \\
\text { laterally }>2 \mathrm{~km} \\
\text { from fluid source }\end{array}$ & $\begin{array}{l}\text { Indicator of } \\
\text { paleowater table; } \\
\text { may be distal from } \\
\text { fluid source }\end{array}$ & $\begin{array}{l}\mathrm{Hg} \text { (steam-heated); } \\
\mathrm{As}, \mathrm{Sb}, \mathrm{Au}, \mathrm{Ag} \\
\text { (if deep fluid } \\
\text { contributed) }\end{array}$ & $\begin{array}{l}\text { Low-, intermediate-, } \\
\text { and high-sulfidation }\end{array}$ \\
\hline $\begin{array}{l}\text { Chalcedony veins, } \\
\text { colloform layers; } \\
\text { cryptocrystalline } \\
\text { veins }\end{array}$ & $\begin{array}{l}\text { Low temperature } \\
\text { fluids, colloidal } \\
\text { transport of silica; } \\
\text { recrystllization of } \\
\text { silica gels }\end{array}$ & $\begin{array}{l}\text { Shallow, }<150 \mathrm{~m} \\
\text { depth }\end{array}$ & $\begin{array}{l}\text { Fluid temperature } \\
<200^{\circ} \mathrm{C} \text {, rapidly } \\
\text { cooling fluid, } \\
\text { boiling at depth; } \\
\text { cryptocrystalline at } \\
\sim 200^{\circ} \mathrm{C}\end{array}$ & $\mathrm{As}, \mathrm{Sb}, \mathrm{Se}, \mathrm{Au}, \mathrm{Ag}$ & $\begin{array}{l}\text { Low- and } \\
\text { intermediate- } \\
\text { sulfidation; late } \\
\text { high-sulfidation }\end{array}$ \\
\hline Quartz veins, vugs & Cooling solution & $>150 \mathrm{~m}$ depth & $\begin{array}{l}\text { Fluid temperature } \\
\qquad>200^{\circ} \mathrm{C}\end{array}$ & Au Ag, base metals & $\begin{array}{l}\text { Low- and } \\
\text { intermediate- } \\
\text { sulfidation; late } \\
\text { high-sulfidation }\end{array}$ \\
\hline $\begin{array}{l}\text { Residual silica } \\
\text { (vuggy quartz) }\end{array}$ & $\begin{array}{l}\text { Extreme leaching } \\
\qquad\left(>95 \% \mathrm{SiO}_{2}\right) \text { at } \\
\mathrm{pH}<2\end{array}$ & $\begin{array}{l}\text { Core of magmatic- } \\
\text { hydrothermal } \\
\text { system }\end{array}$ & $\begin{array}{l}\text { Permeable zones, } \\
\text { main host to } \\
\text { quartz-alunite } \\
\text { deposits }\end{array}$ & $\begin{array}{l}\text { Barren or } \mathrm{Cu}, \mathrm{As}, \\
\quad \mathrm{Au}, \mathrm{Ag}\end{array}$ & High-sulfidation \\
\hline Silicification & From cooling water & $\begin{array}{l}\text { Surface to } 500 \mathrm{~m} \text {, } \\
\text { massive at depths } \\
<150 \mathrm{~m}\end{array}$ & $\begin{array}{l}\text { Shallow part of } \\
\text { hydrothermal } \\
\text { system; pervasive } \\
\text { fluid flow }\end{array}$ & Trace Au, Ag & $\begin{array}{l}\text { Low- and } \\
\text { intermediate- } \\
\text { sulfidation; mid-late } \\
\text { high-sulfidation }\end{array}$ \\
\hline
\end{tabular}

\section{Structural, Stratigraphic, Chemical, and Physical Controls}

Alteration mineral assemblages are produced by reactions between hydrothermal fluids and primary (and older hydrothermal) minerals in wall rocks and breccia fragments. These mostly hydrolytic reactions are controlled largely by fluid temperature and $\mathrm{pH}$. Structurally controlled alteration mineral zones initially develop in and adjacent to groundwater-saturated fault zones, fractures, intrusion breccias (breccias marginal to intrusions), and intrusive breccias (fragmental intrusions such as diatremes and pebble dikes). Hydrothermal fluid is created when groundwater in conduits is heated and acidified by devolatilization of subjacent magma, which also adds varying amounts of magmatic water to the fluid (see "Stable Isotope
Geochemistry"). Wall-rock permeability progressively increases as primary minerals are incrementally decomposed by the hot, acidic fluid before neutralization, leaving lower density, porous aggregates of residual quartz and hydrous minerals, or porous residual quartz if fluid is highly acidic $(\mathrm{pH} \leq 2$; Stoffregen, 1987). This chemically induced permeability allows acidic fluid, continuously supplied by magmatic devolatilization, to migrate further into wall rocks, advancing the neutralization boundary meters to tens of meters from conduits. Thus, the zoned alteration mineral assemblages in high-sulfidation deposits are transformed in space for the duration of acidic fluid supply. At the termination of devolatilization, the stabilities of the static alteration mineral assemblages broadly reflect increasing fluid $\mathrm{pH}$ with distance from conduits, and, to an extent, wall-rock compositions. 
Stratigraphic control of alteration mineral zones occurs where host rocks include sedimentary strata, predominantly stratiform volcaniclastic deposits, with high lateral permeability. Groundwater in these strata, similar to water in structural conduits, is heated and acidified by condensation of volatiles degassed from subjacent magmas. Permeability is subsequently enhanced by decomposition of primary minerals and rock fragments. This process is chemically and physically identical to structurally controlled alteration, but hydrodynamically distinct. It produces similar alteration mineral assemblages but with pronounced subhorizontal to stratiform aspects, and contacts between zones that are more gradational. In large, low-grade gold deposits, stratigraphically controlled alteration zones are broadly cospatial with gold \pm silver \pm copper ore (for example, Pierina; Rainbow and others, 2005; Fifarek and Rye, 2005; fig. F2). However, alteration mineral zones in most deposits reflect varying degrees of structural and stratigraphic control of fluid flow.

\section{Mineralogy, Lateral Zoning, and Paragenesis}

For descriptive purposes, alteration zones are commonly divided spatially into core or central (silicic), inner medial (advanced argillic), outer medial (argillic), and distal (propylitic) mineral assemblages. Spatial relations of these zoned assemblages, and their temporal relations to ore mineral assemblages, are summarized for structurally controlled and stratigraphically controlled high-sulfidation deposits.

Structurally controlled deposits are centered on core zone mineral assemblages that formed adjacent to conduits and include breccia fragments in conduits. Core zones consist predominantly of residual quartz, and minor titanium oxide minerals, aluminosilicate-sulfate-phosphate (APS) minerals, and zircons. These latter minerals, which are stable in low-pH fluid, are also largely residual, but hydrothermally concentrated rutile and anatase, and suspected hydrothermal zircon, occur in several districts (for example, Goldfield, Paradise Peak).

Core zones are variably porous to dense, depending on wall-rock fabric and mineralogy, and on degree of subsequent infilling of porosity by hydrothermal quartz and other minerals. Coarsely porous core zones, often termed "vuggy quartz," "vuggy silica," or "residual quartz," are characteristic of high-sulfidation deposits, and are most prominently developed in porphyritic volcanic rocks, fragmental volcaniclastic rocks, and granitic rocks (figs. L4 $A$, $\mathrm{L} 4 B$ ). Vuggy quartz is largely residual quartz remaining from completely decomposed ("leached") primary silicate minerals, lesser primary quartz (in quartz-saturated wall rocks), and voids (source of the term "vuggy"). Voids, which represent sites of phenocrysts and rock fragments, comprise as much as tens of volume percent of coarsely porous core zones. In some vuggy quartz core zones, voids are encrusted or filled with paragenetically younger hydrothermal minerals, including quartz, alunite, kaolinite, sulfide minerals, ore minerals, and sulfur, commonly as millimeter to centimeter euhedra (for example, Summitville, Goldfield, Pascua-Lama; Vikre, 2000;
Deyell and others, 2004; 2005a). Less porous to dense core zones, or parts of core zones, consist of residual quartz and hydrothermal silica minerals (quartz, moganite, cristobalite, tridymite), and in some core zones, other hydrothermal minerals (alunite, kaolinite, sulfide minerals, ore minerals, and sulfur) that have filled pore spaces, voids, and fractures. The hydrothermal silica minerals are derived in large part from decomposition of silicate minerals in wall rocks (Vikre and Henry, 2011).

Core zones form in and adjacent to fault zones, along dome margins (intrusion breccias) and in phreatic and phreatomagmatic (intrusive) breccias, which commonly represent a succession of tectonic and magmatic events in large and high-grade deposits, and in unmineralized alteration zones. Reactivated tectonism and subsequent phreatic eruptions fracture and brecciate core zones, creating conduits for fluids that deposited gold \pm copper \pm silver minerals in most deposits (see "Hypogene and Supergene Ore Characteristics"). Some core zones in high-grade gold deposits (for example, Goldfield) consist of multigenerational breccias in which fragments are encrusted and cemented by hydrothermal minerals, including ore minerals, quartz, alunite, and aluminosilicate minerals (fig. I1). In many low-grade deposits, ore minerals occupy fractures, veins, voids, and breccia matrices, or are disseminated in variably porous to dense core zones. Significantly, repeated rupturing of core zones, and the spatial and temporal association of core zones to ore, demonstrate that (1) the initial structural control of mineralized core zones is maintained during deposition of ore minerals, and (2) mineralized core zone conduits extend to depths of magmatic devolatilization and fluid phase separation (see "Fluid Inclusion Petrography, Thermometry, and Geochemistry"). In contrast, the numerous single-generation, unmineralized core zones at Goldfield, and in other structurally controlled districts and alteration zones, terminate as shallow keels that were only ephemerally associated with subjacent magmatic devolatilization (Vikre and Henry, 2011).

Inner medial (advanced argillic) alteration mineral assemblages consist of quartz, cation-deficient hydrous aluminosilicate and aluminum hydroxide minerals (predominantly kaolinite, dickite, pyrophyllite, lesser topaz, zunyite, and diaspore), sulfate, and alumino-sulfate-phosphate minerals (predominantly alunite, lesser barite, gypsum, woodhouseite, and svanbergite). These minerals replace phenocrysts, matrices, and rock fragments in porphyritic volcanic and volcaniclastic rocks, feldspars and mafic minerals in granitic rocks immediately adjacent to core zones, and variably fill voids, breccia matrices, and fractures in core zones. These spatial and paragenetic relationships suggest that inner medial assemblages formed simultaneously with and after core zones during the progressive time-space development of alteration zones. In some deposits (for example, Pascua-Lama), alunite is texturally coeval with gold-copper-silver ore minerals and other sulfide and telluride minerals. In other deposits, alunite and kaolinite occur with or adjacent to ore minerals in layered veins, and in breccia fragment encrustations that include ore minerals (for example, Tambo; Goldfield). Alunite in inner medial and core assemblages is mostly of magmatic-hydrothermal origin, although blankets of later steam-heated kaolinite+alunite, local 
magmatic steam alunite, and supergene alunite are associated with gold-silver deposits and areas of altered rocks in South America (for example, Pascua-Lama; Tambo; Pierina). Outer medial (argillic) assemblages consist of potassium-magnesiumsodium hydrous silicate minerals (sericite [fine-grained illite or muscovite], montmorillonite) that are stable in less acidic fluids. These minerals partially to entirely replace primary minerals and rock fragments in wall rocks. Distal (propylitic) assemblages consist of minerals stable in near-neutral $\mathrm{pH}$ fluids (chlorite, calcite, epidote) that partially replace primary minerals and rock fragments in wall rocks. Residual and hydrothermal quartz, dominant minerals in core and inner medial assemblages, occur in variable but minor amounts in outer medial and distal assemblages. Variable amounts of pyrite (usually $<1$ to several volume percent) occur in most medial and distal assemblages.

Widths of individual alteration zones, which vary mostly from meters to tens of meters, depend largely on the duration of subjacent magmatic devolatilization, on fracture density, and on initial wall-rock permeability. Wall-rock composition also has influenced configuration of alteration zones in some structurally controlled districts and deposits. For example, at Goldfield, selvages of inner medial assemblages in rhyolite, which is less effective than andesite in buffering acidic fluid, are thicker than those in andesite, and include larger proportions of alunite from hydrolysis of relatively abundant primary sanidine.

Contacts of core and inner medial assemblages are commonly relatively planar $(<1-2 \mathrm{~m}$ wide), whereas contacts of medial and distal assemblages are typically gradational and span many meters. In areas of closely spaced conduits (marked by core zones), core zones or medial zones have merged into large volumes of quartz \pm alunite \pm kaolinite/dickite \pm pyrite-altered rocks, and rocks altered to clay minerals, sericite (fine-grained illite or muscovite), and pyrite, that laterally span hundreds of meters (for example, Yanacocha, Teal and Benavides, 2010). Pervasively silicified rocks commonly represent coalesced core zones in which original conduits are disguised. The distribution of gold and other minor elements in masses of silicified rocks can be used to identify original conduits (fig. F1).

Stratigraphically controlled deposits occur in porous to densely silicified sedimentary strata of volcanic-sedimentary sequences in which clastic minerals and rock fragments have been variably leached and replaced. Similar to structurally controlled core zones, densely silicified strata reflect hydrolytic decomposition of silicate minerals and infilling of pores by silica minerals. Voids and fractures in leached and silicified strata may be encrusted and filled with paragenetically late minerals (quartz, alunite, kaolinite, sulfide minerals, ore minerals, and sulfur). Clastic minerals and fragments in adjacent and (or) overlying strata have been variably replaced by quartz, alunite, kaolinite, dickite, pyrophyllite, and pyrite. Distal alteration minerals include sericite (fine-grained illite or muscovite), montmorillonite, chlorite, and pyrite (fig. F2). In addition to lateral permeability, wall-rock composition and spacing of fluid conduits broadly control thickness and coherence of assemblages in stratiform deposits.
Structurally and stratigraphically controlled alteration mineral assemblages commonly erode to characteristic landforms consisting of resistant, tabular ridges ("ledges" at Goldfield; Ransome and others, 1909), spines and mesas flanked by taluscovered slopes, and depressions of low-density clay-mica-pyritealtered rocks that are more susceptible to weathering. These landforms and mottled white, red-brown, and beige coloration of large quartz-alunite alteration zones are often visible from tens of kilometers, in part because of the dearth of vegetation on cationdeficient, low-pH soils.

\section{Vertical Zoning}

The vertical distribution of structurally controlled alteration mineral assemblages is partially known for the deeply mined (as much as $\sim 500 \mathrm{~m}$ below the erosion surface) and drilled $(\sim 1,500 \mathrm{~m})$ gold-copper-silver deposits at El Indio, Goldfield, Summitville, and Pascua-Lama. Mapped mine workings at El Indio show that widths of medial alteration zones (alunite-kaolinite-quartzpyrophyllite-sericite [fine-grained illite or muscovite]-pyrite assemblages) decrease from about 10 to $70 \mathrm{~m}$ at the erosion surface to less than $10 \mathrm{~m}$ at $\sim 500 \mathrm{~m}$ depth (fig. F1). At Goldfield, core zone widths narrow gradually or abruptly with depth, and unmineralized core zones thin and become unrecognizable in enclosing clay mineral+sericite (fine-grained illite or muscovite) +pyrite-altered rocks at depths of tens to several hundreds of meters (Vikre and Henry, 2011). In deep drill holes at Summitville and Goldfield, abundances of alunite and pyrophyllite in medial zones diminish with depth. Alunite does not occur below $\sim 650 \mathrm{~m}$, and pyrophyllite does not occur below $\sim 600 \mathrm{~m}$. Quartz+kaolinite/ dickite persists to $\sim 1,400 \mathrm{~m}$ below the erosion surface, although muscovite \pm illite+quartz+pyrite is the dominant hydrous silicate assemblage below $\sim 500 \mathrm{~m}$, and montmorillonite+pyrite dominates below $\sim 1,300 \mathrm{~m}$. Concentrations of diaspore and zunyite occur sporadically from about 600 to $1,400 \mathrm{~m}$, but neither of these minerals is reported in mines in the Summitville and Goldfield districts, which are mostly less than $400 \mathrm{~m}$ deep (P. Vikre, unpublished data). At Pascua-Lama (fig. L5), quartz-alunite-, quartz-alunite-kaolinite-, and quartz-alunite-dickite-altered rocks extend from less than 50 to about $750 \mathrm{~m}$ below the erosion surface, and overlie quartz-alunite-pyrophyllite-altered rocks. An irregularly bordered zone of silicification at $\sim 125$ to $300 \mathrm{~m}$ depth, with an approximately horizontal aspect, includes most ore-grade $(0.4 \mathrm{~g} / \mathrm{t})$ and high-grade $(4 \mathrm{~g} / \mathrm{t})$ gold-mineralized rocks.

\section{Hydrothermal Alteration in Low- and Intermediate- Sulfidation Deposits}

\section{By Peter G. Vikre}

Feldspars were largely stable in fluids that formed lowand intermediate-sulfidation deposits, and host rocks are not as extensively decomposed as those in high-sulfidation districts. In some low-sulfidation vein districts, primary wall-rock texture 
$\boldsymbol{A}$

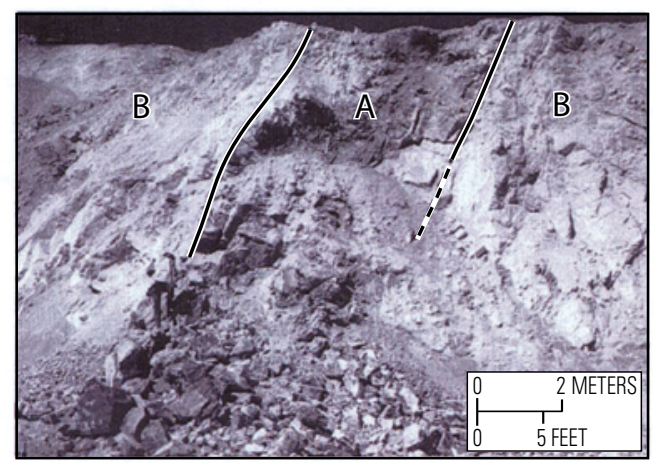

B

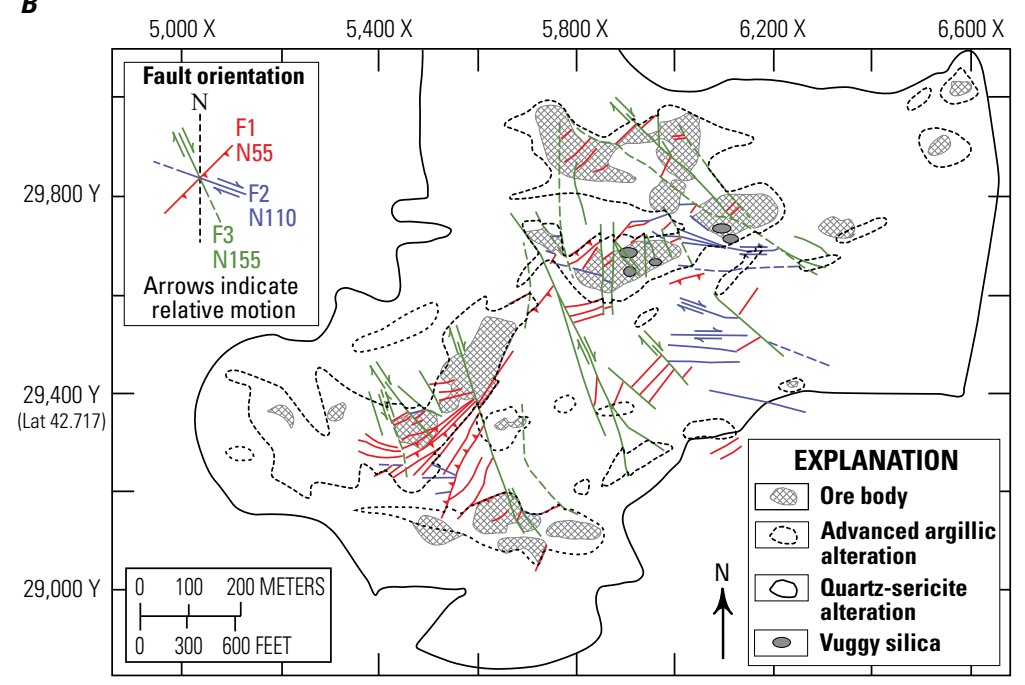

C
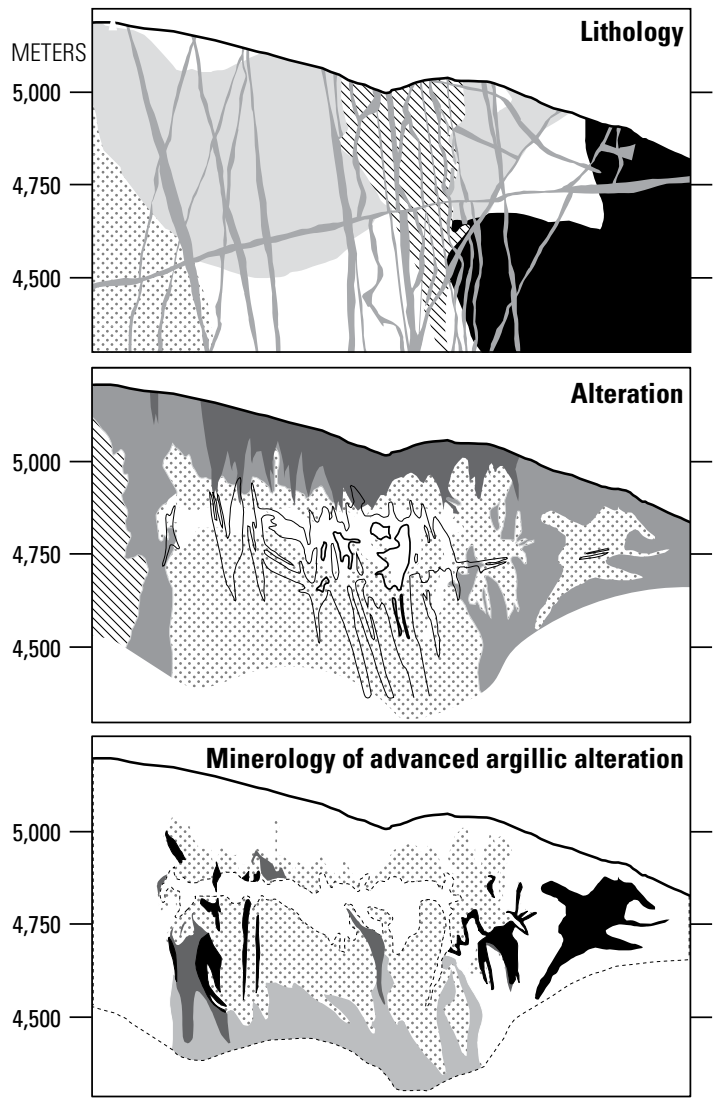

D

EXPLANATION

NW Breccia (heterolithic, matrix supported) Crowded granite Leucocratic diorite Porphyritic granite Hybrid diorite-granite Fault

\section{EXPLANATION}

Propylitic

Quartz-illite

Quartz-alunite ( \pm kao, dick, pyl, jar)

Silicification

Steam-heated quartzkaolinite (alun-ill)

Gold (Au) contours

$\triangle 4$ grams per ton $\mathrm{Au}$

0.4 grams per ton $\mathrm{Au}$

EXPLANATION

Propylitic

Otz-alun-dick

Otz-alun-pyl

Otz-alun (tjar)

Silicification (as

shown on fig. 6B)

$\stackrel{0}{0}_{600 \text { FEET }}^{200 \text { METERS }}$

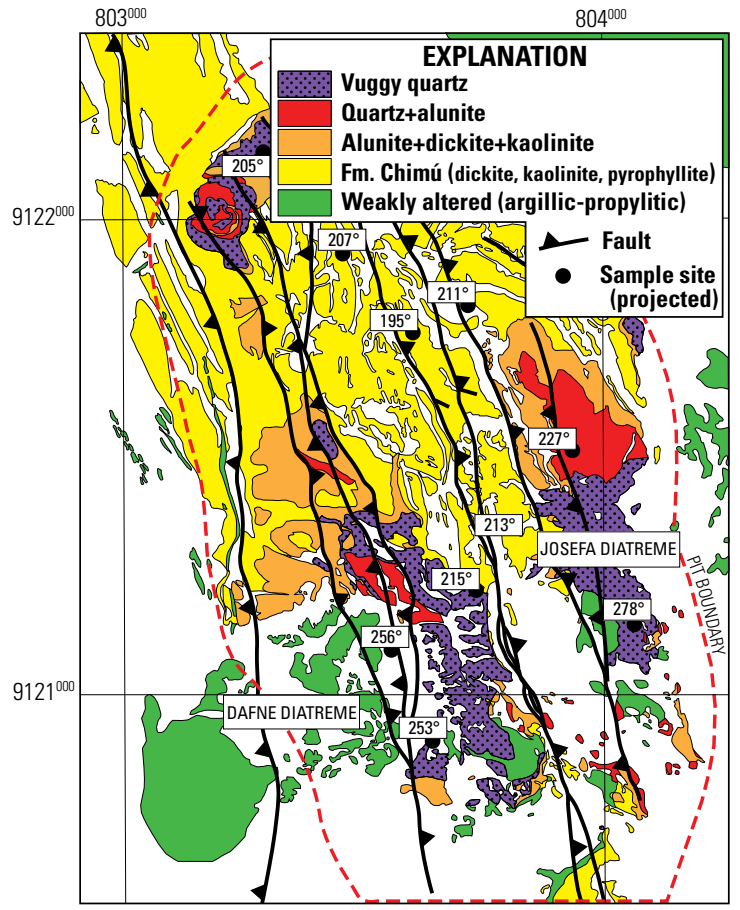

Figure L5. Sections and plan maps of high-sulfidation gold-copper-silver deposits with representative zoning patterns of alteration types and mineral assemblages. A, Summitville, U.S.A., gold deposit. Bench face showing silica-rich core zone (A, vuggy quartz+alunite ore) in quartz latite, enclosed by quartz latite altered to quartz+kaolinite (B, waste). From Gray and others (1994). B, Chelopech, Bulgaria, copper-gold deposit. Plan showing orebodies, advanced argillic alteration, quartz-sericite alteration, vuggy silica, and fault sets (red, green, and blue lines); faults dashed where approximated. From Chambefort and Moritz (2006). C, Pascua-Lama, Chile-Argentina, gold-silver deposit. Top section, lithology; center section, distribution of alteration types: propylitic (pyl), quartz (qtz)-illite (ill), quartz-alunite (alun), silicification, and steam-heated; and gold grade contours (grams per metric ton gold [Au]); bottom section, distribution of advanced argillic alteration mineral assemblages that include quartz, alunite, kaolinite (kao), dickite (dick), pyrophyllite, and jarosite (jar), and silicification. From Deyell and others (2005a). D, Lagunas Norte, Peru, gold deposit. Distribution of vuggy quartz, quartz+alunite, alunite+dickite+kaolinite, and dickite, kaolinite, pyrophyllite, and areas of weakly argillically and propylitically altered rocks. Sulfur isotope equilibrium temperatures (alunite-pyrite) in two mineralization stages are highest near the Dafne and Josefa diatremes. From Cerpa and others (2013). 
and coloration have been retained at vein contacts. In other lowsulfidation vein deposits and in intermediate-sulfidation deposits, extensive volumes of host rocks adjacent to veins have been metasomatically altered to variable proportions of quartz, adularia, sericite (fine-grained illite or muscovite), chlorite, and pyrite, and primary wall-rock texture adjacent to veins has been partially to entirely obscured.

Abundances and modes of hydrothermal minerals that make up alteration zones in low- and intermediate-sulfidation districts usually define distinct selvages adjacent to fluid conduits; selvages parallel conduits and are broadly planar but have gradational boundaries. Fluid conduits commonly are filled by veins. Alteration mineral assemblages in selvages vary somewhat with host rock composition, number of fluid events (represented by vein stages and vein mineral parageneses), vein thickness and attitude, and depth below erosion surfaces and paleosurfaces. Alteration minerals commonly represent a composite of several superimposed assemblages.

\section{Structural, Stratigraphic, Chemical, and Physical Controls}

Structures, commonly planar to subplanar fault zones, rather than stratigraphy, control vein deposit locations and wall-rock alteration in most low- and intermediate-sulfidation districts (see "Tectonic Structures" and "Hydrothermal Structures"). Significant districts include equidimensional to elongate groups of several to numerous veins with similar to contrasting strikes (for example, Tonopah, U.S.A.; Tayolita, Mexico; Nolan, 1935; Saunders, 2000; Smith and others, 1982). The largest districts consist of veins that formed in en echelon and branching fault systems as much as $21 \mathrm{~km}$ in composite strike length (for example, Tayoltita, Guanajuato, Mexico; Smith and others, 1982; Mango and others, 2014), and minimally extend as much as $2 \mathrm{~km}$ below paleosurfaces, based on mining depths and hydrodynamic reconstructions (for example, Comstock Lode, U.S.A.; Tonopah; Vikre, 1989a; Fahley, 1981). Zoned selvages of alteration mineral assemblages in these multvein districts commonly coalesce and (or) are superimposed, resulting in complicated space-time relationships among assemblages.

In some large low- and intermediate-sulfidation districts with high gold and silver grades ( $>10 \mathrm{~g} / \mathrm{t}$ gold; hundreds of grams per metric ton silver), these large-dimension fault systems displace physically homogenous rocks that have relatively low permeability (volcanic flows and domes, subvolcanic intrusions, and granitic rocks; for example, Comstock Lode; Tayoltita; Bodie and Aurora, Vikre and others, 2015). In other large low-sulfidation districts, sequences of volcaniclastic strata (tuffs and epiclastic deposits) are the predominant or major host rocks (for example, Hishikari, Izawa and others, 1990; Shikazono and Nagayama, 1993; Bullfrog, Eng and others, 1996; Guanajuato, Mango and others, 2014), demonstrating that planar, open-space fractures are maintained in compacted volcanic rocks of several eruptive forms. However, widths of alteration selvages vary with wallrock permeability and competency as well as with vein width and number of cospatial vein-forming events.

\section{Mineralogy, Lateral Zoning, and Paragenesis}

In most districts, alteration mineral assemblages in wall rocks adjacent to planar veins comprise geometrically regular and mineralogically consistent selvages that parallel vein margins. Proximal assemblages adjacent to most layered veins, consist predominantly of quartz, adularia (sometimes designated potassium feldspar), variable abundances of smectite, sericite (fine-grained illite or muscovite), chlorite, and albite, and as much as several volume percent pyrite (for example, Simpson and Mauk, 2011). Minor amounts of zeolite minerals, sphalerite, galena, and chalcopyrite occur in some proximal assemblages (for example, Midas, Leavitt and Arehart, 2005; Buritica, Colombia, Lesage and others, 2013). These minerals variably replace feldspars, mafic minerals, and matrices of mafic and silicic wall rocks; some occur in fractures. Extensive replacement of primary minerals by quartz and potassium feldspar (sometimes termed "flooding") commonly obscures wall-rock fabric, or increases porosity by mineral dissolution and molar volume differences between primary and replacement minerals. Assemblages that include potassium feldspar are sometimes referred to as "potassic alteration." In some deposits (Co-O mine, Philippines, Sonntag and others, 2012; San Jose district, Argentina, Dietrich and others, 2012), illite is the most abundant mineral in proximal alteration mineral selvages (and also in "intermediate" [medial] and distal assemblages), and potassium feldspar is absent. Proximal assemblages extend meters (for example, El Peñón, Chile, Warren and others, 2004, 2008) to tens of meters (for example, Bullfrog, Eng and others, 1996; Midas, Leavitt and others, 2004; Leavitt and Arehart, 2005; figs. L6, L7) from vein margins in most districts.

Proximal alteration mineral selvages adjacent to multistage veins may be partially to entirely overprinted by later alteration mineral assemblages or include narrow veins with one or more later alteration mineral assemblages and (or) vein stages. At Hishikari, Japan, alteration minerals in selvages adjacent to deep and high-grade vein segments in Cretaceous siliciclastic and Quaternary volcaniclastic strata are dominantly quartz, chlorite, and sericite (fine-grained illite or muscovite), and lesser interstratified illite-smectite, adularia, calcite, plagioclase, and zeolite minerals, whereas higher elevation, largely stratiform assemblages consist of variable proportions of quartz and claymica minerals (Izawa and others, 1990). The distribution and mineralogy of these alteration zones reflect overprinting of earlier assemblages by subsequent different fluid regimes (Shikazono and Takahashi, 2010).

In some low- and intermediate-sulfidation districts, wall-rock composition apparently controls alteration mineral assemblages. At Hishikari and Tayoltita, pre-Tertiary sedimentary and igneous rocks and matrices of Tertiary and Quaternary andesites adjacent to mid-level and deep veins, more than $100 \mathrm{~m}$ below erosion surfaces, are silicified, chloritized, and sericitized; plagioclase and mafic mineral phenocrysts in andesite are replaced by epidote, chlorite, albite, actinolite, calcite, pyrite, and hematite. At Hishikari, volcaniclastic strata adjacent to some veins are predominantly altered to interstratified clay minerals. At Tayoltita, feldspars in rhyolite and granodiorite wall rocks adjacent to midand deep-level veins are altered to quartz, potassium feldspar, 

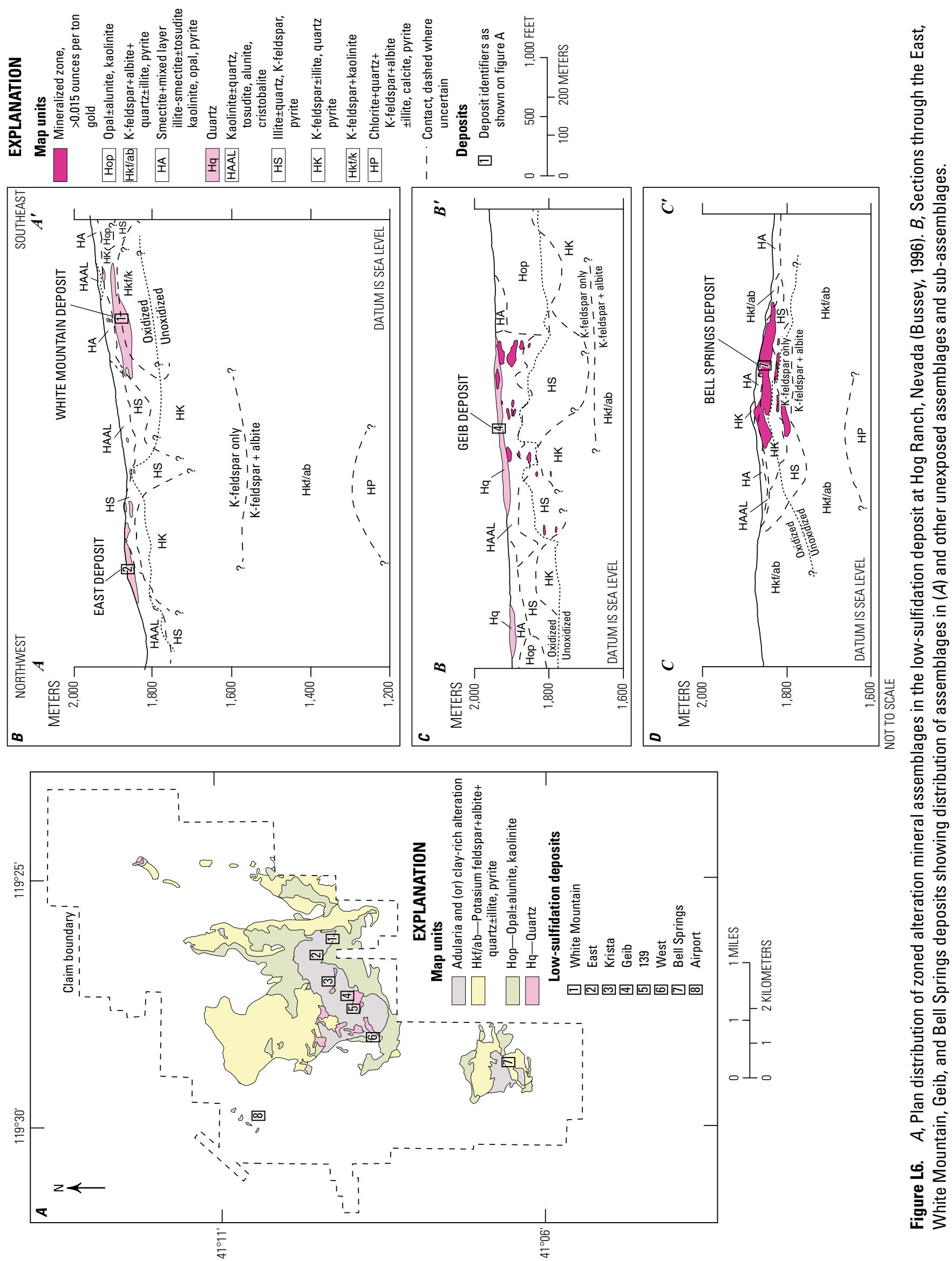
$\boldsymbol{A}$

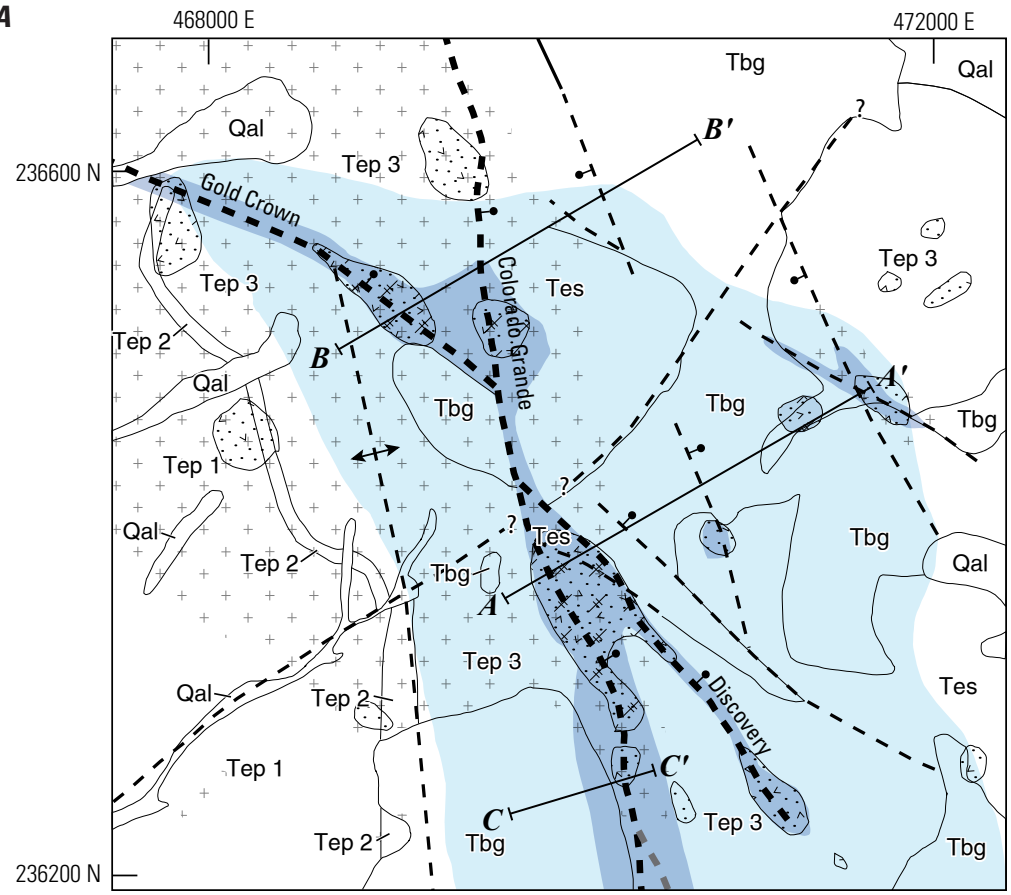

\section{EXPLANATION}

Pot, IPot, SPot-Potassic, intense potassic, silicic-potassic

MPro, IPro-Moderate, intense propylitic

WPro-Weak propylitic

Arg-Argillic

Sil-Silicic

Stwk-Stockwork

- I - Fault and vein-Dashed where uncertain, ball and bar on downthrown block $\perp$ - Fault-Dashed where uncertain,
ball and bar on downthrown block - $\mathfrak{f}$ - Anticline-Dashed where uncertain

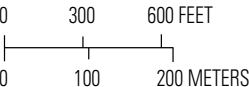

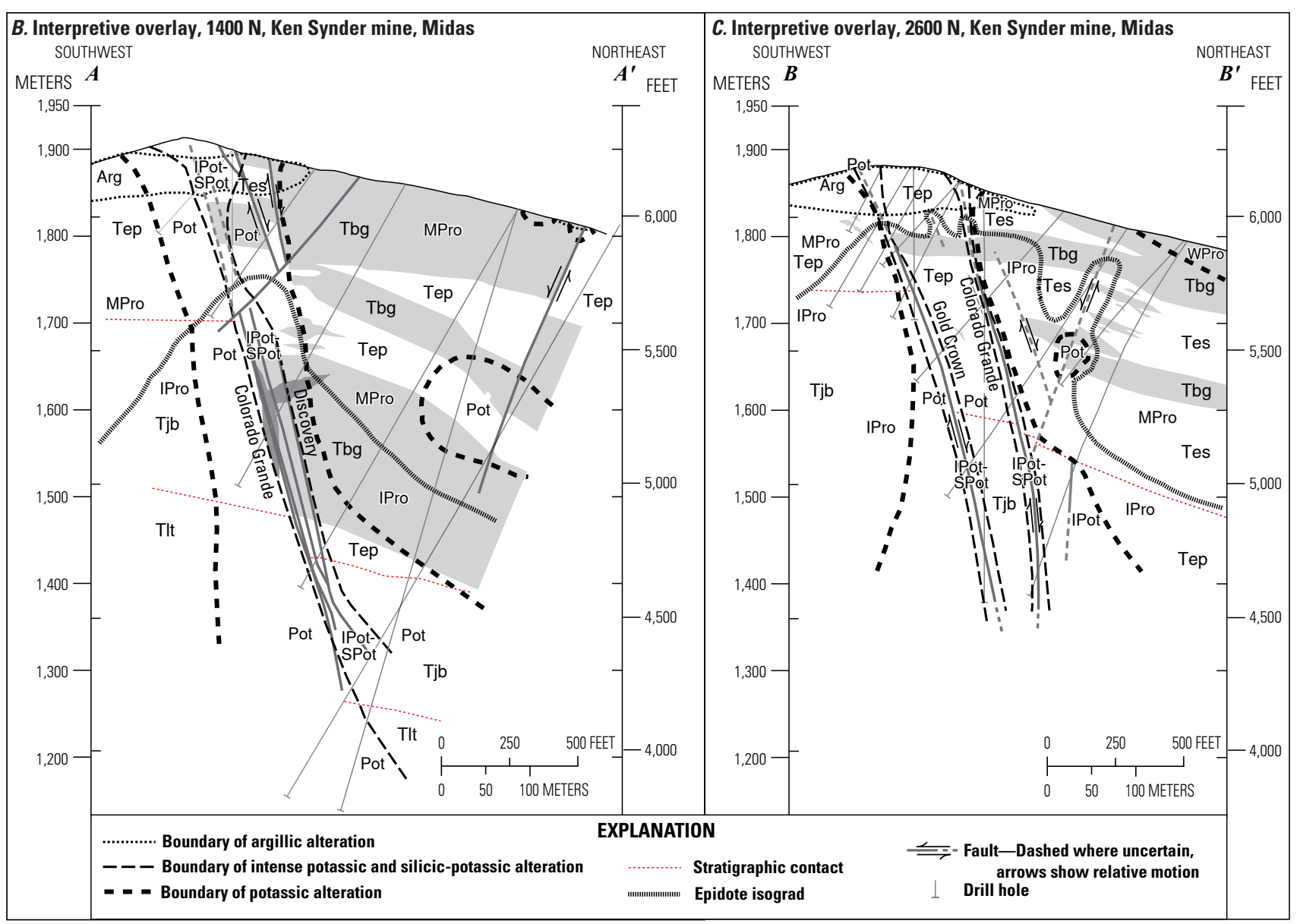

Figure L7. Plan map and cross sections showing hydrothermal alteration at the Midas low-sulfidation deposit, Nevada (Leavitt and Arehart, 2005). $A$, Plan distribution of zoned alteration mineral assemblages. $B$ and $C$, Southwest-northeast sections through mined veins showing assemblages in $A$. Vertical scales in feet. Geologic units: Qal, Quaternary alluvium; Tes, tuffs and volcaniclastic strata; Tbg, basalt and basaltic andesite dikes, sills, and flows; Tep3, lapilli tuff; Tep2, carbonaceous siltstone and sandstone; Tep1, lithic tuff; Tep, tuffs, siltstone, and sandstone, undifferentiated; Tjp, rhyolite; Tlt, tuffs. 
sericite (fine-grained illite or muscovite), calcite, and pyrite. However, these modal relationships at least in part reflect vertical and temporal differences among alteration mineral abundances (Smith and others, 1982; Izawa and others, 1990; Conrad and others, 1992).

In most districts with increasing distance from vein margins, proximal alteration mineral assemblages gradationally merge with medial assemblages consisting of variable proportions of sericite (fine-grained illite or muscovite), montmorillonite/smectite, and lesser chlorite, calcite, quartz, pyrite, and epidote (quantified at Midas and Hishikari, Leavitt and Arehart, 2005; Shikazono and Takahashi, 2010; fig. L8). These assemblages, sometimes referred to as "argillic" or "intermediate argillic" alteration, variably replace feldspars and mafic minerals in mafic and silicic wall rocks. Medial assemblages may extend several tens of meters from proximal assemblages, and selvages of both assemblages invariably thin with depth.

Selvages of proximal and medial alteration mineral assemblages adjacent to nonvertical veins are commonly thicker in hanging walls than in footwalls, probably a result of fluid upflow in more extensive hanging wall fracture systems. Some to many mined veins in the Comstock Lode and Tonopah districts occur in the hanging walls of moderate- to low-angle faults that are also mineralized. Medial alteration selvages in these mineralized hanging walls merge, forming large volumes of volcanic rocks pervasively altered to mica and clay minerals, quartz, and pyrite.

Medial alteration selvages may include veins of montmorillonite, calcite, pyrite, and other minerals, that reflect fluid flow associated with later vein stages. Kaolinite, halloysite, and quartz have replaced, in part, proximal and medial potassium minerals (adularia, illite, sericite) in wall rocks and veins in some multistage low-sulfidation districts (for example, National, Vikre, 200; Guanajuato, Mango and others, 2014), reflecting episodic fluid boiling and condensation of exsolved acid-forming gases in groundwater. Coeval steam-heated alunite overlies gold-silver veins and stockworks in some of these districts (for example, National; Ivanhoe, Bartlett and others, 1991; Hog Ranch, Bussey, 1996; figs. L6, L9). Replacement of calcite by quartz psuedomorphs and perimorphs is common in layered veins, and also reflects late stage fluid acidification or cooling, causing calcite to dissolve and quartz to precipitate.

Distal alteration mineral assemblages, tens to several hundreds of meters or more from veins, include chlorite, calcite, montmorillonite, and minor pyrite that variably replace feldspars, mafic minerals, and matrices of volcanic rocks. Zeolite minerals, epidote, and hematite are commonly part of distal assemblages, which are usually termed "propylitic" in intermediate host rocks. Propylitic alteration assemblages produce characteristic dark-green coloration of andesite and dacite, and may or may not be spatially associated with veins, and may be paragenetically earlier than proximal and medial vein-related alteration mineral assemblages (for example, Tayoltita; Conrad and others, 1992). In rhyolite host rocks, distal alteration assemblages include quartz, illite-smectite, and lesser pyrite that are infrequently termed propylitic, perhaps because of subdued color contrast with unaltered rhyolite.
Alteration of paleosurface and subjacent strata (sinter, sinter breccia, vent breccia, eruption breccia, epiclastic deposits, eruptive rocks) in uneroded low-sulfidation districts is dominated near main fluid conduits by fine-grained silica phases (chalcedony, opal, cristobalite, tridymite) that comprise chemical sediments (sinter), fill matrices of breccias and volcaniclastic and epiclastic deposits, and variably replace detrital components of clastic deposits (for example, Ivanhoe; McLaughlin; Republic, Hog Ranch; National; Bartlett and others, 1991; Sherlock and others, 1995; Fifarek and others, 1996; Bussey, 1996; Vikre, 2007; figs. F5, L8). With increasing distance from fluid conduits, paleosurface and subjacent strata are progressively altered to clay-mica minerals (kaolinite; illite/smectite) \pm pyrite. In some cases, later, steam-heated alunite forms in near-surface strata where boiling is induced by depression of the water table (for example, National; Ivanhoe; Hog Ranch; possibly Hishikari; fig. L8) and coincides with alteration of earlier formed vein and wall-rock potassium-bearing minerals to clay minerals. These minerals replace clastic matrices, rock fragments, and phenocrysts. Fluid boiling and (or) decompression also degasses $\mathrm{CO}_{2}$, which may condense in near-surface vein interstices, fracture, and faults, forming calcite, commonly with "bladed" texture (for example, Golden Cross, New Zealand, Simmons and others, 2000; see "Veins").

In some intermediate-sulfidation districts (for example, Tayoltita, Smith and others, 1982; Comstock Lode, Vikre, 1989a; Tonopah, Bonham and Garside, 1979), wall rocks and breccia fragments adjacent to and in vein segments near the erosion surface are partly altered to kaolinite and other clay minerals, reflecting condensation of acidic volatiles degassed by fluid boiling or decompression. In some districts, veins containing large proportions of paragenetically late calcite are distal to quartzdominant veins (for example, Comstock Lode, Tayoltita), and apparently reflect encroachment of cooler groundwater in conduits and heating of cooler groundwater by higher temperature wall rocks (see " $\mathrm{CO}_{2}$-rich steam-heated waters" on fig. L1).

\section{Vertical Zoning}

Within the vertical limits of mined vein systems, grain sizes of alteration minerals broadly increase with depth, crystal structures of some clay-mica minerals become more ordered (for example, fine-grained illite transitions to more crystalline muscovite), and alteration mineral selvages adjacent to veins thin appreciably (for example, Cuelebra vein, Tayoltita; Smith and others, 1982). In systems with preserved paleosurfaces, silicification of near-surface strata and wall rocks diminishes with increasing depth, and fine-grained quartz becomes the dominant silica phase over opal and chalcedony. Poorly crystalline illite in near-surface wall rocks and veins is gradually transformed to muscovite structure with increasing depth, presumably by increasing fluid temperature. In some well-studied systems, proportions of illite, sericite, montmorillonite/smectite, and other minerals vary with position relative to erosion surfaces and paleosurfaces, leading to subdivision of assemblages into subassemblages (for example, "shallow argillic," "deep argillic," "phyllic," "cristobalite-smectite"; for example, Hishikari, Hog 
A. Alteration of mafic rocks

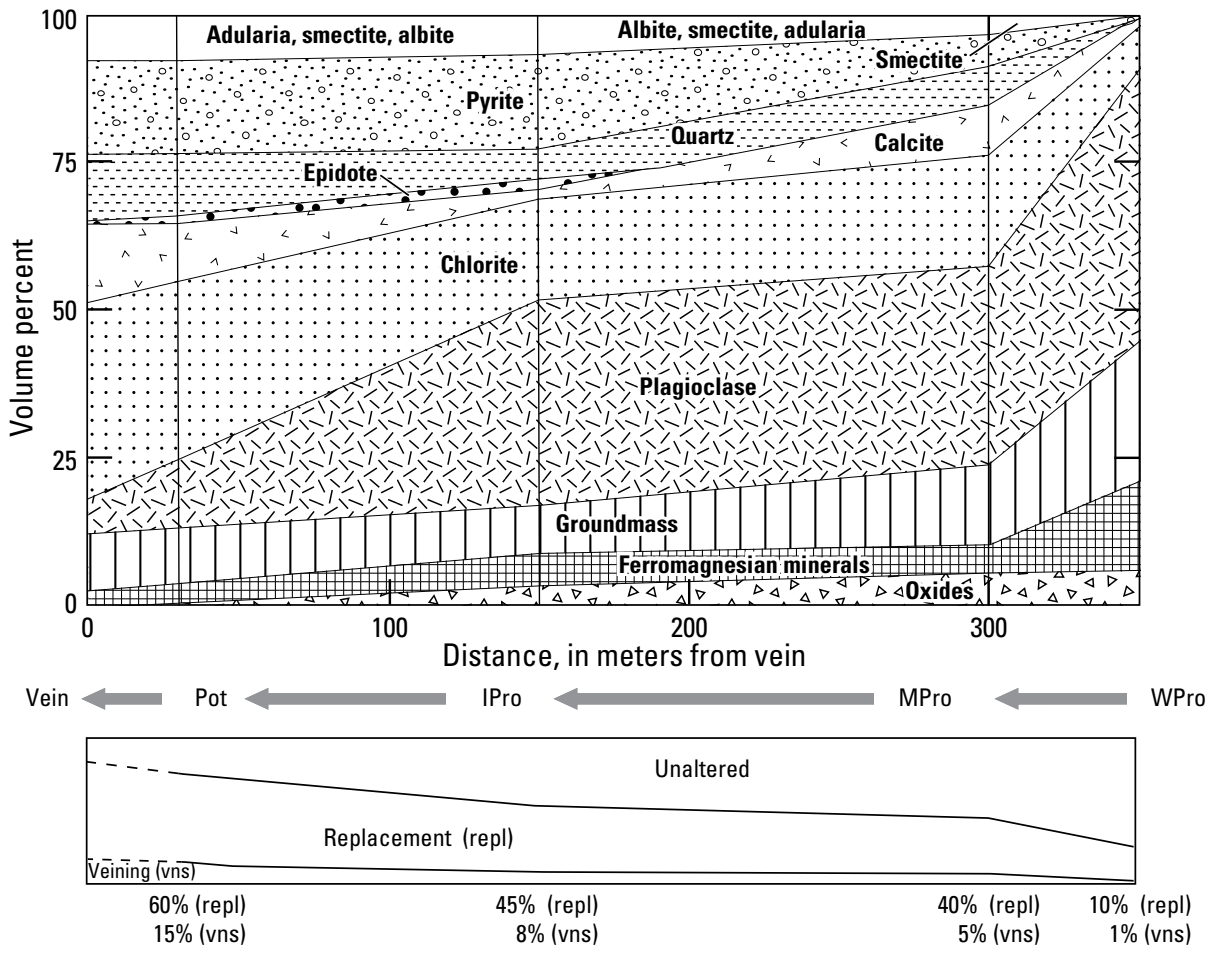

B. Alteration of felsic rocks

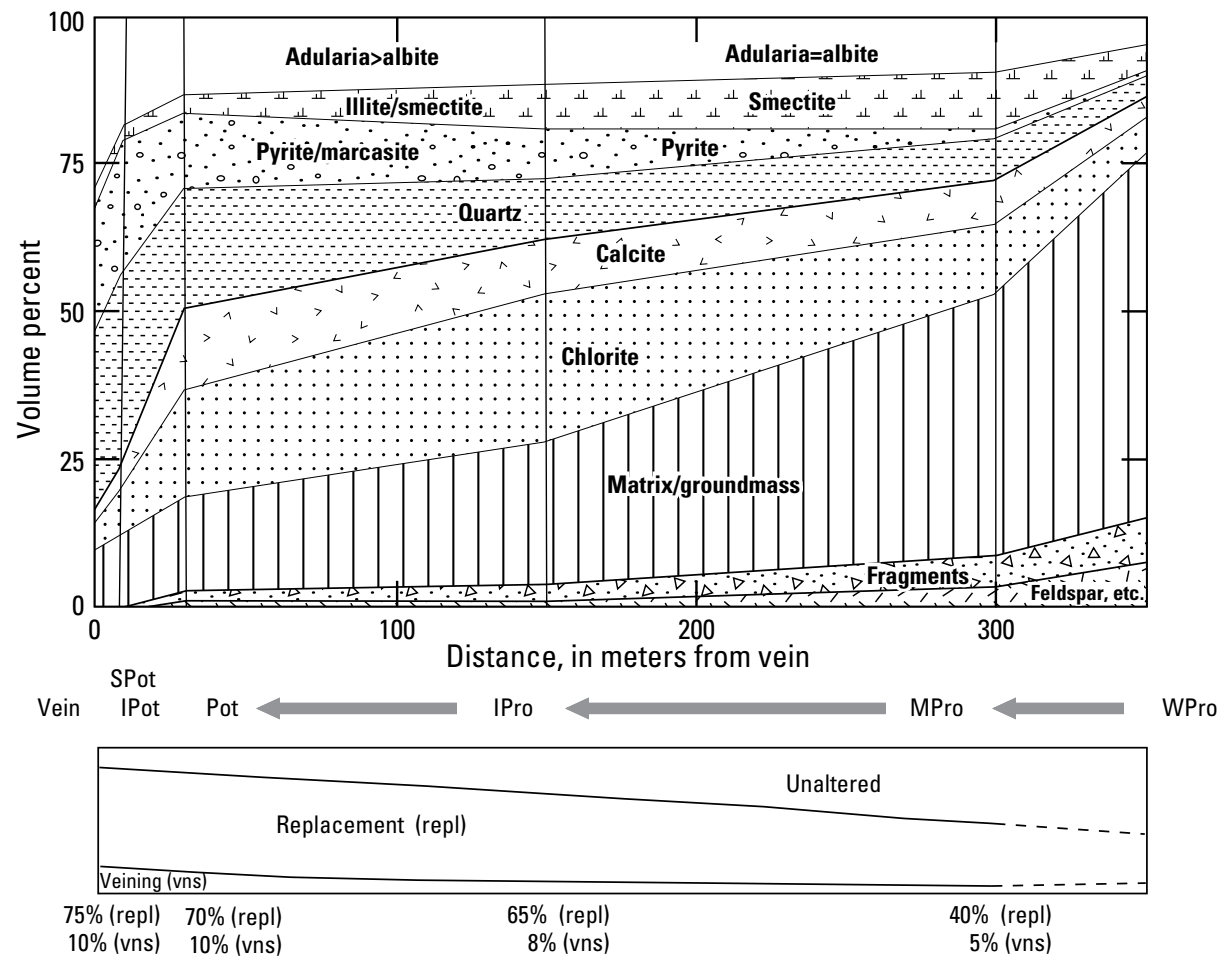

Figure L8. Schematic sections through mafic (top) and felsic (bottom) wall-rock alteration selvages at Midas, Nevada, showing relative abundances of minerals comprising alteration mineral assemblages designated by Pot (potassic), IPro (intense propylitic), MPro (moderate propylitic), and WPro (weak propylitic; top section), and SPot, (silicic potassic), IPot (intense potassic), Pot (potassic), IPro, MPro, and WPro (bottom section; Leavitt and Arehart, 2005). 

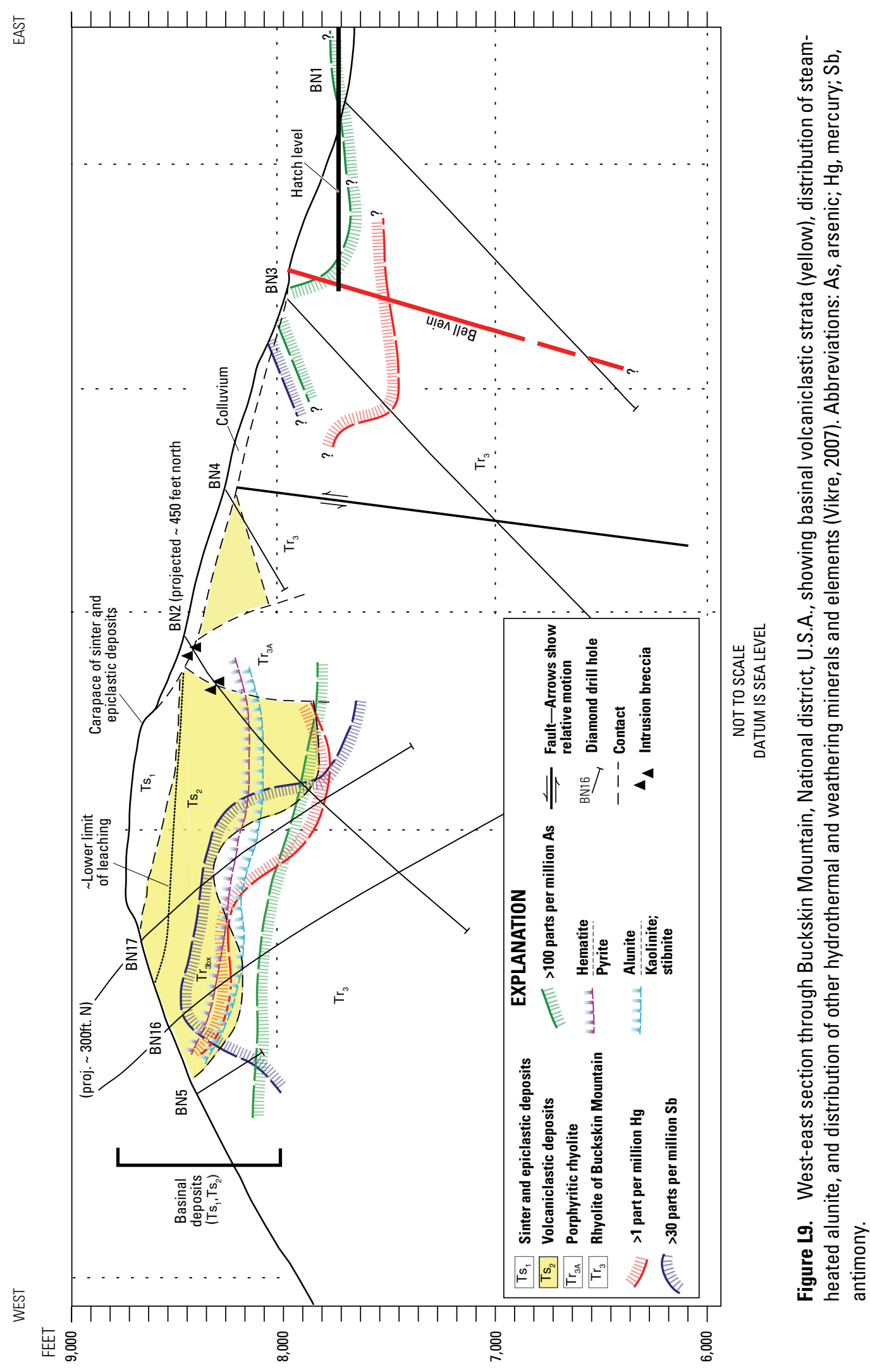
Ranch, Izawa and others, 1990; Bussey, 1996; fig. L6). At

Hishikari, stratiform assemblages of silica and clay minerals that overlie veins apparently reflect control by volcaniclastic-dominant stratigraphy, whereas wall rocks adjacent to veins in volcaniclastic deposits and subjacent Cretaceous shale and sandstone are largely altered to chlorite and sericite (fine-grained illite or muscovite) (Izawa and others, 1990).

\section{Supergene Alteration}

Supergene alteration minerals are predominantly iron oxide and sulfate minerals, clay minerals, and lesser alunite (for example, Round Mountain, U.S.A., Fifarek and Gerike, 1991) that form by decomposition of hypogene sulfide and aluminosilicate minerals during one or more weathering cycles. They are volumetrically minor in most low- and intermediate-sulfidation districts, because of the relatively low abundance of pyrite in altered wall rocks, and limited generation of low-pH fluids that alter hypogene minerals. Supergene iron oxides and clay minerals are relatively abundant, although not quantified, near erosion surfaces in some large intermediate-sulfidation districts (for example, Comstock Lode, Tonopah), which include closely spaced veins with coalesced hypogene alteration mineral selvages. During mining, weathering of pyrite in near-surface vein selvages may render stope margins incompetent and necessitate ground support to allow access and control grade dilution. 


\title{
Chapter M. Petrology of Associated Igneous Rocks
}

\author{
By Edward A. du Bray
}

Neither geochemical nor petrographic characteristics of igneous rocks associated with epithermal deposits are distinct. Essentially all epithermal precious and base-metal deposits are associated with either calc-alkaline subduction-related arc magmatism or calc-alkaline to tholeiitic back-arc continental rift magmatism (Sawkins, 1990; Sillitoe and Hedenquist, 2003; Simmons and others, 2005). A distinct class of epithermal $\mathrm{Au}-\mathrm{Ag} \pm \mathrm{Te}$ deposits, with relatively few members, is strongly associated with alkaline volcanic centers. These deposits are important because of their large size and are the subject of the alkaline intrusion-related epithermal gold deposits model (Kelley and others, in press). Arc and back-arc continental rift magmatism can persist in the appropriate, stable tectonic regimes for several to tens of millions of years; given appropriate circumstances, epithermal deposits can develop at any time during the associated, protracted magmatism. Igneous rocks associated with epithermal mineral deposits are compositionally diverse, and most are extrusive but include minor intrusive rocks. Demonstrating that a particular epithermal deposit is genetically related to specific igneous rocks is seldom possible, however. Common calc-alkaline igneous rocks host these deposits, but these host relations do not necessarily confirm a genetic relation. For the purposes of this deposit model, data for igneous rocks that are temporally (rocks with ages within several million years of the deposit age) and spatially (rocks within $<10 \mathrm{~km}$ of the deposit) related to a particular epithermal deposit were considered. Importantly, a subset of the low-sulfidation epithermal deposits, including Sunnyside (Casadevall and Ohmoto, 1977), Hycroft (Ebert and Rye, 1997), Dixie Comstock (Vikre, 1994), and Florida Canyon (Fifarek and others, 2011), are not spatially associated with plausibly coeval igneous rocks. Consequently, whether magmatic activity contributed to the genesis of these deposits is uncertain; similar deposits throughout the Great Basin are considered to be amagmatic (John, 2001; Fifarek and others, 2011).

Subduction-related rocks associated with epithermal deposits form parts of convergent-margin magmatic arcs in continental and oceanic settings. These rocks form composite stratovolcanoes of mafic to intermediate composition, intermediate- to felsiccomposition exogenous to endogenous lava dome complexes, and less commonly, ash-flow (ignimbrite) calderas of intermediate to felsic composition. These volcanoes coalesce to essentially continuous chains of eruptive centers along the length of associated magmatic arcs. The mafic- to felsic-composition backarc volcanic rocks, commonly bimodal, that are associated with epithermal deposits represent more widely distributed volcanic centers typical of magmatism in extensional settings.

During decades of research on epithermal deposits, a wide array of igneous rocks has been identified as being spatially and presumably genetically associated with these deposits. However, except for a small compilation of data for igneous rocks associated with epithermal deposits (140 samples representing 12 deposits; Arribas, 1995), no synoptic compilation of geochemical and petrographic data has been completed. Simmons and others (2005) defined a representative subset of epithermal deposits whose characteristics exemplify this broad class of deposits. Using a slightly modified and augmented version (appendix 1) of that representative deposit subset as a starting point, du Bray (2014) compiled data for 1,497 samples of essentially unaltered igneous rock associated with about 50 individual epithermal deposits or districts. Disproportionately large numbers of geochemical analyses are available for igneous rocks associated with several of the representative epithermal deposits. Inclusion of all of these analyses in the interpretation of the geochemical systematics of igneous rocks associated with epithermal deposits might bias the interpreted dataset. Accordingly, a derivative version (du Bray, 2017) of the principal database was created by random selection of subsets of available analyses for igneous rock samples associated with the Bodie, Aurora, Comstock Lode, Martha HillFavona, and Banska deposits. The derivative version of the new data compilation was the primary source for the characteristics synthesized below.

\section{Rock Names}

Igneous rocks associated with epithermal deposits have been described as having intermediate or andesitic compositions, although supporting documentation is generally sparse. The compilation of du Bray (2014) shows that most of these rocks are subalkaline volcanic rocks composed (Le Maitre, 2002) of basalt, basaltic andesite, andesite, dacite, and rhyolite (fig. M1). However, some of these rocks, predominantly those in the Bodie Hills volcanic field astride the California-Nevada border, are somewhat more alkaline (especially potassic) and are therefore composed of basaltic trachyandesite, trachyandesite, or trachydacite. Epithermal deposits are most commonly associated with andesitic rocks (40 percent, low- and intermediate-sulfidation deposits; 40 percent, high-sulfidation deposits), but dacitic rocks (19 percent, low- and intermediate-sulfidation deposits; 35 percent, high-sulfidation deposits) and rhyolitic rocks ( 24 percent, low- and intermediatesulfidation deposits; 20 percent, high-sulfidation deposits) are also common; epithermal deposits are less commonly associated with rocks composed of basaltic andesite (14 percent, low- and intermediate-sulfidation deposits; 5 percent, high-sulfidation deposits) and basalt (3 percent, low- and intermediate-sulfidation deposits; <1 percent, high-sulfidation deposits) (fig. M2). The 


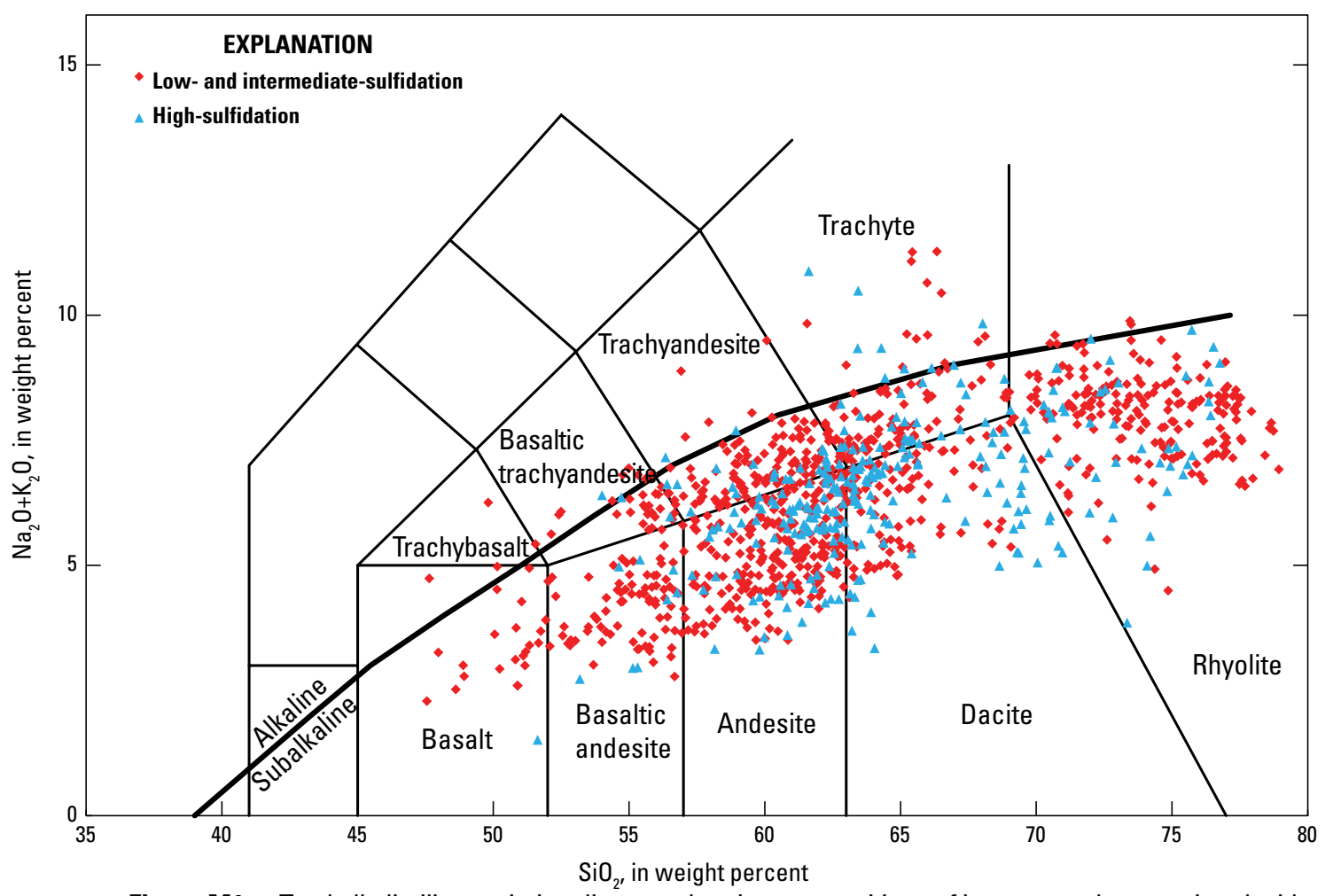

Figure M1. Total alkali-silica variation diagram showing compositions of igneous rocks associated with low- and intermediate-sulfidation and high-sulfidation epithermal mineral deposits. Field boundaries from Le Maitre (2002). Boundary between alkaline and subalkaline compositions from Irvine and Baragar (1971).

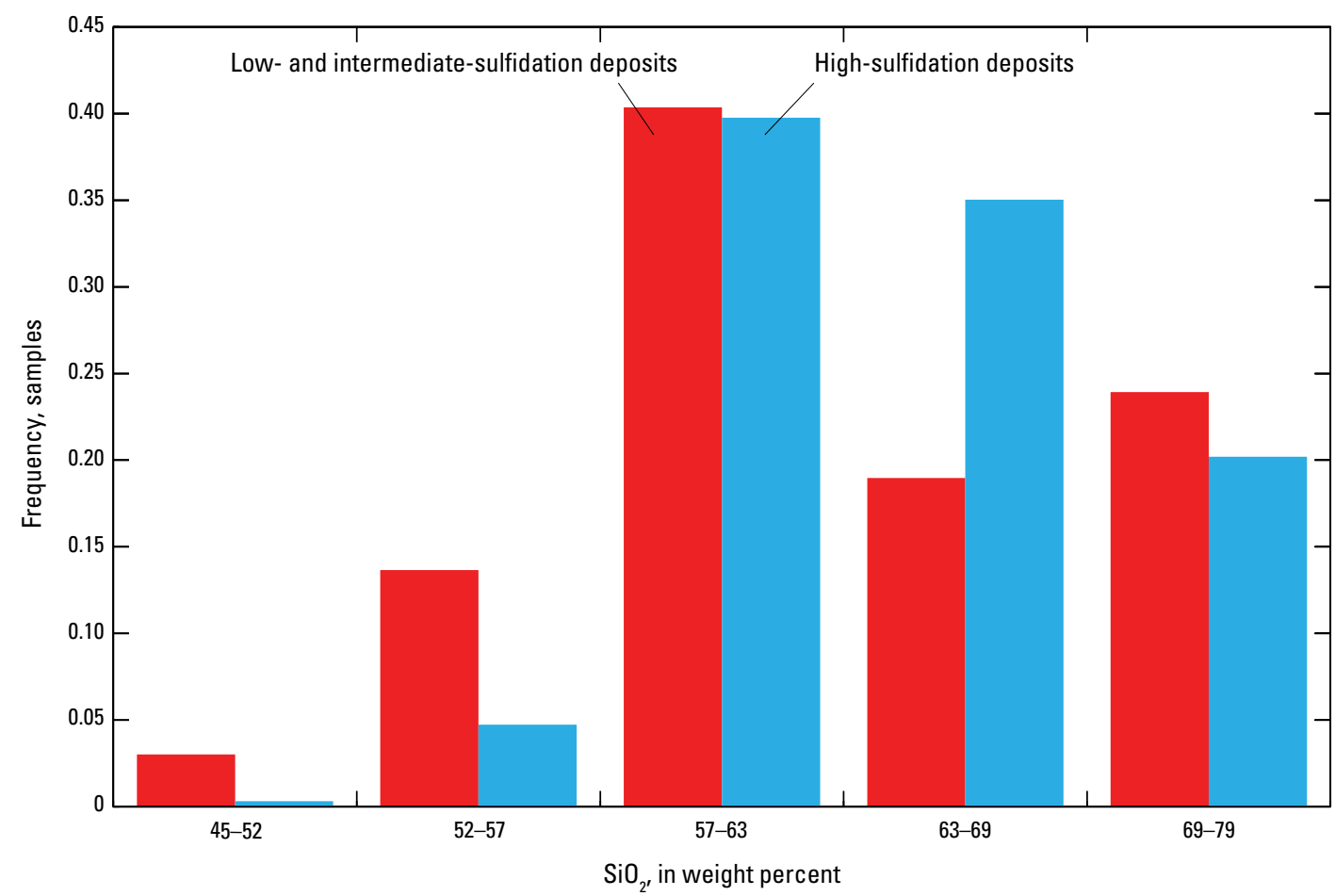

Figure M2. Histogram showing the frequency distribution of samples of igneous rocks associated with low- and intermediate-sulfidation and high-sulfidation epithermal mineral deposits as a function of $\mathrm{SiO}_{2}$, where boundaries between individual $\mathrm{SiO}_{2}$ ranges correspond to those between basalt, basaltic andesite, andesite, dacite, and rhyolite. 
compositions (Streckeisen, 1976) of relatively rare intrusive igneous rocks associated with epithermal deposits are very poorly documented but include granodiorite, quartz diorite, diorite, granite, monzogranite, and tonalite (du Bray, 2014).

\section{Forms of Igneous Rocks and Rock Associations}

The forms of igneous rocks associated with epithermal deposits are as diverse as their compositions. As components of convergent margin magmatic arcs, and less volumetrically important back-arc continental rift magmatism, these rocks principally form composite stratovolcanoes, lava dome complexes, diatremes, and, less significantly, ash-flow (ignimbrite) calderas; additional igneous forms include the intrusive parts of the associated magmatic systems. Consequently, lava flows, blockand-ash-flow deposits, debris-flow deposits, ash-flow tuff sheets, endogenous and exogenous lava domes, and shallow intrusions, including dikes, sills, laccoliths, plugs, stocks, and plutons, may host and be genetically associated with epithermal deposits. Lava flow deposits are most commonly associated with epithermal deposits (78 percent, low- and intermediate-sulfidation deposits; 58 percent, high-sulfidation deposits); hypabyssal intrusive bodies are the next most common host (du Bray, 2014).

\section{Mineralogy}

Given that epithermal deposits are generally associated with volcanic rocks, principally lava flows, most of these rocks consist of a variably devitrified and (or) recrystallized glass matrix that includes diverse phenocryst populations; some of these rocks preserve fresh groundmass glass. Although published quantitative modal data for igneous rocks associated with epithermal deposits are scarce, basic petrographic features of these rocks were gleaned from available data. Phenocryst abundances and species principally reflect whole rock compositions and temperature and pressure conditions prevailing during magma solidification. Among volcanic rocks associated with epithermal deposits, total phenocryst abundances vary widely between essentially zero and about 45 percent. The average phenocryst content of these rocks is about 21 percent (low- and intermediate-sulfidation deposits) or 30 percent (high-sulfidation deposits). Euhedral plagioclase is a nearly ubiquitous phenocryst-forming mineral in these rocks; its abundance (14 percent, low- and intermediate-sulfidation deposits; 17 percent, high-sulfidation deposits) increases systematically with total phenocryst content. Subhedral alkali feldspar and variably embayed quartz phenocrysts (about 1 percent) are much less abundant. Subhedral to euhedral mafic-silicate-mineral phenocrysts ( 6 percent, low- and intermediate-sulfidation deposits; 10 percent, high-sulfidation deposits) include varying combinations of pyroxene, hornblende, biotite, and rarely olivine. Abundances of these minerals are limited to several percent and none is systematically more abundant among igneous rocks associated with epithermal deposits. These rocks also include 1 to 2 percent subhedral to anhedral crystals of opaque oxide minerals and varying combinations of fine-grained accessory minerals, including apatite, titanite, and zircon. Hypabyssal intrusive rocks associated with epithermal deposits range from porphyritic rocks (porphyries) having phenocrysts in a quenched groundmass to fine- to coarse-grained holocrystalline, equigranular through porphyritic rocks; minerals present in these intrusive rocks are similar to phenocryst species characteristic of the volcanic rocks.

\section{Textures and Structures}

Textures and structures of igneous rocks associated with epithermal deposits are also as varied as their compositions. Most associated volcanic rocks are porphyritic. In some lava flow rocks, in particular, phenocrysts are trachytically aligned and some volcanic rocks are vesicular. Caldera-related ash-flow tuffs associated with these deposits have a groundmass that includes variably preserved glass shards. Compaction foliation in these rocks results from variable welding. Similarly, some commonly nearly aphyric rhyolite lava flows associated with epithermal deposits are intensely flow laminated and exhibit convoluted flow fabrics.

Coarse, typically poorly sorted breccias that are common constituents of many of the composite stratovolcanoes associated with epithermal deposits primarily reflect deposition as either debris-flow or block-and-ash flow deposits. Most debris-flow deposits are compositionally heterogeneous, have a matrix that includes a significant clay-size component, and represent eruptive products fluidized by interaction with water and (or) ice; gravitational instability leads to subsequent flowage down the flanks of associated volcanoes. In contrast, compositionally homogeneous block-and-ash deposits result from the mechanical disaggregation of growing lava domes; as lava dome complexes swell and their outer quenched rinds disintegrate and collapse, cognate blocks mix with and are surrounded by a matrix consisting of finely comminuted ash produced during lateral flow down oversteepened slopes.

\section{Grain Size}

Like phenocryst abundances and mineralogy, the grain size characteristic of individual volcanic rocks associated with epithermal deposits primarily reflect physicochemical conditions prevailing during magma solidification and consequently are highly variable. More rapidly cooled or pressure-quenched magmas have smaller phenocrysts than those typical of more slowly cooled magmas. The Bodie Hills volcanic field (John and others, 2015a) includes about two dozen diverse eruptive centers. Its products are reasonably representative of igneous rocks associated with epithermal deposits and constitute the principal source of grain-size information summarized below. Plagioclase laths, 2 to $10 \mathrm{~mm}$ long, are typically the most coarse-grained phenocrysts in igneous rocks associated with epithermal deposits. Less abundant alkali feldspar and quartz phenocrysts are commonly a bit finer grained and $1-3 \mathrm{~mm}$ in size. Phenocrysts of the mafic silicate minerals are typically $1-4 \mathrm{~mm}$ in size. Opaque 
oxide minerals and accessory minerals form crystals from 0.01 to as much as $0.5 \mathrm{~mm}$ long. Aside from groundmass constituents, crystals in the hypabyssal intrusive rocks are uniformly somewhat larger than those characteristic of associated volcanic rocks. However, given solidification of associated magmas in the shallow subsurface, these rocks rarely attain the coarse grain sizes $(5-10 \mathrm{~mm})$ that are typical of more slowly cooled plutonic rocks.

\section{Petrochemistry}

Major oxide characteristics of igneous rocks associated with epithermal deposits are largely consistent with a genesis involving subduction-related magmatism. More than 95 percent of these rocks are subalkaline (Irvine and Baragar, 1971) (fig. M1). The majority are also metaluminous (Shand, 1951) to weakly peraluminous (molar $\mathrm{Al}_{2} \mathrm{O}_{3} /\left[\mathrm{Na}_{2} \mathrm{O}+\mathrm{K}_{2} \mathrm{O}+\mathrm{CaO}\right]$ $\leq 1.1$ ), and none are peralkaline (molar $\left[\mathrm{Na}_{2} \mathrm{O}+\mathrm{K}_{2} \mathrm{O}\right] / \mathrm{Al}_{2} \mathrm{O}_{3}$ $\geq 1.0$; fig. M3). A small number of samples that are moderately peraluminous (molar $\mathrm{Al}_{2} \mathrm{O}_{3} /\left[\mathrm{Na}_{2} \mathrm{O}+\mathrm{K}_{2} \mathrm{O}+\mathrm{CaO}\right] \geq 1.1$ ) probably result from undetected alkali loss (particularly $\mathrm{Na}_{2} \mathrm{O}$ and $\mathrm{CaO}$ ) associated with weak alteration in the halo of associated ore-forming systems (Warren and others, 2007). Samples with 50 to about 65 weight percent $\mathrm{SiO}_{2}$ have compositions that are calcic to calc-alkalic (fig. M4), whereas samples with more than 65 weight percent $\mathrm{SiO}_{2}$ are generally calc-alkalic to alkali-calcic (Frost and others, 2001). Although the preponderance of these rocks are calc-alkaline (magnesian), a significant subset at the full range of $\mathrm{SiO}_{2}$ abundances are tholeiitic (ferroan) (Frost and others, 2001; fig. M5).

$\mathrm{SiO}_{2}$ abundances of these rocks range essentially continuously from about 48 to 78 weight percent. However, samples with 65 to 70 weight percent $\mathrm{SiO}_{2}$ are somewhat less abundant than those with higher or lower silica contents and a disproportionate number of samples have $\mathrm{SiO}_{2}$ contents that cluster between 55 and 65 weight percent $\mathrm{SiO}_{2}$ (fig. M1). Igneous rocks associated with low- and intermediate-sulfidation epithermal deposits have $\mathrm{SiO}_{2}$ contents that range continuously to as low as about 48 weight percent $\mathrm{SiO}_{2}$, but the principal igneous rock population associated with high-sulfidation epithermal deposits only extends to about 54 weight percent $\mathrm{SiO}_{2}$; only two samples associated with high-sulfidation deposits contain $\leq 54$ weight percent $\mathrm{SiO}_{2}$. The fact that silica contents of igneous rocks associated with low- and intermediatesulfidation deposits range to values about six percent lower than those of igneous rocks associated with high-sulfidation deposits is a minor distinction but is the principal geochemical difference between igneous rocks associated with the two epithermal deposit types. Concentrations of $\mathrm{TiO}_{2}$ and $\mathrm{P}_{2} \mathrm{O}_{5}$ vary considerably at lower $\mathrm{SiO}_{2}$ abundances but scatter less and decrease to lower values at higher $\mathrm{SiO}_{2}$ contents. Concentrations of $\mathrm{FeO}^{*}$ (total $\mathrm{Fe}$ as $\mathrm{FeO}$ ), $\mathrm{CaO}$, and $\mathrm{MnO}$ decrease linearly with increasing $\mathrm{SiO}_{2}$. $\mathrm{Al}_{2} \mathrm{O}_{3}$ abundances also decrease with increasing $\mathrm{SiO}_{2}$, but a significant subset of the igneous rocks associated with low- and intermediate-sulfidation epithermal deposits that contain $\leq 60$ weight percent $\mathrm{SiO}_{2}$ have anomalously low $\mathrm{Al}_{2} \mathrm{O}_{3}$ abundances at any given silica content. The petrogenesis of this sample subset, which consists of mafic lava flow rocks in the Coromandel volcanic zone (New Zealand) and Great Basin Province (United States), was clearly distinct from that of other igneous rocks associated with epithermal mineral deposits. Abundances of $\mathrm{MgO}$ decrease in a systematic but curvilinear fashion with increasing $\mathrm{SiO}_{2}$ to produce a concave-up data array. $\mathrm{Na}_{2} \mathrm{O}$ abundances vary widely and seem to increase among samples with less than about 65 weight percent $\mathrm{SiO}_{2}$ and then decrease somewhat in samples with the highest $\mathrm{SiO}_{2}$ contents. Abundances of $\mathrm{K}_{2} \mathrm{O}$ increase broadly with increasing $\mathrm{SiO}_{2}$ content, forming a data array astride the medium- to high-potassium (Gill, 1981) divide in samples with $\leq 65$ weight percent $\mathrm{SiO}_{2}$; samples with $\mathrm{SiO}_{2}$ abundances $\geq 65$ weight percent have $\mathrm{K}_{2} \mathrm{O}$ abundances largely coincident with the high-potassium field (du Bray, 2017).

\section{Trace-Element Geochemistry}

Igneous rocks associated epithermal deposits have largeion lithophile element and low high-field-strength element abundances similar to those of other subduction-related and back-arc extension magmatic systems. Abundances of $\mathrm{Cs}, \mathrm{Rb}$, $\mathrm{Th}, \mathrm{U}$, and Ta increase significantly and systematically with increasing silica content, whereas abundances of $\mathrm{Ba}, \mathrm{Nb}, \mathrm{La}$, and $\mathrm{Pb}$ are highly variable but increase slightly with increasing silica content. In contrast, abundances of $\mathrm{Sr}, \mathrm{Y}, \mathrm{Ga}, \mathrm{Co}, \mathrm{Sc}, \mathrm{V}$, and $\mathrm{Zn}$ decrease systematically with increasing silica content, and abundances of $\mathrm{Cr}, \mathrm{Ni}$, and $\mathrm{Cu}$ are highly variable but decrease slightly with increasing silica content. Abundances of $\mathrm{Zr}$ increase in samples with 48 to about 70 weight percent $\mathrm{SiO}_{2}$ and then decrease with increasing silica content. Abundances of $\mathrm{Hf}, \mathrm{Mo}, \mathrm{Sn}$, and $\mathrm{W}$ display no consistent variation with varying $\mathrm{SiO}_{2}$ content.

Rare-earth element (REE) abundances in igneous rocks associated with epithermal deposits are typical of subductionrelated, calc-alkaline igneous rocks. REE patterns for these rocks have negative slopes and most have only weakly developed negative europium anomalies. Total REE contents of these samples exhibit no consistent variation with variable silica content. Values of $(\mathrm{La} / \mathrm{Yb})_{\mathrm{N}}$ are somewhat inconsistent with varying silica content but seem to increase in samples with 48 to about 65 weight percent $\mathrm{SiO}_{2}$; in samples with higher $\mathrm{SiO}_{2}$ contents, values of $(\mathrm{La} / \mathrm{Yb})$ vary inconsistently with respect to increasing silica content. Values of $\mathrm{Eu} / \mathrm{Eu}^{*}$ $\left(\mathrm{Eu} / \mathrm{Eu}^{*}=\mathrm{Eu}_{\mathrm{N}} /\left[\mathrm{Sm}_{\mathrm{N}}+\mathrm{Gd}_{\mathrm{N}}\right] / 2\right)$ in most igneous rocks associated with epithermal deposits decrease from values of about 0.9 at 50 weight percent $\mathrm{SiO}_{2}$ to about 0.5 at 77 weight percent $\mathrm{SiO}_{2}$ probably as a consequence of more significant plagioclase fractionation among magmas represented by increasingly felsic igneous rocks associated with epithermal deposits.

Abundances of metals (especially $\mathrm{Cu}, \mathrm{Pb}$, and $\mathrm{Zn}$ ) in igneous rocks associated with epithermal deposits (du Bray, 2014) are 


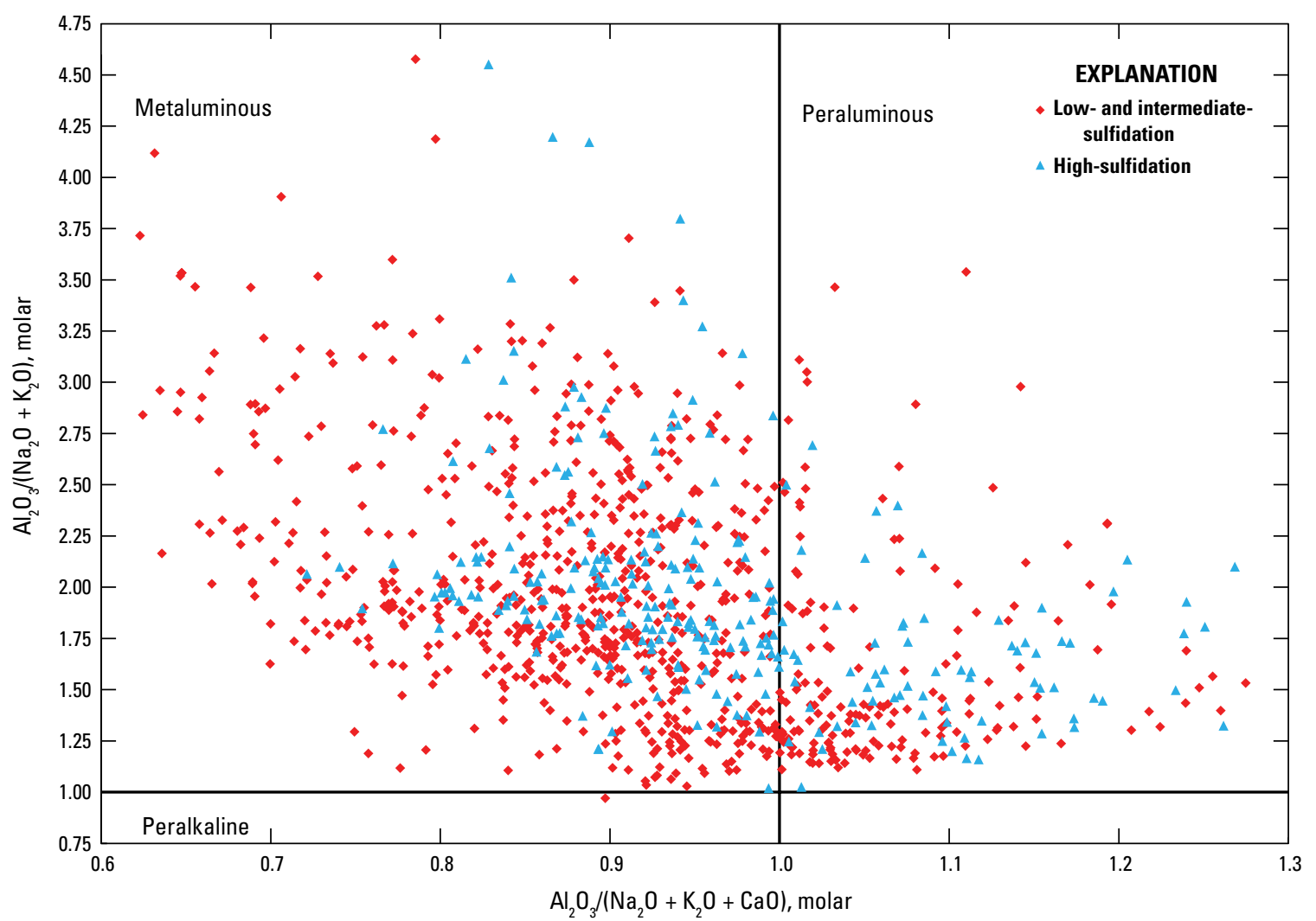

Figure M3. Variation diagram showing molar major-oxide compositions of igneous rocks associated with low- and intermediate-sulfidation and high-sulfidation epithermal mineral deposits as a function of relative alumina and alkali saturation.

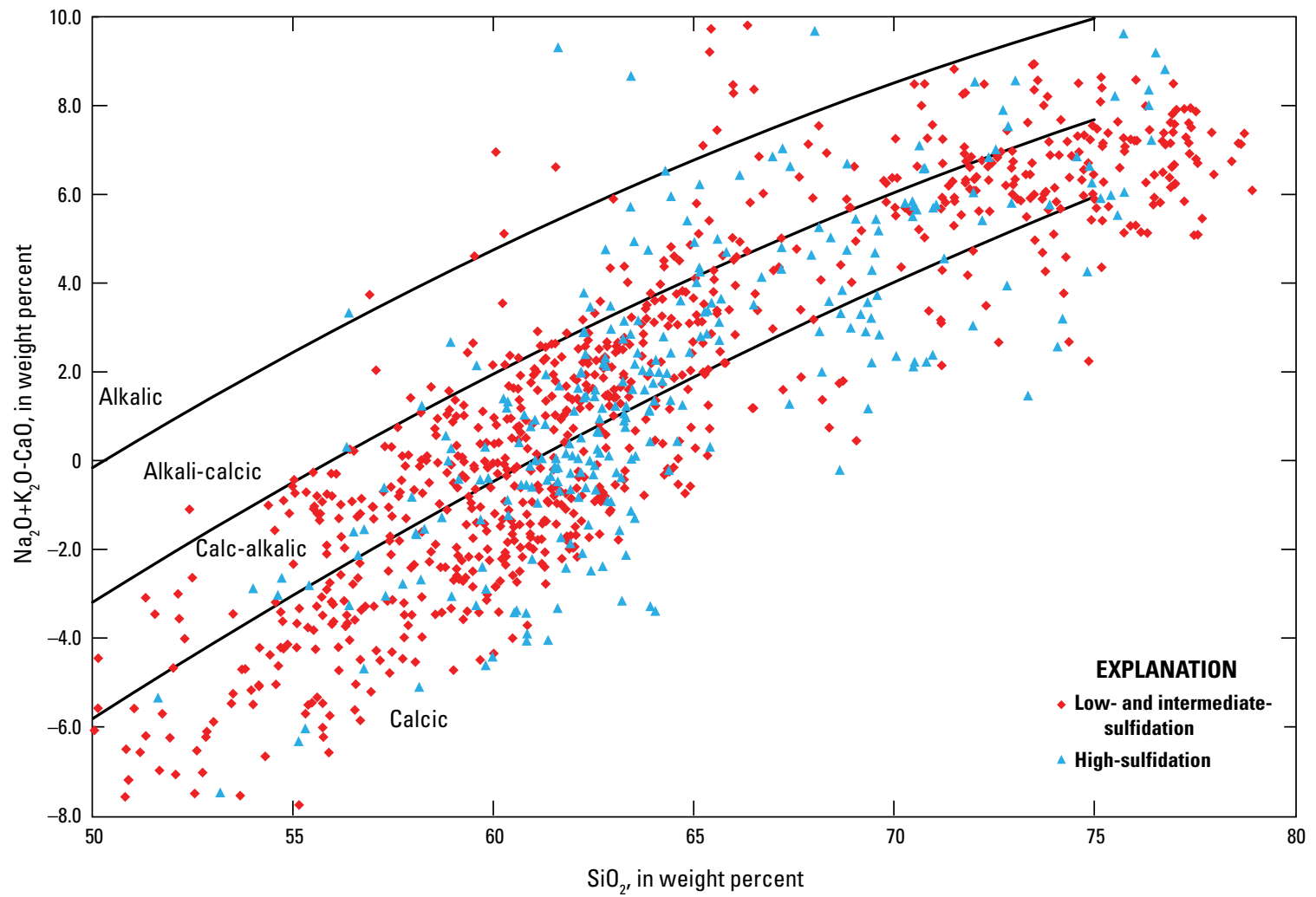

Figure M4. $\mathrm{Na}_{2} \mathrm{O}+\mathrm{K}_{2} \mathrm{O}-\mathrm{CaO}$ versus $\mathrm{SiO}_{2}$ variation diagram showing the composition of igneous rocks associated with low- and intermediate-sulfidation and high-sulfidation epithermal mineral deposits. Boundaries between various rock series from Frost and others (2001). 


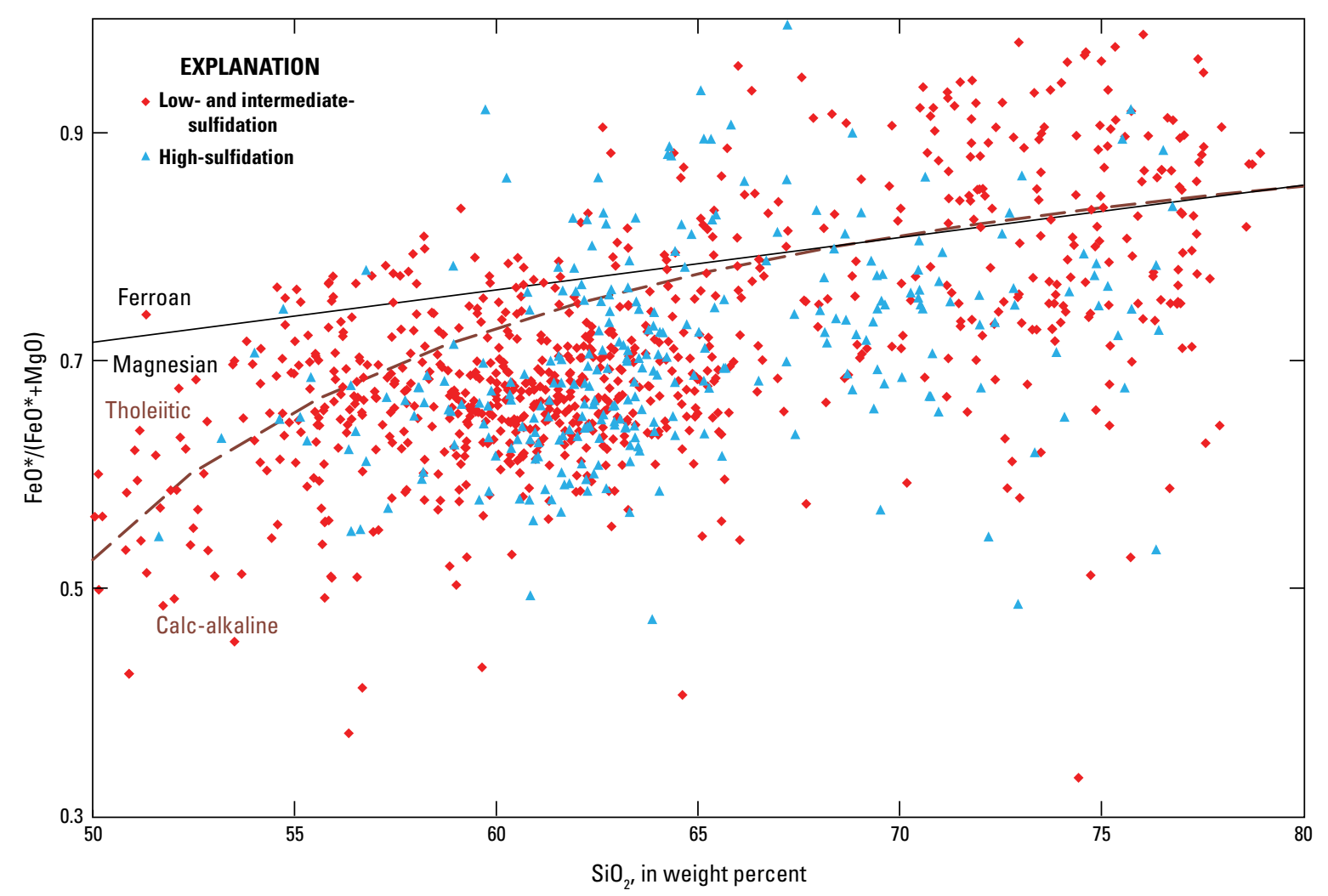

Figure M5. $\mathrm{FeO} /(\mathrm{Fe} 0+\mathrm{MgO})$ variation diagram showing the composition of igneous rocks associated with low- and intermediate-sulfidation and high-sulfidation epithermal mineral deposits relative to boundaries between ferroan and magnesian rocks as well as between tholeiitic and calc-alkaline rocks. Ferroan versus magnesian boundary (black line) from Frost and others (2001), tholeiitic versus calc-alkaline boundary (dashed brown line) from Miyashiro (1974).

within the bounds defined by average abundances (Turekian and Wedepohl, 1961) for basaltic and granitic rocks; highly anomalous abundances are very uncommon but may reflect unidentified or poorly characterized hydrothermal processes. Abundances of molybdenum in about half of these samples are comparable with those characteristic of basaltic and granitic rocks; however, the remaining samples, representative of igneous rocks associated with low- and intermediate-sulfidation and high-sulfidation deposits, appear to have anomalous values that range from about 3 to as high as $14 \mathrm{ppm}$. Abundance data for other metals, including Sn, W, Ag, and Au, are sparse (du Bray, 2014) and lack sufficient precision to allow an evaluation of whether igneous rocks associated with epithermal deposits contain elevated abundances of these components.

Trace element characteristics help constrain the petrogenesis of igneous rocks associated with epithermal deposits. Wood and others (1979) and Gill (1981) established that $\mathrm{Ba} / \mathrm{Ta}, \mathrm{Ba} / \mathrm{Nb}$, and $\mathrm{La} / \mathrm{Nb}$ ratios for modern arc rocks are more than 450 , more than 26 , and 2 to 7 , respectively. Average $\mathrm{Ba} / \mathrm{Ta}, \mathrm{Ba} / \mathrm{Nb}$, and $\mathrm{La} /$ $\mathrm{Nb}$ ratios for igneous rocks associated with epithermal deposits are 1332, 104, and 4 (low- and intermediate-sulfidation deposits) and 1706, 95, and 4 (high-sulfidation deposits), respectively; and further document the subduction-related nature of these rocks. More than half of these rocks have adakitic compositions with
$\mathrm{Sr} / \mathrm{Y}>20$ (Defant and Drummond, 1993). These compositions are consistent with subduction-related partial melting at elevated, plagioclase-unstable, garnet-stable pressures beneath thick continental crust and subsequent hornblende fractionation (Sisson, 1994). Values of $(\mathrm{Sr} / \mathrm{P})_{\mathrm{N}}$ for most igneous rocks associated with epithermal deposits range from about 0.5 to 5 , whereas Borg and others (2002) suggest that subduction-related magmas with a fluid component derived from subducted-slab dehydration have $(\mathrm{Sr} / \mathrm{P})_{\mathrm{N}}>5.5$. Consequently, petrogenesis of most of the igneous rocks associated with epithermal deposits does not seem to involve significant slab-fluid inputs. Finally, among igneous rocks associated with epithermal deposits, $\mathrm{CaO} /$ $\mathrm{Al}_{2} \mathrm{O}_{3}$ decreases, and $\mathrm{La} / \mathrm{Sm}$ and $\mathrm{Zr} / \mathrm{Sm}$ increase with increasing $\mathrm{SiO}_{2}$, which Cousens and others (2008) suggested reflects increased amounts of crustal contamination. Similarly, values of $\mathrm{P}_{2} \mathrm{O}_{5} / \mathrm{K}_{2} \mathrm{O}$ systematically increase with increasing $\mathrm{MgO}$, which is consistent with contamination of mantle-derived partial melts by crustal assimilation (Farmer and others, 2002).

\section{Isotope Geochemistry}

As summarized by Simmons and others (2005), epithermal deposits are the shallow manifestations of intrusion-centered hydrothermal systems. For example, volcanic-rock-hosted 
epithermal ore deposits in the Yanacocha district (Peru) are known to overlie an array of epizonal intrusions, which, in turn, host genetically related porphyry copper-gold deposits (Gustafson and others, 2004; Harvey and others, 1999; Teal and Benavides, 2010). Consequently, because many high-sulfidation and some intermediate-sulfidation epithermal deposits are spatially and temporally associated with deeper seated porphyry copper deposits, and because the two deposit types are the products of districtscale magmatism, the particular igneous rocks associated with both deposit types share many characteristics, including isotopic compositions. The isotopic systematics of igneous rocks associated with epithermal and porphyry copper deposits are dominated by the tectonic and magmatic processes that prevail in their convergent margin settings; ultimately, high-sulfidation, and to a lesser extent, intermediate-sulfidation epithermal and porphyry copper deposits are manifestations of and reflect arc magmatic processes. The following observations concerning relative isotopic abundances in fresh igneous rocks associated with epithermal ore deposits were gleaned from an isotopic data compilation (appendix 3) derived from a variety of published sources.

\section{Radiogenic Isotopes}

The updated and comprehensive porphyry copper deposit model prepared by John and others (2010) summarizes the utility and implications of radiogenic isotope data relative to petrogenesis of associated igneous rocks. Most concepts and observations relative to the use of radiogenic isotope abundances in establishing the petrogenesis of subduction-related magmatic rocks associated with porphyry copper deposits are equally applicable, and consequently not restated, to understanding the history of magmas associated with high-sulfidation and, to a lesser extent, intermediate-sulfidation epithermal deposits. Importantly, radiogenic isotope data provide insights into the tectonic setting, age, source, and degree to which primary mantle-derived magmas are contaminated by crustal elements during their transit through continental crust. Relative radiogenic isotopic abundances of lead, strontium, and neodymium are those most commonly determined and employed in petrogenetic investigations; similarly, these are the systems considered relevant to genesis of igneous rocks associated with epithermal ore deposits. Three principal conclusions about the relative abundances of radiogenic isotopes in fresh igneous rocks associated with epithermal ore deposits are immediately obvious (figs. M6-M9):

1. Radiogenic isotopic compositions for the low- and intermediate-sulfidation and high-sulfidation epithermal deposit variants are essentially indistinguishable.

2. Radiogenic isotopic data for epithermal-deposit-associated igneous rocks are essentially indistinguishable from those of igneous rocks associated with porphyry copper deposits.

3. Radiogenic isotopic data for igneous rocks associated with epithermal deposits are indistinguishable from those of most other subduction-related magmatic arc igneous rocks and are non-diagnostic of mineralized systems.

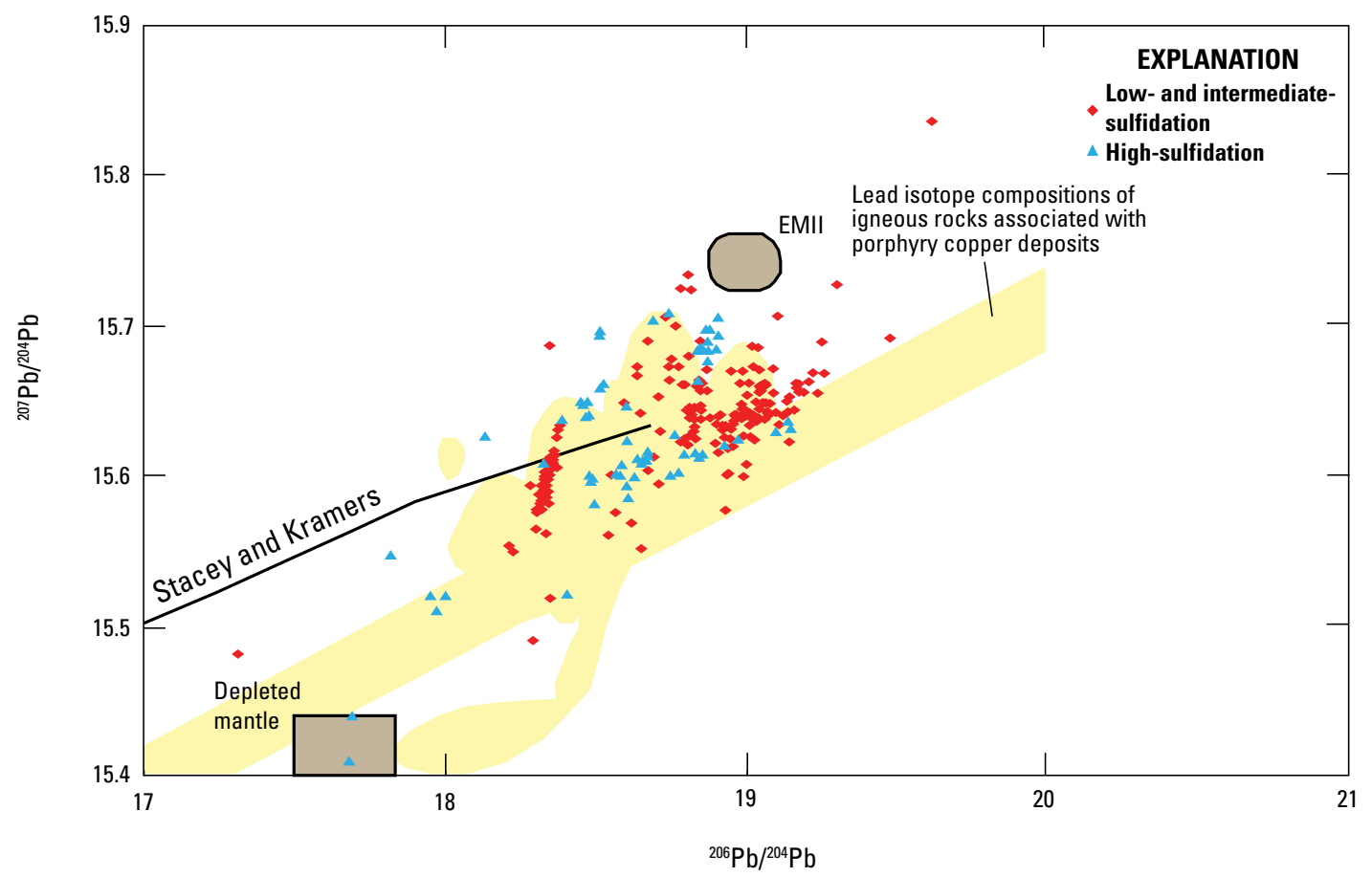

Figure M6. ${ }^{207} \mathrm{~Pb} /{ }^{204} \mathrm{~Pb}-{ }^{206} \mathrm{~Pb} / 204 \mathrm{~Pb}$ diagram showing compositions of igneous rocks associated with lowand intermediate-sulfidation and high-sulfidation epithermal deposits. Sources of data given in appendix 3. Also plotted for reference are the crustal lead evolution curve of Stacey and Kramers (1975) and a field for enriched mantle (EMII) from Zindler and Hart (1986). 


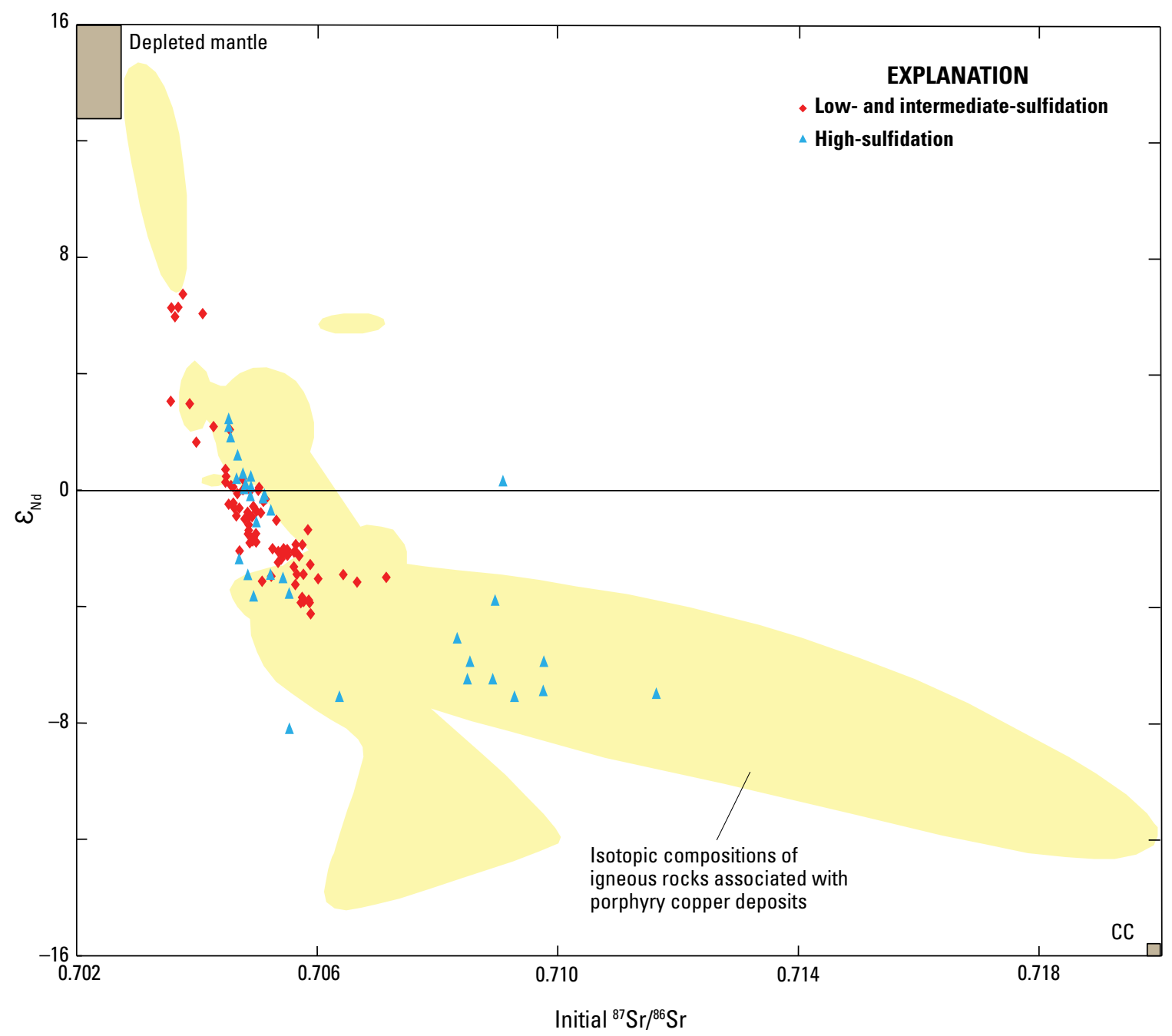

Figure M7. Neodymium-strontium isotope compositions of igneous rocks associated with low- and intermediatesulfidation and high-sulfidation epithermal deposits. Data sources given in appendix 3 . Average continental crust (CC) has ${ }^{87} \mathrm{Sr} /{ }^{86} \mathrm{Sr}$ about 0.720, and ${ }^{143} \mathrm{Nd} /{ }^{144} \mathrm{Nd}$ about 0.5118 (Hofmann, 1997; Rudnick and Gao, 2003).

\section{Oxygen Isotopes}

Stable isotopic investigations of fresh igneous rocks associated with epithermal deposits are largely restricted to oxygen isotope relative abundances. Unfortunately, relatively few $\delta^{18} \mathrm{O}$ analyses are available for these rocks (appendix 3, fig. M10). Although $\delta^{18} \mathrm{O}$ data for igneous rocks associated with high-sulfidation deposits are very scarce (two samples), available information suggests that $\delta^{18} \mathrm{O}$ compositions of igneous rocks associated with low- and intermediate-sulfidation deposits are indistinguishable from those associated with high-sulfidation deposits (fig. M10). As defined in $\delta^{18} \mathrm{O}$ data compilations (Bindeman, 2008; Taylor, 1968), most common igneous rocks whose petrogenesis is dominated by mantle inputs have $\delta^{18} \mathrm{O}$ values that are largely restricted to the 6.5 to $10 \%$ range; igneous rocks associated with epithermal deposits have $\delta^{18} \mathrm{O}$ values that largely correspond with this range. Epithermal-deposit-associated igneous rocks with $\delta^{18} \mathrm{O}$ values in the upper part of this range, especially sedimentary rocks that interacted with seawater at low temperatures (Bindeman, 2008), must have assimilated at least some ${ }^{18} \mathrm{O}$-enriched sialic crustal contaminants. In contrast, the single igneous rock sample associated with a low- or intermediate-sulfidation epithermal deposit has a very low $\delta^{18} \mathrm{O}$ value $(2.1 \%$ ) and was probably hydrothermally altered and exchanged with isotopically light meteoric water.

\section{Depth of Emplacement}

Epithermal deposits form in the shallow parts of hydrothermal systems (Simmons and others, 2005), in nearsurface environments, at paleodepths less than about 1,500 m. Several types of data, especially local-scale stratigraphic reconstructions of the volcanic rocks associated with these deposits and depth estimates gleaned from fluid inclusion analyses, 


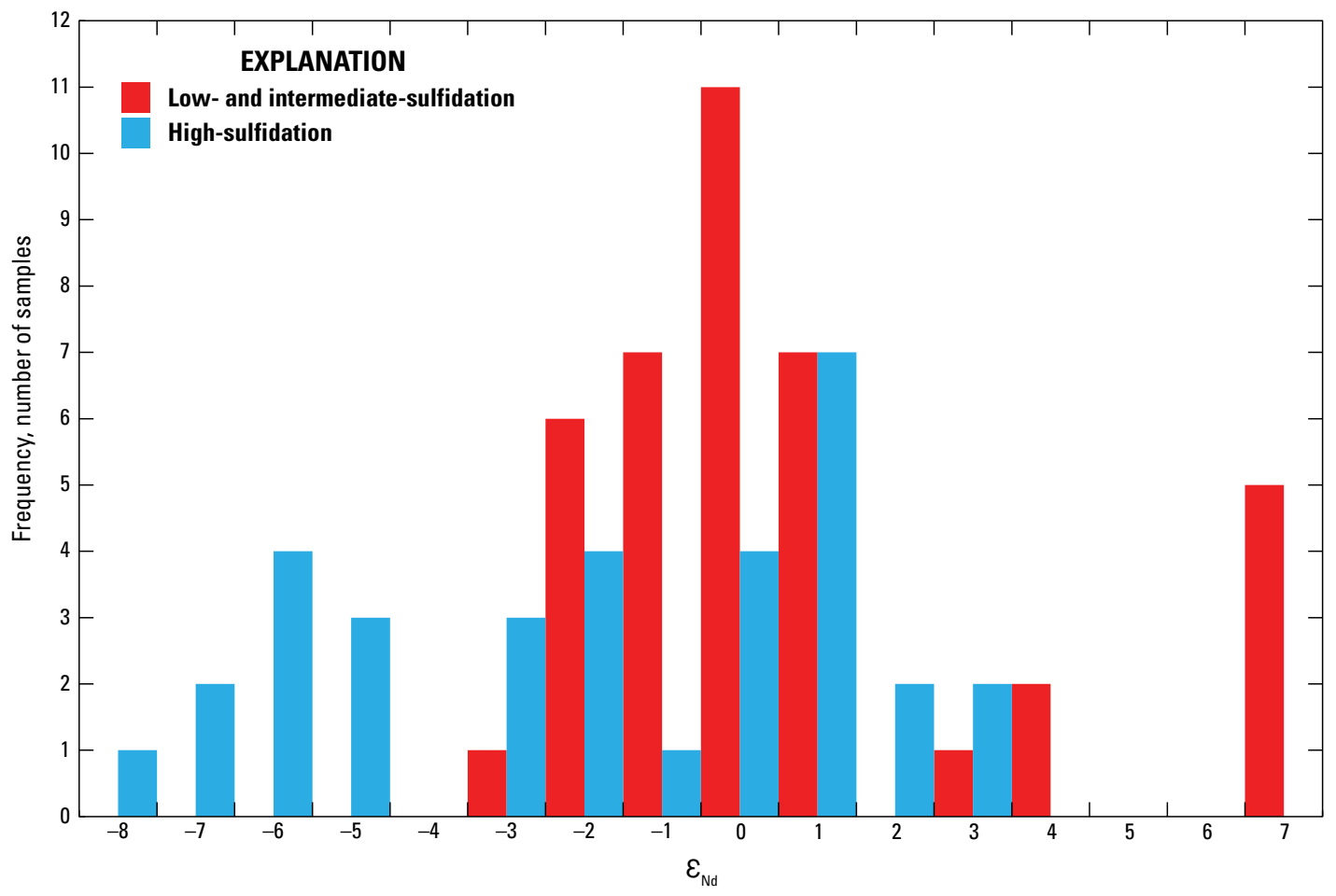

Figure M8. Histogram showing the frequency distribution of samples of igneous rocks associated with low- and intermediate-sulfidation and high-sulfidation epithermal mineral deposits as a function of $\varepsilon_{\mathrm{Nd}}$ values.

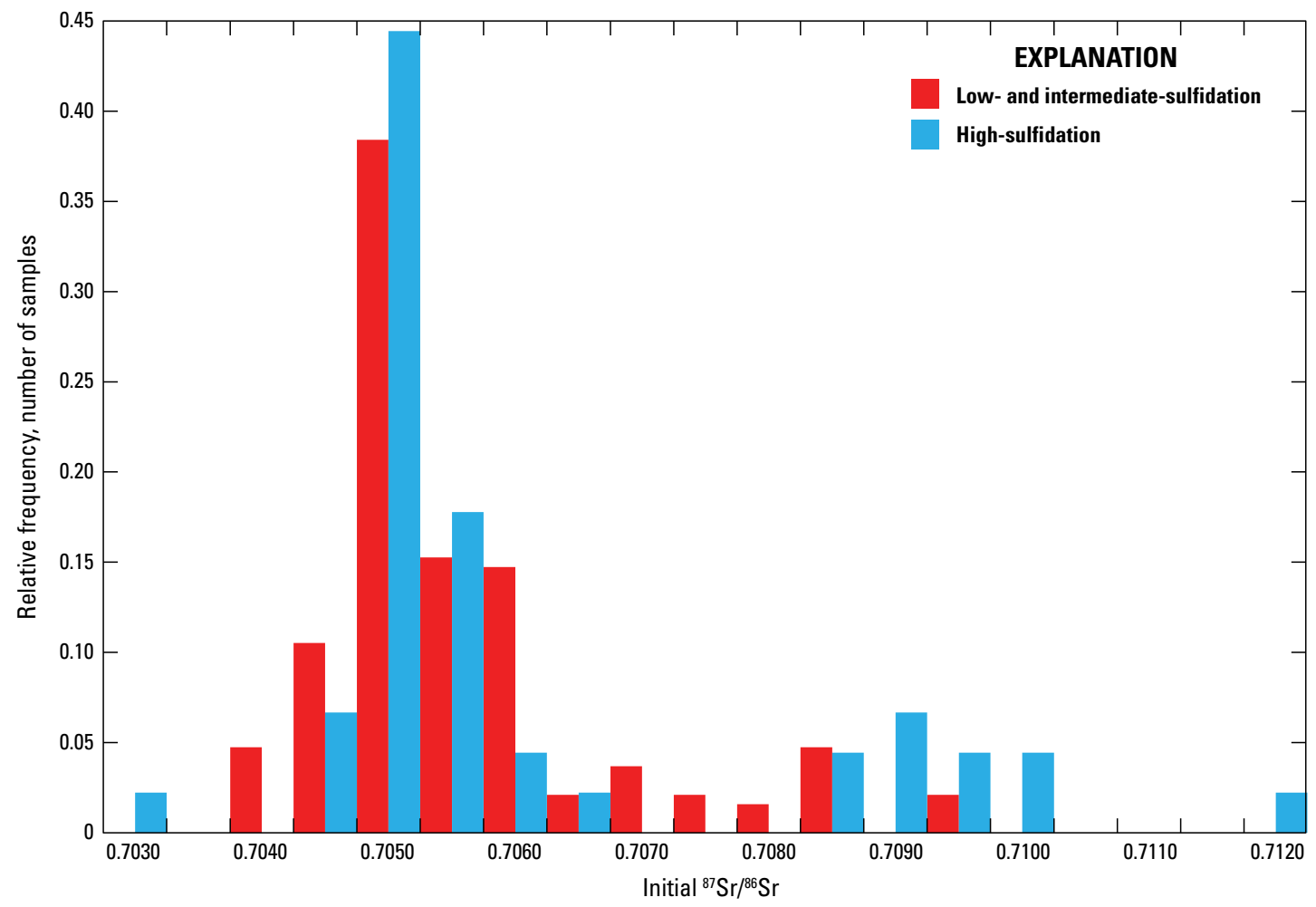

Figure M9. Histogram showing the frequency distribution of samples of igneous rocks associated with low- and intermediate-sulfidation and high-sulfidation epithermal mineral deposits as a function of initial ${ }^{87} \mathrm{Sr} /{ }^{86} \mathrm{Sr}$ values. 


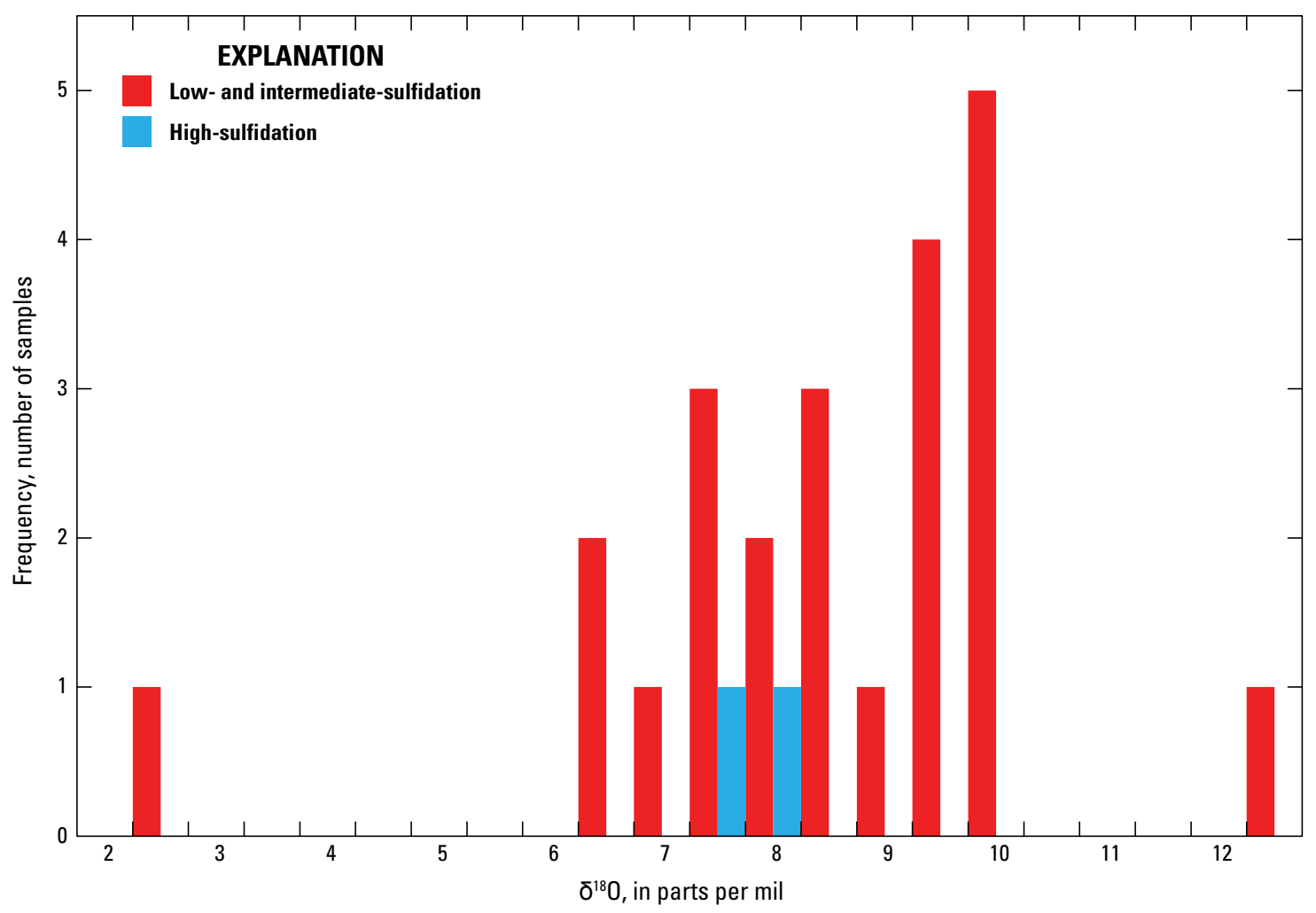

Figure M10. Histogram showing the frequency distribution of samples of igneous rocks associated with low- and intermediate-sulfidation and high-sulfidation epithermal mineral deposits as a function of $\delta^{18} 0$.

have been used to constrain the depth at which epithermal deposits form. The combined evidence, as summarized by Simmons and others (2005), indicates that these deposits form within 50 to about $1,500 \mathrm{~m}$ depth below the prevailing paleowater table. Standard fluid inclusion pressure estimates indicate epithermal deposit formation at depths limited to 50 to about $1,100 \mathrm{~m}$, but these results may be low by as much as several hundred meters if the analyzed fluid inclusions contain any dissolved $\mathrm{CO}_{2}$
(Hedenquist and Henley, 1985a). Most epithermal deposits form in an environment in which ambient conditions are governed by the hydrostatic pressure gradient; consequently, any geologic process that perturbs the water table level similarly affects the depth at which epithermal deposits form. Available data indicate that ore deposition extends through a vertical range of tens to more than a thousand meters (see "Fluid Inclusion Petrography, Thermometry, and Geochemistry"; appendix 1). 


\title{
Chapter N. Petrology of Associated Sedimentary Rocks
}

\author{
By Edward A. du Bray
}

Sedimentary rocks are not an intrinsic component of oreforming systems associated with the genesis of most epithermal mineral deposits (Simmons and others, 2005), although some of these deposits are sedimentary rock hosted. Factors that contribute to sedimentary rocks hosting these deposits are those critical to formation of essentially any hydrothermal ore deposit. Features most important to enhancing the potential for sedimentary rocks to host epithermal deposits include geochemical reactivity, hydrothermal fluid conductivity, and the ability to maintain open fractures developed in response to local tectonic conditions. Because hydrothermal fluids precipitate dissolved ore metals when and where significant changes in the physicochemical environment conducive to ore deposition are encountered, sedimentary rocks that present redox, geochemical, temperature, or pressure contrasts to hydrothermal fluids with which they interact constitute favorable environments for ore deposition. For instance, the abundance of highly reactive carbonate-rich rocks was critical to the formation of epithermal deposits at Cerro de Pasco (Einaudi, 1977). Sedimentary rocks most favorable for hosting epithermal deposits are those that achieve a suitable balance of ore fluid transmissivity. Rocks with excessive permeability, such as those in the Red Wash Creek area of the northern Bodie Hills, California (John and others, 2015a; Vikre and others, 2015), allow wide dissemination of ore fluids, resulting in low-grade metal accumulations. In contrast, highly permeable fanglomerates at Hycroft, Nevada, were an effective host for the epithermal mineralization in the Sulphur district (Ebert and Rye, 1997). Sedimentary rocks that are either too soft to sustain through-going fractures, or those that are strong and resist fracture formation, have low potential to host epithermal mineral deposits. The well-developed fracture network in volcaniclastic rocks of Aurora, Nevada (John and others, 2015a; Vikre and others, 2015), was critical to formation of epithermal vein deposits in that district. Finally, the potential for sedimentary rocks to host highand intermediate-sulfidation epithermal deposits is low, because most of these deposits are associated with large-volume volcanism that results in thick accumulations of volcanic rock that inundates and buries all other rocks, including sedimentary rocks. and these deposits form in shallow, near-surface environments, well above the pre-volcanic terrane. However, most low-sulfidation epithermal deposits form distal to volcanic centers and therefore may be hosted in sedimentary rocks. 



\title{
Chapter O. Petrology of Associated Metamorphic Rocks
}

\author{
By Edward A. du Bray
}

As is true for sedimentary rocks, metamorphic rocks are not an intrinsic component of ore-forming systems associated with the genesis of high- and intermediate-sulfidation epithermal deposits, although they do rarely host deposits of this type. The same rock characteristics that enhance the potential for sedimentary rocks to host high- and intermediate-sulfidation epithermal deposits also apply to the favorability of metamorphic rocks hosting these deposits. The likelihood of metamorphic rocks hosting high- and intermediate-sulfidation epithermal deposits is also limited by the strong association of these deposits with voluminous, thick accumulations of volcanic rock and the general tendency for these deposits to develop in near-surface environments. However, most low-sulfidation epithermal deposits form distal to volcanic centers and therefore may be hosted in metamorphic rocks. 



\title{
Chapter P. Theory of Deposit Formation
}

\author{
By Peter G. Vikre and David A. John
}

\section{Ore Deposit System Affiliations}

By David A. John

Epithermal gold-silver deposits form in the shallow, upper parts of hydrothermal systems in a variety of geotectonic environments, each of which may have several types of associated ore deposits (fig. C1; appendix 1; see "Brief Description" and "Regional Environment").

Most epithermal deposits form in subduction-related convergent margin arcs, in continental and oceanic settings, and some may be parts of larger porphyry copper systems (Sillitoe, 2010). In addition to epithermal gold-silver deposits and porphyry copper deposits, porphyry copper systems may include skarn deposits (including $\mathrm{Cu}, \mathrm{Fe}$, $\mathrm{Au}$, and $\mathrm{Zn}$ types), polymetallic replacement and manto deposits, polymetallic and Cordilleran vein deposits, distal disseminated gold-silver and (or) Carlin-like gold deposits, and stratiform sulfur deposits.

In the Bolivian tin belt, epithermal silver-antimony \pm tin veins and disseminated mineralization, including Cerro Rico de Potosi, the world's largest silver deposit, are hosted in vuggy residual quartz alteration in lithocaps formed in rhyodacite domes (Sillitoe and others, 1998). The epithermal silver deposits are underlain by polymetallic massive sulfide veins containing tin, tungsten, bismuth, and base metals, and are associated with quartz-tourmaline and sericitic alteration. These deposits formed from reduced magmas in a compressional back-arc setting (Sillitoe and Hedenquist, 2003).

Middle Miocene low-sulfidation gold-silver deposits of the northern Nevada rift formed in an extensional back-arc or continental rift setting and are associated with bimodal basalt-rhyolite volcanism related to the Yellowstone Hot Spot or mantle plume magmatism (John, 2001; Saunders and others, 2008). In addition to the precious metal and mercury hot spring deposits, several types of deposits are associated with rhyolite domes, calderas, and caldera moat sediments derived from the rhyolites, including deposits mined for uranium, lithium, gallium, and tin.

In areas of postsubduction continental extension, such as the northern Great Basin, western United States, epithermal gold-silver deposits, formed by deep circulation of groundwater along basin-bounding faults, are associated with hot spring mercury, stratiform sulfur, and alunite vein deposits (for example, Hycroft [Sulphur] and Florida Canyon, Nevada, Ebert and Rye, 1997; Fifarek and others, 2011).

\section{Controls on Permeability and Fluid Flow}

\author{
By David A. John
}

Fluid flow between metal sources and ore deposition sites in hydrothermal systems is controlled by gradients in fluid pressure, buoyancy effects, and the permeability structure (Cox and others, 2001). High permeability and high pressure gradients lead to high fluid-flow rates that result in large heat, solute, and metal fluxes favorable to formation of epithermal deposits (Ingebritsen and Appold, 2012). However, because high permeability is a shortlived feature relative to the life span of typical hydrothermal systems, fluid flow paths are transient features and periods of high fluid flow are episodic and generally related to increases in fracture permeability resulting from seismic or magmatic events (Rowland and Simmons, 2012).

In subaerial hydrothermal systems that form epithermal goldsilver deposits, pressure is dominantly hydrostatic (hydrodynamic in conduits), and the regional water table controls the hydrostatic pressure gradient (Henley, 1985). Hydrostatic pressure (pressure resulting from the weight of the overlying column of fluid) generally prevails below the water table in water-saturated, permeable rocks and in open, hydraulically conductive fractures. Pressure buildup to greater than hydrostatic values may develop locally where hot fluids ascend into zones of low permeability, by release of magmatic heat from igneous intrusions, or by transmission of higher fluid pressure from a compressible gas cap (mostly steam and $\mathrm{CO}_{2}$ ) that separates during boiling of deep hydrothermal fluids (Hedenquist and Henley, 1985a; Nelson and Giles, 1985). In areas of steep topography, gravity driven flow of cool near-surface fluids prevails, which allows lateral fluid flow and mixing of cold groundwater with hotter upwelling fluids (fig. L1).

Buoyancy forces arise from heating of fluids, most commonly by magma emplacement, crystallization, and release of magmatic vapor, at depths of several to approximately $10 \mathrm{~km}$ (fig. L1). The heated, lower density fluids form buoyant plumes that rise along fractures and faults and may extend to the top of the water table. Where the water table intersects the Earth's surface, the ascending hot fluids may vent and form hot springs (fig. L1). High pore fluid pressure can build up at intersections of the hot, upwelling fluids with low-permeability zones resulting from either low-permeability rocks or by sealing of faults and fractures by mineral deposition (most commonly quartz). Pressure buildup may lead to hydrofracturing and (or) hydrothermal brecciation resulting in increased fracture permeability and renewed fluid flow (see "Hydrothermal Structures" and "Fluid Inclusion Petrography, Thermometry, and Geochemistry"). 
Permeability structure is complex in most hydrothermal systems. Bulk permeability consists of interconnected intergranular porosity (primary permeability) and hydraulically conductive fractures (secondary permeability). Primary permeability varies over many orders of magnitude depending on the rock or sedimentary rock type (Ingebritsen and Manning, 2010) and may vary significantly laterally and vertically because of changes in rock type. Intergranular porosity and permeability also may vary through time because of water-rock interaction and mineral precipitation that fills pore space or mineral dissolution that increases pore space.

In the shallow epithermal environment, there commonly are wide variations in permeability $(k)$ between geologic units and within individual units, such as in variably welded tuffs whose permeability may vary by a factor of $10^{4}$ (Ingebritsen and Manning, 2010). Primary permeability is low in rock types with low interconnected intergranular porosity $(k$ less than approximately $10^{-16} \mathrm{~m}^{2}$ ), such as densely welded tuffs, shales, and weakly fractured granitic and metamorphic rocks, and fluid flow depends on secondary permeability. In contrast, lithologies with high primary permeabilities ( $k$ greater than $\left.10^{-16} \mathrm{~m}^{2}\right)$, such as unwelded tuffs, poorly indurated volcaniclastic and clastic sedimentary rocks, and carbonate rocks, are hydrolytically conductive and hydrothermal fluids flow through them in response to fluid pressure gradients. This latter situation is common in young volcanic fields and in the shallow, unconsolidated parts of sedimentary basins that have not been affected by hydrothermal alteration, deposition of secondary minerals, and reduction of primary permeability. In rocks with high primary permeability, there may be considerable lateral fluid flow from surface waters following topographic (gravity) gradients and from ascending hydrothermal fluids that intersect permeable horizons.

In hydrothermal systems with low intergranular porosity, pore connectivity generally is low, and fluid flow typically is controlled by fracture permeability (for example, Cox and others, 2001; Ingebritsen and Manning, 2010; Rowland and Simmons, 2012). The three-dimensional distribution of fracture permeability is controlled primarily by stress and fluid pressure fields, but may also be influenced by preexisting mechanical anisotropies in the rock mass (Cox and others, 2001). Fracture growth is favored in zones of high pore fluid pressure, which commonly develop where fluids discharge from faults or shear zones beneath lowpermeability flow barriers. Fluid flow is focused within faults and shear zones in areas with the largest fracture apertures and highest fracture density, such as damage zones associated with fault jogs, bends, and splays. Therefore, dilational and contractional bends and jogs on faults and shear zones, as well as fault termination zones (wing cracks and splays) and fault intersections, form structural sites with high potential for localizing fluid flow (fig. E8; Cox and others, 2001; Micklethwaite, 2009; Faulds and others, 2011; Rowland and Simmons, 2012). However, because sealing of fractures by mineral precipitation can be rapid relative to the lifetimes of hydrothermal systems, sustained fluid flow occurs only in active structures where permeability is repeatedly renewed. Therefore, positive feedback between deformation, fluid flow, and fluid pressure promotes fluid-driven growth of hydraulically linked networks of faults, fractures, and shear zones.

\section{Sources of Fluids and Metals}

\author{
By Peter G. Vikre
}

Sources of fluids, primarily water and $\mathrm{CO}_{2}$, from which hydrothermal minerals in epithermal gold-silver deposits derived components and were precipitated, have been interpreted from measured and calculated $\delta \mathrm{D}, \delta^{18} \mathrm{O}$, and $\delta^{13} \mathrm{C}$ values of water, $\mathrm{CO}_{2}$, and hydrothermal minerals. These stable isotope values are either derived from analysis of water and $\mathrm{CO}_{2}$ extracted from fluid inclusions in quartz and other minerals, or calculated from $\delta \mathrm{D}, \delta^{18} \mathrm{O}$, and $\delta^{13} \mathrm{C}$ values of hydrothermal and igneous minerals, experimentally determined fluid-mineral isotope fractionations, and depositional temperatures of hydrothermal and igneous minerals estimated from fluid inclusion microthermometry, mineral assemblages, and paloedepths of analyzed samples (see "Geochemical Characteristics").

Based on stable isotope analyses, waters that formed lowand intermediate-sulfidation deposits were primarily meteoric waters that variably exchanged $\delta \mathrm{D}$ and $\delta^{18} \mathrm{O}$ with minerals in wall rocks and subjacent rocks, and lesser mixtures of meteoric and magmatic waters. The dominance of meteoric water in the formation of many low- and intermediate-sulfidation deposits is reflected by $\delta^{18} \mathrm{O}$ "depletion" in altered wall rocks (Taylor, 1973, 1974, 1997; see "Geochemical Characteristics"). Waters that formed high-sulfidation deposits include magmatic water, meteoric water, mixtures of magmatic and meteoric water, and mixtures of magmatic and "exchanged" meteoric water, in which $\delta \mathrm{D}-\delta^{18} \mathrm{O}_{\text {water }}$ and $\delta \mathrm{D}-\delta^{18} \mathrm{O}_{\text {mineral }}$ variably exchanged before mixing (fig. K10).

Sources of other water solutes, including sulfur (in gases, ions, and complex ions), lead (in ions and complex ions), strontium (in unknown forms), and other elements with radiogenic isotopes, have been estimated by (1) comparison of isotope values $\left(\delta^{34} \mathrm{~S},{ }^{206} \mathrm{~Pb} /{ }^{204} \mathrm{~Pb},{ }^{207} \mathrm{~Pb} /{ }^{204} \mathrm{~Pb},{ }^{208} \mathrm{~Pb} /{ }^{204} \mathrm{~Pb}\right.$, and $\left.{ }^{87} \mathrm{Sr} /{ }^{86} \mathrm{Sr}\right)$ of hydrothermal minerals and wall rocks with isotopic characteristics of hydrothermal minerals and wall rocks in similar deposits and with isotopic characteristics of possible source rocks; and (2) evaluation of diagnostic isotope fractionations that reveal chemical reactions specific to magmatic-hydrothermal processes. Assumed solute $\delta^{34} \mathrm{~S}$ during deposit formation is calculated from measured $\delta^{34} \mathrm{~S}$ values of hydrothermal sulfide and sulfate minerals, experimentally determined fluid-mineral isotope fractionations, and depositional temperatures of sulfide and sulfate minerals (estimated from fluid inclusion microthermometry, mineral assemblages, and paleodepths of analyzed samples). Similarly, assumed solute ${ }^{206} \mathrm{~Pb},{ }^{207} \mathrm{~Pb},{ }^{208} \mathrm{~Pb}$, and ${ }^{87} \mathrm{Sr}$ values during deposit formation are measured in hydrothermal sulfide and sulfate minerals and corrected for postdepositional decay of parent isotopes. Possible sources of solutes are evaluated from the range and magnitude of isotope values compared with published isotope analyses and fractionation processes. An implicit but unverified assumption in many isotope investigations is that, in common minerals and in mineral assemblages, the sources of all elements are the same as sources of elements interpreted from stable and radiogenic isotope values (sulfur, lead, strontium). 
Based on sulfur isotope analyses, sources of sulfur in epithermal gold-silver deposits are primarily magmas, which apparently obtained most sulfur from isotopically homogenized sources including mantle and crustal rocks. Based on radiogenic isotope values, possible sources of lead and strontium in epithermal gold-silver deposits in the western United States are wall rocks, subjacent sedimentary rocks, some with relatively radiogenic isotope compositions, magmas that derived isotope compositions from these rocks, and enriched mantle rocks (Comstock Lode, Tonopah, and Goldfield, Vikre and others, 2014c; Hart district, California, Ausburn, 1991; McLaughlin, Sherlock and others, 1995; northern Great Basin deposits, Kamenov and others, 2007; Saunders and others, 2014). Sources of lead and strontium at Summitville (Lipman and others, 1978; Doe and others, 1979), Brewer, North Carolina (Ayuso and others, 2005; Foley and Ayuso, 2012), Rodalquilar, Spain (Arribas and others, 1995a), and Hishikari, Japan (Hosono and Nakano, 2004; Morishita and Nakano, 2008), are thought to range from Precambrian metamorphic and igneous rocks, deep and nearsurface crustal rocks, primitive mantle rocks, and magmas that derived isotope compositions from these rocks (see "Geochemical Characteristics").

Sources of solutes other than sulfur in epithermal gold-silver deposits have not been widely investigated. Lithophile element, chalcophile element, and gas concentrations in fluid inclusions have been determined in some deposits. These concentrations implicate numerous sources, including magmas, crustal rocks, and mantle rocks (see "Geochemical Characteristics").

\section{Chemical and Physical Transport and Transfer Processes}

\section{By Peter G. Vikre}

Transport and transfer of components of epithermal goldsilver deposits from sources to depositional sites are nearly entirely accomplished by simple and complex ions in aqueous fluids, which are the predominant solutes and media, respectively. In some deposits components have been, in part, transported as crystals and crystalline aggregates (for example, "vein" sediments in the Bohemia, Goldfield, and Masonic districts, U.S.A., Schieber and Katsura, 1986; Vikre, 1989b; Vikre and others, 2015). Other proposed methods of transport include nanoparticles (for example, National district and other northern Great Basin low-sulfidation deposits, Vikre, 2007; Saunders and others, 2011, 2013; Saunders, 2012), and critical fluids (high-sulfidation deposits; for example, Bethke and others, 2005).

Many to most gold, copper, and silver ore minerals, and other hydrothermal minerals in low-sulfidation veins and in highsulfidation deposits are fine-grained $(<1 \mathrm{~mm})$ to microcrystalline, reflecting multiple, usually simultaneous nucleation sites, large temperature and pressure gradients that caused fluid saturation and supersaturation in mineral components, and, in part, recrystallization from hydrogels and other noncrystalline aggregates and flocculates. However, distinguishing transport modes and mechanisms by using mineral textures needs to account for postdepositional maturation of amorphous and unstable particles (in hydrogels) and crystals deposited, in part, by amorphous silica-saturated and quartz-saturated aqueous fluid. For example, amorphous silica and nanoparticles reorganize into quartz, apparently relatively soon after aggregation (for example, Iler, 1979). In low-sulfidation veins, evidence for these processes remains as (1) tens to hundreds of conformable, millimeter- to submillimeter-thick layers of very fine-grained quartz, adularia, sulfide, and selenide minerals, some to many of which consist of modified dendrites that reflect multiple nucleation sites and rapid crystal growth; (2) aggregates of submillimeter, equidimensional quartz crystals, reflecting multiple simultaneous nucleation sites; (3) trains, commonly dendritic, of solid and liquid inclusions within quartz crystals that reflect initial dendritic growth; and (or) (4) spalled fragments of quartz-adularia overgrown by younger layers (for example, Vikre, 2007), suggesting separation and redistribution of incoherent, semicrystalline, water-rich layers (hydrogels) by gravity or fluid flow.

Solid solutions stable at elevated temperatures (for example, the $\mathrm{Cu}-\mathrm{Fe}-\mathrm{S}$ system), separate during cooling into several minerals (for example, bornite, chalcopyrite, and digenite in the $\mathrm{Cu}-\mathrm{Fe}-\mathrm{S}$ system). In some high-sulfidation deposits (for example, Goldfield, Masonic, U.S.A., Vikre and others, 2015), intricate intergrowths, replacement textures, and exsolution textures, including arrays of inclusions, and symplectic textures, among the numerous $\mathrm{Cu}-\mathrm{As}-\mathrm{Sb}-\mathrm{Pb}-\mathrm{Fe}-\mathrm{Zn}$-Bi-Ag-Sn-V-S-Se-Te minerals in some highsulfidation deposits, suggest that these minerals reflect subsolidus re-equilibration, at lower temperatures, of complex intermediate solid solutions (ISS) that solidified at higher temperatures: processes commonly observed in the $\mathrm{Cu}-\mathrm{Fe}-\mathrm{S}$ system (Vikre and others, 2014b). In other high-sulfidation deposits (for example, El Indio; Summitville; Mavrogenes and others, 2010; Henley and others, 2012), symplectic and other mineral textures are attributed to quenching of high-temperature $\left(>600^{\circ} \mathrm{C}\right)$ sulfosalt melts produced by expansion of magmatic "vapor."

\section{Heat Transport and Transfer Processes}

\section{By David A. John}

In the shallow epithermal environment, heat transport and transfer are dominantly advective and related to convection of hydrothermal fluids. However, hydrothermal fluid flow is intimately tied to the permeability structure, and advective heat transport is only significant for host rock permeabilities greater than about $10^{-16} \mathrm{~m}^{2}$ (Ingebritsen and others, 2010; see "Controls on Permeability and Fluid Flow"). Heat input for most epithermal systems is related to emplacement of magma: intrusions at depths greater than several kilometers and shallowly emplaced dikes (Henley and Ellis, 1983; fig. L1). Advective heat transfer from these intrusions to epithermal systems takes place by expulsion of hot aqueous fluids from these intrusions and by heating of external fluids convectively circulated into thermal haloes of intrusions, thereby forming the deep reservoir fluids of hydrothermal systems. The high heat flux into fluids above magma bodies results in hydrothermal 
plumes that rise buoyantly towards the surface in through-going fracture and fault zones and constitute the main mechanism of heat and solute transport in epithermal systems. High permeability promotes high fluid-flow rates that lead to the large heat and solute fluxes conducive to formation of ore deposits. In contrast, where permeability is low, heat and solute transport occur mainly by the relatively slow processes of conduction and diffusion (Ingebritsen and Appold, 2012).

An important aspect of heat transport in epithermal systems is the temperature of the deep fluid reservoir that gives rise to upwelling hydrothermal plumes. The depth of boiling (the depth at which an ascending fluid enters the vapor plus liquid field) is proportional to the temperature of the upwelling fluid (fig. P1). Higher temperature fluids will begin boiling at greater depths than lower temperature fluids. Once an ascending fluid enters the vapor plus liquid (boiling) field, it is unlikely to leave it as it continues to rise, because of the large heat of vaporization (Ingebritsen and others, 2010). Therefore, vertically extensive two-phase (liquid+vapor) boiling zones can develop above the first level of boiling (Hayba and Ingebritsen, 1997). Boiling is an important mechanism for ore deposition in many epithermal gold-silver deposits (appendix 1; see "Wall-Rock Reactions and Ore-Mineral Depositional Processes").

A second important aspect of heat transport and transfer in epithermal systems is its close relation to permeability. Ore zones typically require episodic high permeability and are surrounded by low-permeability zones that maintain and focus the hydrothermal system (Ingebritsen and Appold, 2012). Low-permeability zones surrounding high-permeability zones can limit the overall permeability and focus fluid flow, thereby allowing high temperatures to occur relatively near the surface and stabilizing the ore-forming environment. This prevents ore-forming processes, such as boiling or mixing, from migrating widely. For example, the depth of boiling will not change drastically as the hydrothermal system waxes and wanes (Ingebritsen and Appold, 2012).

\section{Pressure Gradients during Ore Formation}

\section{By Peter G. Vikre}

Pressure gradients in epithermal gold-silver deposits during ore formation are seldom reported or calculated. However, paleodepths in these ore-forming systems, most commonly derived from paleofluid pressure estimates, are important quantities for guiding exploration programs as they are used to estimate postmineralization erosion and fault displacement to predict present depths of unexposed ore. Depths and configuration of ore and alteration zones relative to paleosurfaces and to paleowater tables (potentiometric surfaces) reflect control of mineralizing fluids and processes by stratigraphy (aspect; permeability), structure (faults; uplift), and climate (depth of meteoric water saturation). Paleosurface elevations relative
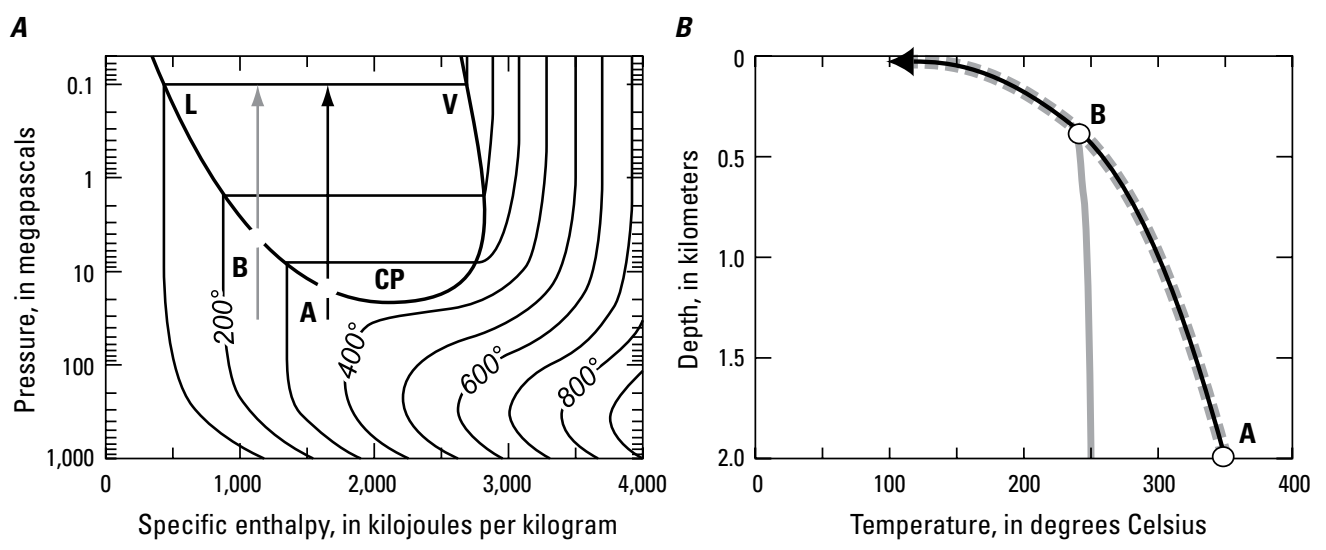

Figure P1. Diagrams showing boiling relations for water. $A$, Enthalpy-pressure diagram for pure water showing two-phase (boiling) relations. $B$, Temperature-depth diagram for water showing boiling curve for water (heavy dashed line). An upwelling fluid with higher temperature has greater enthalpy and will intersect the two-phase, liquid (L)+vapor (V) field at higher pressure (point $A$ ) and boil at greater depth than a lower temperature fluid (point B). Consequently, fluid A may boil over a large depth range beginning about 2,000 $\mathrm{m}$, whereas boiling of fluid $\mathrm{B}$ is limited to depths less than about $300 \mathrm{~m}$. Figure modified from Ingebritsen and others (2010). In a temperature-depth context, this affords one explanation of why hydrothermal systems boil to various depths. The dashed gray curve in part $B$ represents the boiling point curve, that is, the increase in boiling temperature with depth (pressure). The initially $350^{\circ} \mathrm{C}$ fluid (black curve with arrow) boils at $\sim 2 \mathrm{~km}$ depth, and the initially $250^{\circ} \mathrm{C}$ fluid (gray curve) boils at $\sim 0.4 \mathrm{~km}$ depth. The open circles in both parts $A$ and $B$ indicate where the rising fluid intercepts the two-phase region (boils). Because of the large heat of vaporization of water, expressed as the width of the two-phase region in part $A$, rising hydrothermal plumes are unlikely to depart from the boiling point curve once they intercept it. 
to paleowater tables may have changed significantly during formation of some deposits (for example, Simmons and others, 1988; Simmons and Browne, 1990; Bissig and others, 2002; Deyell and others, 2005a; Vikre, 2007).

Paleofluid pressures and paleodepths of many partially eroded deposits can be relatively accurately determined, because the deposits mostly formed, all or in part, in nearsurface hydrostatic systems in which fluids boiled, or in which paleosurfaces or paleowater tables remain. Paleodepths of partially eroded deposits are estimated, in order of accuracy, from (1) remnant paleosurfaces and paleowater tables; (2) fluid temperature-pressure gradients determined by fluid inclusion microthermometry; (3) comparison of hydrothermal mineral assemblage stratigraphy (vertical distribution of minerals and textures) to stratigraphy of similar, well-documented deposits, including geothermal systems; (4) stable isotope equilibrium temperatures; and (5) stratigraphic and structural restoration, constrained by geochronology (see "Geochemical Characteristics").

Relatively precise paleodepths derive from (a) districts that include sinter, paleosurfaces, or paleowater tables that are coeval with deposits; and (b) microthermometry of deposits in which the ore fluid boiled (coexisting liquid-rich and vapor-rich fluid inclusions; for example, National, McLaughlin, U.S.A., Vikre, 1985, 2007; Sherlock and others, 1995). In districts with coeval sinter, or other paleosurfaces (a), paleodepths are present depths below the sinter or paleosurface if there has been no postmineralization displacement of the paleosurface relative to the deposit and if the paleosurface was at the same elevation as paleowater table; precise paleodepths are obtained if displacement can be accurately restored. In deposits in which ore fluid boiled (b), depths below paleowater table (and paleopressures) can be graphically determined by positioning homogenization temperature modes on appropriate liquid-vapor equilibrium curves for water and $\mathrm{NaCl}-\mathrm{CO}_{2}$ aqueous solutions (Haas, 1971; Hedenquist and Henley, 1985a). In the absence of paleosurfaces or paleowater tables, paleodepth projections or minimum paleowater table elevation estimates (corresponding to $100{ }^{\circ} \mathrm{C}$ on liquid-vapor equilibrium curves) using boiling fluid modes are more valid where modes are precise (homogenization temperatures span $<\sim 10^{\circ} \mathrm{C}$ ) and represent many different elevations, and less accurate where modes are poorly defined (homogenization temperatures span tens of degrees Celsius) or represent few elevations (for example, Christie and others, 2007). Hydrothermal mineral crystal forms and textures, which comprise a somewhat equivocal surrogate for fluid boiling, have also been used for hydrodynamic reconstruction of deposits and districts (for example, Moncada and others, 2012). In districts and deposits with no remnant paleosurfaces nor evidence of fluid boiling, estimation of minimum paleodepths (and paleopressures) can be obtained from fluid inclusion microthermometry but also requires application of methods (3), (4), and (5), mentioned previously.

Paleodepths based on fluid inclusion microthermometry have mostly been determined in low- and intermediatesulfidation deposits, because quartz and other hydrothermal minerals in these deposits are invariably coarser grained than in high-sulfidation deposits, and parageneses are more easily determined. Complications in the application of fluid inclusion microthermometry to estimate paleodepths arise in epithermal gold-silver deposits that were episodically under lithostatic pressure during formation, commonly attributed to sealing of fluid conduits by hydrothermal mineral precipitation. Episodic lithostatic pressure is usually represented by breccias with clasts of hydrothermal mineral assemblages (for example, sinter or vein fragments), clasts of wall rocks, and clasts of overlying strata (recognizable where stratigraphy is preserved) in matrices consisting of comminuted wall rocks and (or) hydrothermal minerals. These hydroclastic breccias also are termed "hydrothermal," "diatreme," and "explosion" breccias, although some descriptions are equivocal and could apply to tectonic breccias that have been altered by hydrothermal fluids.

Paleodepth ranges of hydrothermal mineral assemblages in some high-sulfidation deposits were apparently not static because fluid inclusion populations with diverse liquid-vapor ratios, salinities, including salt saturation, and homogenization temperatures occur at common elevations and at the scale of a hand sample (for example, Summitville). These fluid inclusion populations imply a complex hydrodynamic evolution of some systems, with boiling and brine-vapor separation occurring several times at paleodepths differing by hundreds of meters (Stoffregen and others, 2004; Bethke and others, 2005).

Based primarily on homogenization temperature modes of low-salinity ore-stage fluids that exhibit evidence for boiling $\left(\sim 220-270^{\circ} \mathrm{C}\right)$ and (or) paleosurfaces and water table surfaces, paleodepths of low-sulfidation deposits vary from meters to $\sim 0.7 \mathrm{~km}$. These paleodepths correspond to a pressure range of $\sim 1-55$ bars (Haas, 1971) and pressure gradient of $\sim 0.08$ bars $/ \mathrm{m}$. Somewhat higher homogenization temperature modes, and absence of evidence for ore-stage fluid boiling in deeper ore minerals indicate that paleodepths of large intermediate-sulfidation deposits exceed $1 \mathrm{~km}$ (see "Geochemical Characteristics"). These paleodepths correspond to pressures more than 80 bars for lowto moderate-salinity fluids at temperatures greater than or equal to $300{ }^{\circ} \mathrm{C}$ (Haas, 1971), and pressure gradients of $\sim 0.08 \mathrm{bars} / \mathrm{m}$. Based on homogenization temperature modes and other reasoning, including depths to vapor-brine separation in deeper parts of systems, ore in most high-sulfidation deposits formed at depths of less than $\sim 0.7 \mathrm{~km}$ (fluid pressures $<55$ bars), although ore-grade drill-hole intercepts may exceed paleodepths of $1 \mathrm{~km}$ in some districts (for example, Summitville).

\section{Wall-Rock Reactions and Ore-Mineral Depositional Processes}

\section{By Peter G. Vikre}

At a deposit scale, reactions between wall-rock minerals and hydrothermal fluids (hydrothermal alteration), and deposition of ore and associated hydrothermal minerals in fractures and breccia matrices, are broadly simultaneous in epithermal 
gold-silver deposits. At the scale of a fracture or fault breccia wall-rock selvage, zoning of hydrothermal alteration mineral assemblages reflects sequential and superimposed reactions that attest to changes in composition of the altering fluid and changes in composition and form of hydrothermal minerals that replace wall-rock minerals (see "Hydrothermal Alteration"). Spatial and temporal zoning of assemblages consisting of ore and other hydrothermal minerals (gangue), often called "stages" or "paragenetic stages," also reflects sequential reactions and variations in fluid temperature, pressure, and composition (see "Hypogene and Supergene Ore Characteristics"). These usually transgressive processes are occasionally disrupted by physical instability marked by internal and external tectonic (fault) and hydroclastic (hydrothermal, diatreme, explosion) breccias. 


\title{
Chapter 0. Weathering and Supergene Processes
}

\author{
By David A. John
}

\section{Introduction}

Near-surface weathering of epithermal gold-silver deposits, which results in oxidation of sulfide minerals, and in some deposits, enrichment of gold and (or) silver, is an important process that leads to the economic viability of many low-grade bulk tonnage deposits (for example, Yanacocha, Peru, Teal and Benavides, 2010; Veladero, Argentina, Holley, 2012; La Coipa, Chile, Oviedo and others, 1991b; Pueblo Viejo, Dominican Republic, Kesler and others, 1981; Round Mountain, Nevada, Fifarek and Gerike, 1991). During weathering, meteoric water dissolves metal ions from hypogene sulfide minerals and reprecipitates them in more reduced, generally higher $\mathrm{pH}$ areas (fig. Q1). Fluid movement is mainly downward through permeable material, although lateral movement can be substantial in areas that have large topographic relief. Supergene enrichment occurs when precipitation of secondary minerals increases the grade from that of hypogene ore and is especially common in porphyry copper deposits (for example, Sillitoe, 2005).

The effects of weathering and the formation of supergene ores and enriched zones in epithermal gold-silver deposits have long been discussed (for example, Burgess, 1911; Emmons, 1917; Bastin and Laney, 1918; Bastin, 1922; Lindgren, 1933; Mann, 1984; Webster and Mann, 1984; Saunders, 1993; Sillitoe, 2009). Supergene silver minerals (for example, acanthite, native silver, and silver halides) and high-fineness gold were major ore minerals in shallow, oxidized bonanza zones in several epithermal deposits in the western United States (for example, Tonopah, Nevada, Burgess, 1911; National, Nevada, Lindgren, 1915). In general, however, significant redistribution and supergene enrichment of gold and silver are not evident in most epithermal gold-silver deposits (for example, Bastin, 1922; Saunders, 1993; Sillitoe and Lorson, 1994; Sillitoe, 2009). The most important effect of weathering and supergene oxidation of many low-grade, bulk tonnage deposits is liberation of gold hosted by hypogene sulfide minerals (principally pyrite), which allows recovery of gold by cyanide leaching techniques. For many of these large deposits, the unweathered hypogene ore is not economic; only the weathered part of the mineralization, where gold and silver are available for leaching, can be mined and processed economically.

Gold and silver mobility in the supergene environment is controlled by several factors, including ore and host rock mineralogy, climate, geomorphology, hydrology, and groundwater composition (Emmons, 1917; Webster and Mann, 1984; Saunders, 1993; Williams-Jones and others, 2009). Different combinations of these factors result in variations in the species that transport gold and silver, mechanisms that precipitate gold and silver, and the coupling or separation of gold and silver in the supergene zone (table Q1; Webster and Mann, 1984; Gray and others, 1992; Butt, 1998).

\section{Mineralogy}

Common supergene silver ore minerals are listed in table Q2. Native gold and electrum, commonly of high fineness, are the primary supergene gold minerals. Uytenbogaardtite $\left(\mathrm{Ag}_{3} \mathrm{AuS}_{2}\right)$ and petrovskaite (AgAuS) are less common goldbearing minerals that may form under supergene conditions (Cocker and others, 2013).

\section{Geochemistry}

The formation of aqueous complexes of gold and silver during weathering and supergene oxidation depends on groundwater chemistry developed by rock-water reactions, locally mediated by microbes (Mills, 1999), organic matter, and climatic and topographic (geomorphic) conditions (table Q1; Gray and others, 1992; Williams-Jones and others, 2009).

In pyrite (iron-sulfide)-rich rocks, pyrite oxidation strongly affects acid formation and $\mathrm{pH}$ of the oxidizing fluids and the geochemistry of gold and silver. Pyrite oxidation releases sulfur and ferric $\left(\mathrm{Fe}^{+3}\right)$ iron, which generates acid through a series of generalized reactions (Plumlee, 1999; Nordstrom and Alpers, 1999):

$$
\begin{aligned}
& \mathrm{FeS}_{2}+3.5 \mathrm{O}_{2}+\mathrm{H}_{2} \mathrm{O} \rightarrow \mathrm{Fe}^{2+}{ }_{(\text {aq }}+2 \mathrm{SO}_{4}{ }^{2-}{ }_{(\mathrm{aq})}+2 \mathrm{H}^{+}{ }_{(\mathrm{aq})}
\end{aligned}
$$

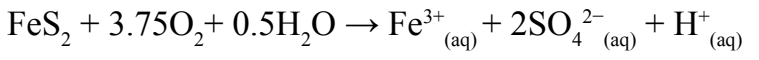

$$
\begin{aligned}
& \mathrm{FeS}_{2}+3.75 \mathrm{O}_{2}+3.5 \mathrm{H}_{2} \mathrm{O} \rightarrow 2 \mathrm{SO}_{4}{ }^{2-}{ }_{(\mathrm{aq})}+4 \mathrm{H}^{+}{ }_{\text {(aq) }}+\mathrm{Fe}(\mathrm{OH})_{3(\mathrm{~s})}(\mathrm{Q} 3) \\
& \mathrm{FeS}_{2}+14 \mathrm{Fe}^{+3}+8 \mathrm{H}_{2} \mathrm{O}=15 \mathrm{Fe}^{+2}+2 \mathrm{SO}_{4}^{2-}+16 \mathrm{H}^{+}
\end{aligned}
$$




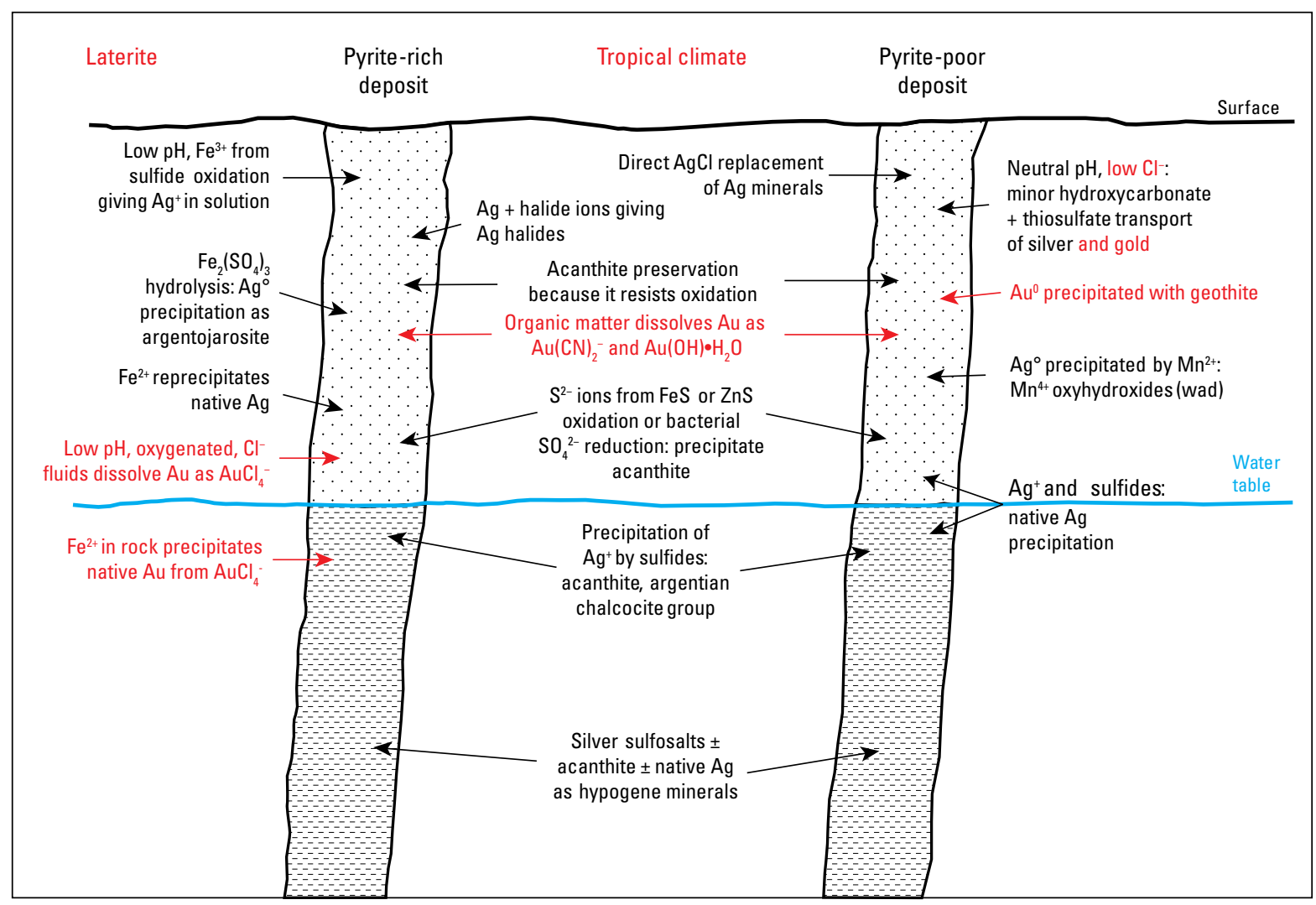

Figure 01. Schematic diagram showing behavior of silver and gold (red lettering) in the supergene environment. Deposits are divided into pyrite-rich and pyrite-poor types; gold deposits also are divided into laterites (arid climates) and tropical climates. Silver relations modified from Sillitoe (2009). See text for discussion of gold relations. Abbreviations: $\mathrm{Ag}$, silver; $\mathrm{Au}$, gold; C, carbon; Cl, chlorine; Fe, iron; Mn, manganese; N, nitrogen; O, oxygen; S, sulfur; Zn, zinc.

tends to be more abundant near this front and in underlying sulfide zones (fig. Q1; Sillitoe, 2009).

In regions with saline, oxygenated groundwater, especially in arid and semiarid environments, silver and gold are readily soluble as chloride complexes. In these conditions, silver is transported as $\mathrm{AgCl}^{0}, \mathrm{AgCl}^{2-}$, and $\mathrm{AgCl}_{2}^{3-}$ (Gammons and $\mathrm{Yu}, 1997)$, whereas gold is transported primarily as $\mathrm{AuCl}_{4}^{-}$(Webster and Mann, 1984). However, chloride, bromide, and iodide anions effectively precipitate silver at surficial temperatures over a wide range of redox and $\mathrm{pH}$ conditions attributable to the extremely low solubility of silver halide minerals (Gammons and Yu, 1997). Therefore, under moderately saline supergene conditions and regardless of fluid $\mathrm{pH}$, silver sulfides, sulfosalts, and native silver may undergo direct replacement by silver halide minerals (fig. Q1). Vertical zoning of silver halide minerals, from chloride (chlorargyrite, $\mathrm{AgCl})$ near the paleosurface through mixed chloride-bromide (embolite, $\mathrm{Ag}[\mathrm{Cl}, \mathrm{Br}]$ ) and bromide (bromargyrite, $\mathrm{AgBr}$ ) to iodide (iodargyrite, AgI) near the base of the oxidized zone, as described at Tonopah, Nevada (Burgess, 1911), results from initial formation of the least soluble halide, iodargyrite, and its subsequent conversion to bromine- and chlorine-bearing species under higher oxidation states (Gammons and Yu, 1997; Sillitoe, 2009).

Precipitation of native silver is favored by the progressive neutralization of acidic, silver-bearing supergene solutions (Gammons and $\mathrm{Yu}, 1997$ ), conditions that also lead to sorption of $\mathrm{Ag}^{+}$by ferric oxyhydroxide (goethite) or its coprecipitation as argentojarosite or argentian plumbojarosite during hydrolysis of ferric sulfate $\left(\mathrm{Fe}_{2}\left[\mathrm{SO}_{4}\right]_{3}\right)$ in solution (fig. Q1). Under nearneutral or alkaline conditions, in manganoan carbonate-bearing deposits, oxidation of $\mathrm{Mn}^{2+}$ to $\mathrm{Mn}^{4+}$ causes precipitation of silver, which may be an important component of several of the manganese $\left(\mathrm{Mn}^{4+}\right)$ oxide minerals that constitute manganese wad (Webster and Mann, 1984).

Under reducing conditions at and immediately below the water table, $\mathrm{Ag}^{+}$in solution progressively substitutes for copper, zinc, and iron in less-soluble sulfide minerals forming acanthite, the process of supergene silver enrichment (fig. Q1). If copper accompanies the silver in solution, stromeyerite or argentian chalcocite-group minerals may either coprecipitate with or form instead of acanthite. 
Table 01. Mechanisms of gold mobilization and precipitation during weathering (modified from Butt, 1998)

\begin{tabular}{llll}
\hline \multicolumn{1}{c}{ Complex } & \multicolumn{1}{c}{ Dissolution conditions } & \multicolumn{1}{c}{ Precipitation conditions } & \multicolumn{1}{c}{ Product } \\
\hline Halide & Acid, oxidizing, high chloride & Dilution, increasing $\mathrm{pH}$, reduction & Gold, high fineness \\
Thiosulfate & Alkaline, mildly oxidizing & Dilution, acidification, oxidation, reduction & Electrum \\
Thiosulfate & Acid, oxidizing, low chloride & Dilution, increasing $\mathrm{pH}$, reduction & Fine-grained electrum \\
Organic & Alkaline to acid & Reduction & Fine-grained gold, high fineness \\
\hline
\end{tabular}

Table 02. Common silver-bearing minerals in supergene zones of epithermal gold-silver deposits (modified from Sillitoe, 2009).

\begin{tabular}{|c|c|}
\hline Mineral & Chemical Formula \\
\hline \multicolumn{2}{|c|}{ Supergene zone } \\
\hline Chlorargyrite (cerargyrite) & $\mathrm{AgCl}$ \\
\hline Embolite & $\mathrm{Ag}(\mathrm{Cl}, \mathrm{Br})$ \\
\hline Bromargyrite & $\mathrm{AgBr}$ \\
\hline Iodargyrite & $\mathrm{AgI}$ \\
\hline Iodembolite & $\mathrm{Ag}(\mathrm{Cl}, \mathrm{Br}, \mathrm{I})$ \\
\hline Argentojarosite & $\mathrm{AgFe}_{3}\left(\mathrm{SO}_{4}\right)_{2}(\mathrm{OH})_{6}$ \\
\hline Argentian plumbojarosite & $(\mathrm{Pb}, \mathrm{Ag}) \mathrm{Fe}_{3-6}\left(\mathrm{SO}_{4}\right)_{2-4}(\mathrm{OH})_{6-12}$ \\
\hline Argentian beudantite & $(\mathrm{Pb}, \mathrm{Ag}) \mathrm{Fe}_{3} \mathrm{AsO}_{4} \mathrm{SO}_{4}(\mathrm{OH})_{6}$ \\
\hline Manganese oxides and oxyhydrates (for example, cryptomelane) & $\mathrm{K}_{12}\left(\mathrm{Mn}^{3+} \mathrm{Mn}^{4+}\right)_{8} \mathrm{O}_{16} \cdot \mathrm{H}_{2} \mathrm{O}$ \\
\hline \multicolumn{2}{|c|}{ Supergene and hypogene zones } \\
\hline Electrum & $\begin{array}{l}\mathrm{Au}_{\mathrm{x}} \mathrm{Ag}_{1-\mathrm{x}} \text { (supergene electrum may have higher gold } \\
\text { content than hypogene electrum) }\end{array}$ \\
\hline Native silver & $\mathrm{Ag}$ \\
\hline Argentite & $\alpha \mathrm{Ag}_{2} \mathrm{~S}$ \\
\hline Acanthite & $\beta \mathrm{Ag}_{2} \mathrm{~S}$ \\
\hline Stromeyerite & $\mathrm{Ag}_{1-\mathrm{x}} \mathrm{CuS}$ \\
\hline Mckinstryite & $\mathrm{Ag}_{1.2} \mathrm{Cu} 0.8 \mathrm{~S}$ \\
\hline Jalpaite & $\mathrm{Ag}_{3} \mathrm{CuS}_{2}$ \\
\hline
\end{tabular}

The extremely low solubility of silver halide minerals under most supergene conditions is the main reason for efficient silver fixation above the water table, although the precipitation of native silver, argentojarosite, and silver-bearing manganese oxides may also be effective in removing silver from descending solutions under some conditions (Sillitoe, 2009). Therefore, little silver remains in solution for sulfide enrichment at and beneath the groundwater table. Thus, major silver sulfide enrichment zones overlain by silver-deficient leached cap do not appear to have developed, even in pyrite-rich deposits that generate highly acidic fluids conducive to silver transport during oxidation of silverbearing minerals (Sillitoe, 2009). The principal reason for the lack of supergene enrichment zones is that silver is not appreciably leached in either acidic or alkaline environments, because the extremely low solubility of silver halide minerals causes precipitation if groundwater recharge contains halogen contents as low as average rainwater (Gammons and Yu, 1997; Sillitoe, 2009).

Gold behaves somewhat differently than silver in arid climates and in areas of low topographic relief characterized by acidic, saline groundwater and iron-rich laterites, which are ideal conditions for gold transportation as $\mathrm{AuCl}_{4}^{-}$(fig. Q1; Webster and
Mann, 1984). At shallow depth, atmospheric oxygen is available as a strong oxidizing agent, which leads to gold or electrum dissolution:

$$
2 \mathrm{Au}+8 \mathrm{Cl}^{-}+3 / 2 \mathrm{O}_{2}+6 \mathrm{H}^{+}=2 \mathrm{AuCl}_{4}^{-}+3 \mathrm{H}_{2} \mathrm{O}
$$

Silver is soluble as $\mathrm{AgCl}_{0}$ or $\mathrm{AgCl}^{2-}$ complexes, which are stable in the presence of reducing agents, such as ferrous iron and saline, oxygenated groundwater (Mann, 1984; Gammons and Yu, 1997). However, gold may reprecipitate during ferrolysis onto amorphous ferric iron oxides and hydroxides during oxidation of ferrous iron, while silver remains in solution, which leads to crystallization of high-fineness electrum or native gold and goethite $(\mathrm{FeOOH})$ :

$$
2 \mathrm{AuCl}_{4}^{-}+3 \mathrm{Fe}^{2}++6 \mathrm{H}_{2} \mathrm{O}=\mathrm{Au}+4 \mathrm{Cl}^{-}+3 \mathrm{FeOOH}+9 \mathrm{H}^{+}
$$

In contrast with the acidic, saline fluids characteristic of arid and semiarid environments, Stoffregen (1986) showed that acidic, chloride-poor fluids in the oxidized parts of the Summitville high-sulfidation deposit dissolved coarse, primary 
gold. The dissolved gold was transported short distances within the oxidized zone to where it was reprecipitated as finegrained gold intergrown with goethite. The secondary gold had similar or higher silver contents (as much as 20 weight percent silver) than primary gold. Because of the low chloride content of the oxidizing fluids, Stoffregen suggested that gold was transported as a thiosulfate complex.

In oxidizing, neutral to alkaline conditions, which may result from low iron sulfide content and (or) carbonaterich host rocks, oxidation of sulfide minerals also can form thiosulfate $\left(\mathrm{S}_{2} \mathrm{O}_{3}{ }^{2-}\right)$. Gold and silver form thiosulfate complexes, $\mathrm{Au}\left(\mathrm{S}_{2} \mathrm{O}_{3}\right)_{2}{ }^{3-}$ and $\mathrm{Ag}\left(\mathrm{S}_{2} \mathrm{O}_{3}\right)_{2}{ }^{3-}$, respectively, and may become mobile (Webster and Mann, 1984; Webster, 1986; Benedetti and Boulègue, 1991; Krupp and Weiser, 1992; Cocker and others, 2013). However, this process is limited by oxidation of thiosulfate to sulfate (Webster, 1986; Benedetti and Boulègue, 1991), and transport by thiosulfate complexes generally does not lead to large-scale mobility or supergene enrichment. Silver generally is much less mobile in this environment than in more acidic conditions.

Microbes (bacteria) may be an important contributor to supergene oxidation of some epithermal deposits. Mills (1999) discussed the function of bacteria in oxidation and reduction of sulfur-bearing minerals, especially iron sulfide minerals. At the oxidized Pierina high-sulfidation deposit, Peru, oxygen and sulfur isotope data of barite and acanthite provide strong evidence for microbial involvement during supergene oxidation (Rainbow and others, 2006). Late barite precipitated during supergene activity has variable but correlated $\delta^{34} \mathrm{~S}$ and ${ }^{18} \mathrm{O}$ values that record the enrichment of ${ }^{34} \mathrm{~S}$ and ${ }^{18} \mathrm{O}$ in supergene aqueous sulfate resulting from preferential use of light isotopes by microbes during aqueous sulfate reduction. Rainbow and others conclude that microbes probably also were involved in the economically important oxidation of the primary precious-metal sulfide assemblage.

Electrum composition commonly changes during weathering and supergene oxidation, and increased fineness of gold and electrum has been used to indicate secondary gold migration in oxidized deposits (for example, Saunders, 1993; Greffié and others, 2002; table Q1). In arid and semiarid climates, especially in lateritic soils, acidic chloride-rich fluids dissolve gold and silver as chloride complexes (Mann, 1984; Webster and Mann, 1984). Secondary gold, precipitated by reaction with ferrous iron below the water table, has a marked increase in fineness (lower silver contents) compared with primary gold. In contrast, in other environments where fluids are chloride poor, the fineness of primary and secondary gold are not substantially different, probably attributable to transport as different complexes (for example, thiosulfate complexes, Wau, Papua-New Guinea, Webster and Mann, 1984; Summitville, Colorado, Stoffregen, 1986; Mt. Muro, Indonesia, Simmons and Browne, 1990).

\section{Effects of Climate}

Climate strongly affects the chemistry of groundwater, which controls the solubility and transport of silver and gold, but groundwater chemistry and precious metal complexing also are a function of host rocks and sulfide content. In semiarid to arid environments, where groundwater is hypersaline, acidic, and oxidizing, gold and silver are transported as halide complexes; gold predominantly as $\mathrm{AuCl}_{4}^{-}$, or possibly as $\mathrm{AuOH} \cdot\left(\mathrm{H}_{2} \mathrm{O}\right)$ where conditions are slightly less oxidizing and acidic (Webster and Mann, 1984; Saunders, 1993; Gammons and others, 1997; Freyssinet and others, 2005); and silver as $\mathrm{AgCl}^{0}, \mathrm{AgCl}^{2-}$, and $\mathrm{AgCl}_{2}{ }^{3-}(\mathrm{Gammons}$ and $\mathrm{Yu}$, 1997). In contrast, in tropical and equatorial climates, where soils have relatively high concentrations of organic matter, gold concentrations in pore waters strongly correlate with concentrations of cyanide, ammonia, and dissolved organic species, suggesting transport as $\mathrm{Au}(\mathrm{CN})_{2}{ }^{-}$and $\mathrm{AuOH} \cdot\left(\mathrm{H}_{2} \mathrm{O}\right)$ (Bowell and others, 1993). At Summitville in a high-altitude, temperate climate, oxidation of the pyrite-rich high-sulfidation deposit produced acidic but chloride-poor fluids, and gold was transported primarily as thiosulfate complexes (Stoffregen, 1986). In the tropical environment at Wau, Papua New Guinea, oxidation of the quartz-adularia veins containing carbonate minerals resulted in low chloride, alkaline fluids in which precious metals also were transported as thiosulfate complexes (Webster and Mann, 1984).

In regions of arid and semiarid climate with relatively deep water tables, supergene oxidation, and in places, enrichment, has affected many large replacement-type high-sulfidation deposits (for example, Yanacocha, Peru, and Veladero, Argentina) as well as disseminated and vein-type low- and intermediate-sulfidation deposits (for example, Round Mountain and Tonopah, Nevada). In contrast, supergene minerals are rare and low in abundance in epithermal deposits of the tropical southwestern Pacific, where water tables are close to the surface (White and others, 1995). 


\title{
Chapter R. Geoenvironmental Features
}

\author{
By David L. Fey
}

\section{Weathering Processes}

Weathering of epithermal gold-silver deposits at or near the surface results in the transformation of hypogene (primary) minerals into secondary phases. For example, copper sulfide minerals may be converted to minerals with a higher sulfidation state (for example, chalcopyrite to chalcocite), to oxide minerals (for example, cuprite and tenorite), to carbonate minerals (azurite and malachite), or to sulfates (for example, chalcanthite). The weathering of iron sulfide minerals results in the formation of sulfuric acid and iron oxide and oxyhydroxide phases. The acid formed may or may not be partially to completely neutralized by carbonate and other minerals; the resulting drainage, if it has a low $\mathrm{pH}$, is termed acid mine drainage (AMD) if related to mining, or acid rock drainage (ARD) if naturally occurring. The effect of the mine drainage can range from being relatively innocuous to causing serious environmental problems and affecting the costs of mining operations.

Physical breakdown of ore and country rock (made weaker by acid from sulfide weathering) results in mass transport of various sizes of detrital material, which become incorporated into soil and stream sediment. Weathering and breakdown of primary and secondary minerals release depositrelated elements, which are then transported by water into surface or groundwater. The rates at which these processes occur are related to the climate and topography of the deposit locality. These topics and effects are discussed in more detail in the following sections on soil and sediment signatures, secondary minerals, metal mobility from mine waste, and drainage signatures.

\section{Soil and Sediment Signatures Before Mining}

Soil and sediment signatures of epithermal deposits are influenced by several factors, including host rock mineralogy, hypogene hydrothermal ore mineralogy, and secondary mineralogy (supergene minerals and minerals resulting from weathering in the vadose zone), climate, topography, and permeability and porosity of the deposit (Plumlee, 1999).

Primary ore-related minerals of high-sulfidation deposits include pyrite, enargite, chalcopyrite, digenite, chalcocite, covellite, bornite, tennantite-tetrahedrite, famatinite, native gold and electrum, gold tellurides, silver sulfosalts, sphalerite (rare), galena (rare), orpiment (very rare), native sulfur, and mercury minerals in shallow deposits (Sillitoe, 1999; Einaudi and others, 2003; Arribas, 1995). The primary mineral suite related to low- and intermediate-sulfidation deposits is different from that associated with high-sulfidation deposits, because of the different $\mathrm{pH}$-oxidation properties of fluids responsible for the formation of each deposit type. Primary minerals of low-and intermediate-sulfidation deposits include pyrite, sphalerite, galena, chalcopyrite, arsenopyrite, electrum, tellurides, selenides (White and Hedenquist, 1995), polybasite, native silver (Greffié and others, 2002), silver sulfosalts, rare pyrrhotite, orpiment, realgar, stibnite, and cinnabar (Einaudi and others, 2003). A complete list of primary minerals associated with all deposit subtypes is presented in appendix 1.

Transfer of geochemical components from mineralized rock into soil and sediment reflects physical (weathering and mass wasting) and hydromorphic processes (mineral decomposition resulting from weathering and elemental transport by solution and sorption and water movement). The acidity of secondary fluids associated with individual deposits reflects the balance between acid-forming and acid-neutralizing processes and influences the rate at which minerals break down and the type and range of hydromorphic transport (creation of iron oxide colloidal/suspended material and subsequent sorption and transport of trace elements). Climate and topography also affect mineral weathering and elemental transport. Deposit porosity and permeability affect access of minerals to oxygen and water, and the rate at which metal-laden, acidic water can flow from the deposit and transport elements through surface and groundwater flow.

Ore minerals associated with high-sulfidation epithermal deposits contain $\mathrm{Au}, \mathrm{Cu}, \mathrm{Ag}$, As, S, Sb, Mo, Hg, Zn, Pb, Te, $\mathrm{Bi}, \mathrm{Sn}$, and $\mathrm{W}$; these elements may be enriched in soil and stream sediments proximal to these deposits. Geochemical signatures associated with low- and intermediate-sulfidation deposits include $\mathrm{Au}, \mathrm{Ag}, \mathrm{As}, \mathrm{Sb}, \mathrm{Hg}, \mathrm{Zn}, \mathrm{Pb}, \mathrm{Se}, \mathrm{K}, \mathrm{Ag} / \mathrm{Au}$, low $\mathrm{Cu}, \mathrm{Te} / \mathrm{Se}$ (White and Hedenquist, 1995), and Mo (N. White, written commun., 2016). Robert and others (2007) suggested that $\mathrm{Au}, \mathrm{Ag}, \mathrm{As}, \mathrm{Cu}, \mathrm{Sb}, \mathrm{Bi}$, and $\mathrm{Hg}$ exploration analyses of soils may define, at a local scale, anomalies associated with outcropping or subcropping deposits. Although published geochemical soil survey analyses are sparse, Anglo American (Van Kervoort and others, 2009) used anomalous $\mathrm{Cu}, \mathrm{Au}$, and $\mathrm{Ag}$ abundances to define a $650 \mathrm{~m}$ by $300 \mathrm{~m}$ soil anomaly at the Caspiche property in Chile.

\section{Secondary Minerals}

Mine waste associated with epithermal deposits includes overburden (covering soil and weakly mineralized rock) removed during mining operations, waste rock, and processed tailings. Associated secondary minerals include supergene 
minerals (formed under a leached gossaneous cap) that form in the vadose (oxidized) zone of a mineral deposit at or near the surface, and minerals that form on waste piles, tailings material, and on material affected by mine drainage waters. Common secondary copper minerals include chalcocite, atacamite, azurite, chalcanthite, antlerite, chrysocolla, covellite, cuprite, malachite, and tenorite (Sillitoe, 1999; Lattanzi and others, 2008). Covellite may be present either as a primary or secondary mineral. Geochemical processes associated with weathering enargite and luzonite release more copper than arsenic, because arsenic becomes bound in other secondary minerals such as scorodite (Lattanzi and others, 2008). Jarositeand hematite-rich limonites formed in the oxidized zone reflect pyrite oxidation (Sillitoe, 1999). Other common weathering products of iron sulfides include goethite, schwertmannite, and ferrihydrite (Dold and Fontboté, 2001). Goslarite, a highly soluble zinc sulfate, and smithsonite (zinc carbonate) form as weathering products of zinc sulfide minerals and cerussite (lead carbonate), anglesite (lead sulfate), and plumbojarosite form as weathering products of galena.

\section{Metal Mobility from Solid Mine Waste}

\section{Acid-Base Accounting}

Acid-base accounting is used to assess the potential for mine waste or tailings to produce acidic mine drainage (AMD), or for naturally formed altered or mineralized rock to produce acidic rock drainage (ARD). Most commonly, iron sulfide minerals in the presence of water and oxygen weather to produce sulfuric acid. There are numerous chemical reactions that describe the processes; commonly, the first reaction involving pyrite oxidation and acid production is (Seal, 2010):

$$
\mathrm{FeS}_{2}+7 / 2 \mathrm{O}_{2}+\mathrm{H}_{2} \mathrm{O} \rightarrow \mathrm{Fe}^{2}++2 \mathrm{SO}_{4}{ }^{2-}+2 \mathrm{H}^{+}
$$

Once pyrite oxidation begins, some ferrous iron is converted to ferric iron (Seal, 2010):

$$
2 \mathrm{Fe}^{2+}+1 / 2 \mathrm{O}_{2}+2 \mathrm{H}^{+} \rightarrow 2 \mathrm{Fe}^{3+}+\mathrm{H}_{2} \mathrm{O}
$$

In the presence of the bacterium Acidithiobacillus ferrooxidans, the reaction rate increases 100,000 times. Once the $\mathrm{pH}$ of the solution decreases to about 4, pyrite oxidation by ferric iron (equation R3 below) produced in equation R2 becomes more important (Nordstrom and Alpers, 1999). Ferric iron highly effectively oxidizes pyrite, according to (Seal, 2010):

$$
\mathrm{FeS}_{2}+14 \mathrm{Fe}^{3+}+8 \mathrm{H}_{2} \mathrm{O} \rightarrow 15 \mathrm{Fe}^{2+}+2 \mathrm{SO}_{4}{ }^{2-}+16 \mathrm{H}^{+}
$$

A simplified acid production summary reaction by pyrite oxidation, which involves as many as 15 separate reactions involving oxygen and ferric iron (Nordstrom and Alpers, 1999), each with characteristic reaction rates, is

$$
\mathrm{FeS}_{2}+15 / 4 \mathrm{O}_{2}+7 / 2 \mathrm{H}_{2} \mathrm{O} \rightarrow \mathrm{Fe}(\mathrm{OH})_{3}+2 \mathrm{H}_{2} \mathrm{SO}_{4}
$$

Equation R4 implies that one mole of pyrite can produce two moles of sulfuric acid, or four moles of hydronium ion (sulfuric acid is diprotic), resulting in four moles of acid per mole of pyrite. Carbonate minerals, notably calcite, are the most effective acid neutralizers. The neutralization reaction at $\mathrm{pH}<6.4$ (White and others, 1999), the acidity condition of most interest, is given by

$$
\mathrm{CaCO}_{3}(\mathrm{~s})+2 \mathrm{H}^{+}(\mathrm{aq}) \rightarrow \mathrm{H}_{2} \mathrm{CO}_{3}(\mathrm{aq})+\mathrm{Ca}^{2+}(\mathrm{aq})
$$

Equation R5 shows that one mole of calcite can neutralize two moles of acid, and equations R4 and R5 together indicate that two moles of calcite are required to neutralize the acid produced from one mole of pyrite. The formula weight of pyrite is $120 \mathrm{~g} / \mathrm{mole}$ and calcite has a formula weight of $100 \mathrm{~g} / \mathrm{mole}$; thus, about 1.7 weight percent calcite is required to neutralize 1.0 weight percent pyrite. Other sulfide minerals can also produce acid, by reaction with oxygen, or by oxidation by ferric iron (for example, marcasite, pyrrhotite, bornite, arsenopyrite, enargite, tennantite/tetrahedrite, realgar, orpiment, stibnite, chalcopyrite, covellite, cinnabar, and greenockite; Plumlee, 1999).

Dissolution of acid-storing salts, such as melanterite or copiapite, can also generate acid, as can hydrolysis of metal ions. Reactions involving carbonate minerals neutralize acid and some silicate minerals, such as biotite, feldspars, and chlorite, have limited neutralization potential. Diverse geologic materials (for example rock or waste from different deposit types, different degrees or types of alteration) have different amounts of either acid-producing and or acidneutralizing capacity. Because high-sulfidation epithermal deposits lack carbonate minerals, attributable to the strong acid leaching of host rock before ore deposition (Hedenquist and others, 2000), they can generate highly acidic drainage as a result of oxidation and weathering of sulfide minerals.

Various analytical approaches have been used to predict acid-generation potential. Total sulfur analyses can be used to estimate acidity, assuming that sulfur is present entirely as sulfide minerals (often a questionable assumption); sulfate minerals, such as barite or gypsum, do not produce acid because their sulfur is already oxidized. Sulfide sulfur content (in weight percent) multiplied by 31.25 yields values for acid potential (AP) in $\mathrm{kg} /$ ton $\mathrm{CaCO}_{3}$ equivalent (Sobek and others, 1978). Neutralization potential (NP) is determined either by adding acid to a sample and back titrating, or by direct titration of a sample slurry (U.S. Environmental Protection Agency, 1994). Net acid production (NAP) can also be measured directly by oxidizing sample powder with hydrogen peroxide; acid produced from sulfides, or released from soluble acid salts, is in contact with neutralizing minerals in the sample. After sufficient time for all acid-producing and acid-consuming reactions to proceed to completion, the resulting solution is titrated to a $\mathrm{pH}$ of 7 (Lapakko and Lawrence, 1993), and the volume of dilute sodium hydroxide needed to neutralize the solution is converted to $\mathrm{kg} / \mathrm{ton}$ 
$\mathrm{CaCO}_{3}$ equivalent. The measurement yields the net acid potential of the available acidity versus the available neutralization potential, and is expressed in $\mathrm{kg}$ /ton $\mathrm{CaCO}_{3}$ equivalent.

The net neutralization potential is defined as $\mathrm{NNP}=\mathrm{NP}-$ AP, that is, the difference between the neutralization potential and the acid potential. The neutralization potential ratio is defined as $\mathrm{NPR}=\mathrm{NP} / \mathrm{AP}$. If the NNP is less than $20 \mathrm{~kg} /$ ton $\mathrm{CaCO}_{3}$, then the material being evaluated will probably produce acid, whereas if the NNP is greater than $20 \mathrm{~kg} /$ ton $\mathrm{CaCO}_{3}$, then acid production is unlikely. Similarly, if the neutralization potential ratio is less than 1:1, acid production is likely, and if it is greater than $3: 1$, acid production is unlikely. The interpretation of the NAP value for a material is similar to the NNP, but materials with a NAP greater than $20 \mathrm{~kg} /$ ton are likely to produce acid, whereas those with a NAP less than $20 \mathrm{~kg} / \mathrm{ton}$ are unlikely to produce acid.

Fey and others (2000) measured the NAP of about 100 mine-waste materials from the upper Animas River (Colorado) watershed, including 9 samples from waste derived from highsulfidation deposits and 90 samples from waste derived from polymetallic deposits. Plumlee (1999) considered polymetallic vein deposits to have characteristics similar to those of lowsulfidation epithermal deposits; NAP data for the polymetallic vein deposits are included here for comparison with the highsulfidation waste samples. In addition to NAP analyses, each of these samples was also subjected to a passive water leach test (Desborough and Fey, 1997) and the solutions analyzed for metals. Figure R1 shows a plot of measured NAP versus the sum of dissolved metals $(\mathrm{Zn}+\mathrm{Cd}+\mathrm{Cu}+\mathrm{As}+\mathrm{Pb})$ resulting from the passive water leach. The median NAP for the highsulfidation samples was $56 \mathrm{~kg} / \mathrm{ton} \mathrm{CaCO}_{3}$, and the maximum was $167 \mathrm{~kg} /$ ton $\mathrm{CaCO}_{3}$. The sum of metal concentrations for the high-sulfidation samples ranged from 6,000 to $18,000 \mu \mathrm{g} / \mathrm{L}$, with a median concentration of $14,600 \mu \mathrm{g} / \mathrm{L}$. Dissolved iron concentrations in leachates of these samples ranged from $2,400 \mu \mathrm{g} / \mathrm{L}$ to $210,000 \mu \mathrm{g} / \mathrm{L}$, and dissolved aluminum (another element of environmental concern) ranged from $400 \mu \mathrm{g} / \mathrm{L}$ to $5,200 \mu \mathrm{g} / \mathrm{L}$. The high-sulfidation sample with the lowest $\mathrm{NAP}, 15 \mathrm{~kg} /$ ton $\mathrm{CaCO}_{3}$, had the highest metal content sum, $18,200 \mu \mathrm{g} / \mathrm{L}$, and is dominated by $10,000 \mu \mathrm{g} / \mathrm{L}$ zinc, which is soluble even in low acidity conditions. These relations illustrate the challenges associated with predicting the environmental contributions of waste materials that have appear to have low bulk acidity.

In comparison, the polymetallic vein waste samples have a median of $8 \mathrm{~kg} /$ ton $\mathrm{CaCO}_{3}$ net acidity, a maximum of $78 \mathrm{~kg} /$ ton $\mathrm{CaCO}_{3}$, and a minimum of $1.5 \mathrm{~kg} /$ ton $\mathrm{CaCO}_{3}$. The metal concentration sums of the polymetallic vein wastes range from $230 \mu \mathrm{g} / \mathrm{L}$ to $21,000 \mu \mathrm{g} / \mathrm{L}$, and again, commonly

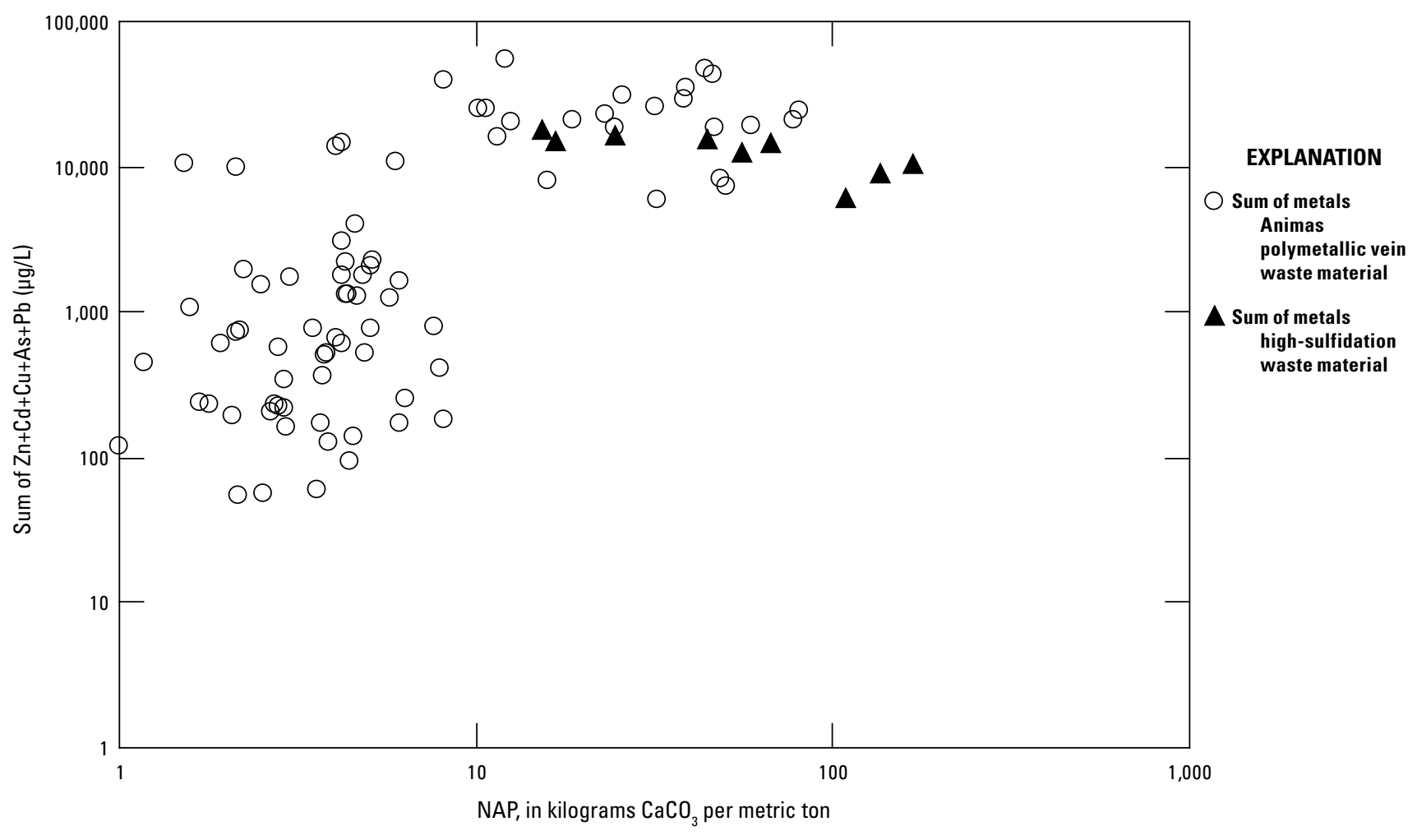

Figure R1. Plot of net acid production (NAP) versus the sum of dissolved metals $(\mathrm{Zn}+\mathrm{Cd}+\mathrm{Cu}+\mathrm{As}+\mathrm{Pb})$ from a static water 1:20 leach for samples from the upper Animas River watershed, southwest Colorado. Filled triangles are samples from high-sulfidation deposits; open circles are samples from polymetallic vein deposit waste, serving as an approximation for low- and intermediate-sulfidation epithermal deposits. Modified from Fey and others (2000). 
contain high zinc concentrations. Both types of samples had elevated metals sums when the NAP was greater than $20 \mathrm{~kg} /$ ton $\mathrm{CaCO}_{3}$. In summary, these characteristics indicate that (1) mineralized material associated with low-sulfidation deposits tends to have lower acidity and total metal contents, and (2) NAP and total metal contents for mineralized material associated with low- and intermediate-sulfidation and highsulfidation deposits overlap considerably.

\section{Drainage Signatures}

Many mineral deposits and mining operations contribute metals and acid to their spatially proximal drainage network and to groundwater. Physical, mineralogical, chemical, climatic, and topographic characteristics influence the nature and extent of these contributions (Plumlee, 1999).

\section{Ground and Surface Water}

Hydrothermal alteration and mineralization during formation of high-sulfidation epithermal deposits result in (1) large volumes of rock that have been leached of carbonate and other acid-neutralizing minerals and (2) deposition of sulfide minerals. These deposits are therefore likely to strongly affect associated surface and groundwater. For example, weathering and decomposition of enargite releases copper and arsenic, the decomposition of other copper sulfide minerals releases additional copper, and the dissolution of sphalerite contributes high concentrations of zinc to surface and (or) groundwater.

Portrayals of the sum of elements of environmental concern $(\mathrm{Zn}+\mathrm{Cu}+\mathrm{Cd}+\mathrm{Pb}+\mathrm{Co}+\mathrm{Ni})$ versus the $\mathrm{pH}$ of deposit drainage water are known as Ficklin plots (Plumlee and others, 1999); in some cases, these plots may be modified to include arsenic or other elements in the sum. Plumlee and others (1999) compiled examples of drainage $\mathrm{pH}$ and metal concentrations from a variety of sources, which, in addition to samples from the upper Animas River basin in Colorado, are plotted in figure R2. Drainage samples associated with highsulfidation mineralized rock have low $\mathrm{pH}$ (mostly between 2 and 4) and contain total metal concentrations that range from 10,000 to $1,000,000 \mu \mathrm{g} / \mathrm{L}$. The five samples with $\mathrm{pH}$ less than 4 and metal concentrations between 10 and $1,000 \mu \mathrm{g} / \mathrm{L}$ (open squares) are from a "stream affected by natural drainage waters" (Plumlee and others, 1999, p. 428). They appear to represent low-pH waters, unaffected by mining operations, that drain hydrothermally altered but weakly mineralized areas, as indicated by low metal contents. The two samples plotted as open diamonds represent background samples from drainages upstream from the upper Animas high-sulfidation deposits. Background values for summed concentrations of $(\mathrm{Zn}+\mathrm{Cu}+\mathrm{Cd}+\mathrm{Co}+\mathrm{As}+\mathrm{Ni}+\mathrm{Pb})$ are below 1,000 . In addition, (1) water draining the high-sulfidation deposits tends to have lower $\mathrm{pH}$ and higher summed concentrations than

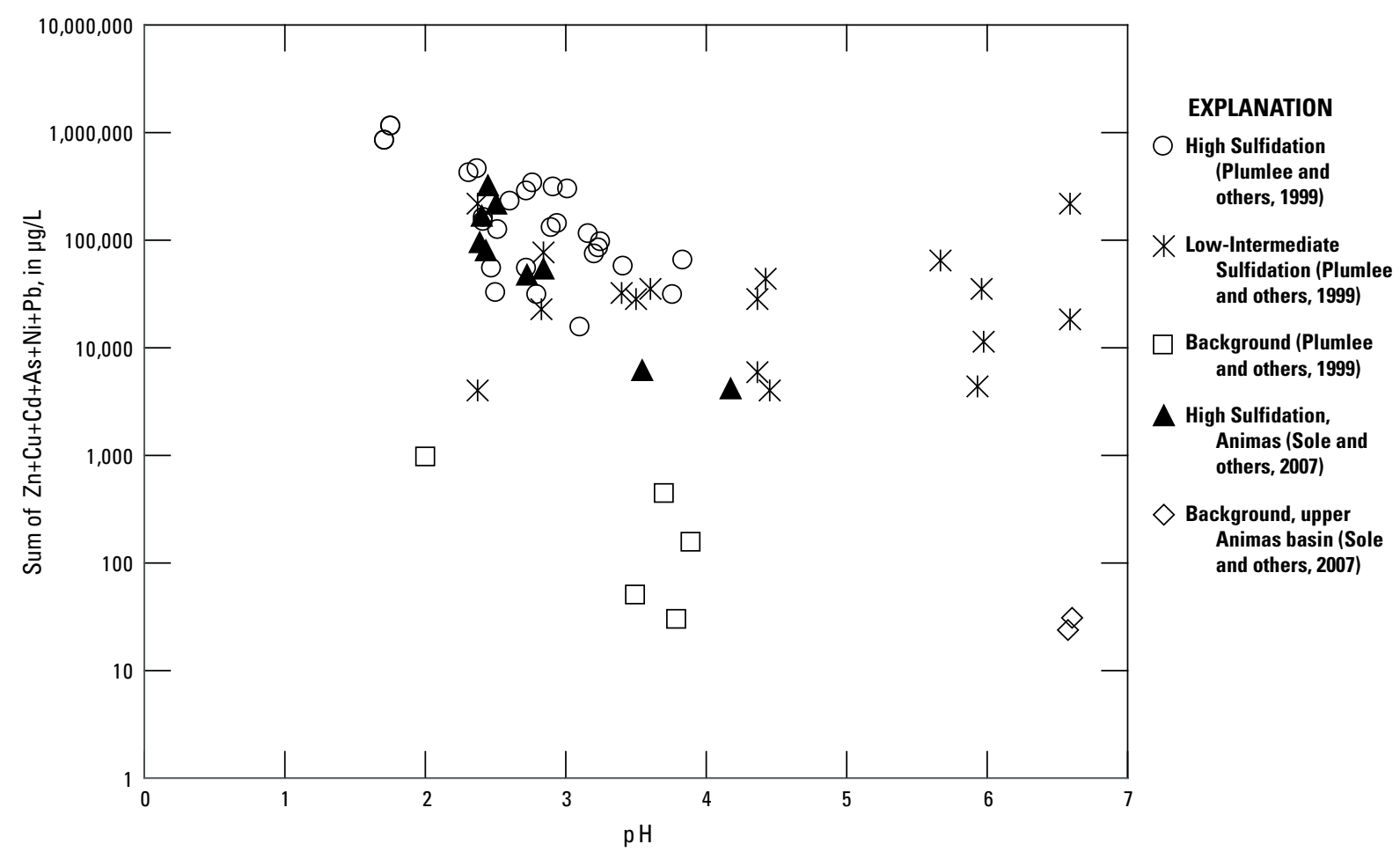

Figure R2. Modified Ficklin plot of drainage waters from high-sulfidation and lowand intermediate-sulfidation epithermal deposits. Data from Plumlee and others (1999) and Sole and others (2007). 
low-sulfidation deposits, (2) the low-sulfidation deposits have a wider range of $\mathrm{pH}$, which probably reflects their neutralizing mineral content diversity, relative to contained sulfide minerals, and (3) the low-sulfidation deposits tend to have lower, but occasionally elevated summed metal concentrations; the higher metal contents are commonly dominated by elevated zinc abundances.

The geochemical characteristics of water draining high-sulfidation deposits are well documented by summary statistics for 37 samples (table R1). Two samples of seep water collected from Summitville, subjected to extreme evaporation, have the highest sulfate contents and the maximum concentrations of most of the metals. Summary statistics for 13 samples of water draining low-sulfidation deposits (Plumlee and others, 1999) indicate that drainages associated with these types of deposits are minimally affected by these deposits (table R2). Most epithermal deposits have low concentrations of cobalt or nickel; consequently, cobalt and nickel contribute insignificantly to the total metal content of water associated with these deposits.

Table R1. Summary statistics for $\mathrm{pH}$, specific conductance, and sulfate ( $\left.\mathrm{SO}_{4}^{-}\right)$, aluminum (Al), arsenic (As), calcium (Ca), cadmium (Cd), cobalt $(\mathrm{Co})$, copper $(\mathrm{Cu})$, iron $(\mathrm{Fe})$, manganese $(\mathrm{Mn})$, nickel $(\mathrm{Ni})$, lead $(\mathrm{Pb})$, zinc $(\mathrm{Zn})$, and the sum of $(\mathrm{Zn}+\mathrm{Cu}+\mathrm{Cd}+\mathrm{Co}+\mathrm{As}+\mathrm{Ni}+\mathrm{Pb})$ concentrations for 37 water samples directly associated with high-sulfidation epithermal deposits. Data from Plumlee and others (1999) and Sole and others (2007).

[mg/L, milligrams per liter; $\mu \mathrm{g} / \mathrm{L}$, micrograms per liter; $\mu \mathrm{S} / \mathrm{cm}$, micro-Siemens per centimeter]

\begin{tabular}{lccrrrrrrrrrr}
\hline & $\mathbf{p H}$ & $\begin{array}{c}\text { Specific conductance } \\
(\boldsymbol{\mu S} / \mathbf{c m})\end{array}$ & $\begin{array}{c}\mathbf{S O}_{\mathbf{4}}^{-} \\
(\mathbf{m g} / \mathbf{L})\end{array}$ & $\begin{array}{c}\mathbf{A l} \\
(\mathbf{m g} / \mathbf{L})\end{array}$ & $\begin{array}{c}\mathbf{A s} \\
(\boldsymbol{\mu} \mathbf{g} / \mathbf{L})\end{array}$ & $\begin{array}{c}\mathbf{C a} \\
(\mathbf{m g} / \mathbf{L})\end{array}$ & $\begin{array}{c}\mathbf{C d} \\
(\boldsymbol{\mu} \mathbf{g} / \mathbf{L})\end{array}$ & $\begin{array}{c}\text { Co } \\
(\boldsymbol{\mu} \mathbf{g} / \mathbf{L})\end{array}$ & $\begin{array}{c}\mathbf{C u} \\
(\boldsymbol{\mu} \mathbf{g} / \mathbf{L})\end{array}$ & $\begin{array}{c}\mathbf{F e} \\
(\mathbf{m g} / \mathbf{L})\end{array}$ & $\begin{array}{c}\mathbf{M n} \\
(\boldsymbol{\mu} \mathbf{g} / \mathbf{L})\end{array}$ & $\begin{array}{c}\mathbf{N i} \\
(\boldsymbol{\mu} \mathbf{g} / \mathbf{L})\end{array}$ \\
\hline Minimum & 1.7 & 54 & 78 & 5 & $<20$ & 10 & 5 & 63 & 1,250 & 1 & 10 & 7 \\
Median & 2.7 & 2,430 & 2,510 & 290 & 450 & 93 & 180 & 950 & 61,100 & 350 & 14,500 & 610 \\
Average & 2.8 & 5,260 & 8,400 & 8,300 & 2,900 & 140 & 330 & 1,950 & 122,000 & 1,700 & 32,800 & 1,950 \\
Maximum & 4.2 & 38,000 & 125,800 & 71,400 & 28,000 & 560 & 3,000 & 16,000 & 706,000 & 28,000 & 370,000 & 28,000 \\
\hline
\end{tabular}

\begin{tabular}{lrrc}
\hline & $\begin{array}{c}\mathbf{P b} \\
(\boldsymbol{\mu} \mathbf{g} / \mathbf{L})\end{array}$ & $\begin{array}{c}\mathbf{Z n} \\
(\boldsymbol{\mu} \mathbf{g} / \mathbf{L})\end{array}$ & $\begin{array}{c}\mathbf{Z n + C u + C d + C o + A s + N i + P b} \\
(\boldsymbol{\mu g} / \mathbf{L})\end{array}$ \\
\hline Minimum & 1 & 580 & 15,500 \\
Median & 90 & 20,500 & 128,000 \\
Average & 130 & 53,000 & 217,000 \\
Maximum & 800 & 610,000 & $1,132,000$ \\
\hline
\end{tabular}

Table R2. Summary statistics for $\mathrm{pH}$, specific conductance, and sulfate ( $\mathrm{SO}_{4}-$ ), aluminum (Al), arsenic (As), calcium (Ca), cadmium (Cd), cobalt (Co), copper (Cu), iron (Fe), manganese (Mn), nickel ( $\mathrm{Ni})$, lead (Pb), zinc ( $\mathrm{Zn})$, and the sum of $(\mathrm{Zn}+\mathrm{Cu}+\mathrm{Cd}+\mathrm{Co}+\mathrm{As}+\mathrm{Ni}+\mathrm{Pb})$ concentrations for 13 water samples collected from low- and intermediate-sulfidation epithermal deposits. Data from Plumlee and others (1999).

$[\mathrm{mg} / \mathrm{L}$, milligrams per liter; $\mu \mathrm{g} / \mathrm{L}$, micrograms per liter; $\mu \mathrm{S} / \mathrm{cm}$, micro-Siemens per centimeter $]$

\begin{tabular}{|c|c|c|c|c|c|c|c|c|c|c|c|c|}
\hline & pH & $\begin{array}{c}\text { Specific conductance } \\
(\mu \mathrm{S} / \mathrm{cm})\end{array}$ & $\begin{array}{c}\mathrm{SO}_{4}^{-} \\
(\mathrm{mg} / \mathrm{L})\end{array}$ & $\begin{array}{c}\mathrm{Al} \\
(\mathrm{mg} / \mathrm{L})\end{array}$ & $\begin{array}{c}\text { As } \\
(\mu \mathrm{g} / \mathrm{L})\end{array}$ & $\begin{array}{c}\mathrm{Ca} \\
(\mathrm{mg} / \mathrm{L})\end{array}$ & $\begin{array}{c}\text { Cd } \\
(\mu g / L)\end{array}$ & $\begin{array}{c}\mathrm{Co} \\
(\mu \mathrm{g} / \mathrm{L})\end{array}$ & $\begin{array}{c}\mathrm{Cu} \\
(\mu \mathrm{g} / \mathrm{L})\end{array}$ & $\begin{array}{c}\mathrm{Fe} \\
(\mathrm{mg} / \mathrm{L})\end{array}$ & $\underset{(\mu \mathrm{g} / \mathrm{L})}{\mathrm{Mn}}$ & $\begin{array}{c}\mathrm{Ni} \\
(\mu \mathrm{g} / \mathrm{L})\end{array}$ \\
\hline Median & 4.37 & 975 & 520 & 2.0 & 8 & 130 & 110 & 44 & 620 & 13 & 29,000 & 36 \\
\hline Maximum & 6.59 & 4,890 & 12,200 & 200 & 2,300 & 420 & 620 & 82 & 48,000 & 890 & 150,000 & 240 \\
\hline
\end{tabular}

\begin{tabular}{lrcc} 
& $\begin{array}{c}\mathbf{P b} \\
(\boldsymbol{\mu g} / \mathbf{L})\end{array}$ & $\begin{array}{c}\mathbf{Z n} \\
(\boldsymbol{\mu} \mathbf{g} / \mathbf{L})\end{array}$ & $\begin{array}{c}\mathbf{Z n + C u + C d + C o + A s + N i + P b} \\
(\boldsymbol{\mu} \mathbf{g} / \mathbf{L})\end{array}$ \\
\hline Minimum & 1 & 2,600 & 3,990 \\
Median & 26 & 28,000 & 29,000 \\
Average & 220 & 37,000 & 43,000 \\
Maximum & 1,100 & 170,000 & 222,000 \\
\hline
\end{tabular}




\section{Past and Present Mining Methods and Ore Treatment}

Before the 1980s, underground mining methods were used to extract most ore associated with epithermal mineral deposits because their high grade allowed this to be economically feasible. After the 1970 s, the decoupling of world currencies from gold values led to a rise in gold prices, which encouraged mining of lower grade deposits by open-pit methods. The trend of gold recovered from all deposit types worldwide has been one of declining ore grade (Mudd, 2007) to around 3-4 g/t today, and thus, open-pit mining, which is easier, less expensive, and quicker to develop, dominates modern gold mining operations (Norgate and Haque, 2012). Open-pit mines yield ore of lower unit value, but with much greater volumes mined, so greater amounts of gold, silver, copper, and other commodities are recovered.

In historical operations (pre-1900s), gold was recovered by amalgamation, followed by mercury removal by roasting. This method is little used today, as issues relating to the cost of mercury and the attendant risks to human health and to the environment from lost mercury, render it unattractive. However, amalgamation is still used in some low-technology artisanal mining operations.

Industrial scale mining operations recover gold today by crushing the ore, and by using a sodium (or potassium) cyanide leach to recover gold by way of the following reaction:

$$
4 \mathrm{Au}+8 \mathrm{NaCN}+\mathrm{O}_{2}+2 \mathrm{H}_{2} \mathrm{O}=4 \mathrm{NaAu}(\mathrm{CN})_{2}+4 \mathrm{NaOH}
$$

(the Elsener equation; Smith and Mudder, 1999). Another way of writing the equation is

$$
4 \mathrm{Au}+8 \mathrm{CN}^{-}+\mathrm{O}_{2}+2 \mathrm{H}_{2} \mathrm{O}=4 \mathrm{Au}(\mathrm{CN})_{2}^{-}+4 \mathrm{OH}^{-}
$$

which illustrates that neither the sodium nor potassium ion participates in the reaction, but that the active reactant is the cyanide ion.

The cyanide solution concentration is typically in the range of 0.01 to 0.05 percent (Logsdon and others, 1999). Leaching can proceed in tanks, or for the case of lower grade ores, coarsely ground ore is leached on pads ("heaps") for weeks or months, and the "pregnant" solution is processed.

The pregnant solution is processed in one of two ways. In one process, activated carbon is added to the solution causing gold-cyanide complex sorption to the carbon. Two variants of the first process exist, the first being carbon-in-leach (CIL), where the carbon is added to the leach solution, and gold-cyanide complex formation and sorption to carbon occur essentially simultaneously. In the other variant of carbon sorption, carbon-in-pulp (CIP), the activated carbon is added to the slurry in tanks downstream from the leaching tanks, so that gold-cyanide formation is followed by sorption to carbon. In both variants, the carbon-gold-cyanide solid is then removed from the slurry by filtration. The gold cyanide complex is then released from the carbon by reverse stripping using a hot caustic cyanide solution, and the gold is subsequently recovered by electrolysis and reaction with iron.

The Merrill-Crowe process, the other method of recovering gold from the pregnant solution, involves removing dissolved oxygen by vacuum, and adding finely ground zinc to the solution, which by a replacement reaction causes gold precipitation and zinc dissolution. Final processing involves electrowinning and smelting (Norgate and Haque, 2012). Alternative lixiviants, such as thiourea and thiosulfate, are not widely used because of chemical management issues and environmental concerns (Zanbak, 2012) although they are used locally in China.

Some epithermal gold ore is relatively refractory, because the gold is bound tightly in sulfide minerals or is encapsulated in other minerals, mostly pyrite or quartz; these ore types require alternative processing, including flotation concentration, regrinding, roasting, pressure oxidation, or bio-oxidation, to liberate gold. Roasting, pressure oxidation, and bio-oxidation are alternative techniques used to oxidize and decompose sulfide minerals, which renders the gold more easily leachable by the cyanide solution (Norgate and Haque, 2012); they do not affect gold encapsulated in quartz, which can only be accessed by fine grinding.

\section{Volume and Footprint of Mine Waste and Tailings}

The volume of waste and tailings associated with mining of epithermal gold deposits is related to the size, shape, and depth of the deposit, and country rock competency; deposit depth and country rock competency dictate stripping ratios for open-pit mines (Seal, 2010). Underground mines generally have much smaller footprints than surface mines. However, in addition to the area occupied by mine pits, adits, or shafts, mine operations include mill tailings, waste piles, cyanide heap leach pads, cyanide tank leaching operations, and other facilities that support the actual mining activity, all of which contribute to the "disturbed ground" footprint. A particular mine may or may not have grinding facilities or mill operations, in which case ore may be transported offsite to a separate mill, or to another mine with those operations. Thus, the footprint of one mine with no facilities would be smaller than suggested by its mined production, and the footprint of a mine that also processes ore from other locations would have a footprint larger than that suggested by its mined production.

Once mining operations have ceased at a particular deposit, production records can be used to estimate the mass of waste rock and tailings produced by mining. Approximate volumes can be estimated by dividing the mass of rock removed by mining by a suitable density factor and applying an estimated expansion factor. Diggles and others (1996) applied a density of $2.7 \mathrm{t} / \mathrm{m}^{3}$ and an expansion factor of 1.2 to estimate the volume of material associated with mining the McLaughlin, California, low-sulfidation deposit. For example, ore production-plusreserves at the high-sulfidation El Indio, Chile, mine are $23.2 \mathrm{Mt}$ (Porter Geoconsultancy, 2017), which converts to an estimated minimum volume of about 10 million $\mathrm{m}^{3}$. The total volume 
must be augmented to account for the stripping ratio, the ratio of the mass of waste rock to the mass of ore removed by open-pit mining. Stripping ratios for most open-pit mines vary from 2 to 10 (Mudd, 2007). For example, Norgate and Haque (2012) employed a ratio of 3:1 to perform life cycle assessment (LCA) evaluations for gold mines. The total reserves and resources for the Yanacocha, Peru, high-sulfidation deposit is about 1.7 billion metric tons (appendix 2); if totally mined at a 1:1 stripping ratio, this deposit would produce a minimum of 1.7 billion $\mathrm{m}^{3}$ $\left(1.5 \mathrm{~km}^{3}\right)$ of waste and tailings.

Many mines are visible on aerial imagery, thereby enabling open-pit and total operation footprint size estimates (tables R3, R4). These area estimates do not necessarily reflect official mine property descriptions but reflect disturbances from all operations associated with a given mine. Surface mining operations where obvious pits are lacking, or pit dimensions are otherwise difficult to discern, could not be determined.

Imagery from 17 open-pit high-sulfidation epithermal deposit mines indicates a median pit size of 40 hectares (ha); the smallest pit is 0.8 ha (Lerokis, Indonesia) and the largest single pit is 230 ha (Pierina, Peru). The Yanacocha, Peru, deposit includes multiple pits with an aggregate area of about 270 ha. The associated total median footprint size, based on 23 deposits, is about 330 ha; the minimum total footprint is 10 ha at Lerokis, Indonesia, and the maximum footprint is 4,130 ha, at Yanacocha, Peru. The fraction of area occupied by the pit relative to the total mine footprint ranges from 3 percent at Guanaco and Choquilimpie, Chile, to 39 percent at Pierina, Peru; the median pit area is 12 percent. A footprint size determination was made for only one deposit mined by underground methods: Rodalquilar, Spain, 17 ha.

Table R3. Total disturbed area footprints, pit areas, in hectares, and ratio of pit area to total disturbed area for selected high-sulfidation epithermal deposits.

[ha, hectares; n.d., size of pit area could not be determined from imagery; --, no data]

\begin{tabular}{|c|c|c|c|c|}
\hline High-sulfidation deposit & $\begin{array}{l}\text { Mining } \\
\text { method }\end{array}$ & $\begin{array}{l}\text { Disturbed area } \\
\text { (ha) }\end{array}$ & $\begin{array}{c}\text { Pit area } \\
\text { (ha) }\end{array}$ & Area ratio \\
\hline Bor, Serbia & Surface & 1,420 & 140 & 0.10 \\
\hline Brewer, U.S.A. & Surface & 100 & n.d. & -- \\
\hline Chimberos, Chile & Surface & 64 & 10 & 0.16 \\
\hline Choquelimpie, Chile & Surface & 310 & 10 & 0.03 \\
\hline Colquijirca, Peru & Surface & 390 & 67 & 0.17 \\
\hline El Hueso, Chile & Surface & 380 & 40 & 0.11 \\
\hline Fuertei, Sardinia & Surface & 38 & n.d. & -- \\
\hline Goldfield, USA & Surface & 130 & 7 & 0.05 \\
\hline Guanaco, Chile & Surface & 430 & 12 & 0.03 \\
\hline La Coipa, Chile & Surface & 1,310 & 81 & 0.06 \\
\hline Lerokis, Indonesia & Surface & 10 & 0.80 & 0.08 \\
\hline Majdanpek, Serbia & Surface & 1,330 & 180 & 0.14 \\
\hline Mulatos, Mexico & Surface & 330 & 51 & 0.16 \\
\hline Paradise Peak, U.S.A. & Surface & 240 & 40 & 0.17 \\
\hline Peak Hill, Australia & Surface & 320 & 38 & 0.12 \\
\hline Pierina, Peru & Surface & 590 & 230 & 0.39 \\
\hline Pueblo Viejo, Dominican Republic & Surface & 725 & n.d. & -- \\
\hline Rodalquilar, Spain & Underground & 17 & -- & -- \\
\hline El Sauzal, Mexico & Surface & 830 & 100 & 0.12 \\
\hline Summitville, U.S.A. & Surface & 215 & 34 & 0.16 \\
\hline Teine, Japan & Surface & 27 & n.d. & -- \\
\hline Zijinshan, China & Surface & 858 & 215 & 0.25 \\
\hline Yanacocha, Peru & & 4,130 & 270 (five pits) & 0.06 \\
\hline Minimum & & 10 & 0.80 & 0.03 \\
\hline Maximum & & 4,130 & 270 & 0.39 \\
\hline Median & & 330 & 41 & 0.12 \\
\hline Average & & 620 & 82 & 0.13 \\
\hline
\end{tabular}


Table R4. Total disturbed area footprints, pit areas, in hectares, and ratio of pit area to total disturbed area for selected surface-mined low- and intermediate-sulfidation epithermal deposits.

[ha, hectares; n.d., size of pit area could not be determined from imagery; --, no data]

\begin{tabular}{llrrr}
\hline \multicolumn{1}{c}{ Deposit } & \multicolumn{1}{c}{ Mining method } & $\begin{array}{c}\text { Disturbed area } \\
\text { (ha) }\end{array}$ & $\begin{array}{c}\text { Pit area } \\
\text { (ha) }\end{array}$ & $\begin{array}{c}\text { Area } \\
\text { ratio }\end{array}$ \\
\hline Baguio Philex Open Pit, Philippines & Surface & 345 & 120 & 0.35 \\
Baleyskoye, Russia & Surface & 610 & 70 & 0.12 \\
Dukat, Russia & Underground and surface & 500 & n.d. & -- \\
Castle Mountain, California & Surface & 315 & 55 & 0.17 \\
Golden Cross, New Zealand & Surface & 140 & 20 & 0.15 \\
\hline Kubaka, Russia & Surface & 380 & 80 & 0.21 \\
Martha Mine, New Zealand & Surface & 300 & 50 & 0.17 \\
\hline Mahd adh Dhahab, Saudi Arabia & Underground and surface & 110 & $n . d$. & -- \\
McLaughlin Mine, California & Surface & 280 & 60 & 0.21 \\
\hline Ocampo, Mexico & Underground and surface & 620 & n.d. & -- \\
Roşia Montană, Romania & Surface & 260 & 80 & 0.3 \\
\hline Round Mountain, Nevada & Surface & 2,220 & 300 & 0.14 \\
\hline Sleeper Mine, Nevada & Surface & 590 & 100 & 0.18 \\
\hline Vera-Nancy Pajingo Mines, Australia & Underground and surface & 80 & 10 & 0.12 \\
\hline \multicolumn{1}{c}{ Minimum } & & 80 & 10 & 0.12 \\
\hline Maximum & & 2,220 & 300 & 0.35 \\
\hline Median & & 330 & 70 & 0.17 \\
\hline Average & & 500 & 86 & 0.19 \\
\hline
\end{tabular}

Disturbed areas for low-sulfidation deposits are listed in table R4 (for surface or underground and surface-mined deposits) and table R5 (underground-mined deposits). In table R4, Round Mountain, Nevada, has the largest pit size (300 ha) and disturbed ground area (2,220 ha). The smallest total disturbed area (80 ha) and the smallest open-pit surface area (20 ha) are at the VeraNancy Pajingo mines in Australia, although underground methods were used there as well as surface mining. The median size for total disturbed area is about 330 ha, and the median for pit area is $70 \mathrm{ha}$. The ratio of pit area to total disturbed area ranges from 0.12 to 0.35 , with a median of 0.17 .

Table R5 contains area estimates for deposits mined by underground methods. Total area footprints for underground mines are much smaller than for surface mines. The largest disturbed area is at the Ken Snyder mine in Nevada, at about 60 ha, and the smallest estimated disturbed area is at the Hishikari mine in Japan at about 9 ha. The median size of disturbed area for the six mines is 16 ha and the average is 23 ha.

\section{Smelter Signatures}

Ores from epithermal deposits were commonly smelted in the past, but data relating to soil compositions near historical epithermal gold mines are lacking (Plumlee and others, 1995). Plumlee and others (1995) cited smelter signatures from Butte, Montana, as a possible analogue for soil signatures near smelters
Table R5. Total disturbed area footprints in hectares for selected underground-mined low- and intermediate-sulfidation epithermal deposits.

\begin{tabular}{llc} 
[ha, hectares] & \multicolumn{1}{c}{$\begin{array}{c}\text { Mining } \\
\text { method }\end{array}$} & $\begin{array}{c}\text { Disturbed area } \\
\text { (ha) }\end{array}$ \\
\hline Muzhievo, Ukraine & Underground & 10 \\
\hline Fresnillo, Mexico & Underground & 22 \\
\hline Gunung Pongkor, Indonesia & Underground & 9 \\
\hline Hishikari, Japan & Underground & 9 \\
Ken Snyder Mine, Nevada & Underground & 60 \\
Mazarron, Spain & Underground & 32 \\
\hline Minimum & & 9 \\
Maximum & & 60 \\
\hline Median & & 16 \\
Average & & 23 \\
\hline
\end{tabular}

that may have processed epithermal gold+copper ores. There, soil close to smelters is highly enriched in copper, arsenic, zinc, and lead. Chaffee and King (2014) discussed the dispersion of ore-related elements from historical smelter operations (more than 100 years old) at Eureka, Nevada. Although the Eureka mines principally produced lead, silver, and gold from polymetallic carbonate replacement deposits, associated ores contained minor concentrations of the following elements that are also components 
of epithermal gold deposits: $\mathrm{As}, \mathrm{Bi}, \mathrm{Cd}, \mathrm{Co}, \mathrm{Cu}, \mathrm{Hg}, \mathrm{Mo}, \mathrm{Ni}$, $\mathrm{Sb}, \mathrm{Se}, \mathrm{Sn}, \mathrm{Te}, \mathrm{W}$, and Zn. Chaffee and King (2014) applied factor analysis to geochemical analyses of 186 soil samples, and demonstrated that smelting operations affected the geochemistry of soil as much as $5 \mathrm{~km}$ away. The dispersion of smelter-derived components was probably controlled by prevailing wind direction and topography. Silver, $\mathrm{As}, \mathrm{Bi}, \mathrm{Cd}, \mathrm{Pb}, \mathrm{Hg}$, In, and $\mathrm{Sn}$ have median concentrations in soils between five and ten times local or regional background values. Consequently, historical smelting operations have had demonstrable and long-term effects on soils for distances as far as several kilometers (Plumlee, 1999; Chaffee and King, 2014). Modern smelter operations, equipped with particulate (dust) collection and flue gas scrubbing, probably affect the geochemistry of nearby soils less than historical operations, but smelter impacts on the environment are still a concern.

\section{Climate Effects on Geoenvironmental Signatures}

The climatic setting of sulfide-bearing mineral deposits can affect chemical reaction rates and compositions of waters that interact with ore, waste material, and (or) tailings; in this regard, temperature, total precipitation, and evaporation are important factors (Seal and Ayuso, 2011). The overall environmental contributions derived from sulfide-mineralized rock are likely to be greatest in wet climates because of the increased availability of water to interact with sulfidic material (Seal, 2010). In arid and semiarid climates, interactions between mineralized rock and precipitation/runoff are less significant (Plumlee and others, 1999), but these waters are likely to be more acidic and metal rich because of evaporation effects and formation of acid-storing soluble metal-sulfate salts (Seal, 2010). In addition, in arid climates, windblown transport of metal-laden dust from waste and tailings may be significant.

Dold (1999) demonstrated that tailings from mineral deposits with similar primary mineralogy can generate distinctly different secondary mineral assemblages as a function of varied climatic settings. Dold and Fontboté (2001) studied the effects of three different climatic settings on porphyry copper flotation tailings in Chile. Although this study pertains to a deposit type different from epithermal gold deposits, and focused on processed tailings and not ore or waste, their observations provide a useful framework within which to consider climatic effects related to sulfide deposits. The first setting was precipitation dominant (alpine climate, $2,150 \mathrm{~m}$ elevation), where annual precipitation $(700 \mathrm{~mm})$ exceeds evaporation $(70 \mathrm{~mm})$. The next was evaporation dominant (Mediterranean climate, $725 \mathrm{~m}$ elevation) with $540 \mathrm{~mm}$ annual precipitation and high summer evaporation. The final setting was a hyperarid climate at an elevation of 2,270 m, with only $20 \mathrm{~mm}$ annual precipitation and very high evaporation.

In the precipitation-dominant climate, bivalent cations, such as those of copper and zinc, were leached from upper oxidation zones; below this zone, increasing $\mathrm{pH}$ controlled the sorption of these cations onto secondary manganese (II) and iron (III) hydroxides and clay minerals. Below the water table, with somewhat more reducing conditions (relative to the vadose zone), replacement processes, such as the transformation of chalcopyrite to covellite, dominate. Iron released from the chalcopyrite forms goethite (Sillitoe and Clark, 1969). In contrast, where evaporation exceeded precipitation, upward migration of water in the vadose zone resulting from capillary forces transported mobilized elements towards the top of the tailings. Further evaporation near the surface led to supersaturation of some mineral salts, resulting in precipitation of water-soluble secondary sulfates (for example, bonnatite and chalcanthite). Low temperatures and low precipitation characteristic of arctic environments would probably result in very slow rates of mineral decomposition and element leaching, and accordingly slow transport of either soluble or sorbed elements.

\section{Potential Ecosystem Impacts}

Mining and processing epithermal gold ore can potentially impact surrounding ecosystems. Acid mine drainage and attendant metal loads can affect surface and groundwater resources, and be introduced into sediment of surface drainages, especially in humid or wet climate settings with high topographic relief. Zinc, $\mathrm{Cu}, \mathrm{Pb}$, and $\mathrm{As}$ are the elements most likely to affect water quality. Low-pH waters produced by interactions between sulfide minerals, oxygen, and water can also introduce dissolved or colloidal iron and aluminum. Impacts associated with some elements can be partially ameliorated by water hardness (Seal, 2010). Water hardness attributable to carbonate minerals from lowand intermediate-sulfidation deposits will have some amelioration effect, but because high-sulfidation epithermal deposits do not contain residual carbonate, aquatic life is relatively unprotected in waters affected by them. The U.S. Environmental Protection Agency has developed specific regulatory guidelines for $\mathrm{Zn}, \mathrm{Cu}$, $\mathrm{Pb}$, and As abundances. Because many epithermal gold deposits contain arsenic-bearing minerals (for example, arsenopyrite, enargite, arsenical pyrite), abandoned underground mine drainage and water draining waste and tailing piles associated with underground and open-pit mines can significantly impact ecosystems. Pit lakes formed following cessation of mining and pumping are likely to intersect and therefore interact with the water table. In dry climates, acidic water and its dissolved metals can be further concentrated by evaporation affecting pit lakes. Waste or tailings piles in settings where wetting/drying cycles prevail commonly generate easily soluble efflorescent sulfate salts that store acid and metals (Plumlee and others, 1999; Seal, 2010), which are available for release in rain and (or) snowmelt events; these events can cause metal concentrations and loads to increases dramatically in receiving streams (Wirt and others, 1999; Fey and others, 2002).

In addition to effects on receiving waters, mining of gold deposits requires large volumes of water and energy to enable metal production. The trend toward mining and processing progressively lower grade gold ore will necessitate greater amounts of water and energy per ton of ore processed or mass of gold produced. The life cycle assessment for gold deposit types (Norgate and Haque, 2012) predicts that for an ore grade decrease of from $3.5 \mathrm{~g} / \mathrm{t}$ to $2 \mathrm{~g} / \mathrm{t}$, approximately 1.8 times as 
much water (7,750 L versus $14,000 \mathrm{~L})$ and approximately 1.6 times as much energy (6,200 MJ versus 10,200 MJ are required per ounce of gold produced.

Although the use of sodium cyanide is carefully controlled and its use in ore processing is well understood and regulated, accidental releases of cyanide have caused public concern. Cyanide is acutely toxic to humans through inhalation or ingestion at low concentrations, and aquatic organisms, such as fish and invertebrates, and birds and mammals are also sensitive at low levels (International Cyanide Management Code, 2014). Highprofile examples of cyanide releases into the environment include a tailings impoundment failure in 2000 at Baia Mare, Romania, which released 20,000 tons of sediment containing 120 tons of cyanide (Baia Mare Task Force, 2000); an accident involving a truck delivering cyanide to the Kumtor minesite in 1998 in Kyrgyzstan that released $1,760 \mathrm{~kg}$ of sodium cyanide into the Barskaun River (Hynes and others, 1998); and cyanide released at the Summitville mine in Colorado (U.S Environmental Protection Agency, 2004).

Cyanide, as total cyanide, weak-acid-dissociable (WAD) cyanide, or free cyanide, forms several geochemical species. Free cyanide is the most toxic and is stable in low-pH solutions as $\mathrm{CN}^{-}$ or HCN. Hydrogen cyanide gas $(\mathrm{HCN})$ is the predominant form of cyanide prevailing for $\mathrm{pH}<8$; under these conditions, cyanide gas is volatilized and dispersed in the air. WAD cyanide includes weak and moderately strong metal-cyanide complexes (for example, $\mathrm{Ag}, \mathrm{Cd}, \mathrm{Cu}, \mathrm{Ni}$, and $\mathrm{Zn}$ complexes; Botz, 2001; Logsdon and others, 1999). These WAD complexes pose toxicological concerns because they can dissociate to form free cyanide and metals; these processes mostly depend on (low) $\mathrm{pH}$ (Logsdon and others, 1999; Mudder and others, 2001). Metals such as gold and iron form strong cyanide complexes that do not easily dissociate in the environment.

Until the late 1970s, natural degradation of cyanide in tailings ponds was the only common effluent detoxification process. Subsequently, the gold mining industry has developed chemical treatment technology designed to enhance or replace the natural processes (Demopoulos and Cheng, 2004). This technology includes chemical oxidation by sulfur dioxide and air (INCO process) to create cyanate $\left(\left[\mathrm{OCN}^{-}\right]\right)$, oxidation by hydrogen peroxide, oxidation by peroxymonosulfuric acid $\left(\mathrm{H}_{2} \mathrm{SO}_{5}\right.$, also known as Caro's acid), alkaline chlorination (formerly widely used but mostly replaced by other processes), iron-cyanide precipitation, and biodegradation. Cyanide can also be stripped and recovered from leach solutions by lowering the $\mathrm{pH}$ to below 8 , thereby creating aqueous $\mathrm{HCN}$, which is air-stripped, volatilized as $\mathrm{HCN}$ gas, and absorbed into an alkaline solution of sodium hydroxide (the Cyanisorb and AVR processes; Botz, 2001). Other recovery processes include SART (sulfidize, acidify, recycle, thicken), the Hannah process (strong base resin extraction of free cyanide and metal cyanides), and the AuGMENT process (strong base resin extraction of copper and cyanide) (SGS, 2013). Demopoulos and Cheng (2004) studied the relative costs of cyanide recovery versus destruction and concluded that destruction was more effective; recovery alone does not yield solutions that meet environmental standards. However, recovery followed by secondary treatment, involving cyanide destruction, would be effective, and concerns over cyanide use and management in some parts of the world may make cyanide recovery with additional destructive treatment an attractive alternative.

Natural processes operating in the environment also act to attenuate cyanide. For instance, metal chelation (complexation), predominantly with iron, tends to immobilize the total cyanide via sorption onto organic or inorganic surfaces. Iron cyanide-metal complexes also precipitate over a broad range of $\mathrm{pH}$ (Mudder and others, 2001). Alternatively, cyanide oxidation produces cyanate $\left(\mathrm{OCN}^{-}\right)$, which is significantly less toxic than cyanide. This reaction requires a strong oxidizer, and consequently probably does not occur on a large scale in natural systems, but it can be used in engineered processes to decompose cyanide. Bioattenuation, the bacterial conversion of cyanides to ammonia and then to nitrates in soil, is most effective under aerobic conditions. Finally, formation of thiocyanate from free cyanide by reaction with forms of sulfur, mostly polysulfides and thiosulfate, yield reactants less toxic than free cyanide (Mudder and others, 2001). Mudder and others (2001), Botz (2001), Logsdon and others (1999), and Demopoulos and Cheng (2004) provide thorough overviews of cyanide chemistry and geochemistry.

Other ecosystem concerns associated with mining epithermal deposits include the effects of windblown dust containing sulfide or sulfate salts on soil and surface water systems, and the effect of smelter emissions on air quality. Mercury derived from low-sulfidation epithermal deposits can be released into the environment, especially in warm, humid climates where methylated compounds of particular environmental concern may form. Most high-sulfidation gold deposits do not contain high mercury concentrations (Paradise Peak, Nevada, is an exception), but at historical sites, or where mercury is used in gold recovery as in some present-day artisanal operations, mercury losses pose environmental risks.

Tailings and waste piles need to be properly engineered in arctic or tundra settings to prevent seepage into permafrost and to prevent impoundment dam failure resulting from basal permafrost saturation.

\section{Potential Human Health Issues}

Human health and safety issues related to mining epithermal gold deposits are those related to the industrial nature of operation and exposure to waste products on site and in the surrounding environment. Proper training and practices must be implemented to safeguard workers involved in the use of acids, bases, and cyanide, in particular. The $\mathrm{pH}$ of extraction solutions must be maintained at sufficiently high values $(>10)$ to prevent volatilization of free $\mathrm{HCN}$ gas in confined environments. Safe practices must also be used in transporting and using sodium cyanide bricks. Pit wall and underground mine stability and tailings and waste pile slope stability represent additional significant safety concerns. The use of mercury for gold amalgamation and recovery, although long since abandoned by commercial mines, is still used by some artisanal miners. 
Safeguards regarding its use and recovery are commonly minimal; consequently, this practice exposes its practitioners and the local environment to mercury poisoning. Mercury methylation and incorporation into the human food chain are of particular concern (Seal and Piatak, 2012).

Monitoring of acid mine drainage and contained metals in solution resulting from mining and ore processing of highsulfidation epithermal deposits could be useful to those tasked with diverting these waters from pathways that would allow contamination of surface and groundwater that may be sources for human drinking water. Low-sulfidation deposits tend to develop more neutral $\mathrm{pH}$ drainage, but some have lower carbonate than sulfide content, and so can also produce acid drainage. In settings where evaporation prevails, dissolved metals can be concentrated, for example, in pit lakes, which may then intercept and interact with groundwater supplies (Seal, 2010). Constituents of concern that may be present in epithermal mine drainage include $\mathrm{Al}, \mathrm{Cu}$, $\mathrm{As}, \mathrm{Fe}, \mathrm{Mn}, \mathrm{Sb}, \mathrm{Bi}, \mathrm{W}, \mathrm{Mo}, \mathrm{Hg}$, sulfate, and $\mathrm{Zn}$. In managing very high elevation regions for water quality (for example, at the Pascua-Lama deposit, Argentina/Chile, Reuters, 2013), the possible impact of mining on local glaciers and therefore local water supply would be carefully considered. 



\title{
Chapter S. Exploration and Assessment Techniques
}

\author{
By David A. John, Peter G. Vikre, and Frederick T. Graybeal
}

\section{Exploration Versus Resource Assessment}

\author{
By David A. John
}

Although the initial objectives of exploration programs and resource assessments are similar, their ultimate objectives differ. Discovery of previously unidentified economic deposits is the ultimate objective of exploration programs, whereas delineation of areas permissive or favorable for the occurrence of undiscovered deposits and (or) estimation of the quantity of undiscovered resources are the objectives of resource assessments. In their early stages, objectives of these two activities overlap, specifically deciding whether a region is permissive for undiscovered deposits and therefore worth exploring, and the applicable datasets and techniques are similar. At later stages, the nature of applicable techniques and datasets commonly diverge. Specifically, exploration is increasingly focused on more detailed studies and data acquisition for small areas often by using geophysical and (or) geochemical techniques not used in resource assessments; these data may ultimately lead to prospect evaluation by drilling (see Simmons and others, 2005, their table 6).

Characteristics of epithermal gold-silver deposits applicable to exploration for new deposits have been discussed by White and Hedenquist (1990, 1995), White and others (1995), Corbett and Leach (1998), Sillitoe (1999), Hedenquist and others (2000), Simmons and others (2005), and Taylor (2007). Further, Sillitoe (1995, 2000) reviewed exploration histories of 68 major precious- and base-metal deposits, including 26 epithermal gold-silver deposits, discovered in the circumpacific region from 1969 to 1998. Finally, Allis (1990), Clarke and Govett (1990), Irvine and Smith (1990), Ellis and Robbins (2000), Wright and Lide (2000), and Dentith and Mudge (2014) describe specific geochemical and geophysical techniques successfully used in epithermal deposit exploration.

By comparison, Singer and Menzie (2010) summarized the history of resource assessment and methods of quantitative mineral resource assessment. Resource assessments of large land areas that contain numerous epithermal gold-silver deposits include those of the western Great Basin, U.S.A., which contains more than 100 known epithermal gold-silver deposits (John and others, 1993; Cox and others, 1996; Peters and others, 1996; Wallace and others, 2004), and of the Hauraki Goldfield, North Island, New Zealand, which includes about 50 known deposits (Christie and others, 2001, 2007; Crown Minerals, 2003; Rattenbury and Partington, 2003).

\section{Geological Parameters}

\author{
By David A. John
}

Epithermal gold-silver deposits form at shallow crustal depths (less than about 1,500 m below the paleowater table) and are hosted by nearly all rock types and by poorly consolidated sedimentary deposits. They form in diverse magmatic-tectonic settings, including convergent margin magmatic arcs, back arc, and continental rift environments, and in extensional settings that lack associated magmatism. Magmas associated with epithermal gold-silver deposits have compositions that range from basalt to rhyolite, from calc-alkaline to alkaline, and from magnesian to ferroan. Gold-silver minerals in these deposits precipitate from hydrothermal fluids that form structurally controlled veins and breccias, replacement bodies in chemically reactive rocks, and disseminations in permeable rocks within larger volumes of hydrothermally altered rock. The spatial extent of mineralized epithermal systems varies from narrow zones less than a few tens of meters wide and adjacent to faults to areas that range over tens of square kilometers and have no apparent relationship with individual structural features. Associated ore minerals precipitate in response to hydrothermal fluid evolution resulting from fluid boiling and (or) cooling, fluid mixing, vapor condensation, or combinations of these processes. Consequently, epithermal goldsilver deposits may form and be preserved in geologic terrains in which the shallow parts of subaerial hydrothermal systems are covered and protected from erosion by younger deposits.

Initially, exploration and assessment activities must define the study area and the deposit type(s) of interest. In assessment studies, the study area generally is determined by the needs of land-managing agencies or governments, and commonly involves assessing all types of mineral deposits potentially contained within the area. In contrast, exploration programs identify areas prospective for occurrence of a specific deposit type with the hope that exploration will lead to discovery of an economic deposit.

Developing an understanding of the geologic framework in the study area and characterizing known deposits contained within the area are critical early steps in assessment and exploration activities. For epithermal gold-silver deposits, these activities include identifying subtype(s) of known epithermal deposits, characterizing possibly genetically related deposits, and understanding their geologic setting(s), including their age and relation to magmatism and structures. Although host rock lithology is not a primary limiting factor in determining whether an area is permissive for epithermal gold-silver deposits, the 
vast majority of known deposits formed in magmatic arcs; consequently, developing an understanding of the regional magmatic-tectonic history generally is critical. In resource assessments, once the deposit type(s) to be considered have been determined, the geologic characteristics of known deposits are compared with those of the area being assessed to delineate permissive tracts, those areas outside of which the probability of deposits is negligible (for example, less than 1 in 100,000; Singer and Menzie, 2010). In exploration, geologic knowledge is used to identify those areas most prospective for new deposits and thus warranting more focused exploration. For example, Sillitoe's $(1995,2000)$ reviews of exploration histories for 26 epithermal deposits discovered in the circumpacific region between 1969 and 1998 indicate that 20 deposits were discovered during reexamination of pre-existing districts. Literature review played a major role in discovery of 5 deposits and only one of these deposits was found outside a known district.

Geologic maps are critical in the early phases of assessments and many exploration programs. Sillitoe's $(1995,2000)$ reviews of recent epithermal deposit discoveries show that geological inspection, including geologic mapping, was a major factor in discovery of 24 of 26 deposits. Regional geologic maps and derivative interpretative maps that allow definition of areas that include rocks having the appropriate lithology, age, and erosional depth, are especially important. Scale is a key limitation in exploration and assessment projects. Detailed assessments at large scales (for example, at 1:24,000 or larger) and definition of drill targets in exploration programs require detailed data including detailed geologic maps, and an assessment based on 1:1,000,000-scale data cannot be used to conduct detailed larger scale evaluations of smaller areas, such as a specific mining district or mountain range.

Geologic characteristics can be used to identify prospective areas that warrant more detailed exploration and delineate areas within large permissive tracts that are favorable for occurrence of undiscovered deposits as part of a resource assessment. Geologic features useful in exploration and assessment activities include the presence of (1) epithermal deposits and prospects, (2) rock units that host known deposits, (3) hydrothermal alteration of types known to accompany epithermal deposits, (4) structures and structural zones of types known to localize mineralization, and (5) shallow hydrothermal features, such as sinters and hydrothermal eruption breccias.

In exploration programs, after areas containing epithermal systems are identified, additional data are used to determine relative lateral and vertical positions within the system (Hedenquist and others, 2000). Specifically, explorationists seek to define the margins and center of the hydrothermal systems and determine whether particular exposures represent shallow paleodepths near the top of a system, within ore zones, or deeper levels, possibly below ore horizons. Several types of geologic data can be used to estimate relative position within epithermal systems, including (1) vein textures and vein mineralogy (for example, variations in intermediate-sulfidation vein deposits of the Hauraki Goldfield, New Zealand, Christie and others, 2007); (2) the type and origin of alunite in advanced argillic alteration (steam-heated, magmatic-hydrothermal, magmatic-steam, or supergene [Rye and others, 1992]); (3) the type and origin of silicic alteration and silica mineralogy (for example, residual [vuggy] quartz or silicification and opaline silica or quartz, table L2; Hedenquist and others, 2000); (4) presence of shallow hydrothermal features, especially paleosurface indicators, such as sinter deposits (fig. E13), and position of the paleowater table (Sillitoe, 2015); (5) systematic distribution of hydrothermal alteration assemblages and temperature-sensitive hydrothermal minerals, especially around inferred fluid upflow zones (figs. L2, L3; Reyes, 1990; Simmons and others, 2005); and (6) mineralogical (for example, presence of bladed calcite or quartz replacements of bladed calcite; Simmons and Christenson, 1994; Dong and others, 1995) or fluid inclusion (Bodnar and others, 1985) evidence for boiling hydrothermal fluids and position relative to the boiling zone (Moncada and others, 2012). As these data are compiled, paleotopography, and thus the hydraulic gradient during hydrothermal activity, can be reconstructed and hydrothermal fluid upflow zones identified. Having developed such a framework, ore targets can more easily be identified and prioritized for further study and (or) drilling.

\section{Geochemical Parameters}

\section{By David A. John}

Epithermal gold-silver deposits form in two principal geochemical environments: (1) those dominated by or containing a significant magmatic fluid contribution (high-sulfidation deposits) and (2) those dominated by meteoric waters that include variable but smaller magmatic fluid contributions (intermediate- and low-sulfidation deposits). The geochemical signature of ore and hydrothermally altered wall rock vary significantly between these two environments. The two environments may be present within a single district and form nearly simultaneously (for example, the Lepanto high-sulfidation and Victoria intermediate-sulfidation deposits, Philippines; Arribas and others, 1995b; Sajona and others, 2002) or several million years apart (for example, Comstock Lode intermediatesulfidation and Geiger Grade high-sulfidation systems, Nevada, Vikre and others, 1988; Hudson, 2003). Different types of spatially and temporally overlapping epithermal systems yield potentially complicated geochemical relationships.

Geochemical studies are integral to most epithermal deposit exploration programs and many resource assessments. As noted in Sillitoe's $(1995,2000)$ reviews of exploration in the circumpacific region, geochemical surveys were an important factor in nearly 80 percent of major epithermal gold-silver deposit discoveries in the latter third of the 20th century. Geochemical surveys employed in epithermal deposit exploration commonly involve several media, including rock, drainage (stream sediment and [or] panned concentrate), talus, and soil samples. In addition to gold and silver, $\mathrm{As}, \mathrm{Sb}, \mathrm{Hg} \pm \mathrm{Tl}$, Se concentrations, which are generally elevated in and near epithermal deposits, are usually determined; the analytical protocol may be expanded to include combinations of 
$\mathrm{Ba}, \mathrm{Cu}, \mathrm{Zn}, \mathrm{Pb}, \mathrm{Mo}, \mathrm{Te}, \mathrm{Sn}$, and $\mathrm{Bi}$ where high-sulfidation deposits are present or suspected. However, as noted by Hedenquist and others (2000), differences in the epithermal environment cause large geochemical variations, and therefore, selecting a suite of elements whose abundances are always indicative of epithermal deposit formation is not possible nor are concentrations of individual elements that constitute anomalous levels quantifiable (see "Geochemistry").

Stream sediment samples, including conventional (generally -80 mesh) and low-density bulk leach extractable gold (BLEG) samples, and pan concentrates commonly are employed in the early (regional) stages of exploration and in many resource assessments. Traditional panning for gold, a form of stream sediment sampling performed by prospectors for hundreds of years, aided discovery of many historical epithermal deposits (for example, Comstock Lode, Nevada, Smith, 1998; Bodie, California, Piatt, 2003) and is credited with several recent (late 20th century) discoveries (for example, Kelian, Indonesia, van Leeuwen and others, 1990). Several epithermal deposits have been discovered recently by tracing stream sediment samples with anomalous gold concentrations in stream sediment samples upstream (for example, Gosowong, Indonesia, Carlile and others, 1998, and Mule Canyon, Nevada, John and others, 2003). The Navidad, Argentina, polymetallic (Ag-Pb-Zn) intermediatesulfidation deposit was discovered after recognition of anomalous concentrations of silver, lead, and zinc in BLEG stream sediment samples with very low ( $\leq 2.58 \mathrm{ppb}$ ) gold contents (Lhotka, 2010). In exploration programs, once areas of interest have been defined by early stream sediment surveys, follow-up studies commonly involve grid-based soil surveys.

Rock geochemistry was an important aspect in about 75 percent of late 20th century epithermal deposit discoveries (Sillitoe, 1995, 2000). Among many elements included in analytical protocols, those of gold may be the most diagnostic; however, a large suite of elements are associated with epithermal deposits, including Ag, $\mathrm{Cu}, \mathrm{Zn}, \mathrm{Pb}, \mathrm{As}, \mathrm{Sb}, \mathrm{Bi}, \mathrm{Se}, \mathrm{Te}, \mathrm{Tl}, \mathrm{Mo}, \mathrm{W}$, $\mathrm{Sn}$, and $\mathrm{Hg}$, may have anomalous abundances in rocks associated with epithermal deposits. Notably, absolute concentrations of these elements vary dramatically among epithermal deposits. Many related factors, including basement and host rock types, compositional variation related to the character of igneous activity, and weathering and supergene oxidation, influence elemental abundances, which precludes rigorous definition of anomalous concentrations for individual elements.

Once geochemically anomalous areas have been defined where sources are covered by soil or talus, bedrock is often exposed by trenching. Subsequently, rock-chip sampling is used to define the source of the anomaly and facilitate detailed geologic mapping. Once geochemical anomaly sources are located, and the geology mapped, further exploration requires target evaluation at depth by drilling.

In low- and intermediate-sulfidation systems hosted by volcanic rocks, variations in major element ratios of altered rocks have been used to vector within mineralized zones (Warren and others, 2004, 2007; Booden and others, 2011). Mineralized zones in low- and intermediate-sulfidation systems are characterized by potassium metasomatism, which is manifested by formation of adularia and (or) illite and systematically increasing molar $\mathrm{K} / \mathrm{Al}$ and $\mathrm{K} /(2 \mathrm{Ca}+\mathrm{Na}+\mathrm{K})$ with proximity to mineralized rock. Potassically metasomatized halos around mineralized rock commonly extend much greater distances laterally and vertically than anomalous abundances of gold, silver, and other epithermal pathfinder elements; consequently, potassium enrichment patterns provide a vector toward low- and intermediate-sulfidation deposits.

\section{Geophysical Parameters}

\section{By David A. John}

Although geophysical techniques played a major role in only 2 of 26 major epithermal deposits discovered in the late 20th century, they were considered important in postdiscovery resource delineation for about one-quarter of these deposits (Sillitoe, 1995, 2000). Furthermore, discovery of 8 deposits involved examination of visible anomalies, and with recent technological advances and increasing availability of remote-sensing data, additional epithermal deposit discoveries may be made by using remote-sensing data. In addition to remote-sensing techniques, a wide variety of geophysical techniques are commonly used in exploration and assessment activities, but interpretation of geophysical data requires careful integration with geologic data.

In resource assessments, geophysical data are often used to help define areas permissive for undiscovered deposits and reduce the extent of areas considered favorable for these deposits. Gravity data are commonly used to estimate thickness of unconsolidated basin fill and thereby exclude areas where postmineral cover precludes potential exploitation (for example, Jachens and others, 1996). Gravity data also have been used to identify and define the boundaries of ignimbrite calderas and potentially related epithermal deposits concealed by younger deposits (for example, Smith and others, 2006). Aeromagnetic data can provide information about the extent and intensity of hydrothermal alteration, especially primary magnetite destruction in igneous rocks by fluids associated with high-sulfidation and low- and intermediate-sulfidation systems, which results in smooth magnetic lows ("magnetic quiet zones"; for example, Morrell and others, 2011). Aeromagnetic data also can be used to infer the subsurface extent of magnetic granitoid plutons (for example, Grauch, 1996), the plutonic roots of volcanoes (for example, John and others, 2012), and the distribution of shallowly covered volcanic rocks (for example, Blakely and others, 1996), all of which are important features in defining permissive and favorable areas. Linear magnetic boundaries commonly define the locations of high-angle faults and contacts between lithologic units with contrasting magnetic properties (for example, Blakely and others, 2007). Linear magnetic anomalies may also coincide with the subsurface extent of mafic dike swarms and related epithermal low-sulfidation deposits (Ponce and Glen, 2002).

In exploration, geophysical data are used, as in resource assessments, in regional-scale studies, and more commonly, 
in detailed district- and prospect-scale studies that generally include (1) higher resolution data (more closely spaced data and [or] airborne data collected at lower altitudes) and (2) employ a wider variety of geophysical techniques. Other commonly used geophysical techniques include electrical (induced polarization, resistivity), electromagnetic, and radiometric (Allis, 1990; Irvine and Smith, 1990; White and others, 1995; Dentith and Mudge, 2014).

Gravity studies can delineate volumes of rock with relatively higher or lower densities that arise from hydrothermal alteration. For example, Locke and de Ronde (1987) showed that a gravity low revealed by a detailed gravity survey is incident with the extent of hydrothermally altered rock at the Golden Cross deposit, New Zealand.

High-resistivity siliceous zones are intimately associated with epithermal deposits in residual (vuggy) and massive quartz and in quartz veins. At the Pajingo low-sulfidation deposit, highresistivity zones correspond to silicification that encloses quartz veins coincident with high-angle structures identified from an aeromagnetic survey (Hoschke and Sexton, 2005). These features were used to site drill holes that led to discovery of an ore zone beneath shallow $(5-15 \mathrm{~m})$ alluvial cover.

Extensive zones of disseminated pyrite that characterize most high-sulfidation deposits hosted by advanced argillic alteration are easily identified by induced polarization (IP) surveys; if sulfide minerals are unoxidized, IP chargeability responses will correspond with pyrite. Conductive clay minerals in the advanced argillic and argillic zones associated with high-sulfidation systems and in argillic halos around quart-adularia veins also can be detected by IP surveys. For example, an IP survey at Gunung Pongkor, Indonesia, helped define the strike and continuity of quartz-adularia veins hosted by argillic alteration (Basuki and others, 1994).

Combinations of radiometric and aeromagnetic data have been used to outline broad areas of potassically metasomatized rock related to hydrothermal systems and potential epithermal intermediate-sulfidation mineralization in the Hauraki Goldfield, New Zealand (Harris and others, 2006; Morrell and others, 2011). In this large area, broad K/Th anomalies defined by airborne radiometric surveys (1) correlate with the extent of the magnetic quiet zones and (2) indicate widespread potassium enrichment with more localized potassium anomalies that represent intensely potassium metasomatized rock associated with the cores of hydrothermal systems and quartz-adularia mineralization.

The distribution of hydrothermal minerals commonly associated with epithermal deposits can be accomplished by remote sensing using airborne hyperspectral and spaceborne multispectral data. In particular, high-resolution hyperspectral data can be used to distinguish silicic, illitic (sericitic), and advanced argillic alteration (alunite, pyrophyllite, dickite), which may be proximal to ore zones, from more widespread and distal propylitic and argillic alteration.

\section{Attributes Required for Inclusion in Permissive Tracts at Various Scales}

\author{
By David A. John
}

Because nearly all rock types as well as poorly consolidated sediments can host epithermal gold-silver deposits, and because these deposits form from subaerial hydrothermal systems at shallow depths in many geologic settings, permissive tracts for epithermal deposits can be extremely large. These tracts might be more effectively defined by attributes that exclude areas from the permissive domain. Two criteria that can be used to exclude areas from permissive tracts are (1) potential host rocks are buried too deeply by postmineralization cover or (2) exposed rocks are too deeply eroded; essentially all other geologic settings are permissive for epithermal deposits. Both criteria require information about the geologic history and ages of known deposits or hydrothermal systems within the area of interest, because younger epithermal mineralization may be superimposed on old deeply eroded terrains or thick postmineralization basin fill may cover potentially mineralized rock units.

\section{Knowledge that Enables Favorability Zonation of Permissive Tracts}

\author{
By David A. John
}

Definition of favorable zones within permissive tracts requires detailed knowledge about known epithermal deposits within these tracts, including the geologic (magmatic-tectonic) setting, type and age of host rocks, and approximate age of mineralization. Favorable zones normally include all known deposits, because most recently discovered deposits are within existing districts (Sillitoe, 1995, 2000). Data applicable to definition of favorability zonation include (1) detailed geologic maps that distinguish specific rock units known to host deposits or that are lithologically and temporally similar to host rocks of known deposits (for example, volcanic and volcaniclastic rocks that are coeval with similar rocks known to host deposits); (2) maps that show the distribution of regional and local structural features that are similar to those associated with known deposits or are intrinsically conducive to the formation of epithermal systems (for example, extensional stepover zones within strike-slip fault zones); (3) maps that show the distribution of hydrothermal mineral assemblages comparable with alteration assemblages characteristic of epithermal systems; (4) maps that show the distribution of near-surface deposits, such as sinter and hydrothermal eruption breccias, which are associated with shallow hydrothermal processes; (5) interpretive maps that depict the position of erosional surfaces at a time(s) coeval with epithermal deposit formation elsewhere in the permissive tract; (6) maps that delineate areas within permissive tracts that are eroded to levels 
commensurate with deposit preservation; and finally, (7) maps that delineate thin geologic cover above otherwise prospective ground. The utility of these map-based data depends on scale; more detailed, larger scale maps are required for more accurate favorable zone definition.

\section{Factors Affecting Undiscovered Deposit Estimates (Deposit Size and Density)}

\author{
By David A. John
}

Delineating areas favorable for the occurrence of undiscovered deposits and estimating numbers of these deposits requires knowledge concerning the distribution, origin, and size of known deposits. Districts that contain numerous deposits were demonstrably affected by the geologic processes required for epithermal deposit formation. Consequently, these districts have fair likelihood for the presence of additional undiscovered deposits, especially if exploration has not been sufficiently exhaustive. Similarly, districts that contain large deposits are those within which additional discoveries could be analogously large. Particular districts in which one or more epithermal deposit recognition criteria are well developed represent areas within which it can be shown that the processes required for deposit formation operated with significant intensity and efficiency. Consequently, districts in which recognition criteria are most well developed have the highest potential for undiscovered deposits; by analogy, well-explored areas in which epithermal deposit recognition criteria are less well developed likely have lower undiscovered deposit potential.

Gold is not uniformly distributed in the upper crust but tends to be concentrated in gold-rich deposits in "gold belts" (Sillitoe, 2008). Especially notable is the terrane that hosts Carlin-type gold deposits in northern Nevada, which mostly occur in linear belts or trends that probably coincide with deep crustal faults (Cline and others, 2005). Many epithermal gold-silver deposits are similarly concentrated in belts that are spatially associated with major tectono-magmatic features. These include the northtrending El Indio-Tambo-Veladero-Pascua-Lama belt in Chile and Argentina (Bissig and others, 2003), the southern ancestral Cascade arc ("Walker Lane belt") in Nevada and California (John and others, 2015b), and the northern Nevada rift (John, 2001). However, within these tectono-magmatic features, epithermal gold deposits are not uniformly distributed. For example, the PascuaLama, Veladero, and El Indio deposits formed along northwesttrending structural zones that may represent transverse basement faults (Bissig and others, 2003; Charchaflié and others, 2007), and many deposits related to the northern Nevada rift are aligned along prominent north-northwest-striking magnetic anomalies interpreted as unexposed mafic intrusions elated to incipient continental rifting (Ponce and Glen, 2002). Within the southern ancestral Cascade arc, the larger ( $>1 \mathrm{Moz}$ gold production) epithermal deposits are concentrated in long-lived (several million years) volcanic fields overlying continental crust and continentally derived sedimentary rocks (John and others, 2015b). Consequently, as mentioned previously, exploration in regions or terranes known to host epithermal deposits, and especially along mineralized structural features, is more likely to be successful than exploration in adequately studied regions and terranes that do not contain known epithermal deposits.

\section{Exploration Strategy}

\section{By Peter G. Vikre and Frederick T. Graybeal}

As with other deposit types, descriptions of exploration strategies for epithermal gold-silver deposits over the previous century were seldom published, with the exception of case histories of the small percentage of exploration programs that resulted in discoveries. Records of many exploration programs, techniques, and strategies reside in company files or have been discarded. However, most exploration over the past several decades has been conducted by small exploration companies (that is, junior exploration companies, also known as "Canadian juniors"), who obtained funding from sales of securities. Since 1997, security and regulatory agencies in Canada and other countries have required technical reports by companies seeking public financing, and in some countries for private financing, thus increasing transparency of exploration projects. Exploration histories, along with technical information on projects, are commonly documented in "43-101" reports that are available on company websites during exploration and development.

Reviews of exploration case histories invariably demonstrate that new geologic interpretations, coupled with a detailed understanding of ore deposit models and their limitations, and the application of straightforward ore guides (for example, element geochemistry and alteration zoning), are still the primary reasons that discoveries are made (for example, Schodde, 2013). Geochemical sampling is invariably a standard component of successful exploration programs, with geophysical surveys less so, partly because of their expense and because of the proliferation of junior exploration companies with small budgets that are commonly depleted within one year of funding.

Regional area selection and field reconnaissance are usually followed by acquisition of mineral rights in established mining districts, in areas of hydrothermally altered rocks, and in real or perceived deposit trends, which are packaged as the "right" address for investors. During periods of intense competition for mineral rights and funding, combined with pressure from investors for immediate drill results, adequate geological characterization of targets is ignored, and many heavily drilled districts and areas of altered rocks retain their exploration potential.

Most discoveries of epithermal gold-silver deposits since about 1980 have been made by drilling altered, geochemically 
anomalous, usually Tertiary volcanic rocks, commonly in established gold-silver-mercury districts or near prospects, and by drilling near-recent discoveries. Exploration resulting in discovery has been promoted by elevated gold prices, by economically successful open-pit mining of numerous lowgrade gold-silver deposits with reserves of millions to tens of millions of ounces, by a rapid discovery rate that fosters a "rush mentality" and increased investor interest, and by alignment and clustering of significant deposits (for example, Pascua-Lama-El Indio belt, Chile and Argentina; Carlin trend, Nevada, U.S.A.). The terms "close in" and "on trend" are frequently misused when writing a prospectus for a new public company, but they accurately reflect the most important attributes of areas where the potential for discovery is greatest.

Exploration in existing mining districts or near existing mines is commonly called brownfield exploration, which, because of geological databases and production legacies, carries much less risk of failure compared with regional exploration (also called greenfield, frontier, or grassroots exploration). Brownfield exploration also benefits from established infrastructure, private land, and existing exploration and operating permits. It is increasingly the focus of junior exploration companies and major mining companies. Although discoveries by junior companies have often ended up in major company portfolios via mergers and acquisitions, junior companies have made important discoveries by optioning inactive projects from major companies. The increasing risk and cost of exploration have caused many junior exploration and major mining companies to concentrate their exploration efforts in areas where data are available for analysis and reinterpretation.

A continuing concern for explorationists working for junior exploration companies with no cash flow will be the tendency for investors to fund programs on an annual basis. This predilection adds pressure for immediate and positive results as a prerequisite for additional funding and is incompatible with the trend of increasing costs of discovery (fig. S1). The effect is to drive those companies with funding toward brownfield opportunities where the abundance of historical data is greater and the risk of failure reduced, or into rushed drilling programs, leaving the frontier or greenfield regions underexplored.

Finally, experienced explorationists realize that ore deposit models are simply composites of many similar, but not identical deposit types that describe the essential attributes of a single deposit type. Models, particularly those based on genetic attributes, provide guidance and clues to what may be unexposed, but individual deposits that may belong to a particular model type may differ importantly from the composite. Recognizing those differences will continue to require knowledge of numerous deposit types and variants, in addition to well-honed field skills, which may seem outmoded in the 21 st century, but which will continue to be essential for exploration success.

\section{Exploration Techniques}

\section{By Peter G. Vikre and Frederick T. Graybeal}

Techniques applied in exploration for epithermal goldsilver deposits vary with the size of the budget or company, depth of the target, nature of the target (disseminated, vein, breccia pipe, stratiform, or stratabound), company protocols, and past experiences of exploration geologists. At Hishikari, Japan, the highest gold grade deposit and among the largest deposits discovered in recent decades, concealed veins were discovered by drilling beneath previously mined veins and through adjacent, propylitically altered Quaternary volcanic rocks into Cretaceous sedimentary rocks (Izawa and others, 1990). Initial drill holes were sited, in part, by resistivity and gravity anomalies. At Midas, Nevada, concealed goldsilver veins with subtle expression on erosion surfaces were discovered by drilling near mines in the Gold Circle (Midas) district that initially produced in 1908 (Lapointe and others, 1991; Goldstrand and Schmidt, 2000). Other epithermal vein discoveries in established districts were made by drilling host rocks between elevations that contain most to all oregrade vein segments (for example, the "favorable zone" at Tayoltita, Mexico, Smith and others, 1982). Recognition that large-scale disseminated gold and silver deposits, such as those discovered at La Pitarrilla, Mexico (Somers and others, 2010), Navidad, Argentina (Lhotka, 2010), and Hardshell, Arizona, U.S.A. (Koutz, 1984), may occur in physically or chemically favorable strata where cut by vein structures required knowledge and drill testing of the entire stratigraphic section, preceded by detailed geologic mapping to determine if favorable strata exist at depths compatible with mining.

Less conventional exploration approaches and techniques that have been applied or proposed, but infrequently described in the literature, include (1) four-dimensional configuration of stratigraphy and zoning of hydrothermal mineral assemblages, specifically paleosurface and near-surface assemblages, for predicting locations of concealed disseminated, stockwork, and vein deposits or their offset extensions, and, in partly eroded districts and alteration zones, major fluid conduits (for example, fault intersections); (2) fluid inclusion petrography, microthermometry, and volatile concentrations for constraining (a) paleodepths of exposed or drilled parts of systems, and (b) spatial relations of exposures and drill-hole intercepts to ore zones (favorable zones); (3) comparison of hydrothermal mineral forms, textures, fluid inclusions characteristics, and element concentrations for prediction of subjacent gold-silver-mineralized veins or vein segments; (4) $\delta^{18} \mathrm{O}$ depletion profiles and halos to define major conduits of fluid circulation and possible ore deposition (for example, Naito and others, 1993); (5) geophysical modelling of subtle doming by intrusions that may have fractured overlying strata and provided heat for circulation of mineralizing fluids (Morishita and Nakano, 2008); (6) geophysical detection of 
concealed lineaments that may represent extensions of mined veins or concealed veins (for example, Ushijima and others, 1993); (7) isotope ( $\mathrm{Sr}, \mathrm{C}, \mathrm{O}$ ) compositions of vein minerals that distinguish mineralized and barren veins (Morishita and Nakano, 2008); and (8) alunite typing to model system configuration and predict location of gold-silver-mineralized rocks (for example, Pierina, Peru; Fifarek and Rye, 2005; Rainbow and others, 2005). Exploration applications and modelling using some of these techniques and approaches are briefly described below.

At National, Nevada, U.S.A., stratigraphic, structural, and temporal controls of the distribution of hydrothermal mineral assemblages in Tertiary volcanic rocks, including mined gold-silver veins, were used successfully to guide drilling for concealed veins beneath a paleosurface (Vikre 1985, 2007). By comparing characteristics of numerous epithermal

A. Gold exploration expenditures and ounces found—primary gold found in the western world: 1950-2011

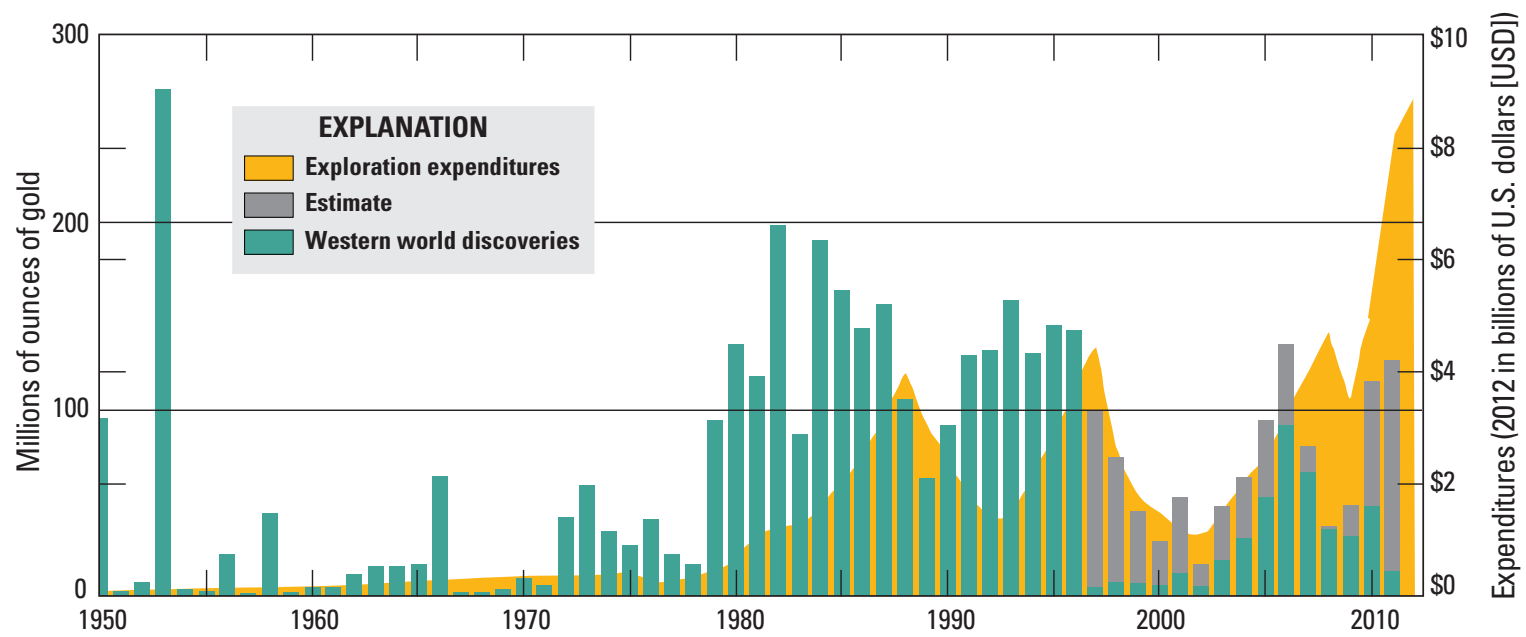

B. Depth of cover and discovery method_prospect-scale gold discoveries in the world: 1900-2012

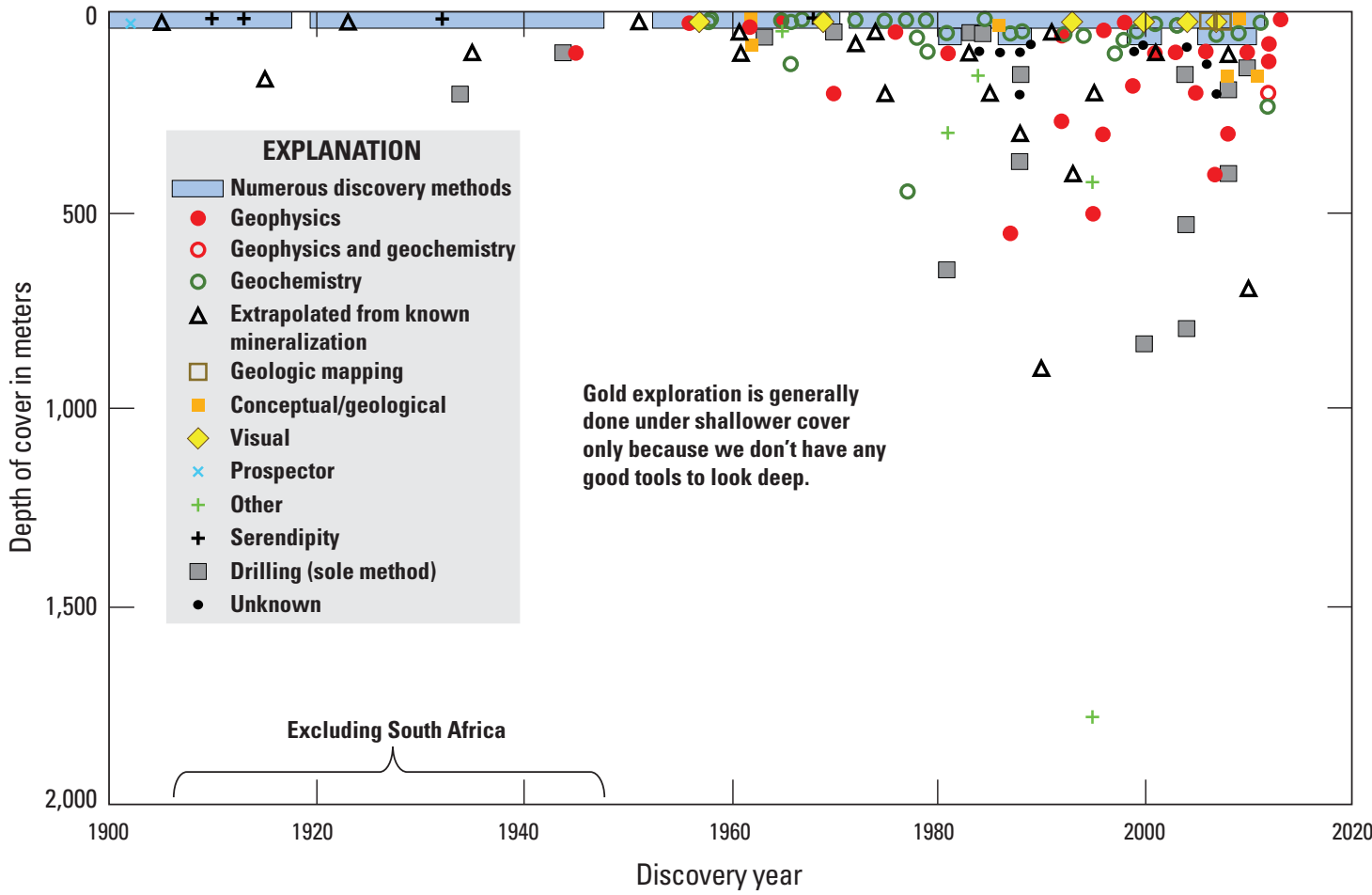

Figure S1. Gold deposit exploration cost and discovery trends (Schodde, 2013). A, Expenditures (US\$B) for gold exploration, 1950-2013, and millions of ounces of gold (Moz) discovered. B, Deposit discovery rate from 1900 to 2013, thickness of cover (meters), and method of discovery. 
gold-silver, silver-gold, gold-silver-base metal, silver-base metal, and zinc-lead-silver deposits in Mexico, Albinson and others (2001) constructed integrated depth-zoning models of deposits mined to 2,000 -m paleodepths based on (a) metal ratios, (b) wall-rock alteration mineral zoning, (c) fluid inclusion petrography, microthermometry, and volatile ratios, (d) assemblages including ore minerals, and (e) silica minerals and textures. These graphical models represent valuable first-order correlations of paleodepths and epithermal deposit characteristics, a prerequisite of exploration for concealed deposits. Christie and others (2007) synthesized similar data for numerous epithermal deposits in the Hauraki Goldfield, New Zealand. At Guanajuato, Mexico, comparison of (1) fluid inclusion populations in vein quartz that represent boiling (based on petrography); (2) vein mineral forms and textures, including colloform quartz, plumose quartz, bladed calcite, and bladed calcite perimorphs, interpreted to represent deposition from boiling fluids; and (3) gold, silver, and other element concentrations in samples of these minerals, showed that elevated precious metal concentrations strongly correlate with colloform quartz and do not correlate with boiling based on fluid inclusions petrography (Moncada and others, 2012). Although these vein mineral characteristics may distinguish some oregrade veins at Guanajuato, another investigation that includes fluid inclusion petrography and microthermometry (Mango and others, 2014) suggests a more complex paleohydrology in this very large (in terms of area and production) silver-gold district. Viable exploration targets remain in large precious metal districts where four-dimensional characterization of the ore-forming system is incomplete.

\section{Assessment Techniques}

\section{By Peter G. Vikre and Frederick T. Graybeal}

Four-dimensional ore deposit models and zoning patterns intrinsic to the models have become increasingly important to explorationists and to mineral resources assessors as the search for new deposits is directed at areas covered by postmineral rocks and at increasing depth (fig. S1). Application of models by explorationists still require what some might call "old fashioned" prospecting and mapping with a hand lens and rock hammer. However, exploration success will increasingly require a more detailed (four-dimensional) understanding of potential oreforming environments. An important part of that understanding, particularly for the unraveling of mineral and metal zoning patterns, will come from detailed field mapping supplemented by hand-held spectrometers, by low-cost multielement analytical techniques (for example, Halley and others, 2015), and by geochronology. Fluid inclusion petrography also will become an important part of the exploration process. Quantitative automated mineralogical techniques such as QEMSCAN may see increased use, although costs are currently too high for widespread use, particularly by junior exploration companies. Mineral resource assessors will need broad access to exploration records, especially drill-hole data, to factor spatial and temporal geological characteristics into favorability of mineral tracts. Future mineral resource assessments, including those for epithermal precious metal deposits, will increasingly rely on subsurface data and interpretations obtained from mining and exploration companies. 


\title{
Chapter T. Research Directions
}

\author{
By Peter G. Vikre
}

Many research investigations of epithermal gold-silver deposits have been published over the past several decades, commensurate with increased production from these deposits. However, there remain large uncertainties in spatial, temporal, and genetic relationships within and between high-sulfidation and low- and intermediate-sulfidation deposits and between epithermal deposits and other deposit types. Some of the following research themes address these uncertainties.

\section{High-Sulfidation Deposits}

1. Spatial relations among source, crystallization, emplacement, and devolatilization of magmas associated with high-sulfidation deposits.

2. Differences between high-sulfidation deposits and unmineralized quartz-alunite alteration zones.

3. Depositional mechanisms of sulfide and metallic minerals: vapor condensation, precipitation from aqueous solution, or both?

4. Differences between high-sulfidation systems unassociated with porphyry copper systems and those associated in time and space with porphyry copper systems.

5. Causes of electrum + pyrite association and gold + enargite (no iron mineral) association in some deposits.

\section{Low- and Intermediate-Sulfidation Deposits}

1. Spatial and temporal relations among boiling fluids, isothermal fluids, fluid mixing, fluid decompression, and ore-grade vein segments.

2. Controls of high-grade vein segments versus low-grade and unmineralized vein segments.
3. Structural, mineralogical, and isotopic characteristics of veins and host rocks above and below ore zones that distinguish "blind" veins, ore-grade veins, and barren veins.

4. Relation of crystal form, growth mechanism, and aggregation (electrum, sulfide minerals, quartz, adularia, calcite, others) to layering and other vein mineral textures.

5. Application of volcanic and hydrothermal mineral stratigraphy, stable isotope systematics (alunite and kaolinite), and floras to paleoelevation, paleoclimate, and landform evolution, as in the Pascua-Lama-El Indio belt of gold \pm silver \pm copper deposits.

6. Causes of different metal (and other element) abundances in similar vein deposits (for example, Au-Ag associations; $\mathrm{Au}-\mathrm{Ag}-\mathrm{Hg}-\mathrm{Se}$ associations; Au-Ag-Te associations).

7. Gold and silver grade control by supergene and hypogene processes.

\section{All Epithermal Gold-Silver Deposits Subtypes}

1. Sources of metals, sulfur, and other hydrothermal mineral components.

2. Relative significance of transport of hydrothermal mineral components as ions and nanoparticles.

3. Evolution of volcanic fields that include proximal and (or) coeval deposits of high-sulfidation and low- or intermediatesulfidation.

4. Uneven distribution or absence of all epithermal deposit subtypes along and above subduction-related magmatic arcs (for example, western U.S.A.).

5. Dominant association of all epithermal deposit subtypes with Tertiary magmatism. 


\section{Acknowledgments}

Noel White and Jim Saunders reviewed draft versions of this model and provided helpful comments and suggestions that markedly improved it. Thanks to Toru Shimizu, Shannon Martin, Mark Simpson, James Mortimer, and James Rytuba for photographs. Sarah Nagorsen and Regan Austin edited the revised manuscript.

\section{References Cited}

Abbott, M.B., and Wolfe, A.P., 2003, Intensive Pre-Incan metallurgy recorded by lake sediments from the Bolivian Andes: Science, v. 301, p. 1893-1895.

Adams, S.F., 1920, A microscopic study of vein quartz: Economic Geology, v. 15, p. 623-664.

Afifi, A.M., Kelly, W.C., and Essene, E.J., 1988, Phase relations among tellurides, sulfides, and oxides; Pt. II, Applications to telluride-bearing ore deposits: Economic Geology, v. 83, p. 395-404.

Alamos Gold, 2015, Mulatos Mine, Mexico: Alamos Gold web page, accessed August 28, 2015, at http://www.alamosgold. $\mathrm{com} / \mathrm{mines}$-and-projects/producing-mine/mulatos-minemexico/.

Albino, G.V., and Margolis, J., 1991, Differing styles of adularia-sericite epithermal deposits - Contrasts in geologic setting and mineralogy [abs.]: Geological Society of America Abstracts with Programs, v. 23, p. A230.

Albinson, T., Norman, D.I., Cole, D., and Chomiak, B.A., 2001, Controls on formation of low-sulfidation epithermal deposits in Mexico-Constraint from fluid inclusion and stable isotope data: Society of Economic Geologists Special Publication 8, p. 1-32.

Albinson, T., and Rubio, M.A., 2001, Mineralogic and thermal structure of the Zuloaga vein, San Martin de Bolaños district, Jalisco, Mexico, in Albinson, T., and Nelson, C.E., eds., New Mines and Discoveries in Mexico and Central America: Society of Economic Geologists Special Publication 8, p. 115-132.

Alderton, D.H.M., and Fallick, A.E., 2000, The nature and genesis of gold-silver-tellurium mineralization in the Metaliferi Mountains of western Romania: Economic Geology, v. 95, p. 495-515.

Alfieris, Dimitrios, 2006, Geological, geochemical and mineralogical studies of shallow submarine epithermal mineralization in an emergent volcanic edifice at Milos Island (western side), Greece: Hamburg, Germany, Hamburg University, Ph.D. thesis, 294 p.
Alfieris, D., Voudouris, P., and Spry, P.G., 2013, Shallow submarine epithermal $\mathrm{Pb}-\mathrm{Zn}-\mathrm{Cu}-\mathrm{Au}-\mathrm{Ag}-\mathrm{Te}$ mineralization on western Milos Island, Aegean Volcanic Arc, GreeceMineralogical, geological and geochemical constraints: Ore Geology Reviews, v. 53, p. 159-180.

Allibone, A.H., Cordery, G.R., Morrison, G.W., Jaireth, S., and Lindhorst, J.W., 1995, Synchronous advanced argillic alteration and deformation in a shear zone-hosted magmatic hydrothermal $\mathrm{Au}-\mathrm{Ag}$ deposit at the Temora (Gidginbung) mine, New South Wales, Australia: Economic Geology, v. 90, p. 1570-1603.

Allied Nevada Gold Corp., 2013, Hycroft mine, Winnemucca, Nevada, USA: Allied Nevada Gold Corp., Technical report, 145 p., accessed November 18, 2014, at http://www. alliednevada.com/properties/hycroft-mine/hycroft-minetechnical-reports.

Allis, R.G., 1990, Geophysical anomalies over epithermal systems: Journal of Geochemical Exploration, v. 36, p. 339-374.

Andreeva, E.D., 2013, Genesis of precious metal mineralization in the central Kamchatka, Far East of Russia: Hokkaido, Japan, Hokkaido University, Ph.D. thesis, 240 p.

Andreeva, E.D., Matsueda, H., Okrugin, V.M., Takahashi, R., and Ono, S., 2013, Au-Ag-Te mineralization of the lowsulfidation epithermal Aginskoe deposit, central Kamchatka, Russia: Resource Geology, v. 63, p. 337-349.

Anglo Gold Ashanti, 2015a, Annual Reports: Anglo Gold Ashanti web page, accessed August 31, 2015, at http://www. anglogoldashanti.com/investors/annual-reports/.

Anglo Gold Ashanti, 2015b, Cerro Vanguardia: Anglo Gold Ashanti web page, accessed August 31, 2015, at http://www. anglogoldashanti.com/americas/.

Aoki, M., Comsti, E.C., Lazo, F.B., and Matsuhisa, Y., 1993, Advanced argillic alteration and geochemistry of alunite in an evolving hydrothermal system at Baguio, northern Luzon, Philippines: Resource Geology, v. 43, p. 155-164.

Arancibia, G., Matthews, S.J., Cornejo, P., de Arce, C.P., Zuluaga, J.I., and Kasaneva, S., 2006, ${ }^{40} \mathrm{Ar} /{ }^{39} \mathrm{Ar}$ and K-Ar geochronology of magmatic and hydrothermal events in a classic lowsuphidation epithermal bonanza deposit-El Peñon, northern Chile: Mineralium Deposita, v. 41, p. 505-516.

Arizanov, A., and Terziyski, S., 2004, Chelopech $\mathrm{Cu}-\mathrm{Au}$ deposit: Society of Economic Geologists Guidebook Series, v. 36, p. 79-90.

Arribas, A., Jr., 1995, Characteristics of high-sulfidation epithermal deposits, and their relation to magmatic fluid, in Thompson, J.F.H., ed., Magmas, fluids, and ore deposits: Mineralogical Association of Canada Short Course, v. 23, p. 419-454. 
Arribas, A., Jr., Arribas, I., Draper, G., Hall, C., Kesler, S.E., McEwan, C., and Muntean, J.L., 2011, ${ }^{40} \mathrm{Ar} /{ }^{39} \mathrm{Ar}$ dating of alunite from the Pueblo Viejo gold-silver deposit, Dominican Republic: Economic Geology, v. 106, p. 1059-1070.

Arribas, A., Jr., Cunningham, C.G., Rytuba, J.J., Rye, R.O., Kelly, W.C., Podwysocki, M.H., McKee, E.H., and Tosdal, R.M., 1995a, Geology, geochronology, fluid inclusions, and isotope geochemistry of the Rodalquilar gold alunite deposit, Spain: Economic Geology, v. 90, p. 795-822.

Arribas, A., Jr., Hedenquist, J.W., Itaya, T., Okada, T., Concepción, R.A., and Garcia, J.S., 1995b, Contemporaneous formation of adjacent porphyry and epithermal $\mathrm{Cu}-\mathrm{Au}$ deposits over $300 \mathrm{ka}$ in northern Luzon, Philippines: Geology, v. 23, p. 337-340.

Arribas, A., Jr., Schalamuk, I.B., de Barrio, R., Fernández, R., and Itaya, T., 1996, Edades radiométricas de mineralizaciones epitermales auríferas del Macizo del Deseado, provincia de Santa Cruz, Argentina: 29th Brazilian Geological Congress [Proceedings], v. 7, p. 254-257.

Ashley, R.P., 1974, Goldfield mining district: Nevada Bureau of Mines and Geology Report 19, p. 49-66.

Ashley, R.P., 1979, Relation between volcanism and ore deposition at Goldfield, Nevada: Nevada Bureau of Mines and Geology Report 33, p. 77-86.

Ashley, R.P., 1982, Occurrence model for enargite-gold deposits: U.S. Geological Survey Open-File Report 82-795, p. 144-147.

Ashley, R.P., 1990a, The Goldfield gold district, Esmeralda and Nye Counties, Nevada, in Shawe, D.R., and Ashley, R.P., eds., Epithermal Gold Deposits_-Part 1: U.S. Geological Survey Bulletin 1857-H, p. H1-H7, https://pubs.usgs.gov/ bul/1857h/report.pdf.

Ashley, R.P., 1990b, The Tonopah precious-metal district, Esmeralda and Nye Counties, Nevada, in Shawe, D.R., and Ashley, R.P., eds., Epithermal Gold Deposits—Part 1: U.S. Geological Survey Bulletin 1857-H, p. H8-H13, https://pubs. usgs.gov/bul/1857h/report.pdf.

Ashley, R.P., Goetz, A.F.H., Rowan, L.C., and Abrams, M.J., 1979, Detection and mapping of hydrothermally altered rocks in the vicinity of the Comstock Lode, Virginia Range, Nevada, using enhanced Landsat images: U.S. Geological Survey Open-File Report 79-960, 46 p.

Ashley, R.P., and Keith, W.J., 1976, Distribution of gold and other metals in silicified rocks of the Goldfield mining district, Nevada: U.S. Geological Survey Professional Paper 843-B, 17 p.

Ashley, R.P., and Silberman, M.L., 1976, Direct dating of mineralization at Goldfield, Nevada, by potassium-argon and fission track methods: Economic Geology, v. 71, p. 904-924.
Ausburn, K.E., 1991, Ore-petrogenesis of Tertiary volcanic hosted epithermal gold mineralization at the Hart mining district, Castle Mountains, northeast San Bernardino County, California, in Raines, G.L., Lisle, R.E., Schafer, R.W., and Wilkinson, W.H., eds., Proceedings of the Geology and Ore Deposits of the Great Basin Symposium, Reno, April 1990: Geological Society of Nevada, p. 1147-1188.

Ayuso, R.A., Wooden, J.L., Foley, N.K., Seal, R.R., and Sinha, A.K., 2005, U-Pb zircon ages and $\mathrm{Pb}$ isotope geochemistry of gold deposits in the Carolina Slate Belt of South Carolina: Economic Geology, v. 100, p. 225-252.

Baia Mare Task Force, 2000, Report of the International Task Force for assessing the Baia Mare Accident: report of the Baia Mare Task Force, accessed November 19, 2014, at http://viso. jrc.ec.europa.eu/pecomines_ext/docs/bmtf_report.pdf.

Bailly, L., Stein, G., and Genna, A., 2002, Preliminary microthermometric measurements in quartz, sphalerite and enargite from the Bor and Majdanpek deposits, Serbia: Geology and Metallogeny of Copper and Gold Deposits in the Bor Metallogenic Zone-Bor 100 Years International Symposium, Bor Lake, Yugoslavia, 2002 [Proceedings], p. $71-75$.

Baker, T., Mustard, R., Brown, V., Pearson, N., Stanley, C.R., Radford, N.W., and Butler, I., 2006, Textural and chemical zonation of pyrite at Pajingo-A potential vector to epithermal gold veins: Geochemistry Exploration Environment Analysis, v. 6, p. 283-293.

Barrick Gold, 2015, Barrick Gold annual reports: Barrick Gold web page, accessed August 31, 2015, at http://www.barrick. com/investors/annual-report/default.aspx.

Baron, S., Tamas, C.G., Cauuet, B., and Munoz, M., 2011, Lead isotope analyses of gold-silver ores from Roşia Montană (Romania) - A first step of a metal provenance study of Roman mining activity in Alburnus Maior (Roman Dacia): Journal of Archaeological Science, v. 38, p. 1090-1100.

Bartlett, M.W., Enders, M.S., and Hruska, D.C., 1991, Geology of the Hollister Gold Deposit, Ivanhoe district, Elko County, Nevada, in Raines, G.L., Lisle, R.E., Schafer, R.W., and Wilkinson, W.H., eds., Proceedings of the Geology and Ore Deposits of the Great Basin Symposium, Reno, April 1990: Geological Society of Nevada, p. 957-978.

Barton, P.B., Bethke, P.M., Jr., and Roedder, E., 1977, Environment of ore deposition in the Creede mining district, San Juan Mountains, Colorado; Part III, Progress toward interpretation of the chemistry of the ore-forming fluid for the $\mathrm{OH}$ vein: Economic Geology, v. 72, p. 1-24.

Bartos, P.J., 2000, The Pallacos of Cerro Rico de Potosi, Bolivia-A new deposit type: Economic Geology, v. 95, p. 645-654. 
Bastin, E.S., 1922, Bonanza ores of the Comstock Lode, Virginia City, Nevada: U.S. Geological Survey Bulletin 735-C, p. 41-63.

Bastin, E.S., 1941, Paragenetic relations in the silver ores of Zacatecas, Mexico: Economic Geology, v. 36, p. 371-400.

Bastin, E.S., and Laney, F.B., 1918, The genesis of the ores at Tonopah, Nevada: U.S. Geological Survey Professional Paper 104, $50 \mathrm{p}$.

Basuki, A., Sumanagara, D.A., and Sinambela, D., 1994, The Gunung Pongkor gold-silver deposit, West Java, Indonesia: Journal of Geochemical Exploration, v. 50, p. 371-391.

Baumgartner, R., Fontboté, L., Spikings, R., Ovtcharova, M., Schaltegger, U., Schneider, J., Page, L., and Gutjahr, M., 2009, Bracketing the age of magmatic-hydrothermal activity at the Cerro de Pasco epithermal polymetallic deposit, central Peru-A U-Pb and ${ }^{40} \mathrm{Ar} /{ }^{39} \mathrm{Ar}$ study: Economic Geology, v. 104, p. 479-504.

Baumgartner, R., Fontboté, L., and Vennemann, T., 2008, Mineral zoning and geochemistry of epithermal polymetallic $\mathrm{Zn}-\mathrm{Pb}-\mathrm{Ag}$-Cu-Bi mineralization at Cerro de Pasco, Peru: Economic Geology, v. 103, p. 493-537.

Becker, G.F., 1882, Geology of the Comstock Lode and the Washoe district: U.S. Geological Survey Monograph 3, $422 \mathrm{p}$.

Begbie, M.J., Spörli, K.B., and Mauk, J.L., 2007, Structural evolution of the Golden Cross epithermal Au-Ag deposit, New Zealand: Economic Geology, v. 102, p. 873-892.

Belanger, M., Pareja, G., and Nahan, P., 2011, Peñasquito polymetallic operation Zacatecas State, Mexico: Silver Wheaton NI 43-101 Technical Report, 142 p., accessed July 24, 2014, at http://www.silverwheaton.com/ Theme/SilverWheaton/files/docs mine $\% 20$ tech $\% 20$ reports/2011-04-01\%20Penasquito\%20Technical\%20 Report $\% 20 \% 28$ final\%29.pdf.

Bendezú, R., 2007, Shallow polymetallic and precious metal mineralization associated with a Miocene diatreme-dome complex-The Colquijirca district of the Peruvian Andes: Geneva, Switzerland, University of Geneva, Ph.D. thesis, $221 \mathrm{p}$.

Bendezú, R., and Fontboté, L., 2009, Cordilleran epithermal $\mathrm{Cu}-\mathrm{Zn}-\mathrm{Pb}-(\mathrm{Au}-\mathrm{Ag})$ mineralization in the Colquijirca district, central Peru—Deposit-scale mineralogical patterns: Economic Geology, v. 104, p. 905-955.

Bendezú, R., Fontboté, L., and Cosca, M., 2003, Relative age of Cordilleran base metal lode and replacement deposits, and high sulfidation $\mathrm{Au}-(\mathrm{Ag})$ epithermal mineralization in the Colquijirca mining district, central Peru: Mineralium Deposita, v. 38, p. 683-694.
Bendezú, R., Page, L., Spikings, R., Pecskay, Z., and Fontboté, L., 2008, New ${ }^{40} \mathrm{Ar} /{ }^{39} \mathrm{Ar}$ alunite ages from the Colquijirca district, Peru-Evidence of a long period of magmatic $\mathrm{SO}_{2}$ degassing during formation of epithermal $\mathrm{Au}-\mathrm{Ag}$ and Cordilleran polymetallic ores: Mineralium Deposita, v. 43, p. 777-789.

Benedetti, Marc, and Boulègue, Jacques, 1991, Mechanism of gold transfer and deposition in a supergene environment: Geochimica et Cosmochimica Acta, v. 55, p. 1539-1547.

Berger, B.R., Anderson, R.E., Phillips, J.D., and Tingley, J.V., 2005 , Plate-boundary transverse deformation zones and their structural roles in localizing mineralization in the Virginia City, Goldfield, and Silver Star mining districts, Nevada, in Rhoden, H.N., Steininger, R.C., and Vikre, P.G., eds., Proceedings of the Window to the World Symposium 2005, Reno, May 2005: Geological Society of Nevada, p. 269-281.

Berger, B.R., and Bethke, P.M., eds., 1985, Geology and geochemistry of epithermal systems: Reviews in Economic Geology, v. 2, 298 p.

Berger, B.R., and Eimon, P., 1983, Conceptual models of epithermal precious metal deposits-Cameron volume on unconventional mineral deposits: Society of Mining Engineers of AIME, p. 195-205.

Berger, B.R., and Henley, R.W., 1989, Advances in the understanding of epithermal gold-silver deposits, with special reference to the western United States: Economic Geology Monograph 6, p. 405-423.

Berger, B.R., Henley, R.W., Lowers, H.A., and Pribil, M.J., 2014, The Lepanto $\mathrm{Cu}-\mathrm{Au}$ deposit, Philippines-A fossil hyperacidic volcanic lake complex: Journal of Volcanology and Geothermal Research, v. 271, p. 70-82.

Berger, B.R., and Silberman, M.L., 1985, Relationships of traceelement patterns to alteration and morphology in hot-spring type precious-metal deposits: Reviews in Economic Geology, v. 2, p. 233-247.

Berger, B.R., Tingley, J.V., and Drew, L.J., 2003, Structural localization and origin of compartmentalized fluid flow, Comstock Lode, Virginia City, Nevada: Economic Geology, v. 98, p. 387-408.

Bergman Weihed, J., Berstrom, U., Billstrom, K., and Weihed, P., 1996, Geology, tectonic setting, and origin of the Paleoproterozoic Boliden Au-Cu-As deposit, Skellefte district, northern Sweden: Economic Geology, v. 91, p. 1073-1097.

Berry, J.M., Mobley, R.M., Gillon, K.A., Yogodzinski, G.M., and Bates, C.C., 2016, A Neoproterozoic epithermal gold deposit-The Haile gold mine, South Carolina, USA, in Doar, W.R., III, ed., Gold, Structures, and Landforms in Central South Carolina-Field Guides for the 2016 GSA Southeastern Section Meeting, Columbia, South Carolina: Geological Society of America Field Guide 42, p. 1-8, https://doi. org/10.1130/2016.0042(01). 
Bethke, P.M., Barton, P.B., Jr., Lanphere, M.A., and Steven, T.A., 1976, Environment of ore deposition in the Creede mining district, San Juan Mountains, Colorado-Part II, Age of mineralization: Economic Geology, v. 71, p. 1006-1011.

Bethke, P.M., and Rye, R.O., 1979, Environment of ore deposition in the Creede mining district, San Juan Mountains, ColoradoPart IV, Source of fluids from oxygen, hydrogen and carbon isotope studies: Economic Geology, v. 74, p. 1832-1851.

Bethke, P.M., Rye, R.O., Stoffregen, R.E., and Vikre, P.G., 2005, Evolution of the magmatic-hydrothermal acid-sulfate system at Summitville, Colorado - Integration of geological, stableisotope, and fluid-inclusion evidence: Chemical Geology, v. 215 , p. 281-315.

Bindeman, I., 2008, Oxygen isotopes in mantle and crustal magmas as revealed by single crystal analysis: Reviews in Mineralogy and Geochemistry, v. 69, p. 445-478.

Bissig, T., Clark, A.H., Lee, J.K.W., and Hodgson, C.J., 2002, Miocene landscape evolution and geomorphologic controls on epithermal processes in El Indio-Pascua Au-Ag-Cu belt, Chile and Argentina: Economic Geology, v. 97, p. 971-996.

Bissig, T., Clark, A.H., Lee, J.K.W., and von Quadt, A., 2003, Petrogenetic and metallogenic responses to Miocene slab flattening - New constraints from the El Indio-Pascua Au-Ag-Cu belt, Chile/Argentina: Mineralium Deposita, v. 38, p. 844-862.

Bissig, T., Donoso, D., Guerra, N.C., and Dipple, G.M., 2010, Vein carbonates in the low sulfidation epithermal $\mathrm{Au}-\mathrm{Ag}$ District of El Peñón, II Región, Chile - Environment of formation and exploration implications: Andean Geology, v. 34, p. 291-304.

Blakely, R.J., 1995, Potential Theory in Gravity and Magnetic Applications: Cambridge, UK, Cambridge University Press, $441 \mathrm{p}$.

Blakely, R.J., John, D.A., Box, S.E., Berger, B.R., Fleck, R.J., Ashley, R.P., Newport, G.R., and Heinemeyer, G.R., 2007, Crustal controls on magmatic-hydrothermal systems - A geophysical comparison of White River, Washington, with Goldfield, Nevada: Geosphere, v. 3, no. 2, p. 91-107, https:// doi.org/10.1130/GES00071.1. doi:10.1130/GES00071.1

Blakely, R.J., Schruben, P.G., and Moring, B.C., 1996, Shallow magnetic lithologies as interpreted from low altitude aeromagnetic data: Nevada Bureau of Mines and Geology, Open-File Report 96-2, chapter 3, p. 3-1-3-8.

Blakely, R.J., Sherrod, B.L., Weaver, C.S., Wells, R.E., Rohay, A.C., Barnett, E.A., and Knepprath, N.E., 2011, Connecting the Yakima fold and thrust belt to active faults in the Puget Lowland, Washington: Journal of Geophysical Research, v. 116, B07105, https://doi.org/10.1029/2010JB008091.

Blattner, P., 1985, Isotope shift data and the natural evolution of geothermal systems: Chemical Geology, v. 49, p. 187-203.
Bobis, R.E., Jaireth, S., and Morrison, G.W., 1995, The anatomy of a Carboniferous epithermal ore shoot at Pajingo, Queensland - Setting, zoning, alteration, and fluid conditions: Economic Geology, v. 90, p. 1776-1798.

Bodnar, R.J., Lecumberri-Sanchez, P., Moncada, D., and SteeleMacInnis, M., 2014, Fluid Inclusions in Hydrothermal Ore Deposits, in Holland, H.D., and Turekian, K.K., eds., Treatise on Geochemistry, v. 13 (2d ed.): Oxford, Elsevier, p. 119-142.

Bodnar, R.J., Reynolds, T.J., and Kuehn, C.A., 1985, Fluidinclusion systematics in epithermal systems: Reviews in Economic Geology, v. 2, p. 73-97.

Bonev, I.K., Kerestedjian, T., Atanassova, R., and Andrew, C.J., 2002, Morphogenesis and composition of native gold in the Chelopech volcanic-hosted $\mathrm{Au}-\mathrm{Cu}$ deposit, Srednorgorie zone, Bulgaria: Mineralium Deposita, v. 37, p. 614-629.

Bonham, H.F., Jr., 1986, Models for volcanic-hosted epithermal precious metal deposits: A review: Volcanism, Hydrothermal Systems and Related Mineralisation, International Volcanological Congress, 5th, University of Auckland, Auckland, New Zealand, Proceedings, p. 13-17.

Bonham, H.F., Jr., 1988, Models for volcanic-hosted epithermal precious metal deposits, in Hedenquist, J.W., White, N.C., and Siddeley, G., eds., Epithermal gold mineralization of the Circum-Pacific - Geology, geochemistry, origin, and exploration, II: Journal of Geochemical Exploration, v. 36, p. 339-374.

Bonham, H.F., Jr., and Garside, L.J., 1979, Geology of the Tonopah, Lone Mountain, Klondike, and northern Mud Spring Lake quadrangles, Nevada: Nevada Bureau of Mines and Geology Bulletin 92, $136 \mathrm{p}$.

Bonham, H.F., Jr., and Garside, L.J., 1982, Geochemical reconnaissance of the Tonopah, Lone Mountain, Klondike, and Northern Mud Lake quadrangles, Nevada: Nevada Bureau of Mines and Geology, Bulletin 96, 68 p.

Bonham, H.F., Jr., and Papke, K.G., 1969, Geology and mineral deposits of Washoe and Storey Counties, Nevada: Nevada Bureau of Mines and Geology Bulletin 70, $140 \mathrm{p}$.

Booden, M.A., Mauk, J.L., and Simpson, M.P., 2011, Quantifying metasomatism in epithermal Au-Ag deposits - A case study from the Waitekauri area, New Zealand: Economic Geology, v. 106 , p. $999-1030$.

Borg, L.E., Blichert-Toft, J., and Clynne, M.A., 2002, Ancient and modern subduction zone contributions to the mantle sources of lavas from the Lassen region of California inferred from Lu-Hf isotopic systematics: Journal of Petrology, v. 43, p. 705-723

Botz, M.M., 2001, Overview of cyanide treatment methods, Mining Environmental Management, Mining Journal Ltd., May 2001, p. 28-30, http://chemistry.mdma.ch/hiveboard/rhodium/ pdf/cyanide.destruction.overview.pdf. 
Bove, D.J., Mast, M.A., Dalton, J.B., Wright, W.G., and Yager, D.B., 2007, Major styles of mineralization and hydrothermal alteration and related solid- and aqueous-phase geochemical signatures, in Church, S.E., von Guerard, P., and Finger, S.E., eds., Integrated investigations of environmental effects of historical mining in the Animas River watershed, San Juan County, Colorado: U.S. Geological Survey Professional Paper 1651, p. 165-230, https://pubs.usgs.gov/pp/1651/ downloads/Vol1_combinedChapters/vol1_chapE3.pdf.

Bowell, R.J., Foster, R.P., and Gize, A.P., 1993, The mobility of gold in tropical rain forest soils: Economic Geology, v. 88, p. 999-1016.

Boychuk, K.G., Garcia, D.H., Sharp, A.W., Vincent, J.D., and Yeomans, T.J., 2012, NI 43-101 technical report on the Pitarrilla project, Durango State, Mexico: Vancouver, British Columbia, Silver Standard, 435 p., accessed August 14, 2014, at http:/www.silverstandard.com/_resources/ Pitarrilla_Technical_Report_Dec_14_2012.pdf.

Brathwaite, R.L., 1989, Geology and exploration of the Karangahake gold-silver deposit: Australasian Institute of Mining and Metallurgy Monograph 13, p. 73-78.

Brathwaite, R.L., Christie, A.B., and Skinner, D.N.B., 1989, The Hauraki Goldfield-Regional setting, mineralisation and recent exploration: Australasian Institute of Mining and Metallurgy Monograph 13, p. 45-56.

Brathwaite, R.L., and Faure, K., 2002, The Waihi epithermal gold-silver base metal sulfide quartz vein system, New Zealand-Temperature and salinity controls on electrum and sulfide deposition: Economic Geology, v. 97, p. 269-290.

Brathwaite, R.L., Simpson, M.P., Faure, K., and Skinner, D.N.B., 2001, Telescoped porphyry $\mathrm{Cu}-\mathrm{Mo}-\mathrm{Au}$ mineralisation, advanced argillic alteration and quartzsulphide-gold-anhydrite veins in the Thames district, New Zealand: Mineralium Deposita, v. 36, p. 623-640.

Braund, K.G., 2006, Geology, geochemistry and paragenesis of the Royal, Crown and Roses Pride low sulphidation epithermal quartz vein structures, Cracow, South-East Queensland: Brisbane St. Lucia, Queensland, Australia, University of Queensland, MPhil thesis, 334 p.

Breit, F., and Lawrence, E.F., 1995, Road log from Hawthorne to Aurora and description of the Aurora district: Geological Society of Nevada Special Publication 22, p. 54-65.

Brown, K.L., 1986, Gold deposition from geothermal discharges in New Zealand: Economic Geology, v. 81, p. 979-983.

Browne, P.R.L., 1978, Hydrothermal alteration in active geothermal fields: Annual Review of Earth and Planetary Sciences, v. 6, p. 229-248.
Browne, P.R.L., and Ellis, A.J., 1970, The Ohaki-Broadlands hydrothermal area, New Zealand-Mineralogy and related geochemistry: American Journal of Science, v. 269, p. 97-131.

Browne, P.R.L., and Lawless, J.V., 2001, Characteristics of hydrothermal eruptions, with examples from New Zealand and elsewhere: Earth-Science Reviews, v. 52, p. 299-331.

Bryson, R.H., Brown, F.H., Rivera, R., and Butcher, M.G., 2009, Penasquito project technical report, Concepion del Oro district, Zacatecas State, Mexico: Goldcorp Inc., 144 p., accessed August 14, 2014, at http://www.silverwheaton. com/Theme/SilverWheaton/files/docs_silver $\% 20$ streams $\% 20$ tech.\%20reports/www.sedar.com_PenasquitoTechReport_ March\%2010,\%202009.pdf.

Buchanan, L.J., 1979, The Los Torres mine, Guanajuato, Mexico-Ore controls on a fossil geothermal system: Golden, Colorado School of Mines, Ph.D. thesis, 138 p.

Buchanan, L.J., 1981, Precious metal deposits associated with volcanic environment in the southwest: Arizona Geological Society Digest, v. 14, p. 237-262.

Burbank, W.S., 1947, Lake City area, Hinsdale County, in Vanderwilt, J.W., ed., Mineral resources of Colorado: Denver, Colorado, Colorado Mineral Resources Board, p. 439-443.

Burgess, J.A., 1911, The halogen salts of silver and associated minerals at Tonopah, Nevada: Economic Geology, v. 6, p. 13-21.

Bussey, S.D., 1996, Gold mineralization and associated rhyolitic volcanism at the Hog Ranch district, northwest Nevada, in Coyner, A.R., and Fahey, P.L., eds., Proceedings of the Geology and Ore Deposits of the American Cordillera Symposium, Reno, April 1995: Geological Society of Nevada, p. 181-207.

Butt, C.R.M., 1998, Supergene gold deposits: AGSO Journal of Australian Geology and Geophysics, v. 17, p. 89-96.

Caira, N.M., 2013, National instrument 43-101 F1 technical report on the El Oro property, Mexico: Report prepared for Candente Gold Corp., 219 p., http://www.candentegold. com/i/pdf/reports/El-Oro-NI-43-101-Report-Nov-30-13.pdf.

Camprubi, A., and Albinson, T., 2007, Epithermal deposits in Mexico - Update of current knowledge, and an empirical reclassification: Geological Society of America Special Paper 422, p. $377-415$.

Camprubi, A., Canals, A., Cardellach, E., Prol-Ledesma, R.M., and Rivera, R., 2001a, The La Guitarra Ag-Au low-sulfidation epithermal deposit, Temascaltepec district, Mexico-Vein structure, mineralogy, and sulfide-sulfosalt chemistry, in Albinson, T., and Nelson, C.E., eds., New Mines and Discoveries in Mexico and Central America: Society of Economic Geologists Special Publication 8, p. 133-158. 
Camprubi, A., Cardellach, E., Canals, A., and Lucchini, R., 2001b, The La Guitarra Ag-Au low-sulfidation epithermal deposit, Temascaltepec district, Mexico-Fluid inclusion and stable isotope data, in Albinson, T., and Nelson, C.E., eds., New Mines and Discoveries in Mexico and Central America: Society of Economic Geologists Special Publication 8, p. 159-185.

Camprubi, A., Chomiak, B.A., Villanueva-Estrada, R.E., Canals, A., Norman, D.J., Cardellach, E., and Stute, M., 2006, Fluid sources for the La Guitarra epithermal deposit (Temascaltepec district, Mexico)—Volatile and helium isotope analyses in fluid inclusions: Chemical Geology, v. 231, p. 252-284.

Camprubi, Antoni, Ferrari, Luca, Cosca, M.A., Cardellach, Esteve, and Canals, Angels, 2003, Ages of epithermal deposits in Mexico-Regional significance and links with the evolution of Tertiary volcanism: Economic Geology, v. 98, p. 1029-1037.

Camus, F., Boric, R., Skewes, M.A., Castelli, J.C., Reichhard, E., and Mestre, A., 1991, Geologic, structural and fluid inclusion studies of El Bronce epithermal vein system, Petorca, central Chile: Economic Geology, v. 86, p. 1317-1345.

Candiotti de Los Rios, Hugo, Noble, D.C., and McKee, E.H., 1990, Geologic setting and epithermal silver veins of the Arcata district, southern Peru: Economic Geology, v. 85, p. 1473-1490.

Carlile, J.C., Davey, G.R., Kadir, I., Langmead, R.P., and Rafferty, W.J., 1998, Discovery and exploration of the Gosowong epithermal gold deposit, Halmahera, Indonesia: Journal of Geochemical Exploration, v. 60, p. 207-227.

Casadevall, T., and Ohmoto, H., 1977, Sunnyside mine, Eureka mining district, San Juan County, Colorado-Geochemistry of gold and base metal ore deposition in a volcanic environment: Economic Geology, v. 72, p. 1285-1320.

Cathles, L.M., Erendi, A.H.J., and Barrie, T., 1997, How long can a hydrothermal system be sustained by a single intrusive event?: Economic Geology, v. 92, p. 766-771.

Cerpa, L.M., Bissig, Thomas, Kyser, Kurt, McEwan, Craig, Macassi, Arturo, and Rios, H.W., 2013, Lithologic controls on mineralization at the Lagunas Norte high-sulfidation epithermal gold deposit, northern Peru: Mineralium Deposita, v. 48 , p. $653-673$.

Chaffee, M.A., and King, H.D., 2014, Geochemistry of soil contamination from lead smelters near Eureka, Nevada: Geochemistry Exploration Environment Analysis, v. 14, p. 71-84.

Chambefort, Isabelle, 2005, The $\mathrm{Cu}-\mathrm{Au}$ Chelopech deposit, Panagyurishte district, Bulgaria-Volcanic setting, hydrothermal evolution and tectonic overprint of a Late Cretaceous high-sulfidation epithermal deposit: Geneva, Switzerland, University of Geneva, Ph.D. thesis, 173 p.
Chambefort, I., Dilles, J.H., and Longo, A.A., 2013, Amphibole geochemistry of the Yanacocha Volcanics, Peru-Evidence for diverse sources of magmatic volatiles related to gold ores: Journal of Petrology, v. 54, p. 1017-1046.

Chambefort, I., and Moritz, R., 2006, Late Cretaceous structural control and Alpine overprint of the high-sulfidation $\mathrm{Cu}-\mathrm{Au}$ epithermal Chelopech deposit, Srednogorie zone, Bulgaria: Mineralium Deposita, v. 41, p. 259-280.

Chambefort, I., Moritz, R., and von Quadt, A., 2007, Petrology, geochemistry and $\mathrm{U}-\mathrm{Pb}$ geochronology of magmatic rocks from the high-sulfidation epithermal $\mathrm{Au}-\mathrm{Cu}$ Chelopech deposit, Srednogorie belt, Bulgaria: Mineralium Deposita, v. 42, p. 665-690.

Charchaflié, D., Tosdal, R.M., and Mortensen, J.K., 2007, Geologic framework of the Veladero high-sulfidation epithermal deposit area, Cordillera Frontal, Argentina: Economic Geology, v. 102, p. 171-192.

Chesterman, C.W., Chapman, R.H., and Gray, C.H., Jr., 1986, Geology and ore deposits of the Bodie mining district, Mono County, California: California Division of Mines and Geology Report 206, 36 p.

Chiaradia, M., Fontbote, L., and Beate, B., 2004, Cenozoic continental arc magmatism and associated mineralization in Ecuador: Mineralium Deposita, v. 39, p. 204-222.

Chiaradia, M., Merino, D., and Spikings, R., 2009, Rapid transition to long-lived deep crustal magmatic maturation and the formation of giant porphyry-related mineralization (Yanacocha, Peru): Earth and Planetary Science Letters, v. 288, p. 505-515.

Chouinard, A., Williams-Jones, A.E., Leonardson, R.W., Hodgson, C.J., Silva, P., Tellez, C., Vega, J., and Rojas, F., 2005, Geology and genesis of the multistage high-sulfidation epithermal Pascua $\mathrm{Au}-\mathrm{Ag}-\mathrm{Cu}$ deposit, Chile and Argentina: Economic Geology, v. 100, p. 463-490.

Christie, A.B., 1982, Fluid inclusions, stable isotopes and geochemistry of porphyry copper and epithermal vein deposits of the Hauraki gold-silver province, New Zealand: Wellington, Victoria, University of Wellington, Ph.D. thesis, 769 p.

Christie, A.B., and Brathwaite, R.L., eds., 2006, Geology and exploration of New Zealand mineral deposits: Australian Institute of Mining and Metallurgy Monograph 25, 353 p.

Christie, A.B., Brathwaite, R.L., Rattenbury, M.S., and Skinner, D.N.B., 2001, Mineral Resource assessment of the Coromandel region, New Zealand: Institute of Geological and Nuclear Sciences Science Report 2001/11, 84 p.

Christie, A.B., Simpson, M.P., Brathwaite, R.L., Mauk, J.L., and Simmons, S.F., 2007, Epithermal Au-Ag and related deposits of the Hauraki Goldfield, Coromandel volcanic zone, New Zealand: Economic Geology, v. 102, p. 785-816. 
Christie, Gary, Lipiec, Ignacy, Simpson, R.G., Horton, Jay, and Borntradger, Bruno, 2014, Blackwater gold project, British Columbia, NI 43-101 Technical Report on Feasibility Study, 336 p., accessed November 18, 2014, at http://www.sedar.com/DisplayCompanyDocuments. do?lang $=\mathrm{EN} \&$ issuerNo $=00004818$.

Churchill, R.K., 1980, Meteoric water leaching and ore genesis at the Tayoltita silver-gold mine, Durango, Mexico: Minneapolis, University of Minnesota, Ph.D. thesis, 162 p.

Clark, R.N., 1999, Spectroscopy of rocks and minerals, and principles of spectroscopy, in Rencz, A.N., ed., Remote sensing for the earth sciences: New York, John Wiley, p. 3-58, http://speclab.cr.usgs.gov/PAPERS.refl-mrs/ refl4.html.

Clark, R.N., Swayze, G.A., Livo, K.E., Kokaly, R.F., Sutley, S.J., Dalton, J.B., McDougal, R.R., and Gent, C.A., 2003, Imaging spectroscopy_-Earth and planetary remote sensing with the USGS Tetracorder and expert systems: Journal of Geophysical Research, v. 108, no. E12, 44 p., https://doi. org/10.1029/2002JE001847.

Clark, R.N., Swayze, G.A., Wise, R., Livo, K.E., Hoefen, T.M., Kokaly, R.F., and Sutley, S.J., 2007, USGS Digital Spectral Library splib06a: U.S. Geological Survey Digital Data Series 231, http://speclab.cr.usgs.gov/spectral.lib06/.

Clarke, D.S., and Govett, G.J.S., 1990, Southwest Pacific epithermal gold-A rock geochemistry prospective: Journal of Geochemical Exploration, v. 35, p. 225-240.

Clarke, D.S., Lewis, R.W., and Waldron, H.M., 1990, Geology and trace-element geochemistry of the Umuna gold-silver deposit, Misima Island, Papua New Guinea: Journal of Geochemical Exploration, v. 36, p. 201-223.

Clarke, M., and Titley, S.R., 1988, Hydrothermal evolution in the formation of silver-gold veins, Tayoltita Mine, San Dimas district, Mexico: Economic Geology, v. 83, p. 1830-1840.

Claveria, R.J.R., 2001, Mineral paragenesis of the Lepanto copper and gold and the Victoria gold deposits, Mankayan mineral district, Philippines: Resource Geology, v. 51, p. 97-106.

Cline, J.S., Hofstra, A.H., Muntean, J.L., Tosdal, R.M., and Hickey, K.A., 2005, Carlin-type gold deposits in NevadaCritical geologic characteristics and viable models: Economic Geology 100th Anniversary Volume, p. 451-484.

Cocker, H.A., Mauk, J.L., and Rabone, S.D.C., 2013, The origin of $\mathrm{Ag}-\mathrm{Au}-\mathrm{S}-\mathrm{Se}$ minerals in adularia-sericite epithermal deposits - Constraints from the Broken Hills deposit, Hauraki Goldfield, New Zealand: Mineralium Deposita, v. 48, p. 249-266.
Collins, S.E., Moore, C.M., and Scott, K.E., 2010, Technical report on the El Peñón mine, northern Chile-NI-43-101 report: Toronto, Canada, Scott Wilson Mining, accessed August 31, 2015, http://www.sec.gov/Archives/edgar/ data/1264089/000110465911018283/a11-6607_7ex99d1.htm.

Columba, C.M., and Cunningham, C.G., 1993, Geologic model for the mineral deposits of the La Joya district, Oruro, Bolivia: Economic Geology, v. 88, p. 701-708.

Conrad, J.E., and McKee, E.H., 1996, High precision ${ }^{40} \mathrm{Ar} /{ }^{39} \mathrm{Ar}$ ages of rhyolitic host rock and mineralized veins at the Sleeper deposit, Humboldt County, Nevada, in Coyner, A.R., and Fahey, P.L., eds., Proceedings of the Geology and Ore Deposits of the American Cordillera Symposium, Reno, April 1995: Geological Society of Nevada, p. 257-262.

Conrad, J.E., McKee, E.H., Rytuba, J.J., Nash, J.T., and Utterback, W.C., 1993, Geochronology of the Sleeper deposit, Humboldt Country, Nevada-Epithermal gold-silver mineralization following emplacement of a silicic flow-dome complex: Economic Geology, v. 88, p. 317-327.

Conrad, M.E., O’Neil, J.R., and Petersen, U., 1995, The relation between widespread ${ }^{18} \mathrm{O}$ depletion patterns and precious metal mineralization in the Tayoltita mine, Durango, Mexico: Economic Geology, v. 90, p. 322-342.

Conrad, M.E., Petersen, U., and O’Neil, J.R., 1992, Evolution of an Au-Ag-producing hydrothermal system - The Tayoltita mine, Durango, Mexico: Economic Geology, v. 87, p. $1451-1474$.

Cook, N.J., and Ciobanu, C.L., 2005, Tellurides in Au deposits-Implications for modeling, in Mao, Jingwen, and Bierlein, F.P., eds., Mineral Deposit Research-Meeting the Global Challenge: Berlin Heidelberg, Springer-Verlag, p. 1387-1390.

Cook, N.J., Ciobanu, C.L., Spry, P.G., and Voudouris, P., 2009, Understanding gold-(silver)-telluride-(selenide) mineral deposits: Episodes, v. 32, p. 249-263.

Cooke, C., Abbott, M., and Wolfe, A., 2008, Metallurgy in Southern South America, in Selin, H., ed., Encyclopedia of the History of Science, Technology, and Medicine in NonWestern Cultures: Springer Netherlands, p. 1658-1662.

Cooke, D.R., and Bloom, M.S., 1990, Epithermal and subjacent porphyry mineralization, Acupan, Baguio district, Philippines - A fluid inclusion and paragenetic study: Journal of Geochemical Exploration, v. 35, p. 297-340.

Cooke, D.R., Deyell, C.L., Water, P.J., Gonzales, R.I., and Zaw, Khin, 2011, Evidence for magmatic-hydrothermal fluids and ore-forming processes in epithermal and porphyry deposits of the Baguio district, Philippines: Economic Geology, v. 106, p. 1399-1424. 
Cooke, D.R., and McPhail, D.C., 2001, Epithermal Au-Ag-Te mineralization, Acupan, Baguio district, PhilippinesNumerical simulations of mineral deposition: Economic Geology, v. 96, p. 109-132.

Cooke, D.R., McPhail, D.C., and Bloom, M.S., 1996, Epithermal gold mineralization, Acupan, Baguio district, Philippines - Geology, mineralization, alteration and thermochemical environment of ore deposition: Economic Geology, v. 91, p. 243-272.

Cooke, D.R., and Simmons, S.F., 2000, Characteristics and genesis of epithermal gold deposits: Society of Economic Geologists Reviews, v. 13, p. 221-244.

Corbett, G.J., and Leach, T.M., 1998, Southwest Pacific rim gold-copper systems: Society of Economic Geologists Special Publication 6, $237 \mathrm{p}$.

Cousens, B.L., Prytulak, J., Henry, C.D., Alcazar, A., and Brownrigg, T., 2008, Geology, geochronology, and geochemistry of the Miocene-Pliocene ancestral Cascades arc, northern Sierra Nevada, California and Nevada-The roles of the upper mantle, subducting slab, and the Sierra Nevada lithosphere: Geosphere, v. 4, p. 829-853.

Cox, D.P., Ludington, Steve, Berger, B.R., Moring, B.C., Sherlock, M.G., Singer, D.A., and Tingley, J.V., 1996, Delineation of mineral resource assessment tracts and estimates of numbers of undiscovered deposits in Nevada: Nevada Bureau of Mines and Geology Open-File Report 96-2, chapter 12 , p. $12-1$ to $12-25$.

Cox, D.P., and Singer, D.A., eds., 1986, Mineral deposit models: U.S. Geological Survey Bulletin 1693, 379 p.

Cox, S.F., Knackstedt, M.A., and Brown, J., 2001, Principle of structural control on permeability and fluid flow in hydrothermal systems, in Richards, J.P., and Tosdal, R.M., eds., Structural control on ore genesis: Reviews in Economic Geology, v. 14, p. 1-24.

Crafford, A.E.J., 2007, Geologic map of Nevada: U.S. Geological Survey Data Series 249, 1 CD-ROM, 46 p., 1 plate, scale 1:250,000, https://pubs.usgs.gov/ds/2007/249/.

Criss, R.E., and Champion, D.E., 1991, Oxygen isotope study of the fossil hydrothermal system in the Comstock Lode mining district, Nevada, in Taylor, H.P., O'Neil, J.R., and Kaplan, I.R., eds., Stable Isotope Geochemistry-A Tribute to Samuel Epstein: Geochemical Society Special Publication 3, p. 437-447.

Crosta, A.P., Ducart, D.F., de Souza Filho, C.R., Azevedo, F., and Brodie, C.G., 2009, Mineral exploration for epithermal gold in northern Patagonia, Argentina - From regional to deposit-scale prospecting using Landsat TM and terra ASTER: Reviews in Economic Geology, v. 16, p. 97-108.
Crown Minerals, 2003, Epithermal gold in New Zealand-GIS data package and prospectivity modeling: Published jointly by Ministry of Economic Development and Institute of Geological and Nuclear Sciences (CD-ROM).

Cunningham, C.G., Rye, R.O., Rockwell, B.W., Kunk, M.J., and Councell, T.B., 2005, Supergene destruction of a hydrothermal replacement alunite deposit at Big Rock Candy Mountain, Utah-Mineralogy, spectroscopic remote sensing, stable isotope and argon age evidences: Chemical Geology, v. 215, p. 317-337, https://doi.org/10.1016/j. chemgeo.2004.06.055.

Cunningham, C.G., Rye, R.O., Steven, T.A., and Mehnert, H.H., 1984, Origins and exploration significance of replacement and vein-type alunite deposits in the Marysvale volcanic field, west central Utah: Economic Geology, v. 79, p. 50-71, https://doi.org/10.2113/gsecongeo.79.1.50.

Cunningham, C.G., Zartman, R.E., McKee, E.H., Rye, R.O., Naeser, C.W., Sanjinés, V.O., Ericksen, G.E., and Tavera, V.F., 1996, The age and thermal history of Cerro Rico de Potosi, Bolivia: Mineralium Deposita, v. 31, p. 374-385.

Dalton, J.B., Bove, D.J., Mladinich, C.S., and Rockwell, B.W., 2007, Imaging spectroscopy applied to the Animas River watershed and Silverton caldera, in Church, S.E., von Guerard, P., and Finger, S.E., eds., Integrated investigations of environmental effects of historical mining in the Animas River watershed, San Juan County, Colorado: U.S. Geological Survey Professional Paper 1651, p. 143-159, https://pubs.usgs.gov/pp/1651/downloads/Vol1_ combinedChapters/vol1_chapE2.pdf.

Davies, A.G.S., Cooke, D.R., and Gemmell, J.B., 2003, The Kelian breccia complex-A giant epithermal goldsilver deposit in Kalimantan, Indonesia, in Eliopoulos, D., ed., Mineral exploration and sustainable development: Proceedings of the Seventh Biennial SGA Meeting, Rotterdam, Millpress, v. 1, p. 465-468.

Davies, A.G.S., Cooke, D.R., Gemmell, J.B., van Leeuwen, Theo, Cesare, Pat, and Hartshorn, Greg, 2008b, Hydrothermal breccias and veins at the Kelian gold mine, Laimantan, Indonesia - Genesis of a large epithermal gold deposit: Economic Geology, v. 103, p. 717-757.

Davies, A.G.S., Cooke, D.R., Gemmell, J.B., and Simpson, K.A., 2008a, Diatreme breccias at the Kelian gold mine, Laimantan, Indonesia—Precursors to epithermal gold mineralization: Economic Geology, v. 103, p. 689-716.

De Mark, Pamela, Chulick, J.J., Williams, D.K., Spring, Damian, Wells, J.A., 2009, Navidad project, Chubat Province, Argentina: Aqualine Resources Inc., NI 43-101 report, 247 p., accessed May 27, 2014, at http://www. panamericansilver.com/operations/argentina/navidad/. 
de Ronde, C.E.J., and Blattner, P., 1988, Hydrothermal alteration, stable isotopes, and fluid inclusions of the Golden Cross epithermal gold-silver deposit, Waihi, New Zealand: Economic Geology, v. 83, p. 895-917.

Deen, J.A., Rye, R.O., Munoz, J.L., and Drexler, J.W., 1994, The magmatic hydrothermal system at Julcani, Peru-Evidence from fluid inclusions and hydrogen and oxygen isotopes: Economic Geology, v. 89, p. 1924-1938.

Defant, M.J., and Drummond, M.S., 1993, Mount St HelensPotential example of the partial melting of the subducted lithosphere in a volcanic arc: Geology, v. 21, p. 547-550.

Demopoulos, G.P., and Cheng, T.C., 2004, A case study of CIP tailings slurry treatment-Comparison of cyanide recovery to cyanide destruction: The European Journal of Mineral Processing and Environmental Protection, v. 4, p. 1-9.

Dentith, Michael, and Mudge, S.T., 2014, Geophysics for the mineral exploration geoscientist: Cambridge, United Kingdom, Cambridge University Press, 438 p.

Desborough, G.A., and Fey, D.L., 1997, Preliminary characterization of acid-generating potential and toxic metal solubility of some abandoned metal-mining related wastes in the Boulder River headwaters, northern Jefferson County, Montana: U.S. Geological Survey Open-File Report 97-478, $20 \mathrm{p}$.

DeWitt, E., Thorson, J.P., and Smith, R.C., 1991, Geology and gold deposits of the Oatman district, northwestern Arizona: U.S. Geological Survey Bulletin 1857-I, p. I1-I28.

Deyell, C.L., Bissig, T., and Rye, R.O., 2004, Isotopic evidence for magmatic-dominated epithermal processes in the El IndioPascua $\mathrm{Au}-\mathrm{Cu}-\mathrm{Ag}$ belt and relationship to geomorphologic setting, in Sillitoe, R.H., Perello, J., and Vidal, C.E., eds., Andean Metallogeny-New Discoveries, Concepts, and Update: Society of Economic Geologists, Special Publication 11, p. 55-73.

Deyell, C.L., Leonardson, R., Rye, R.O., Thompson, J.F.H., Bissig, T., and Cooke, D.R., 2005a, Alunite in the PascuaLama high-sulfidation deposit — Constraints on alteration ore deposition using stable isotope geochemistry: Economic Geology, v. 100, p. 131-148.

Deyell, C.L., Rye, R.O., Landis, G.P., and Bissig, T., 2005b, Alunite and the role of magmatic fluids in the Tambo highsulfidation deposit, El Indio-Pascua belt, Chile: Chemical Geology, v. 215, p. 185-218.

Diakow, L.J., Panteleyev, A., and Schroeter, T.G., 1991, Jurassic epithermal deposits in the Toodoggone River area, northern British Columbia - Examples of well-preserved, volcanichosted, precious metal mineralization: Economic Geology, v. 86 , p. $529-554$.
Dickson, B.L., and Scott, K.M., 1997, Interpretation of aerial gamma-ray surveys - Adding the geochemical factors: AGSO Journal of Australian Geology and Geophysics, v. 17, no. 2, p. 187-200.

Dietrich, A., Gutierrez, R., Nelson, E.P., and Layer, P.W., 2012, Geology of the epithermal Ag-Au Huevos Verdes vein system and San Jose district, Deseado massif, Patagonia, Argentina: Mineralium Deposita, v. 47, p. 233-249.

Diggles, M.F., Rytuba, J.J., Moring, B.C., Wrucke, C.T., Cox, D.P., Ludington, Steve, Ashley, R.P., Pickthorn, W.J., Hillman, C.T., and Miller, R.J., 1996, Geology and minerals issues, chap. 18 of Status of the Sierra Nevada - The Sierra Nevada Ecosystem Project, Final report to Congress, vol. II, Assessments and scientific basis for management options: University of California Davis, Centers for Water and Wildland Resources, $28 \mathrm{p}$.

Disini, A.F., Robertson, B.M., and Claveria, R.J.R., 1998, The Mankayan mineral district, Luzon, Philippines, in Porter, T.M., ed., Porphyry and hydrothermal copper and gold deposits - A global perspective: Australian Mineral Foundation, November 30-December 1, 1998, Perth [Proceedings], p. 75-86.

Dobak, P.J., 1988, Alteration and paragenesis of the Paradise Peak gold/silver deposit: Fort Collins, Colorado State University, M.S. thesis, $141 \mathrm{p}$.

Doe, B.R., Steven, T.A., Delevaux, M.H., Stacey, J.S., Lipman, P.W., and Fisher, F.S., 1979, Genesis of ore deposits in the San Juan volcanic field, southwestern Colorado-Lead isotope evidence: Economic Geology, v. 74, p. 1-26.

Doebrich, J.L., and LeAnderson, J.P., 1984, Geology and hydrothermal alteration at the Mahd adh Dhahab epithermal precious-metal deposit, Kingdom of Saudi Arabia: U.S. Geological Survey Open-File Report 84-640, 36 p., 2 pls.

Dold, B., 1999, Mineralogical and geochemical changes of copper flotation tailings in relation to their original composition and climatic setting - Implications for acid mine drainage and element mobility: Terre \& Environment, Section des Sciences de la Terre, Universite de Geneve, v. 18, 230 p.

Dold, B., and Fontboté, L., 2001, Element cycling and secondary mineralogy in porphyry copper tailings as a function of climate, primary mineralogy, and mineral processing: Journal of Geochemical Exploration, v. 74, p. 3-55.

Dong, Guoyi, Morrison, Gregg, and Jaireth, Subhash, 1995, Quartz textures in epithermal veins, QueenslandClassification, origin, and implication: Economic Geology, v. 90 , p. 1841-1856.

Dong, G.Y., and Zhou, T., 1996, Zoning in the CarboniferousLower Permian Cracow epithermal vein system, central Queensland, Australia: Mineralium Deposita, v. 31, p. 210-224. 
Dreier, J.E., 1976, The geochemical environment of ore deposition in the Pachuca-Real del Monte district, Hidalgo, Mexico: Unpublished Ph.D. thesis, Tucson, University of Arizona, $115 \mathrm{p}$.

Dreier, J.E., 2005, The environment of vein formation and ore deposition in the Purisima-Colon-Pachuca Real del Monte district, Hidalgo, Mexico: Economic Geology, v. 100, p. $1325-1347$.

Drew, L.J., 2005, A tectonic model for the spatial occurrence of porphyry copper and polymetallic vein depositsApplications to central Europe: U.S. Geological Survey Scientific Investigations Report 2005-5272, 36 p.

du Bray, E.A., 2014, Geochemical and modal data for igneous rocks associated with epithermal mineral deposits: U.S. Geological Survey Data Series 875, 13 p.

du Bray, E.A., 2017, Geochemical characteristics of igneous rocks associated with epithermal mineral deposits-A review: Ore Geology Reviews, v. 80, p. 767-783.

Dubé, Benôit, Dunning, Greg, and Lauzière, Kathleen, 1998, Geology of the Hope Brook mine, Newfoundland, Canada - A preserved Late Proterozoic high-sulfidation epithermal gold deposit and its implications for exploration: Economic Geology, v. 93, p. 405-436.

Ducart, D.F., Crósta, A.P., Filho, C.R.S., and Coniglio, J., 2006, Alteration mineralogy at the Cerro La Mina epithermal prospect, Patagonia, Argentina — Field mapping, shortwave infrared spectroscopy, and ASTER images: Economic Geology, v. 101, no. 5, p. 981-996.

Durning, W.P., and Buchanan, L.J., 1984, The geology and ore deposits of Oatman, Arizona: Arizona Geological Society Digest, v. 15, p. 141-158.

Earthman, M.A., 2010, Sulfur isotope and fluid inclusion study of fluid sources within the Fresnillo southwest silver district, Zacatecas, Mexico: Socorro, New Mexico Institute of Mining and Technology, M.S. thesis, $66 \mathrm{p}$.

Ebert, S.W., and Rye, R.O., 1997, Secondary precious metal enrichment by steam-heated fluids in the Crofoot-Lewis hot spring gold-silver deposit and relation to paleoclimate: Economic Geology, v. 92, p. 578-600.

Einaudi, M.T., 1977, Environment of ore deposition at Cerro de Pasco, Peru: Economic Geology, v. 72, p. 893-924.

Einaudi, M.T., Hedenquist, J.W., and Inan, E., 2003, Sulfidation state of hydrothermal fluids - The porphyry-epithermal transition and beyond, chap. 15 of Simmons, S.F., and Graham, I.J., eds., Volcanic, geothermal and ore-forming fluids - rulers and witnesses of processes within the Earth: Society of Economic Geologists and Geochemical Society Special Publication 10, p. 285-313.
Ellis, Robert, and Robbins, Charles, 2000, Geophysics at the El Peñón gold-silver deposits, Chile: Spokane, Wash., Northwest Mining Association, Practical Geophysics III, CD-ROM, 14 p.

Emmons, W.H., 1917, The enrichment of ore deposits: U.S. Geological Survey Bulletin 625, 530 p.

Emmons, W.H., 1918, The principles of economic geology: New York, McGraw-Hill Book Company, Inc., 606 p.

Emmons, W.H., and Larsen, E.S., 1923, Geology and ore deposits of the Creede district, Colorado: U.S. Geological Survey Bulletin 718, $198 \mathrm{p}$.

Enderlin, Dean, 2002, Geology of the McLaughlin deposit, accessed June 24, 2014, at http://nrs.ucdavis.edu/McL/natural/ geology/region/region1.htm.

Eng, T., 1991, Geology and mineralization of the Freedom Flats gold deposit, Borealis mine, Mineral County, Nevada, in Raines, G.L., Lisle, R.E., Schafer, R.W., and Wilkinson, W.H., Proceedings of the Geology and Ore Deposits of the Great Basin Symposium, Reno, April 1990: Geological Society of Nevada, p. 995-1019.

Eng, T., Boden, D.R., Reischman, M.R., and Biggs, J.O., 1996, Geology and mineralization of the Bullfrog mine and vicinity, Nye county, Nevada, in Coyner, A.R., and Fahey, P.L., eds., Proceedings of the Geology and Ore Deposits of the American Cordillera Symposium, Reno, April 1995: Geological Society of Nevada, p. 353-402.

Enriquez, E., and Rivera, R., 2001a, Geology of the Santa Rita Ag-Au deposit, San Dimas district, Durango, Mexico, in Albinson, T., and Nelson, C.E., eds., New Mines and Discoveries in Mexico and Central America: Society of Economic Geologists Special Publication 8, p. 39-58.

Enriquez, E., and Rivera, R., 2001b, Timing of magmatic and hydrothermal activity in the San Dimas district, Durango, Mexico: Society of Economic Geologists Special Publication 8, p. $22-38$.

Etoh, J., Izawa, E., Watanabe, K., Taguchi, S., and Sekine, R., 2002, Bladed quartz and its relationship to gold mineralization in the Hishikari low-sulfidation epithermal gold deposit, Japan: Economic Geology, v. 97, p. 1841-1851.

Ewers, G.R., Mackenzie, D.E., Wyborn, D., Oversby, B.S., McPhie, J., and Andrew, A.S., 1994, Regional ${ }^{18} \mathrm{O}$ depletions in igneous rocks from the northern Drummond Basin, Queensland, Australia, and their implications for epithermal gold mineralization: Economic Geology, v. 89, p. 662-673.

Facca, G., and Tonani, F., 1967, The self-sealing geothermal field: Bulletin of Volcanology, v. 30, p. 271-273.

Fahley, M.P., 1981, Fluid inclusion study of Tonopah district, Nevada: Golden, Colorado School of Mines, M.S. thesis, 106 p. 
Farmer, G.L., Glazner, A.F., and Manley, C.R., 2002, Did lithospheric delamination trigger late Cenozoic potassic volcanism in the southern Sierra Nevada, California?: Geological Society of America Bulletin, v. 114, p. 754-768.

Faulds, J.E., Coolbaugh, M.F., and Hinz, N.H., 2011, Structural investigations of Great Basin geothermal fields-Applications and implications, in Steininger, Roger, and Pennell, Bill, eds., Proceedings of the Great Basin Evolution and Metallogeny Symposium, Reno, 2010: Geological Society of Nevada, p. 361-372.

Faure, K., Matsuhisa, Y., Metsugi, H., Mizota, C., and Hayashi, S., 2002, The Hishikari Au-Ag epithermal deposit, Japan-Oxygen and hydrogen isotope evidence in determining the source of paleohydrothermal fluids: Economic Geology, v. 97, p. 481-498.

Feebrey, C.A., Hishida, H., Yoshioka, K., and Nakayama, K., 1998, Geophysical expression of low sulphidation epithermal Au-Ag deposits and exploration implicationsExamples from the Hokusatsu region of SW Kyushu, Japan: Resource Geology, v. 48, p. 75-86.

Feiss, P.G., Vance, R.K., and Wesolowski, D.J., 1993, Volcanic rock-hosted gold and base-metal mineralization associated with Neoproterozoic-Early Paleozoic back-arc extension in the Carolina terrane, southern Appalachian Piedmont: Geology, v. 21, p. 439-442.

Ferguson, C.A., McIntosh, W.C., and Miller, C.F., 2013, Silver Creek caldera-The tectonically dismembered source of the Peach Spring Tuff: Geology, v. 41, p. 3-6.

Ferguson, H.G., 1921, The Mogollon district, New Mexico: U.S. Geological Survey Bulletin 787, 100 p.

Fey, D.L., Desborough, G.A., and Church, S.E., 2000, Comparison of two leach procedures applied to metalmining related wastes in Colorado and Montana and a relative ranking method for mine wastes, in Proceedings of the Fifth International Conference on Acid Rock Drainage, May 20-23, 2000, Denver: Society of Mining Engineering, p. 1477-1487.

Fey, D.L., Wirt, L., Besser, J.M., and Wright, W.G., 2002, Water quality and biological toxicity data of 2002 spring thaw conditions in the upper Animas River watershed, Silverton, Colorado: U.S. Geological Survey Open-File Report 02-0488, 20 p.

Fifarek, R.H., 2009, Evidence for the brittle-ductile transition at the Summitville high-sulfidation Au deposit, $\mathrm{CO}$, based on petrographic, thermometric and LA-ICP-MS analysis of fluid inclusions [abs.]: Geological Society of America Abstracts with Programs, v. 41, p. 256.
Fifarek, R.H., Devlin, B.D., and Tschauder, R.J., Jr., 1996, Au-Ag mineralization at the Golden Promise deposit, Republic district, Washington-Relation to graben development and hot spring processes, in Coyner, A.R., and Fahey, P.L., eds., Proceedings of the Geology and Ore Deposits of the American Cordillera Symposium, Reno, April 1995: Geological Society of Nevada, p. $1063-1088$.

Fifarek, R.H., and Gerike, G.N., 1991, Oxidation of hydrothermal sulfides at Round Mountain, Nevada - Origin and relation to gold mineralization, in Raines, G.L., Lisle, R.E., Schafer, R.W., and Wilkinson, W.H., eds., Proceedings of the Geology and Ore Deposits of the Great Basin Symposium, Reno, April 1990: Geological Society of Nevada, p. 1111-1121.

Fifarek, R.H., Rusk, B.G., and Rye, R.O., 2006, Fluid inclusion evidence for magmatic brine below the Summitville highsulfidation $\mathrm{Cu}-\mathrm{Au}$ deposits, $\mathrm{CO}$, and its potential relation to the brittle-ductile transition and mineralization [abs.]: Geological Society of America Abstracts with Programs, v. 38, p. 348.

Fifarek, R.H., and Rye, R.O., 2005, Stable-isotope geochemistry of the Pierina high-sulfidation $\mathrm{Au}-\mathrm{Ag}$ deposit, Peru-Influence of hydrodynamics on $\mathrm{SO}_{4}^{2-}-\mathrm{H}_{2} \mathrm{~S}$ sulfur isotopic exchange in magmatic-steam and steam-heated environments: Chemical Geology, v. 215, p. 253-279.

Fifarek, R.H., Samal, A.R., and Miggins, D.P., 2011, Genetic implications of mineralization and alteration ages at the Florida Canyon epithermal Au-Ag deposit, Nevada, in Steininger, R., and Pennell, B., eds., Proceedings of the Great Basin Evolution and Metallogeny Symposium, Reno, 2010: Geological Society of Nevada, p. 861-879.

Filimonova, L.G., and Chugaev, A.V., 2006, Chronology of hydrothermal and magmatic activity in the Dukat gold-silver ore field: Geology of Ore Deposits, v. 48, p. 489-498.

Foley, N.K., and Ayuso, R.A., 1994, Lead isotope compositions as guides to early gold mineralization - The North Amethyst vein system, Creede district, Colorado: Economic Geology, v. 89, p. $1842-1859$.

Foley, N.K., and Ayuso, R.A., 2012, Gold deposits of the Carolina Slate Belt, southeastern United States-Age and origin of the major gold producers: U.S. Geological Survey Open-File Report 2012-1179, 26 p.

Foley, N.K., Bethke, P.M., and Rye, R.O., 1989, A reinterpretation of the $\delta \mathrm{D}_{\mathrm{H} 2 \mathrm{O}}$ and inclusion fluids in contemporaneous quartz and sphalerite, Creede mining district, Colorado-A generic problem for shallow orebodies?: Economic Geology, v. 84, p. 1966-1977.

Folinsbee, R.E., Kirkland, K., Nekolaichuk, A., and Smejkal, V., 1972, Chinkuashih - A gold pyrite-enargite-barite hydrothermal deposit, Taiwan, in Doe, B.R., and Smith, D.K., eds., Studies in Mineralogy and Precambrian Geology: Geological Society of America Memoir, v. 135, p. 323-336. 
Fournier, R.O., 1985, The behavior of silica in hydrothermal solutions: Reviews in Economic Geology, v. 2, p. 45-61.

Fournier, R.O., and Rowe, J.J., 1966, Estimation of underground temperatures from the silica content of water from hot springs and wet-steam wells: American Journal of Science, v. 264, p. 685-697.

Freyssinet, P., Butt, C.R.M., Morris, R.C., and Piantone, P., 2005, Ore-forming processes related to lateritic weathering: Economic Geology, 100th Anniversary Volume, p. 681-722.

Fries, C., 1991, Pachuca-Real del Monte mining district, Hidalgo, in Salas, G.P., ed., Economic Geology of Mexico: Boulder, CO, Geological Society of America, p. 323-326.

Frimmel, H.E., 2008, Earth's continental crust gold endowment: Earth and Planetary Science Letters, v. 267, p. $45-55$.

Fritz, F., Lide, C., and Kern, R., 2011, Fire Creek deep mineralization defined with detailed gravity and MT, Elko County, Nevada, in Steininger, R., and Pennell, B., eds., Proceedings of the Great Basin Evolution and Metallogeny Symposium, Reno, 2010: Geological Society of Nevada, p. 153-166.

Frost, B.R., Barnes, C.G., Collins, W.J., Arculus, R.J., Ellis, D.J., and Frost, C.D., 2001, A geochemical classification for granitic rocks: Journal of Petrology, v. 42, p. 2033-2048.

Gammons, C.H., and Yu, Y., 1997, The stability of aqueous silver bromide and iodide complexes at $25-300{ }^{\circ} \mathrm{C}-$ Experiments, theory and geologic applications: Chemical Geology, v. 137, p. 155-173.

Gammons, C.H., Yu, Y., and Williams-Jones, A.E., 1997, The disproportionation of gold (I) chloride complexes at 25 to $200{ }^{\circ} \mathrm{C}$ : Geochimica et Cosmochimica Acta, v. 61, p. 1971-1983.

Garagan, T., and MacKinnon, H., 2003, Technical report, Kupol project, Chukotka, A.O., Russian Federation: Prepared for Bema Gold Corporation, 118 p., http://www. sedar.com.

Garcia, J.S., 1991, Geology and mineralisation characteristics of the Mankayan mineral district, Philippines: Geological Survey of Japan Report, v. 277, p. 21-30.

Garde, A.A., Whitehouse, M., and Christensen, R., 2012, Mesoarchean epithermal gold mineralization preserved at upper amphibolite-facies grade, Qussuk, southern West Greenland: Economic Geology, v. 107, p. 881-908.

Garwin, Steve, Hall, Robert, and Watanabe, Yasushi, 2005, Tectonic setting, geology, and gold and copper mineralization in Cenozoic magmatic arcs of southeast Asia and the west Pacific: Economic Geology 100th Anniversary Volume, p. 891-930.
Gemmell, J.B., 2007, Hydrothermal alteration associated with the Gosowong epithermal Au-Ag deposit, Halmahera, Indonesia-Mineralogy, geochemistry, and exploration implications: Economic Geology, v. 102, p. 893-922.

Gemmell, J.B., Simmons, S.F., and Zantop, H., 1988, The St. Niño silver-lead-zinc vein, Fresnillo district, Zacatecas, Mexico-Part I. Structure, vein stratigraphy and mineralogy: Economic Geology, v. 83, p. 1597-1618.

Geyne, A.R., Fries, C., Jr., Segerstrom, K., Black, R.F., and Wilson, I.F., 1963, Geology and mineral deposits of the Pachuca-Real del Monte district, State of Hidalgo, Mexico: Mexico, Consejo de Recursos Naturales no Renovabales Publication 5E, 203 p.

Giggenbach, W.F., 1992, Magma degassing and mineral deposition in hydrothermal systems along convergent plate boundaries: Economic Geology, v. 87, p. 1927-1944.

Giggenbach, W.F., 1997, The origin and evolution of fluids in magmatic-hydrothermal systems, in Barnes, H.L., ed., Geochemistry of hydrothermal ore deposits (3d ed.): New York, John Wiley \& Sons, p. 737-796.

Giles, D.I., and Nelson, C.E., 1982, Principal features of epithermal lode gold deposits of the circum-Pacific rimCircum-Pacific Energy and Minerals Resources Conference, 3rd, Honolulu, 1982, Transactions: American Association of Petroleum Geologists, p. 273-278.

Gill, J., 1981, Orogenic andesites and plate tectonics: New York, Springer-Verlag, 390 p.

Goldcorp, 2015, Peñasquito, accessed April 29, 2015, at https://www.goldcorp.com/English/portfolio/operations/ Peñasquito/default.aspx.

Goldie, M., 2002, Self-potential associated with the Yanacocha high-sulfidation gold deposit in Peru: Geophysics, v. 67, p. 684-689.

Goldstrand, P.M., and Schmidt, K.W., 2000, Geology, mineralization, and ore controls at the Ken Snyder goldsilver mine, Elko Country, Nevada-Proceedings of the Geology and Ore Deposits 2000 - The Great Basin and Beyond Symposium, Reno, May 15-18, 2000: Geological Society of Nevada, p. 265-287.

Goryachev, N.A., and Pirajno, F., 2014, Gold deposits and gold metallogeny of Far East Russia: Ore Geology Reviews, v. 59 , p. $123-151$.

Grancea, L., Bailly, L., Leroy, J., Banks, D., Marcoux, E., Milési, J.P., Cuney, M., André, A.S., Istvan, D., and Fabre, C., 2002, Fluid evolution in the Baia Mare epithermal gold/polymetallic district, Inner Carpathians, Romania: Mineralium Deposita, v. 37, p. 630-647. 
Graney, J.R., and Kesler, S.E., 1995, Gas composition of inclusion fluid in ore deposits-Is there a relation to magmas?, in Thompson, J.F.H., ed., Magmas, fluids, and ore deposits: Mineralogical Association of Canada, Short Course, v. 23, p. 221-245.

Grauch, V.J.S., 1988, Geophysical tools for defining covered geologic features - significance for disseminated gold deposits in Nevada: USA Bicentennial Gold 88, Melbourne, May 1988, Geological Society of Australia, abstract 23(2), p. 527-529.

Grauch, V.J.S., 1996, Magnetically interpreted, granitoid plutonic bodies in Nevada: Nevada Bureau of Mines and Geology, Open-File Report 96-2, chapter 7, p. 7-1-7-16.

Grauch, V.J.S., 2001, High-resolution aeromagnetic data, a new tool for mapping intrabasinal faults - An example from the Albuquerque basin, New Mexico: Geology, v. 29, p. 367-370.

Gray, D.J., Butt, C.R.M., and Lawrance, L.M., 1992, The geochemistry of gold in lateritic terrains, in Butt, C.R.M., and Zeegers, H., eds., Regolith exploration geochemistry in tropical and subtropical terrains: Amsterdam, Elsevier, Handbook of Exploration Geochemistry, v. 4, p. 461-482.

Gray, J.E., and Coolbaugh, M.F., 1994, Geology and geochemistry of Summitville, Colorado-An epithermal acid-sulfate deposit in a volcanic dome: Economic Geology, v. 89 , p. 1906-1923.

Gray, J.E., Coolbaugh, M.F., Plumlee, G.S., and Atkinson, W.W., 1994, Environmental geology of the Summitville mine, Colorado: Economic Geology, v. 89, p. 2006-2014.

Graybeal, F.T., and Vikre, P.G., 2010, A review of silverrich mineral deposits and their metallogeny: Society of Economic Geologists Special Publication 15, p. 85-117.

Greffié, Catherine, Bailly, Laurent, and Milési, Jean-Pierre, 2002, Supergene alteration of primary ore assemblages from low-sulfidation Au-Ag epithermal deposits at Pongkor, Indonesia, and Nazareño, Peru: Economic Geology, v. 97, p. 561-571.

Gröpper, H., Calvo, M., Crespo, H., Bisso, C.R., Cuadra, W.A., Dunkerley, P.M., and Aguirre, E., 1991, The epithermal gold-silver deposit of Choquelimpie, northern Chile: Economic Geology, v. 86, p. 1206-1221.

Gustafson, L.B., Vidal, C.E., Pinto, R., and Noble, D.C., 2004, Porphyry-epithermal transition, Cajamarca region, northern Peru: Society of Economic Geologists Special Publication 11, p. 279-299.

Haas, J.L., 1971, The effect of salinity on the maximum thermal gradient of a hydrothermal system at hydrostatic pressure: Economic Geology, v. 66, p. 940-946.
Hallberg, A., 1994, The Enåsen gold deposit, central Sweden-1. A Palaeoproterozoic high-sulphidation epithermal gold mineralization: Mineralium Deposita, v. 29, p. $150-162$.

Hallberg, A., and Fallick, A.E., 1994, The Enåsen gold deposit, central Sweden-2. Light element stable isotope evidence of premetamorphic hydrothermal activity: Mineralium Deposita, v. 29 , p. $163-169$.

Halley, S., Dilles, J.H., and Tosdal, R.M., 2015, Footprints: Hydrothermal alteration and geochemical dispersion around porphyry copper deposits: Society of Economic Geologists Newsletter, no. 100, p. 1, 12-17.

Harlan, J.B., Jones, M.L., and Sutopo, B., 2005, Discovery and characterization of the Martabe epithermal gold deposits, North Sumatra, Indonesia, in Rhoden, H.N., Steininger, R.C., and Vikre, P.G., eds., Proceedings of the Window to the World Symposium 2005, Reno, May 2005: Geological Society of Nevada, p. 917-942.

Harris, A.C., White, N.C., McPhie, J., Bull, S.W., Line, M.A., Skrzeczynski, R., Mernagh, T.P., and Tosdal, R.M., 2009, Early Archean hot springs above epithermal veins, North Pole, Western Australia - New insights from fluid inclusion microanalysis: Economic Geology, v. 104, p. 793-814.

Harris, M.C., Cassidy, J., Locke, C.A., Mauk, J.L., Stevens, M., and Vidanovich, P., 2006, Geophysical characteristics of the Karangahake epithermal deposit, Hauraki Goldfield, New Zealand, in New Zealand Minerals and Mining Conference, Auckland, 2005, Proceedings: Ministry of Economic Development, p. 115-124.

Harvey, B., Myers, S., and Klein, T., 1999, Yanacocha gold district, northern Peru, in Pacific Rim Congress, Bali, Indonesia, 1999, Proceedings: Australasian Institute of Mining and Metallurgy, p. 445-459.

Hayashi, T., 2001, Field stops - Kasuga, Iwato, and Akeshi mines, in Feebry, C.A., Hayashi, T., and Taguchi, S., eds., Epithermal gold mineralization and modern analogues, Kyushu, Japan: Society of Economic Geologists Guidebook Series, v. 34, p. 133-138.

Hayashi, K.-I., Maruyama, T., and Satoh, H., 2001, Precipitation of gold in a low-sulfidation epithermal gold deposit - Insights from a submillimeter-scale oxygen isotope analysis of vein quartz: Economic Geology, v. 96, p. 211-216.

Hayashi, T., and Taguchi, S., 2001, Epithermal gold exploration in the Iriki district, Kagoshima, Japan: Society of Economic Geologists Guidebook Series, v. 34, p. 61-83.

Hayba, D.O., 1997, Environment of ore deposition in the Creede mining district, San Juan mountains, Colorado-Part V. Epithermal mineralization from fluid mixing in the $\mathrm{OH}$ vein: Economic Geology, v. 92, p. 29-44. 
Hayba, D.O., Bethke, P.M., Heald, P., and Foley, N.K., 1985, Geologic, mineralogic, and geochemical characteristics of volcanic-hosted epithermal precious-metal deposits, in Berger, B.R., and Bethke, P.M., eds., Geology and geochemistry of epithermal systems: Reviews in Economic Geology, v. 2, p. 129-167.

Hayba, D.O., and Ingebritsen S.E., 1997, Multiphase groundwater flow near cooling plutons: Journal of Geophysical Research, v. 102, p. 12,235-12,252.

Heald, P., Foley, N.K., and Hayba, D.O., 1987, Comparative anatomy of volcanic-hosted epithermal deposits-Acidsulphate and adularia-sericite types: Economic Geology, v. 82, p.1-26.

Hedenquist, J.W., 1987, Mineralization associated with volcanic-related hydrothermal systems in the CircumPacific basin: Transactions of the Fourth Circum Pacific Conference on Energy and Mineral Resources Conference, Singapore, American Association of Petroleum Geologists, p. 513-524.

Hedenquist, J.W., 1990, The thermal and geochemical structure of the Broadlands-Ohaaki geothermal system, New Zealand: Geothermics, v. 19, p. 151-185.

Hedenquist, J.W., 1995, The ascent of magmatic fluidDischarge versus mineralization: Mineralogical Association of Canada Short Course, v. 23, p. 263-289.

Hedenquist, J.W., Arribas, A.R., and Gonzalez-Urien, E., 2000, Exploration for epithermal gold deposits, in Hagemann, S.G., and Brown, P.E., eds., Gold in 2000: Society of Economic Geologists, Reviews in Economic Geology, v. 13, p. 245-277.

Hedenquist, J.W., Arribas, A., and Reynolds, T.J., 1998, Evolution of an intrusion-centered hydrothermal systemFar Southeast-Lepanto porphyry and epithermal $\mathrm{Cu}-\mathrm{Au}$ deposits, Philippines: Economic Geology, v. 93, p. 373-404.

Hedenquist, J.W., and Browne, P.R.L., 1989, The evolution of the Waiotapu geothermal system, New Zealand, based on the chemical and isotopic composition of its fluids, minerals, and rocks: Geochimica et Cosmochimica Acta, v. 53 , p. $2235-2257$.

Hedenquist, J.W., and Henley, R.W., 1985a, The importance of $\mathrm{CO}_{2}$ on freezing point measurements of fluid inclusionsEvidence from active geothermal systems and implications for epithermal ore deposition: Economic Geology, v. 80, p. 1379-1406.

Hedenquist, J.W., and Henley, R.W., 1985b, Hydrothermal eruptions in the Waiotapu geothermal system, New Zealand-Their origin, associated breccias, and relation to precious metal mineralization: Economic Geology, v. 80, p. $1640-1668$.
Hedenquist, J.W., Matsuhisa, Y., Izawa, E., White, N.C., Giggenbach, W.F., and Aoki, M., 1994, Geology, geochemistry, and origin of high sulfidation $\mathrm{Cu}-\mathrm{Au}$ mineralization in the Nansatsu district, Japan: Economic Geology, v. 89, p. 1-30.

Hedenquist, J.W., Simmons, S.F., Giggenbach, W.F., and Eldridge, C.S., 1993, White Island, New Zealand, volcanic hydrothermal system represents the geochemical environment of high sulfidation $\mathrm{Cu}$ and $\mathrm{Au}$ ore deposition: Geology, v. 21, p. $731-734$.

Hedenquist, J.W., and Taran, Y.A., 2013, Modeling the formation of advanced argillic lithocaps-Volcanic vapor condensation above porphyry intrusions: Economic Geology, v. 108, p. $1523-1540$.

Heinrich, C.A., 2005, The physical and chemical evolution of low-salinity magmatic fluids at the porphyry to epithermal transition-A thermodynamic study: Mineralium Deposita, v. 39 , p. $864-889$.

Heinrich, C.H., and Neubauer, F., 2002, Cu-Au-Pb-Zn-Ag metallogeny of the Alpine-Balkan-Carpathian-Dinaride geodynamic province: Mineralium Deposita, v. 37, p. 533-540.

Henderson, R.D., 2011, Kupol mine, Russian Federation, NI 43-101 Technical Report: Kinross Gold Corporation, 147 p., accessed on May 28, 2014, at http://fb.kinross.com/ media/56569/kupol\%20tr\%20may\%202011.pdf.

Henley, R.W., 1985, The geothermal framework of epithermal deposits: Reviews in Economic Geology, v. 2, p. 1-24.

Henley, R.W., and Ellis, A.J., 1983, Geothermal systems, ancient and modern - A geochemical review: Earth-Science Reviews, v. 19, p. $1-50$.

Henley, R.W., and Hughes, G.O., 2000, Underground fumaroles"Excess heat" effects in vein formation: Economic Geology, v. 95, p. $453-466$.

Henley, R.W., Mavrogenes, J., and Tanner, D., 2012, Sulfosalt melts and heavy metal (As-Sb-Bi-Sn-Pb-Tl) fractionation during volcanic gas expansion-The El Indio (Chile) paleofumarole: Geofluids, v. 12, p. 199-215.

Henley, R.W., Truesdell, A.H., and Barton, P.B., Jr., eds., 1984, Fluid-mineral equilibria in hydrothermal systems: Reviews in Economic Geology, v. 1, 267 p.

Henry, C.D., Elson, H.B., McIntosh, W.C., Heizler, M.T., and Castor, S.B., 1997, Brief duration of hydrothermal activity at Round Mountain, Nevada, determined from ${ }^{40} \mathrm{Ar} /{ }^{39} \mathrm{Ar}$ geochronology: Economic Geology, v. 92, p. 807-826.

Herdianita, N.R., Browne, P.R.L., Rodgers, K.A., and Campbell, K.A., 2000, Mineralogical and textural changes accompanying ageing of silica sinter: Mineralium Deposita, v. 35, no. 1, p. $48-62$. 
Herrera, P.T., Closs, L.G., and Silberman, M.L., 1993, Alteration and geochemical zoning in Bodie Bluff, Bodie mining district, eastern California: Journal of Geochemical Exploration, v. 48, p. 259-275.

Herrington, R.J., Jankovic, S., and Kozelj, D., 1998, The Bor and Majdanpek copper-gold deposits in the context of the Nor metallogenic zone (Serbia, Yugoslavia), in Porter, T.M., ed., Porphyry and hydrothermal copper and gold deposits a global perspective: Australian Mineral Foundation Conference, November 30-December 1, 1998, Perth [Proceedings], p. 169-178.

Hill, D.P., 1977, A model for earthquake swarms: Journal of Geophysical Research, v. 82, p. 1347-1352.

Hill, J.M., 1915, Some mining districts in northeastern California and northwestern Nevada: U.S. Geological Survey Bulletin 594, 200 p.

Hofmann, A.W., 1997, Mantle geochemistry_-The message from oceanic volcanism: Nature, v. 385, p. 219-229.

Holley, E.A., 2012, The Veladero high-sulfidation epithermal Au-Ag deposit, Argentina - Volcanic stratigraphy, alteration, mineralization, and quartz paragenesis: Golden, Colorado School of Mines, Ph.D. thesis, 218 p.

Holley, E.A., Bissig, Thomas, and Monecke, Thomas, 2016, The Veladero high-sulfidation epithermal gold deposit, El IndioPascua belt, Argentina - Geochronology of alunite and jarosite: Economic Geology, v. 111, p. 311-330.

Holley, E.A., Bissig, Thomas, and Reynolds, T.J., 2017, Evolution of high-level magmatic-hydrothermal systems - New insights from ore paragenesis of the Veladero high-sulfidation epithermal Au-Ag deposit, El Indio-Pascua belt, Argentina: Economic Geology, v. 112, p. 1747-1771.

Hollister, V.F., and Silberman, M.L., 1995, Silver-gold and polymetallic quartz veins in the Bodie mining district, eastcentral California-Are they related to a porphyry $\mathrm{Cu}-\mathrm{Mo}$ system at depth?: Arizona Geological Society Digest, v. 20, p. 297-305.

Hoschke, T., and Sexton, M., 2005, Geophysical exploration for epithermal gold deposits at Pajingo, North Queensland, Australia: Exploration Geophysics, v. 36, p. 401-406.

Hosono, T., and Nakano, T., 2004, Pb-Sr isotopic evidence for contribution of deep crustal fluid to the Hishikari epithermal gold deposit, southwestern Japan: Earth and Planetary Science Letters, v. 222, p. 61-69.

Hudson, D.M., 2003, Epithermal alteration and mineralization in the Comstock district, Nevada: Economic Geology, v. 98, p. 367-385.
Hudson, D.M., Castor, S.B., Garside, L.J., and Henry, C.D., 2009, Geology of the Virginia City quadrangle, Washoe, Storey, and Lyon Counties, and Carson City, Nevada: Nevada Bureau of Mines and Geology, Map 165, scale 1:24,000, 37 p.

Hudson, D.M., John, D.A., and Fleck, R.J., 2006, Geology, geochemistry, and geochronology of epithermal gold-silver deposits in the Seven Troughs district, Pershing County, Nevada: Geological Society of Nevada Special Publication 42, p. 110-126.

Huston, D.L., Blewett, R.S., Keillor, B., Standing, J., Smithies, R.H., Marshall, A., Mernagh, T.P., and Kamprad, J., 2002, Lode gold and epithermal deposits of the Mallina basin, North Pilbara terrain, Western Australia: Economic Geology, v. 97, p. 801-818.

Hutchinson, R.M., 1988, Structure and ore deposits of the Camp Bird mine, Colorado, in Hutchinson, R.M., ed., Epithermal base-metal and precious-metal systems, San Juan Mountains, Colorado: Society of Economic Geologists Guidebook Series, v. 3, p. 5-44.

Hynes, T.P., Harrison, J., Bonitenko, E., Doronina, T.M., Baikowitz, H., James, M., and Zinck, J.M., 1998, The International Scientific Commission's assessment of the impact of the cyanide spill at Barskaun, Kyrgyz Republic, May 20, 1998: CANMET Mining and Mineral Services Laboratories Report MMSL 98-039(CR), 13 p.

Iler, R.K., 1979, The chemistry of silica-Solubility, polymerization, colloid and surface properties and biochemistry of silica: New York, John Wiley and Sons, 896 p.

Imai, A., Motomura, Y., and Watanabe, K., 2005, Characteristics of gold mineralization at the Ciurug vein, Pongkor gold-silver deposit, West Java, Indonesia: Resource Geology, v. 55, p. 225-238.

Imai, A., Shimazaki, H., and Nishizawa, T., 1998, Hydrogen isotope study of fluid inclusions in vein quartz of the Hishikari gold deposits, Japan: Resource Geology, v. 48, p. 159-170.

Ingebritsen, S.E., and Appold, M.S., 2012, The physical hydrogeology of ore deposits: Economic Geology, v. 107, p. 559-584.

Ingebritsen, S.E., Geiger, S., Hurwitz, S., and Driesner, T., 2010, Numerical simulation of magmatic hydrothermal systems: Reviews of Geophysics, v. 48, 33 p.

Ingebritsen, S.E., and Manning, C.E., 2010, Permeability of the continental crust - Dynamic variations inferred from seismicity and metamorphism: Geofluids, v. 10, p. 193-205.

International Cyanide Management Code, 2014, Environmental and Health Effects: International Cyanide Management Code web page, http:/www.cyanidecode.org/cyanide-facts/ environmental-health-effects. 
Irvine, R.J., and Smith, M.J., 1990, Geophysical exploration for epithermal gold deposits: Journal of Geochemical Exploration, v. 36 , p. $375-412$.

Irvine, T.N., and Baragar, W.R.A., 1971, A guide to the chemical classification of the common volcanic rocks: Canadian Journal of Earth Sciences, v. 8, p. 523-548.

Izawa, E., and Cunningham, C.G., 1989, Hydrothermal breccia pipes and gold mineralization in the Iwashita orebody, Iwato deposit, Kyushu, Japan: Economic Geology, v. 84, p. 715-724.

Izawa, E., Etoh, J., Honda, M., Motomura, Y., and Sekine, Y., 2001, Hishikari gold mineralization-A case study of the Hosen no. 1 vein hosted by basement Shimanto sedimentary rocks, southern Kyushu, Japan: Society of Economic Geologists Guidebook Series, v. 34, p. 21-30.

Izawa, E., Naito, K., Ibaraki, K., and Suzuki, R., 1993, Mudstones in a hydrothermal eruption crater above the gold-bearing vein system of the Yamada deposit at Hishikari, Japan, in Shikazono, N., Naito, K., and Izawa, E., eds., High Grade Epithermal Gold Mineralization-The Hishikari Deposit: Resource Geology Special Issue, no. 14, p. 85-92.

Izawa, E., Urashima, Y., Ibaraki, K., Suzuki, R., Yokoyama, T., Kawasaki, K., Koga, A., and Taguchi, S., 1990, The Hishikari gold deposit - High grade epithermal veins in Quaternary volcanics of southern Kyushu, Japan: Journal of Geochemical Exploration, v. 36, p. 1-56.

Izawa, E., and Watanabe, K., 2001, Quaternary gold mineralization and its geologic environments in Kyushu, Japan: Society of Economic Geologists Guidebook Series, v. 34, p. 11-15.

Izawa, E., Yoshida, T., Sakai, T., 1981, Fluid inclusion studies on the gold-silver quartz veins at Kushikino, Kagoshima, Japan: Mining Geology Special Issue, no. 10, p. 25-34.

Izawa, E., and Zeng, N., 2001, Kushikino gold mineralization in a Pliocene volcanic region, Kyushu, Japan: Society of Economic Geologists Guidebook Series, v. 34, p. 53-60.

Jachens, R.C., Moring, B.C., and Schruben, P.G., 1996, Thickness of Cenozoic deposits and the isostatic residual gravity over basement: Nevada Bureau of Mines and Geology Open-File Report 96-2, chapter 2, p. 2-1-2-10.

James, R., and Cumming, G.V., 2007, Geology and mineralization of the Chatree epithermal Au-Ag deposit, Phetchabun Province, central Thailand, Proceedings of the International Conference on Geology of Thailand-Towards Sustainable Development and Sufficiency Economy, Bangkok, November 21-22, 2007: Department of Mineral Resources, p. 378-390.

Jankovic, S., 1990, Types of copper deposits related to volcanic environment in the Bor district, Yugoslavia: Geologische Rundschau, v. 79, p. 467-478.
Jankovic, S.R., Jelenkovic, R.J., and Kozelj, D., 2002, The Bor copper and gold deposit: Bor, Serbia, QWERTY, 298 p.

Jannas, R.R., Beane, R.E., Ahler, B.A., and Brosnahan, D.R., 1990, Gold and copper mineralization at the El Indio deposit, Chile: Journal of Geochemical Exploration, v. 36, p. 233-266.

Jannas, R.R., Bowers, T.S., Petersen, U., and Beane, R.E., 1999, High-sulfidation deposit types in the El Indio district, Chile, in Skinner, B.J., ed., Geology and Ore Deposits of the Central Andes: Society of Economic Geologists, Special Publication 7, p. 219-266.

Jébrak, M., 1997, Hydrothermal breccias in vein-type ore deposits - A review of mechanisms, morphology and size distribution: Ore Geology Reviews, v. 12, p. 111-134.

Jelenkovic, Rade, Kozelj, Dejan, and Serafimovski, Todor, 2001, Some genetic aspects of the Bor copper-gold deposit, Serbia: Geologica Macedonica, v. 15-16, p. 1-5.

Jensen, E.P., and Barton, M.D., 2000, Gold deposits related to alkaline magmatism: Reviews in Economic Geology, v. 13, p. 279-314.

Jobson, D.H., Boulter, C.A., and Foster, R.P., 1994, Structural controls and genesis of epithermal gold-bearing breccias at Lebong Tandai mine, western Sumatra, Indonesia: Journal of Geochemical Exploration, v. 50, p. 409-428.

John, D.A., 2001, Miocene and early Pliocene epithermal gold-silver deposits in the northern Great Basin, western United States - Characteristics, distribution, and relationship to magmatism: Economic Geology, v. 96, p. $1827-1853$.

John, D.A., Ayuso, R.A., Barton, M.D., Blakely, R.J., Bodnar, R.J., Dilles, J.H., Gray, Floyd, Graybeal, F.T., Mars, J.C., McPhee, D.K., Seal, R.R., Taylor, R.D., and Vikre, P.G., 2010, Porphyry copper deposit model, chap. B of Mineral deposit models for resource assessment: U.S. Geological Survey Scientific Investigations Report 2010-5070-B, $169 \mathrm{p}$.

John, D.A., du Bray, E.A., Blakely, R.J., Fleck, R.J., Vikre, P.G., Box, S.E., and Moring, B.C., 2012, Miocene magmatism in the Bodie Hills volcanic field, California and Nevada-A long-lived eruptive center in the southern segment of the ancestral Cascades arc: Geosphere, v. 8, no. 1, p. 44-97.

John, D.A., du Bray, E.A., Box, S.E., Vikre, P.G., Rytuba, J.J., Fleck, R.J., and Moring, B.C., 2015a, Geologic map of the Bodie Hills, California and Nevada: U.S. Geological Survey Scientific Investigations Map 3318, 64 p., 2 sheets, scale 1:50,000, https://doi.org/10.3133/sim3318. 
John, D.A., du Bray, E.A., Henry, C.D., and Vikre, P.G., 2015b, Cenozoic magmatism and epithermal gold-silver deposits of the southern ancestral Cascade arc, western Nevada and eastern California: Proceedings of the New Concepts and Discoveries Symposium, Reno, 2015: Geological Society of Nevada, p. 611-635.

John, D.A., Hofstra, A.H., Fleck, R.J., Brummer, J.E., and Saderholm, E.C., 2003, Geologic setting and genesis of the Mule Canyon low-sulfidation epithermal gold-silver deposit, north-central Nevada: Economic Geology, v. 98, p. $425-463$.

John, D.A., Nash, J.T., Clark, C.W., and Wulftange, W., 1991, Geology, hydrothermal alteration, and mineralization at the Paradise Peak gold-silver-mercury deposit, Nye County, Nevada, in Raines, G.L., Lisle, R.E., Schafer, R.W., and Wilkinson, W.H., eds., Proceedings of the Geology and Ore Deposits of the Great Basin Symposium, Reno, April 1990: Geological Society of Nevada, p. 1020-1050.

John, D.A., Stewart, J.H., Kilburn, J.E., Silberling, N.J., and Rowan, L.C., 1993, Geology and mineral resources of the Reno $1^{\circ}$ by $2^{\circ}$ quadrangle, Nevada and California: U.S. Geological Survey Bulletin 2019, 65 p., https://pubs.er.usgs. gov/publication/b2019.

John, D.A., Thomason, R.E., and McKee, E.H., 1989, Geology and K-Ar geochronology of the Paradise Peak mine and the relationship of pre-Basin and Range extension to early Miocene precious metal mineralization in west-central Nevada: Economic Geology, v. 84, p. 631-649.

John, D.A., Wallace, A.R., Ponce, D.A., Fleck, R.B., and Conrad, J.E., 2000, New perspectives on the geology and origin of the northern Nevada Rift, in Cluer, J.K., Price, J.G., Struhsacker, E.M., Hardyman, R.F., and Morris, C.L., eds., Proceedings of the Geology and Ore Deposits 2000 The Great Basin and Beyond Symposium, Reno, May 15-18, 2000: Geological Society of Nevada, p. 127-154.

Kamenov, G.D., Saunders, J.A., Hames, W.E., and Unger, D.L., 2007, Mafic magmas as sources for gold in middle Miocene epithermal deposits of the northern Great Basin, United States-Evidence from $\mathrm{Pb}$ isotope compositions of native gold: Economic Geology, v. 102, p. 1191-1195.

Kamilli, R.J., 1994, The Mogollon mining district—results from mapping, paragenesis, and fluid-inclusion studies in Carter, L.M.H., Toth, M.I., and Day, W.C., USGS research on mineral resources, 1994 - part A, program and abstracts: U.S. Geological Survey Circular 1103-A, p. 52-53, https:// pubs.er.usgs.gov/publication/cir1103A.

Kamilli, R.J., and Ohmoto, H., 1977, Paragenesis, zoning, fluid inclusion, and isotopic studies of the Finlandia vein, Colqui district, Central Peru: Economic Geology, v. 72, p. $950-982$.
Kamilli, R.J., and Ratté, J.C., 1995, Geologic studies of the Mogollon mining district, New Mexico-Does a porphyry system lie below?: Arizona Geological Digest, v. 20, p. $455-463$.

Kassem, O.K., Al Bassam, A., and Zaidi, F., 2013, Structural analysis for metavolcanics and their metapyroclastics at gold deposit of the Mahd Ad Dahab area, Arabian Shield, Saudi Arabia: Geology of Ore Deposits, v. 55, p. 482-493.

Keith, W.J., Calk, L., and Ashley, R.P., 1979, Crystals of coexisting alunite and jarosite, Goldfield, Nevada, in Shorter contributions to mineralogy and petrology, 1979: U.S. Geological Survey Professional Paper 1124-C, p. C1-C5, https://pubs.er.usgs.gov/ publication/pp1124AF.

Keller, G.V., 1987, Rock and mineral properties, in Nabighian, M.N., ed., Electromagnetic methods in applied geophysics theory, v. 1: Tulsa, Okla., Society of Exploration Geophysicists, p. $13-51$.

Kelley, K.D., Spry, P.G., McLemore, V.T., Fey, D.L., and Anderson, E.D., In Press, A deposit model for alkaline igneous rock-related epithermal gold deposits: U.S. Geological Survey Scientific Investigations Report.

Kesler, S.E., Campbell, I.H., Smith, C.H., Hall, C.M., and Allen, C.M., 2005, Age of the Pueblo Viejo gold silver deposit and its significance to models of high-sulfidation epithermal mineralization: Economic Geology, v. 100, p. 253-272.

Kesler, S.E., Russell, Norman, and McCurdy, Karr, 2003, Tracemetal content of the Pueblo Viejo precious-metal deposits and their relation to other high-sulfidation epithermal systems: Mineralium Deposita, v. 38, p. 668-682.

Kesler, S.E., Russell, N., Seaward, M., Rivera, J., McCurdy, K., Cumming, G.L., and Sutter, J.F., 1981, Geology and geochemistry of sulfide mineralization underlying the Pueblo Viejo gold-silver oxide deposit, Dominican Republic: Economic Geology, v. 76, p. 1096-1117.

Kesler, S.E., and Wilkinson, B.H., 2009, Resources of gold in Phanerozoic epithermal deposits: Economic Geology, v. 104, p. $623-633$.

Kettler, R.M., Rye, R.O., Kesler, S.E., Meyers, P.A., Polanco, J., and Russell, N., 1992, Gold deposition by sulfidation of ferrous Fe in the lacustrine sediments of the Pueblo Viejo district (Dominican Republic)-The effect of Fe-C-S diagenesis on later hydrothermal mineralization in a maar-diatreme complex: Chemical Geology, v. 99, p. 29-50.

Khashgerel, B.-E., Rye, R.O., Kavalieris, I., and Hayashi, K., 2009, The sericitic to advanced argillic transition-Stable isotope and mineralogical characteristics from the Hugo Dummett porphyry Cu-Au deposit, Oyu Tolgoi District, Mongolia: Economic Geology, v. 104, no. 8, p. 1087-1110, https://doi.org/10.2113/gsecongeo.104.8.1087. 
Kilias, S.P., Naden, J., Cheliotis, I., Shepherd, T.J., Constandinidou, H., Crossing, J., and Simos, I., 2001, Epithermal gold mineralization in the active Aegean volcanic arc-The Profitis ilias deposit, Milos Island, Greece: Mineralium Deposita, v. 36, p. 32-44.

Kim, K.H., Lee, S., Nagao, K., Sumino, H., Yang, K., and Lee, J.I., 2012, He-Ar-H-O isotopic signatures in Au-Ag bearing ore fluids of the Sunshin epithermal gold-silver ore deposits, South Korea: Chemical Geology, v. 320-321, p. 128-139.

Kirk, J.D., Ruiz, Joaquin, Kesler, S.E., Simon, Adam, and Muntean, J.L., 2014, Re-Os age of the Pueblo Viejo epithermal deposit, Dominican Republic: Economic Geology, v. 109, p. 503-512.

Klondex Mines Ltd., 2015, Midas reserves and resources: Klondex Mines web page, accessed August 31, 2015, at http://klondexmines.com/s/midas.asp.

Koděra, P., Lexa, J., Fallick, A.E., Wälle, M., and Biroň, A., 2014, Hydrothermal fluids in epithermal and porphyry Au deposits in the Central Slovakia Volcanic Field: Geological Society of London, Special Publications, v. 402, p. 177-206.

Koděra, P., Lexa, J., Rankin, A.H., and Fallick, A.E., 2005, Epithermal gold veins in a caldera setting-Banská Hodruša, Slovoki: Mineralium Deposita, v. 39, p. 921-943.

Koichiro, Syafrizal, Watanabe, Yasushi, Imai, Akira, and Motomura, Yoshinobu, 2005, Alteration and gold mineralization of the Ciurug vein, Pongkor Au-Ag deposit, Indonesia, in Mao, Jingwen, Bierlein, F.P., eds., Mineral Deposit Research-Meeting the Global Challenge: Berlin Heidelberg, Springer-Verlag, p. 995-998.

Konstantinov, M.M., Kalinin, A.I., Natalenko, V.E., Struzhkov, S.F., and Dvurechenskaya, S.S., 1995, The Dukat gold-silver deposit, Russia: Geology of Ore Deposits, v. 37, p. 274-290.

Koschmann, A.H., and Bergendahl, M.H., 1968, Principal goldproducing districts of the United States: U.S. Geological Survey Professional Paper 610, 283 p., https://pubs.usgs. gov/pp/0610/report.pdf.

Koutz, F., 1984, The Hardshell silver, base-metal, manganese oxide deposit, Patagonia Mountains, Santa Cruz County, Arizona-A Field Trip Guide, in Wilkins, J., Jr., ed., Gold and Silver Deposits of the Basin and Range province, Western USA: Arizona Geological Society Digest, v. 15, p. 199-217.

Kouzmanov, K., Ramboz, C., Bailly, L., and Bogdanov, K., 2004, Genesis of high-sulfidation vinciennite-bearing $\mathrm{Cu}-\mathrm{As}-\mathrm{Sn}(\mathrm{Au})$ assemblage from the Radka epithermal copper deposit, Bulgaria-Evidence from mineralogy and infrared microthermometry of enargite: Canadian Mineralogist, v. 42, p. 1501-1521.
Kravtsova, R.G., Zakharov, M.N., and Korkina, O.I., 2005, Rare-earth elements in metasomatites and ores of the Dukat gold-silver deposit (northeastern Russia): Russian Geology and Geophysics, v. 46, p. 603-616.

Krupp, R.E., and Weiser, T., 1992, On the stability of gold-silver alloys in the weathering environment: Mineralium Deposita, v. 27 , p. $268-275$.

Kruse, F.A., Bedell, R.L., Taranik, J.V., Peppin, W.A., Weatherbee, O., and Calvin, W.M., 2012, Mapping alteration minerals at prospect, outcrop and drill core scales using imaging spectrometry: International Journal of Remote Sensing, v. 33, no. 6, p. 1780-1798, https://doi.org/10.1080/01431161.2011.6 00350 .

Lambert, R.J., Valliant, W.W., and Altman, K.A., 2014, Technical report on the Mesquite mine, Imperial County, California, U.S.A.: Toronto, New Gold Inc., 120 p., accessed August 26, 2015, at http://www.newgold.com/files/documents_properties/ mesquite/2014-02-28_MSQ_NI-43-101-Tech-Rept.pdf.

Lanfranchini, M.E., Etcheverry, R.O., de Barrio, R.E., and Recio Hernández, R., 2013, Precious metal-bearing epithermal deposits in western Patagonia (NE Lago Fontana region), Argentina: Journal of South American Earth Sciences, v. 43, p. $86-100$.

Lang, B., Steinitz, G., Sawkins, F.J., and Simmons, S.F., 1988, $\mathrm{K}-\mathrm{Ar}$ age studies in the Fresnillo Silver district, Zacatecas: Economic Geology, v. 83, p. 1642-1646.

Lang, B., Edelstein, O., Steinitz, G., Kovacs, M., and Halga, S., 1994, Ar-Ar dating of adularia-A tool in understanding genetic relations between volcanism and mineralization, Baia Mare area (Gutii Mountains), northwestern Romania: Economic Geology, v. 89 , p. $174-180$.

Lange, I.M., Zehner, R.E., and Hahn, G.A., 1994, Geology, geochemistry, and ore deposits of the Oligocene Hog Heaven volcanic field, northwestern Montana: Economic Geology, v. 89 , p. 1939-1963.

Lapakko, K., and Lawrence, L.W., 1993, Modification of the net acid production (NAP) test, in Proceedings of the Seventeenth Annual British Columbia Mine Reclamation Symposium, Port Hardy, British Columbia, May 4-7, 1993: Ministry of Energy, Mines and Petroleum Resources, p. 145-159.

Lapointe, D.D., Tingley, J.V., and Jones, R.B., 1991, Mineral resources of Elko County, Nevada: Nevada Bureau of Mines and Geology Bulletin 106, 236 p.

Lattanzi, P., Da Pelo, S., Musu, E., Atzei, D., Elsener, B., Fantauzzi, M., and Rossi, A., 2008, Enargite oxidation-A review: Earth-Science Reviews, v. 86, p. 62-88.

Le Maitre, R.W., ed., 2002, Igneous rocks - A classification and glossary of terms (2d ed.): Cambridge University Press, 236 p. 
Leavitt, E.D., and Arehart, G.B., 2005, Alteration, geochemistry, and paragenesis of the Midas epithermal gold-silver deposit, Elko County, Nevada: Proceedings of the Window to the World Symposium 2005, Reno, May 2005: Geological Society of Nevada, p. 563-627.

Leavitt, E.D., Spell, T.L., Goldstrand, P.M., and Arehart, G.B., 2004, Geochronology of the Midas low-sulfidation epithermal gold-silver deposit, Elko County, Nevada: Economic Geology, v. 99 , p. 1665-1686.

Lehrman, N.J., 1986, The McLaughlin mine, Napa and Yolo Counties, California, in Tingley, J.V., and Bonham Jr., H.F., eds., Precious-metal mineralization in hot-spring systems, Nevada-California. Nevada Bureau of Mines and Geology Report 41, p. 85-89.

Lerouge, C., Bailly, L., Béchu, E., Fléhoc, C., Genna, A., Lescuyer, J.L., Stein, G., Gillot, P.Y., and Kozelj, D., 2005, Age and origin of advanced argillic alteration at the Bor $\mathrm{Cu}-\mathrm{Au}$ deposit, Serbia, in Mao, Jingwen, Bierlein, F.P., eds., Mineral Deposit Research-Meeting the Global Challenge: Berlin Heidelberg, Springer-Verlag, p. 541-544.

Lesage, G., Richards, J.P., Muehlenbachs, K., and Spell, T.L., 2013, Geochronology, geochemistry, and fluid characterization of the Late Miocene Buritica gold deposit, Antioquia Department, Colombia: Economic Geology, v. 108, p. 1067-1097.

Lewis, R.W., and Wilson, G.I., 1990, Misima gold deposit: Australasian Institute of Mining and Metallurgy Monograph Series, v. 14, p. 1741-1745.

Lexa, J., 1999, Outline of the Alpine geology and metallogeny of the Carpatho-Pannonian region: Society of Economic Geologists Guidebook Series, v. 31, p. 65-108.

Lexa, J., Štohl, J., and Konečný, V., 1999, Banksá Štiavnica ore district-Relationship between metallogenic processes and the geological evolution of a stratovolcano: Mineralium Deposita, v. 34, p. $639-654$.

Lhotka, P.G., 2010, Discovery history of the Navidad silver deposits, Chubat, Argentina - One thousand years in the waiting: Society of Economic Geologists Special Publication 15, p. 181-201.

Lindgren, Waldemar, 1913, Mineral Deposits: New York, McGraw-Hill, 883 p.

Lindgren, Waldemar, 1915, Geology and mineral deposits of the National mining district, Nevada: U.S. Geological Survey Bulletin 601, 58 p., https://pubs.er.usgs.gov/publication/b601.

Lindgren, Waldemar, 1928, Mineral Deposits (3d ed.): New York, McGraw-Hill, 1,049 p.

Lindgren, Waldemar, 1933, Mineral Deposits (4th ed.): New York, McGraw-Hill, $930 \mathrm{p}$.
Lindgren, Waldemar, and Creveling, J.G., 1928, The ores of Potosi, Bolivia: Economic Geology, v. 23, p. 233-262.

Lipman, P.W., Doe, B.R., Hedge, C.E., and Steven, T.A., 1978, Petrologic evolution of the San Juan volcanic field, southwestern Colorado- $\mathrm{Pb}$ and $\mathrm{Sr}$ isotope evidence: Geological Society of America Bulletin, v. 89, p. 59-82.

Locke, C.A., and de Ronde, C.E.J., 1987, Delineation of goldbearing hydrothermally altered rocks using gravity data-A New Zealand example: Geoexploration, v. 24, p. 471-481.

Locke, C.A., Johnson, S.A., Cassidy, J., and Mauk, J.L., 1999, Geophysical exploration of the Puhipuhi epithermal area, Northland, New Zealand: Journal of Geochemical Exploration, v. 65, p. $91-109$.

Logsdon, M.J., Hagelstein, K., and Mudder, T.I., 1999, The management of cyanide in gold extraction: Ottawa, International Council on Metals and the Environment, $44 \mathrm{p}$.

Long, K.R., DeYoung, J.H., Jr., and Ludington, S.D., 1998, Database of significant deposits of gold, silver, copper, lead, and zinc in the United States: U.S. Geological Survey Open-File Report 98-206 A, B, 33 p., https://pubs.usgs.gov/ of/1998/0206a-b/.

Long, X., Hayward, N., Begg, G., Minlu, F., Fangzheng, W., and Pirajno, F., 2005, The Jinxi-Yelmand high-sulfidation epithermal gold deposit, Western Tianshan, Xinjiang Province, P.R. China: Ore Geology Reviews, v. 26, p. 17-37.

Longo, A.A., 2000, The San Jose-Carachugo-Chaquicocha gold trend, Yanacocha district, northern Perú, in Cluer, J.K., Price, J.G., Struhsacker, E.M., Hardyman, R.F., and Morris, C.L., eds., Proceedings of the Geology and Ore Deposits 2000-The Great Basin and Beyond Symposium, Reno, May 15-18, 2000: Geological Society of Nevada, p. 201-220.

Longo, A.A., 2005, Evolution of volcanism and hydrothermal activity in the Yanacocha mining district, northern Perú: Corvallis, Oregon State University, Ph.D. dissertation, 469 p.

Longo, A.A., Dilles, J.H., Grunder, A.L., and Duncan, R., 2010, Evolution of calc-alkaline volcanism and associated hydrothermal gold deposits at Yanacocha, Peru: Economic Geology, v. 105, p. 1191-1241.

Longo, A.A., and Teal, L., 2005, A summary of the volcanic stratigraphy and the geochronology of magmatism and hydrothermal activity in the Yanacocha gold district, northern Peru, in Rhoden, H.N., Steininger, R.C., and Vikre, P.G., eds., Proceedings of the Window to the World Symposium 2005, Reno, May 2005: Geological Society of Nevada, p. 797-808.

Looby, E.L., 2015, The timing and genesis of the Blackwater gold-silver deposit, central British Columbia-Constraints from geology, geochronology, and stable isotopes: Vancouver, University of British Columbia, M.S. thesis, 172 p. 
Losada-Calderón, A.J., McBride, S.L., and Bloom, M.S., 1994, The geology and ${ }^{40} \mathrm{Ar} /{ }^{39} \mathrm{Ar}$ geochronology of magmatic activity and related mineralization in the Nevados del Famatina mining district, La Rioja province, Argentina: Journal of South American Earth Sciences, v. 7, p. 9-24.

Losada-Calderón, A.J., and McPhail, D.C., 1996, Porphyry and high sulfidation epithermal mineralisation in the Nevados del Famatina mining district, Argentina: Society of Economic Geologists Special Publication 5, p. 91-118.

Loucks, R.R., Lemish, John, and Damon, P.E., 1988, Polymetallic epithermal fissure vein mineralization, Topia, Durango, Mexico-Part I, District geology, geochronology, hydrothermal alteration, and vein mineralogy: Economic Geology, v. 83, p. 1499-1528.

Loucks, R.R., and Peterson, Ulrich, 1988, Polymetallic epithermal fissure vein mineralization, Topia, Durango, Mexico-Part II, Silver mineral chemistry and high resolution patterns of chemical zoning in veins: Economic Geology, v. 83, p. $1529-1559$.

M3 Engineering \& Technology Corporation, 2011, Corani Project: Bear Creek Mining, Form NI 43-101 Technical Report, 291 p., accessed November 18, 2014, at http://www.bearcreekmining. $\mathrm{com} / \mathrm{s} /$ corani.asp?ReportID $=619755$.

Macdonald, A.J., Kreczmer, M.J., and Kesler, S.E., 1986, Vein, manto and chimney mineralization at the Fresnillo silver-leadzinc mine, Mexico: Canadian Journal of Earth Sciences, v. 23, p. 1603-1614.

MacIntosh, L.L., 1980, Geology of the Consolidated Imperial open pit Au-Ag mine, Comstock Lode district, Storey Co., Nevada in Epithermal precious metal deposits of northern Nevada: U.S. Geological Survey and Society of Economic Geologists Field Trip Guidebook, p. 64-69.

Maddry, J.W., and Kilbey, T.R., 1995, Geology of the Haile gold mine: Society of Economic Geologists Guidebook Series, v. 24, p. 147-172.

Mallette, P.M., Rojas, R.E., and Gutierrez, A.R., 2004, Geology, mineralization, and genesis of the La Quiana gold deposit, Yanacocha district, northern Peru: Society of Economic Geologists Special Publication 11, p. 301-312.

Mancano, D.P., and Campbell, A.R., 1995, Microthermometry of enargite-hosted fluid inclusions from the Lepanto, Philippines high-sulfidation $\mathrm{Cu}-\mathrm{Au}$ deposit: Geochimica et Cosmochimica Acta, v. 59, p. 3909-3916.

Mango, Helen, Arehart, Greg, Oreskes, Naomi, and Zantop, Half, 2014, Origin of epithermal Ag-Au-Cu-Pb-Zn mineralization in Guanajuato, Mexico: Mineralium Deposita, v. 49, p. 119-143.

Mango, H.N., Zantop, H., and Oreskes, N., 1991, A fluid inclusion and isotope study of the Rayas $\mathrm{Ag}-\mathrm{Au}-\mathrm{Cu}-\mathrm{Pb}-\mathrm{Zn}$ mine, Guanajuato, Mexico: Economic Geology, v. 86, p. 1554-1561.
Mann, A.W., 1984, Mobility of gold and silver in lateritic weathering profiles - Some observations from Western Australia: Economic Geology, v. 79, p. 38-49.

Manske, S.L., 1991, Epithermal gold in gneissic rocks of the Mesquite district, Imperial County, California: Stanford University, Ph.D. dissertation, 347 p.

Manske, S.L., Hedenquist, J.W., O’Connor, G., Tamas, C., Cauuet, B., Leary, S., and Minut, A., 2006, Roşia Montană, RomaniaEurope's largest gold deposit: Society of Economic Geologists Newsletter, no. 64, p. 1, 9-15.

Marcoux, E., and Milési, J.-P., 1994, Epithermal gold deposits in West Java, Indonesia — Geology, age and crustal source: Journal of Geochemical Exploration, v. 50, p. 393-408.

Marinova, I., Ganev, V., and Titorenkova, R., 2014, Colloidal origin of colloform-banded textures in the Paleogene lowsulfidation Khan Krum gold deposit, SE Bulgaria: Mineralium Deposita, v. 49, p. 49-74.

Marma, J.C., and Vance, R.B., 2011, Importance of cymoid loops and implications for exploration and development of epithermal gold-silver veins in the Gold Circle district, Midas, Nevada, in Steininger, R., and Pennell, B., eds., Proceedings of the Great Basin Evolution and Metallogeny Symposium, Reno, 2010: Geological Society of Nevada, p. 777-793.

Mars, J.C., 2013, Hydrothermal alteration maps of the central and southern Basin and Range province of the United States compiled from Advanced Spaceborne Thermal Emission and Reflection Radiometer (ASTER) data (ver. 1.1, April 8, 2014): U.S. Geological Survey Open-File Report 2013-1139, 5 p., 13 plates, scale 1:1,300,000, https://pubs.usgs.gov/of/2013/1139/.

Martini, B.A., 2015, Corescan contributes to Barrick's exploration success at El Indio, Chile: Corescan press release, July 14, 2015, http:/www.corescan.com.au/assets/PR20151407 BarrickAlturasCorescanSuccess.pdf.

Masterman, G.J., White, N.C., Wilson, C.J.L., and Pape, D., 2002, High-sulfidation gold deposits in ancient volcanic terrannesInsights from the mid-Paleozoic Peak Hill deposits, NSW: Society of Economic Geologists Newsletter, no. 51, p. 1, 10-16.

Matsuhisa, Y., and Aoki, M., 1994, Temperature and oxygen isotope variations during formation of the Hishikari epithermal gold-silver veins, southern Kyushu, Japan: Economic Geology, v. 89 , p. 1608-1613.

Matsuhisa, Y., Morishita, Y., and Sato, Y., 1985, Oxygen and carbon isotope variations in gold-bearing hydrothermal veins in the Kushikino mining area, southern Kyushu, Japan: Economic Geology, v. 80, p. 283-293.

Mauk, J.L., and Hall, C.M., 2004, ${ }^{40} \mathrm{Ar} /{ }^{39} \mathrm{Ar}$ ages of adularia from the Golden Cross, Neavesville and Komata epithermal deposits, Hauraki Goldfield, New Zealand: New Zealand Journal of Geology and Geophysics, v. 47, p. 227-231. 
Mauk, J.L., Hall, C.M., Chesley, J.T., and Barra, F., 2011, Punctuated evolution of a large epithermal province-The Hauraki Goldfield, New Zealand: Economic Geology, v. 106, p. $921-943$.

Mauk, J.L., and Simpson, M.P., 2007, Geochemistry and stable isotope composition of altered rocks at the Golden Cross epithermal Au-Ag deposit, New Zealand: Economic Geology, v. 102 , p. $841-871$.

Mavrogenes, J.M., Henley, R.Q., Reyes, A.G., and Berger, B., 2010, Sulfosalt melts - Evidence of high-temperature vapor transport of metals in the formation of high-sulfidation lode gold deposits: Economic Geology, v. 105, p. 257-262.

McKee, E.H., Dreier, J.E., and Noble, D.C., 1992, Early Miocene hydrothermal activity at Pachuca-Real del Monte, Mexico-An example of space-time association of volcanism and epithermal $\mathrm{Ag}-\mathrm{Au}$ vein mineralization: Economic Geology, v. 87, p. $1635-1637$.

McKibben, M.A., and Elders, W.A., 1985, Fe-Zn-Cu-Pb mineralization in the Salton Sea geothermal system, Imperial Valley, California: Economic Geology, v. 80, p. 539-559.

Merchant, R.J., 1986, Mineralisation in the Thames district, Coromandel: Berlin, Gebruder Borntraeger Monograph Series on Mineral Deposits 26, p. 165-183.

Micklethwaite, Steven, 2009, Mechanisms of faulting and permeability enhancement during epithermal mineralizationCracow goldfield, Australia: Journal of Structural Geology, v. 31, p. 288-300.

Micklethwaite, Steven, Sheldon, H.A., and Baker, Timothy, 2010, Active fault and shear processes and their implications for mineral deposit formation and discovery: Journal of Structural Geology, v. 32, p. 151-165.

Milési, J.P., Marcoux, E., Sitorus, T., Simandjuntak, M., Leroy, J., and Bailly, L., 2009, Pongkor (west Java, Indonesia)-A Pliocene suépergene-enriched epithermal $\mathrm{Au}-\mathrm{Ag}$-(Mn) deposit: Mineralium Deposita, v. 34, p. 131-149.

Mills, A.L., 1999, The role of bacteria in environmental geochemistry, in Plumlee, G.S., and Logsdon, M.J., eds., The environmental geochemistry of mineral deposits, Part AProcesses, techniques, and health issues: Reviews in Economic Geology, v. 6A, p. 125-132.

Mixa, P., Dobeš, P., Žáček, V., Lukeš, P., and Quintanilla, E.M., 2001, Epithermal gold mineralization in Costa Rica, Cordillera de Tilarán-Exploration geochemistry and genesis of gold deposits: Journal of Geosciences, v. 56, p. 81-104.

Miyashiro, Akiho, 1974, Volcanic rock series in island arcs and active continental margins: American Journal of Science, v. 274, p. 321-355.
Mobley, R.M., Yogodzinski, G.M., Creaser, R.A., and Berry, J.M., 2014, Geologic history and timing of mineralization at the Haile gold mine, South Carolina: Economic Geology, v. 109 , p. $1863-1881$.

Moller, S.A., Islas F., J.E., and Davila F., R.T., 2001, New discoveries in the La Colorada district, Zacatecas state, Mexico, chap. 7 of Albinson, T., and Nelson, C.E., eds., New Mines and Discoveries in Mexico and Central America: Society of Economic Geologists Special Publication 8, p. 95-104.

Moncada, D., Mutchler, S., Nieto, A., Reynolds, T.J., Rimstidt, J.D., and Bodnar, R.J., 2012, Mineral textures and fluid inclusion petrography of the epithermal Ag-Au deposits at Guanajuato, Mexico-Application to exploration: Journal of Geochemical Exploration, v. 114, p. 20-35.

Montgomery, A.T., 2012, Metallogenetic controls on Miocene high-sulphidation epithermal gold mineralization, Alto Chicama district, La Libertad, northern Peru: Kingston, Ontario, Queens University, Ph.D. dissertation, 455 p.

Morishita, Y., and Nakano, T., 2008, Role of basement in epithermal deposits-The Kushikino and Hishikari gold deposits, southwestern Japan: Ore Geology Reviews, v. 34, p. 597-609.

Moritz, R., Jaquat, S., Chambefort, I., Fontignie, D., Petrunov, R., Georgieva, S., and von Quadt, A., 2003, Controls on ore formation at the high-sulfidation $\mathrm{Au}-\mathrm{Cu}$ Chelopech deposit, Bulgaria-Evidence from infrared fluid inclusion microthermometry of energite and isotopic systematics of barite, in Eliopoulos, D., ed., Mineral exploration and sustainable development: Proceedings of the Seventh Biennial SGA Meeting, Rotterdam, Millpress, v. 1, p. 1209-1212.

Morrell, A.E., Locke, C.A., Cassidy, J., and Mauk, J.L., 2011, Geophysical characteristics of adularia-sericite epithermal gold-silver deposits in the Waihi-Waitekauri region, New Zealand: Economic Geology, v. 106, p. 1031-1041.

Moyle, A.J., Bischoff, K., Alexander, K.R., and Hoogvliet, H., 1996, Mt. Muro gold deposit, Indonesia: Australian Mineral Foundation, Porphyry Related Copper and Gold Deposits of the Asia Pacific Region, 12-August 13, 1996, Cairns, Australia, Conference Proceedings, p. 7.1-7.9.

Moyle, A.J., Doyle, B.J., Hoogvliet, H., and Ware, A.R., 1990, Ladolam gold deposit, Lihir Island, in Hughes, F.E., ed., Geology of the mineral deposits of Australia and Papua New Guinea: Melbourne, Australia, AusIMM Monograph 14, p. $1793-1805$.

Mudd, G.M., 2007, Global trends in mining-Towards quantifying environmental and resource sustainability?: Resources Policy, v. 32, p. 42-56. 
Mudder, T.I., Botz, M.M., and Smith, A., 2001, Chemistry and treatment of cyanidation wastes: London, Mining Journal Books, $373 \mathrm{p}$.

Muntean, J.L., and Einaudi, M.T., 2000, Porphyry gold deposits of the Refugio district, Maricunga belt, northern Chile: Economic Geology, v. 95, p. 1445-1472.

Muntean, J.L., Kesler, S.E., Russell, N., and Polanco, J., 1990, Evolution of the Monte Negro acid-sulfate $\mathrm{Au}-\mathrm{Ag}$ deposit, Pueblo Viejo, Dominican Republic - Important factors in grade development: Economic Geology, v. 85, p. 1738-1758.

Murakami, H., and Feebrey, C.A., 2001, Geology and geophysical expression of the Yamagano low-sulfidation epithermal $\mathrm{Au}-\mathrm{Ag}$ deposit, southwest Kyushu, Japan: Society of Economic Geologists Field Trip Guidebook, v. 34, p. 31-47.

Nagayama, T., 1993, Precipitation sequence of veins at the Hishikari deposits, Kyushu, Japan: Resource Geology Special Issue, no. 1, p. 13-27.

Naito, K., 1993, Occurrences of quartz veins in the Hishikari gold deposits, southern Kyushu, Japan, in Shikazono, N., Naito, K., and Izawa, E., eds., High Grade Epithermal Gold Mineralization-The Hishikari Deposit: Resource Geology Special Issue, no. 14, p. 37-46.

Naito, K., Matsuhisa, Y., Izawa, I., and Takaoka, H., 1993, Oxygen isotopic zonation of hydrothermally altered rocks in the Hishikari gold deposit, southern Kyushu, Japan - Its implications for mineral prospecting, in Shikazono, N., Naito, K., and Izawa, E., eds., High Grade Epithermal Gold Mineralization-The Hishikari Deposit: Resource Geology Special Issue, no. 14, p. 71-83.

Nash, J.T., and Trudel, W.S., 1996, Bulk mineable gold ore at the Sleeper mine, Nevada - importance of extensional faults, breccia, framboids, and oxidation, in Coyner, A.R., and Fahey, P.L., eds., Proceedings of the Geology and Ore Deposits of the American Cordillera Symposium, Reno, April 1995: Geological Society of Nevada, p. 235-256.

Nash, J.T., Utterback, W.C., and Saunders, J.A., 1991, Geology and geochemistry of the Sleeper gold deposits, Humboldt County, Nevada, an interim report, in Raines, G.L., Lisle, R.E., Schafer, R.W., and Wilkinson, W.H., eds., Proceedings of the Geology and Ore Deposits of the Great Basin Symposium, Reno, April 1990: Geological Society of Nevada, p. 1063-1084.

Nash, J.T., Utterback, W.C., and Trudel, W.C., 1995, Geology and geochemistry of Tertiary volcanic host rocks, Sleeper goldsilver deposit, Humboldt County, Nevada: U.S. Geological Survey Bulletin 2090, 63 p., https://pubs.usgs.gov/bul/2090/ report.pdf.

Nelson, C.E., 2000, Volcanic domes and gold mineralization in the Pueblo Viejo district, Dominican Republic: Mineralium Deposita, v. 35, p. 511-525.
Nelson, C.E., and Giles, D.L., 1985, Hydrothermal eruption mechanisms and hot spring gold deposits: Economic Geology, v. 80, p. 1633-1639.

Nevada Bureau of Mines and Geology, 2014, Special Publication MI-2013: The Nevada Mineral Industry, 2013, 155 p., accessed July 10, 1014, at http://data.nbmg.unr.edu/ public/freedownloads/mi/mi2013.zip.

New Gold, 2015, New Gold annual report: New Gold web page, accessed August 31, 2015, at http://www.newgold. com/files/documents_financials/2014/AR/New_Gold Annual_Report_2014.pdf.

Newmont Gold, 2015, Quarterly Reports: Newmont Gold web page, accessed on August 26, 2015, at http://www.newmont. com/investor-relations/financial-reports/quarterly-reports/ default.aspx.

Noble, D.C., McCormack, J.K., McKee, E.H., Silberman, M.L., and Wallace, A.B., 1988, Time of mineralization in the evolution of the McDermitt caldera complex, NevadaOregon, and the relation of middle Miocene mineralization in the northern Great Basin to coeval regional basaltic magmatic activity: Economic Geology, v. 83, p. 859-863.

Noble, D.C., and McKee, E.H., 1999, The Miocene metallogenic belt of central and northern Peru: Society of Economic Geologists Special Publication 7, p. 155-193.

Nolan, T.B., 1935, The underground geology of the Tonopah mining district, Nevada: Nevada Bureau of Mines and Geology Bulletin 29, 49 p.

Nordstrom, D.K., and Alpers, C.N., 1999, Geochemistry of acid mine waters, in Plumlee, G.S., and Logsdon, M.J., eds., The environmental geochemistry of mineral deposits, Part A-Processes, techniques, and health issues: Reviews in Economic Geology, v. 6A, p. 161-182.

Norgate, T., and Haque, N., 2012, Using life cycle assessment to evaluate some environmental impacts of gold production: Journal of Cleaner Production, v. 29-30, p. 53-63.

Northern Miner, 1994, ASARCO bids for Russian gold mine: Northern Miner web page, September 5, 1994, accessed December 21, 2017, at http://www.northernminer.com/ news/asarco-bids-for-russian-gold-mine/1000137899/.

Olberg, D.J., 2001, Ore shoot targeting in the Gosowong vein zone, Halmahera, Indonesia: Hobart, University of Tasmania, M.S. thesis, 140 p., accessed July 6, 2015, at http://eprints.utas.edu.au/11602/2/Whole-Olberg,_2001_ thesis.pdf.

O’Neil, J.R., and Silberman, M.L., 1974, Stable isotope relations in epithermal Au-Ag deposits: Economic Geology, v. 69 , p. $902-909$. 
O’Neil, J.R., Silberman, M.L., Fabbi, B.P., and Chesterman, C.W., 1973, Stable isotope and chemical relations during mineralization in the Bodie mining district, Mono County, California: Economic Geology, v. 68, p. 765-784.

Osborne, M.A., 1991, Epithermal mineralization at Aurora, Nevada, in Raines, G.L., Lisle, R.E., Schafer, R.W., and Wilkinson, W.H., eds., Proceedings of the Geology and Ore Deposits of the Great Basin Symposium, Reno, April 1990: Geological Society of Nevada, p. 1097-1110.

Overbay, W.J., Page, T.C., Krasowski, D.J., Bailey, M.H., and Matthews, T.C., 2001, Geology, structural setting, and mineralization of the Dolores district, Chihuahua, Mexico, in Albinson, T., and Nelson, C.E., eds., New Mines and Discoveries in Mexico and Central America: Society of Economic Geologists Special Publication 8, p. 71-85.

Oviedo, L., Aguilar, A., Grez, E., Fuster, N., Ribba, L., Tschischow, N., and Zuccone, A., 1991a, General geology of La Coipa precious metal deposit, Atacama, Chile, in Sillitoe, R.H., Camus, F., Saric, N., Bonham, H.F., and Garside, L.J., (leaders), Gold/silver Deposits of Chile, April 13-24, 1991, Itinerary and Guidebook, Association of Exploration Geochemists/Society of Economic Geologists Field Conference, 32 p.

Oviedo, L., Fuster, N., Tschischow, N., Ribba, L., Zuccone, A., Grez, E., and Aguilar, A., 1991b, General geology of La Coipa precious metal deposit, Atacama, Chile: Economic Geology, v. 86, p. $1287-1300$.

Paramount Gold Nevada, 2015, Sleeper gold project: Paramount Gold Nevada web page, accessed August 23, 2015, at http:// www.paramountnevada.com/projects/sleeper-gold-project/.

Parks, J., and Robertson, I.D.M., 2003, Pajingo epithermal gold deposits, NE Queensland: Cooperative Research Centre for Landscapes, Environments and Mineral Exploration Report, $4 \mathrm{p}$.

Pearson, M.F., Clark, K.F., Porter, E.W., and Gonzalez S., O. 1988, Mineralogy, fluid characteristics and silver distribution at Real de Angeles, Zacatecas: Economic Geology, v. 83, p. 1737-1759.

Perelló, J.A., 1994, Geology, porphyry Cu-Au, and epithermal $\mathrm{Cu}-\mathrm{Au}-\mathrm{Ag}$ mineralization of the Tombulilato district, North Sulawesi, Indonesia: Journal of Geochemical Exploration, v. 50, p. 221-256.

Perelló, J., Urzua, F., Cabello, J., and Ortiz, F., 1996, Clustered, gold-bearing Oligocene porphyry copper and associated epithermal mineralization at La Fortuna, Vallenar region, northern Chile, in Camus, F., Sillitoe, R.M., and Petersen, R., eds., Andean Copper Deposits-New Discoveries, Mineralization, Styles, and Metallogeny: Society of Economic Geologists Special Publication 5, p. 81-90.
Peters, S.G., Nash, J.T., John, D.A., Spanski, G.T., King, H.D., Connors, K.A., Moring, B.C., Doebrich, J.L., McGuire, D.J., Albino, G.V., Dunn, V.C., Theodore, T.G., and Ludington, Steve, 1996, Metallic mineral resources in the U.S. Bureau of Land Management's Winnemucca district and Surprise Resource Area, northwest Nevada and northeast California: U.S. Geological Survey Open-File Report 96-172, 147 p., https://pubs.er.usgs.gov/publication/ofr96712.

Petersen, U., Mayta, O., Gamarra, L., Vidal, C.E., and Sabastizagal, A., 2004, Uchucchacua-A major silver producer in South America, in Sillitoe, R.H., Perello, J., and Vidal, C.E., eds., Andean Metallogeny-New Discoveries, Concepts, and Update: Society of Economic Geologists Special Publication 11, p. 243-257.

Petersen, Ulrich, Noble, D.C., Arenas, M.J., and Goodell, P.C., 1977, Geology of the Julcani mining district, Peru: Economic Geology, v. 72, p. 931-949.

Phillips, J.D., Hansen, R.O., and Blakely, R.J., 2007, The use of curvature in potential-field interpretation: Exploration Geophysics, v. 38, p. 111-119.

Phillipson, S.E., and Romberger, S.B., 2004, Volcanic stratigraphy, structural controls, and mineralization in the San Cristobal $\mathrm{Ag}-\mathrm{Zn}-\mathrm{Pb}$ deposit, southern Bolivia: Journal of South American Earth Sciences, v. 16, p. 667-683.

Piatt, M.H., 2003, Bodie "The mines are looking well...", a history of the Bodie mining district, Mono County, California: El Sobrante, Calif., North Day Books, 288 p.

Plumlee, G.S., 1994, Fluid chemistry evolution and mineral deposition in the main stage Creede epithermal system: Economic Geology, v. 89, p. 1860-1882.

Plumlee, G.S., 1999, The environmental geology of mineral deposits, in Plumlee, G.S., and Logsdon, M.J., eds., The environmental geochemistry of mineral deposits, Part AProcesses, techniques, and health issues: Reviews in Economic Geology, v. 6A, p.71-116.

Plumlee, G.S., Smith, K.S., Gray, J.E., and Hoover, D.B., 1995, Epithermal quartz-alunite gold deposits, in du Bray, E.A., ed., Preliminary compilation of descriptive geoenvironmental mineral deposit models: U.S. Geological Survey Open-File Report 95-831, p. 162-169, https://pubs.usgs.gov/of/1995/ofr95-0831/.

Plumlee, G.S., Smith, K.S., Montour, M.R., Ficklin, W.H., and Mosier, E.L., 1999, Geologic controls on the composition of natural waters and waters draining diverse mineraldeposit types, in Plumlee, G.S., and Logsdon, M.J., eds., The environmental geochemistry of mineral deposits, Part B - Case Studies and research topics: Reviews in Economic Geology, v. 6 B, p. 373-432. 
Plumlee, G.S., and Whitehouse-Veaux, P.H., 1994, Mineralogy, paragenesis and mineral zoning of the Bulldog Mountain vein system, Creede district, Colorado: Economic Geology, v. 89, p. 1883-1905.

Poblete, J.A., Bissig, T., Mortensen, J.K., Gabites, J., Friedman, R., and Rodriguez, M., 2014, The Cerro Bayo district, Chilean Patagonia - Late Jurassic to Cretaceous magmatism and protracted history of epithermal Ag-Au mineralization: Economic Geology, v. 109, p. 487-502.

Ponce, D.A., and Glen, J.M.G., 2002, Relationship of epithermal gold deposits to large-scale fractures in northern Nevada: Economic Geology, v. 97, p. 3-9.

Ponce S., B.F., and Clark, K.F., 1988, The Zacatecas mining district-A Tertiary caldera complex associated with precious and base metal mineralization: Economic Geology, v. 83, p. $1668-1682$.

Porter Geoconsultancy, 2012a, Martabe, Sumatra, Indonesia: Porter Geoconsultancy web page, accessed August 31, 2015, at http://www.portergeo.com.au/tours/epithermalgold2012/ epithermalgold2012deposits.asp\#martabe.

Porter Geoconsultancy, 2012b, Lepanto-Far Southeast, Luzon, Phillipines: Porter Geoconsultancy web page, accessed August 31, 2015, at http://www.portergeo.com.au/tours/ epithermalgold2012/epithermalgold2012deposits.asp\#lepanto.

Porter Geoconsultancy, 2015a, Temora, Gidginbung, New South Wales, NSW, Australia: Porter Geoconsultancy web page, accessed August 28, 2015, at http://www.portergeo.com.au/ database $/$ mineinfo. $a s p ?$ mineid= $=\mathrm{mn} 442$.

Porter Geoconsultancy, 2015b, Database, El Indio Belt, Chile: Porter Geoconsultancy web page, accessed August 28, 2015, at http://www.portergeo.com.au/database/mineinfo. asp? $\mathrm{mineid}=\mathrm{mn} 071$.

Porter Geoconsultancy, 2017, El Indio Belt-El Indio, Tambo, Pascua Lama, Chile: Porter Geoconsultancy web page, accessed December 18, 2017, at http://www.portergeo.com.au/ database/mineinfo.asp?mineid=mn071.

Porter Geoconsultancy, 2018, Hishikari, Kyushu, Japan: Porter Geoconsultancy web page, accessed June 11, 2018, at http://www.portergeo.com.au/database/mineinfo. asp? $\mathrm{mineid}=\mathrm{mn} 059$.

Pour, A.B., and Hashim, M., 2012, The application of ASTER remote sensing data to porphyry copper and epithermal gold deposits: Ore Geology Reviews, v. 44, p. 1-9.

Pudack, C., Halter, W.E., Heinrich, C.A., and Pettke, T., 2009, Evolution of magmatic vapor to gold-rich epithermal liquid-The porphyry to epithermal transition at Nevados de Famatina, northwest Argentina: Economic Geology, v. 104, p. 449-477.
Querol S., F., Lowther, G.K., and Navarro, E., 1991, Mineral deposits of the Guanajuato mining district, Guanajuato, in Salas, G.P., ed., Economic Geology, Mexico: Boulder, Colo., Geological Society of America, Geology of North America, v. P-3, p. 403-414.

Rainbow, Amelia, 2009, Genesis and evolution of the Pierina highsulphidation epithermal Au-Ag Deposit, Ancash, Perú: Toronto, Queens University, Ph.D. dissertation, 292 p.

Rainbow, A., Clark, A.H., Kyser, T.K., Gaboury, F., and Hodgson, C.J., 2005, The Pierina epithermal Au-Ag deposit, Ancash, Peru-Paragenetic relationships, alunite textures, and stableisotope geochemistry: Chemical Geology, v. 215, p. 235-252.

Rainbow, A., Kyser, T.K., and Clark, A.H., 2006, Isotopic evidence for microbial activity during supergene oxidation of a high-sulfidation epithermal Au-Ag deposit: Geology, v. 34, p. 269-272.

Ramdohr, P., 1980, The ore minerals and their intergrowths (2d ed.): New York, Pergamon Press, 1,207 p.

Randall R., J.A., Saldaña A., E., and Clark, K.F., 1994, Exploration in a volcano-plutonic center at Guanajuato, Mexico: Economic Geology, v. 89, p. 1722-1751.

Ransome, F.L., 1901, A report on the economic geology of the Silverton Quadrangle, Colorado: U.S. Geological Survey Bulletin 182, 265 p., https://pubs.er.usgs.gov/publication/b182.

Ransome, F.L., 1907, The association of alunite with gold in the Goldfield district, Nevada: Economic Geology, v. 2, p. 667-692.

Ransome, F.L., 1923, Geology of the Oatman gold district, Arizona-A preliminary report: U.S. Geological Survey Bulletin 743, 58 p., https://pubs.usgs.gov/bul/0743/report.pdf.

Ransome, F.L., Emmons, W.H., and Garrey, G.H., 1909, The geology and ore deposits of Goldfield, Nevada: U.S. Geological Survey Professional Paper 66, 258 p., https://pubs.er.usgs.gov/ publication/pp66.

Ransome, F.L., Garrey, G.H., and Emmons, W.H., 1910, Geology and ore deposits of the Bullfrog district: U.S. Geological Survey Bulletin 407, 130 p., https://pubs.er.usgs.gov/publication/b407.

Rattenbury, M.S., and Partington, G.A., 2003, Prospectivity models and GIS data for the exploration of epithermal gold mineralization in New Zealand, in Epithermal gold in New Zealand - GIS data package and prospectivity modelling: Published jointly by Crown Minerals, Ministry of Economic Development and Institute of Geological and Nuclear Sciences, 68 p. [CD-ROM]

Reed, M.H., and Spycher, N.F., 1985, Boiling, cooling and oxidation in epithermal systems - A numerical modeling approach, in Bethke, P.M., and Berger, B.R., eds., Geology and Geochemistry of Epithermal Systems: Reviews in Economic Geology, v. 2, p. 249-272. 
Reesman, R.H., 1968, Strontium isotopic compositions of gangue minerals from hydrothermal vein deposits: Economic Geology, v. 63 , p. 731-736.

Reuters, 2013, Chile court to issue suspension order on PascuaLama mine-report: Reuters web page, accessed December 19, 2017, at http://www.reuters.com/article/2013/07/15/chilebarrick-court-idUSL1N0FL09T20130715.

Reyes, A.G., 1990, Petrology of Philippine geothermal systems and the application of alteration mineralogy to their assessment: Journal of Volcanology and Geothermal Research, v. 43, p. 279-309.

Reyes, A.G., Grapes, R., and Clemente, V.C., 2003, Fluid-rock interaction at the magmatic-hydrothermal interface of the Mt. Cagua geothermal system: Society of Economic Geologists Special Publication 10, p. 197-222.

Rice, C.M., Steele, G.B., Barfod, D.N., Boyce, D.N., and Pringle, M.S., 2005, Duration of magmatic, hydrothermal, and supergene activity at Cerro Rico de Potosi, Bolivia: Economic Geology, v. 100, p. 1647-1656.

Rimstidt, J.D., 1997, Gangue mineral transport and deposition, in Barnes, H.L., ed., Geochemistry of Hydrothermal Ore Deposits: New York, John Wiley and Sons, p. 487-515.

Robbins, C.H., 2000, Geology of the El Peñón gold-silver deposit, northern Chile, in Cluer, J.K., Price, J.G., Struhsacker, E.M., Hardyman, R.F. and Morris, C.L., eds., Proceedings of the Geology and Ore Deposits 2000 - The Great Basin and Beyond Symposium, Reno, May 15-18, 2000: Geological Society of Nevada, p. 249-264.

Robert, F., Brommecker, R., Bourne, B.T., Dobak, P.J., McEwan, C.J., Rowe, R.R., and Zhou, X., 2007, Models and exploration methods for major gold deposit types, in Milkereit, B., ed., Proceedings of Exploration 078: Fifth Decennial International Conference on Mineral Exploration, p. 691-711.

Robinson, R.W., and Norman, D.I., 1984, Mineralogy and fluid inclusion study of the southern Amethyst vein system, Creede mining district, Colorado: Economic Geology, v. 79, p. 439-447.

Rockwell, B.W., 2002, Descriptions, spectral plots, and digital spectra of samples applied to spectral analysis of imaging spectroscopy data - Utah (East Tintic Mountains, Oquirrh Mountains, Wasatch Mountains, and Tushar Mountains), Nevada (Goldfield Hills), and New Mexico (Jemez Mountains), USA, 1999-2002: U.S. Geological Survey Open-File Report 02-407, 3 p., https://pubs.usgs.gov/of/2002/ofr-02-407/.

Rockwell, B.W., 2009, Comparison of ASTER- and AVIRISderived mineral and vegetation maps of the White Horse replacement alunite deposit and surrounding area, Marysvale volcanic field, Utah: U.S. Geological Survey Scientific Investigations Report 2009-5117, 31 p., https://pubs.usgs.gov/ sir/2009/5117/.
Rockwell, B.W., 2010, Mineral and vegetation maps of the Bodie Hills, Sweetwater Mountains, and Wassuk Range, California/ Nevada, generated from ASTER satellite data: U.S. Geological Survey Scientific Investigations Map 3104, scale 1:62,000, 4 plates, pamphlet, 5 p., https://pubs.usgs.gov/sim/3104/.

Rockwell, B.W., 2012, Description and validation of an automated methodology for mapping mineralogy, vegetation, and hydrothermal alteration type from ASTER satellite imagery with examples from the San Juan Mountains, Colorado: U.S. Geological Survey Scientific Investigations Map 3190, 35 p. pamphlet, 5 map sheets, scale 100,000, https://pubs.usgs.gov/ $\operatorname{sim} / 3190 /$.

Rockwell, B.W., 2013, Automated mapping of mineral groups and green vegetation from Landsat Thematic Mapper imagery with an example from the San Juan Mountains, Colorado: U.S. Geological Survey Scientific Investigations Map 3252, 25 p. pamphlet, 1 map sheet, scale 1:325,000, https://pubs.usgs.gov/ $\operatorname{sim} / 3252 /$.

Rockwell, B.W., and Bonham, L.C., 2013, USGS National Map of Surficial Mineralogy: U.S. Geological Survey Online Map Resource, http://cmerwebmap.cr.usgs.gov/usminmap.html.

Rockwell, B.W., Cunningham, C.G., Breit, G.N., and Rye, R.O., 2006, Spectroscopic mapping of the White Horse alunite deposit, Marysvale volcanic field, Utah - Evidence of a magmatic component: Economic Geology, v. 101, no. 7, p. 1377-1395, https://doi.org/10.2113/gsecongeo.101.7.1377.

Rockwell, B.W., and Hofstra, A.H., 2008, Identification of quartz and carbonate minerals across northern Nevada using ASTER thermal infrared emissivity data-Implications for geologic mapping and mineral resource investigations in well-studied and frontier areas: Geosphere, v. 4, no. 1, p. 218-246, https:// doi.org/10.1130/GES00126.1.

Rockwell, B.W., McDougal, R.R., and Gent, C.A., 2005, Remote sensing for environmental site screening and watershed evaluation in Utah mine lands - East Tintic Mountains, Oquirrh Mountains, and Tushar Mountains: U.S. Geological Survey Scientific Investigations Report 2004-5241, 84 p., https://pubs. usgs.gov/sir/2004/5241/ and http://speclab.cr.usgs.gov/earth. studies/Utah-1/sir5241txto_bredit.html.

Rodgers, K.A., Browne, P.R.L., Buddle, T.F., Cook, K.L., Greatrex, R.A., Hampton, W.A., Herdianita, N.R., Holland, G.R., Lynne, B.Y., Martin, R., Newton, Z., Pastars, D., Sannazarro, K.L., and Teece, C.I.A., 2004, Silica phases in sinters and residues from geothermal fields of New Zealand: Earth-Science Reviews, v. 66, p. 1-61.

Rodionov, S.M., Fredericksen, R.S., and Berdnikov, N.V., 2005, The Kuranakh epithermal gold deposit, East Russia, in Mao, Jingwen, and Bierlein, F.P., eds., Mineral Deposit ResearchMeeting the Global Challenge: Berlin Heidelberg, SpringerVerlag, p. 1053-1056. 
Rodionov, S.M., Fredericksen, R.S., Berdnikov, N.V., and Yakubchuk, A.S., 2014, The Kuranakh epithermal gold deposit, Aldan Shield, East Russia: Ore Geology Reviews, v. 59 , p. 55-65.

Rodriguez, C., and Warden, A.J., 1993, Overview of some Colombian gold deposits and their development potential: Mineralium Deposita, v. 28, p. 47-57.

Rossetti, P., and Colombo, F., 1999, Adularia-sericite gold deposits of Marmato (Caldas, Colombia) - Field and petrographical data, in McCaffrey, K.J.W., Lonergan, L., and Wilkinson, J.J., eds., Fractures, fluid flow and mineralization: Geological Society of London Special Publication 155, p. 167-182.

Roth, D.K., Ibrado, A.S., Snider, J.W., Pennstrom, W.J., Browne, R.A., Harris, D.A., and Peterson, A.T., 2014, Hycroft project: Allied Nevada Gold Corp. web page, technical report NI 43-101FI, 253 p., accessed August 23, 2015, at http://www.alliednevada.com.

Rowan, L.C., Hook, S.J., Abrams, M.J., and Mars, J.C., 2003, Mapping hydrothermally altered rocks at Cuprite, Nevada, using the Advanced Spaceborne Thermal Emission and Reflection Radiometer (ASTER), a new satellite-imaging system: Economic Geology, v. 98, no. 5, p. 1019-1027.

Rowland, J.V., and Simmons, S.F., 2012, Hydrologic, magmatic, and tectonic controls on hydrothermal flow, Taupo volcanic zone, New Zealand-Implications for the formation of epithermal vein deposits: Economic Geology, v. 107, p. 427-457.

Rudnick, R.L., and Gao, S., 2003, The composition of the continental crust, in Holland, H.D., and Turekian, K.K., eds., Treatise on geochemistry, v. 3: Oxford, Elsevier-Pergamon, p. $1-64$.

Ruggieri, G., Lattanzi, P., Luxoro, S.S., Dessi, R., Benvenuti, M., and Tanelli, G., 1997, Geology, mineralogy, and fluid inclusion data of the Furtei high-sulfidation gold deposit, Sardinia, Italy: Economic Geology, v. 92, p. 1-19.

Russell, N., and Kesler, S.E., 1991, Geology of the maardiatreme complex hosting precious metal mineralization at Pueblo Viejo, Dominican Republic: Geological Society of America Special Paper 262, p. 203-216.

Russin, T.Z., and Fifarek, R.H., 2009, Origin of late auriferous barite-base metal sulfide and goethite-hematite stages at the Summitville high-sulfidation $\mathrm{Cu}-\mathrm{Au}-\mathrm{Ag}$ deposit, Colorado [abs.]: Geological Society of America Abstracts with Programs, v. 41, p. 86-87.

Rye, R.O., 2005, A review of the stable-isotope geochemistry of sulfate minerals in selected igneous environments and related hydrothermal systems: Chemical Geology, v. 215, p. 5-36.
Rye, R.O., and Alpers, C.N., 1997, The stable isotope geochemistry of jarosite: U.S. Geological Survey Open-File Report 97-88, 28 p., https://pubs.er.usgs.gov/publication/ ofr9788.

Rye, R.O., Bethke, P.M., and Wasserman, M.D., 1992, The stable isotope geochemistry of acid-sulfate alteration: Economic Geology, v. 87, p. 225-262.

Rye, R.O., Hall, W.E., Cunningham, C.G., Czamanske, G.K., Afifi, A.M., and Stacey, J.S., 1983, Preliminary mineralogic, fluid inclusion, and stable isotope study of the Mahd adh Dhahab gold mine, Kingdom of Saudi Arabia: U.S. Geological Survey Open-File Report 83-291, p. 26.

Rytuba, J.J., Arribas, A., Jr., Cunningham, C.G., McKee, E.H., Podwysocki, M.H., Smith, J.G., Kelly, W.C., and Arribas, A., 1990, Mineralized and unmineralized calderas in Spain; Part II, Evolution of the Rodalquilar caldera complex and associated gold-alunite deposits: Mineralium Deposita, v. 25, p. S29-S35.

Sajona, F.G., Izawa, E., Motomura, Y., Imai, A., Sakakibara, H., and Watanabe, K., 2002, Victoria carbonate-base metal gold deposit and its significance in the Mankayan mineral district, Luzon, Philippines: Resource Geology, v. 52, p. 315-328.

Sakai, H., and Matsubaya, O., 1977, Stable isotope studies of Japanese geothermal systems: Geothermics, v. 5, p. 97-124.

Salam, A., Zaw, K., Meffre, S., McPhie, J., and Lai, C.-K., 2014, Geochemistry and geochronology of the Chatree epithermal gold-silver deposit-Implications for the tectonic setting of the Loei Fold Belt, central Thailand: Gondwana Research, v. 26, p. 198-217.

Salem, A., Williams, S., Samson, E., Fairhead, D., Ravat, D., and Blakely, R.J., 2010, Sedimentary basins reconnaissance using the magnetic tilt-depth method: Exploration Geophysics, v. 41, p. 198-209.

Samal, A.R., and Fifarek, R.H., 2005, Steam-heated alteration at the Florida Canyon epithermal gold deposit, NevadaAssemblages, timing and possible fluid sources [abs.]: Geological Society of America Abstracts with Programs, v. 37, no. 7, p. 420, https://gsa.confex.com/gsa/2005AM/ finalprogram/abstract_97451.htm.

Sander, M.V., 1991, The Tonopah and Divide districts, Nye and Esmeralda Counties, Nevada, in Buffa, R.H., and Coyner, A.R., eds., Geology and Ore Deposits of the Great Basin: Geological Society of Nevada, Field Trip Guidebook Compendium, v. 2, p. 789-796.

Sander, M.V., and Black, J.E., 1988, Crystallization and recrystallization of growth-zoned vein quartz crystals from epithermal systems; implications for fluid inclusion studies: Economic Geology, v. 83, p. 1052-1060. 
Sander, M.V., and Einaudi, M., 1990, Epithermal deposition of gold during transition from propylitic to potassic alteration at Round Mountain: Economic Geology, v. 85, p. 285-311.

Sanematsu, Kenzo, Duncan, Robert, Imai, Akira, and Watanabe, Koichiro, 2005, Geochronological constraints using ${ }^{40} \mathrm{Ar} /{ }^{39} \mathrm{Ar}$ dating on the mineralization of the Hishikari epithermal gold deposit, Japan: Resource Geology, v. 55, p. 249-265.

Sanematsu, K., Watanabe, K., Duncan, R.A., and Izawa, E., 2006, The history of vein formation determined by ${ }^{40} \mathrm{Ar} /{ }^{39} \mathrm{Ar}$ dating of adularia in the Hosen-1 vein at the Hishikari epithermal gold deposit, Japan: Economic Geology, v. 101, p. 685-698.

Sänger-von Oepen, P., Friedrich, G., and Vogt, J.H., 1989, Fluid evolution, wallrock alteration and ore mineralisation associated with the Rodalquilar epithermal gold deposit in southeast Spain: Mineralium Deposita, v. 24, p. 235-243.

Sanmiguel, O.G.B., 1998, Geology, hydrothermal alteration, paragenetic sequence and fluid inclusion analysis of La Maruja level, Marmato district, Caldas Department, Colombia: Fort Collins, Colorado State University, M.S. thesis, $332 \mathrm{p}$.

Saunders, F.T., 2000, Geology of the Tonopah mining district, Nye/Esmeralda Counties, Nevada: Geological Society of Nevada, Field Trip Guidebook 10, p. 123-166.

Saunders, J.A., 1990, A colloidal transport of gold and silica in epithermal precious-metal systems; evidence from Sleeper Deposit, Nevada: Geology, v. 18, p. 757-760.

Saunders, J.A., 1993, Supergene oxidation of bonanza Au-Ag veins at the Sleeper deposit, Nevada, USA-Implications for hydrogeochemical exploration in the Great Basin: Journal of Geochemical Exploration, v. 47, p. 359-375.

Saunders, J.A., 1994, Silica and gold textures in bonanza ores of the Sleeper deposit, Humboldt County, Nevada - Evidence for colloids and implications for epithermal ore-forming processes: Economic Geology, v. 89, p. 628-638.

Saunders, J.A., 2012, Textural evidence of episodic introduction of metallic nanoparticles into bonanza epithermal ores: Minerals, v. 2, p. 228-243.

Saunders, J.A., Hofstra, A.H., Goldfarb, R.J., and Reed, M.H., 2014, Geochemistry of hydrothermal gold deposits, in Holland, H.D., and Turekian, K.K., eds., Treatise on Geochemistry (2d ed.), v. 13: Oxford, Elsevier, p. 383-424.

Saunders, J.A., Kamenov, G.D., Mathur, R., Shimizu, T., and Brueseke, M.E., 2013, Transport and deposition of metallic nanoparticles and the origin of bonanza epithermal ores, in Jonsson, E., and others, eds., 2013: Mineral deposit research for a high-tech world. Proceedings of the 12th Biennial SGA Meeting, 12-15 August 2013, Uppsala, Sweden, p. 868-871.
Saunders, J.A., Mathur, R., Kamenov, G.D., Shimizu, T., and Brueseke, M.E., 2016, New isotopic evidence bearing on bonanza ( $\mathrm{Au}-\mathrm{Ag}$ ) epithermal ore-forming processes: Mineralium Deposita, v. 51, p. 1-11.

Saunders, J.A., and Schoenly, P.A., 1995, Boiling, colloid nucleation and aggregation, and the genesis of bonanza $\mathrm{Au}-\mathrm{Ag}$ ores of the Sleeper deposit, Nevada: Mineralium Deposita, v. 30, p. 199-210.

Saunders, J., Unger, D., Kamenov, G., Fayek, M., Hames, W., and Utterback, W., 2008, Genesis of middle Miocene Yellowstone hotspot-related bonanza epithermal $\mathrm{Au}-\mathrm{Ag}$ deposits, northern Great Basin, USA: Mineralium Deposita, v. 43, no. 7, p. 715-734.

Saunders, J.A., Vikre, P., Unger, D.L., and Beasley, L., 2011, Colloidal and physical transport textures exhibited by electrum and naumannite in bonanza epithermal veins from western USA, and their significance, in Steininger, R., and Pennell, B., eds., Proceedings of the Great Basin Evolution and Metallogeny Symposium, Reno, 2010: Geological Society of Nevada, p. $825-831$.

Savva, N.E., Pal'yanova, G.A., and Byankin, M.A., 2012, The problem of genesis of gold and silver sulfides and selenides in the Kupol deposit, Chukotka, Russia: Russian Geology and Geophysics, v. 53, p. 457-466.

Sawkins, F.J., 1990, Metal deposits in relation to plate tectonics: Berlin, Springer-Verlag, $461 \mathrm{p}$.

Sawkins, F.J., O'Neil, J.R., and Thompson, J.M., 1979, Fluid inclusion and geochemical studies of vein gold deposits, Baguio district, Philippines: Economic Geology, v. 74, p. 1420-1434.

Schalamuk, I.B., Zubia, M., Genini, A., and Fernandez, R.R., 1997, Jurassic epithermal Au-Ag deposits of Patagonia, Argentina: Ore Geology Reviews, v. 12, p. 173-186.

Scher, S., Williams-Jones, A.E., and Williams-Jones, G., 2013, Fumarolic activity, acid-sulfate alteration, and high sulfidation epithermal precious metal mineralization in the crater of Kawah Ijen volcano, Java, Indonesia: Economic Geology, v. 108, p. 1099-1118.

Schieber, J., and Katsura, K.T., 1986, Sedimentation in epithermal veins of the Bohemia mining district, Oregon, USAInterpretations and significance: Mineralium Deposita, v. 21, p. 322-328.

Schodde, R., 2013, Long term outlook for the global exploration industry-gloom or boom?: GeoForum 2013 Conference, Geological Society of South Africa, Johannesburg, South Africa, accessed July 14, 2015, at http://minexconsulting.com/ publications/jul2013.html.

Schoen, R., White, D.E., and Hemley, J.J., 1974, Argillization by descending acid at Steamboat Springs, Nevada: Clays and Clay Minerals, v. 22, p. 1-22. 
Seal, R.R., 2010, Geoenvironmental features, section S of John, D.A., Ayuso, R.A., Barton, M.D., Blakely, R.J., Bodnar, R.J., Dilles, J.H., Gray, Floyd, Graybeal, F.T., Mars, J.C., McPhee, D.K., Seal, R.R., Taylor, R.D., and Vikre, P.G., Porphyry copper deposit model: U.S. Geological Survey Scientific Investigations Report 2010-5070-B, p. 122-125.

Seal, R.R., and Ayuso, R.A., 2011, Understanding processes affecting mineral deposits in humid environments: U.S. Geological Survey Fact Sheet 2010-3105, 6 p., https://pubs. usgs.gov/fs/2010/3105/.

Seal, R.R., and Piatak, N., 2012, Geoenvironmental features, in Shanks, W.C., III, and Thurston, R., eds., Volcanogenic massive sulfide occurrence model: U.S. Geological Survey Scientific Investigations Report 2010-5070-C, p. 323-335.

Segal, D.B., and Rowan, L.C., 1989, Map showing exposures of limonitic rocks and hydrothermally altered rocks in the Dillon 1 degrees by 2 degrees Quadrangle, Idaho and Montana: U.S. Geological Survey Map Serial Report I-1803-A, scale 1:250,000, https://pubs.usgs.gov/ imap/1803b/report.pdf.

Seki, Y., 1993, Geologic setting of the Takatama gold deposit, Japan-An example of caldera-related epithermal gold mineralization: Resource Geology Special Issue, no. 14, p. 123-136.

Sekine, R., Izawa, E., and Watanabe, K., 2002, Timing of fracture formation and duration of mineralization at the Hishikari deposit, southern Kyushu, Japan: Resource Geology, v. 52, p. 395-404.

Sellepack, S.M., 1997, The geology and geochemistry of the El Sauzal gold prospect, southwest Chihuahua, Mexico: El Paso, University of Texas at El Paso, M.S. thesis, 89 p.

SGS, 2013, Cyanide Recovery, SGS Minerals Technical Document T3 SGS 019, 6 p., http://www.sgs.com/ /media/ Global/Documents/Flyers\%20and\%20Leaflets/SGS-MINWA016-Cyanide-Recovery-Comparison-EN-11.pdf.

Shand, S.J., 1951, Eruptive rocks: New York, John Wiley, 488 p.

Shannon, J.M., and Stoker, P.T., 2013, Misima gold-copper project, Milne Bay Province, Papua New Guinea: Technical report prepared by AMC Mining Consultants for WCB Resources Limited, 158 p., accessed August 22, 2015, at http://www.wcbresources.com/sites/default/ files/reports/713006_WCB_Resources_Misima_Project Technical_Report_FINAL_SEDAR.pdf.

Sharpe, R., Riveros, C., and Scavuzzo, V., 2002, Stratigraphy of the Chon Aike Formation ignimbrite sequence at Cerro Vanguardia Au-Ag epithermal vein district [abs.]: Congreso Geológico Argentino, 15th, Argentina, Actas, article no. 232, 6 p. [CD-ROM]
Shen, J.J.-S., and Yang, H.-J., 2004, Sources and genesis of the Chinkuashih Au-Cu deposits in northern TaiwanConstraints from Os and $\mathrm{Sr}$ isotopic compositions of sulfides: Earth and Planetary Science Letters, v. 222, p. 71-83.

Sherlock, R.L., 1996, Hydrothermal alteration of volcanic rocks at the McLaughlin gold deposit, northern California: Canadian Journal of Earth Sciences, v. 33, p. 493-508.

Sherlock, R.L., 2005, The relationship between the McLaughlin gold-mercury deposit and active hydrothermal systems in the Geysers-Clear Lake area, northern Coast Ranges, California: Ore Geology Reviews, v. 26, p. 349-382.

Sherlock, R.L., Tosdal, R.M., Lehrman, N.J., Graney, J.R., Losh, S., Jowett, E.C., and Kesler, S.E., 1995, Origin of the McLaughlin mine sheeted vein complex-Metal zoning, fluid inclusion and isotopic evidence: Economic Geology, v. 90 , p. 2156-2181.

Sherrod, B.L., Blakely, R.J., Weaver, C.S., Kelsey, H.M., Barnett, E., Liberty, L., Meagher, K.L., and Pape, K., 2008, Finding concealed active faults - Extending the Southern Whidbey Island fault across the Puget Lowland, Washington: Journal of Geophysical Research, v. 113, B05313, https://doi.org/10.1029/2007JB005060.

Shikazono, N., and Nagayama, T., 1993, Origin and depositional mechanism of the Hishikari gold-quartzadularia mineralization: Resource Geology Special Issue, no. 14 , p. $47-56$.

Shikazono, Naotatsu, and Takahashi, Hiroyuki, 2010, Compositional variation of hydrothermally altered volcanic rocks in Hishikari gold epithermal system-A useful geochemical indicator of gold-silver epithermal mineralization: Resource Geology, v. 60, p. 117-128.

Shimizu, Toru, 2014, Reinterpretation of quartz textures in terms of hydrothermal fluid evolution at the Koryu $\mathrm{Au}-\mathrm{Ag}$ deposit, Japan: Economic Geology, v. 109, p. 2051-2065.

Shimizu, T., Matsueda, H., Ishiyama, D., and Matsubaya, O., 1998, Genesis of epithermal Au-Ag mineralization of the Koryu mine, Hokkaido, Japan: Economic Geology, v. 93, p. 303-325.

Sibson, R.H., 1987, Earthquake rupturing as a hydrothermal mineralizing agent in hydrothermal systems: Geology, v. 15, p. 701-704.

Sibson, R.H., 1996, Structural permeability of fluid-driven fault-fracture meshes: Journal of Structural Geology, v. 18, p. 1031-1042.

Sibson, R.H., Moore, J.M., and Rankin, A.H., 1975, Seismic pumping-A hydrothermal fluid transport mechanism: Journal of the Geological Society, v. 131, p. 653-659. 
Sidorov, A.A., Belyi, V.F., Volkov, A.V., Kravtsov, V.S., and Prokof'ev, V.Y., 2007, Geology and formation conditions of the unique gold-silver deposit in Chukotka: Doklady Earth Sciences, v. 412, no. 1, p. 29-34.

Sidorov, A.A., Volkov, A.V., Belyi, V.F., Alekseev, V.Yu., and Kolova, E.E., 2009, The gold-silver Okhotsk - Chukotka volcanic belt: Geology of Ore Deposits, v. 51, p. 441-455.

Silberman, M.L., and Berger, B.R., 1985, Relationship of traceelement patterns to alteration and morphology in epithermal precious-metal deposits: Reviews in Economic Geology, v. 2, p. 203-232.

Silberman, M.L., Chesterman, C.W., Kleinhampl, F.J., and Gray, C.H., Jr., 1972, K-Ar ages of volcanic rocks and gold-bearing quartz-adularia veins in the Bodie mining district, Mono County, California: Economic Geology, v. 67, p. 597-603.

Sillitoe, R.H., 1985, Ore-related breccias in volcanoplutonic arcs: Economic Geology, v. 80, p. 1467-1514.

Sillitoe, R.H., 1993, Epithermal models - Genetic types, geometrical controls and shallow features: Geological Association of Canada Special Paper 40, p. 403-417.

Sillitoe, R.H., 1994, Erosion and collapse of volcanoes-Causes of telescoping in intrusion-centered ore deposits: Geology, v. 22 , p. $945-948$.

Sillitoe, R.H., 1995, Exploration and discovery of base- and precious-metal deposits in the circum-Pacific region during the last 25 years: Resource Geology Special Issue, no. 19, 119 p.

Sillitoe, R.H., 1999, Styles of high sulfidation gold, silver and copper mineralization in the porphyry and epithermal environments, in Weber, G., ed., Pacrim '99 Congress Proceedings: Australasian Institute of Mining and Metallurgy, p. 29-44.

Sillitoe, R.H., 2000, Exploration and discovery of base- and precious-metal deposits in the Circum-Pacific region-A late 1990s update: Resource Geology Special Issue, no. 21, 65 p.

Sillitoe, R.H., 2005, Supergene oxidized and enriched porphyry copper and related deposits: Economic Geology 100th Anniversary Volume, p. 723-768.

Sillitoe, R.H., 2008, Major gold deposits and belts of the North and South American Cordillera-Distribution, tectonomagmatic settings, and metallogenic considerations: Economic Geology, v. 103, p. 663-687.

Sillitoe, R.H., 2009, Supergene silver enrichment reassessed: Society of Economic Geologists Special Publicaton 14, p. 15-32.

Sillitoe, R.H., 2010, Porphyry copper systems: Economic Geology, v. 105, p. 3-41.
Sillitoe, R.H., 2015, Epithermal paleosurfaces: Mineralium Deposita, v. 50, p. 767-793.

Sillitoe, R.H., Angeles, C.A., Jr., Comia, G.M., Antioquia, E.C., and Abeya, R.B., 1990, An acid-sulphate-type lode gold deposit at Nalesbitan, Luzon, Philippines: Journal of Geochemical Exploration, v. 35, p. 387-411.

Sillitoe, R.H., and Bonham, H.F., 1984, Volcanic landforms and ore deposits: Economic Geology, v. 79, p. 1286-1298.

Sillitoe, R.H., and Clark, A.H., 1969, Copper and copper-iron sulfides as the initial products of supergene oxidation, Copiapo mining district, northern Chile: The American Mineralogist, v. 64 , p. $1684-1710$.

Sillitoe, R.H., Cooper, C., Sale, M.J., Soechiting, W., Echavarria, D., and Gallardo, J.L., 2002, Discovery and geology of the Esquel low-sulfidation epithermal gold deposit, Patagonia, Argentina: Society of Economic Geologists Special Publication 9, p. 227-240.

Sillitoe, R.H., Hall, D.J., Redwood, S.D., and Waddell, A.H., 2006, Pueblo Viejo high-sulfidation epithermal gold-silver deposit, Dominican Republic: a new model of formation beneath barren limestone cover: Economic Geology, v. 101, p. 1427-1435.

Sillitoe, R.H., and Hedenquist, J.W., 2003, Linkages between volcanotectonic settings, ore fluid compositions, and epithermal precious metal deposits: Society of Economic Geologists Special Publication 10, p. 315-343.

Sillitoe, R.H., and Lorson, R.C., 1994, Epithermal gold-silvermercury deposits at Paradise Peak, Nevada - Ore controls, porphyry gold association, detachment faulting, and supergene oxidation: Economic Geology, v. 89, p. 1228-1248.

Sillitoe, R.H., McKee, E.H., and Vila, T., 1991, Reconnaissance K-Ar geochronology of the Maricunga gold-silver belt, northern Chile: Economic Geology, v. 86, p. 1261-1270.

Sillitoe, R.H., Steele, G.B., Thompson, J.F.H., and Lang, J.R., 1998, Advanced argillic lithocaps in the Bolivian tin-silver belt: Mineralium Deposita, v. 33, p. 539-546.

Simmons, S.F., 1991, Hydrologic implications of alteration and fluid inclusion studies in the Fresnillo District, MexicoEvidence for a brine reservoir and a descending water table during the formation of hydrothermal $\mathrm{Ag}-\mathrm{Pb}-\mathrm{Zn}$ orebodies: Economic Geology, v. 86, p. 1579-1601.

Simmons, S.F., Arehart, G., Simpson, M.P., and Mauk, J.L., 2000, Origin of massive calcite veins in the Golden Cross, lowsulfidation epithermal Au-Ag deposit, New Zealand: Economic Geology, v. 95, p. 99-112.

Simmons, S.F., and Brown, K.L., 2006, Gold in magmatic hydrothermal solutions and the rapid formation of a giant ore deposit: Science, v. 314, p. 288-291. 
Simmons, S.F., and Brown, K.L., 2007, The flux of gold and related metals through a volcanic arc, Taupo Volcanic Zone, New Zealand: Geology, v. 35, p. 1099-1102.

Simmons, S.F., and Browne, P.R.L., 1990, Mineralogic, alteration and fluid inclusion studies of epithermal goldbearing veins at the Mt. Muro prospect, Central Kalimantan (Borneo), Indonesia: Journal of Geochemical Exploration, v. 35, p. 63-103.

Simmons, S.F., and Browne, P.R.L., 2000, Hydrothermal minerals and precious metals in the Broadlands-Ohaaki geothermal system - Implications for understanding lowsulfidation epithermal environments: Economic Geology, v. 95 , p. $971-999$.

Simmons, S.F., and Christenson, B.W., 1994, Origins of calcite in a boiling geothermal system: American Journal of Science, v. 294 , p. $361-400$.

Simmons, S.F., Gemmell, J.B., and Sawkins, F.J., 1988, The Santo Nino silver-lead-zinc vein, Fresnillo district, Zacatecas-Part II, Physical and chemical nature of ore forming solutions: Economic Geology, v. 83, p. 1619-1641.

Simmons, S.F., White, N.C., and John, D.A., 2005, Geological characteristics of epithermal precious and base metal deposits: Economic Geology 100th Anniversary Volume, p. $485-522$.

Simpson, M.P., and Mauk, J.L., 2000, Geochemistry of wall rock alteration at the Golden Cross deposit, New Zealand: New Zealand Minerals and Mining Conference, Wellington, New Zealand [Proceedings], p. 197-208.

Simpson, M.P., and Mauk, J.L., 2007, The Favona epithermal gold-silver deposit, Waihi, New Zealand: Economic Geology, v. 102 , p. $817-839$.

Simpson, M.P., and Mauk, J.L., 2011, Hydrothermal alteration and veins at the epithermal $\mathrm{Au}-\mathrm{Ag}$ deposits and prospects of the Waitekauri area, Hauraki Goldfield, New Zealand: Economic Geology, v. 106, p. 945-973.

Simpson, M.P., Mauk, J.L., and Simmons, S.F., 2001, Hydrothermal alteration and paleohydrology of the Golden Cross epithermal deposit, Waihi, New Zealand: Economic Geology, v. 96, p. 773-796.

Simpson, M.P., Palinkas, S.S., Mauk, J.L., and Bodnar, R.J., 2015, Fluid inclusion chemistry of adularia-sericite epithermal Au-Ag deposits of the southern Hauraki Goldfield, New Zealand: Economic Geology, v. 110, p. 763-786.

Sims, John, 2015, Kupol mine and Dvoinoye mine-Russian Federation: National Instrument 43-101 Technical Report, 140 p., accessed January 4, 2017, at http://fb.kinross.com/ media/261550/2015\%20kupol-dvoinoye\%20tr.pdf.
Singer, D.A., 1995, World class base and precious metal deposits-A quantitative analysis: Economic Geology, v. 90, p. 88-104.

Singer, D.A., and Menzie, W.D., 2010, Quantitative mineral resource assessments: New York, Oxford University Press, $219 \mathrm{p}$.

Sisson, T.W., 1994, Hornblende-melt trace-element partitioning measured by ion microprobe: Chemical Geology, v. 117, p. 331-344.

Slack, J.F., 1980, Multistage vein ores of the Lake City district, western San Juan Mountains, Colorado: Economic Geology, v. 75 , p. $963-991$.

Smith, A.C.S, and Mudder, T.I., 1999, The environmental geochemistry of cyanide, in Plumlee, G.S., and Logsdon, M.J., eds., The environmental geochemistry of mineral deposits, Part A-Processes, techniques, and health issues: Reviews in Economic Geology, v. 6A, p. 229-248.

Smith, D.M., Albinson, T., and Sawkins, F.J., 1982, Geologic and fluid inclusion studies of the Tayoltita silver-gold vein deposit, Durango, Mexico: Economic Geology, v. 77, p. $1120-1145$.

Smith, G.H., 1998, History of the Comstock Lode: Nevada Bureau of Mines and Geology, Special Publication 24, 344 p.

Smith, N., Cassidy, J., Locke, C.A., Mauk, J.L., and Christie, A.B., 2006, The role of regional-scale faults in controlling a trapdoor caldera, Coromandel Peninsula, New Zealand: Journal of Volcanology and Geothermal Research, v. 149, p. 312-328.

Snider, Josh, Patterson, E.L., Gochnour, Lee, Marek, John, and Burkhalter, C.J., 2015, Haile gold mine project, NI 43-101 Technical report, Project update, Lancaster County, South Carolina: Technical report prepared for Oceana Gold, 158 p., accessed January 10, 2017, at https://www.oceanagold.com/ wp-content/uploads/2015/07/Haile-NI-43-101-TechnicalReport-Project-Update-Reduced.pdf.

So, C.-S., Zhang, D.-Q., Yun, S.-T., and Li, D.-X., 1998, Alteration-mineralization zoning and fluid inclusions of the high-sulfidation epithermal $\mathrm{Cu}$-Au mineralization at Zijinshan, Fujian Province, China: Economic Geology, v. 93, p. 961-980.

Sobek, W.W., Schuller, W.A., Freeman, J.R., and Smith, R.M., 1978, Field and laboratory methods applicable to overburdens and minesoils: U.S. Environmental Protection Agency Environmental Protection Technology Series, U.S. EPA 600/2-78/054, 203 p.

Soechting, Walter, Rubinstein, Nora, and Godeas, Marta, 2008, Identification of ammonium-bearing minerals by shortwave infrared reflectance spectroscopy at the Esquel gold deposit, Argentina: Economic Geology, v. 103, p. 865-869. 
Sole, T.C., Granitto, M., Rich, C.L., Litke, D.W., and Pelltier, R.T., 2007, Digital Databases and CD-ROM for the Animas River Watershed, chap. G of Church, S.E., von Guerard, P., and Finger, S.E., eds., Integrated investigations of environmental effects of historical mining in the Animas River Watershed, San Juan County, Colorado: U.S. Geological Survey Professional Paper 1651, p. 1079-1096, https://pubs.usgs.gov/pp/1651/.

Somers, C., Gibson, H., and Burk, R., 2010, The La Pitarrilla silver-lead-zinc deposit, Sierra Madre Occidental, Mexico-A description of the mineralisation and a reconstruction of its volcano-sedimentary environment: Society of Economic Geologists Special Publication 15, p. 133-164.

Sonntag, I., Laukamp, C., and Hagemann, S.G., 2012, Lowpotassium hydrothermal alteration in low sulfidation epithermal systems as detected by IRS and XRD-An example from the Co-O mine, Eastern Mindanao, Philippines: Ore Geology Reviews, v. 45, p. 47-60.

Speer, W.E., and Maddry, J.W., 1993, Geology and recent discoveries at the Haile gold mine, Lancaster County, South Carolina: South Carolina Geology, v. 35, p. 9-26.

Spencer, R.M., Montenegro, J.L., Gaibor, A., Perez, E.P., Mantilla, G., Viera, F., and Spencer, C.E., 2002, The Portovelo-Zaruma mining camp, southwest EcuadorPorphyry and epithermal environments: Society of Economic Geologists Newsletter 49, p. 1, 8-14.

Spiridonov, A.M., Zorina, L.D., Letunov, S.P., and Prokof'ev, V.Yu., 2010, The fluid regime of ore formation in the Balei gold-bearing ore-magmatic system (eastern Transbaikalia, Russia): Russian Geology and Geophysics, v. 51, p. 1102-1109.

Spurr, J.E., 1905, Geology of the Tonopah mining district, Nevada: U.S. Geological Survey Professional Paper 42, 295 p., https://pubs.er.usgs.gov/publication/pp42.

Spurr, J.E., 1915, Geology and ore deposition at Tonopah, Nevada: Economic Geology, v. 10, p. 713-769.

Squire, R.J., Herrmann, W., Pape, D., and Chalmers, D.I., 2007, Evolution of the peak Hill high-sulfidation epithermal $\mathrm{Au}-\mathrm{Cu}$ deposit, eastern Australia: Mineralium Deposita, v. 42, p. 489-503.

Staatz, M.H., and Pearson, R.C., 1990, The Republic gold district, Ferry County, Washington: U.S. Geological Survey Bulletin 1857-H, p. H14-H20.

Stacey, J.S., and Kramers, J.D., 1975, Approximation of terrestrial lead isotope evolution by a two-stage model: Earth and Planetary Science Letters, v. 26, p. 207-221.
Staude, J.-M., 2001, Geology, geochemistry, and formation of the $\mathrm{Au}-(\mathrm{Cu})$ mineralization and advanced argillic alteration in the Mulatos district, Sonora, Mexico, in Albinson, T., and Nelson, C.E., eds., New Mines and Discoveries in Mexico and Central America: Society of Economic Geologists Special Publication 8, p. 199-216.

Sterner, S.M., Hall, D.L., and Bodnar, R.J., 1988, Synthetic fluid inclusions; $\mathrm{V}$, Solubility relations in the system $\mathrm{NaCl}-$ $\mathrm{KCl}-\mathrm{H}_{2} \mathrm{O}$ under vapor-saturated conditions: Geochimica et Cosmochimica Acta, v. 52, p. 989-1005.

Steven, T.A., and Eaton, G., 1975, Environment of ore deposition in the Creede mining district, San Juan Mountains, Colorado-I. Geologic, hydrologic, and geophysical setting: Economic Geology, v. 70, p. 1023-1037.

Steven, T.A., and Ratté, J.C., 1960, Geology and ore deposits of the Summitville district, San Juan Mountains, Colorado: U.S. Geological Survey Professional Paper 343, 70 p., https://pubs. usgs.gov/pp/0343/report.pdf.

Steven, T.A., and Ratté, J.C., 1965, Geology and structural control of ore deposition in the Creede district, San Juan Mountains, Colorado: U.S. Geological Survey Professional Paper 487, 90 p., https://pubs.usgs.gov/pp/0487/report.pdf.

Stoffregen, R., 1986, Observations on the behavior of gold during supergene oxidation at Summitville, Colorado, U.S.A., and implications for electrum stability in the weathering environment: Applied Geochemistry, v. 1, p. 549-558.

Stoffregen, R.E., 1987, Genesis of acid-sulfate alteration and $\mathrm{Au}-\mathrm{Cu}-\mathrm{Ag}$ mineralization at Summitville, Colorado: Economic Geology, v. 82, p. 1575-1591.

Stoffregen, R.E., Vikre, P.G., and Bethke, P.M., 2004, Homogenization temperature and salinity data for fluid inclusions from the Summitville, Colorado, $\mathrm{Cu}-\mathrm{Au}-\mathrm{Ag}$ deposit: U.S. Geological Survey Open-File Report 2004-1066, 12 p.

Straits Resources Ltd., 2012, Mt. Muro Mine: Straits Resources Ltd. web page, accessed August 28, 2015, at http://www.straits. com.au/latestnews/preview.html?path=NewsReleases $\% 2$ F2010 $\% 2 \mathrm{FMt}+$ Muro+Mine+Presentation.pdf.

Streckeisen, A., 1976, To each plutonic rock its proper name: Earth-Science Reviews, v. 12, p. 1-33.

Sugaki, A., Kojima, S., and Shimada, N., 1988, Fluid inclusion studies of the polymetallic hydrothermal ore deposits in Bolivia: Mineralium Deposita, v. 23, p. 9-15.

Sutopo, Bronto, 2013, The Martabe Au-Ag high-sulfidation epithermal deposits, Sumatra, Indonesia-Implications for ore genesis and exploration: University of Tasmania, Ph.D. dissertation, $332 \mathrm{p}$. 
Swarthout, Andrew, Leduc, Marc, and Rios, Christian, 2010, The discovery history and geology of Corani-A significant new Ag-Pb-Zn epithermal deposit, Puno Department, Peru: Society of Economic Geologists Special Publication 15, p. 165-179.

Swayze, G.A., Clark, R.N., Goetz, A.F.H., Livo, K.E., Breit, G.N., Kruse, F.A., Sutley, S.J., Snee, L.W., Lowers, H.A., Post, J.L., Stoffregen, R.E., and Ashley, R.P., 2014, Mapping advanced argillic alteration at Cuprite, Nevada, using imaging spectroscopy: Economic Geology, v. 109, no. 5, p. 1179-1221, https://doi.org/10.2113/econgeo.109.5.1179.

Takahashi, Ryohei, Matsueda, Hiroharu, Okrugin, V.M., Shikazono, Naotatsu, Ono, Shuji, Imai, Akira, Andreeva, E.D., and Watanabe, Koichiro, 2013, Ore-forming ages and sulfur isotope study of hydrothermal deposits in Kamchatka, Russia: Resource Geology, v. 63, p. 210-223.

Tan, L., 1991, The Chinkuashih gold-copper deposits, Taiwan: Society of Economic Geologists Newsletter 7, p. 1, 22-24.

Tan, L., Ni, J.M., and Jeng, R.C., 1987, A geochemical prospecting for the gold mineralizations in the Chinkuashih district, Taiwan: Acta Geologica Taiwanica Science Reports of the National Taiwan University, no. 25, p. 151-172.

Tangwattananukul, L., Ishiyama, D., Matsubaya, O., Mizuta, T., Charusiri, P., Sato, H., and Sera, K., 2014, Characteristics of Triassic epithermal Au mineralization at the $\mathrm{Q}$ prospect, Chatree mining area, Central Thailand: Resource Geology, v. 64, p. $167-181$.

Tanner, D., Henley, R.W., Mavrogenes, J.A., and Holden, P., 2013, Combining in situ isotopic, trace element and textural analyses of quartz from four magmatic-hydrothermal ore deposits: Contributions to Mineralogy and Petrology, v. 166, p. 1119-1142.

Taranik, J.V., and Aslett, Z.L., 2009, Development of hyperspectral imaging for mineral exploration: Reviews in Economic Geology, v. 16, p. 83-95.

Tassinari, C.C.G., Pinzon, F.D., and Buena Ventura, J., 2008, Age and sources of gold mineralization in the Marmato mining district, NW Columbia-A Miocene-Pliocene epizonal gold deposit: Ore Geology Reviews, v. 33, p. 505-518.

Taylor, B.E., 2007, Epithermal gold deposits, in Goodfellow, W.D., ed., Mineral Deposits of Canada—A Synthesis of Major Deposit-Types, District Metallogeny, the Evolution of Geological Provinces, and Exploration Methods: Geological Association of Canada, Mineral Deposits Division, Special Publication 5, p. 113-139.

Taylor, H.P., Jr., 1968, The oxygen isotope geochemistry of igneous rocks: Contributions to Mineralogy and Petrology, v. 19 , p. $1-71$.
Taylor, H.P., 1973, $\mathrm{O}^{18} / \mathrm{O}^{16}$ evidence for meteoric-hydrothermal alteration and ore deposition in the Tonopah, Comstock Lode, and Goldfield mining districts, Nevada: Economic Geology, v. 68 , p. $747-764$.

Taylor, H.P., 1974, The application of oxygen and hydrogen isotope studies to problems of hydrothermal alteration and ore deposition: Economic Geology, v. 69, p. 843-883.

Taylor, H.P., 1997, Oxygen and hydrogen isotope relationships in hydrothermal mineral deposits, in Barnes, H.L., ed., Geochemistry of Hydrothermal Ore Deposits: New York, John Wiley and Sons, p. 229-302.

Teal, L.B., and Benavides, A., 2010, History and geologic overview of the Yanacocha mining district, Cajamarca, Peru: Economic Geology, v. 105, p. 1173-1190.

Telford, W.M., Geldart, L.P., and Sheriff, R.E., 1990, Applied Geophysics (2d. ed.): Cambridge, UK, Cambridge University Press, $770 \mathrm{p}$.

Thompson, J.F.H., Lessman, J., and Thompson, A.J.B., 1986, The Temora gold-silver deposit—A newly recognized style of high sulfur mineralization in the lower Paleozoic of Australia: Economic Geology, v. 81, p. 732-738.

Thompson, J.F.H., Sillitoe, R.H., Baker, T., Lang, J.R., and Mortensen, J.K., 1999, Intrusion-related gold deposits associated with tungsten-tin provinces: Mineralium Deposita, v. 34, p. 323-334.

Tingley, J.V., and Berger, B.R., 1985, Lode gold deposits of Round Mountain, Nevada: Nevada Bureau of Mines and Geology Bulletin 100, $62 \mathrm{p}$.

Titley, Malcom, Bennett, Julian, and Meik, Simon, 2014, NI 43-101 Technical report, mineral resource and mineral reserve update, Chelopech project, Chelopech, Bulgaria: Sedar web page, 171 p., accessed August 26, 2015, at www.sedar.com.

Tohma, Yuki, Imai, Akira, Sanematsu, Kenzo, Yonezu, Kotaro, Takahashi, Ryohei, Koyama, Masaski, Sekine, Ryota, Duncan, Robert, and Watanabe, Koichiro, 2010, Characteristics and mineralization age of Fukusen No. 1 vein, Hishikari epithermal gold deposits, southern Kyushu, Japan: Resource Geology, v. 60 , p. $348-358$.

Tosdal, R.M., Sherlock, R.L., Nelson, G.C., Enderlin, D.A., and Lehrman, N.J., 1996, Structural evolution of the McLaughlin precious metal deposit, northern California, in Coyner, A.R., and Fahey, P.L., eds., Proceedings of the Geology and Ore Deposits of the America Cordillera Symposium, Reno, April 1995: Geological Society of Nevada, p. 839-854.

Trejo, P., 2001, Geology of the Fresnillo southeast mine, Fresnillo, Zacatecas, Mexico: Society of Economic Geologists Special Publication 8, p. 105-113. 
Turekian, K.K., and Wedepohl, K.H., 1961, Distribution of the elements in some major units of the Earth's crust: Geological Society of America Bulletin, v. 72, p. 175-192.

Turneaure, F.S., 1960a, A comparative study of major ore deposits of central Bolivia, Part I: Economic Geology, v. 55, no. 2, p. 217-254.

Turneaure, F.S., 1960b, A comparative study of major ore deposits of central Bolivia, Part II: Economic Geology, v. 55, no. 3, 574-606.

Turner, S., 1997, The Yanacocha epithermal gold deposits, northern Peru-High sulfidation mineralization in a flow dome setting: Boulder, Colorado School of Mines, Ph.D. dissertation, $338 \mathrm{p}$.

Urasima, Yukitosi, 1956, "Bosa” quartz veins, especially the fine-grained quartz aggregates, of the Konomai mine in Hokkaido, Japan: Journal of the Faculty of Science, Hokkaido University, Series 4: Geology and Mineralogy, v. 9, no. 3 , p. 371-380.

Urasima, Yukitosi, 1957, Mineralization of Central Kitami mining district in Hokkaido, Japan: Journal of the Faculty of Science, Hokkaido University, Series 4: Geology and Mineralogy, v. 9, no. 4, p. 597-606.

Ushijima, K., Kawasaki, K., and Nishikawa, N., 1993, Geophysical explorations for epithermal gold deposits, in Shikazono, N., Naito, K., and Izawa, E., eds., High Grade Epithermal Gold Mineralization-The Hishikari Deposit: Resource Geology Special Issue, no. 14, p. 93-102.

U.S. Environmental Protection Agency, 1994, Acid mine drainage prediction Technical Document, Report EPA530-R-94-036 (NTIS PB94-201829): Washington, D.C., EPA Office of Solid Waste, 52 p., https://www.epa.gov/osw/ nonhaz/industrial/special/mining/techdocs/amd.pdf.

U.S. Environmental Protection Agency, 2004, Summitville Mine: U.S. Environmental Protection Agency Fact Sheet, https://www. epa.gov/superfund/accomp/factsheets04/summit.htm.

U.S. Geological Survey (USGS), 2014, Frequently asked questions about the Landsat missions: U.S. Geological Survey web page, https://landsat.usgs.gov/band designations_landsat_satellites.php.

U.S. Geological Survey, 2015, Mineral Resources Data System (MRDS): U.S. Geological Survey web page, https://mrdata. usgs.gov/mrds/map-us.html.

Valencia, V.A., Eastoe, C., Ruiz, J., Ochoa-Landin, L., Gehrels, G., Gonzalez-Leon, C., Barra, F., and Espinoza, E., 2008, Hydrothermal evolution of the porphyry copper deposit at La Caridad, Sonora, Mexico, and the relationship with a neighboring high-sulfidation epithermal deposit: Economic Geology, v. 103, p. 473-491.
Van Kervoort, G., Tolman, J., and Hernandez, O., 2009, Caspiche porphyry $\mathrm{Au}-\mathrm{Cu}$ deposit, Maricunga Belt, Chile, Exploration, discovery and resource development, 2009 NewGenGold Conference, Perth, Australia, 23 November 2009, 17 p., http:// www.exeterresource.com/pdf/reports/Caspiche_discovery_ history_paper.pdf.

van Leeuwen, T.M., Leach, T., Hawke, A.A., and Hawke, M.M., 1990, The Kelian disseminated gold deposit, East Kalimantan, Indonesia: Journal of Geochemical Exploration, v. 35, p. 1-61.

Van Thournout, F., Salemink, J., Valenzuela, G., Merlyn, M., Boven, A., and Muchez, P., 1996, Portovelo-A volcanichosted epithermal vein system in Ecuador, South America: Mineralium Deposita, v. 31, p. 269-276.

Vanderwilt, J.W., 1947, Mineral resources of Colorado: State of Colorado Mineral Resources Board, 547 p.

Velador, J.M., Heizler, M.T., and Campbell, A.R., 2010, Timing of magmatic activity and mineralization and evidence of a long-lived hydrothermal system in the Fresnillo silver district, Mexico - Constraints from ${ }^{40} \mathrm{Ar} /{ }^{39} \mathrm{Ar}$ geochronology: Economic Geology, v. 105, p. 1335-1349.

Vennemann, T.W., Muntean, J.L., Kesler, S.E., O’Neil, J.R., Valley, J.W., and Russell, N., 1993, Stable isotope evidence for magmatic fluids in the Pueblo Viejo epithermal acid sulfate Au-Ag deposit, Dominican Republic: Economic Geology, v. 88, p. 55-71.

Vidal, C.E., and Ligarda, R., 2004, Enargite-gold deposits at Marcapunta, Colquijirca mining district, central PeruMineralogic and geochemical zoning in subvolcanic, limestonereplacement deposits of high-sulfidation epithermal type, in Sillitoe, R.H., Perello, J., and Vidal, C.E., eds., Andean Metallogeny_-New Discoveries, Concepts, and Update: Society of Economic Geologists Special Publication 11, p. 231-241.

Vikentyev, Ilya, Banda, Richard, Tsepin, Anatoliy, Prokofiev, Vsevolod, and Vikentyeva, Olga, 2005, Mineralogy and formation conditions of Portovelo-Zaruma gold-sulphide vein deposit, Ecuador: Geochemistry Mineralogy and Petrology, v. 43 , p. $148-154$.

Vikre, P.G., 1985, Precious metal vein systems in the National district, Humboldt County, Nevada: Economic Geology, v. 80, p. $360-393$.

Vikre, P.G., 1987, Paleohydrology of Buckskin Mountain, National district, Humboldt County, Nevada: Economic Geology, v. 82, p. 934-950.

Vikre, P.G., 1989a, Fluid-mineral relations in the Comstock Lode: Economic Geology, v. 84, p. 1574-1613.

Vikre, P.G., 1989b, Ledge formation at the Sandstorm and Kendall gold mines, Goldfield, Nevada: Economic Geology, v. 84, p. 2115-2138. 
Vikre, P.G., 1994, Gold mineralization and fault evolution at the Dixie Comstock Mine, Churchill County, Nevada: Economic Geology, v 89, p. 707-719.

Vikre, P.G., 2000, Elemental sulfur $\left(\mathrm{S}^{\circ}\right)$ deposits and $\mathrm{S}^{\mathrm{o}}$ associated with precious metals, mercury, and thermal springs in the Great Basin, in Cluer, J.K., Price, J.G., Struhsacker, E.M., Hardyman, R.F., and Morris, C.L., eds., Proceedings of the Geology and Ore Deposits 2000-The Great Basin and Beyond Symposium, May 15-18, 2000: Geological Society of Nevada, p. 735-767.

Vikre, P.G., 2007, Sinter-vein correlations at Buckskin Mountain, National District, Humboldt County, Nevada: Economic Geology, v. 102, p. 193-224.

Vikre, P.G., Fleck, R.J., and Rye, R.O., 2005, Ages and geochemistry of alunites in the Goldfield district, Esmeralda County, Nevada: Proceedings of the Window to the World Symposium 2005, Reno, May 2005: Geological Society of Nevada, p. 1330-1331.

Vikre, P.G., Graybeal, F.T., Fleck, R.J., Barton, M.D., and Seedorff, E., 2014a, Succession of Laramide magmatic and magmatic-hydrothermal events in the Patagonia Mountains, Santa Cruz County, Arizona: Economic Geology, v. 109, p. 1667-1704.

Vikre, P.G., Graybeal, F.T., and Koutz, F.R., 2014b, Concealed basalt-matrix diatremes with $\mathrm{Cu}-\mathrm{Au}-\mathrm{Ag}$-(Mo)-mineralized xenoliths, Santa Cruz porphyry Cu-(Mo) system, Pinal County, Arizona: Economic Geology, v. 109, p. 1271-1289.

Vikre, P.G., and Henry, C.D., 2011, Quartz-alunite alteration cells in the southern segment of the ancestral Cascade magmatic arc, in Steininger, R., and Pennell, B., eds., Proceedings of the Great Basin Evolution and Metallogeny Symposium, Reno, 2010: Geological Society of Nevada, p. 701-745.

Vikre, P.G., John, D.A., du Bray, E.A., and Fleck, R.J., 2015, Gold-silver mining districts, alteration zones, and paleolandforms in the Miocene Bodie Hills volcanic field, California and Nevada: U.S. Geological Survey Scientific Investigations Report 2015-5012, 160 p., https:/doi. org/10.3133/sir20155012.

Vikre, P.G., McKee, E.H., and Silberman, M.L., 1988, Chronology of Miocene hydrothermal and igneous events in the western Virginia Range, Washoe, Storey, and Lyon counties, Nevada: Economic Geology, v. 83, p. 864-874.

Vikre, P., Premo, W., and Cosca, M., 2014c, Linkages between crustal stratigraphy, magmatic-hydrothermal evolution, and sources of components of gold-silver deposits in the adjoining Goldfield and Tonopah districts, Nevada [abs.]: Geological Society of America Abstracts with Programs, v. 46 , no. 6 , p. 249.
Vityk, M.O., Krouse, H.R., and Skakun, L.Z., 1994, Fluid evolution and mineral formation in the Beregovo gold-base metal deposit, Transcarpathia, Ukraine: Economic Geology, v. 89 , p. $547-565$.

Volkov, A.V., Prokof'ev, V.Y., Savva, N.E., Sidorov, A.A., Bayankin, M.A., Uyutnov, K.V., and Kolova, E.E., 2012, Ore formation at the Kupol epithermal gold-silver deposit in northeastern Russia deduced from fluid inclusion study: Geology of Ore Deposits, v. 54, p. 295-303.

Voudouris, P.C., Melfos, V., Spry, P.G., Moritz, R., Papavassiliou, C., and Falalakis, G., 2011, Mineralogy and geochemical environment of formation of the Perama Hill high-sulfidation epithermal Au-Ag-Te-Se deposit, Petrota Graben, NE Greece: Mineralogy and Petrology, v. 103, p. 79-100.

Wallace, A.R., Mihalasky, M.J., John, D.A., and Ponce, D.A., 2004, Assessment of epithermal Au-Ag deposits and occurrences, in Wallace, A.R., Ludington, Steve, Mihalasky, M.J., Peters, S.G., Theodore, T.G., Ponce, D.A., John, D.A., and Berger, B.R., Assessment of metallic mineral resources in the Humboldt River Basin, northern Nevada: U.S. Geological Survey Bulletin 2218, p. 227-295, https://pubs.usgs.gov/bul/ b2218/.

Wallier, Stefan, Rey, Roger, Kouzmanov, Kalin, Pettke, Thomas, Heinrich, C.A., Leary, Stephen, O’Connor, Gary, Tămas, C.G., Vennemann, Torsten, and Ullrich, Thomas, 2006, Magmatic fluids in the breccia-hosted epithermal Au-Ag deposit of Roşia Montană, Romania: Economic Geology, v. 101, p. 923-954.

Walter, C., Wameyo, P., Shalev, E., and Malin, P.E., 2012, Electromagnetic study of mineralized and active fracture zones in the southern Hauraki Goldfield, New Zealand: Proceedings of the 45th Annual Conference, New Zealand Branch of the AusIMM, Rotorua, 2012, p. 445-453.

Wang, Y., 2010, Physical and chemical characteristics of the host rocks in controlling the mineralization of the Chinkuashih highsulfidation gold-copper deposits, northeastern Taiwan: Journal of Geochemical Exploration, v. 104, p. 61-68.

Wang, Y., Sasaki, M., Sasada, M., and Chen, C.-H., 1999, Fluid inclusion studies of the Chinkuashih high-sulfidation goldcopper deposits in Taiwan: Chemical Geology, v. 154, p. $155-167$.

Warmada, I.W., Lehmann, B., and Simandjuntak, M., 2003, Polymetallic sulfides and sulfosalts of the Pongkor epithermal gold-silver deposit, West Java, Indonesia: Canadian Mineralogist, v. 41, p. 185-200.

Warmada, I.W., Lehmann, B., Simandjuntak, M., and Hemes, H.S., 2007, Fluid inclusion, rare-earth element and stable isotope study of carbonate minerals from the Pongkor epithermal gold-silver deposit, West Java, Indonesia: Resource Geology, v. 57, p. 124-135. 
Warren, Ian, Archibald, D.A., and Simmons, S.F., 2008, Geochronology of epithermal Au-Ag mineralization, magmatic-hydrothermal alteration, and supergene weathering in the El Peñón district, northern Chile: Economic Geology, v. 103, p. 851-864.

Warren, Ian, Simmons, S.F., and Mauk, J.L., 2007, Wholerock geochemical techniques for evaluating hydrothermal alteration, mass changes, and compositional gradients associated with epithermal $\mathrm{Au}-\mathrm{Ag}$ mineralization: Economic Geology, v. 102, p. 923-948.

Warren, Ian, Zuluaga, J.I., Robbins, C.H., Wulftange, W.H., and Simmons, S.F., 2004, Geology and geochemistry of epithermal Au-Ag mineralization in the El Peñón district, northern Chile: Society of Economic Geologists Special Publication 11, p. 113-139.

Watanabe, Yasushi, 1996, Genesis of vein-hosting fractures in the Kitami region, Hokkaido, Japan: Resource Geology, v. 46 , no. 3 , p. $151-166$.

Waters, P.J., Cooke, D.R., Gonzales, R.I., and Phillips, D., 2011, Porphyry and epithermal deposits and ${ }^{40} \mathrm{Ar} /{ }^{39} \mathrm{Ar}$ geochronology of the Baguio district, Philippines: Economic Geology, v. 106, p. 1335-1363.

Webster, J.G., 1986, The solubility of gold and silver in the system Au-Ag-S-O $-\mathrm{H}_{2} \mathrm{O}$ at $25^{\circ} \mathrm{C}$ and 1 atm.: Geochimica et Cosmochimica Acta, v. 50, p. 1837-1845.

Webster, J.G., and Mann, A.W., 1984, The influence of climate, geomorphology and primary geology on the supergene migration of gold and silver: Journal of Geochemical Exploration, v. 22, p. 21-42.

Weiss, S.I., Espinoza, E., and Ronkos, C., 2010, Update on the El Sauzal high-sulfidation gold-silver deposit at the initiation of mining, Municipio de Urique, Chichuahua, Mexico, in Gastelum, G., ed., Northern Sierra Madre Occidental Gold-Silver Mines, Mexico: Society of Economic Geologists Field Trip Guidebook Series, v. 42, p. 95-102.

White, D.E., 1955, Thermal springs and epithermal ore deposits: Economic Geology, 50th Anniversary Volume, p. 99-154.

White, D.E., 1974, Diverse origins of hydrothermal ore fluids: Economic Geology, v. 69, p. 954-973.

White, D.E., 1980, Active geothermal systems and hydrothermal ore deposits: Economic Geology, 75th Anniversary Volume, p. 392-423.
White, D.E., Fournier, R.O., Muffler, L.J.P., and Truesdell, A.H., 1975, Physical results of research drilling in thermal areas of Yellowstone National Park, Wyoming: U.S. Geological Survey Professional Paper 892, 70 p., https:// pubs.er.usgs.gov/publication/pp892.

White, N.C., and Hedenquist, J.W., 1990, Epithermal environments and styles of mineralization-Variations and their causes, and guidelines for exploration, in Hedenquist, J., White, N.C., and Siddeley, G., eds., Epithermal Gold Mineralization of the Circum-Pacific, Geology, Geochemistry, Origin and Exploration, II: Journal of Geochemical Exploration, v. 36, p. 445-474.

White, N.C., and Hedenquist, J.W., 1995, Epithermal gold deposits - Styles, characteristics and exploration: Society of Economic Geologists Newsletter 23, p. 1, 9-13.

White, N.C., Leake, M.J., McCaughey, S.N., and Parris, B.W., 1995, Epithermal deposits of the southwest Pacific: Journal of Geochemical Exploration, v. 54, p. 87-136.

White, W.W., III, Lapakko, K.A., and Cox, R.L., 1999, Statictest methods most commonly used to predict acid-mine drainage - Practical guidelines for use and interpretation, in Plumlee, G.S., and Logsdon, M.J., eds., The environmental geochemistry of mineral deposits, Part A, Processes, techniques, and health issues: Reviews in Economic Geology, v. 6A, p. 325-338.

Williams, D.K., 2012, The geology and mineralization of the Navidad project, Chubut Province, Argentina: Society of Economic Geologists Special Publication 15, p. 203-227.

Williams-Jones, A.E., Bowell, R.J., and Migdisov, A.A., 2009, Gold in solution: Elements, v. 5, p. 281-287.

Willis, G.F., and Tosdal, R.M., 1992, Formation of gold veins and breccias during dextral strike-slip faulting in the Mesquite mining district, southeastern California: Economic Geology, v. 87, p. 2002-2022.

Wirt, L., Leib, K.J., Bove, D.J., Mast, M.A., Evans, J.B., and Meeker, G.P., 1999, Determination of chemical constituent loads during base-flow and storm runoff conditions near historical mines in Prospect Gulch, Upper Animas River Watershed, southwestern Colorado: U.S. Geological Survey Open-File Report 99-159, 43 p., https://pubs.usgs.gov/ of/1999/ofr-99-0159/ofr-99-159.pdf.

Wise, J.M., 2005, Undulatory silver-rich polymetallic veins of the Castrovirreyna district, central Peru-Fault growth and mineralization in a perturbed local stress field: Economic Geology, v. 100, p. 689-705. 
Wood, D.A., Joron, J.L., and Treuil, M., 1979, A re-appraisal of the use of trace elements to classify and discriminate between magma series erupted in different tectonic settings: Earth and Planetary Science Letters, v. 45, p. 326-336.

Wood, D., and MacCorquodale, F., 2015, Persistence can pay off: Discovery of the Gosowong district bonanza-grade gold-silver epithermal orebodies, Halmahera Island, Indonesia: Society of Economic Geologists Newsletter, no. 102, p. 1, 10-16.

Wright, J.L., and Lide, C.S., 2000, Geophysical exploration for gold in northern Nevada: Spokane, Wash., Northwest Mining Association, Practical Geophysics III, 89 p. [CD-ROM]

Wurst, A.T., 2004, Geology and genesis of the Permata - Batu Badinding - Julubai and Kerkil Au-Ag low sulfidation epithermal deposits, Mt. Muro, Kalimantan, Indonesia: University of Tasmania, $\mathrm{PhD}$ dissertation, $338 \mathrm{p}$.

Wynn, J.C., and Luce, R.W., 1984, Geophysical methods as mapping tools in a strata-bound gold deposit, Haile Mine, South Carolina Slate Belt: Economic Geology, v. 79, p. 382-388.

Yamana Gold, 2017, Yamana Gold annual reports: Yamana Gold web page, at http://www.yamana.com/English/portfolio/ reserves-and-resources/default.aspx.

Yilmaz, Huseyin, 2002, Ovacik gold deposit—An example of quartz-adularia-type gold mineralization in Turkey: Economic Geology, v. 97, p. 1829-1839.

Yilmaz, Huseyin, Oyman, Tolga, Arehart, G.B., Colakoglu, A.R., and Billor, Zeki, 2007, Low-sulfidation type Au-Ag mineralization at Bergama, Izmir, Turkey: Ore Geology Reviews, v. 32, p. 81-124.
Zakharov, M.N., Kravtsova, R.G., and Pavlova, L.A., 2002, Geochemical features of rocks of volcanoplutonic associations of the Dukat gold-silver deposit: Russian Geology and Geophysics, v. 43, p. 928-939.

Zanbak, C., 2012, Heap leaching technique in mining, within the context of best available techniques (BAT): Brussels, Belgium, Euromines (European Association of Mining Industries, Metal Ores \& Industrial Minerals), 36 p.

Zindler, A., and Hart, S., 1986, Chemical geodynamics: Annual Review of Earth and Planetary Science, v. 14, p. 493-571.

Zijin Mining Group, Ltd., 2011, Zijinshan, Zijin Mining Group web page, accessed August 24, 2015, at http://www. zijinmining.com/tabid/1017/InfoID/29281/frtid/1110/ Default.aspx.

Zoback, M.L., McKee, E.H., Blakely, R.J., and Thompson, G.A., 1994, The northern Nevada rift-Regional tectonomagmatic relations and middle Miocene stress direction: Geological Society of America Bulletin, v. 106, p. 371-382.

Zoback, M.L., and Thompson, G.A., 1978, Basin and Range rifting in northern Nevada - Clues from a mid-Miocene rift and its subsequent offsets: Geology, v. 6, p. 111-116.

Zorin, Yu.A., Zorina, L.D., Spiridonov, A.M., and Rutshtein, I.G., 2001, Geodynamic settings of gold deposits in the Transbaikal region (Eastern Siberia, Russia): Ore Geology Reviews, v. 17, p. 215-232. 



\section{Appendix 1. Characteristics of Epithermal Gold-Silver Deposits}

This appendix is available online only as an .xlsx table at https://doi.org/10.3133/sir20105070Q.

\section{References Cited}

Afifi, A.M., Kelly, W.C., and Essene, E.J., 1988, Phase relations among tellurides, sulfides, and oxides; Pt. II, Applications to telluride-bearing ore deposits: Economic Geology, v. 83, p. 395-404.

Albinson, T., Norman, D.I., Cole, D., and Chomiak, B.A., 2001, Controls on formation of low-sulfidation epithermal deposits in Mexico - Constraint from fluid inclusion and stable isotope data: Society of Economic Geologists Special Publication 8, p. $1-32$.

Alderton, D.H.M., and Fallick, A.E., 2000, The nature and genesis of gold-silver-tellurium mineralization in the Metaliferi Mountains of western Romania: Economic Geology v. 95, p. $495-515$.

Alfieris, Dimitrios, 2006, Geological, geochemical and mineralogical studies of shallow submarine epithermal mineralization in an emergent volcanic edifice at Milos Island (western side), Greece: Hamburg, Germany, Hamburg University, Ph.D. thesis, 294 p.

Alfieris, D., Voudouris, P., and Spry, P.G., 2013, Shallow submarine epithermal $\mathrm{Pb}-\mathrm{Zn}-\mathrm{Cu}-\mathrm{Au}-\mathrm{Ag}-\mathrm{Te}$ mineralization on western Milos Island, Aegean Volcanic Arc, GreeceMineralogical, geological and geochemical constraints: Ore Geology Reviews, v. 53, p. 159-180.

Allibone, A.H., Cordery, G.R., Morrison, G.W., Jaireth, S., and Lindhorst, J.W., 1995, Synchronous advanced argillic alteration and deformation in a shear zone-hosted magmatic hydrothermal $\mathrm{Au}-\mathrm{Ag}$ deposit at the Temora (Gidginbung) mine, New South Wales, Australia: Economic Geology, v. 90, p. 1570-1603.

Allied Nevada Gold Corp., 2013, Hycroft mine, Winnemucca, Nevada, USA, Technical report, 145 p.: Allied Nevada Gold Corp. web page, accessed November 18, 2014, at http://www. alliednevada.com/properties/hycroft-mine/hycroft-minetechnical-reports.

Andreeva, E.D., 2013, Genesis of precious metal mineralization in the central Kamchatka, Far East of Russia: Hokkaido, Japan, Hokkaido University, Ph.D. thesis, 240 p.

Andreeva, E.D., Matsueda, H., Okrugin, V.M., Takahashi, R., and Ono, S., 2013, Au-Ag-Te mineralization of the low-sulfidation epithermal Aginskoe deposit, central Kamchatka, Russia: Resource Geology, v. 63, p. 337-349.
Aoki, M., Comsti, E.C., Lazo, F.B., and Matsuhisa, Y., 1993, Advanced argillic alteration and geochemistry of alunite in an evolving hydrothermal system at Baguio, northern Luzon, Philippines: Resource Geology, v. 43, p. 155-164.

Arancibia, G., Matthews, S.J., Cornejo, P., de Arce, C.P., Zuluaga, J.I., and Kasaneva, S., 2006, ${ }^{40} \mathrm{Ar} /{ }^{39} \mathrm{Ar}$ and K-Ar geochronology of magmatic and hydrothermal events in a classic low-suphidation epithermal bonanza deposit-El Peñon, northern Chile: Mineralium Deposita, v. 41, p. 505-516.

Arizanov, A., and Terziyski, S., 2004, Chelopech Cu-Au deposit: Society of Economic Geologists Guidebook Series, v. 36, p. 79-90.

Arribas, A., Jr., 1995, Characteristics of high-sulfidation epithermal deposits, and their relation to magmatic fluid, in Thompson, J.F.H., ed., Magmas, fluids, and ore deposits: Mineralogical Association of Canada Short Course, v. 23, p. 419-454.

Arribas, A., Jr., Arribas, I., Draper, G., Hall, C., Kesler, S.E., McEwan, C., and Muntean, J.L., 2011, ${ }^{40} \mathrm{Ar} /{ }^{39} \mathrm{Ar}$ dating of alunite from the Pueblo Viejo gold-silver deposit, Dominican Republic: Economic Geology, v. 106, p. 1059-1070.

Arribas, A., Jr., Cunningham, C.G., Rytuba, J.J., Rye, R.O., Kelly, W.C., Podwysocki, M.H., McKee, E.H., and Tosdal, R.M., 1995a, Geology, geochronology, fluid inclusions, and isotope geochemistry of the Rodalquilar gold alunite deposit, Spain: Economic Geology, v. 90, p. 795-822.

Arribas, A., Jr., Hedenquist, J.W., Itaya, T., Okada, T., Concepción, R.A., and Garcia, J.S., 1995b, Contemporaneous formation of adjacent porphyry and epithermal $\mathrm{Cu}-\mathrm{Au}$ deposits over $300 \mathrm{ka}$ in northern Luzon, Philippines: Geology, v. 23, p. 337-340.

Arribas, A., Jr., Schalamuk, I.B., de Barrio, R., Fernández, R., and Itaya, T., 1996, Edades radiométricas de mineralizaciones epitermales auríferas del Macizo del Deseado, provincia de Santa Cruz, Argentina: 29th Brazilian Geological Congress [Proceedings], v. 7, p. 254-257.

Ashley, R.P., 1974, Goldfield mining district: Nevada Bureau of Mines and Geology Report 19, p. 49-66.

Ashley, R.P., 1979, Relation between volcanism and ore deposition at Goldfield, Nevada: Nevada Bureau of Mines and Geology Report 33, p. 77-86. 
Ashley, R.P., 1990a, The Goldfield gold district, Esmeralda and Nye Counties, Nevada, in Shawe, D.R., and Ashley, R.P., eds., Epithermal Gold Deposits - Part 1: U.S. Geological Survey Bulletin 1857-H, p. H1-H7, https://pubs.usgs.gov/bul/1857h/ report.pdf.

Ashley, R.P., 1990b, The Tonopah precious-metal district, Esmeralda and Nye Counties, Nevada, in Shawe, D.R., and Ashley, R.P., eds., Epithermal Gold Deposits-Part 1: U.S. Geological Survey Bulletin 1857-H, p. H8-H13, https://pubs. usgs.gov/bul/1857h/report.pdf.

Ashley, R.P., and Silberman, M.L., 1976, Direct dating of mineralization at Goldfield, Nevada, by potassium-argon and fission track methods: Economic Geology, v. 71, p. 904-924.

Ayuso, R.A., Wooden, J.L., Foley, N.K., Seal, R.R., and Sinha, A.K., 2005, U-Pb zircon ages and $\mathrm{Pb}$ isotope geochemistry of gold deposits in the Carolina Slate Belt of South Carolina: Economic Geology, v. 100, p. 225-252.

Bailly, L., Stein, G., and Genna, A., 2002, Preliminary microthermometric measurements in quartz, sphalerite and enargite from the Bor and Majdanpek deposits, Serbia: Geology and Metallogeny of Copper and Gold Deposits in the Bor Metallogenic Zone-Bor 100 Years International Symposium, Bor Lake, Yugoslavia, 2002 [Proceedings], p. 71-75.

Baker, T., Mustard, R., Brown, V., Pearson, N., Stanley, C.R., Radford, N.W., and Butler, I., 2006, Textural and chemical zonation of pyrite at Pajingo-A potential vector to epithermal gold veins: Geochemistry Exploration Environment Analysis, v. 6 , p. $283-293$.

Barton, P.B., Bethke, P.M., Jr., and Roedder, E., 1977, Environment of ore deposition in the Creede mining district, San Juan Mountains, Colorado; Part III, Progress toward interpretation of the chemistry of the ore-forming fluid for the $\mathrm{OH}$ vein: Economic Geology, v. 72, p. 1-24.

Bartos, P.J., 2000, The Pallacos of Cerro Rico de Potosi, Bolivia-A new deposit type: Economic Geology, v. 95, p. 645-654.

Bastin, E.S., 1941, Paragenetic relations in the silver ores of Zacatecas, Mexico: Economic Geology, v. 36, p. 371-400.

Basuki, A., Sumanagara, D.A., and Sinambela, D., 1994, The Gunung Pongkor gold-silver deposit, West Java, Indonesia: Journal of Geochemical Exploration, v. 50, p. 371-391.

Baumgartner, R., Fontboté, L., Spikings, R., Ovtcharova, M., Schaltegger, U., Schneider, J., Page, L., and Gutjahr, M., 2009, Bracketing the age of magmatic-hydrothermal activity at the Cerro de Pasco epithermal polymetallic deposit, central Peru-A U-Pb and ${ }^{40} \mathrm{Ar}{ }^{39} \mathrm{Ar}$ study: Economic Geology, v. 104, p. 479-504.
Baumgartner, R., Fontboté, L., and Vennemann, T., 2008, Mineral zoning and geochemistry of epithermal polymetallic $\mathrm{Zn}-\mathrm{Pb}$ $\mathrm{Ag}$-Cu-Bi mineralization at Cerro de Pasco, Peru: Economic Geology, v. 103, p. 493-537.

Becker, G.F., 1882, Geology of the Comstock Lode and the Washoe district: U.S. Geological Survey Monograph 3, 422 p.

Belanger, M., Pareja, G., and Nahan, P., 2011, Peñasquito Polymetallic Operation Zacatecas State, Mexico: Silver Wheaton NI 43-101 Technical Report, 142 p., accessed July 24, 2014, at http://www.silverwheaton.com/ Theme/SilverWheaton/files/docs_mine $\% 20$ tech $\% 20$ reports/2011-04-01\%20Penasquito $\% 20$ Technical $\% 20$ Report $\% 20 \% 28$ final\%29.pdf.

Bendezú, R., 2007, Shallow polymetallic and precious metal mineralization associated with a Miocene diatreme-dome complex - The Colquijirca district of the Peruvian Andes: Geneva, Switzerland, University of Geneva, Ph.D. thesis, 221 p.

Bendezú, R., and Fontboté, L., 2009, Cordilleran epithermal $\mathrm{Cu}-\mathrm{Zn}-\mathrm{Pb}-(\mathrm{Au}-\mathrm{Ag})$ mineralization in the Colquijirca district, central Peru-Deposit-scale mineralogical patterns: Economic Geology, v. 104, p. 904-955.

Bendezú, R., Fontboté, L., and Cosca, M., 2003, Relative age of Cordilleran base metal lode and replacement deposits, and high sulfidation Au-(Ag) epithermal mineralization in the Colquijirca mining district, central Peru: Mineralium Deposita, v. 38 , p. 683-694.

Bendezú, R., Page, L., Spikings, R., Pecskay, Z., and Fontboté, L., 2008, New ${ }^{40} \mathrm{Ar} /{ }^{39} \mathrm{Ar}$ alunite ages from the Colquijirca district, Peru—Evidence of a long period of magmatic $\mathrm{SO}_{2}$ degassing during formation of epithermal $\mathrm{Au}-\mathrm{Ag}$ and Cordilleran polymetallic ores: Mineralium Deposita, v. 43, p. $777-789$.

Berger, B.R., Tingley, J.V., and Drew, L.J., 2003, Structural localization and origin of compartmentalized fluid flow, Comstock Lode, Virginia City, Nevada: Economic Geology, v. 98 , p. $387-408$.

Bergman Weihed, J., Berstrom, U., Billstrom, K., and Weihed, P., 1996, Geology, tectonic setting, and origin of the Paleoproterozoic Boliden Au-Cu-As deposit, Skellefte district, northern Sweden: Economic Geology, v. 91, p. 1073-1097.

Berry, J.M., Mobley, R.M., Gillon, K.A., Yogodzinski, G.M., and Bates, C.C., 2016, A Neoproterozoic epithermal gold deposit-The Haile gold mine, South Carolina, USA, in Doar, W.R., III, ed., Gold, Structures, and Landforms in Central South Carolina-Field Guides for the 2016 GSA Southeastern Section Meeting, Columbia, South Carolina: Geological Society of America Field Guide 42, p. 1-8, https://doi. org/10.1130/2016.0042(01). 
Bethke, P.M., Barton, P.B., Jr., Lanphere, M.A., and Steven, T.A., 1976, Environment of ore deposition in the Creede mining district, San Juan Mountains, Colorado-Part II, Age of mineralization: Economic Geology, v. 71, p. 1006-1011.

Bethke, P.M., and Rye, R.O., 1979, Environment of ore deposition in the Creede mining district, San Juan Mountains, ColoradoPart IV, Source of fluids from oxygen, hydrogen and carbon isotope studies: Economic Geology, v. 74, p. 1832-1851.

Bethke, P.M., Rye, R.O., Stoffregen, R.E., and Vikre, P.G., 2005, Evolution of the magmatic-hydrothermal acid-sulfate system at Summitville, Colorado - Integration of geological, stableisotope, and fluid-inclusion evidence: Chemical Geology, v. 215 , p. $281-315$.

Bissig, T., Clark, A.H., Lee, J.K.W., and Hodgson, C.J., 2002, Miocene landscape evolution and geomorphologic controls on epithermal processes in El Indio-Pascua Au-Ag-Cu belt, Chile and Argentina: Economic Geology, v. 97, p. 971-996.

Bissig, T., Donoso, D., Guerra, N.C., and Dipple, G.M., 2010, Vein carbonates in the low sulfidation epithermal Au-Ag District of El Peñón, II Región, Chile-Environment of formation and exploration implications: Andean Geology, v. 34, p. 291-304.

Bobis, R.E., Jaireth, S., and Morrison, G.W., 1995, The anatomy of a Carboniferous epithermal ore shoot at Pajingo, Queensland - Setting, zoning, alteration, and fluid conditions: Economic Geology, v. 90, p. 1776-1799.

Bonev, I.K., Kerestedjian, T., Atanassova, R., and Andrew, C.J., 2002, Morphogenesis and composition of native gold in the Chelopech volcanic-hosted $\mathrm{Au}-\mathrm{Cu}$ epithermal deposit, Srednorgorie zone, Bulgaria: Mineralium Deposita, v. 37, p. 614-629.

Bonham, H.F., Jr., and Garside, L.J., 1982, Geochemical reconnaissance of the Tonopah, Lone Mountain, Klondike, and Northern Mud Lake quadrangles, Nevada: Nevada Bureau of Mines and Geology, Bulletin 96, 68 p.

Bonham, H.F., Jr., and Papke, K.G., 1969, Geology and mineral deposits of Washoe and Storey Counties, Nevada: Nevada Bureau of Mines and Geology Bulletin 70, $140 \mathrm{p}$.

Boychuk, K.G., Garcia, D.H., Sharp, A.W., Vincent, J.D., Yeomans, T.J., 2012, NI 43-101 technical report on the Pitarrilla project, Durango State, Mexico: Vancouver, British Columbia, Silver Standard, 435 p., accessed August 14, 2014, at http:// www.silverstandard.com/_resources/Pitarrilla_Technical_ Report_Dec_14_2012.pdf.

Brathwaite, R.L., 1989, Geology and exploration of the Karangahake gold-silver deposit: Australasian Institute of Mining and Metallurgy Monograph 13, p. 73-78.
Brathwaite, R.L., Christie, A.B., and Skinner, D.N.B., 1989, The Hauraki Goldfield-Regional setting, mineralisation and recent exploration: Australasian Institute of Mining and Metallurgy Monograph 13, p. 45-56.

Brathwaite, R.L., and Faure, K., 2002, The Waihi epithermal gold-silver base metal sulfide quartz vein system, New Zealand-Temperature and salinity controls on electrum and sulfide deposition: Economic Geology, v. 97, p. 269-290.

Brathwaite, R.L., Simpson, M.P., Faure, K., and Skinner, D.N.B., 2001, Telescoped porphyry Cu-Mo-Au mineralisation, advanced argillic alteration and quartz-sulphide-gold-anhydrite veins in the Thames district, New Zealand: Mineralium Deposita, v. 36, p. 623-640.

Braund, K.G., 2006, Geology, geochemistry and paragenesis of the Royal, Crown and Roses Pride low sulphidation epithermal quartz vein structures, Cracow, South-East Queensland: Brisbane St. Lucia, Queensland, Australia, University of Queensland, MPhil thesis, $334 \mathrm{p}$.

Breit, F., and Lawrence, E.F., 1995, Road log from Hawthorne to Aurora and description of the Aurora district: Geological Society of Nevada Special Publication 22, p. 54-65.

Bryson, R.H., Brown, F.H., Rivera, R., and Butcher, M.G., 2009, Penasquito project technical report, Concepion del Oro district, Zacatecas State, Mexico: Goldcorp Inc., 144 p., accessed August 14, 2014, at http://www.silverwheaton.com/Theme/ SilverWheaton/files/docs_silver $\% 20$ streams $\% 20$ tech. $\% 20$ reports/www.sedar.com_PenasquitoTechReport_March\%20 $10, \% 202009$.pdf.

Buchanan, L.J., 1979, The Los Torres mine, Guanajuato, Mexico - Ore controls on a fossil geothermal system: Golden, Colorado School of Mines, Ph.D. thesis, $138 \mathrm{p}$.

Buchanan, L.J., 1981, Precious metal deposits associated with volcanic environment in the southwest: Arizona Geological Society Digest, v. 14, p. 237-262.

Caira, N.M., 2013, National instrument 43-101 F1 technical report on the El Oro property, Mexico: Report prepared for Candente Gold Corp., 219 p., http://www.candentegold.com/i/pdf/reports/ El-Oro-NI-43-101-Report-Nov-30-13.pdf.

Camprubi, A., and Albinson, T., 2007, Epithermal deposits in Mexico - Update of current knowledge, and an empirical reclassification: Geological Society of America Special Paper 422, p. 377-415.

Camprubi, Antoni, Ferrari, Luca, Cosca, M.A., Cardellach, Esteve, and Canals, Angels, 2003, Ages of epithermal deposits in Mexico-Regional significance and links with the evolution of Tertiary volcanism: Economic Geology, v. 98, p. 1029-1037. 
Camus, F., Boric, R., Skewes, M.A., Castelli, J.C., Reichhard, E., and Mestre, A., 1991, Geologic, structural and fluid inclusion studies of El Bronce epithermal vein system, Petorca, central Chile: Economic Geology, v. 86, p. 13171345.

Candiotti de Los Rios, Hugo, Noble, D.C., and McKee, E.H., 1990, Geologic setting and epithermal silver veins of the Arcata district, southern Peru: Economic Geology, v. 85, p. 1473-1490.

Carlile, J.C., Davey, G.R., Kadir, I., Langmead, R.P., and Rafferty, W.J., 1998, Discovery and exploration of the Gosowong epithermal gold deposit, Halmahera, Indonesia: Journal of Geochemical Exploration, v. 60, p. 207-227.

Casadevall, T., and Ohmoto, H., 1977, Sunnyside mine, Eureka mining district, San Juan County, Colorado-Geochemistry of gold and base metal ore deposition in a volcanic environment: Economic Geology, v. 72, p. 1285-1320.

Cerpa, L.M., Bissig, Thomas, Kyser, Kurtis, McEwan, Craig, Macassi, Arturo, and Rios, H.W., 2013, Lithologic controls on mineralization at the Lagunas Norte high-sulfidation epithermal gold deposit, northern Peru: Mineralium Deposita, v. 48 , p. $653-673$.

Chambefort, Isabelle, 2005, The $\mathrm{Cu}-\mathrm{Au}$ Chelopech deposit, Panagyurishte district, Bulgaria_-Volcanic setting, hydrothermal evolution and tectonic overprint of a Late Cretaceous high-sulfidation epithermal deposit: Geneva, Switzerland, University of Geneva, Ph.D. thesis, 173 p.

Chambefort, I., Dilles, J.H., and Longo, A.A., 2013, Amphibole geochemistry of the Yanacocha Volcanics, Peru-Evidence for diverse sources of magmatic volatiles related to gold ores: Journal of Petrology, v. 54, p. 1017-1046.

Chambefort, I., and Moritz, R., 2006, Late Cretaceous structural control and Alpine overprint of the high-sulfidation $\mathrm{Cu}-\mathrm{Au}$ epithermal Chelopech deposit, Srednogorie zone, Bulgaria: Mineralium Deposita, v. 42, p. 259-280.

Chambefort, I., Moritz, R., and von Quadt, A., 2007, Petrology, geochemistry and $\mathrm{U}-\mathrm{Pb}$ geochronology of magmatic rocks from the high-sulfidation epithermal $\mathrm{Au}-\mathrm{Cu}$ Chelopech deposit, Srednogorie belt, Bulgaria: Mineralium Deposita, v. 41, p. 665-690.

Charchaflié, D., Tosdal, R.M., and Mortensen, J.K., 2007, Geologic framework of the Veladero high-sulfidation epithermal deposit area, Cordillera Frontal, Argentina: Economic Geology, v. 102, p. 171-192.

Chesterman, C.W., Chapman, R.H., and Gray, C.H., Jr., 1986, Geology and ore deposits of the Bodie mining district, Mono County, California: California Division of Mines and Geology Report 206, 36 p.
Chiaradia, M., Fontbote, L., and Beate, B., 2004, Cenozoic continental arc magmatism and associated mineralization in Ecuador: Mineralium Deposita, v. 39, p. 204-222.

Chiaradia, M., Merino, D., and Spikings, R., 2009, Rapid transition to long-lived deep crustal magmatic maturation and the formation of giant porphyry-related mineralization (Yanacocha, Peru): Earth and Planetary Science Letters, v. 288, p. 505-515.

Chouinard, A., Williams-Jones, A.E., Leonardson, R.W., Hodgson, C.J., Silva, P., Tellez, C., Vega, J., and Rojas, F., 2005, Geology and genesis of the multistage high-sulfidation epithermal Pascua Au-Ag-Cu deposit, Chile and Argentina: Economic Geology, v. 100 , p. $463-490$.

Christie, A.B., 1982, Fluid inclusions, stable isotopes and geochemistry of porphyry copper and epithermal vein deposits of the Hauraki gold-silver province, New Zealand: Wellington, Victoria, University of Wellington, Ph.D. thesis, 769 p.

Christie, A.B., Simpson, M.P., Brathwaite, R.L., Mauk, J.L., and Simmons, S.F., 2007, Epithermal Au-Ag and related deposits of the Hauraki Goldfield, Coromandel volcanic zone, New Zealand: Economic Geology, v. 102, p. 785-816.

Christie, Gary, Lipiec, Ignacy, Simpson, R.G., Horton, Jay, and Borntradger, Bruno, 2014, Blackwater gold project, British Columbia, NI 43-101 Technical Report on Feasibility Study, 336 p., accessed November 18, 2014, at http://www.sedar.com/DisplayCompanyDocuments. do?lang $=\mathrm{EN} \&$ issuerNo $=00004818$.

Churchill, R.K., 1980, Meteoric water leaching and ore genesis at the Tayoltita silver-gold mine, Durango, Mexico: Minneapolis, University of Minnesota, Ph.D. thesis, $162 \mathrm{p}$.

Clarke, D.S., Lewis, R.W., and Waldron, H.M., 1990, Geology and trace-element geochemistry of the Umuna gold-silver deposit, Misima Island, Papua New Guinea: Journal of Geochemical Exploration, v. 36, p. 201-223.

Clarke, M., and Titley, S.R., 1988, Hydrothermal evolution in the formation of silver-gold veins, Tayoltita Mine, San Dimas district, Mexico: Economic Geology, v. 83, p. 1830-1840.

Claveria, R.J.R., 2001, Mineral paragenesis of the Lepanto copper and gold and the Victoria gold deposits, Mankayan mineral district, Philippines: Resource Geology, v. 51, p. 97-106.

Columba, C.M., and Cunningham, C.G., 1993, Geologic model for the mineral deposits of the La Joya district, Oruro, Bolivia: Economic Geology, v. 88, p. 701-708.

Conrad, J.E., and McKee, E.H., 1996, High precision ${ }^{40} \mathrm{Ar} /{ }^{39} \mathrm{Ar}$ ages of rhyolitic host rock and mineralized veins at the Sleeper deposit, Humboldt County, Nevada, in Coyner, A.R., and Fahey, P.L., eds., Proceedings of the Geology and Ore Deposits of the American Cordillera Symposium, Reno, April 1995: Geological Society of Nevada, p. 257-262. 
Conrad, M.E., O’Neil, J.R., and Petersen, U., 1995, The relation between widespread ${ }^{18} \mathrm{O}$ depletion patterns and precious metal mineralization in the Tayoltita mine, Durango, Mexico: Economic Geology, v. 90, p. 322-342.

Cooke, D.R., and Bloom, M.S., 1990, Epithermal and subjacent porphyry mineralization, Acupan, Baguio district, Philippines-A fluid inclusion and paragenetic study: Journal of Geochemical Exploration, v. 35, p. 297-340.

Cooke, D.R., Deyell, C.L., Water, P.J., Gonzales, R.I., and Zaw, Khin, 2011, Evidence for magmatic-hydrothermal fluids and ore-forming processes in epithermal and porphyry deposits of the Baguio district, Philippines: Economic Geology, v. 106, p. 1399-1424.

Cooke, D.R., and McPhail, D.C., 2001, Epithermal Au-Ag-Te mineralization, Acupan, Baguio district, PhilippinesNumerical simulations of mineral deposition: Economic Geology, v. 96, p. 109-132.

Cooke, D.R., McPhail, D.C., and Bloom, M.S., 1996, Epithermal gold mineralization, Acupan, Baguio district, PhilippinesGeology, mineralization, alteration and thermochemical environment of ore deposition: Economic Geology, v. 91, p. 243-272.

Corbett, G.J., and Leach, T.M., 1998, Southwest Pacific rim gold-copper systems: Society of Economic Geologists Special Publication 6, $237 \mathrm{p}$.

Cunningham, C.G., Zartman, R.E., McKee, E.H., Rye, R.O., Naeser, C.W., Sanjinés, V.O., Ericksen, G.E., and Tavera, V.F., 1996, The age and thermal history of Cerro Rico de Potosi, Bolivia: Mineralium Deposita, v. 31, p. 374-385.

Davies, A.G.S., Cooke, D.R., and Gemmell, J.B., 2003, The Kelian breccia complex-A giant epithermal gold-silver deposit in Kalimantan, Indonesia, in Eliopoulos, D., ed., Mineral exploration and sustainable development: Proceedings of the Seventh Biennial SGA Meeting, Rotterdam, Millpress, v. 1, p. $465-468$.

Davies, A.G.S., Cooke, D.R., Gemmell, J.B., van Leeuwen, Theo, Cesare, Pat, and Hartshorn, Greg, 2008b, Hydrothermal breccias and veins at the Kelian gold mine, Laimantan, Indonesia - Genesis of a large epithermal gold deposit: Economic Geology, v. 103, p. 717-757.

Davies, A.G.S., Cooke, D.R., Gemmell, J.B., and Simpson, K.A., 2008a, Diatreme breccias at the Kelian gold mine, Laimantan, Indonesia- Precursors to epithermal gold mineralization: Economic Geology, v. 103, p. 689-716.

De Mark, Pamela, Chulick, J.J., Williams, D.K., Spring, Damian, Wells, J.A., 2009, Navidad project, Chubat Province, Argentina: Aqualine Resources Inc., NI 43-101 report, 247 p., accessed May 27, 2014, at http://www.panamericansilver.com/ operations/argentina/navidad/. de Ronde, C.E.J., and Blattner, P., 1988, Hydrothermal alteration, stable isotopes, and fluid inclusions of the Golden Cross epithermal gold-silver deposit, Waihi, New Zealand: Economic Geology, v. 83, p. 895-917.

Deen, J.A., Rye, R.O., Munoz, J.L., and Drexler, J.W., 1994, The magmatic hydrothermal system at Julcani, PeruEvidence from fluid inclusions and hydrogen and oxygen isotopes: Economic Geology, v. 89, p. 1924-1938.

DeWitt, E., Thorson, J.P., and Smith, R.C., 1991, Geology and gold deposits of the Oatman district, northwestern Arizona: U.S. Geological Survey Bulletin 1857-I, p. I1-I28.

Deyell, C.L., Bissig, T., and Rye, R.O., 2004, Isotopic evidence for magmatic-dominated epithermal processes in the El Indio-Pascua $\mathrm{Au}-\mathrm{Cu}-\mathrm{Ag}$ belt and relationship to geomorphologic setting, in Sillitoe, R.H., Perello, J., and Vidal, C.E., eds., Andean Metallogeny-New Discoveries, Concepts, and Update: Society of Economic Geologists Special Publication 11, p. 55-73.

Deyell, C.L., Leonardson, R., Rye, R.O., Thompson, J.F.H., Bissig, T., and Cooke, D.R., 2005a, Alunite in the PascuaLama high-sulfidation deposit - Constraints on alteration ore deposition using stable isotope geochemistry: Economic Geology, v. 100, p. 131-148.

Deyell, C.L., Rye, R.O., Landis, G.P., and Bissig, T., 2005b, Alunite and the role of magmatic fluids in the Tambo highsulfidation deposit, El Indio-Pascua belt, Chile: Chemical Geology, v. 215, p. 185-218.

Doebrich, J. L., and LeAnderson, J. P., 1984, Geology and hydrothermal alteration at the Mahd adh Dhahab epithermal precious-metal deposit, Kingdom of Saudi Arabia, U.S. Geological Survey Open-File Report 84-640, p. 36, and 2 plates.

Dong, G.Y., and Zhou, T., 1996, Zoning in the CarboniferousLower Permian Cracow epithermal vein system, central Queensland, Australia: Mineralium Deposita, v. 31, p. 210-224.

Dreier, J.E., 1976, The geochemical environment of ore deposition in the Pachuca-Real del Monte district, Hidalgo, Mexico: Unpublished Ph.D. thesis, Tucson, University of Arizona, $115 \mathrm{p}$.

Dreier, J.E., 2005, The environment of vein formation and ore deposition in the Purisima-Colon-Pachuca Real del Monte district, Hidalgo, Mexico: Economic Geology, v. 100, p. $1325-1347$.

Drew, L.J., 2005, A tectonic model for the spatial occurrence of porphyry copper and polymetallic vein depositsApplications to central Europe: U.S. Geological Survey Scientific Investigations Report 2005-5272, 36 p. 
Dubé, Benôit, Dunning, Greg, and Lauzière, Kathleen, 1998, Geology of the Hope Brook mine, Newfoundland, Canada-A preserved Late Proterozoic high-sulfidation epithermal gold deposit and its implications for exploration: Economic Geology, v. 93 , p. $405-436$.

Durning, W.P., and Buchanan, L.J., 1984, The geology and ore deposits of Oatman, Arizona: Arizona Geological Society Digest, v. 15, p. 141-158.

Earthman, M.A., 2010, Sulfur isotope and fluid inclusion study of fluid sources within the Fresnillo southwest silver district, Zacatecas, Mexico: Socorro, New Mexico Institute of Mining and Technology, M.S. thesis, $66 \mathrm{p}$.

Ebert, S.W., Groves, D.I., and Jones, J.K., 1996, Geology, alteration, and ore controls of the Crofoot-Lewis mine, Sulphur, Nevada-A well-preserved hot-spring gold-silver deposit, in Coyner, A.R., and Fahey, P.L., eds., Proceedings of the Geology and Ore Deposits of the American Cordillera Symposium, Reno, April 1995: Geological Society of Nevada, p. 209-234.

Ebert, S.W., and Rye, R.O., 1997, Secondary precious metal enrichment by steam-heated fluids in the Crofoot-Lewis hot spring gold-silver deposit and relation to paleoclimate: Economic Geology, v. 92, p. 578-600.

Einaudi, M.T., 1977, Environment of ore deposition at Cerro de Pasco, Peru: Economic Geology, v. 72, p. 893-924.

Eng, T., Boden, D.R., Reischman, M.R., and Biggs, J.O., 1996, Geology and mineralization of the Bullfrog mine and vicinity, Nye county, Nevada, in Coyner, A.R., and Fahey, P.L., eds., Proceedings of the Geology and Ore Deposits of the American Cordillera Symposium, Reno, April 1995: Geological Society of Nevada, p. 353-402.

Enriquez, E., and Rivera, R., 2001a, Geology of the Santa Rita Ag-Au deposit, San Dimas district, Durango, Mexico, in Albinson, T., and Nelson, C.E., eds., New Mines and Discoveries in Mexico and Central America: Society of Economic Geologists Special Publication 8, p. 39-58.

Enriquez, E., and Rivera, R., 2001b, Timing of magmatic and hydrothermal activity in the San Dimas district, Durango, Mexico: Society of Economic Geologists Special Publication 8, p. 22-38.

Etoh, J., Izawa, E., Watanabe, K., Taguchi, S., and Sekine, R., 2002, Bladed quartz and its relationship to gold mineralization in the Hishikari low-sulfidation epithermal gold deposit, Japan: Economic Geology, v. 97, p. 1841-1851.

Ewers, G.R., Mackenzie, D.E., Wyborn, D., Oversby, B.S., McPhie, J., and Andrew, A.S., 1994, Regional ${ }^{18} \mathrm{O}$ depletions in igneous rocks from the northern Drummond Basin, Queensland, Australia, and their implications for epithermal gold mineralization: Economic Geology, v. 89, p. 662-673.
Fahley, M.P., 1981, Fluid inclusion study of Tonopah district, Nevada: Golden, Colorado School of Mines, M.S. thesis, 106 p.

Faure, K., Matsuhisa, Y., Metsugi, H., Mizota, C., and Hayashi, S., 2002, The Hishikari Au-Ag epithermal deposit, JapanOxygen and hydrogen isotope evidence in determining the source of paleohydrothermal fluids: Economic Geology, v. 97, p. $481-498$.

Ferguson, C.A., McIntosh, W.C., and Miller, C.F., 2013, Silver Creek caldera-The tectonically dismembered source of the Peach Spring Tuff: Geology, v. 41, p. 3-6.

Ferguson, H.G., 1921, The Mogollon district, New Mexico: U.S. Geological Survey Bulletin 787, 100 p.

Fifarek, R.H., and Gerike, G.N., 1991, Oxidation of hydrothermal sulfides at Round Mountain - Origin and relation to gold mineralization, in Raines, G.L., Lisle, R.E., Schafer, R.W., and Wilkinson, W.H., eds., Proceedings of the Geology and Ore Deposits of the Great Basin Symposium, Reno, April 1990: Geological Society of Nevada, p. 1111-1121.

Fifarek, R.H., Rusk, B.G., and Rye, R.O., 2006, Fluid inclusion evidence for magmatic brine below the Summitville highsulfidation $\mathrm{Cu}-\mathrm{Au}$ deposits, $\mathrm{CO}$, and its potential relation to the brittle-ductile transition and mineralization [abs.]: Geological Society of America Abstracts with Programs, v. 38, p. 348.

Fifarek, R.H., and Rye, R.O., 2005, Stable-isotope geochemistry of the Pierina high-sulfidation $\mathrm{Au}-\mathrm{Ag}$ deposit, Peru—influence of hydrodynamics on $\mathrm{SO}_{4}^{2-}-\mathrm{H}_{2} \mathrm{~S}$ sulfur isotopic exchange in magmatic-steam and steam-heated environments: Chemical Geology, v. 215, p. 253-279.

Filimonova, L.G., and Chugaev, A.V., 2006, Chronology of hydrothermal and magmatic activity in the Dukat gold-silver ore field: Geology of Ore Deposits, v. 48, p. 489-498.

Foley, N.K., and Ayuso, R.A., 1994, Lead isotope compositions as guides to early gold mineralization-The North Amethyst vein system, Creede district, Colorado: Economic Geology, v. 89, p. $1842-1859$.

Foley, N.K., and Ayuso, R.A., 2012, Gold deposits of the Carolina Slate Belt, southeastern United States-Age and origin of the major gold producers: U.S. Geological Survey Open-File Report 2012-1179, 26 p.

Folinsbee, R.E., Kirkland, K., Nekolaichuk, A., and Smejkal, V., 1972, Chinkuashih - A gold pyrite-enargite-barite hydrothermal deposit, Taiwan, in Doe, B.R., and Smith, D.K., eds., Studies in Mineralogy and Precambrian Geology: Geological Society of America Memoir, v. 135, p. 323-336.

Fries, C., 1991, Pachuca-Real del Monte mining district, Hidalgo, in Salas, G.P., ed., Economic Geology of Mexico: Boulder, CO, Geological Society of America, p. 323-326. 
Garagan, T., and MacKinnon, H., 2003, Technical report, Kupol project, Chukotka, A.O., Russian Federation: Prepared for Bema Gold Corporation, http://www.sedar.com, 118 p.

Garcia, J.S., 1991, Geology and mineralisation characteristics of the Mankayan mineral district, Philippines: Geological Survey of Japan Report, v. 277, p. 21-30.

Garwin, Steve, Hall, Robert, and Watanabe, Yasushi, 2005, Tectonic setting, geology, and gold and copper mineralization in Cenozoic magmatic arcs of southeast Asia and the west Pacific: Economic Geology 100th Anniversary Volume, p. 891-930.

Gemmell, J.B., 2007, Hydrothermal alteration associated with the Gosowong epithermal Au-Ag deposit, Halmahera, IndonesiaMineralogy, geochemistry, and exploration implications: Economic Geology, v. 102, p. 893-922.

Gemmell, J.B., Simmons, S.F., and Zantop, H., 1988, The St. Niño silver-lead-zinc vein, Fresnillo district, Zacatecas, MexicoPart I. Structure, vein stratigraphy and mineralogy: Economic Geology, v. 83, p. 1597-1618.

Geyne, A.R., Fries, C., Jr., Segerstrom, K., Black, R.F., and Wilson, I.F., 1963, Geology and mineral deposits of the Pachuca-Real del Monte district, State of Hidalgo, Mexico: Mexico, Consejo de Recursos Naturales no Renovabales Publication 5E, 203 p.

Goldstrand, P.M., and Schmidt, K.W., 2000, Geology, mineralization, and ore controls at the Ken Snyder gold-silver mine, Elko Country, Nevada_-Proceedings of the Geology and Ore Deposits 2000 - The Great Basin and Beyond Symposium, Reno, May 15-18, 2000: Geological Society of Nevada, p. $265-287$.

Goryachev, N.A., and Piranjno, F., 2014, Gold deposits and gold metallogeny of Far East Russia: Ore Geology Reviews, v. 59, p. $123-151$.

Grancea, L., Bailly, L., Leroy, J., Banks, D., Marcoux, E., Milési, J.P., Cuney, M., André, A.S., Istvan, D., and Fabre, C., 2002, Fluid evolution in the Baia Mare epithermal gold/polymetallic district, Inner Carpathians, Romania: Mineralium Deposita, v. 37 , p. $630-647$.

Gray, J.E., and Coolbaugh, M.F., 1994, Geology and geochemistry of Summitville, Colorado-An epithermal acid-sulfate deposit in a volcanic dome: Economic Geology, v. 89, p. 1906-1923.

Hallberg, A., 1994, The Enåsen gold deposit, central Sweden-1. A Palaeoproterozoic high-sulphidation epithermal gold mineralization: Mineralium Deposita, v. 29, p. 150-162.

Hallberg, A., and Fallick, A.E., 1994, The Enåsen gold deposit, central Sweden-2. Light element stable isotope evidence of premetamorphic hydrothermal activity: Mineralium Deposita, v. 29 , p. $163-169$.
Harlan, J.B., Jones, M.L., and Sutopo, B., 2005, Discovery and characterization of the Martabe epithermal gold deposits, North Sumatra, Indonesia, in Rhoden, H.N., Steininger, R.C., and Vikre, P.G., eds., Proceedings of the Window to the World Symposium 2005, Reno, May 2005: Geological Society of Nevada, p. 917-942.

Harvey, B., Myers, S., and Klein, T., 1999, Yanacocha gold district, northern Peru, in Pacific Rim Congress, Bali, Indonesia, 1999, Proceedings: Australasian Institute of Mining and Metallurgy, p. 445-459.

Hayashi, T., 2001, Field stops-Kasuga, Iwato, and Akeshi mines, in Feebry, C.A., Hayashi, T., and Taguchi, S., eds., Epithermal gold mineralization and modern analogues, Kyushu, Japan: Society of Economic Geologists Guidebook Series, v. 34, p. 133-138.

Hayba, D.O., 1997, Environment of ore deposition in the Creede mining district, San Juan mountains, Colorado-Part $\mathrm{V}$. Epithermal mineralization from mixing in the $\mathrm{OH}$ vein: Economic Geology, v. 92, p. 29-44.

Hedenquist, J.W., Arribas, A., and Reynolds, T.J., 1998, Evolution of an intrusion-centered hydrothermal system-Far Southeast-Lepanto porphyry and epithermal $\mathrm{Cu}-\mathrm{Au}$ deposits, Philippines: Economic Geology, v. 93, p. 373-404.

Hedenquist, J.W., Matsuhisa, Y., Izawa, E., White, N.C., Giggenbach, W.F., and Aoki, M., 1994, Geology, geochemistry, and origin of high sulfidation $\mathrm{Cu}-\mathrm{Au}$ mineralization in the Nansatsu district, Japan: Economic Geology, v. 89, p. 1-30.

Heinrich, C.H., and Neubauer, F., 2002, Cu-Au-Pb-Zn-Ag metallogeny of the Alpine-Balkan-Carpathian-Dinaride geodynamic province: Mineralium Deposita, v. 37, p. 533-540.

Henderson, R.D., 2011, Kupol mine, Russian Federation, NI 43-101 Technical Report: Kinross Gold Corporation, 147 p., accessed on May 28, 2014, at http://fb.kinross.com/ media/56569/kupol\%20tr\%20may\%202011.pdf.

Henry, C.D., Elson, H.B., McIntosh, W.C., Heizler, M.T., and Castor, S.B., 1997, Brief duration of hydrothermal activity at Round Mountain, Nevada, determined from ${ }^{40} \mathrm{Ar} /{ }^{39} \mathrm{Ar}$ geochronology: Economic Geology, v. 92, p. 807-826.

Herrera, P.T., Closs, L.G., and Silberman, M.L., 1993, Alteration and geochemical zoning in Bodie Bluff, Bodie mining district, eastern California: Journal of Geochemical Exploration, v. 48, p. 259-275.

Hill, J.M., 1915, Some mining districts in northeastern California and northwestern Nevada: U.S. Geological Survey Bulletin 594, 200 p. 
Holley, E.A., 2012, The Veladero high-sulfidation epithermal Au-Ag deposit, Argentina-Volcanic stratigraphy, alteration, mineralization, and quartz paragenesis: Golden, Colorado School of Mines, Ph.D. thesis, 218 p.

Holley, E.A., Bissig, Thomas, and Monecke, Thomas, 2016, The Veladero high-sulfidation epithermal gold deposit, El Indio-Pascua belt, Argentina - Geochronology of alunite and jarosite: Economic Geology, v. 111, p. 311-330.

Holley, E.A., Bissig, Thomas, and T.J. Reynolds, 2017, Evolution of high-level magmatic-hydrothermal systemsNew insights from ore paragenesis of the Veladero highsulfidation epithermal Au-Ag deposit, El Indio-Pascua belt, Argentina: Economic Geology, v. 112, p. 1747-1771.

Hollister, V.F., and Silberman, M.L., 1995, Silver-gold and polymetallic quartz veins in the Bodie mining district, eastcentral California-Are they related to a porphyry $\mathrm{Cu}-\mathrm{Mo}$ system at depth?: Arizona Geological Society Digest, v. 20, p. 297-305.

Hoschke, T., and Sexton, M., 2005, Geophysical exploration for epithermal gold deposits at Pajingo, North Queensland, Australia: Exploration Geophysics, v. 36, p. 401-406.

Hudson, D.M., 2003, Epithermal alteration and mineralization in the Comstock district, Nevada: Economic Geology, v. 98, p. 367-386.

Hudson, D.M., Castor, S.B., Garside, L.J., and Henry, C.D., 2009, Geology of the Virginia City quadrangle, Washoe, Storey, and Lyon Counties, and Carson City, Nevada: Nevada Bureau of Mines and Geology, Map 165, scale 1:24,000, 37 p.

Izawa, E., and Cunningham, C.G., 1989, Hydrothermal breccia pipes and gold mineralization in the Iwashita orebody, Iwato deposit, Kyushu, Japan: Economic Geology, v. 84, p. 715-724.

Izawa, E., Etoh, J., Honda, M., Motomura, Y., and Sekine, Y., 2001, Hishikari gold mineralization - A case study of the Hosen no. 1 vein hosted by basement Shimanto sedimentary rocks, southern Kyushu, Japan: Society of Economic Geologists Guidebook Series, v. 34, p. 21-30.

Izawa, E., Naito, K., Ibaraki, K., and Suzuki, R., 1993, Mudstones in a hydrothermal eruption crater above the gold-bearing vein system of the Yamada deposit at Hishikari, Japan, in Shikazono, N., Naito, K., and Izawa, E., eds., High Grade Epithermal Gold Mineralization-The Hishikari Deposit: Resource Geology Special Issue, no. 14, p. 85-92.

Izawa, E., Urashima, Y., Ibaraki, K., Suzuki, R., Yokoyama, T., Kawasaki, K., Koga, A., and Taguchi, S., 1990, The Hishikari gold deposit—High grade epithermal veins in Quaternary volcanics of southern Kyushu, Japan: Journal of Geochemical Exploration, v. 36, p. 1-56.
Izawa, E., and Watanabe, K., 2001, Quaternary gold mineralization and its geologic environments in Kyushu, Japan: Society of Economic Geologists Guidebook Series, v. 34, p. 11-15.

Izawa, E., Yoshida, T., Sakai, T., 1981, Fluid inclusion studies on the gold-silver quartz veins at Kushikino, Kagoshima, Japan: Mining Geology Special Issue, no. 10, p. 25-34.

Izawa, E., and Zeng, N., 2001, Kushikino gold mineralization in a Pliocene volcanic region, Kyushu, Japan: Society of Economic Geologists Guidebook Series, v. 34, p. 53-60.

James, R., and Cumming, G.V., 2007, Geology and mineralization of the Chatree epithermal Au-Ag deposit, Phetchabun Province, central Thailand, Proceedings of the International Conference on Geology of Thailand-Towards Sustainable Development and Sufficiency Economy, Bangkok, November 21-22, 2007: Department of Mineral Resources, p. 378-390.

Jankovic, S., 1990, Types of copper deposits related to volcanic environment in the Bor district, Yugoslavia: Geologische Rundschau, v. 79, p. 467-478.

Jankovic, S.R., Jelenkovic, R.J., and Kozelj, D., 2002, The Bor copper and gold deposit: Bor, Serbia, QWERTY, 298 p.

Jannas, R.R., Beane, R.E., Ahler, B.A., and Brosnahan, D.R., 1990, Gold and copper mineralization at the El Indio deposit, Chile: Journal of Geochemical Exploration, v. 36, p. 233-266.

Jannas, R.R., Bowers, T.S., Petersen, U., and Beane, R.E., 1999, High-sulfidation deposit types in the El Indio district, Chile, in Skinner, B.J., ed., Geology and Ore Deposits of the Central Andes: Society of Economic Geologists, Special Publication 7, p. 219-266.

Jelenkovic, Rade, Kozelj, Dejan, and Serafimovski, Todor, 2001, Some genetic aspects of the Bor copper-gold deposit, Serbia: Geologica Macedonica, v. 15-16. p. 1-5.

Jobson, D.H., Boulter, C.A., and Foster, R.P., 1994, Structural controls and genesis of epithermal gold-bearing breccias at Lebong Tandai mine, western Sumatra, Indonesia: Journal of Geochemical Exploration, v. 50, p. 409-428.

John, D.A., du Bray, E.A., Blakely, R.J., Fleck, R.J., Vikre, P.G., Box, S.E., and Moring, B.C., 2012, Miocene magmatism in the Bodie Hills volcanic field, California and Nevada-A long-lived eruptive center in the southern segment of the ancestral Cascades arc: Geosphere, v. 8, no. 1, p. 44-97.

John, D.A., Hofstra, A.H., Fleck, R.J., Brummer, J.E., and Saderholm, E.C., 2003, Geologic setting and genesis of the Mule Canyon low-sulfidation epithermal gold-silver deposit, north-central Nevada: Economic Geology, v. 98, p. 425-463. 
John, D.A., Nash, J.T., Clark, C.W., and Wulftange, W., 1991, Geology, hydrothermal alteration, and mineralization at the Paradise Peak gold-silver-mercury deposit, Nye County, Nevada, in Raines, G.L., Lisle, R.E., Schafer, R.W., and Wilkinson, W.H., eds., Proceedings of the Geology and Ore Deposits of the Great Basin Symposium, Reno, April 1990: Geological Society of Nevada, p. 1020-1050.

John, D.A., Thomason, R.E., and McKee, E.H., 1989, Geology and K-Ar geochronology of the Paradise Peak mine and the relationship of pre-Basin and Range extension to early Miocene precious metal mineralization in west-central Nevada: Economic Geology, v. 84, p. 631-649.

Kamilli, R.J., 1994, The Mogollon mining district—Results from mapping, paragenesis, and fluid-inclusion studies in Carter, L.M.H., Toth, M.I., and Day, W.C., USGS research on mineral resources, 1994 - part A, program and abstracts: U.S. Geological Survey Circular 1103-A, p. 52-53, https://pubs. er.usgs.gov/publication/cir1103A.

Kamilli, R.J., and Ohmoto, H., 1977, Paragenesis, zoning, fluid inclusion, and isotopic studies of the Finlandia vein, Colqui district, Central Peru: Economic Geology, v. 72, p. 950-982.

Kamilli, R.J., and Ratté, J.C., 1995, Geologic studies of the Mogollon mining district, New Mexico-Does a porphyry system lie below?: Arizona Geological Digest 20, p. $455-463$.

Kassem, O. K., Al Bassam, A., and Zaidi, F., 2013, Structural analysis for metavolcanics and their metapyroclastics at gold deposit of the Mahd Ad Dahab area, Arabian Shield, Saudi Arabia: Geology of Ore Deposits, v. 55, p. 482-493.

Kesler, S.E., Campbell, I.H., Smith, C.H., Hall, C.M., and Allen, C.M., 2005, Age of the Pueblo Viejo gold silver deposit and its significance to models of high-sulfidation epithermal mineralization: Economic Geology, v. 100, p. 253-272.

Kesler, S.E., Russell, Norman, and McCurdy, Karr, 2003, Tracemetal content of the Pueblo Viejo precious-metal deposits and their relation to other high-sulfidation epithermal systems: Mineralium Deposita, v. 38, p. 668-682.

Kesler, S.E., Russell, N., Seaward, M., Rivera, J., McCurdy, K., Cumming, G.L., and Sutter, J.F., 1981, Geology and geochemistry of sulfide mineralization underlying the Pueblo Viejo gold-silver oxide deposit, Dominican Republic: Economic Geology, v. 76, p. 1096-1117.

Kettler, R.M., Rye, R.O., Kesler, S.E., Meyers, P.A., Polanco, J., and Russell, N., 1992, Gold deposition by sulfidation of ferrous Fe in the lacustrine sediments of the Pueblo Viejo district (Dominican Republic) - The effect of Fe-C-S diagenesis on later hydrothermal mineralization in a maardiatreme complex: Chemical Geology, v. 99, p. 29-50.
Kilias, S.P., Naden, J., Cheliotis, I., Shepherd, T.J., Constandinidou, H., Crossing, J., and Simos, I., 2001, Epithermal gold mineralization in the active Aegean volcanic arc-The Profitis ilias deposit, Milos Island, Greece: Mineralium Deposita, v. 36, p. 32-44.

Kirk, J.D., Ruiz, Joaquin, Kesler, S.E., Simon, Adam, and Muntean, J.L., 2014, Re-Os age of the Pueblo Viejo epithermal deposit, Dominican Republic: Economic Geology, v. 109, p. 503-512.

Koděra, P., Lexa, J., Fallick, A.E., Wälle, M., and Biroň, A., 2014, Hydrothermal fluids in epithermal and porphyry Au deposits in the Central Slovakia Volcanic Field: Geological Society, London, Special Publications, v. 402, SP402-5.

Koděra, P., Lexa, J., Rankin, A.H., and Fallick, A.E., 2005, Epithermal gold veins in a caldera setting-Banská Hodruša, Slovoki: Mineralium Deposita, v. 39, p. 921-943.

Koichiro, Syafrizal, Watanabe, Yasushi, Imai, Akira, and Motomura, Yoshinobu, 2005, Alteration and gold mineralization of the Ciurug vein, Pongkor Au-Ag deposit, Indonesia, in Mao, Jingwen, Bierlein, F.P., eds., Mineral Deposit ResearchMeeting the Global Challenge: Berlin Heidelberg, SpringerVerlag, p. 995-998.

Konstantinov, M.M., Kalinin, A.I., Natalenko, V.E., Struzhkov, S.F., and Dvurechenskaya, S.S., 1995, The Dukat gold-silver deposit, Russia: Geology of Ore Deposits, v. 37, p. 274-290.

Kouzmanov, K., Ramboz, C., Bailly, L., and Bogdanov, K., 2004, Genesis of high-sulfidation vinciennite-bearing $\mathrm{Cu}-\mathrm{As}-\mathrm{Sn}(\mathrm{Au})$ assemblage from the Radka epithermal copper deposit, Bulgaria-Evidence from mineralogy and infrared microthermometry of enargite: Canadian Mineralogist, v. 42, p. $1501-1521$.

Kravtsova, R.G., Zakharov, M.N., and Korkina, O.I., 2005, Rare-earth elements in metasomatites and ores of the Dukat gold-silver deposit (northeastern Russia): Russian Geology and Geophysics, v. 46, p. 603-616.

Lambert, R.J., Valliant, W.W., and Altman, K.A., 2014, Technical report on the Mesquite mine, Imperial County, California, U.S.A.: Toronto, New Gold Inc., 120 p., accessed August 26, 2015, at http://www.newgold.com/files/documents_properties/ mesquite/2014-02-28_MSQ_NI-43-101-Tech-Rept.pdf.

Lang, B., Steinitz, G., Sawkins, F.J., and Simmons, S.F., 1988, K-Ar age studies in the Fresnillo Silver district, Zacatecas: Economic Geology, v. 83, p. 1642-1646.

Lang, B., Edelstein, O., Steinitz, G., Kovacs, M., and Halga, S., 1994, Ar-Ar dating of adularia - A tool in understanding genetic relations between volcanism and mineralization, Baia Mare area (Gutii Mountains), northwestern Romania: Economic Geology, v. 89 , p. $174-180$. 
Leavitt, E.D., and Arehart, G.B., 2005, Alteration, geochemistry, and paragenesis of the Midas epithermal gold-silver deposit, Elko County, Nevada: Proceedings of the Window to the World Symposium 2005, Reno, May 2005: Geological Society of Nevada, p. 563-627.

Leavitt, E.D., Spell, T.L., Goldstrand, P.M., and Arehart, G.B., 2004, Geochronology of the Midas low-sulfidation epithermal gold-silver deposit, Elko County, Nevada: Economic Geology, v. 99, p. 1665-1686.

Lehrman, N.J., 1986, The McLaughlin mine, Napa and Yolo Counties, California, in Tingley, J.V., and Bonham Jr., H.F., eds., Precious-metal mineralization in hot-spring systems, Nevada-California. Nevada Bureau of Mines and Geology Report 41, p. 85-89.

Lerouge, C., Bailly, L., Béchu, E., Fléhoc, C., Genna, A., Lescuyer, J.L., Stein, G., Gillot, P.Y., and Kozelj, D., 2005, Age and origin of advanced argillic alteration at the Bor Cu-Au deposit, Serbia, in Mao, Jingwen, Bierlein, F.P., eds., Mineral Deposit Research-Meeting the Global Challenge: Berlin Heidelberg, Springer-Verlag, p. 541-544.

Lewis, R.W., and Wilson, G.I., 1990, Misima gold deposit: Australasian Institute of Mining and Metallurgy Monograph 14, p. 1741-1745.

Lexa, J., 1999, Outline of the Alpine geology and metallogeny of the Carpatho-Pannonian region: Society of Economic Geologists Guidebook Series, v. 31, p. 65-108.

Lexa, J., Štohl, J., and Koneečný, V., 1999, Banksá Štiavnica ore district—Relationship between metallogenic processes and the geological evolution of a stratovolcano: Mineralium Deposita, v. 34, p. 639-665.

Lhotka, P.G., 2010, Discovery history of the Navidad silver deposits, Chubat, Argentina - One thousand years in the waiting: Society of Economic Geologists Special Publication 15, p. 181-201.

Lindgren, Waldemar, 1915, Geology and mineral deposits of the National mining district, Nevada: U.S. Geological Survey Bulletin 601, 58 p., https://pubs.er.usgs.gov/ publication/b601.

Lindgren, Waldemar, and Creveling, J.G., 1928, The ores of Potosi, Bolivia: Economic Geology, v. 23, p. 233-262.

Long, K.R., DeYoung, J.H., Jr., and Ludington, S.D., 1998, Database of significant deposits of gold, silver, copper, lead, and zinc in the United States: U.S. Geological Survey Open-File Report 98-206 A, B, 33 p., https://pubs.usgs.gov/ of/1998/0206a-b/.
Longo, A.A., 2000, The San Jose-Carachugo-Chaquicocha gold trend, Yanacocha district, northern Perú, in Cluer, J.K., Price, J.G., Struhsacker, E.M., Hardyman, R.F., and Morris, C.L., eds., Proceedings of the Geology and Ore Deposits 2000-The Great Basin and Beyond Symposium, Reno, May 15-18, 2000: Geological Society of Nevada, p. 201-220.

Longo, A.A., 2005, Evolution of volcanism and hydrothermal activity in the Yanacocha mining district, northern Perú: Corvallis, Oregon State University, Ph.D. dissertation, 469 p.

Longo, A.A., Dilles, J.H., Grunder, A.L., and Duncan, R., 2010, Evolution of calc-alkaline volcanism and associated hydrothermal gold deposits at Yanacocha, Peru: Economic Geology, v. 105, p. 1191-1241.

Longo, A.A., and Teal, L., 2005, A summary of the volcanic stratigraphy and the geochronology of magmatism and hydrothermal activity in the Yanacocha gold district, northern Peru, in Rhoden, H.N., Steininger, R.C., and Vikre, P.G., eds., Proceedings of the Window to the World Symposium 2005, Reno, May 2005: Geological Society of Nevada, p. 797-808.

Looby, E.L., 2015, The timing and genesis of the Blackwater gold-silver deposit, central British Columbia-Constraints from geology, geochronology, and stable isotopes: Vancouver, University of British Columbia, M.S. thesis, 172 p.

Losada-Calderón, A.J., McBride, S.L., and Bloom, M.S., 1994, The geology and ${ }^{40} \mathrm{Ar} /{ }^{39} \mathrm{Ar}$ geochronology of magmatic activity and related mineralization in the Nevados del Famatina mining district, La Rioja province, Argentina: Journal of South American Earth Sciences, v. 7, p. 9-24.

Losada-Calderón, A.J., and McPhail, D.C., 1996, Porphyry and high sulfidation epithermal mineralisation in the Nevados del Famatina mining district, Argentina: Society of Economic Geologists Special Publication 5, p. 91-118.

M3 Engineering \& Technology Corporation, 2011, Corani Project: Form NI 43-101 Technical Report, 291 p., accessed November 18, 2014, at http://www.bearcreekmining.com/s/corani. asp?ReportID=619755.

Macdonald, A.J., Kreczmer, M.J., and Kesler, S.E., 1986, Vein, manto and chimney mineralization at the Fresnillo silver-leadzinc mine, Mexico: Canadian Journal of Earth Sciences, v. 23, p. 1603-1614.

Maddry, J.W., and Kilbey, T.R., 1995, Geology of the Haile gold mine: Society of Economic Geologists Guidebook Series, v. 24, p. $147-172$.

Mallette, P.M., Rojas, R.E., and Gutierrez, A.R., 2004, Geology, mineralization, and genesis of the La Quiana gold deposit, Yanacocha district, northern Peru: Society of Economic Geologists Special Publication 11, p. 301-312. 
Mancano, D.P., and Campbell, A.R., 1995, Microthermometry of enargite-hosted fluid inclusions from the Lepanto, Philippines high-sulfidation $\mathrm{Cu}-\mathrm{Au}$ deposit: Geochimica et Cosmochimica Acta, v. 59, p. 3909-3916.

Mango, Helen, Arehart, Greg, Oreskes, Naomi, and Zantop, Half, 2014, Origin of epithermal Ag-Au-Cu-Pb-Zn mineralization in Guanajuato, Mexico: Mineralium Deposita, v. 49, p. 119-143.

Mango, H.N., Zantop, H., and Oreskes, N., 1991, A fluid inclusion and isotope study of the Rayas $\mathrm{Ag}-\mathrm{Au}-\mathrm{Cu}-\mathrm{Pb}-\mathrm{Zn}$ mine, Guanajuato, Mexico: Economic Geology, v. 86, p. 1554-1561.

Manske, S.L., 1991, Epithermal gold in gneissic rocks of the Mesquite district, Imperial County, California: Stanford University, Ph.D. dissertation, 347 p.

Manske, S.L., Hedenquist, J.W., O'Connor, G., Tamas, C., Cauuet, B., Leary, S., and Minut, A., 2006, Roşia Montană, RomaniaEurope's largest gold deposit: Society of Economic Geologists Newsletter, no. 64, p. 1, 9-15.

Marcoux, E., and Milési, J.-P., 1994, Epithermal gold deposits in West Java, Indonesia — Geology, age and crustal source: Journal of Geochemical Exploration, v. 50, p. 393-408.

Marma, J.C., and Vance, R.B., 2011, Importance of cymoid loops and implications for exploration and development of epithermal gold-silver veins in the Gold Circle district, Midas, Nevada, in Steininger, R., and Pennell, B., eds., Proceedings of the Great Basin Evolution and Metallogeny Symposium, Reno, 2010: Geological Society of Nevada, p. 777-793.

Matsuhisa, Y., Morihsita, Y., and Sato, Y., 1985, Oxygen and carbon isotope variations in gold-bearing veins in the Kushikino mining area, southern Kyushu, Japan: Economic Geology, v. 80 , p. $283-293$.

Mauk, J.L., Hall, C.M., Chesley, J.T., and Barra, F., 2011, Punctuated evolution of a large epithermal province-The Hauraki Goldfield, New Zealand: Economic Geology, v. 106, p. 921-943.

Mauk, J.L., and Simpson, M.P., 2007, Geochemistry and stable isotope composition of altered rocks at the Golden Cross epithermal Au-Ag deposit, New Zealand: Economic Geology, v. 102 , p. $841-871$.

McKee, E.H., Dreier, J.E., and Noble, D.C., 1992, Early Miocene hydrothermal activity at Pachuca-Real del Monte, Mexico-An example of space-time association of volcanism and epithermal Ag-Au vein mineralization: Economic Geology, v. 87, p. 1635-1637.

Merchant, R.J., 1986, Mineralisation in the Thames district, Coromandel: Berlin, Gebruder Borntraeger Monograph Series on Mineral Deposits 26, p. 165-183.
Micklethwaite, Steven, 2009, Mechanisms of faulting and permeability enhancement during epithermal mineralizationCracow goldfield, Australia: Journal of Structural Geology, v. 31, p. 288-300.

Milési, J.P., Marcoux, E., Sitorus, T., Simandjuntak, M., Leroy, J., and Bailly, L., 2009, Pongkor (west Java, Indonesia) - A Pliocene supergene-enriched epithermal Au-Ag-(Mn) deposit: Mineralium Deposita, v. 34, p. 131-149.

Mobley, R.M., Yogodzinski, G.M., Creaser, R.A., and Berry, J.M., 2014, Geologic history and timing of mineralization at the Haile gold mine, South Carolina: Economic Geology, v. 109, p. 1863-1881.

Moncada, D., Mutchler, S., Nieto, A., Reynolds, T.J., Rimstidt, J.D., and Bodnar, R.J., 2012, Mineral textures and fluid inclusion petrography of the epithermal Ag-Au deposits at Guanajuato, Mexico-Application to exploration: Journal of Geochemical Exploration, v. 114, p. 20-35.

Montgomery, A.T., 2012, Metallogenetic controls on Miocene high-sulphidation epithermal gold mineralization, Alto Chicama district, La Libertad, northern Peru: Kingston, Ontario, Queens University, Ph.D. dissertation, 455 p.

Morishita, Y., and Nakano, T., 2008, Role of basement in epithermal deposits - The Kushikino and Hishikari gold deposits, southwestern Japan: Ore Geology Reviews, v. 34, p. 597-609.

Moritz, R., Jaquat, S., Chambefort, I., Fontignie, D., Petrunov, R., Georgieva, S., and von Quadt, A., 2003, Controls on ore formation at the high-sulfidation $\mathrm{Au}-\mathrm{Cu}$ Chelopech deposit, Bulgaria - Evidence from infrared fluid inclusion microthermometry of energite and isotopic systematics of barite, in Eliopoulos, D., ed., Mineral exploration and sustainable development: Proceedings of the Seventh Biennial SGA Meeting, Rotterdam, Millpress, v. 1, p. 1209-1212.

Moyle, A.J., Bischoff, K., Alexander, K.R., and Hoogvliet, H., 1996, Mt. Muro gold deposit, Indonesia: Australian Mineral Foundation, Porphyry Related Copper and Gold Deposits of the Asia Pacific Region, 12-August 13, 1996, Cairns, Australia, Conference Proceedings, p. 7.1-7.9.

Muntean, J.L., Kesler, S.E., Russell, N., and Polanco, J., 1990, Evolution of the Monte Negro acid-sulfate Au-Ag deposit, Pueblo Viejo, Dominican Republic - Important factors in grade control: Economic Geology, v. 85, p. 1738-1758.

Nash, J.T., and Trudel, W.S., 1996, Bulk mineable gold ore at the Sleeper mine, Nevada - importance of extensional faults, breccia, framboids, and oxidation, in Coyner, A.R., and Fahey, P.L., eds., Proceedings of the Geology and Ore Deposits of the American Cordillera Symposium, Reno, April 1995: Geological Society of Nevada, p. 235-256. 
Nash, J.T., Utterback, W.C., and Saunders, J.A., 1991, Geology and geochemistry of the Sleeper gold deposits, Humboldt County, Nevada, an interim report, in Raines, G.L., Lisle, R.E., Schafer, R.W., and Wilkinson, W.H., eds., Proceedings of the Geology and Ore Deposits of the Great Basin Symposium, Reno, April 1990: Geological Society of Nevada, p. 1063-1084.

Nash, J.T., Utterback, W.C., and Trudel, W.C., 1995, Geology and geochemistry of Tertiary volcanic host rocks, Sleeper gold-silver deposit, Humboldt County, Nevada: U.S. Geological Survey Bulletin 2090, 63 p., https://pubs.usgs. gov/bul/2090/report.pdf.

Nelson, C.E., 2000, Volcanic domes and gold mineralization in the Pueblo Viejo district, Dominican Republic: Mineralium Deposita, v. 35, p. 511-525.

Noble, D.C., and McKee, E.H., 1999, The Miocene metallogenic belt of central and northern Peru: Society of Economic Geologists Special Publication 7, p. 155-193.

Nolan, T.B., 1935, The underground geology of the Tonopah mining district, Nevada: Nevada Bureau of Mines and Geology Bulletin 29, 49 p.

Olberg, D.J., 2001, Ore shoot targeting in the Gosowong vein zone, Halmahera, Indonesia: Hobart, University of Tasmania, M.S. thesis, 140 p., accessed July 6, 2015 at http://eprints. utas.edu.au/11602/2/Whole-Olberg,_2001_thesis.pdf.

O’Neil, J.R., and Silberman, M.L., 1974, Stable isotope relations in epithermal $\mathrm{Au}-\mathrm{Ag}$ deposits: Economic Geology, v. 69 , p. $902-909$.

O’Neil, J.R., Silberman, M.L., Fabbi, B.P., and Chesterman, C.W., 1973, Stable isotope and chemical relations during mineralization in the Bodie mining district, Mono County, Nevada: Economic Geology, v. 68, p. 765-784.

Osborne, M.A., 1991, Epithermal mineralization at Aurora, Nevada, in Raines, G.L., Lisle, R.E., Schafer, R.W., and Wilkinson, W.H., eds., Proceedings of the Geology and Ore Deposits of the Great Basin Symposium, Reno, April 1990: Geological Society of Nevada, p. 1097-1110.

Oviedo, L., Aguilar, A., Grez, E., Fuster, N., Ribba, L., Tschischow, N., and Zuccone, A., 1991a, General geology of La Coipa precious metal deposit, Atacama, Chile, in Sillitoe, R.H., Camus, F., Saric, N., Bonham, H.F., and Garside, L.J., (leaders), Gold/silver Deposits of Chile, April 13-24, 1991, Itinerary and Guidebook, Association of Exploration Geochemists/Society of Economic Geologists Field Conference, $32 \mathrm{p}$.

Parks, J., and Robertson, I.D.M., 2003, Pajingo epithermal gold deposits, NE Queensland: Cooperative Research Centre for Landscapes, Environments and Mineral Exploration Report, $4 \mathrm{p}$.
Pearson, M.F., Clark, K.F., Porter, E.W., and Gonzalez S., O. 1988, Mineralogy, fluid characteristics and silver distribution at Real de Angeles, Zacatecas: Economic Geology, v. 83, p. 1737-1759.

Petersen, Ulrich, Noble, D.C., Arenas, M.J., and Goodell, P.C., 1977, Geology of the Julcani mining district, Peru: Economic Geology, v. 72, p. 931-949.

Phillipson, S.E., and Romberger, S.B., 2004, Volcanic stratigraphy, structural controls, and mineralization in the San Cristobal Ag-Zn-Pb deposit, southern Bolivia: Journal of South American Earth Sciences, v. 16, p. 667-683.

Plumlee, G.S., 1994, Fluid chemistry evolution and mineral deposition in the main stage Creede epithermal system: Economic Geology, v. 89, p. 1860-1882.

Plumlee, G.S., and Whitehouse-Veaux, P.H., 1994, Mineralogy, paragenesis and mineral zoning of the Bulldog Mountain vein system, Creede district, Colorado: Economic Geology, v. 89, p. $1883-1905$.

Ponce S., B.F., and Clark, K.F., 1988, The Zacatecas mining district - A Tertiary caldera complex associated with precious and base metal mineralization: Economic Geology, v. 83, p. $1668-1682$.

Pudack, C., Halter, W.E., Heinrich, C.A., and Pettke, T., 2009, Evolution of magmatic vapor to gold-rich epithermal liquidThe porphyry to epithermal transition at Nevados de Famatina, northwest Argentina: Economic Geology, v. 104, p. 449-477.

Querol S., F., Lowther, G.K., and Navarro, E., 1991, Mineral deposits of the Guanajuato mining district, Guanajuato, in Salas, G.P., ed., Economic Geology, Mexico: Boulder, Colo., Geological Society of America, Geology of North America, v. P-3, p. 403-414.

Rainbow, Amelia, 2009, Genesis and evolution of the Pierina high-sulphidation epithermal Au-Ag Deposit, Ancash, Perú: Toronto, Queens University, Ph.D. dissertation, 292 p.

Rainbow, A., Clark, A.H., Kyser, T.K., Gaboury, F., and Hodgson, C.J., 2005, The Pierina epithermal Au-Ag deposit, Ancash, Peru-Paragenetic relationships, alunite textures, and stable-isotope geochemistry: Chemical Geology, v. 215, p. 235-252.

Randall R., J.A., Saldaña A., E., and Clark, K.F., 1994, Exploration in a volcano-plutonic center at Guanajuato, Mexico: Economic Geology, v. 89, p. 1722-1751.

Ransome, F.L., 1907, The association of alunite with gold in the Goldfield district, Nevada: Economic Geology, v. 2, p. 667-692.

Ransome, F.L., 1923, Geology of the Oatman gold district, Arizona-A preliminary report: U.S. Geological Survey Bulletin 743, 58 p., https://pubs.usgs.gov/bul/0743/report.pdf. 
Ransome, F.L., Garrey, G.H., and Emmons, W.H., 1910, Geology and ore deposits of the Bullfrog district: U.S. Geological Survey Bulletin 407, 130 p., https://pubs.er.usgs.gov/publication/b407.

Rice, C.M., Steele, G.B., Barfod, D.N., Boyce, D.N., and Pringle, M.S., 2005, Duration of magmatic, hydrothermal, and supergene activity at Cerro Rico de Potosi, Bolivia: Economic Geology, v. 100, p. 1647-1656.

Robbins, C.H., 2000, Geology of the El Peñon gold-silver deposit, northern Chile, in Cluer, J.K., Price, J.G., Struhsacker, E.M., Hardyman, R.F. and Morris, C.L., eds., Proceedings of the Geology and Ore Deposits 2000-The Great Basin and Beyond Symposium, Reno, May 15-18, 2000: Geological Society of Nevada, p. 249-264.

Robinson, R.W., and Norman, D.I., 1984, Mineralogy and fluid inclusion study of the southern Amethyst vein system, Creede mining district, Colorado: Economic Geology, v. 79, p. 439-447.

Rodionov, S.M., Fredericksen, R.S., and Berdnikov, N.V., 2005, The Kuranakh epithermal gold deposit, East Russia, in Mao, Jingwen, Bierlein, F.P., eds., Mineral Deposit Research—Meeting the Global Challenge: Berlin Heidelberg, SpringerVerlag, p. 1053-1056.

Rodionov, S.M., Fredericksen, R.S., Berdnikov, N.V., and Yakubchuk, A.S., 2014, The Kuranakh epithermal gold deposit, Aldan Shield, East Russia: Ore Geology Reviews, v. 59, p. 55-65.

Rodriguez, C., and Warden, A.J., 1993, Overview of some Colombian gold deposits and their development potential: Mineralium Deposita, v. 28, p. 47-57.

Rossetti, P., and Colombo, F., 1999, Adularia-sericite gold deposits of Marmato (Caldas, Colombia) - Field and petrographical data, in McCaffrey, K.J.W., Lonergan, L., and Wilkinson, J.J., eds., Fractures, fluid flow and mineralization: Geological Society of London Special Publication 155, p. 167-182.

Ruggieri, G., Lattanzi, P., Luxoro, S.S., Dessi, R., Benvenuti, M., and Tanelli, G., 1997, Geology, mineralogy, and fluid inclusion data of the Furtei high-sulfidation gold deposit, Sardinia, Italy: Economic Geology, v. 92, p. 1-19.

Russell, N., and Kesler, S.E., 1991, Geology of the maar-diatreme complex hosting precious metal mineralization at Pueblo Viejo, Dominican Republic: Geological Society of America Special Paper 262, p. 203-216.

Rye, R.O., and Alpers, C.N., 1997, The stable isotope geochemistry of jarosite: U.S. Geological Survey Open-File Report 97-88, 28 p., https://pubs.er.usgs.gov/publication/ ofr9788.

Rye, R.O., Bethke, P.M., and Wasserman, M.D., 1992, The stable isotope geochemistry of acid-sulfate alteration: Economic Geology, v. 87, p. 225-262.
Rye, R.O., Hall, W.E., Cunningham, C.G., Czamanske, G.K., Afifi, A.M., and Stacey, J.S., 1983, Preliminary mineralogic, fluid inclusion, and stable isotope study of the Mahd adh Dhahab gold mine, Kingdom of Saudi Arabia: U.S. Geological Survey Open-File Report 83-291, p. 26.

Rytuba, J.J., Arribas, A., Jr., Cunningham, C.G., McKee, E.H., Podwysocki, M.H., Smith, J.G., Kelly, W.C., and Arribas, A., 1990, Mineralized and unmineralized calderas in Spain; Part II, Evolution of the Rodalquilar caldera complex and associated gold-alunite deposits: Mineralium Deposita, v. 25, p. S29-S35.

Sajona, F.G., Izawa, E., Motomura, Y., Imai, A., Sakakibara, H., and Watanabe, K., 2002, Victoria carbonate-base metal gold deposit and its significance in the Mankayan mineral district, Luzon, Philippines: Resource Geology, v. 52, p. 315-328.

Salam, A., Zaw, K., Meffre, S., McPhie, J., and Lai, C.-K., 2014, Geochemistry and geochronology of the Chatree epithermal gold-silver deposit - Implications for the tectonic setting of the Loei Fold Belt, central Thailand: Gondwana Research, v. 26, p. 198-217.

Sander, M.V., 1991, The Tonopah and Divide districts, Nye and Esmeralda Counties, Nevada, in Buffa, R.H., and Coyner, A.R., eds., Geology and Ore Deposits of the Great Basin: Geological Society of Nevada, Field Trip Guidebook Compendium, v. 2, p. 789-796.

Sander, M.V., and Einaudi, M., 1990, Epithermal deposition of gold during transition from propylitic to potassic alteration at Round Mountain: Economic Geology, v. 85, p. 285-311.

Sanematsu, Kenzo, Duncan, Robert, Imai, Akira, and Watanabe, Koichiro, 2005, Geochronological constraints using ${ }^{40} \mathrm{Ar} /{ }^{39} \mathrm{Ar}$ dating on the mineralization of the Hishikari epithermal gold deposit, Japan: Resource Geology, v. 55, p. 249-266.

Sanematsu, K., Watanabe, K., Duncan, R.A., and Izawa, E., 2006, The history of vein formation determined by ${ }^{40} \mathrm{Ar}{ }^{\beta 9} \mathrm{Ar}$ dating of adularia in the Hosen-1 vein at the Hishikari epithermal gold deposit, Japan: Economic Geology, v. 101, p. 685-698.

Sänger-von Oepen, P., Friedrich, G., and Vogt, J.H., 1989, Fluid evolution, wallrock alteration and ore mineralisation associated with the Rodalquilar epithermal gold deposit in southeast Spain: Mineralium Deposita, v. 24, p. 235-243.

Sanmiguel, O.G.B., 1998, Geology, hydrothermal alteration, paragenetic sequence and fluid inclusion analysis of La Maruja level, Marmato district, Caldas Department, Colombia: Fort Collins, Colorado State University, M.S. thesis, 332 p.

Saunders, F.T., 2000, Geology of the Tonopah mining district, Nye/Esmeralda Counties, Nevada: Geological Society of Nevada, Field Trip Guidebook 10, p. 123-166.

Saunders, J.A., 1990, A colloidal transport of gold and silica in epithermal precious-metal systems; evidence from Sleeper Deposit, Nevada: Geology, v. 18, p. 757-760. 
Saunders, J.A., 1994, Silica and gold textures in bonanza ores of the Sleeper deposit, Humboldt County, Nevada - Evidence for colloids and implications for epithermal ore-forming processes: Economic Geology, v. 89, p. 628-638.

Saunders, J.A., and Schoenly, P.A., 1995, Boiling, colloid nucleation and aggregation, and the genesis of bonanza $\mathrm{Au}-\mathrm{Ag}$ ores of the Sleeper deposit, Nevada: Mineralium Deposita, v. 30, p. 199-210.

Savva, N.E., Pal'yanova, G.A., and Byankin, M.A., 2012, The problem of genesis of gold and silver sulfides and selenides in the Kupol deposit, Chukotka, Russia: Russian Geology and Geophysics, v. 53, p. 457-466.

Sawkins, F.J., O’Neil, J.R., and Thompson, J.M., 1979, Fluid inclusion and geochemical studies of vein gold deposits, Baguio district, Philippines: Economic Geology, v. 74, p. 1420-1434.

Schalamuk, I.B., Zubia, M., Genini, A., and Fernandez, R.R., 1997, Jurassic epithermal Au-Ag deposits of Patagonia, Argentina: Ore Geology Reviews, v. 12, p. 173-186.

Seki, Y., 1993, Geologic setting of the Takatama gold deposit, Japan-An example of caldera-related epithermal gold mineralization: Resource Geology Special Issue, no. 14, p. 123-136.

Sekine, R., Izawa, E., and Watanabe, K., 2002, Timing of fracture formation and duration of mineralization at the Hishikari deposit, southern Kyushu, Japan: Resource Geology, v. 54, p. $395-404$.

Sellepack, S.M., 1997, The geology and geochemistry of the El Sauzal gold prospect, southwest Chihuahua, Mexico: El Paso, University of Texas at El Paso, M.S. thesis, 89 p.

Shannon, J.M., and Stoker, P.T., 2013, Misima gold-copper project, Milne Bay Province, Papua New Guinea: Technical report prepared by AMC Mining Consultants for WCB Resources Limited, 158 p., accessed August 22, 2015, at http:// www.wcbresources.com/sites/default/files/reports/713006 WCB_Resources_Misima_Project_Technical_Report_FINAL_ SEDAR.pdf.

Sharpe, R., Riveros, C., and Scavuzzo, V., 2002, Stratigraphy of the Chon Aike Formation ignimbrite sequence at Cerro Vanguardia Au-Ag epithermal vein district [abs.]: Congreso Geológico Argentino, 15th, Argentina, Actas, article no. 232, 6 p. [CD-ROM]

Sherlock, R.L., 1996, Hydrothermal alteration of volcanic rocks at the McLaughlin gold deposit, northern California: Canadian Journal of Earth Sciences, v. 33, p. 493-508.

Sherlock, R.L., 2005, The relationship between the McLaughlin gold-mercury deposit and active hydrothermal systems in the Geysers-Clear Lake area, northern Coast Ranges, California: Ore Geology Reviews, v. 26, p. 349-382.
Sherlock, R.L., Tosdal, R.M., Lehrman, N.J., Graney, J.R., Losh, S., Jowett, E.C., and Kesler, S.E., 1995, Origin of the McLaughlin mine sheeted vein complex-Metal zoning, fluid inclusion and isotopic evidence: Economic Geology, v. 90, p. 2156-2181.

Shikazono, N., and Nagayama, T., 1993, Origin and depositional mechanism of the Hishikari gold-quartz-adularia mineralization: Resource Geology Special Issue, no. 14, p. 47-56.

Shikazono, Naotatsu, and Takahashi, Hiroyuki, 2010, Compositional variation of hydrothermally altered volcanic rocks in Hishikari gold epithermal system-A useful geochemical indicator of gold-silver epithermal mineralization: Resource Geology, v. 60, p. 117-128.

Sidorov, A.A., Belyi, V.F., Volkov, A.V., Kravtsov, V.S., and Prokof'ev, V.Y., 2007, Geology and formation conditions of the unique gold-silver deposit in Chukotka: Doklady Earth Sciences, v. 412, no. 1, p. 29-34.

Sidorov, A.A., Volkov, A.V., Belyi, V.F., Alekseev, V.Yu., and Kolova, E.E., 2009, The gold-silver Okhotsk-Chukotka volcanic belt: Geology of Ore Deposits, v. 51, p. 441-455.

Silberman, M.L., Chesterman, C.W., Kleinhampl, F.J., and Gray, C.H., Jr., 1972, K-Ar ages of volcanic rocks and goldbearing quartz-adularia veins in the Bodie mining district, Mono County, California: Economic Geology, v. 67, p. 597-603.

Sillitoe, R.H., 2000, Exploration and discovery of base- and precious-metal deposits in the Circum-Pacific region-A late 1990s update: Resource Geology Special Issue, no. 21, 65 p.

Sillitoe, R.H., 2008, Major gold deposits and belts of the North and South American Cordillera - Distribution, tectonomagmatic settings, and metallogenic considerations: Economic Geology, v. 103 , p. $663-687$.

Sillitoe, R.H., Cooper, C., Sale, M.J., Soechiting, W., Echavarria, D., and Gallardo, J.L., 2002, Discovery and geology of the Esquel low-sulfidation epithermal gold deposit, Patagonia, Argentina: Society of Economic Geologists Special Publication 9, p. 227-240.

Sillitoe, R.H., Hall, D.J., Redwood, S.D., and Waddell, A.H., 2006, Pueblo Viejo high-sulfidation epithermal gold-silver deposit, Dominican Republic: a new model of formation beneath barren limestone cover: Economic Geology, v. 101, p. 1427-1435.

Sillitoe, R.H., and Hedenquist, J.W., 2003, Linkages between volcanotectonic settings, ore fluid compositions, and epithermal precious metal deposits: Society of Economic Geologists Special Publication 10, p. 315-343.

Sillitoe, R.H., and Lorson, R.C., 1994, Epithermal gold-silvermercury deposits at Paradise Peak, Nevada - Ore controls, porphyry gold association, detachment faulting, and supergene oxidation: Economic Geology, v. 89, p. 1228-1248. 
Sillitoe, R.H., McKee, E.H., and Vila, T., 1991, Reconnaissance K-Ar geochronology of the Maricunga belt, northern Chile: Economic Geology, v. 86, p. 1261-1270.

Sillitoe, R.H., Steele, G.B., Thompson, J.F.H., and Lang, J.R., 1998, Advanced argillic lithocaps in the Bolivian tin-silver belt: Mineralium Deposita, v. 33, p. 539-546.

Simmons, S.F., 1991, Hydrologic implications of alteration and fluid inclusion studies in the Fresnillo District, MexicoEvidence for a brine reservoir and a descending water table during the formation of hydrothermal $\mathrm{Ag}-\mathrm{Pb}-\mathrm{Zn}$ orebodies: Economic Geology, v. 86, p. 1579-1601.

Simmons, S.F., Arehart, G., Simpson, M.P., and Mauk, J.L., 2000, Origin of massive calcite veins in the Golden Cross, lowsulfidation epithermal Au-Ag deposit, New Zealand: Economic Geology, v. 95, p. 99-113.

Simmons, S.F., and Browne, P.R.L., 1990, Mineralogic, alteration and fluid inclusion studies of epithermal gold-bearing veins at the Mt. Muro prospect, Central Kalimantan (Borneo), Indonesia: Journal Geochemical Exploration, v. 35, p. 63-104.

Simmons, S.F., Gemmell, J.B., and Sawkins, F.J., 1988, The Santo Nino silver-lead-zinc vein, Fresnillo district, Zacatecas - Part II, Physical and chemical nature of ore forming solutions: Economic Geology, v. 83, p. 1619-1641.

Simpson, M.P., and Mauk, J.L., 2007, The Favona epithermal gold-silver deposit, Waihi, New Zealand: Economic Geology, v. 102 , p. $817-839$.

Simpson, M.P., Mauk, J.L., and Simmons, S.F., 2001, Hydrothermal alteration and paleohydrology of the Golden Cross epithermal deposit, Waihi, New Zealand: Economic Geology, v. 96, p. 773-796.

Sims, John, 2015, Kupol mine and Dvoinoye mine-Russian Federation: National Instrument 43-101 Technical Report, 140 p., accessed January 4, 2017, at http://fb.kinross.com/ media/261550/2015\%20kupol-dvoinoye\%20tr.pdf.

Smith, D.M., Albinson, T., and Sawkins, F.J., 1982, Geologic and fluid inclusion studies of the Tayoltita silver-gold vein deposit, Durango, Mexico: Economic Geology, v. 77, p. $1120-1145$.

Snider, Josh, Patterson, E.L., Gochnour, Lee, Marek, John, and Burkhalter, C.J., 2015, Haile gold mine project, NI 43-101 Technical report, Project update, Lancaster County, South Carolina: Technical report prepared for Oceana Gold, 158 p., accessed January 10, 2017, at https://www.oceanagold.com/ wp-content/uploads/2015/07/Haile-NI-43-101-TechnicalReport-Project-Update-Reduced.pdf.

Soechting, Walter, Rubinstein, Nora, and Godeas, Marta, 2008, Identification of ammonium-bearing minerals by shortwave infrared reflectance spectroscopy at the Esquel gold deposit, Argentina: Economic Geology, v. 103, p. 865-869.
So, C.-S., Zhang, D.-Q., Yun, S.-T., and Li, D.-X., 1998, Alteration-mineralization zoning and fluid inclusions of the high-sulfidation epithermal $\mathrm{Cu}$-Au mineralization at Zijinshan, Fujian Province, China: Economic Geology, v. 93, p. 961-980.

Somers, C., Gibson, H., and Burk, R., 2010, The La Pitarrilla silver-lead-zinc deposit, Sierra Madre Occidental, Mexico-A description of the mineralisation and a reconstruction of its volcano-sedimentary environment: Society of Economic Geologists Special Publication 15, p. 133-164.

Speer, W.E., and Maddry, J.W., 1993, Geology and recent discoveries at the Haile gold mine, Lancaster County, South Carolina: South Carolina Geology, v. 35, p. 9-26.

Spencer, R.M., Montenegro, J.L., Gaibor, A., Perez, E.P., Mantilla, G., Viera, F., and Spencer, C.E., 2002, The Portovelo-Zaruma mining camp, southwest Ecuador-Porphyry and epithermal environments: Society of Economic Geologists Newsletter 49, p. 1, 8-14.

Spiridonov, A.M., Zorina, L.D., Letunov, S.P., and Prokof'ev, V.Yu., 2010, The fluid regime of ore formation in the Balei gold-bearing ore-magmatic system (eastern Transbaikalia, Russia): Russian Geology and Geophysics, v. 51, p. 1102-1109.

Spurr, J.E., 1905, Geology of the Tonopah mining district, Nevada: U.S. Geological Survey Professional Paper 42, 295 p., https:// pubs.er.usgs.gov/publication/pp42.

Spurr, J.E., 1915, Geology and ore deposition at Tonopah, Nevada: Economic Geology, v. 10, p. 713-769.

Squire, R.J., Herrmann, W., Pape, D., and Chalmers, D.I., 2007, Evolution of the peak Hill high-sulfidation $\mathrm{Au}-\mathrm{Cu}$ deposit, eastern Australia: Mineralium Deposita, v. 42, p. 489-503.

Staatz, M.H., and Pearson, R.C., 1990, The Republic gold district, Ferry County, Washington: U.S. Geological Survey Bulletin 1857-H, p. H14-H20.

Staude, J.M., 2001, Geology, geochemistry, and formation of $\mathrm{Au}-(\mathrm{Cu})$ mineralization and advanced argillic alteration in the Mulatos distict, Sonora, Mexico: Society of Economic Geologists Special Publication 8, p. 199-216.

Steven, T.A., and Eaton, G., 1975, Environment of ore deposition in the Creede mining district, San Juan Mountains, Colorado-I. Geologic, hydrologic, and geophysical setting: Economic Geology, v. 70, p. 1023-1037.

Steven, T.A., and Ratté, J.C., 1960, Geology and ore deposits of the Summitville district, San Juan Mountains, Colorado: U.S. Geological Survey Professional Paper 343, 70 p., https://pubs. usgs.gov/pp/0343/report.pdf.

Steven, T.A., and Ratté, J.C., 1965, Geology and structural control of ore deposition in the Creede district, San Juan Mountains, Colorado: U.S. Geological Survey Professional Paper 487, 90 p., https://pubs.usgs.gov/pp/0487/report.pdf. 
Stoffregen, R.E., 1987, Genesis of acid-sulfate alteration and $\mathrm{Au}-\mathrm{Cu}-\mathrm{Ag}$ mineralization at Summitville, Colorado: Economic Geology, v. 82, p. 1575-1591.

Sugaki, A., Kojima, S., and Shimada, N., 1988, Fluid inclusion studies of the polymetallic hydrothermal ore deposits in Bolivia: Mineralium Deposita, v. 23, p. 9-15.

Sutopo, Bronto, 2013, The Martabe Au-Ag high-sulfidation epithermal deposits, Sumatra, Indonesia-Implications for ore genesis and exploration: University of Tasmania, Ph.D. dissertation, $332 \mathrm{p}$.

Swarthout, Andrew, Leduc, Marc, and Rios, Christian, 2010, The discovery history and geology of Corani-A significant new Ag-Pb-Zn epithermal deposit, Puno Department, Peru: Society of Economic Geologists Special Publication 15, p. 165-179.

Takahashi, Ryohei, Matsueda, Hiroharu, Okrugin, V.M., Shikazono, Naotatsu, Ono, Shuji, Imai, Akira, Andreeva, E.D., and Watanabe, Koichiro, 2013, Ore-forming ages and sulfur isotope study of hydrothermal deposits in Kamchatka, Russia: Resource Geology, v. 63, p. 210-223.

Tan, L., 1991, The Chinkuashih gold-copper deposits, Taiwan: Society of Economic Geologists Newsletter 7, p. 1, 22-24.

Tan, L., Ni, J.M., and Jeng, R.C., 1987, A geochemical prospecting for the gold mineralizations in the Chinkuashih district, Taiwan: Acta Geologica Taiwanica Science Reports of the National Taiwan University, no. 25, p. 151-172.

Tangwattananukul, L., Ishiyama, D., Matsubaya, O., Mizuta, T., Charusiri, P., Sato, H., and Sera, K., 2014, Characteristics of Triassic epithermal Au mineralization at the Q prospect, Chatree mining area, Central Thailand: Resource Geology, v. 64, p. $167-181$.

Tassinari, C.C.G., Pinzon, F.D., and Buena Ventura, J., 2008, Age and sources of gold mineralization in the Marmato mining district, NW Columbia-A Miocene-Pliocene epizonal gold deposit: Ore Geology Reviews, v. 33, p. 505-518.

Taylor, H.P., 1973, $\mathrm{O}^{18} / \mathrm{O}^{16}$ evidence for meteoric-hydrothermal alteration and ore deposition in the Tonopah, Comstock Lode, and Goldfield mining districts, Nevada: Economic Geology, v. 68 , p. $747-764$.

Teal, L.B., and Benavides, A., 2010, History and geologic overview of the Yanacocha mining district, Cajamarca, Peru: Economic Geology, p. 1173-1190.

Thompson, J.F.H., Lessman, J., and Thompson, A.J.B., 1986, The Temora gold-silver deposit-A newly recognized style of high sulfur mineralization in the lower Paleozoic of Australia: Economic Geology, v. 81, p. 732-738.
Thompson, J.F.H., Sillitoe, R.H., Baker, T., Lang, J.R., and Mortensen, J.K., 1999, Intrusion-related gold deposits associated with tungsten-tin provinces: Mineralium Deposita, v. 34, p. $323-334$.

Tingley, J.V., and Berger, B.R., 1985, Lode gold deposits of Round Mountain, Nevada: Nevada Bureau of Mines and Geology Bulletin 100, 62 p.

Tohma, Yuki, Imai, Akira, Sanematsu, Kenzo, Yonezu, Kotaro, Takahashi, Ryohei, Koyama, Masaski, Sekine, Ryota, Duncan, Robert, and Watanabe, Koichiro, 2010, Characteristics and mineralization age of Fukusen No. 1 vein, Hishikari epithermal gold deposits, southern Kyushu, Japan: Resource Geology, v. 60, p. 348-358.

Tosdal, R.M., Sherlock, R.L., Nelson, G.C., Enderlin, D.A., and Lehrman, N.J., 1996, Structural evolution of the McLaughlin precious metal deposit, northern California, in Coyner, A.R., and Fahey, P.L., eds., Proceedings of the Geology and Ore Deposits of the America Cordillera Symposium, Reno, April 1995: Geological Society of Nevada, p. 839-854.

Trejo, P., 2001, Geology of the Fresnillo southeast mine, Fresnillo, Zacatecas, Mexico: Society of Economic Geologists Special Publication 8, p. 105-113.

Turneaure, F.S., 1960a, A comparative study of major ore deposits of central Bolivia, Part I: Economic Geology, v. 55, no. 2, p. 217-254.

Turneaure, F.S., 1960b, A comparative study of major ore deposits of central Bolivia, Part II: Economic Geology, v. 55, no. 3, 574-606.

Turner, S., 1997, The Yanacocha epithermal gold deposits, northern Peru-High sulfidation mineralization in a flow dome setting: Boulder, Colorado School of Mines, Ph.D. dissertation, $338 \mathrm{p}$.

Urasima, Yukitosi, 1956, "Bosa" quartz veins, especially the finegrained quartz aggregates, of the Konomai mine in Hokkaido, Japan: Journal of the Faculty of Science, Hokkaido University, Series 4: Geology and Mineralogy, v. 9, no. 3, p. 371-380.

Urasima, Yukitosi, 1957, Mineralization of Central Kitami mining district in Hokkaido, Japan: Journal of the Faculty of Science, Hokkaido University, Series 4: Geology and Mineralogy, v. 9, no. 4, p. 597-606.

van Leeuwen, T.M., Leach, T., Hawke, A.A., and Hawke, M.M., 1990, The Kelian disseminated gold deposit, East Kalimantan, Indonesia: Journal of Geochemical Exploration, v. 35 , p. $1-61$.

Van Thournout, F., Salemink, J., Valenzuela, G., Merlyn, M., Boven, A., and Muchez, P., 1996, Portovelo-A volcanichosted epithermal vein system in Ecuador, South America: Mineralium Deposita, v. 31, p. 269-276. 
Velador, J.M., Heizler, M.T., and Campbell, A.R., 2010, Timing of magmatic activity and mineralization and evidence of a long-lived hydrothermal system in the Fresnillo silver district, Mexico - Constraints from ${ }^{40} \mathrm{Ar}{ }^{\beta 9} \mathrm{Ar}$ geochronology: Economic Geology, v. 105, p. 1335-1349.

Vennemann, T.W., Muntean, J.L., Kesler, S.E., O’Neil, J.R., Valley, J.W., and Russell, N., 1993, Stable isotope evidence for magmatic fluids in the Pueblo Viejo epithermal acid sulfate Au-Ag deposit, Dominican Republic: Economic Geology, v. 88, p. 55-71.

Vikentyev, Ilya, Banda, Richard, Tsepin, Anatoliy, Prokofiev, Vsevolod, and Vikentyeva, Olga, 2005, Mineralogy and formation conditions of Portovelo-Zaruma gold-sulphide vein deposit, Ecuador: Geochemistry Mineralogy and Petrology, v. 43 , p. $148-154$.

Vikre, P.G., 1985, Precious metal vein systems in the National district, Humboldt County, Nevada: Economic Geology, v. 80, p. $360-393$.

Vikre, P.G., 1987, Paleohydrology of Buckskin Mountain, National district, Humboldt County, Nevada: Economic Geology, v. 82, p. 934-950.

Vikre, P.G., 1989a, Fluid-mineral relations in the Comstock Lode: Economic Geology, v. 84, p. 1574-1613.

Vikre, P.G., 1989b, Ledge formation at the Sandstorm and Kendall gold mines, Goldfield, Nevada: Economic Geology, v. 84, p. $2115-2138$.

Vikre, P.G., 2007, Sinter-vein correlations at Buckskin Mountain, National District, Humboldt County, Nevada: Economic Geology, v. 102, p. 193-224.

Vikre, P.G., Fleck, R.J., and Rye, R.O., 2005, Ages and geochemistry of alunites in the Goldfield district, Esmeralda County, Nevada: Proceedings of the Window to the World Symposium 2005, Reno, May 2005: Geological Society of Nevada, p. 1330-1331.

Vikre, P.G., John, D.A., du Bray, E.A., and Fleck, R.J., 2015, Gold-silver mining districts, alteration zones, and paleolandforms in the Miocene Bodie Hills volcanic field, California and Nevada: U.S. Geological Survey Scientific Investigations Report 2015-5012, 160 p., https://doi. org/10.3133/sir20155012

Vikre, P.G., McKee, E.H., and Silberman, M.L., 1988, Chronology of Miocene hydrothermal and igneous events in the western Virginia Range, Washoe, Storey, and Lyon counties, Nevada: Economic Geology, v. 83, p. 864-874.

Vityk, M.O., Krouse, H.R., and Skakun, L.Z., 1994, Fluid evolution and mineral formation in the Beregovo gold-base metal deposit, Transcarpathia, Ukraine: Economic Geology, v. 89 , p. $547-565$.
Volkov, A.V., Prokof'ev, V.Y., Savva, N.E., Sidorov, A.A., Bayankin, M.A., Uyutnov, K.V., and Kolova, E.E., 2012, Ore formation at the Kupol epithermal gold-silver deposit in northeastern Russia deduced from fluid inclusion study: Geology of Ore Deposits, v. 54, p. 295-303.

Wallier, Stefan, Rey, Roger, Kouzmanov, Kalin, Pettke, Thomas, Heinrich, C.A., Leary, Stephen, O’Connor, Gary, Tămas, C.G., Vennemann, Torsten, and Ullrich, Thomas, 2006, Magmatic fluids in the breccia-hosted epithermal $\mathrm{Au}-\mathrm{Ag}$ deposit of Roşia Montană, Romania: Economic Geology, v. 101, p. 923-954.

Wang, Y., 2010, Physical and chemical characteristics of the host rocks in controlling the mineralization of the Chinkuashih highsulfidation gold-copper deposits, northeastern Taiwan: Journal of Geochemical Exploration, v. 104, p. 61-68.

Wang, Y., Sasaki, M., Sasada, M., and Chen, C.-H., 1999, Fluid inclusion studies of the Chinkuashih high-sulfidation goldcopper deposits in Taiwan: Chemical Geology, v. 154, p. 155-167.

Warmada, I.W., Lehmann, B., and Simandjuntak, M., 2003, Polymetallic sulfides and sulfosalts of the Pongkor epithermal gold-silver deposit, West Java, Indonesia: Canadian Mineralogist, v. 41, p. 185-200.

Warmada, I.W., Lehmann, B., Simandjuntak, M., and Hemes, H.S., 2007, Fluid inclusion, rare-earth element and stable isotope study of carbonate minerals from the Pongkor epithermal gold-silver deposit, West Java, Indonesia: Resource Geology, v. 57, p. 124-135.

Warren, Ian, Archibald, D.A., and Simmons, S.F., 2008, Geochronology of epithermal Au-Ag mineralization, magmatichydrothermal alteration, and supergene weathering in the El Peñón district, northern Chile: Economic Geology, v. 103, p. 851-864.

Warren, Ian, Simmons, S.F., and Mauk, J.L., 2007, Whole-rock geochemical techniques for evaluating hydrothermal alteration, mass changes, and compositional gradients associated with epithermal Au-Ag mineralization: Economic Geology, v. 102, p. $923-948$.

Warren, Ian, Zuluaga, J.I., Robbins, C.H., Wulftange, W.H., and Simmons, S.F., 2004, Geology and geochemistry of epithermal Au-Ag mineralization in the El Peñón district, northern Chile: Society of Economic Geologists Special Publication 11, p. 113-139.

Watanabe, Yasushi, 1996, Genesis of vein-hosting fractures in the Kitami region, Hokkaido, Japan: Resource Geology, v. 46, no. 3, p. 151-166.

Waters, P.J., Cooke, D.R., Gonzales, R.I., and Phillips, D., 2011, Porphyry and epithermal deposits and ${ }^{40} \mathrm{Ar} /{ }^{39} \mathrm{Ar}$ geochronology of the Baguio district, Philippines: Economic Geology, v. 106, p. 1335-1363. 
Weiss, S.I., Espinoza, E., and Ronkos, C., 2010, Update on the El Sauzal high-sulfidation gold-silver deposit at the initiation of mining, Municipio de Urique, Chichuahua, Mexico, in Gastelum, G., ed., Northern Sierra Madre Occidental GoldSilver Mines, Mexico: Society of Economic Geologists Field Trip Guidebook Series, v. 42, p. 95-102.

Williams, D.K., 2012, The geology and mineralization of the Navidad project, Chubut Province, Argentina: Society of Economic Geologists Special Publication 15, p. 203-227.

Willis, G.F., and Tosdal, R.M., 1992, Formation of gold veins and breccias during dextral strike-slip faulting in the Mesquite mining district, southeastern California: Economic Geology, v. 87, p. 2002-2022.

Wurst, A.T., 2004, Geology and genesis of the Permata - Batu Badinding - Julubai and Kerkil Au-Ag low sulfidation epithermal deposits, Mt. Muro, Kalimantan, Indonesia: University of Tasmania, PhD dissertation, $338 \mathrm{p}$.
Yilmaz, Huseyin, 2002, Ovacik gold deposit-An example of quartz-adularia-type gold mineralization in Turkey: Economic Geology, v. 97, p. 1829-1839.

Yilmaz, Huseyin, Oyman, Tolga, Arehart, G.B., Colakoglu, A.R., and Billor, Zeki, 2007, Low-sulfidation type Au-Ag mineralization at Bergama, Izmir, Turkey: Ore Geology Reviews, v. 32, p. 81-124.

Zakharov, M.N., Kravtsova, R.G., and Pavlova, L.A., 2002, Geochemical features of rocks of volcanoplutonic associations of the Dukat gold-silver deposit: Russian Geology and Geophysics, v. 43, p. 928-939.

Zorin, Yu.A., Zorina, L.D., Spiridonov, A.M., and Rutshtein, I.G., 2001, Geodynamic settings of gold deposits in the Transbaikal region (Eastern Siberia, Russia): Ore Geology Reviews, v. 17, p. 215-232. 


\section{Appendix 2. Grade and Tonnage Data and Data Sources for Epithermal Gold Deposits}

This appendix is available online only as an .xlsx table at https://doi.org/10.3133/sir20105070Q.

\section{References Cited}

\author{
Alamos Gold, 2015, Mulatos Mine, Mexico: Alamos Gold web \\ page, accessed August 28, 2015, at http://www.alamosgold. \\ $\mathrm{com} /$ mines-and-projects/producing-mine/mulatos-mine- \\ mexico/.
}

Albinson, T., and Rubio, M.A., 2001, Mineralogic and thermal structure of the Zuloaga vein, San Martin de Bolaños district, Jalisco, Mexico, in Albinson, T., and Nelson, C.E., eds., New Mines and Discoveries in Mexico and Central America: Society of Economic Geologists Special Publication 8, p. 115-132.

Andreeva, E.D., Matsueda, H., Okrugin, V.M., Takahashi, R., and Ono, S., 2013, Au-Ag-Te mineralization of the low-sulfidation epithermal Aginskoe deposit, central Kamchatka, Russia: Resource Geology, v. 63, p. 337-349.

Anglo Gold Ashanti, 2015a, Annual Reports: Anglo Gold Ashanti web page, accessed August 31, 2015, at http://www. anglogoldashanti.com/investors/annual-reports/.

Anglo Gold Ashanti, 2015b, Cerro Vanguardia: Anglo Gold Ashanti web page, accessed August 31, 2015, at http://www. anglogoldashanti.com/americas/.

Baker, T., Mustard, R., Brown, V., Pearson, N., Stanley, C.R., Radford, N.W., and Butler, I., 2006, Textural and chemical zonation of pyrite at Pajingo-A potential vector to epithermal gold veins: Geochemistry Exploration Environment Analysis v. 6, p. $283-293$.

Barrick Gold, 2015, Barrick Gold annual reports: Barrick Gold web page, accessed August 31, 2015, at http://www.barrick. com/investors/annual-report/default.aspx.

Begbie, M.J., Spörli, K.B., and Mauk, J.L., 2007, Structural evolution of the Golden Cross epithermal Au-Ag deposit, New Zealand: Economic Geology, v. 102, p. 873-892.

Bergman Weihed, J., Berstrom, U., Billstrom, K., and Weihed, P., 1996, Geology, tectonic setting, and origin of the Paleoproterozoic Boliden Au-Cu-As deposit, Skellefte district, northern Sweden: Economic Geology, v. 91, p. 1073-1097.
Boychuk, K.G., Garcia, D.H., Sharp, A.W., Vincent, J.D., Yeomans, T.J., 2012, NI 43-101 technical report on the Pitarrilla project, Durango State, Mexico: Vancouver, British Columbia, Silver Standard, 435 p., accessed August 14, 2014, at http:// www.silverstandard.com/_resources/Pitarrilla_Technical_ Report_Dec_14_2012.pdf.

Caira, N.M., 2013, National instrument 43-101 F1 technical report on the El Oro property, Mexico: Report prepared for Candente Gold Corp., 219 p., http://www.candentegold.com/i/pdf/reports/ El-Oro-NI-43-101-Report-Nov-30-13.pdf.

Camus, F., Boric, R., Skewes, M.A., Castelli, J.C., Reichhard, E., and Mestre, A., 1991, Geologic, structural and fluid inclusion studies of El Bronce epithermal vein system, Petorca, Central Chile: Economic Geology, v. 86, p. 1317-1345.

Candiotti de Los Rios, Hugo, Noble, D.C., and McKee, E.H., 1990, Geologic setting and epithermal silver veins of the Arcata district, southern Peru: Economic Geology, v. 85, p. 1473-1490.

Chiaradia, M., Fontbote, L., and Beate, B., 2004, Cenozoic continental arc magmatism and associated mineralization in Ecuador: Mineralium Deposita, v. 39, p. 204-222.

Christie, A.B., Simpson, M.P., Brathwaite, R.L., Mauk, J.L., and Simmons, S.F., 2007, Epithermal Au-Ag and related deposits of the Hauraki Goldfield, Coromandel volcanic zone, New Zealand: Economic Geology, v. 102, p. 785-816.

Christie, Gary, Lipiec, Ignacy, Simpson, R.G., Horton, Jay, and Borntradger, Bruno, 2014, Blackwater gold project, British Columbia, NI 43-101 Technical Report on Feasibility Study, 336 p., accessed November 18, 2014, at http://www.sedar.com/DisplayCompanyDocuments. do?lang $=$ EN\&issuerNo $=00004818$.

Collins, S.E., Moore, C.M., and Scott, K.E., 2010, Technical report on the El Peñón mine, northern Chile-NI-43-101 report: Toronto, Canada, Scott Wilson Mining, accessed August 31, 2015, http://www.sec.gov/Archives/edgar/ data/1264089/000110465911018283/a11-6607_7ex99d1.htm.

Columba, C., M., and Cunningham, C.G., 1993, Geologic model for the mineral deposits of the La Joya district, Oruro, Bolivia: Economic Geology, v. 88, p. 701-708. 
Davies, A.G.S., Cooke, D.R., Gemmell, J.B., van Leeuwen, Theo, Cesare, Pat, and Hartshorn, Greg, 2008b, Hydrothermal breccias and veins at the Kelian gold mine, Laimantan, Indonesia - Genesis of a large epithermal gold deposit: Economic Geology, v. 103, p. 717-757.

De Mark, Pamela, Chulick, J.J., Williams, D.K., Spring, Damian, Wells, J.A., 2009, Navidad project, Chubat Province, Argentina: Aqualine Resources Inc., NI 43-101 report, 247 p., accessed May 27, 2014, at http://www.panamericansilver.com/ operations/argentina/navidad/.

Dong, G.Y., and Zhou, T., 1996, Zoning in the CarboniferousLower Permian Cracow epithermal vein system, central Queensland, Australia: Mineralium Deposita, v. 31, p. 210-224.

Dubé, Benôit, Dunning, Greg, and Lauzière, Kathleen, 1998, Geology of the Hope Brook mine, Newfoundland, Canada - A preserved Late Proterozoic high-sulfidation epithermal gold deposit and its implications for exploration: Economic Geology, v. 93, p. $405-436$.

Enriquez, E., and Rivera, R., 2001a, Geology of the Santa Rita Ag-Au deposit, San Dimas district, Durango, Mexico, in Albinson, T., and Nelson, C.E., eds., New Mines and Discoveries in Mexico and Central America: Society of Economic Geologists Special Publication 8, p. 39-58.

Fifarek, R.H., and Rye, R.O., 2005, Stable-isotope geochemistry of the Pierina high-sulfidation Au-Ag deposit, Peru-Influence of hydrodynamics on $\mathrm{SO}_{4}{ }^{2-} \mathrm{H}_{2} \mathrm{~S}$ sulfur isotopic exchange in magmatic-steam and steam-heated environments: Chemical Geology, v. 215, p. 253-279.

Gemmell, J.B., 2007 Hydrothermal alteration associated with the Gosowong epithermal Au-Ag deposit, Halmahera, IndonesiaMineralogy, geochemistry, and exploration implications: Economic Geology, v. 102, p. 893-922.

Goldcorp, 2015, Peñasquito: Goldcorp web page, accessed April 29, 2015, at https://www.goldcorp.com/English/portfolio/ operations/Peñasquito/default.aspx.

Graybeal, F.T., and Vikre, P.G., 2010, A review of silver-rich mineral deposits and their metallogeny: Society of Economic Geologists Special Publication 15, p. 85-117.

Hallberg, A., 1994, The Enåsen gold deposit, central Sweden-1. A palaeoproterozoic high-sulphidation epithermal gold mineralization: Mineralium Deposita, v. 29, p. 150-162.

John, D.A., Hofstra, A.H., Fleck, R.J., Brummer, J.E., and Saderholm, E.C., 2003, Geologic setting and genesis of the Mule Canyon low-sulfidation epithermal gold-silver deposit, north-central Nevada: Economic Geology, v. 98, p. 425-463.

Kamilli, R.J., and Ohmoto, H., 1977, Paragenesis, zoning, fluid inclusion, and isotopic studies of the Finlandia vein, Colqui district, Central Peru: Economic Geology, v. 72, p. 950-982.
Kesler, S.E., Russell, Norman, and McCurdy, Karr, 2003, Tracemetal content of the Pueblo Viejo precious-metal deposits and their relation to other high-sulfidation epithermal systems: Mineralium Deposita, v. 38, p. 668-682.

Kilias, S.P., Naden, J., Cheliotis, I., Shepherd, T.J., Contandinidou, H., Crossing, J., and Simos, I., 2001, Epithermal gold mineralisation in the active Aegean volcanic arc - The Profitis Ilias deposit, Milos Island, Greece: Mineralium Deposita, v. 36, p. $32-44$.

Klondex Mines Ltd., 2015, Midas reserves and resources: Klondex Mines web page, accessed August 31, 2015, at http:// klondexmines.com $/ \mathrm{s} /$ midas.asp.

Koichiro, Syafrizal, Watanabe, Yasushi, Imai, Akira, and Motomura, Yoshinobu, 2005, Alteration and gold mineralization of the Ciurug vein, Pongkor Au-Ag deposit, Indonesia, in Mao, Jingwen, Bierlein, F.P., eds., Mineral Deposit ResearchMeeting the Global Challenge: Berlin Heidelberg, SpringerVerlag, p. 995-998.

Kouzmanov, K., Bailly, L., Tamaa, C., and Ivizicanud, P., 2005, 1-2: Epithermal $\mathrm{Pb}-\mathrm{Zn}-\mathrm{Cu}(-\mathrm{Au})$ deposits in the Baia Mare district, Eastern Carpathians, Romania: Ore Geology Reviews, v. 27, p. $48-49$.

Lambert, R.J., Valliant, W.W., and Altman, K.A., 2014, Technical report on the Mesquite mine, Imperial County, California, U.S.A.: Toronto, New Gold Inc., 120 p., accessed August 26, 2015, at http://www.newgold.com/files/documents_properties/ mesquite/2014-02-28_MSQ_NI-43-101-Tech-Rept.pdf.

Long, K.R., DeYoung, J.H., Jr., and Ludington, S.D., 1998, Database of Significant Deposits of Gold, Silver, Copper, Lead, and Zinc in the United States: U.S. Geological Survey Open-File Report 98-206 A, B, 33 p., https://pubs.usgs.gov/ of/1998/0206a-b/.

Longo, A.A., Dilles, J.H., Grunder, A.L., and Duncan, R., 2010, Evolution of calc-alkaline volcanism and associated hydrothermal gold deposits at Yanacocha, Peru: Economic Geology, v. 105, p. 1191-1241.

Losada-Calderón, A.J., and McPhail, D.C., 1996, Porphyry and high sulfidation epithermal mineralisation in the Nevados del Famatina mining district, Argentina: Society of Economic Geologists Special Publication 5, p. 91-118.

M3 Engineering \& Technology Corporation, 2011, Corani Project: Form NI 43-101 Technical Report, 291 p., accessed November 18, 2014, at http://www.bearcreekmining.com/s/corani. asp?ReportID $=619755$.

Manske, S.L., Hedenquist, J.W., O'Connor, G., Tamas, C., Cauuet, B., Leary, S., and Minut, A., 2006, Roşia Montană, RomaniaEurope's largest gold deposit: Society of Economic Geologists Newsletter, no. 64, p. 1, 9-15. 
Nevada Bureau of Mines and Geology, 2014, Special Publication MI-2013: The Nevada Mineral Industry, 2013, 155 p., accessed July 10, 2014, at http://data.nbmg.unr.edu/ public/freedownloads/mi/mi2013.zip.

New Gold, 2015, New Gold annual report: New Gold web page, accessed August 31, 2015, at http://www.newgold.com/ files/documents_financials/2014/AR/New_Gold_Annual_ Report_2014.pdf.

Newmont Gold, 2015, Quarterly Reports: Newmont Gold web page, accessed on August 26, 2015, at http://www.newmont. com/investor-relations/financial-reports/quarterly-reports/ default.aspx.

Northern Miner, 1994, ASARCO bids for Russian gold mine: Northern Miner web page, September 5, 1994, accessed December 21, 2017, at http:/www.northernminer.com/news/ asarco-bids-for-russian-gold-mine/1000137899/.

Paramount Gold Nevada, 2015, Sleeper gold project: Paramount Gold Nevada web page, accessed August 23, 2015, at http:// www.paramountnevada.com/projects/sleeper-gold-project/.

Parks, J., and Robertson, I.D.M., 2003, Pajingo epithermal gold deposits, NE Queensland: Cooperative Research Centre for Landscapes, Environments and Mineral Exploration Report, $4 \mathrm{p}$.

Pearson, M.F., Clark, K.F., Porter, E.W., and Gonzalez S., O. 1988, Mineralogy, fluid characteristics and silver distribution at Real de Angeles, Zacatecas: Economic Geology, v. 83, p. $1737-1759$.

Porter Geoconsultancy, 2012a, Martabe, Sumatra, Indonesia: Porter Geoconsultancy web page, accessed August 31, 2015, at http://www.portergeo.com.au/tours/epithermalgold2012/ epithermalgold2012deposits.asp\#martabe.

Porter Geoconsultancy, 2012b, Lepanto-Far Southeast, Luzon, Phillipines: Porter Geoconsultancy web page, accessed August 31, 2015, at http://www.portergeo.com. au/tours/epithermalgold2012/epithermalgold2012deposits. asp\#lepanto.

Porter Geoconsultancy, 2015a, Temora, Gidginbung, New South Wales, NSW, Australia: Porter Geoconsultancy web page, accessed August 28, 2015, at http://www.portergeo.com.au/ database/mineinfo.asp? mineid $=m n 442$.

Porter Geoconsultancy, 2015b, Database, El Indio Belt, Chile: Porter Geoconsultancy web page, accessed August 28, 2015, at http://www.portergeo.com.au/database/mineinfo. asp? $\operatorname{mineid}=\mathrm{mn} 071$.

Porter Geoconsultancy, 2018, Hishikari, Kyushu, Japan: Porter Geoconsultancy web page, accessed June 11, 2018, at http://www.portergeo.com.au/database/mineinfo. asp? mineid $=\mathrm{mn} 059$.
Rodionov, S.M., Fredericksen, R.S., Berdnikov, N.V., and Yakubchuk, A.S., 2014, The Kuranakh epithermal gold deposit, Aldan Shield, East Russia: Ore Geology Reviews, v. 59 , p. 55-65.

Roth, D.K., Ibrado, A.S., Snider, J.W., Pennstrom, W.J., Browne, R.A., Harris, D.A., and Peterson, A.T., 2014, Hycroft project: Allied Nevada Gold Corp. web page, technical report NI 43-101FI, 253 p., accessed August 23, 2015, at http://www.alliednevada.com.

Ruggieri, G., Lattanzi, P., Luxoro, S.S., Dessi, R., Benvenuti, M., and Tanelli, G., 1997, Geology, mineralogy, and fluid inclusion data of the Furtei high-sulfidation gold deposit, Sardinia, Italy: Economic Geology, v. 92, p. 1-19.

Seki, Y., 1993, Geologic setting of the Takatama gold deposit, Japan-An example of caldera-related epithermal gold mineralization: Resource Geology Special Issue, no. 14, p. 123-136.

Shannon, J.M., and Stoker, P.T., 2013, Misima gold-copper project, Milne Bay Province, Papua New Guinea: Technical report prepared by AMC Mining Consultants for WCB Resources Limited, 158 p., accessed August 22, 2015, at http://www.wcbresources.com/sites/default/ files/reports/713006_WCB_Resources_Misima_Project_ Technical_Report_FINAL_SEDAR.pdf.

Sillitoe, R.H., Cooper, C., Sale, M.J., Soechiting, W., Echavarria, D., and Gallardo, J.L., 2002, Discovery and geology of the Esquel low-sulfidation epithermal gold deposit, Patagonia, Argentina: Society of Economic Geologists Special Publication 9, p. 227-240.

Sillitoe, R.H., and Lorson, R.C., 1994, Epithermal goldsilver-mercury deposits at Paradise Peak, Nevada - Ore controls, porphyry gold association, detachment faulting, and supergene oxidation: Economic Geology, v. 89, p. $1228-1248$.

Simpson, M.P., and Mauk, J.L., 2007, The Favona epithermal gold-silver deposit, Waihi, New Zealand: Economic Geology, v. 102 , p. $817-839$.

Sims, John, 2015, Kupol mine and Dvoinoye mine-Russian Federation: National Instrument 43-101 Technical Report, 140 p., accessed January 4, 2017, at http://fb.kinross.com/ media/261550/2015\%20kupol-dvoinoye\%20tr.pdf.

Snider, Josh, Patterson, E.L., Gochnour, Lee, Marek, John, and Burkhalter, C.J., 2015, Haile gold mine project, NI 43-101 Technical report, Project update, Lancaster County, South Carolina: Technical report prepared for Oceana Gold, 158 p., accessed January 10, 2017, at https://www.oceanagold.com/ wp-content/uploads/2015/07/Haile-NI-43-101-TechnicalReport-Project-Update-Reduced.pdf. 
Staude, J.-M., 2001, Geology, geochemistry, and formation of the $\mathrm{Au}-(\mathrm{Cu})$ mineralization and advanced argillic alteration in the Mulatos district, Sonora, Mexico, in Albinson, T., and Nelson, C.E., eds., New Mines and Discoveries in Mexico and Central America: Society of Economic Geologists Special Publication 8, p. 199-216.

Straits Resources Ltd., 2012, Mt. Muro Mine: Straits Resources Ltd. web page, accessed August 28, 2015, at http:/www.straits. com.au/latestnews/preview.html?path=NewsReleases $\% 2$ F2010 $\% 2 \mathrm{FMt}+\mathrm{Muro}+\mathrm{Mine}+$ Presentation.pdf.

Tangwattananukul, L., Ishiyama, D., Matsubaya, O., Mizuta, T., Charusiri, P., Sato, H., and Sera, K., 2014, Characteristics of Triassic epithermal Au mineralization at the $\mathrm{Q}$ prospect, Chatree mining area, Central Thailand: Resource Geology, v. 64, p. $167-181$.

Tassinari, C.C.G., Pinzon, F.D., and Buena Ventura, J., 2008, Age and sources of gold mineralization in the Marmato mining district, NW Colombia-A Miocene-Pliocene epizonal gold deposit: Ore Geology Reviews, v. 33, p. 505-518.

Thompson, J.F.H., Sillitoe, R.H., Baker, T., Lang, J.R., and Mortensen, J.K., 1999, Intrusion-related gold deposits associated with tungsten-tin provinces: Mineralium Deposita, v. 34, p. 323-334.

Titley, Malcom, Bennett, Julian, and Meik, Simon, 2014, NI 43-101 Technical report, mineral resource and mineral reserve update, Chelopech project, Chelopech, Bulgaria: Sedar web page, 171 p., accessed August 26, 2015, at www.sedar.com.

U.S. Geological Survey, 2015, Mineral Resources Data System (MRDS): U.S. Geological Survey web page, https://mrdata. usgs.gov/mrds/map-us.html.

Vikre, P.G., John, D.A., du Bray, E.A., and Fleck, R.J., 2015, Gold-silver mining districts, alteration zones, and paleolandforms in the Miocene Bodie Hills volcanic field, California and Nevada: U.S. Geological Survey Scientific Investigations Report 2015-5012, 160 p., https://doi. org/10.3133/sir20155012.
Vityk, M.O., Krouse, H.R., and Skakun, L.Z., 1994, Fluid evolution and mineral formation in the Beregovo gold-base metal deposit, Transcarpathia, Ukraine: Economic Geology, v. 89 , p. $547-565$.

Wang, Y., 2010, Physical and chemical characteristics of the host rocks in controlling the mineralization of the Chinkuashih highsulfidation gold-copper deposits, northeastern Taiwan: Journal of Geochemical Exploration, v. 104, p. 61-68.

Warmada, I.W., and Lehmann, B., 2003, Polymetallic sulfides and sulfosalts of the Pongkor epithermal gold-silver deposit, West Java, Indonesia: Canadian Mineralogist, v. 41, p. 185-200.

Weiss, S.I., Espinoza, E., and Ronkos, C., 2010, Update on the El Sauzal high-sulfidation gold-silver deposit at the initiation of mining, Municipio de Urique, Chichuahua, Mexico, in Gastelum, G., ed., Northern Sierra Madre Occidental GoldSilver Mines, Mexico: Society of Economic Geologists Field Trip Guidebook Series, v. 42, p. 95-102.

Wood, D., and MacCorquodale, F., 2015, Persistence can pay off: Discovery of the Gosowong district bonanza-grade gold-silver epithermal orebodies, Halmahera Island, Indonesia: Society of Economic Geologists Newsletter, no. 102, p. 1, 10-16.

Wurst, A.T., 2004, Geology and genesis of the Permata-Batu Badinding-Hulubai and Kerkil Au-Ag low sulfidation epithermal deposits, Mt. Muro, Kalimantan, Indonesia: Hobart, University of Tasmania, Ph.D. dissertation, 429 p.

Yamana Gold, 2017, Yamana Gold annual reports: Yamana Gold web page, at http://www.yamana.com/English/portfolio/ reserves-and-resources/default.aspx.

Yilmaz, Huseyin, Oyman, Tolga, Arehart, G.B., Colakoglu, A.R., and Billor, Zeki, 2007, Low-sulfidation type Au-Ag mineralization at Bergama, Izmir, Turkey: Ore Geology Reviews, v. 32, p. 81-124.

Zijin Mining Group, Ltd., 2011, Zijinshan, Zijin Mining Group web page, accessed August 24, 2015, at http://www.zijinmining. com/tabid/1017/InfoID/29281/frtid/1110/Default.aspx. 


\section{Appendix 3. Compilation of Isotopic Data for Epithermal Gold-Silver Deposits}

This appendix is available online only as an .xlsx table at https://doi.org/10.3133/sir20105070Q. 

Menlo Park Publishing Service Center, California Manuscript approved for publication April 3, 2018 Edited by Sarah E. Nagorsen and Regan Austin Layout by Cory Hurd 


\section{恖}

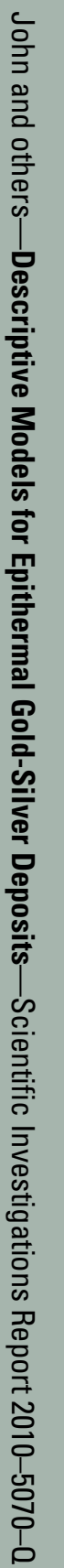

